\title{
ESTUDIOS SISTEMÁTICOS EN TURNERA (TURNERACEAE). IV. SERIES LEIOCARPAE, CONCILIATAE Y SESSILIFOLIAE
}

\author{
MARIA MERCEDES ARBO ${ }^{1}$
}

\begin{abstract}
Summary: Arbo, M. M. 2008. Systematic studies in Turnera (Turneraceae). IV. Series Leiocarpae, Conciliatae and Sessilifoliae. Bonplandia 17(2): 107-334. ISSN: 0524-0476.

In this paper the revision of the series Leiocarpae Urb. is presented, and Turnera callosa Urb. is chosen as lectotype. This series has a distribution similar to that of the genus Turnera in America, most species living in the Chaquean biogeographical region. It has 55 species, the following taxa being new: T. angelicae, T. dasytricha var. crinita, T. diamantinae, T. emendata, T. fissifolia, T. glabrata, T. gouveiana, T. humilis, T. iterata, T. jobertii, T. luetzelburgii var. dubia, T. melochioides var. rugosa, T. paradoxa, T. patens, T. rosulata, T. vallsii, T. venezuelana and T. vicaria. Two new series are also proposed, Conciliatae Arbo for T. rubrobracteata Arbo, a species with an unusual combination of characters, which does not fit in any other series, and Sessilifoliae Arbo, including T. dichotoma and T. revoluta which were excluded from Series Capitatae; the comparative analysis with the members of Leiocarpae has demonstrated that they neither belong to the last series. Keys to identify the different series of the genus and keys for the species of each series treated are provided, as well as morphological descriptions, illustrations and distribution maps.
\end{abstract}

Key words: Epiphyllous flowers, sessile flowers, seed, heterostyly, homostyly, America.

Resumen: Arbo, M. M. 2008. Estudios sistemáticos en Turnera (Turneraceae). IV. Series Leiocarpae, Conciliatae y Sessilifoliae. Bonplandia 17(2): 107-334. ISSN: 0524-0476.

En este trabajo se presenta la revisión de la serie Leiocarpae Urb., seleccionándose a Turnera callosa Urb. como lectotypus. Esta serie tiene una distribución similar a la del género Turnera en América; presenta 55 especies, la mayoría de las cuales vive en la región biogeográfica Chaqueña. Son nuevos los siguientes taxones: T. angelicae, T. dasytricha var. crinita, T. diamantinae, T. emendata, T. fissifolia, T. glabrata, T. gouveiana, T. humilis, T. iterata, T. jobertii, T. luetzelburgii var. dubia, T. melochioides var. rugosa, T. paradoxa, T. patens, T. rosulata, T. vallsii, T. venezuelana y $T$. vicaria. Se proponen también dos series nuevas, Conciliatae Arbo para T. rubrobracteata Arbo, una especie con una combinación inusual de caracteres, que no se ajusta a ninguna otra serie, y Sessilifoliae Arbo, incluyendo $T$. dichotoma y $T$. revoluta, que fueran excluídas de la serie Capitatae; el análisis comparativo con los miembros de Leiocarpae indica que tampoco pertenecen a la última serie. Se presentan claves para identificar las series del género y las especies de cada serie tratada, así como descripciones morfológicas, ilustraciones y mapas de distribución.

Palabras clave: Flores epifilas, flores sésiles, semilla, heterostilia, homostilia, América.

\footnotetext{
${ }^{1}$ Miembro de la Carrera del Investigador Científico y Tecnológico. Instituto de Botánica del Nordeste (UNNECONICET), C.C. 209, 3400 Corrientes, Argentina. E-mail: arbo@agr.unne.edu.ar
} 


\section{Introducción}

Urban (1883) dividió al género Turnera en 9 series. En las contribuciones anteriores se presentó la revisión de las otras series: Salicifoliae, Stenodictyae, Annulares, Capitatae, Microphyllae, Papilliferae, Anomalae y Turnera incluyendo 83 especies (Arbo 1997b, 2000 y 2005). En este trabajo se presenta la revisión de la serie Leiocarpae Urb., la más numerosa y compleja del género Turnera, con 55 especies, siendo 18 entidades nuevas para la ciencia. La mayor parte de las especies de este grupo presenta hojas con un par de nectarios foliares ubicados en la unión de pecíolo y lámina, orientados hacia el envés, o sobre el margen, en la porción basal de la lámina; generalmente las flores son epifilas y el fruto capsular es liso; las semillas presentan el episperma reticulado, y en algunas especies los nudos del retículo son prominentes. Se proponen además dos nuevas series: Conciliatae Arbo para T. rubrobracteata Arbo, con una combinación tal de caracteres que no permite ubicarla en otras series. En la serie Sessilifoliae Arbo se ubican dos especies, $T$. dichotoma y $T$. revoluta, que fueran excluidas de la serie Capitatae (Arbo, 2000); el análisis comparativo de esas dos especies con las entidades de la serie Leiocarpae permitió constatar que tampoco pertenecen a dicha serie. Se presenta una clave para reconocer las series del género.

\section{Materiales y Métodos}

Se utilizó la misma metodología indicada en los trabajos anteriores (Arbo 1997b, 2000 y 2005). Las láminas fueron elaboradas por la ilustradora botánica Liliana Gómez, excepto las figuras 33, 55, 64, 70 y 72 , preparadas por Víctor Maruñak y Ricardo Vispo y publicadas previamente en la Flora del Paraguay (Arbo, 1987); en dichas figuras los detalles florales fueron dibujados a lápiz por la autora. Se reproduce con autorización la ilustración de T. paruana, elaborada por Bruno Manara (Arbo, 1990), y la de T. melochioides var. arenaria, preparada por Liliana Gómez (Arbo, 1997a).

En cada grupo, las entidades taxonómicas se ordenaron alfabéticamente y se las numera a partir del número 84 , siguiendo la secuencia de las contribuciones anteriores. Se incluyen las descripciones y láminas de las especies publicadas en Bonplandia cuando se tratan nuevos caracteres o se amplían. Los ejemplares citados están ordenados por país, estado o provincia, coleccionista principal y número; la secuencia geográfica es la siguiente: América del Norte, América Central, Caribe y América del Sur, con los países dispuestos de norte a sur y de oeste a este. Se excluyen los ejemplares citados en trabajos previos, a menos que se trate de material tipo o de referencia para estudios complementarios, o del único material representativo de un área determinada. Cuando la lista de material estudiado es muy extensa, se citan ejemplares escogidos, los restantes se incluyen en el índice alfabético de exsiccata. Los mapas de distribución han sido elaborados con el software Versamap (Culberson, 1995).

Se revisaron alrededor de 8700 ejemplares de 98 herbarios, que se citan con el acrónimo correspondiente, según el Index Herbariorum: A, AAU, ALCB, ANSM, $\mathrm{AS}, \mathrm{B}, \mathrm{BA}, \mathrm{BAA}, \mathrm{BAB}, \mathrm{BAF}, \mathrm{BHCB}$, $\mathrm{BM}, \mathrm{BR}, \mathrm{C}, \mathrm{CANB}, \mathrm{CAS}, \mathrm{CEN}, \mathrm{CEPEC}$, CESJ, CGE, CORD, CPAP, CTES, DAV, DS, E, EAC, EM, ENCB, ESA, F, FCQ, FEEMA, FI, G, GH, GOET, GUA, HB, HBG, HEPH, HPR, HRCB, HUA, HUEFS, HUFU, HUT, IBGE, ICN, IPA, INPA, K, LE, LIL, LINN, LP, LPB, LY, M, MAC, MBM, MCNS, MEXU, MICH, MO, MU, MVFA, MY, MYF, NY, OXF, P, PORT, PR, PY, R, RB, RFA, S, SI, SP, SPF, TEFH, TEPB, TEX, U, UB, UC, UCWI, UEC, ULM, UNAH, USZ, US, VEN, W, WIS, WU. 


\section{Clave para las series de Turnera (modificada de Arbo, 2000)}

1. Filamentos estaminales soldados en la base al tubo floral (raramente libres) y a veces entre sí.

2. Pedúnculo floral desarrollado. Flores solitarias, a veces reunidas en inflorescencias.

3. Pedúnculo floral completamente libre o inserto en la base del pecíolo siendo el resto libre. Fruto tuberculado o verrucoso.

4. Pedicelo desarrollado, raramente muy breve. Flores solitarias, a veces reunidas en inflorescencias axilares cimosas.

1. Serie Salicifoliae

4'. Pedicelo nulo. Flores solitarias o reunidas en inflorescencias terminales o axilares racemosas.

5. Hojas con nectarios en el pecíolo o en la base de la lámina, sobre el margen.

6. Plantas sin pelos glandulares. Estípulas insertas a ambos lados de la base foliar. Anteras casi basifijas. Semilla obovoide, lado rafeal generalmente plano.

2. Serie Stenodictyae

6'. Plantas con pelos glandulares capitado-sésiles o pelos glandulares microcapitados. Estípulas soldadas a la base foliar y ligeramente al pecíolo. Anteras dorsifijas. Semilla subglobosa, lado rafeal convexo.

3. Serie Annulares

5'. Hojas sin nectarios.

7. Plantas con pelos glandulares capitado-sésiles o con pelos glandulares setiformes. Hojas pequeñas (0,4-4,5 cm long.) con estípulas bien desarrolladas.

5. Serie Microphyllae

7'. Plantas con pelos capitado-estipitados en toda la planta, muy visibles al menos en el cáliz. Hojas pequeñas o medianas (hasta $10 \mathrm{~cm}$ long.) con estípulas reducidas o reemplazadas por coléteres.

6. Serie Papilliferae

3'. Pedúnculo floral parcial o totalmente adnato al pecíolo, al menos las flores apicales epifilas.

8. Sépalos soldados entre sí 1/3-1/2 de su longitud; filamentos estaminales libres entre sí. Fruto impreso-reticulado o liso.

9. Flores generalmente pequeñas, reunidas en racimos capituliformes terminales o laterales. Hojas generalmente medianas (2-12 cm long.); estípulas notorias, 0,5-4,5 mm long. Fruto impreso-reticulado. Semilla con episperma estriado-reticulado; cálaza prominente y cóncava.

4. Serie Capitatae

9'. Flores medianas a pequeñas, solitarias o agrupadas en racimos terminales o axilares. Hojas pequeñas o medianas (0,5-12 cm long.), frecuentemente con nectarios en la unión de pecíolo y lámina, o en la base de la lámina, sobre el margen; estípulas generalmente ausentes o rudimentarias, en algunas especies desarrolladas (hasta $3 \mathrm{~mm}$ long.). Fruto liso (rugoso en Turnera sidoides y T. melochioides var. rugosa). Semilla con episperma reticulado, nudos del retículo a veces elevados (tuberculado en $T$. sidoides); cálaza generalmente redondeada, poco prominente, raramente cónica.

9. Serie Leiocarpae

8'. Sépalos soldados entre sí 2/3 de su longitud; filamentos estaminales soldados entre sí irregularmente, a diferentes alturas. Fruto granuloso.

10. Serie Conciliatae 
2'. Pedúnculo floral no desarrollado, o brevísimo. Flores reunidas en inflorescencias terminales o axilares densas, excepcionalmente solitarias en la axila de nomófilos.

10. Hojas medianas a grandes (4-34 cm long.), pecioladas, no revolutas; estípulas bien desarrolladas, nectarios extraflorales presentes o ausentes.

11. Fruto tuberculado o verrucoso. Semilla pubérula.

1. Serie Salicifoliae

11'. Fruto impreso-reticulado a liso. Semilla generalmente glabra.

6. Serie Capitatae

10'. Hojas muy pequeñas (hasta $16 \mathrm{~mm}$ long.), sésiles, enteras, revolutas; estípulas ausentes, nectarios extraflorales ausentes.

11. Serie Sessilifoliae

1'. Filamentos estaminales soldados por sus bordes a la uña de los pétalos hasta la garganta, formando bolsillos nectaríferos entre cada filamento y el sépalo correspondiente.

12. Pedúnculo floral libre o nulo. Hojas con o sin nectarios.

7. Serie Anomalae

12'. Pedúnculo floral adnato al pecíolo, a veces la porción apical libre. Hojas con nectarios en la unión de pecíolo y lámina.

8. Serie Turnera

\section{Serie Leiocarpae Urb.}

Fig. 1

Urban, I., Jahrb. Königl. Bot. Gart. Berlin 2: 100.1883; Urban, en Martius C.F.P., Fl. Bras. 13(3): 124. 1883.

Hierbas, sufrútices o arbustos de hasta $2 \mathrm{~m}$; pelos tectores generalmente simples, raramente estrellados, y pelos glandulares generalmente microcapitados. Hojas de tamaño pequeño a mediano, generalmente enteras. Estípulas ausentes o rudimentarias, raramente desarrolladas, insertas a ambos lados de la base foliar. Nectarios extraflorales generalmente presentes, al menos en las hojas floríferas. Flores epifilas solitarias o agrupadas en inflorescencias racemosas terminales o axilares. Pedúnculo floral generalmente adnato al pecíolo y a veces a la vena media, ocasionalmente con el ápice libre. Profilos generalmente opuestos y lineares, comúnmente insertos en la base del receptáculo. Pedicelo generalmente ausente. Sépalos generalmente soldados hasta la mitad o menos; lóbulos de prefloración quincuncial. Pétalos amarillos o cremosos, a veces rojos, anaranjados, rosados o blancos. Filamentos estaminales generalmente glabros, sol- dados al tubo floral solamente en la base y por la cara externa; anteras dorsifijas. Ovario frecuentemente con 4-15 óvulos por placenta. Fruto capsular generalmente liso, con la base del tubo floral y los profilos persistentes. Semilla generalmente curvada. Episperma reticulado, con nudos del retículo a veces prominentes; aréolas cóncavas, a veces con una depresión punctiforme, frecuentemente con bastones de cera epicuticular cuando inmaduras. Arilo generalmente unilateral, de células lisas o papilosas.

Cromosomas: x=7 (Fernández, 1987; Solís Neffa \& Fernández, 2000)

Lectotypus, aquí designado: Turnera callosa Urb. Urban incluyó Turnera sidoides L. en esta serie, a pesar de que tiene fruto rugoso, semilla crestada y el pedúnculo floral generalmente libre en las flores basales. La semilla crestada, morfológicamente es única en la familia, y además presenta una ontogenia diferente (Gonzalez, 2000), pero los otros caracteres se presentan excepcionalmente en otras especies de la serie. En el único estudio filogenético molecular realizado hasta el presente, sobre 32 especies (Truyens \& al., 2005), T. sidoides aparece incluida en la serie Leiocarpae; por esta razón se la conserva en dicha serie, a pesar de 
que el análisis filogenético realizado sobre 92 taxones, basado en caracteres morfológicos, indica que debería constituir una serie diferente (Arbo \& Espert, en prensa). Se revisará su posición cuando se concrete la reestructuración del género, disponiendo de información molecular sobre un número más representativo de especies.

La mayoría de las entidades presenta pelos simples, a veces tan densos que resulta difícil ver su base con la lupa (Fig. 2 B-C); las únicas especies con pelos tectores estrellados son Turnera lamiifolia y T. sidoides subsp. sidoides, aunque algunos ejemplares de T. discolor presentan pelos de 1-5 ramas en el cáliz. Los únicos pelos glandulares registrados para este grupo eran los pelos microcapitados (Gonzalez \& Arbo, 2004). Los de T. stachydifolia son capitado-sésiles (Fig. 2 B), pero no se dispuso de material para estudios anatómicos. El fruto liso, que da nombre a la serie, presenta el estrato mecánico externo, constituido por braquiesclereidas subepidérmicas, en todas las especies analizadas (Gonzalez, 2000).

Las especies de Leiocarpae están distribuidas desde México hasta el centro-sur de Argentina. La mayoría vive en la región biogeográfica Chaqueña, en bosque chaqueño, «cerrado», «caatinga», sabanas y pastizales, también hay especies características de «campo rupestre». Muchas se conocen sólo a través del material tipo, o de unos pocos ejemplares y pocas tienen distribución amplia. La mayor diversidad se encuentra en el planalto de Brasil, en el Distrito Federal y NE de Goiás, donde se pueden hallar hasta 10 especies por cuadrícula de un grado sexagesimal. En Minas Gerais, en la Serra do Cipó y adyacencias hay ocho especies registradas, y siete en Bahia, en el área montañosa donde se encuentra Pico das Almas (Fig. 3).

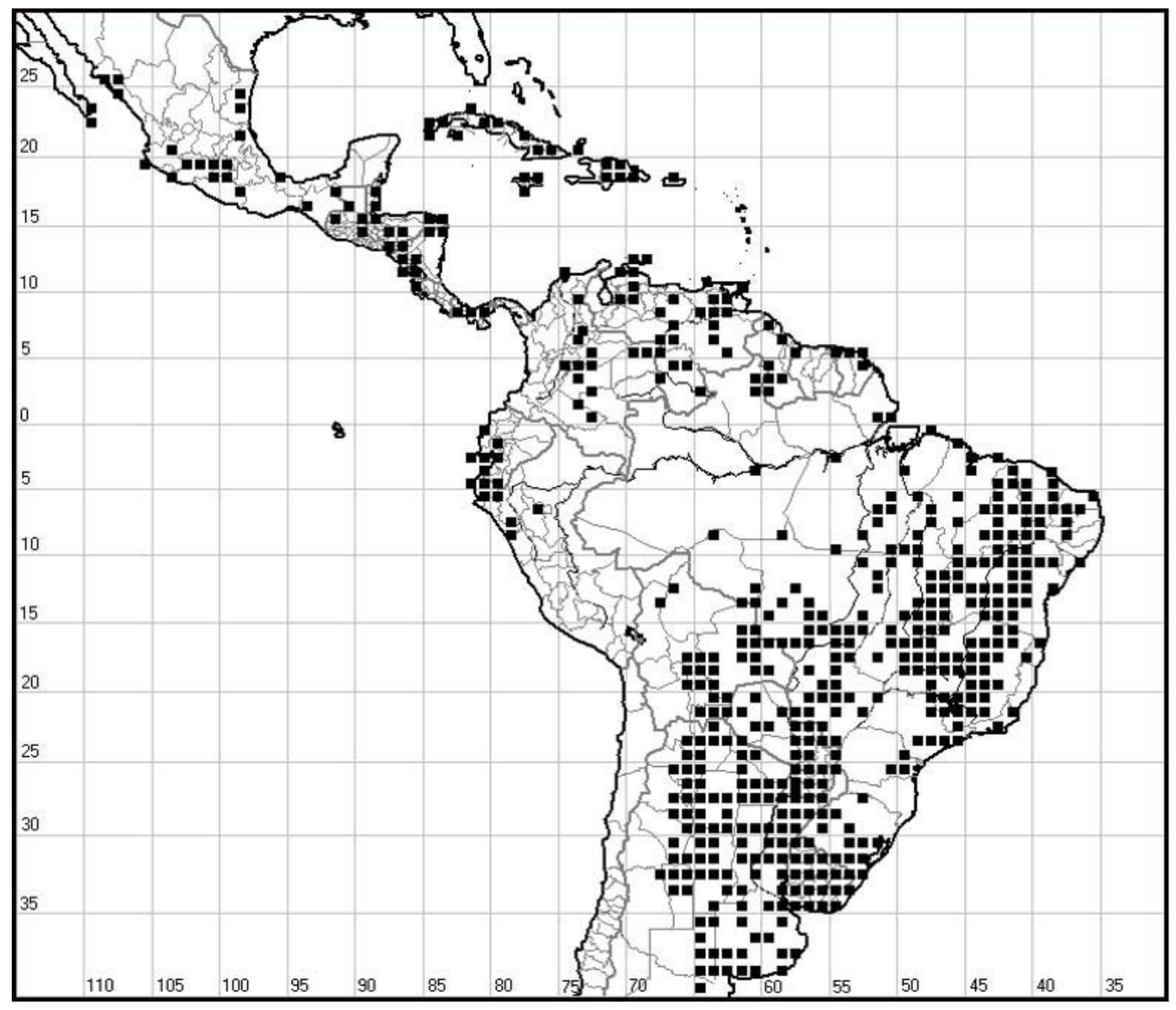

Fig. 1. Distribución de la Serie Leiocarpae. 

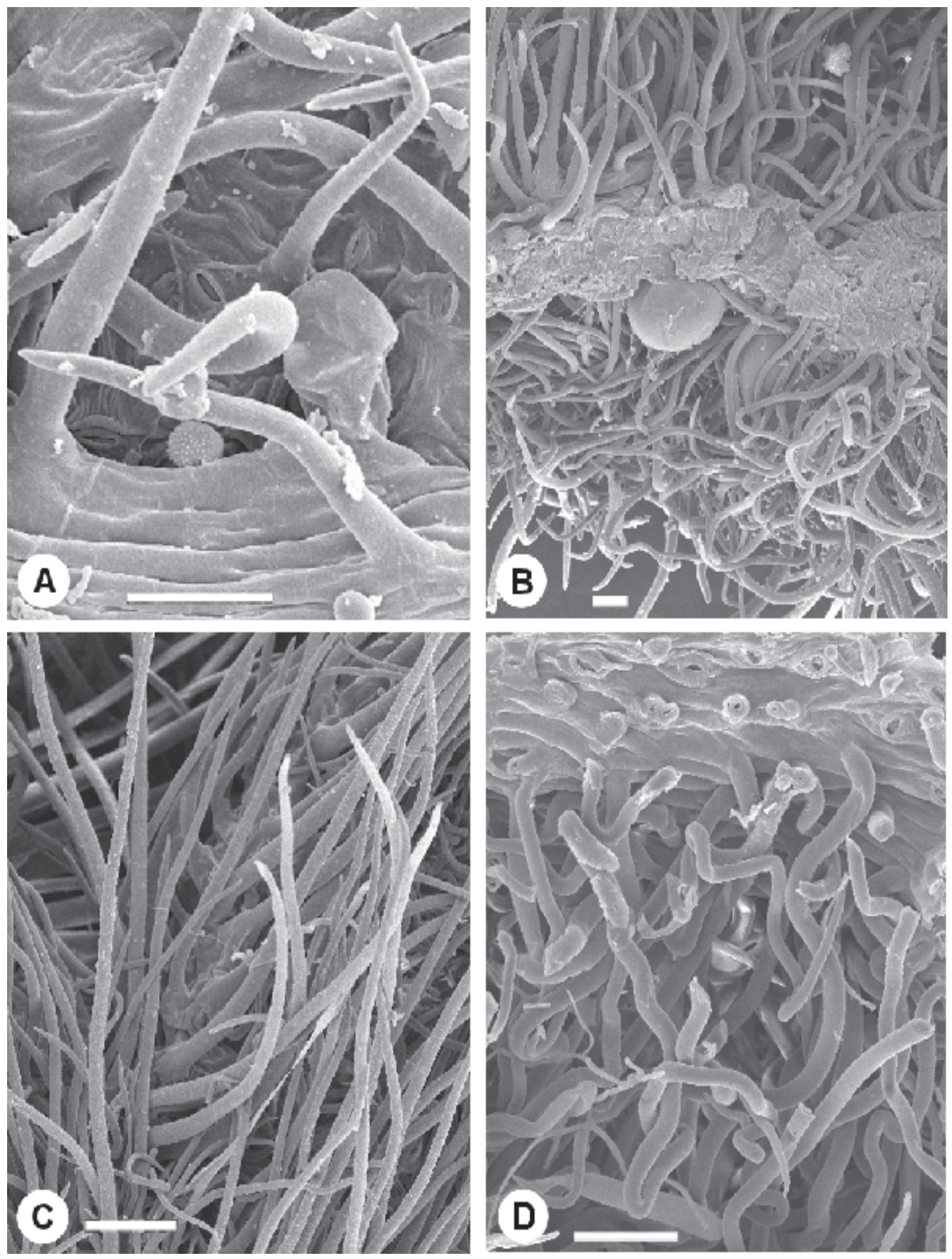

Fig. 2. Tricomas de las series Leiocarpae y Sessiliflora, con MEB. A: Turnera harleyi, hipofilo, mostrando pelos simples, un pelo microcapitado y estomas. B: T. stachydifolia, transcorte de hoja mostrando pelos simples y un pelo capitado-sésil. C: T. incana, epifilo mostrando pelos simples. D: T. dichotoma, transcorte de hoja mostrando pelos simples y estomas en el envés. Escala en A-B, D = 50mì. Escala en $\mathrm{C}=10$ mì. 


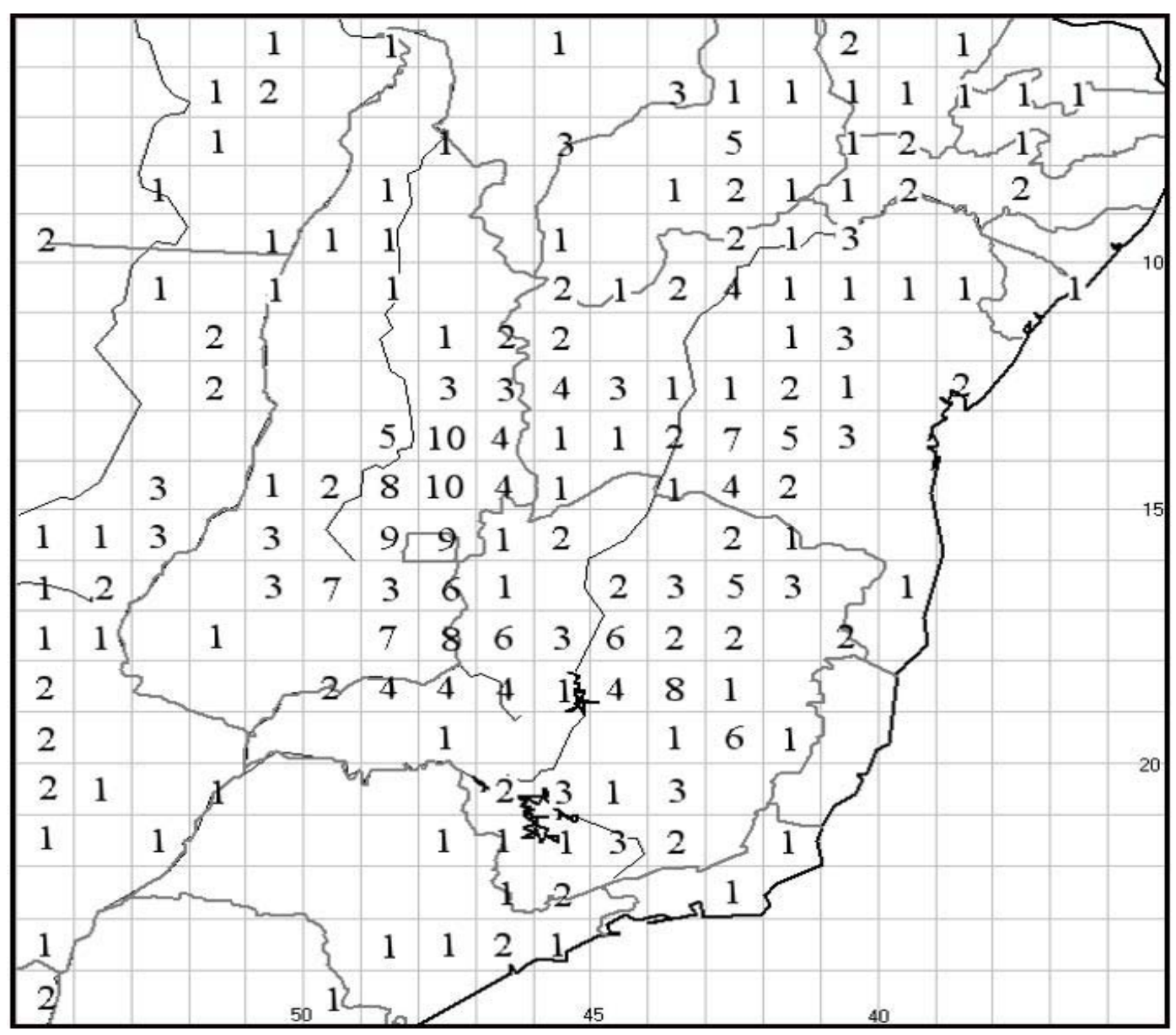

Fig. 3. Diversidad de Leiocarpae: número de especies por grado cuadrado

\section{Clave para las especies, subespecies y variedades de Leiocarpae}

1. Plantas brevicaules en roseta; entrenudos muy cortos.

2. Flores homostilas; pétalos purpúreos; placentas 8-10-ovuladas. Cuba.

T. acaulis Urb.

2'. Flores heterostilas; pétalos de otro color; placentas 3-8-ovuladas .

3. Hojas sin nectarios. Pétalos color lila; placentas 3-ovuladas. Brasil: Goiás.

T. rosulata Arbo

3'. Hojas con nectarios. Pétalos amarillos; placentas 8-ovuladas. Brasil: Distrito Federal.

T. humilis Arbo

1'. Plantas con tallo de entrenudos bien desarrollados.

4. Hojas sin nectarios.

5. Hojas angostas, 0,5-5,5 mm lat., lineares o angustielípticas, enteras o serruladas. Pedicelo floral ausente. Frutos lisos. Semilla reticulada. 
6. Hojas lineares; margen entero, marcadamente revoluto; epifilo lustroso, estrigoso. Brasil: BA y MG.

T. genistoides Cambess.

6'. Hojas lineares o angustielípticas; margen serrulado, plano; epifilo velutino. Brasil: GO.

T. vicaria Arbo

5'. Hojas anchas, 6-32 mm lat., ovadas o elípticas, enteras, pinatífidas o pinatipartidas. Pedicelo floral presente. Frutos granulosos. Semilla tuberculada.

7. Hojas intermedias pinatífidas o pinatipartidas (incisión de la hemilámina 37-95\%); venas secundarias excurvas; pelos simples largos adpresos y pelos cortos crespos. Profilos 0,3-1 mm lat. Flores dimorfas, diferencia en longitud androceo-gineceo $=1-5 \mathrm{~mm}$; pétalos rojo-anaranjados, amarillos o rosados; estigma 0,4-1 mm long. Bolivia, Paraguay, Argentina y Uruguay.

T. sidoides subsp. pinnatifida (Juss. Ex Por.) Arbo

7'. Hojas intermedias enteras, aserradas, a veces pinatífidas (incisión de la hemilámina 8-50\%); venas secundarias incurvas; pelos simples o estrellados. Profilos 0,2-6 mm lat. Flores dimorfas o trimorfas; pétalos de colores diversos.

8. Hipofilo y profilos con pelos simples erectos, 2-3 mm long., raramente también con pelos cortos. Flores dimorfas, diferencia en longitud androceo-gineceo $=1-4 \mathrm{~mm}$; pétalos rosados o color salmón. Paraguay, Argentina, Brasil (RS) y Uruguay.

T. sidoides subsp. integrifolia (Juss. ex Poir.) Arbo

8'. Hipofilo y profilos con pelos simples antrorsos, 1-2,5 mm long. y pelos cortos simples o estrellados. Flores trimorfas, diferencia en longitud androceo-gineceo $=0-4 \mathrm{~mm}$; pétalos de colores variados.

9. Pelos cortos estrellados, a veces mezclados con pelos simples. Profilos 0,5-3 mm lat. Pétalos rosados o magenta; estigma $0,3-0,5 \mathrm{~mm}$. Brasil (RS) y Uruguay.

T. sidoides L. subsp. sidoides

9'. Pelos cortos simples, a veces algunos bídifos. Profilos 0,2-6 mm lat.

10. Indumento laxo, no seríceo-lanoso, hojas verdes. Pétalos rosados o magenta; estigma 0,4-1 mm long. Paraguay, Argentina, Brasil (RS) y Uruguay.

T. sidoides subsp. carnea (Cambess.) Arbo

10'. Indumento seríceo-lanoso, hojas glaucas, a veces amarillentas en seco. Pétalos rojoanaranjados, amarillos o rosados; estigma 0,3-0,4 mm long. Brasil (RS) y Uruguay.

T. sidoides subsp. holosericea (Urb.) Arbo

4'. Hojas con nectarios, al menos las floríferas.

11. Hojas pinatipartidas o pinatisectas.

12. Arbusto 0,2-1 m. Hojas con margen revoluto; nectarios marginales o asentados en el envés foliar. Flores amarillas. Semilla con cálaza cónica. Brasil: BA.

T. luetzelburgii Sleumer var. luetzelburgii

12'. Hierba $20 \mathrm{~cm}$. Hojas con margen plano; nectarios estipitados en el pecíolo. Flores rosadopurpurescentes. Semilla sin cálaza cónica. Brasil: GO: Chapada dos Veadeiros.

T. fissifolia Arbo

11'. Hojas nunca pinatipartidas o pinatisectas.

13. Flores de color rojo vivo.

14. Arbusto virgado; ramas nuevas con pelos simples largos curvado-erectos y pelos simples cortos crespos, a veces hirsuto-tomentosas. Flores grandes, 20-25 mm long. Brasil: GO.

T. longiflora Cambess. 
14'. Arbusto ramoso; ramas estrigosas, a veces tomentosas hacia el ápice. Flores de menor tamaño, 13-18 mm long. Brasil: MG.

T. coccinea Arbo

13 '. Flores de otro color.

15. Tallos jóvenes tomentosos, velutinos o lanosos (pelos tan densos que no se ve la superficie de la epidermis) en los entrenudos apicales.

16. Hojas concoloras en seco.

17. Indumento amarillo-dorado o grisáceo-amarillento en seco; superficie de la epidermis no visible.

18. Planta toda velutino-tomentosa. Pelos glandulares capitado-sésiles ausentes. Hojas elípticas. Brasil: MG.

T. elliptica Urb.

18'. Arbusto ca. $1 \mathrm{~m}$, tallos y hojas lanoso-tomentosos. Pelos glandulares capitadosésiles rojizos o amarillos $(0,05 \mathrm{~mm})$, visibles en el hipofilo o en el tallo o en el cáliz. Brasil: BA.

19. Ramas rectas.

T. stachydifolia Urb. var. stachydifolia

19'. Ramas flexuosas.

T. stachydifolia var. flexuosa Urb.

17'. Indumento verde-grisáceo o verde-plateado en seco; superficie de la epidermis visible o no.

20. Hojas elípticas, obovadas u ovadas, 4-15 mm lat.; margen aserrado o serrulado, raro crenado; relación largo:ancho $=1,5-5(-7,5): 1$; ápice agudo u obtuso; superficie de la epidermis visible en el epifilo. Venezuela, $\mathrm{N}$ de Brasil.

T. lineata Urb.

20'. Hojas lineares o angustielípticas, 2-3 mm lat.; margen entero; relación largo:ancho =7-10:1; ápice obtuso; superficie de la epidermis no visible. Venezuela: Amazonas.

T. argentea Arbo

16'. Hojas discoloras en seco.

21. Arbusto 30-90 cm. Estípulas filiformes, oscuras, 1-3 mm long.

22. Epifilo con pelos simples largos y estrellados cortos, o al menos pelos bífidos o trífidos, raramente lustroso y glabrescente. Corola amarilla. Brasil: DF, GO, MG, BA.

T. lamiifolia Cambess.

22'. Epifilo con pelos simples curvado-antrorsos, a veces también pelos crespos muy densos. Corola rosada, salmón, blanca con centro amarillo o purpúreo, amarilla, a veces rosado-purpúrea. Brasil: GO, MS, TO.

T. incana Cambess.

21'. Hierba o subarbusto 5-40 cm. Estípulas rudimentarias o ausentes.

23. Envés foliar laxa o densamente piloso, superficie de la epidermis visible. Estilos glabros; placentas 4-5-ovuladas. Semilla con el lado rafeal recto.

24. Hojas algo discoloras; lámina 11-35 x 5,5-13 mm, relación largo:ancho = 1,63,2:1; 5-6 pares de venas laterales, ángulo de divergencia $35-40^{\circ}$. Colombia.

T. melochia Triana \& Planch. var. melochia 
24'. Hojas notoriamente discoloras; lámina 20-62 x 5-22 mm, relación largo:ancho $=2,5-6,6: 1 ; 5-8$ pares de venas laterales, ángulo de divergencia $20-35^{\circ}$. Venezuela y Brasil.

T. melochia var. ramosissima (Urb.) Arbo

23'. Envés foliar lanoso, superficie de la epidermis no visible. Estilos glabros o pilosos; placentas 2-3-ovuladas. Semilla con el lado rafeal incurvo.

25. Hojas con 9-10 pares de venas laterales. Estilos glabros; anteras cortas, 0,5 mm long. Brasil: MG.

T. diamantinae Arbo

25'. Hojas con 3-6 pares de venas laterales. Estilos pilosos; anteras largas, 0,9 mm long. Brasil: BA.

T. uleana Urb.

15'. Tallos jóvenes nunca tomentosos, velutinos o lanosos en los entrenudos apicales, superficie de la epidermis visible.

26. Tallos de sección subtriangular, trígonos o subtrialados al menos en la porción media. Hojas adultas glabras o con algunos pelos en la base. Brasil, GO y MG.

T. trigona Urb.

26'. Tallos de sección circular, cilíndricos en toda su extensión, a veces estriado-angulados pero no subtriangulares. Hojas adultas glabras o pilosas.

27. Cáliz completamente glabro por fuera. Hojas adultas glabras o subglabras.

28. Venas laterales prominentes en ambas caras de la hoja. Ovario y fruto pilosos. Profilos más largos que el fruto. Brasil: GO.

T. glabrata Arbo

28'. Venas laterales visibles en el envés o ausentes. Ovario y fruto glabros o con algunos pelos en el ápice. Profilos más cortos que el fruto.

29. Hojas lineares o linear-lanceoladas, frecuentemente sólo las hojas floríferas con nectarios. Placentas 3-7-ovuladas. Venezuela, Trinidad, Guayanas y N de Brasil.

T. guianensis Aubl.

29'. Hojas aciculares generalmente uninervias, con nectarios. Placentas 1-3-ovuladas. Brasil: GO.

T. pinifolia Urb.

27'. Cáliz piloso por fuera, al menos parcialmente. Hojas adultas subglabras o pilosas.

30. Tallos glabros, a veces con unos pocos pelos esparcidos en la base y en el ápice, o con algunos pelos en filas debajo de la inserción de cada hoja. Plantas graminiformes.

31. Hojas linear-lanceoladas o lanceoladas, 15-46 mm long., venación pinnada. Brasil: MT.

T. prancei Arbo

31'. Hojas filiformes o lineares, 3-15 mm long., uninervias. Brasil: GO y MG.

T. subnuda Urb.

30'. Tallos pilosos en toda su longitud, raramente glabrescentes. Plantas graminiformes o no.

32. Hojas lineares uninervias o con venas laterales difícilmente visibles.

33. Lámina foliar marcadamente revoluta, discolora, 0,8-2,5 mm lat., haz oscura, envés con indumento muy denso, blanquecino. Brasil: DF.

T. iterata Arbo

33'. Lámina foliar no revoluta, concolora, 1-3,5 mm lat., estrigosa o glabra. Brasil: GO.

T. tenuicaulis Urb. 
32'. Hojas con venas laterales conspicuas, lámina de ancho variable.

34. Venas laterales prominentes en ambas caras de la hoja.

35. Hojas con borde revoluto, herbáceas; venación menor inconspicua.

36. Hojas verdosas o pardas en seco, con pelos simples laxos a veces sólo sobre las venas. Filamentos estaminales generalmente con pelos simples blandos en la cara interna; placentas 4-15 ovuladas. Brasil: MG, Serra do Cipó.

T. cipoensis Arbo

36'. Hojas castaño-rojizas en seco, glabras excepto algunos pelos en la base. Filamentos estaminales glabros; placentas 1-3 ovuladas. Brasil: GO y MG.

T. riedeliana $\mathrm{Urb}$.

35'. Hojas con borde plano (a veces el margen algo revoluto en partes), herbáceas o coriáceas; venación menor conspicua o no.

37. Hojas generalmente excurvas o patentes.

38. Planta graminiforme, $9-45 \mathrm{~cm}$ alt., no ramificada o escasamente. Hojas excurvas, lineares o linear-lanceoladas, no pardo-rojizas en seco. Flores agrupadas en racimos apicales. Brasil: GO, MG, SP.

T. lanceolata Cambess.

38'. Planta no graminiforme, hasta $25 \mathrm{~cm}$ alt., simple o ramificada. Hojas patentes, elípticas o angustiovadas, pardo-rojizas en seco. Flores extendidas a lo largo del tallo. Brasil: GO, MG.

T. patens Arbo

37'. Hojas generalmente erguidas.

39. Lámina foliar adulta glabra, excepto las venas principales o la base; borde glabro excepto el ápice de los dientes. Flores blanco-cremosas. Semilla con retículo de nudos prominentes. Paraguay, Argentina NE.

T. nervosa Urb.

39'. Lámina foliar adulta con indumento variado, raramente algunas glabras; borde piloso. Flores amarillas. Semilla con retículo de nudos no prominentes.

40. Hojas herbáceas, opacas, con pelos simples laxos o sólo las venas pilosas; envés de aspecto arenáceo en seco, raramente liso. Tubo calicino frecuentemente translúcido en seco, por fuera glabro o con pelos simples cortos. Planta hasta $20 \mathrm{~cm}$ alt. Brasil: DF, GO, MG, SP.

T. hilaireana Urb.

40'. Hojas cartáceas o coriáceas, lustrosas (excepto ejemplares muy pilosos de $T$. oblongifolia), indumento variado; envés uniformemente coloreado o con puntos claros en seco. Tubo calicino opaco, con pelos simples cortos y largos. Planta hasta $60 \mathrm{~cm}$ alt.

41. Planta setosa (pelos $>2 \mathrm{~mm}$ long.). Tallo densamente folioso, ramificado. Nomófilos sin nectarios generalmente. Placentas 1-3 ovuladas. Brasil: DF, GO, MG.

T. foliosa Urb.

41'. Planta con pelos $<2 \mathrm{~mm}$ long. Tallo laxamente folioso. Nomófilos con nectarios generalmente. Placentas 4-15 ovuladas.

42. Hojas generalmente lustrosas, con puntos claros cuando la planta es castaña en seco; indumento laxo formado por un solo estrato de pelos 
simples muy variables, desde cortos y adpresos a muy largos (hasta 2 $\mathrm{mm})$, curvado-erectos o patentes. Brasil.

T. oblongifolia Cambess. var. oblongifolia

42'. Hojas opacas, a veces ligeramente lustrosas y punteadas; indumento denso, formado por dos estratos de pelos simples, unos cortos y crespos y otros largos, antrorsos o erectos. Brasil: DF, GO y MG.

T. oblongifolia var. goyazensis (Urb.) Arbo

34'. Venas laterales prominentes en el envés, y generalmente hundidas en la haz.

43. Base foliar prominente, persistente, cicatrices foliares salientes (absición foliar por encima de la base).

44. Tallo con indumento formado por pelos simples largos (antrorsos, curvado-erectos o patentes) y pelos crespos más cortos, raramente sólo pelos largos o pelos crespos.

45. Semilla con cálaza cónica. Brasil: BA y MG.

T. luetzelburgii var. dubia Arbo

45'. Semilla sin cálaza cónica.

46. Epifilo tomentoso.

47. Lámina de los pétalos con cara adaxial pilosa; filamentos estaminales pilosos; anteras de ápice agudo. Brasil: GO.

T. angelicae Arbo

47'. Lámina de los pétalos con algunos pelos en la base; filamentos estaminales glabros; anteras obtusas. Brasil: GO.

T. vallsii Arbo

46'. Epifilo de indumento variable, nunca tomentoso.

48. Flores epifilas solitarias o agrupadas hacia el extremo de las ramas. Hojas floríferas no bracteiformes.

49. Hojas lineares o angustielípticas, relación largo:ancho=8-23:1. Venezuela y N Brasil.

T. huberi Arbo

49'. Hojas de otra forma.

50. Haz foliar grisácea; envés foliar blanco, lanoso, superficie de la epidermis no visible. Brasil: BA.

T. uleana Urb.

50'. Haz foliar parda; envés foliar nunca blanco ni lanoso, superficie de la epidermis visible.

51. Envés foliar glabro excepto las venas pilosas.

T. venezuelana Arbo

51'. Envés foliar con pelos simples largos, pelos crespos y pelos glandulares microcapitados.

52. Hojas ovadas o angustiovadas, a veces elípticas. México, Antillas Neerlandesas, Centroamérica, Colombia, Venezuela y Guayanas.

T. curassavica Urb.

52'. Hojas obovadas generalmente. Brasil: MG y extremo S de BA.

T. opifera Mart. (rebrotes)

48'. Flores reunidas en racimos apicales o axilares bracteosos. Hojas floríferas bracteiformes o no. 
53. Fruto rugoso, o liso y rugoso en el mismo pie. Brasil: GO.

T.melochioides var. rugosa Arbo

53 '. Fruto liso o de superficie irregular por la base cónica de los pelos simples.

54. Hojas hirsutas en el envés, pelos 1,5-2 mm long.

55. Hojas floríferas con nectarios pequeños, $0,5 \mathrm{~mm}$ long., iguales o menores que los de las hojas vegetativas. Bolivia, SC y Brasil, MT.

T. dasytricha Pilger var. dasytricha

55'. Hojas floríferas con nectarios 0,7-0,8 mm long., más grandes que los de las hojas vegetativas. Brasil, PI.

T. dasytricha var. crinita Arbo

54'. Hojas con otro indumento en el envés, nunca hirsuto.

56. Hojas angustielípticas o lineares, a veces angustiobovadas, extendidas o longitudinalmente plegadas, 2,5-10 mm lat.; relación largo:ancho = 4,1-15,6:1; epifilo glabro o piloso.

T. melochioides var. arenaria Urb.

56'. Hojas de otra forma, extendidas, 8-25 mm lat.; relación largo:ancho=1,6-5,1:1; epifilo piloso.

T. melochioides var. latifolia Urb.

44'. Tallo con indumento estrigoso, formado por pelos simples adpresos, algunas veces también pelos crespos más cortos .

57. Hojas glabras, excepto algunos pelos sobre las venas, algo discoloras. Brasil: BA.

T. paradoxa Arbo

57'. Hojas pilosas, de haz oscura, en general marcadamente discoloras.

58. Lámina foliar 0,4-3,4 x 0,1-0,3(-0,5) cm, relación largo:ancho = (4,7-)6-20:1; margen marcadamente revoluto. Brasil: BA.

T. harleyi Arbo

58'. Lámina foliar 1,2-11 x 0,5-4 cm, relación largo:ancho = 2,5-4,5:1; margen plano o revoluto.

59. Cáliz de 7-13 mm long.

60. Corola apenas más larga que el cáliz. Arilo igual o más corto que la semilla. Brasil: PI.

T. jobertii Arbo

60'. Corola 2,5-8,5 mm más larga que el cáliz. Arilo igual o más largo que la semilla. Brasil: MG y extremo $\mathrm{S}$ de BA.

T. opifera Mart.

59'. Cáliz comúnmente de 5-6 mm long. Brasil, Bolivia, N de Paraguay.

T. melochioides Cambess. var. melochioides

43'. Base foliar no prominente ni persistente.

61. Ovario y fruto glabros excepto en el ápice. Semilla con cálaza cónica, marcadamente curvada; retículo de aréolas grandes y nudos prominentes.

62. Flores homostilas. México y Caribe hasta N de Argentina.

T. pumilea L. var. pumilea 62'. Flores heterostilas. Brasil: BA, PE, PI.

T. pumilea var. piauhyensis Urb. 
61'. Ovario y fruto pilosos. Semilla con otras características.

63. Pelos tectores simples y estrellados, a veces sólo simples en el epifilo. Hojas 1-8,5 cm lat., abolladas, discoloras. Brasil, DF y GO.

T. lamiifolia Cambess.

63'. Pelos tectores simples únicamente. Hojas de 1-3 cm, a veces abolladas, discoloras o no.

64. Lámina del pétalo con pelos en la unión con la uña o en la mitad basal.

65. Hojas notoriamente discoloras en seco; envés lanoso-tomentoso, blanquecino excepto las venas. Brasil central.

T. discolor Urb.

65'. Hojas concoloras en seco, o algo discoloras; envés con indumento laxo.

66. Epifilo glabro. Tubo calicino glabro en la base, con algunos pelos cortos sobre las venas en la parte superior; lámina del pétalo con algunos pelos en la base. Venezuela.

T. paruana Arbo

66'. Epifilo piloso. Tubo calicino piloso desde la base; lámina del pétalo con pelos en la vena media en el tercio basal. Venezuela y N Brasil.

T. huberi Arbo

64'. Lámina del pétalo glabra.

67. Flores epifilas solitarias.

68. Sépalos soldados entre sí sólo en el tercio basal.

69. Cáliz corto, 5,3-9 mm; anteras dorsifijas, filamento inserto en la mitad. Brasil: DF y GO.

T. crulsii Urb.

69'. Cáliz largo, 10-17 mm; anteras subbasifijas, filamento inserto a 1/3 de la base.

70. Hojas floríferas con nectarios asentados sobre el envés, junto al margen. Brasil:

GO.

T. emendata Arbo

70'. Hojas floríferas con nectarios en el margen foliar. Brasil: GO y TO.

T. pohliana Urb.

68'. Sépalos soldados entre sí entre $1 / 3$ y $1 / 2$.

71. Cáliz 12-19 mm long. Profilos más largos que el fruto. México.

T. callosa Urb.

71'. Cáliz 8,5-10 mm long. Profilos más cortos que el fruto. Brasil: MG.

T. gouveiana Arbo

67'. Flores epifilas agrupadas en racimos hojosos o bracteosos apicales, pero frecuentemente flores y frutos basales distanciados.

72. Nectarios presentes sólo en hojas floríferas. Brasil: PI.

T. jobertii Arbo

72'. Nectarios presentes en hojas vegetativas y floríferas.

73. Corola amarilla; profilos más cortos o más largos que el fruto maduro. Semilla con lado rafeal casi recto o curvo; arilo de células papilosas. México, Antillas Neerlandesas, Centroamérica, Colombia, Venezuela y Guayanas.

T. curassavica Urb.

73'. Corola marfilina o cremosa; profilos más cortos que el fruto maduro. Semilla con 
lado rafeal incurvo; arilo de células lisas.

74. Haz foliar con pelos simples largos, 1,4-2,5 mm long., frecuentemente sin orientación definida. Ramas seriales raramente desarrolladas. SE Bolivia, Brasil (MG, MS), NE de Paraguay.

T. dolichostigma Urb.

74'. Haz foliar con pelos simples cortos, 0,2-1(-1,2) mm long., orientados diagonalmente. Ramas seriales generalmente desarrolladas. Bolivia, Brasil, Paraguay y NE de Argentina.

T. hassleriana Urb.

\section{Turnera acaulis Griseb.}

Figs. 4 y 5

Grisebach, A. H. R., Cat. Pl. Cub.: 114. 1866. Typus: Cuba. Cuba occ., 25-VII, Wright 2607 (holotypus GOET!, isotypi BM!, GH!, K!, MO!, P!, US!).

Hierba perenne postrada, con rizoma de 1,5-3 mm diám.; tallos 0,5-3 cm long., con pelos simples largos y antrorsos entremezclados con pelos crespos; entrenudos muy breves, los más largos de $3 \mathrm{~mm}$ long. Hojas dispuestas en roseta. Estípulas subuladas, rojizas, $0,5 \mathrm{~mm}$ long. Pecíolo semicilíndrico, con la cara superior acanalada, 3-8 mm long. Lámina ovada, elíptica u obovada, 15-40 x 8-16 $\mathrm{mm}$, relación largo:ancho 2-3:1; base cuneada o brevemente atenuada; ápice agudo; borde simple o doblemente aserrado o aserradocrenado; haz pardo-rojiza, a veces punteada, con pelos simples largos y adpresos, a veces con base abultada, oblicuamente dispuestos con respecto a la vena media; envés rojizo en seco, con diminutas máculas más claras y pelos simples crespos; vena media y 6-8 pares de venas laterales hundidas en la haz, prominentes y densamente pilosas en el envés, perdiéndose hacia el margen; ángulo de divergencia $35-45^{\circ}$; venas terciarias y venación menor inconspicuas. Nectarios 0-2, minúsculos, circulares, en la unión de pecíolo y lámina. Flores solitarias, epifilas, homostilas. Pedúnculo totalmente soldado al pecíolo, 2-5 mm long. Profilos lanceolados u obovados, 310 x 1-3 mm; ápice agudo; borde entero o aserrado; pilosos en ambas caras; insertos en la base del receptáculo. Pedicelo nulo. Cáliz 12-16 mm long.; tubo calicino 6-7 mm long., cara externa glabra en la base, luego con pelos simples, cortos, crespos; cara interna vellosa; lóbulos triangulares, por fuera con pelos simples largos e hirsutos especialmente sobre las venas y pelos cortos crespos entremezclados, por dentro glabros; mucrón apical 0,2 $\mathrm{mm}$ long. Corola 2-5 mm más larga que el cáliz; pétalos con la uña soldada al tubo calicino y lámina obovada, color lila o púrpura. Filamentos estaminales complanado-subulados en seco, glabros, 7,5-11 mm long., soldados brevemente en la base al tubo calicino; anteras angustiovadas, obtusas, 0,6-1 mm long., el filamento inserto dorsalmente a $0,2-0,3 \mathrm{~mm}$ de la base. Ovario ovoide, hirsuto, 0,9 mm long.; placentas 4-5-ovuladas; estilos cilíndricos, glabros, 6,5-8,5 $\mathrm{mm}$ long.; estigmas penicilados, 1-1,5 mm long. Fruto ovoide, 4-6 mm long., con un reborde anular de $0,6 \mathrm{~mm}$ en la base, dejado por la absición del tubo floral; valvas ovadas, de cara externa lisa, con pelos simples largos y cara interna glabra, jaspeada; vena placentaria terminando en la mitad. Semilla breve, curvada, 1,6-2 x 0,9-1,2 mm; exóstoma cónico, 0,4 mm long.; rafe linear; cálaza ligeramente saliente, orientada hacia la rafe. Episperma reticulado, de aréolas transrectangulares o cuadrangulares, con una depresión punctiforme en cada una: epidermis lisa. Arilo breve, más corto que la semilla, angosto, unilateral, de células papilosas.

Material estudiado: CUBA. Isla de Pinos: San Pedro and vicinity, 12-II/22-III-1916, Britton \& al. 14280 (F, US); San Francisco, between S. Francisco and a hill called «Mal Pais», 26-X-1920, Ekman 11884 (S); inter Santa Ana et Santa Bárbara, 29-X-1920, Ekman 11955 (S); near Compañía Alemán, SE of Santa Bárbara, 19IV-1954, Killip 44023 (US). Pinar del Río: near El 


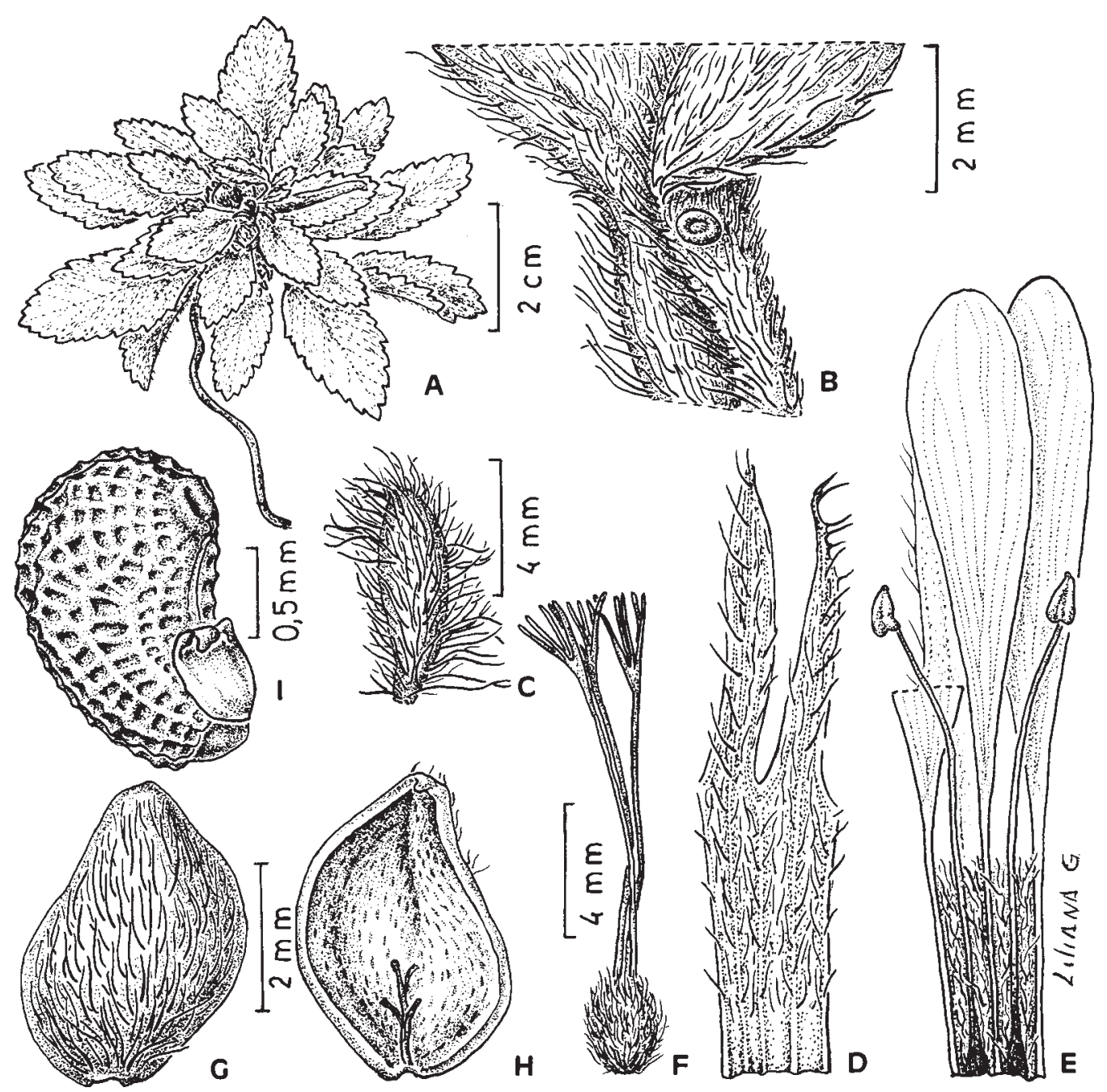

Fig. 4. Turnera acaulis. A: planta. B: pecíolo y porción basal de la lámina con nectario. C: profilo. D: porción del cáliz, cara externa. E: flor homostila, porción del tubo calicino, cara interna, con dos estambres adnatos en la base; se ha sombreado la porción adherida. F: gineceo. G-H: valva del fruto, caras externa e interna. I: semilla con arilo, vista lateral (A, G-I, Ekman 11955; B, Killip 44023; C-F, Ekman 11884). Del. Liliana Gómez

Payuco, between Guane and Remates, near sea level, 23XII-1937, Killip 32364 (US); W of Guane, 1-4-XII1911, Shafer 10683 (NY).

Distribución y fenología: Endémica de la región occidental de Cuba y de la Isla de la Juventud, donde crece en pinares y palmares. Se conocen unos pocos ejemplares, colectados entre octubre y abril.

Obs.: En el holotipo de Turnera acaulis el androceo es ligeramente más largo que el gineceo. Urban no encontró nectarios foliares en esta especie, pero hay ejemplares que los tienen, como el isotipo US y Killip 44023. Especie afín a $T$. rosulata y $T$. humilis, de Brasil, con flores heterostilas de menor tamaño, la primera con pétalos color lila y la segunda de pétalos amarillos.

\section{Turnera angelicae Arbo, sp. nov.}

Figs. 6 y 7

Fruticulus ca. $35 \mathrm{~cm}$ altus, pilis crispulis brevibus et aliis curvato-erectis indutus. Folia tomentosa, suprema sensim decrescentia, flores et 


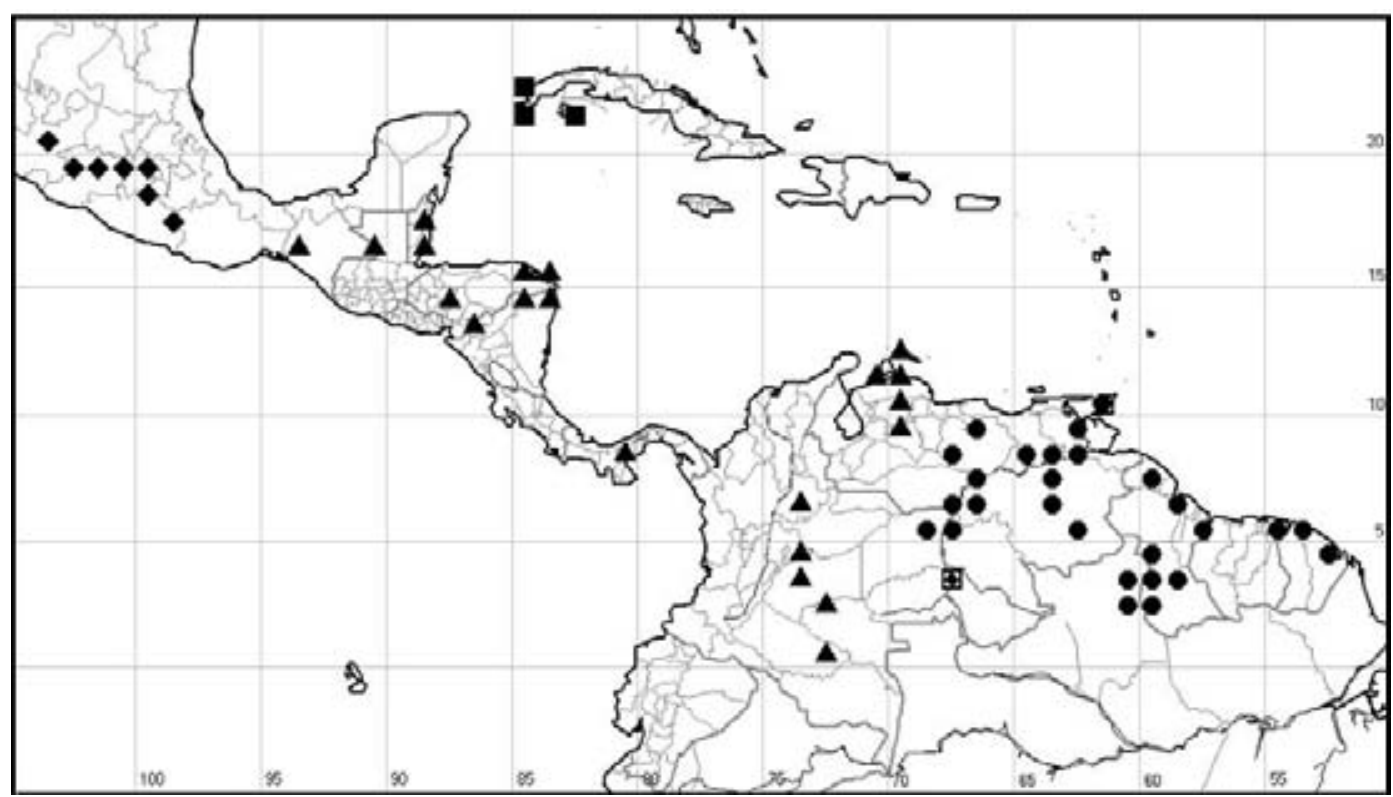

Fig. 5. Distribución de Turnera acaulis

;. argentea $\mathbf{Q}$; callosa

T. curassavica

;. guianensis

nectaria gerentia. Flores heterostyli, plerumque apice caulium capituliformi-conferti, pedunculo petiolo adnato, pedicello nullo; calyce 3,5-4 $\mathrm{mm}$ longo, extus densissime piloso; petalis flavis, pilosis; filamentis pilosis, subulatis, base tubo ca. $1 \mathrm{~mm}$ tota facie adnatis. Fructus dorso laevi. Semina 2,6-3 mm longa, curvata, brunnea, reticulata, chalaza vix prominula.

Typus: Brasil. Goiás: Gruta Angélica, Mun. São Domingos, 550 m, 16-V-2000, Hatschbach G., Schinini A. \& Barbosa E. 71220 (holotypus MBM, isotypus CTES).

Subarbusto ca. $35 \mathrm{~cm}$ alt.; tallo leñoso en la porción basal, $8 \mathrm{~mm}$ diám.; corteza pardooscura, longitudinalmente estriada; ramas 1,5-2 mm diám., densamente pilosas, con pelos amarillentos, curvado-antrorsos o más o menos patentes, $0,4 \mathrm{~mm}$ long., mezclados con pelos simples crespos más cortos y pelos microcapitados. Hojas discoloras. Estípulas rudimentarias con coléteres oscuros, $0,1 \mathrm{~mm}$ long., escondidos en el indumento. Pecíolo 1$3 \mathrm{~mm}$ long., indumento más denso que el del tallo. Lámina ovada, elíptica o suborbicular, 10-18 x 6-11,5 mm, relación largo:ancho = 1,3-1,9:1; base cuneada, brevemente atenuada o redondeada; ápice agudo u obtuso; margen ligeramente revoluto, crenado excepto en la porción basal; haz con pelos simples, antrorsos, orientados oblicuamente hacia el ápice; envés con indumento más denso: pelos simples de base cilíndrica y pelos microcapitados; vena media y 4-5 pares de venas laterales hundidas en la haz, rojizas y prominentes en el envés, rectas o algo incurvas, terminando en las escotaduras o perdiéndose en los dientes y dando ramas hacia las escotaduras; ángulo de divergencia $45-55^{\circ}$; venas terciarias recurvas, poco visibles en el envés. Nectarios ausentes en hojas vegetativas, o diminutos, $0,2 \mathrm{~mm}$ diám, sobre el margen foliar. Hojas floríferas apicales bracteiformes, espatuladas; pecíolo 2-3 mm; lámina muy reducida, 1,5-3,5 mm long., con un par de nectarios rojizos $0,4 \mathrm{~mm}$ diám., asentados sobre el envés, junto al margen foliar dentado. Flores dimorfas aparentemente (sólo se observaron las flores brevistilas), reunidas en los ápices de las ramas en racimos bracteosos abreviados. Pedúnculo $0,5 \mathrm{~mm}$, adnato al pecíolo. Profilos lineares, $2 \times 0,2 \mathrm{~mm}$, enteros, insertos en la base del receptáculo. Pedicelo ausente. Cáliz 3,5-4 mm long.; tubo calicino 1,7-2 mm long., interiormente glabro, por fuera con pelos simples muy densos y pelos más largos sobre las venas; lóbulos angustiovados o triangulares, 


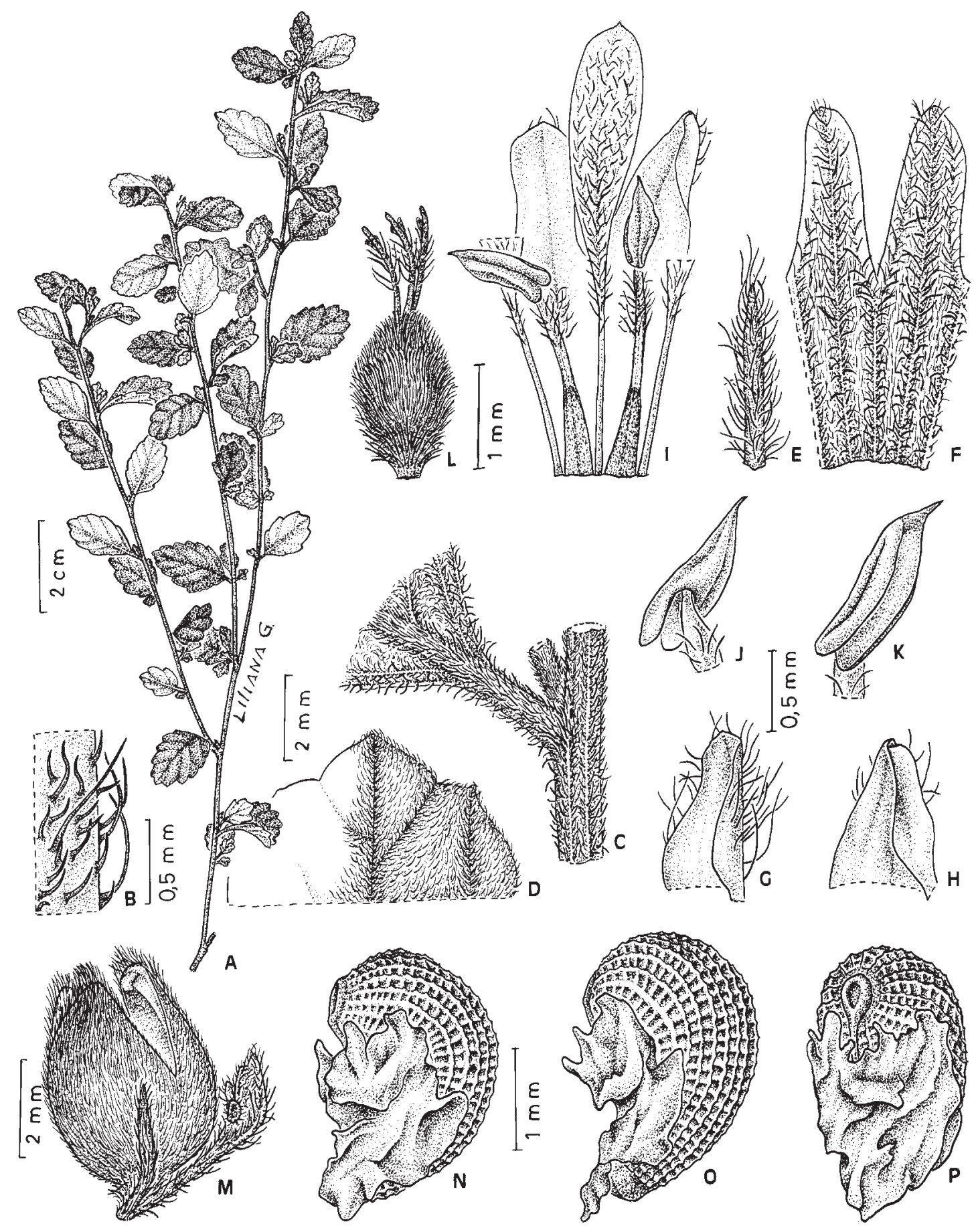

Fig. 6. Turnera angelicae. A: rama. B: porción del tallo mostrando el indumento. C: nudo, mostrando la base de la hoja y la base de una rama axilar. D: ápice de la lámina, cara adaxial. E: profilo. F: porción del cáliz, cara externa. GH: ápice de los lóbulos del cáliz. I: porción del tubo calicino, cara interna, con pétalos y estambres adnatos; se ha punteado la porción adherida de los filamentos. J-K: anteras, vista dorsal y ventral. L: gineceo. M: bráctea con nectario, fruto epifilo y profilo. N-P: semilla con arilo, N: vista lateral, O: mostrando el exóstoma, P: vista rafeal (Barbosa 71220). Del. Liliana Gómez. 


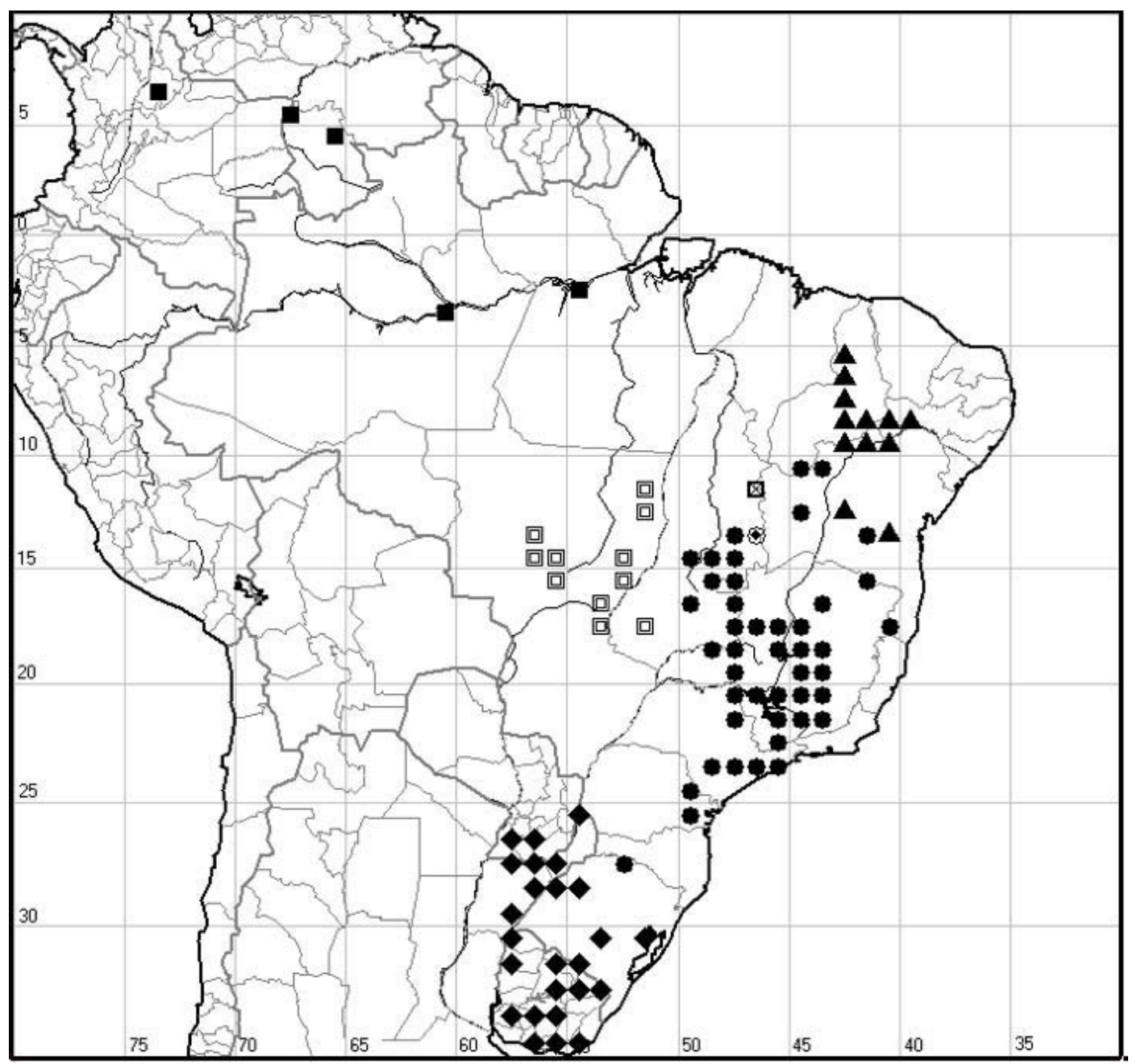

Fig. 7. Distribución de Turnera angelicae $\mathbf{\otimes} ;$ T discolor T. vallsii $\Theta$.

con pelos más largos que el tubo, emucronados. Corola amarilla $0,7 \mathrm{~mm}$ más larga que el cáliz; pétalos de lámina obovada, ca. 2,5 $\mathrm{mm}$ long., pilosa en la cara superior. Filamentos estaminales pilosos y subulados, soldados en la base ca. $1 \mathrm{~mm}$ al tubo calicino, 3,2 $\mathrm{mm}$ long. en flores brevistilas; anteras ovadas u ovado-oblongas, $0,9 \mathrm{x} 0,4 \mathrm{~mm}$, de base emarginada y ápice apiculado, con el filamento inserto dorsalmente a $0,4 \mathrm{~m}$ de la base. Ovario ovoide, densamente piloso, $1 \mathrm{~mm}$ long.; placentas 1-3-ovuladas; estilos cilíndricos, pilosos, 1,2 mm long. en flores brevistilas; estigmas brevísimos, paucirramosos, 0,2 $\mathrm{mm}$ long. En flores brevistilas androceo $1 \mathrm{~mm}$ más largo que el gineceo. Fruto ovoide, 3,2-4 mm long.; valvas de superficie lisa, con pelos simples antrorsos, por dentro glabras y nítidas. Semilla inmadura pardo-oscura, 2,6-3 x 1,5$1,7 \mathrm{~mm}$, angustiobovoide y curvada; exóstoma cónico; rafe linear, lado rafeal incurvo; cálaza redondeada, con una protuberancia negruzca que es continuación de la rafe. Episperma reticulado, nudos no prominentes, aréolas sin depresión punctiforme; epidermis papilosa en las aréolas. Arilo más corto o ligeramente más largo que la semilla, amarillento en seco, de células papilosas. 
Distribución: Se conoce solamente el ejemplar tipo, hallado en afloramientos de calcáreo.

Obs.: Turnera angelicae es la única especie con la cara adaxial de los pétalos completamente pilosa, y una de las pocas en la serie con filamentos estaminales pilosos. Su aspecto vegetativo es muy similar al de T.vallsii, que se diferencia por los filamentos estaminales glabros y por no tener pelos glandulares.

\section{Turnera argentea Arbo}

Figs. 5 y 8

Arbo, M. M., Ann. Missouri Bot. Gard. 77: 340-352. Fig. 2 A-E. 1990. Typus: Venezuela. T. F. Amazonas: Dep. Atabapo, sabanas y bosques al E del Caño Perro de Agua, afluente derecho (oriental) del Río Orinoco, a unos $30 \mathrm{~km}$ al SE de la confluencia Orinoco-Ventuari, aprox. 034' $\mathrm{N}$ $67^{\circ} 00^{\prime} \mathrm{W}$, ca. 100 m, 30-XI/1-XII-1978, Huber \& Tillett 2809 (holotypus VEN, isotypi CTES, US).

Arbusto de $1 \mathrm{~m}$, tallo erecto, ramificado; corteza pardo-negruzca con estrías longitudinales marcadas y estrías transversales muy tenues; cicatrices foliares no prominentes. Tallos jóvenes seríceo-velutinos, con pelos simples, largos, antrorsos o suberectos, muy densos, entremezclados con pelos crespos. Hojas concoloras, densamente dispuestas en los ápices de las ramas. Estípulas subuladas, pilosas, 0,4 mm long. Yemas seriales 2, la basal florífera, la apical vegetativa. Pecíolo semicilíndrico 1,1-2,5 mm long. Lámina foliar verde-plateada, linear o angustielíptica, 10-27 x 2-3 mm, relación largo:ancho $=7-10: 1$, longitudinalmente plegada; base atenuada; ápice obtuso; borde entero; haz y envés seríceo-velutinos; 6-7 pares de venas secundarias apenas salientes sobre el envés. Nectarios 0-2 en la unión de pecíolo y lámina o desplazados sobre el margen, 0,3-0,4 mm diám., parte central cubierta con la membrana cuticular rojiza; borde amarillento, pubérulo. Flores solitarias, epifilas, presumiblemente heterostilas (los ejemplares estudiados presentan flores longistilas), agru- padas en los extremos de las ramas. Pedúnculo 1,5-2 mm long., soldado al pecíolo. Profilos 2 en la base del receptáculo, subulados, 1,5$2,5 \times 0,3 \mathrm{~mm}$, cara externa con indumento como el de las hojas, cara interna glabra. Pedicelo no desarrollado. Cáliz 7-7,7 mm long.; tubo calicino 3,5-3,7 mm long., cara externa seríceo-velutina, cara interna vellosa; lóbulos triangulares, bordes internos membranáceos, cara interna glabra, cara externa con indumento más largo que en el tubo. Corola amarilla tan larga como el cáliz; pétalos con la uña soldada al tubo calicino, lámina 4-5 x 1-1,5 mm, obovada, cara superior con pelos largos en la base y sobre la vena media hasta la mitad. Filamentos estaminales subulados, glabros, soldados en la base 0,5 $\mathrm{mm}$ al tubo calicino, 4-4,7 $\mathrm{mm}$ long. en flores longistilas; anteras ovadas $0,7 \mathrm{~mm}$ long., dorsifijas, base emarginada, ápice apiculado. Ovario 0,7-1 mm long., densamente piloso; placentas 3-ovuladas; estilos 3, cilíndricos, glabros, 3,5-4,2 $\mathrm{mm}$ long. en flores longistilas; estigmas 1,2-1,5 mm long., penicilados, ca. 12 ramas. Fruto 2,5-3 mm long., con un reborde basal $0,4 \mathrm{~mm}$ lat. dejado por la absición del tubo floral; valvas lisas por fuera, con pelos simples crespos y otros largos antrorsos, cara interna lisa, lustrosa, amarillenta, con manchitas oscuras irregulares. Semilla obovoide, 1,6-2 x 1-1,3 mm; exóstoma cónico breve; rafe linear, lado rafeal recto; cálaza apical, excéntrica, poco saliente, oscura, ligeramente deprimida. Episperma pardonegruzco reticulado, muros longitudinales más notables que los transversales, aréolas pequeñitas cuadrangulares o transrectangulares con una depresión punctiforme; epidermis de células ligeramente papilosas y con acúmulos bastoniformes de cera. Arilo unilateral más corto que la semilla, membranáceo y blanquecino en seco, de células lisas.

Distribución: Se conoce solamente el ejemplar tipo, colectado en sabana abierta.

Obs.: Especie afín a Turnera elliptica Urb. de Goiás, Brasil, que se diferencia por sus hojas elípticas sésiles o subsésiles, 4-5 veces más anchas y aproximadamente de la misma longitud. 

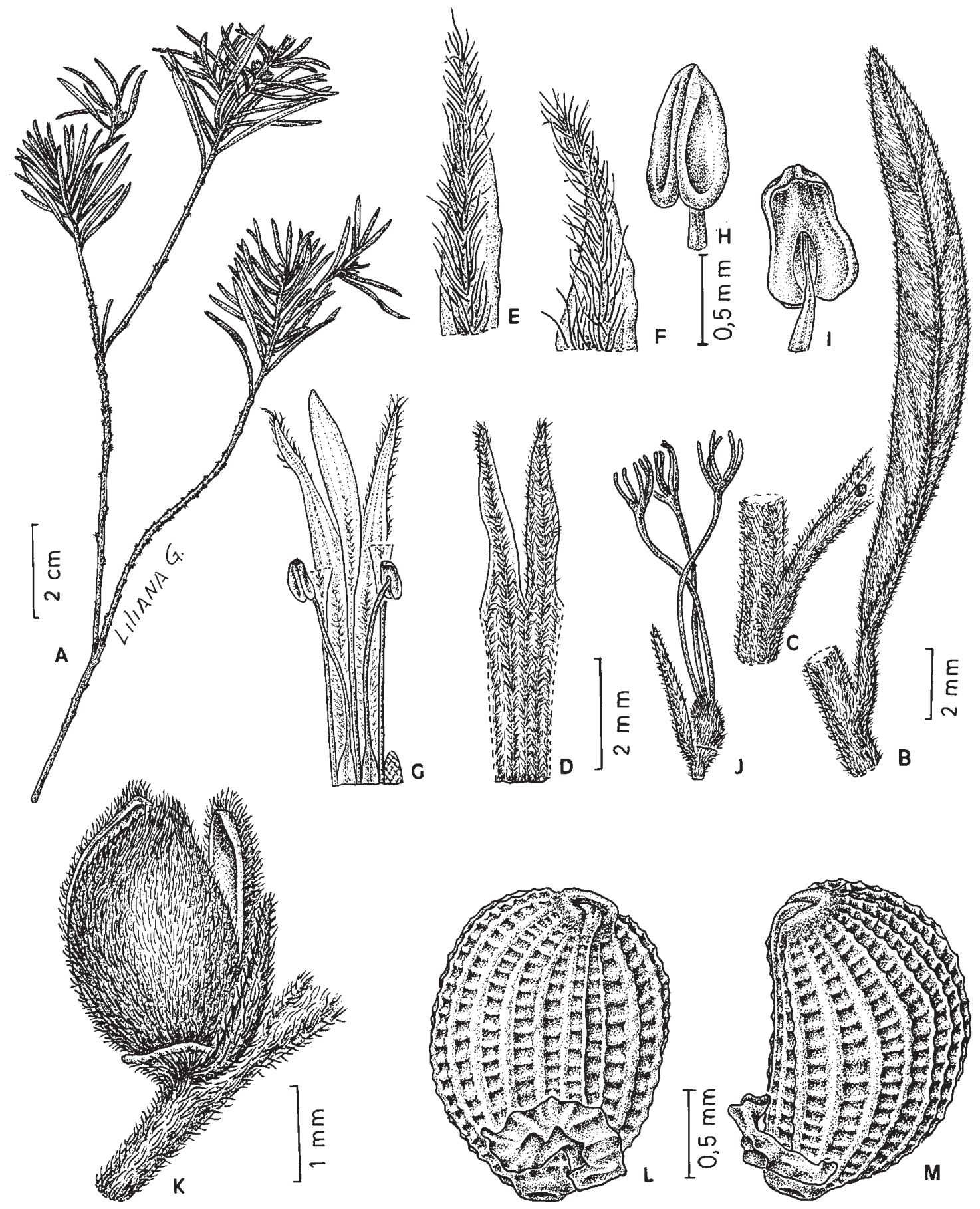

Fig. 8. Turnera argentea. A: rama. B: hoja, cara abaxial. C: base de una hoja florífera con nectario. D: porción del cáliz, cara externa. E-F: ápice de los lóbulos del cáliz, cara externa. G: flor longistila, porción del tubo calicino, cara interna, con pétalos y estambres adnatos; se ha cuadriculado la cicatriz dejada al desprender un estambre. H-I: anteras, vista ventral y dorsal. J: receptáculo con gineceo y profilo. K, fruto epifilo, cara externa, con profilo. L-M, semilla con arilo, vistas rafeal y lateral (A-M: Huber \& Tillett 2809). Del. Liliana Gómez. 


\section{Turnera callosa Urb.}

Figs. 5 y 9

Urban, I., Jahrb. Königl. Bot. Gart. Berlin 2: 105. 1883. Typus: Mexico. [Morelos]: près de Cuernavaca, VIII-1843, Ghiesbrecht 219 (lectotypus, aquí designado, $\mathrm{P}$ !, fototipo $\mathrm{F} \mathrm{n}^{\circ}$ 38454, isolectotypus P!).

Turnera palmeri S. Watson, Proc. Amer. Acad. Arts Sci. 22: 413. 1887. Typus: Mexico. Jalisco: Rio Blanco, VI-X-1886, Palmer 37 (holotypus $\mathrm{GH}$ !, isotypi $\mathrm{BM}$ !, F!, K!, MO!, NY!, P!, US!, WU!).

Hierba hemicriptófita 5-20 cm alt., ramas del año hirsutas, con pelos simples 1-2,5 mm long., y pelos simples cortos, erectos o antrorsos. Yemas axilares 1-2, ramas seriales raramente desarrolladas. Hojas herbáceas. Estípulas rudimentarias, con 3-4 coléteres. Pecíolo semiterete, 1-6 mm long., indumento como el del tallo. Lámina obovada, angustiobovada o elíptica, 19-45 x 7-27 mm; base atenuada; ápice obtuso o agudo; borde plano, piloso, doblemente aserrado-crenado, dientes agudos u obtusos, frecuentemente terminados en un coléter; haz punteada, con pelos simples adpresos 2,5-3 mm long., a veces glabrescente en hojas basales; envés finamente pardomaculado, con pelos simples 1-1,5 mm long. $y$ pelos crespos; vena media y 4-7 pares de venas laterales alternas o subopuestas, prominentes e hirsutas en el envés, rectas o ligeramente incurvas; perdiéndose hacia el margen; ángulo de divergencia $20-35^{\circ}$; venas terciarias a veces conspicuas en haz y envés, venación menor inconspicua. Nectarios marginales 1-2 pares (excepto en las hojas basales) distantes 1-3 mm de la base, 0,3-1 mm long., circulares o elípticos, borde piloso, a veces algo estipitados. Flores solitarias, epifilas, heterostilas. Pedúnculo 3-6 mm long., totalmente soldado al pecíolo e incluso a la vena media. Profilos insertos en la base del receptáculo, lineares o subulados, 5-12 x 0,3-0,5 mm, castaño-rojizos; por fuera hirsutos, cara interna glabra en la base, luego con pelos esparcidos. Pedicelo subnulo. Cáliz 12-19,5 mm long.; tubo calicino 5,5-7 mm long., glabro por fuera, con algunos pelos en la porción apical, o glabro sólo en la base, velloso por dentro; lóbulos triangulares, hirsutos por fuera, pelos simples 1-2,5 mm long. con algunos pelos crespos entremezclados, cara interna glabra, mucrón apical 0,1-0,5 mm long. Corola amarillo-anaranjada, 6-7 mm más larga que el cáliz; pétalos con la uña soldada al tubo calicino, vellosa, lámina obovada, 13,5-19 x 4-11 mm, con algunos pelos simples largos en la base. Filamentos estaminales glabros, complanadosubulados en seco, soldados $0,5-1 \mathrm{~mm}$ en la base al tubo calicino, 7-8,5 $\mathrm{mm}$ long. en flores longistilas, 11-13,5 mm long. en flores brevistilas; anteras angustiovadas, 0,8-1,3 x 0,4-0,8 $\mathrm{mm}$, base emarginada, ápice obtuso recurvado en la dehiscencia, filamento inserto dorsalmente a 0,4-0,6 $\mathrm{mm}$ de la base. Ovario hirsuto, a veces la parte basal glabra, 1,2-1,5 mm long.; placentas 6-8-ovuladas, óvulos insertos hasta la mitad del ovario; estilos cilíndricos, glabros, 7,5-9,5 mm long. en flores longistilas, 4-7 mm long. en flores brevistilas; estigma penicilado, 1,5-3 mm long., 10-24 ramas, glabro o setuloso. En flores longistilas el gineceo es 3-4 mm mayor que el androceo y 6 mm más corto que el cáliz; en flores brevistilas el androceo es 1,8-4,5 mm más largo que el gineceo y 3-4 mm más corto que el cáliz. Fruto ovoide, 3-5 mm long., con un reborde anular de $0,5 \mathrm{~mm}$ dejado por el tubo floral al desprenderse; profilos más largos que el fruto; valvas ovadas, cara externa lisa, pilosa, cara interna glabra, amarillenta o jaspeada de castaño obscuro, vena placentaria prominente en la base. Semilla obovoide, curvada, 1,8-2,5 x 0,9-1,2 mm; exóstoma cónico, excéntrico, muy breve; rafe linear, lado rafeal incurvo; cálaza redondeada, oscura, poco prominente, con células papilosas. Episperma reticulado, aréolas más o menos cuadrangulares, transrectangulares o hexagonales, células de las aréolas papilosas. Arilo unilateral, más corto que la semilla, angosto, de células lisas.

Material estudiado: MEXICO. Sin localidad, Bates s.n. (K, sintipo), Schnée s.n. (P); Huejuquilla, Rose 3562 (US); Novae Hispaniae, 1787-1795-1804, Sessé \& al. 5089 (F). Guanajuato: La Loma, perteneciente a Tócuaro, mun. Acámbaro, 1900 m, 11-VII-1986, Santos- 


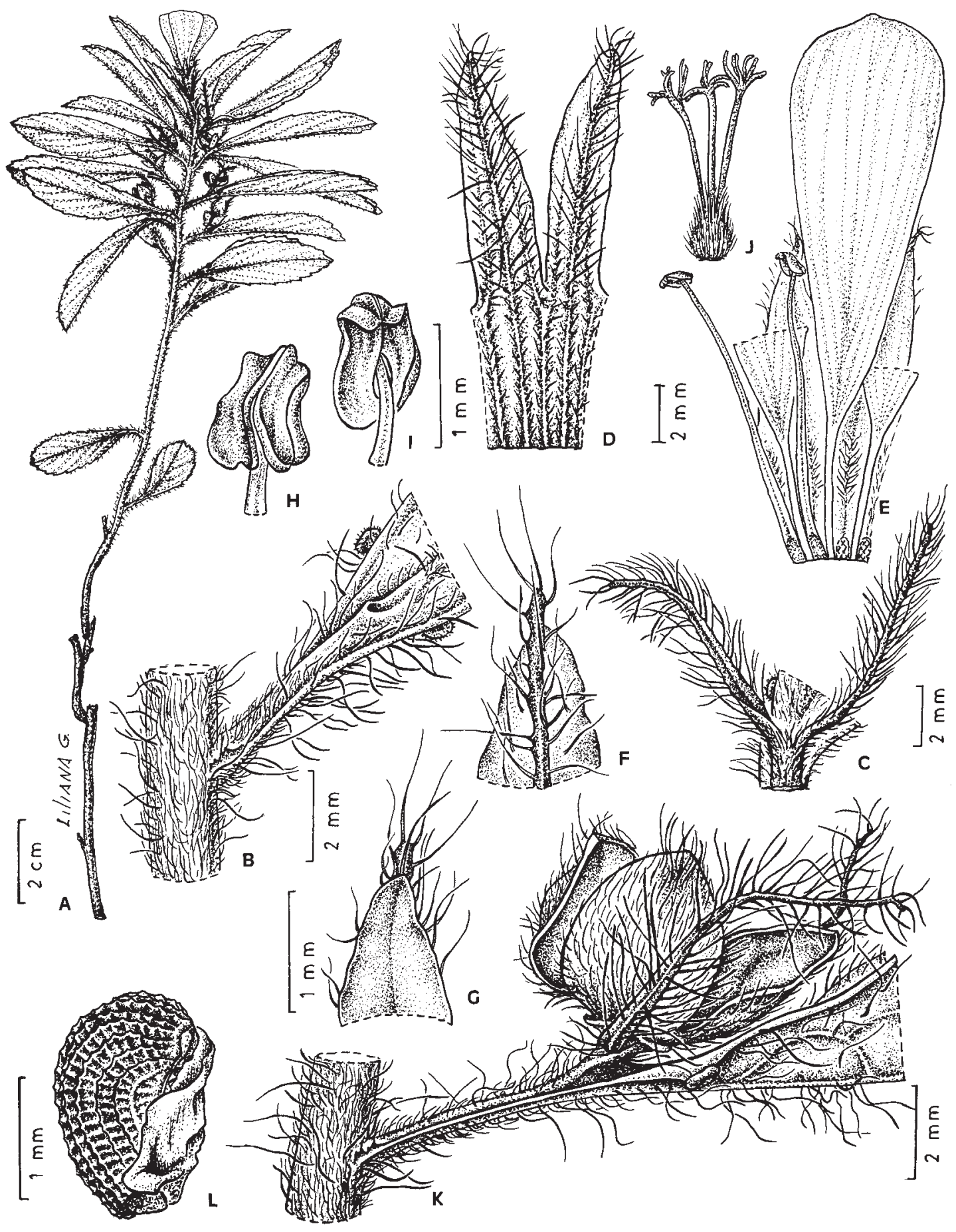

Fig. 9. Turnera callosa. A: Planta. B: nudo y porción basal de una hoja mostrando los nectarios y la cicatriz en la base de la lámina dejada al desprenderse la flor. C: base foliar con pedúnculo adnato y profilos. D: porción del cáliz, cara externa. E, flor brevistila, porción del tubo calicino, cara interna, con pétalos y estambres adnatos; se han cuadriculado las cicatrices dejadas al desprender dos estambres. F-G: ápice de los lóbulos del cáliz, cara externa e interna. H-I: anteras, vista ventral y dorsal. J: gineceo. K: nudo y fruto epifilo, con profilos. L: semilla con arilo, vista lateral (A-B, K-L: Santos Martínez 1500; C-J: Rzedowski 39767). Del. Liliana Gómez. 
Martínez 1500 (CTES). Jalisco: N of Guadalajara on road to Zacatecas, 4300ft, 9-VIII-1973, 73HH2 (NY); HWY 15 between Guadalajara and Tequila, Km 22, 5220ft, 12-VII-1971, Andreasen \& al. 620A (MO, NY); $5 \mathrm{mi} \mathrm{S}$ of Guadala-jara, 5000ft, 12-VIII-1947, Barkley \& al. 7507 (F); Mun. Zapopan, ladera NE del Cerro del Colli, 9-VII1977, Carvajal Hernández 202 (MEXU); E of Guadalajara, 17-V-1848, Gregg 854 (MO); Ixtlahuacan del Rio, 1500 m, 8-VIII-1984, Hernández Magaña \& al. 9433 (F); Guadalajara, 21-VI-1893, Pringle 4405 (BM, BR, E, F, GH, K, HBG, M, MEXU, MO, MU, NY, P, S, US, W, WU); near Guadalajara, 23-V-1891, Pringle 5128 (F); ídem, 5000ft, 14-VII-1902, Pringle 9804 (F, GH, K, LY, MO, US); near Tequila, 5-6-VII-1899, Rose \& Hough 4765 (US); near Guadalajara, near Rio Blanco, 30-IX-1903, Rose \& Painter 7482 (NY, US); on Hwy. 15 between jct. of Hwy. 100 and Lago de Chapala, 14-VIII-1957, Solbrig \& Ornduff 4444 (GH); Temascaltepec, Volcán, 1410 m, 22-I-1932, Hinton 744 (BM, K, NY); México, 1892, Jony 2581 (US). Michoacán: vicinity of Morelia, Loma Sta. María, 1950 m, 7-VI-1911, Arsene 5397 (GH, MO, P); Uruapan, 5425ft, 31VII-1945, Fisher 45199 (US); alrededores de la Presa Cointzio, mun. Morelia, 2100 m, 3-VI-1986, Rzedowski 39767 (CTES). Morelos: Sta. María, 7VI-1911, Arsene 5397 (B, GH, MO, P, US); environs de Cuernavaca, VIII-1843, Ghiesbrecht 148 (F, P); Cuernavaca, 16-VII-1938, Kenoyer A607 (F); near Tepoztlan, ca. 1600 m, 30-V-1939, Nagel $8008(\mathrm{GH})$.

Distribución: Endémica de México. Crece en campos de suelo arcilloso o pedregoso y laderas de cerros, en pastizales o matorrales abiertos, entre 1400 y 2100 m elev. Se adapta a sitios modificados como los bordes de los caminos. Todos los ejemplares conocidos fueron colectados entre mayo y octubre, excepto uno en enero.

Obs.: El aspecto de la planta en seco es similar al de Turnera sidoides L. subsp. integrifolia (Griseb.) Arbo, que se diferencia por tener flor rosada y semilla crestada. En Arsène 5397 las hojas basales son glabrescentes. En Rose 3562 (US) la parte basal del ovario casi no tiene pelos, sólo la porción apical es pilosa.
Spencer \& al. (1985) hallaron compuestos cianogénicos en hojas del ejemplar Barkley \& al. $7507(\mathrm{~F})$.

\section{Turnera cipoensis Arbo}

Fig. 10

Arbo, M. M., Bonplandia 7: 63-99. Fig. 3. 1993. Typus: Brasil. Minas Gerais, 7 km NE de Cardeal Mota, camino a Conceição do Mato Dentro, $19^{\circ} 20^{\prime} \mathrm{S} 43^{\circ} 35^{\prime} \mathrm{W}, 1000-1320 \mathrm{~m}, 8-\mathrm{II}-1991$, Arbo \& al. 4631 (holotypus SPF!, isotypi CTES!, F!, GH!, K!, MBM!, MO!).

Hierba perenne o subarbusto erecto, 8-40 cm alt., base leñosa 1-10 mm diám.; tallos 1-6, ramificados desde cerca de la base, cilíndricos, castaños o negruzcos en la base, luego verdes, 1-2,5 mm diám., glabrescentes en la parte inferior, luego densamente estrigosos, con pelos simples, cortos, gruesos, curvadoantrorsos, amarillentos; entrenudos 0,1-22 mm long., más cortos en la región apical. Hojas herbáceas, erectas a patentes. Estípulas rudimentarias, con un mechón de pelos y coléteres cónicos, rojizos, 0,2-0,4 mm long. Pecíolo estrigoso, 0,5-2,5 mm long. Lámina verdosa o castaña en seco, elíptica, lanceolada, ovada, a veces largamente obovada, 6-33 x 2-13 mm, relación largo:ancho 1,7-5:1; base cuneada o atenuada; ápice agudo; borde revoluto, entero o aserra-do en la porción apical (hasta 70\% de su longitud), glabro o piloso, dientes de aspecto glanduloso, terminados en coléteres; haz punteada o no, generalmente opaca, ambas caras con pelos simples adpresos laxos, a veces solamente las venas pilosas; $2-5$ pares de venas laterales, salientes en ambas caras, opuestas o alternas; ángulo de divergencia 35$50^{\circ}$; venación menor inconspicua. Nectarios $1+1$, raramente $1+2$ o $2+2$, circulares o elípticos, 0,4-1,2 mm long., reborde glabro o pubérulo, generalmente amarillento, centro cubierto con la membrana cuticular oscura, ubicados en la unión de pecíolo y lámina o desplazados 0,5-2 mm sobre el margen foliar. Flores solitarias, heterosti-las, epifilas. Alabastro elipsoide, recto, mucrones libres en el 


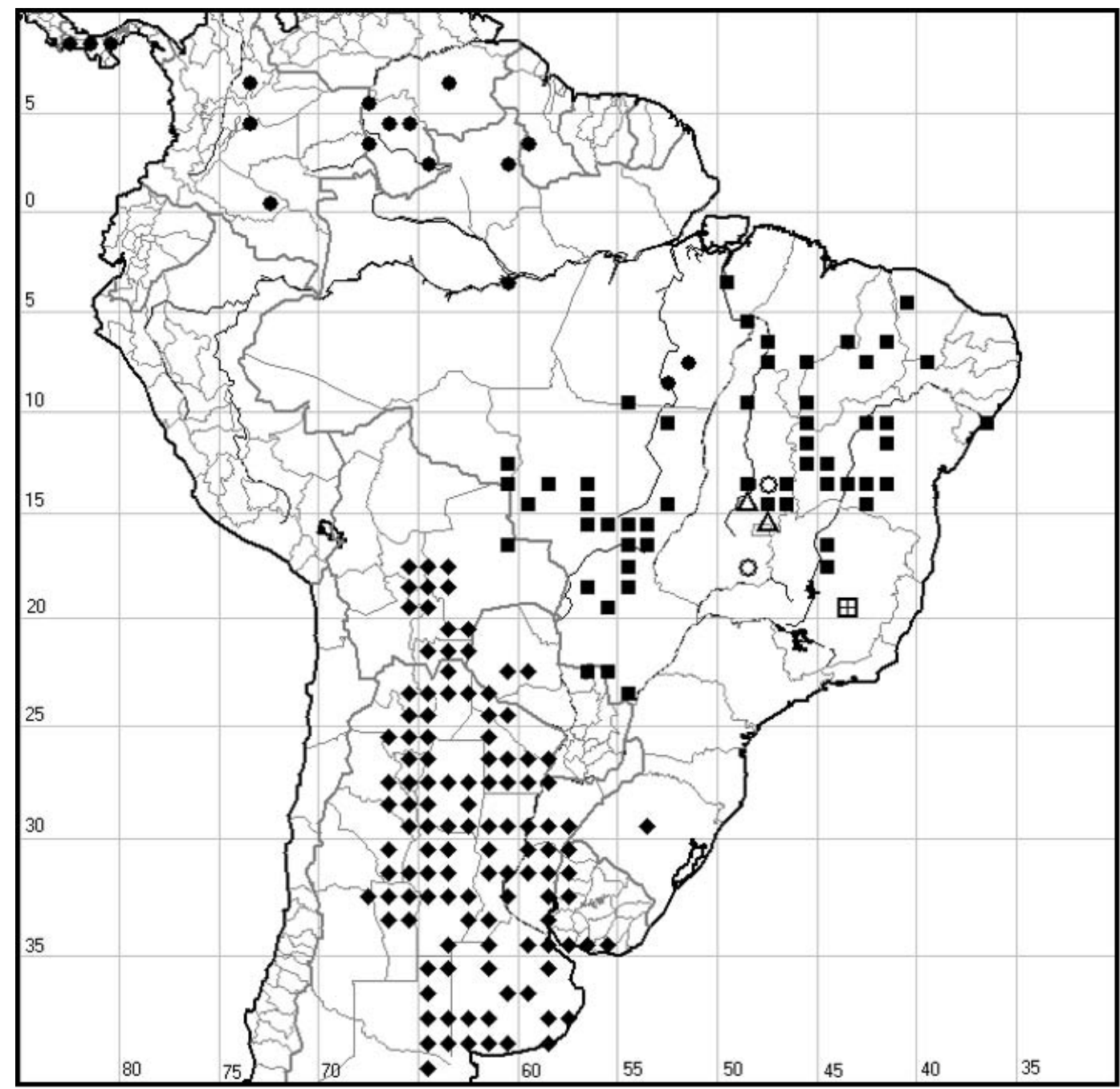

Fig. 10. Distribución de Turnera cipoensis $\mathbf{⿴ 囗 十}$; T.crulsii $\triangle$; T.emendata $\mathrm{O}$; T. lineata $\bigcirc$; T. melochioides var. melochioides

\author{
; T.sidoides ssp. pinnatifida
}

ápice. Pedúnculo 2-5 mm, totalmente soldado al pecíolo y a veces a la vena media. Pedicelo ausente. Profilos opuestos, dispuestos en la base del receptáculo, subulados o triangulares, 2,5-5 x 0,4-1 mm, estrigosos por fuera, borde con 1-4 dientes glandulosos a cada lado, ápice agudo, con pelos. Cáliz 8,5-13 mm long.; tubo calicino 2,5-4 mm long., estrigoso por fuera, velloso por dentro; lóbulos triangulares o lanceolados, por fuera con pelos simples, largos, curvado-antrorsos, por dentro glabros, bordes internos membranáceos y a veces purpúreos, ápice con mucrón 0,3-0,5 $\mathrm{mm}$ long. Corola amarilla, pétalos con uña vellosa, lámina obovada, 10-14 x 5-8 mm, base pilosa por dentro, ápice obtuso. Filamentos estaminales con pelos simples blandos en la cara interna o en ambas, a veces glabros, soldados en la base por $0,3-0,5 \mathrm{~mm}$ al tubo calicino, 4,5-6 mm long. en flores longistilas, 7-8,5 mm long. en flores brevistilas; anteras ovadas, dorsifijas, 1,2-2 x 0,5-0,8 mm, base emarginada, ápice obtuso, rectas o ligeramente curvadas después de la dehiscencia, filamento inserto dorsalmente a $0,5-0,7 \mathrm{~mm}$ de la base. Ovario cónico, 1,1-2 mm long., densamente cubierto de pelos gruesos, rígidos; placentas ca. 8-ovuladas; estilos cilíndricos, 
glabros, 4,5-6 mm long. en flores longistilas, 2,5-3 mm long. en flores brevistilas; estigmas 1,5-3 mm long., divididos en 16-18 ramas cilíndricas. Fruto esferoidal o elipsoidal, a veces apicula-do, 3-7 x 3-5 mm, con un reborde membranáceo $0,3-0,5 \mathrm{~mm}$ lat. alrededor de la base, dejado por la absición del tubo floral; valvas ovadas, dehiscentes hasta la base, pilosas por fuera, glabras y jaspeadas por dentro. Semilla obpiriforme, curvada, castaña, 22,5 x 1,2-1,5 mm; exóstoma cónico; rafe linear, lado rafeal incurvo; cálaza ligeramente saliente, pigmentada. Episperma reticulado, aréolas cuadrangulares o rectangulares, nudos generalmente prominentes; epidermis de células papilosas. Arilo membranáceo en seco, 11,5 mm long., de células lisas.

Material estudiado: BRASIL. Minas Gerais. Serra do Cipó: ca. 1220 m, 20-II-1972, Anderson \& al. 36382 (UB); 10-20 km NE de Cardeal Mota, camino a Conceição do Mato Dentro, $19^{\circ} 20^{\prime} \mathrm{S}$

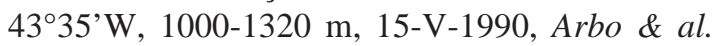
4117 (K, MBM); Mun. Santa Luzia, Km 127, Palácio, 3-IX-1933, Barreto 8180 (F); Mun. Santana do Riacho, Parque Nac. da Serra do Cipó, Serra das Bandeirinhas, 1400-1500 m, 27-VII1991, Giulietti \& al. CFSC 12493 (SPF); ca. Km 120, ca. $145 \mathrm{~km} \mathrm{~N}$ of Belo Horizonte, 1200 m, 15II-1968, Irwin \& al. 20104a (UB); Mun. Jaboticatubas, ao longo da rodovia Lagoa Santa Conceição do Mato Dentro - Diamantina, Km 116, 1175 m, 6-VI-1970, Joly \& al. 109 (SPF); Santana do Riacho, ca. 1300 m, Melo s.n. (BHCB, CTES); Conceição, Fazenda Palacio, 1200 m, 22-XII1948, Palacios \& al. 3590 (R), Serra do Cipó, 1200-1300 m, 16-III-1964, Pereira 8897 (CTES, HB); Mun. Santana do Riacho, Serra do Cipó, Km 125 da Rodovia Belo Horizonte-Conceição do Mato Dentro, 7-XII-1991, Pirani \& al. CFSC 12827 (SPF); Mun. Jaboticatubas: ao longo da rodovia Lagoa Santa - Conceição do Mato Dentro - Diamantina, Km 127, Semir \& Sazima 494 (E, SPF).

Distribución y fenología: Turnera cipoensis es endémica de la Serra do Cipó, Minas Gerais, donde crece en campo de altura, «campo rupestre» y «cerrado», en suelo arenoso, a 1000-1500 m de elevación. Florece prácticamente todo el año.
Obs.: Especie afín a Turnera riedeliana, que se diferencia por su porte menor, y sus hojas lineares, también con margen revoluto. T. hilaireana, de aspecto similar, se distingue por sus hojas con margen plano y sus estambres glabros. Es muy visitada por hormigas negras. En algunos ejemplares se han observado flores con el gineceo constituido por cuatro carpelos.

\section{Turnera coccinea Arbo}

Figs. 11 y 12

Arbo, M. M., Bol. Bot. Univ. São Paulo 24: 126-127. Fig. 2. 2006. Typus: Brasil. Minas Gerais: extremo N de Serra da Bocaina, próximo a las nacientes del río Ventania, aprox. $16^{\circ} 15^{\prime} \mathrm{S}$ 42 ${ }^{\circ} 53^{\prime} \mathrm{W}, 920$ m, 20-XI-1992, Mello-Silva, Arbo \& Nunes 760 (holotypus SPF, isotypi CTES, MBM, NY, G, SI).

Arbusto globoso $0,7-1,5 \mathrm{~m}$, tallos erectos 2,5-4 mm diám., corteza oscura, con grietas longitudinales y transversales; cicatrices foliares salientes.; ramas densamente estrigosas, a veces tomentosas hacia el ápice, con pelos simples amarillos, gruesos, curvado-antrorsos, mezclados con pelos simples, cortos y crespos. Hojas discoloras. Base foliar saliente y persistente después de la absición. Estípulas rudimentarias, con 2-3 coléteres subulados 0,2-0,5 mm long. Pecíolo 2-5 mm long., indumento como el del tallo. Lámina elíptica, ovada, obovada, suborbicular, orbicular, 9-27 × 6-20 mm, relación largo: ancho $=1-2,6: 1 ;$ base redondeada $o$ cuneada; ápice agudo u obtuso; margen revoluto, aserrado-crenado excepto en la porción basal; haz pardo-obscura, estrigosa, superficie irregular debido a los pelos de base abultada, cónica, venas deprimidas; envés tomentoso-velutino, dorado, con pelos microcapitados amarillos subsésiles entremezclados; 4-5 pares de venas laterales prominentes, rectas o ligeramente incurvas, algunas bifurcándose más o menos a la mitad de la lámina, terminando en las escotaduras del borde o dividiéndose antes y con una de las ramas dirigida a la escotadura; ángulo de divergen- 


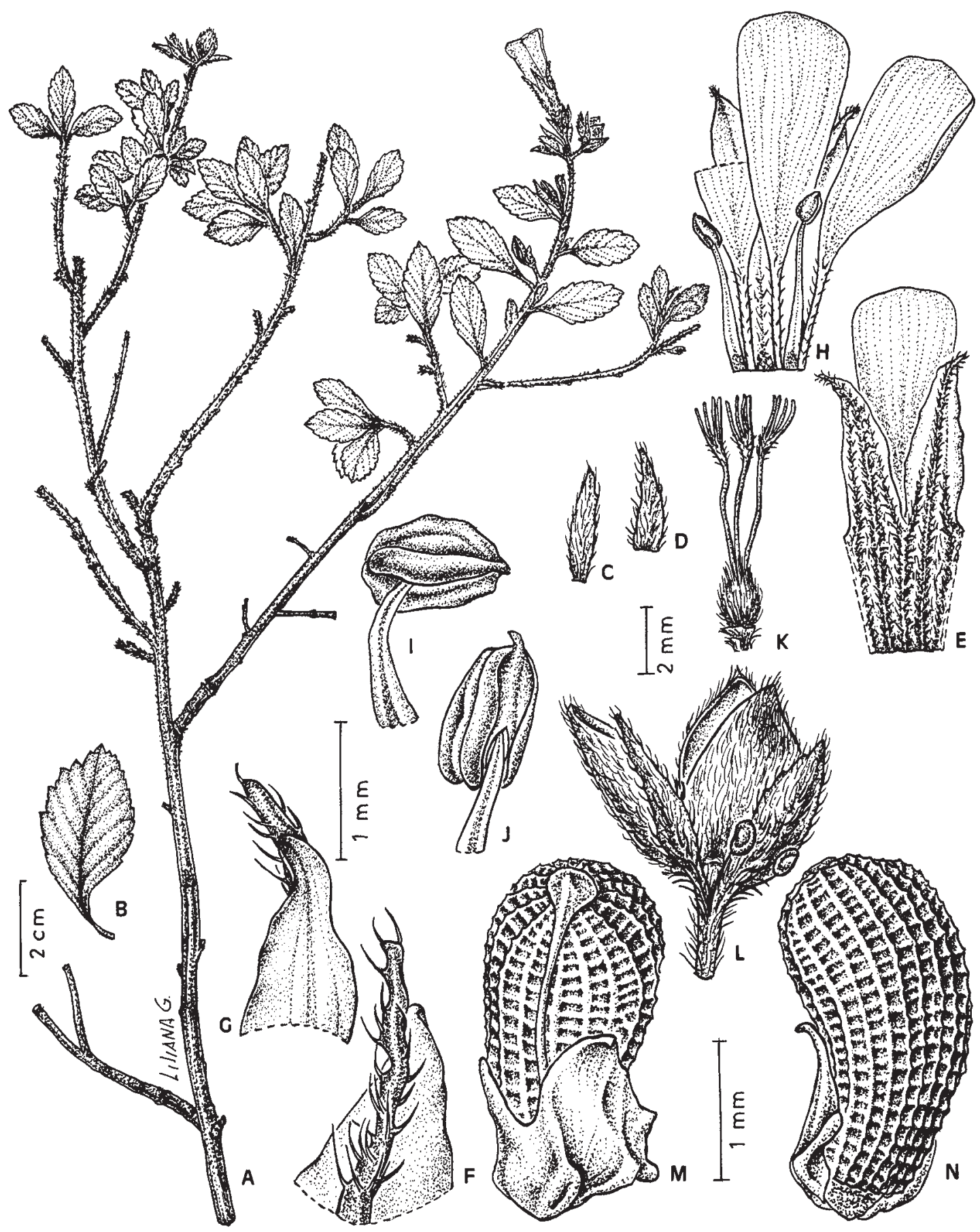

Fig. 11. Turnera coccinea. A: rama florífera. B: hoja, cara adaxial. C-D: profilos. E, porción del cáliz y pétalo, cara externa. F-G: ápice de los lóbulos del cáliz, cara externa e interna. H: flor longistila, porción del tubo calicino, cara interna, con pétalos y estambres adnatos; se ha cuadriculado la cicatriz dejada al desprender un estambre. I-J: anteras, vista lateral y dorsal. K: gineceo. L: bráctea con fruto epifilo y profilo. M-N: semilla con arilo, vistas rafeal y lateral (Mello-Silva \& al. 760). Del. Liliana Gómez. 


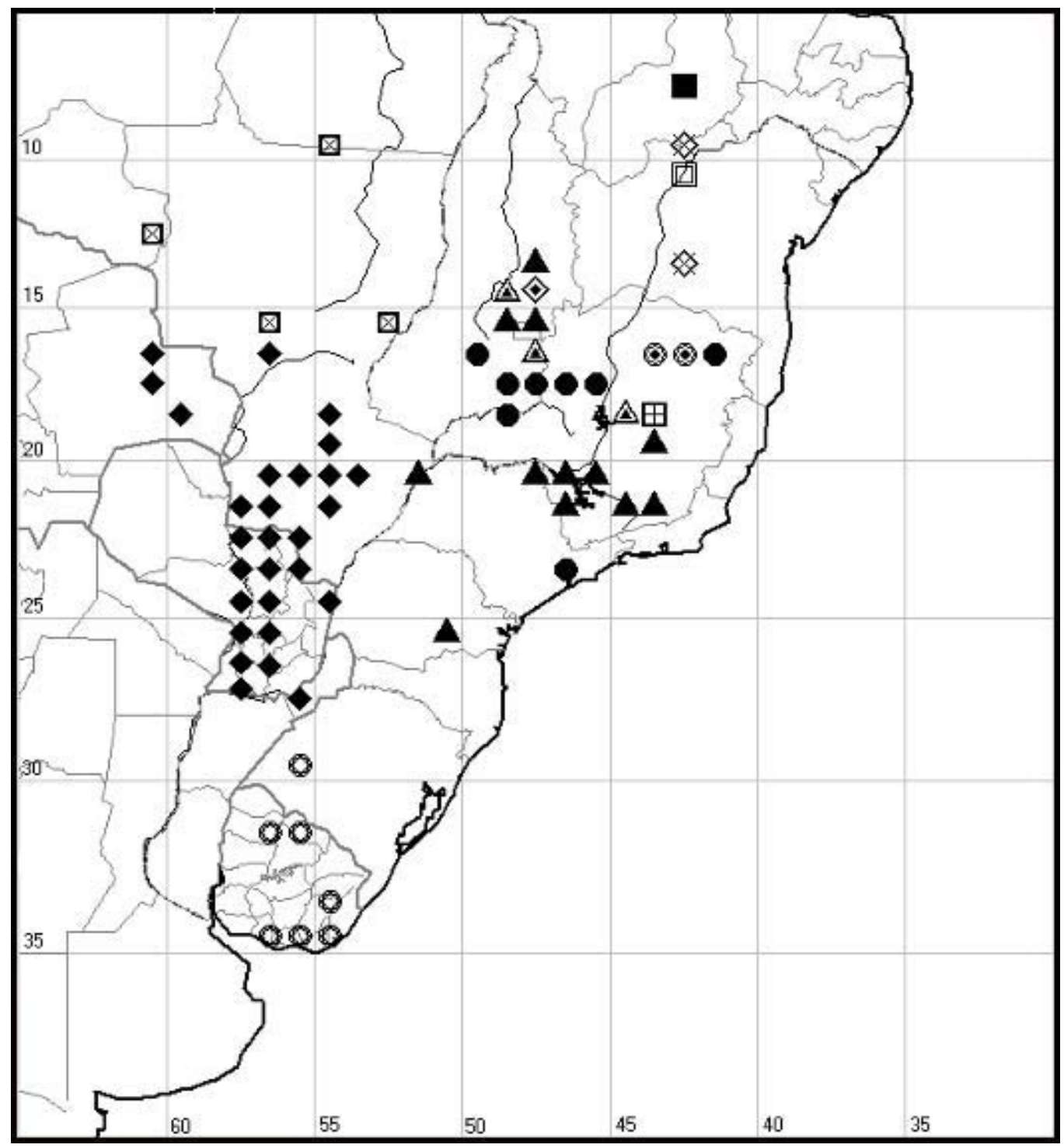

Fig. 12. Distribución de Turnera coccinea $\bigotimes$; T. diamantinae 田; T. fissifolia $\diamond ;$ T. hassleriana $\diamond ;$ T. hilaireana $\mathbf{\Delta}$; T. lanceolata $\mathbf{O}$; T. prancei $\boldsymbol{\otimes} ;$ T. sidoides ssp. sidoides $\mathrm{O}$; T. stachydifolia var. stachydifolia $\mathbf{\square}$; T. stachydifolia var. flexuosa $\square$; T. tenuicaulis $\Delta$; T. uleana

cia ca. $45^{\circ}$; venas terciarias recurvas, visibles en el envés. Nectarios 1+1, circulares, 0,6-0,7 $\mathrm{mm}$ diám., parte central glabra, borde pilosiúsculo, situados en el margen foliar, hacia el envés. Hojas floríferas de tamaño bruscamente decreciente, hasta 6-4 mm long., con un par de nectarios grandes, pardos o negruzcos, 0,6-1 mm diám., asentados sobre el envés. Flores epifilas, probablemente dimorfas (sólo se observó la forma longistila), reunidas en los ápices de las ramas en racimos bracteosos abreviados. Pedúnculo 1,5-3 mm long., totalmente adnato. Profilos lineares o subulados, 3-4 x 0,5 mm, insertos en la base del receptáculo. Cáliz vinoso, 8-11 mm long., con pelos simples, cortos y erectos, pelos curvado-antrorsos y pelos glandulares microcapitados; tubo calicino 3,8-5 mm long., interiormente velloso; lóbulos 3-5 nervados, con pelos de igual longitud que los del tubo, los externos pilosos hasta el borde, los internos con borde membranáceo, ancho y glabro, ner- 
vio medio prolongado en un mucrón $0,5 \mathrm{~mm}$ long. Corola rotácea, 11-17 mm long., 3-6 mm más larga que el cáliz, rojo bermellón con garganta amarilla; pétalos con uña de $3 \mathrm{~mm}$ long., lámina obovada, 8-9 x $4 \mathrm{~mm}$, con algunos pelos en la base en la cara superior. Filamentos estaminales glabros, subulados, soldados $1 \mathrm{~mm}$ al tubo en la porción basal, 5-6 mm long. en flores longistilas; anteras ovado-elípticas, $1-1,5 \times 0,8-1 \mathrm{~mm}$, base emarginada, filamento inserto dorsalmente a $0,4-0,6 \mathrm{~mm}$ de la base, ápice apiculado. Ovario cónico, densamente piloso, 2 × 1,3 mm; placentas 4-6ovuladas; estilos cilíndricos, $4 \mathrm{~mm}$ long. en flores longistilas, porción basal glabra, porción distal partida en 2-4 ramas pilosas; estigmas paucirramosos, $2 \mathrm{~mm}$ long., ramas 2-3 veces divididas. Fruto subesférico o cónico, 6$8 \mathrm{~mm}$ diám., con un reborde anular basal dejado por la absición del tubo floral; valvas castañas por fuera, con pelos largos, adpresos, laxos, entremezclados con pelos cortos, crespos, y pelos glandulares microcapitados, por dentro glabras, nítidas. Semilla 3,5-4 x 1,3 $\mathrm{mm}$, obovoide, curvada, base atenuada; exóstoma redondeado, 0,3 $\mathrm{mm}$ long.; rafe linear saliente, lado rafeal incurvo; cálaza ligeramente prominente, pigmentada. Episperma pardo, reticulado, nudos no prominentes; epidermis papilosa; aréolas muy pequeñas, con cera epicuticular bastoniforme en la semilla inmadura. Arilo más corto que la semilla, unilateral, blanquecino en seco, de células lisas.

Material estudiado: BRASIL. Minas Gerais: Caveira, BR-251, $41 \mathrm{~km}$ da entrada para Grão Mogol, 27-III-1993, Esteves \& Kameyama 2510 (SP, paratipo); Mun. Grão-Mogol: extremidade N da Serra da Bocaina, na rodovia BR-251, nascente do Rio Ventania, 12-VI-1991, Mello-Silva \& al. 452 (CTES, SPF, paratipos).

Distribución: Aparentemente, endémica de la serranía de Grão-Mogol, Minas Gerais.

Obs.: Turnera coccinea es muy afín a $T$. opifera; es difícil de diferenciar el material seco, sin flores, de ambas especies. Las flores de color rojo bermellón son muy raras en el género, en la Serie Leiocarpae la única otra especie con ese color de corola es
T. longiflora Cambess., arbusto virgado con flores de mayor tamaño, endémico de Goiás.

Se estudió la anatomía de tallo, hoja, flor, fruto y semilla en Mello-Silva \& al. 760 (Gonzalez, 2000). También la vascularización floral y nectarios florales (Gonzalez, 2001; sub Turnera sp.).

\section{Turnera crulsii Urb.}

Figs. 10 y 13

Urban, I., Bot. Jahrb. Syst. 25 Beibl. 40: 6. 1898. Typus: Brasil. Goiás, entre Chico Costa et les sources du Rio Torto, 19-XI-1894, Glaziou 21448 (holotypus $\mathrm{B}+$ fototipo $\mathrm{F} \mathrm{n}^{\circ} 13573$ !, isotypi BR!, C!, F!, K!, LY!, P!, R!, S!).

Hierba rizomatosa $5-15 \mathrm{~cm}$ alt., rizoma hasta $1 \mathrm{~cm}$ diám., tallos 0,5-2 mm diám., cilíndricos, entrenudos basales largos, hirsutos, con pelos simples curvado-erectos y pelos patentes, entrenudos apicales cortos, densamente estrigosos. Hojas herbáceas, las de los nudos basales pequeñísimas y glabrescentes, haz y envés con pelos simples cortos; hojas apicales de mayor tamaño y densamente pilosas. Estípulas nulas. Pecíolo 1,5-3 mm long. Lámina orbicular, obovada, elíptica, angustiobovada o angustielíptica, 6-26 x 2,5-10 mm, relación largo:ancho $=1-6: 1$; base cuneada o atenuada; margen ligeramente revoluto, a veces plano, irregularmente crenado; haz oscura, con pelos simples largos, curvadoantrorsos, de base cónica, entremezclados con pelos simples más cortos, erectos o crespos; envés arenáceo, con indumento más denso y blanquecino y pelos glandulares microcapitados; venas laterales ligeramente hundidas en la haz, prominentes en el envés, oscuras. Nectarios marginales, en la porción basal de la lámina, circulares o elípticos, oscuros, 0,3-1 $\mathrm{mm}$ long., borde piloso. Flores epifilas, solitarias, heterostilas. Pedúnculo 10,5-1,7 mm long., totalmente soldado al pecíolo e incluso a la base de la lámina, o la porción apical libre de 0,4-1,5 $\mathrm{mm}$ long. Profilos linearsubulados, 1,7-4 x 0,3-0,4 mm, hirsutos. Pedicelo 0-0,7 mm long. Cáliz 5,3-9 mm long.; tubo calicino 1,7-3,2 mm long., cara 


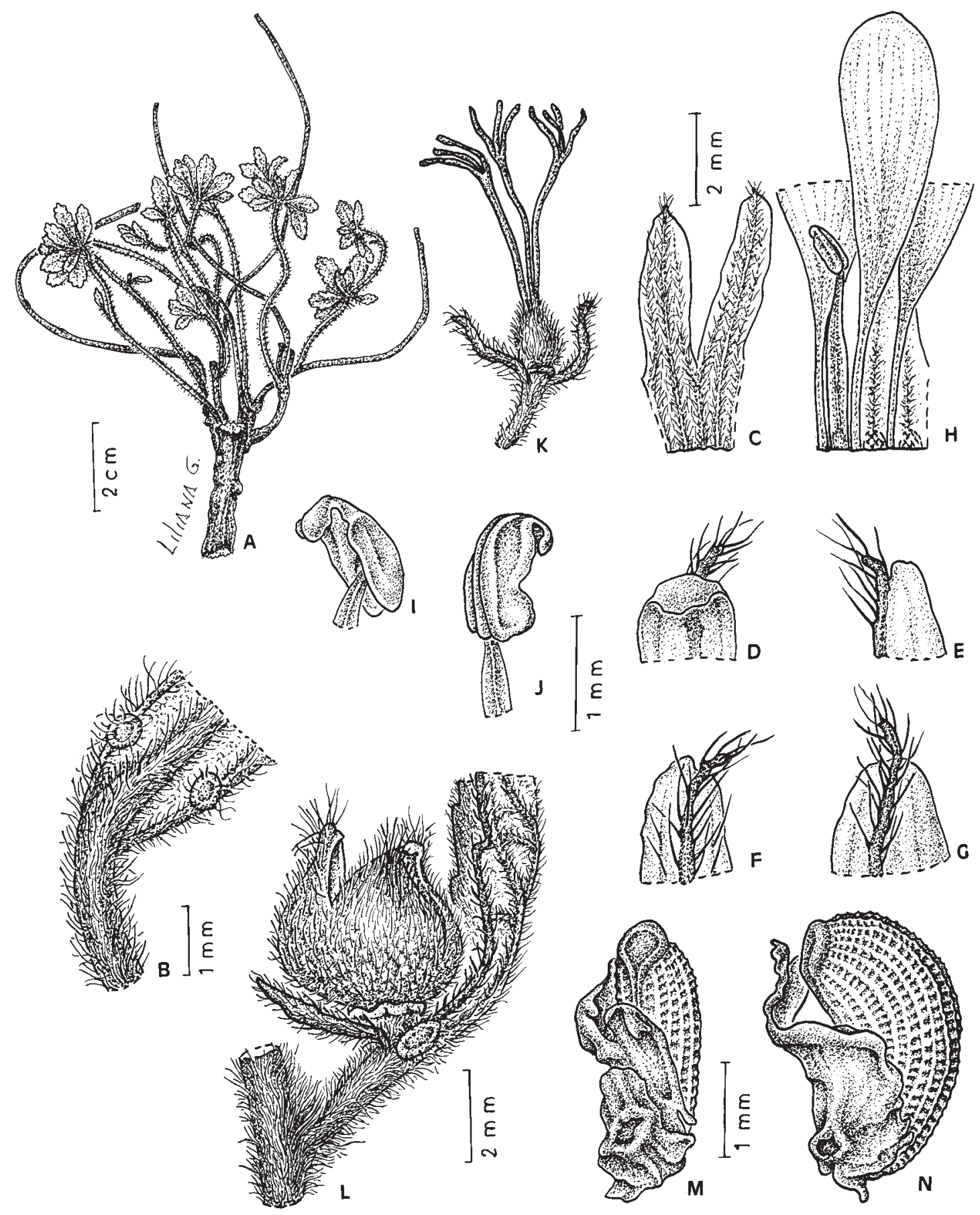

Fig. 13. Turnera crulsii. A: planta. B: base de la hoja con nectarios, cara abaxial. C: porción del cáliz, cara externa. DG: ápice de los lóbulos del cáliz, caras interna y lateral externa, y externa. H: flor longistila, porción del tubo calicino, cara interna, con pétalos y estambre adnatos; se han cuadriculado las cicatrices dejadas al desprender dos estambres. I$\mathrm{J}$ : anteras, vista latero-dorsal y latero-ventral. K: ápice del pedúnculo y receptáculo con profilos y gineceo. L: fruto epifilo y profilo. M-N: semilla arilada, vistas rafeal y lateral (A, C-K: Glaziou 21448; B, L-N: Fonseca \& al. 1543). Del. Liliana Gómez. 
externa con pelos simples crespos y pelos antrorsos sobre las venas, cara interna vellosa; lóbulos triangulares, 3-nervados, con pelos más largos, ápice agudo. Corola amarilla, 1,6-5,5 mm más larga que el cáliz; pétalos obovados, 57 x $4 \mathrm{~mm}$. Filamentos estaminales complanadosubulados, glabros, soldados brevemente en la base al tubo floral, 3,5-4,7 mm long. en flores longistilas, 4,5-6,5 $\mathrm{mm}$ long. en flores brevistilas; anteras $0,8-1,4 \times 0,4-0,8 \mathrm{~mm}$, base emarginada, filamento inserto en una cavidad basi-dorsal de 0,4-0,5 mm, ápice obtuso, recurvado a la dehiscencia. Ovario densamente piloso; placentas 3-4-ovuladas; estilos 3,5-4,5 $\mathrm{mm}$ long. en flores longistilas, 2-2,5 mm long. en flores brevistilas, con algunos pelos patentes hacia el ápice; estigma 0,7-2 mm long., paucirramoso. En flores longistilas el gineceo 0,8-2,5 mm más largo que el androceo, en flores brevistilas 1-3,5 mm más corto que el androceo. Fruto ovoide o subesférico, 3,5-5,5 mm long., con un reborde basal de $0,2 \mathrm{~mm}$ dejado por el tubo floral al desprenderse; profilos más cortos que el fruto; valvas de superficie externa irregular por las bases cónicas de los pelos simples; cara interna glabra, lustrosa. Semilla inmadura obovoide, 2,8 x 1,2 mm, curvada; exóstoma cónico; rafe linear; lado rafeal incurvo; cálaza ligeramente prominente, a veces algo deprimida. Episperma pardo, reticulado, nudos no prominentes, aréolas pequeñas, cóncavas, con epidermis papilosa. Arilo unilateral, lobulado, casi tan largo como la semilla, de células lisas.

Material estudiado: BRASIL. Distrito Federal: Brasília, X-1964, Barroso 564 (RB, UB); area da Proflora na confluencia dos corregos Cana-do-Reino/Vicente Pires, 23-VII-1981, Heringer \& al. 7231 (IBGE); su mmit of Chapada da Contagem, ca. 10 km NE of Brasília, 1000 m, 11-IX-1965, Irwin \& al. 8216 (MO, NY, P, UB); confluence of Rio Torto with Lagoa Paranoá, Brasília, 975 m, 9-X-1965, Irwin_\& al. 9084 (NY, P, UEC); margem do Lago Paranoá, arredores do Córrego Palha, 10-IX-1968, Onishi \& Fonseca 172 (UB). Goiás: Mun. Niquelândia: Fazenda Engenho, ca. $11 \mathrm{~km}$ de Niquelândia em direcão a Dois Irmãos: Cabeceira do rio Traíras, $14^{\circ} 40^{\prime} 28^{\prime \prime} \mathrm{S} 48^{\circ} 25^{\prime} 25^{\prime \prime} \mathrm{W}, 680 \mathrm{~m}$, 14VIII-1997, Fonseca \& al. 1546 (CTES, IBGE), área da Felipa, 14³4'41"S 48²3’43"W, 3-X-1997, Fonseca \& al. 1637 (CTES, IBGE); cabeceira do
Rio Trairas, 14 39'31'S 48 26'47'W, 685 m, 14-VIII1997, Mendonça \& al. 3065 (CTES, IBGE).

Distribución y fenología: Hemicriptófita propia del Distrito Federal y de Goiás, crece en «cerrado», campo y «campo rupestre», en suelo arcilloso. Los rebrotes florecen poco después de la quema de los campos, todos los ejemplares conocidos fueron colectados entre julio y noviembre.

Obs.: La expresión de la heterostilia es variable: Urban describe Turnera crulsii como homostila, sin embargo se encontraron flores longistilas y brevistilas en distintos isotipos. En flores brevistilas el androceo es 2-4 mm mayor que el gineceo; en flores longistilas el gineceo es 2,5-3 mm mayor que el androceo. En el ejemplar Fonseca \& al. 1546 se encuentran flores con el gineceo 0,3-2,2 mm más largo que el androceo, o ligeramente más corto.

En el ejemplar Irwin \& al. 8216 (P) se observaron estípulas de $3 \times 1 \mathrm{~mm}$, filiformes o espatuladas.

Todos estos ejemplares son rebrotes producidos después de la quema de la vegetación de campo o «cerrado», la floración es precoz, se observan flores en ejes de apenas $5 \mathrm{~cm}$ alt. Algunos ejemplares muestran ejes quemados de $15 \mathrm{~cm}$ alt., con hojas grandes, $4 \mathrm{~cm}$ long., con indumento formado por pelos simples muy cortos. Estos rebrotes podrían corresponder a Turnera emendata, pero resulta llamativo que dicha entidad no haya sido coleccionada en el Distrito Federal.

Turnera crulsii es muy parecida a los rebrotes de $T$. opifera, con pedúnculos florales más cortos, hasta $4,5 \mathrm{~mm}$ long. y cáliz más largo, 7,7-13 mm long. La última especie es un arbusto llamativo, de hasta $1,5 \mathrm{~m}$ alt., que no vive en Goiás ni en el Distrito Federal.

\section{Turnera curassavica Urb.}

Figs. 5 y 14

Urban, I., Jahrb. Königl. Bot. Gart. Berlin 2: 118. 1883. Typus: Antillas Holandesas. Curação, Rohr 4 (lectotypus aquí designado C Herb. Vahl!, isotypi $\mathrm{B}+$ fototipo $\mathrm{F}^{\mathrm{o}}$ 13574, $\mathrm{BM}$ !, C!). 


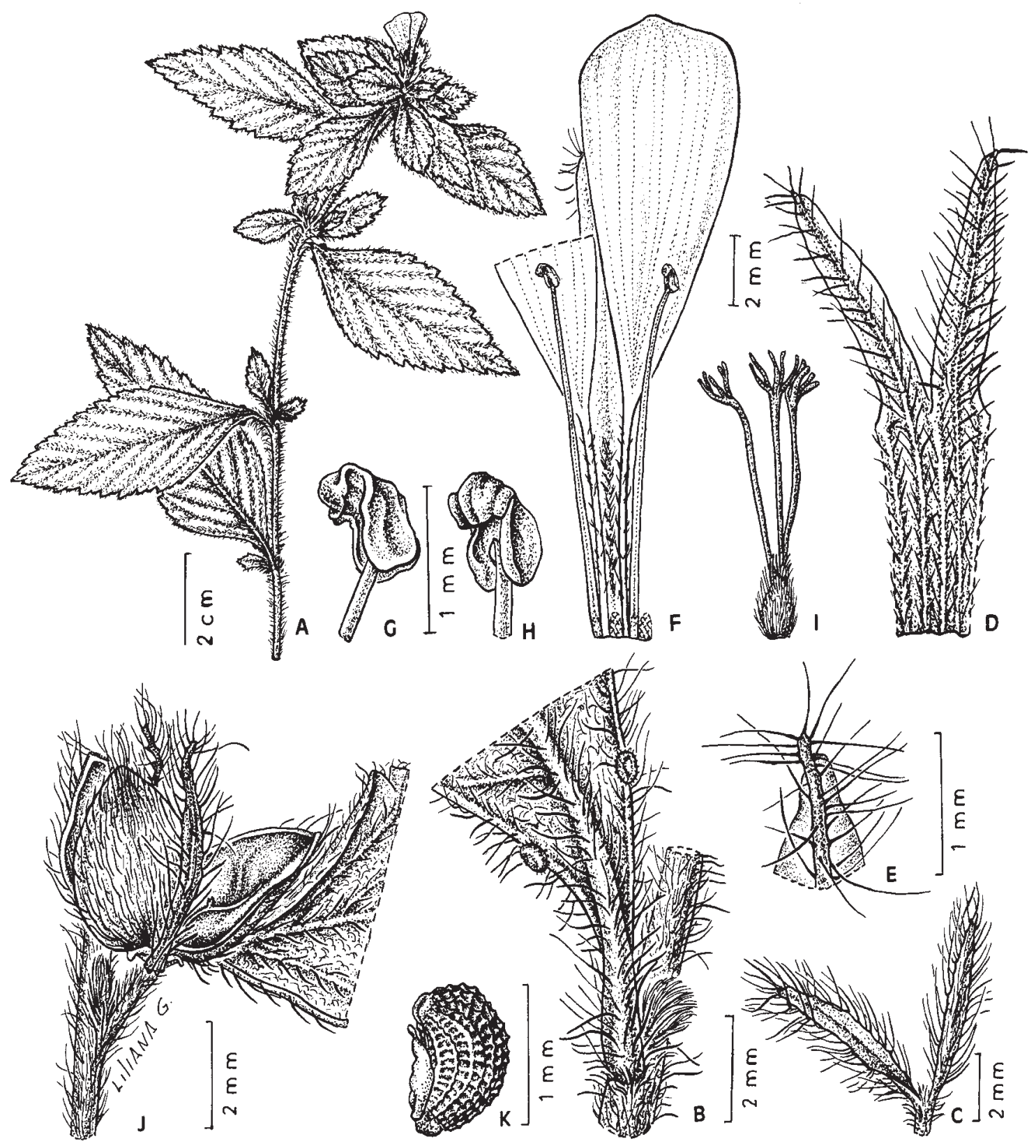

Fig. 14. Turnera curassavica. A, rama florífera. B, nudo mostrando la base de una hoja, cara abaxial, con nectarios y yema axilar. C: profilos. D: porción del cáliz, cara externa. E: ápice del lóbulo del cáliz, cara externa. F: flor brevistila, porción del tubo calicino, cara interna, con pétalos y estambres adnatos; se han cuadriculado las cicatrices dejadas al desprender dos estambres. G-H: anteras, vistas lateral y dorsal. I: gineceo. J: fruto epifilo con profilos. K: semilla arilada, vista lateral (A-I, K: Davidse \& Pohl 2370; J: Wingfield 5074). Del. Liliana Gómez. 
Turnera cuneiformis Juss. ex Poir. var. odorata Poir., Enc.Mét.Bot. 8: 142. 1808; Turnera cuneiformis Juss. ex Poir. var. B DC., Prod. 3: 346. 1828. Typus: Am. Merid., 1797, M. Vahl, Herb. Jussieu 13575 (holotypus P!). El lectotipo de T. curassavica, del Herb. Vahl, dice «Turnera varietas odorata», probablemente el espécimen de Jussieu sea un duplicado de Rohr 4. Urban (1883) colocó por error esta variedad en la sinonimia de $T$. odorata Rich.

Sufrútice de 6-45 cm, generalmente ramificado desde la base leñosa de 4-9 mm diám.; ramas viejas glabrescentes, negruzcas, cilíndricas o irregularmente estriadas; ramas jóvenes ascendentes, a veces fláccidas y apoyantes cuando muy largas, porción apical erecta, cilíndrica o más o menos angulada, con pelos simples, largos, amarillentos, patentes o divaricados, 0,7-2 $\mathrm{mm}$ long., entremezclados con pelos simples crespos o curvados más cortos; entrenudos de $2-5 \mathrm{~cm}$, los apicales muy acortados. Hojas herbáceas. Estípulas frecuentemente rudimentarias, con 1-3 coléteres de 0,2-0,3 mm long., en algunos ejemplares lanceoladas o linear-subuladas, 0,5-1,5 mm long. Yemas axilares 1-2 seriales. Pecíolo 17(-10) mm long. Lámina foliar ovada o elíptica, a veces obovada, las apicales subrómbicas, 11-63 x 6-28 mm, relación largo:ancho $=1,2-$ 4:1; base atenuada o cuneada, a veces obtusa; ápice agudo u obtuso; margen crenado-aserrado, plano o algo revoluto; haz parda, frecuentemente oscura, con pelos simples de 1-1,8 $\mathrm{mm}$ long. de base abultada rojiza, en hojas basales sin orientación definida, en hojas apicales curvado-antrorsos, orientados diagonalmente con respecto a la vena media, mezclados con pelos simples más cortos y crespos, más o menos erguidos y pelos glandulares microcapitados; envés frecuentemente maculado, con indumento igual, más denso; 48 pares de venas laterales subimpresas en la haz, prominentes en el envés, densamente pilosas, perdiéndose hacia el borde, con ramas hacia las escotaduras; ángulo de divergencia $30-45(-55)^{\circ}$; venas terciarias y venación menor inconspicuas, excepto las venas que irrigan los dientes. Nectarios generalmente 2, a veces 4, circulares o elípticos, 0,3-0,9 mm long., pardos o negruzcos, ligeramente cónca- vos y generalmente estipitados $(0,1-0,3 \mathrm{~mm})$, a veces con «poro», margen piloso, situados en la unión de pecíolo y lámina o desplazados 0,5-3,5 $\mathrm{mm}$ sobre el margen foliar. Hojas floríferas apicales de tamaño notoriamente menor (8-4 mm long., pecíolo < $1 \mathrm{~mm}$ long.). Flores epifilas heterostilas, las basales sobre nomofilos, las apicales reunidas en racimos hojosos abreviados. Pedúnculo 6-1 mm long., adnato al pecíolo. Pedicelo nulo. Profilos insertos en la base del cáliz, lineares o linearsubulados, 2-5 x 0,2-0,7 mm, uninervados, cara externa pilosa, cara interna glabra excepto la porción apical. Cáliz 7-15 mm long.; tubo calicino 3-6,5 mm long., cara externa con pelos simples cortos, frecuentemente con la base glabra o subglabra, cara interna albidopubescente en la mitad superior; lóbulos 3nervados, triangulares o subulados, con pelos simples largos, curvado-antrorsos o erectos sobre las venas, márgenes internos membranáceos, ápice mucronado 0,1-0,3 mm. Corola amarilla, 1-3,5(-4,5) mm más larga que el cáliz; pétalos obovado-cuneados, 6-12 x 2,5-8 mm, vena media generalmente glabra en la base. Filamentos estaminales glabros, adnados 0,5-1,2 $\mathrm{mm}$ al tubo calicino, con un nectario en la inserción, 6-10,5 mm long en flores brevistilas, 5-7 $\mathrm{mm}$ long. en flores longistilas; anteras ovadas o elípticas 0,9-1,7 x 0,5-1 mm, base emarginada, ápice truncado, filamento inserto dorsalmente a $0,4-0,5 \mathrm{~mm}$ de la base, rectas o curvadas a la dehiscencia. Ovario 1-1,3 mm long., hirsuto-piloso; placentas 6-9(-12)-ovuladas; estilos glabros o algo pilosos, 6-9,5 $\mathrm{mm}$ long. en flores longistilas, 3-5,5 $\mathrm{mm}$ long. en flores brevistilas; estigma penicilado, 1,5-3,5(-4) mm long., pauci o multirramoso, generalmente glabro. En flores longistilas, el gineceo 0-2 mm menor que el cáliz y 1,5-4 mm más largo que el androceo; en flores brevistilas, el androceo 0-4,5 $\mathrm{mm}$ más corto que el cáliz y 0,5$3,5 \mathrm{~mm}$ más largo que el gineceo. Fruto globoso u ovoide, 2,5-5 mm long., con un reborde basal anular $0,3 \mathrm{~mm}$ lat. dejado por el tubo floral al desprenderse; valvas ovadas, amarillentas, cara externa con pelos simples cortos y otros más largos entremezclados, cara interna glabra, lustrosa, amarillenta, con máculas pardas o rojizas. Semilla pardo-negruzca a la 
madurez, obovoide, 1,2-2,2 x 0,5-1,3 mm; exóstoma breve, semigloboso; rafe linear apenas marcada, lado rafeal casi recto o incurvo; cálaza más o menos prominente, oscura. Episperma reticulado, nudos del retículo algo prominentes, epidermis papilosa, aréolas a veces con bastones de cera epicuticular. Arilo unilateral más corto o casi tan largo como la semilla, de células papilosas.

Material estudiado: EE.UU. South Florida, ex herb. Durand (P) [localidad dudosa]. MÉXICO. Sin localidad, 17-V-1848/49, Gregg 854 (MO). Chiapas: Mun. Villa Corzo, $58 \mathrm{~km} \mathrm{~S}$ of Mexican Highway 190 on road to Nueva Concordia, $900 \mathrm{~m}$, 11-IX-1974, Breedlove 37569 (DS, MO); a 40 km al S de Campamento COFOLASA, a 16 km NW de Boca Lacantum camino a Palenque, a orillas del rio Lacanja, mun. Ocosingo, 120 m, 15-IV-1985, Martínez 12037 (MEXU). BELIZE. Ycacos Lagoon, III-1907, Peck 695 (GH, K); All Pines, 10-III-1931, Schipp 8-193 (F). El Cayo: Mountain Pine ridge, 24-II-1931, Bartlett 11728 (CTES, MICH, US); Augustine, 1658'N 8859' W, 19-III1967, Dwyer \& al. 319 (MO); Blancaneaux Lodge, $17^{\circ} 03^{\prime} \mathrm{N}$ 8858'W, 14-VIII-1970, Wiley 291 (MO). Stann Creek: Big Creek, 25-III-1970, Mc Daniel 12948_(F). Toledo: Swasey Branch, Monkey river, 15-I-1942, Gentle 3875 (A, MICH, NY). HONDURAS. Comayagua: Siguatepeque, $\mathrm{S}$ of town, 2-IX-1991, Chorley 51 (BM); vicinity of Comayagua, about 600 m, 22-23-III-1947, Standley_\& Chacón 5737 B (F). Gracias a Dios (La Mosquitia): Arroyada del rio Dursuna, $70 \mathrm{~km}$ $\mathrm{O}$ de Puerto Lempira, $15^{\circ} 00^{\prime} \mathrm{N} 84^{\circ} 13^{\prime} \mathrm{O}$, nivel del mar, 7-IV-1972, Nelson 739 (UNAH); Orilla del rio Mocorón, aldea de Mocorón, 70 m, 14-II-1979, Nelson \& Vargas 5145 (UNAH); Puerto Lempira, 0-20 m, 1-II-1981, Proctor 38812 (A, BM, UNAH). Morazán: alrededores de la Colonia Río Grande Comayagüela, $950 \mathrm{~m}$, Cámbar 71 pp (MO). NICARAGUA. Comarca del Cabo: area around Bilwascarma, 40 m, 15-VII-1970, Davidse

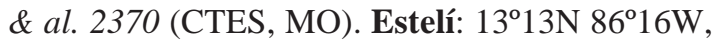
1200-1350 m, 11-VI-1999, Rueda \& al. 11322 (MO). Zelaya: near Tala Has and Puente Mango (over río Kisalaya), ca. $14^{\circ} 41^{\prime} \mathrm{N} 84^{\circ} 03^{\prime} \mathrm{W}, 40-60$ m, 18-IV-1978, Stevens 7590 (CTES, MEXU, MO); Waspam, ca. $14^{\circ} 43^{\prime} \mathrm{N} 83^{\circ} 58^{\prime} \mathrm{W}$, ca. $35 \mathrm{~m}$, 10-III-1981, Stevens \& Moreno_19649 p.p. (MO). PANAMÁ. Veraguas: toma de agua del rio Santa
Maria, 3-I-1986, León 86 (F). COLOMBIA. Caquetá: sabanas del Yari, Vereda El Recreo, Hato El Recreo, frente del aeropuerto, $1^{\circ} 72^{\prime} \mathrm{N}$ 7409'W, 272 m, 31-I-1990, Betancur \& Velasquez 1708 (HUA, MO). Meta: $3 \mathrm{~km}$ of Apiay Airport, $\mathrm{N}$ of Caño Suria (Zuria) on road to Puerto López, $14 \mathrm{~km}$ ESE of Villavicencio, 4²' $\mathrm{N}$ 73³2'E, 25-II-1943, Fosberg 20179 (US); Orénoque, St. Martin, 1844, Goudot s.n. (FI, P, sintipo); San Martín, 400 m, 4-II-1944, Hermann 11199 (US). Santander: mun. los Santos, Mesa de Los Santos, Vereda El Tabacal, 645'-47'S 7306'-03'W, 1600-1690 m, 19-IX-2004, Betancur \& Clavijo-R. 10948 (HUA). Vaupés: Río Guaviare, San José del Guaviare, 240 m, 11XI-1939, Cuatrecasas 7641 (F, US). Vichada: carretera hacia Pto. Gaitán, $30 \mathrm{~km}$ antes del Hato Canaima, ca. 200 m, 23-III-1971, Pinto \&_Sastre 1516 (CTES, P). VENEZUELA. Falcón: Meachiche, 18-I-1942, Lasser 185 (US); Cardón, 2 km SE de Punto Fijo, 20 m, 11-27-1978, Werff \& al. 35 (CTES, U); Playa cerca de Puente de Piedra, 20 km E de Coro, 5 m, 12-19-1978, Werff 3256 (CTES, U); Coro, IUTC, Los Orumitos, 10 m, 10II-1978, Wingfield 5074 (CTES); Paraguaná, Cero Colorado, 200 m, 9-XI-1979, Wingfield 7170 (CTES). Lara: Barquisimeto, El Indio, I-1950, Marcuzzi s.n. (NY); Sanare, 1300 m, V-1930, Saer 487 (F). GUAYANA FRANCESA. Sin localidad: Richard s.n. (P).

Distribución y fenología: Especie propia de México, Centroamérica, Antillas Neerlandesas, Colombia, Venezuela y Guayanas. Vive en bosques de pino y sabanas de suelo arenoso, también en laderas pedregosas, desde el nivel del mar hasta los $1300 \mathrm{~m}$ de altitud. Se adapta a sitios modificados como bordes de caminos. Florece prácticamente todo el año.

Obs.: Turnera curassavica es afín a T. dolichostigma y T. hassleriana, de las que se distingue por presentar el tubo calicino glabro en la base, y por tener los verticilos reproductivos casi tan largos como el cáliz. También se parece a T. callosa, hierba con flores epifilas solitarias, y a T. melochia, hierba o subarbusto con hojas discoloras.

$\mathrm{El}$ indumento foliar es variable, en algunos ejemplares es laxo, y en otros como Stevens 
7590 es casi tomentoso; en Pinto \& Sastre 1516 está constituido sólo por pelos simples largos. La mayor parte de los ejemplares estudiados presenta flores grandes y marcadamente heterostilas, pero Marcuzzi s.n. y Pinto \& Sastre 1516 poseen flores más pequeñas (cáliz de 7-7,5 mm) y flores casi homostilas: el androceo es apenas 0,5 $\mathrm{mm}$ más largo que el gineceo, es decir que estigmas y anteras están en contacto. En McDaniel 12948 el tubo del cáliz es glabro y la semilla es marcadamente curvada. Las semillas de Betancur y Velázquez 1708 son más gruesas, $(1,8-1,9 \times 1,2 \mathrm{~mm})$ con el lado rafeal a veces ligeramente convexo.

\section{Turnera dasytricha Pilg.}

Pilger, R., Engl.Bot.Jahrb. 30: 176. 1901. Typus: Brasil. Mato Grosso: zerstreut im Serrado am FuBe der Serra das Pedras im Cuyabáthal, 16IV-1899, Pilger 471 (B+, fototipo $\mathrm{F} \mathrm{n}^{\circ} 13576$ !). Neotypus, aquí designado: Bolivia. Santa Cruz: prov. Velasco, Estancia Flor de Oro, $1 \mathrm{~km} \mathrm{NW}$ of buildings, on W side of Río Iténez (=Río Guaporé),

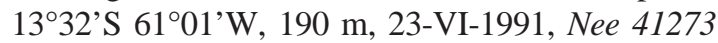
(holotypus CTES, isotypi MO, NY, SP).

\section{2a. Turnera dasytricha Pilger var. dasytricha}

Figs. 15 y 16

Subarbusto o arbusto ramoso hasta $2 \mathrm{~m}$ de alto, erecto o procumbente, entrenudos bien desarrollados; porción basal leñosa ca. $3 \mathrm{~mm}$ diám., con corteza rojiza o pardo-negruzca, longitudinalmente agrietada; ramas del año hirsutas, con pelos curvado-erectos o patentes 1,7-2 mm long., pelos crespos cortos, $0,4 \mathrm{~mm}$ long. y a veces también pelos glandulares microcapitados. Yemas axilares 1-3, ramas seriales floríferas 1-3 desarrolladas en cada nudo. Hojas herbáceas o cartáceas, generalmente discoloras, extendidas. Estípulas rudimentarias, con coléteres oscuros 0,2-0,3 mm long. Pecíolo semicilíndrico, 1-8 mm long., indumento como el del tallo. Lámina foliar elíptica, lanceolada, latielíptica, ovada u obovada, 23-72 x 10-26 $\mathrm{mm}$, relación largo:ancho $=2-3,7: 1$; base cuneada o atenuada; ápice generalmente agudo; borde plano o ligeramente revoluto, doblemente aserradocrenado excepto en la porción basal, dientes agudos u obtusos; haz pardo-oscura en seco, con pelos simples 1,2-1,8 mm long., más o menos erectos, de base cónica abultada, laxamente dispuestos; envés castaño, hirsuto, con pelos simples y pelos glandulares microcapitados; 6-8 pares de venas laterales prominentes, con pelos largos 1,7 mm long., perdiéndose hacia el borde y originando ramas hacia las escotaduras; ángulo de divergencia $25-40^{\circ}$; venas terciarias recurvas. Nectarios circulares, 0,5-1,1 mm diám., reborde micropiloso, situados junto al margen, sobre el envés, distantes 1-2 $\mathrm{mm}$ de la base. Hojas floríferas súbitamente muy reducidas, bracteiformes, 10-4 x 4-0,9 mm, con nectarios $0,3-0,5 \mathrm{~mm}$ sobre el envés. Flores epifilas heterostilas reunidas en racimos apicales bracteosos muy abreviados, las basales sobre nomófilos. Pedúnculo floral totalmente adnato al pecíolo. Pedicelo nulo. Profilos subulados, filiformes o lanceolados, 1,5-5 x $0,2-0,3 \mathrm{~mm}$, a veces rojizos, indumento como el del tallo, insertos en la base del receptáculo. Cáliz 4,5-6(-9,5) mm long.; tubo calicino 23(-4) mm long., pubescente en la cara interna, por fuera con pelos simples, cortos y pelos glandulares microcapitados desde la base; lóbulos triangulares o angustiovados, 3-5nervados, con pelos de $1 \mathrm{~mm}$ long. sobre las venas, a veces los bordes y el ápice rojizos; mucrón 0,3-0,7 mm long. Corola amarilla, 1,5-2,5(-5) mm más larga que el cáliz; pétalos con uña pilosa y lámina obtriangular glabra o con algunos pelos en la base. Filamentos estaminales subula-dos, glabros, soldados brevemente en la base al tubo calicino; 3,7 $\mathrm{mm}$ long. en flores longistilas, 5,5 $\mathrm{mm}$ long. en flores brevistilas; anteras ovadas, dorsifijas, 0,8-1 mm long., base emarginada, ápice obtuso, recurvado después de la dehiscencia. Ovario ovoide, piloso, 0,6-0,8(-1) mm long.; placentas 2-4(-10)-ovuladas; estilos cilíndricos, glabros o pilosos, 2,8 mm long. en flores longistilas, 2,3-2,6 mm long. en flores brevistilas; estigma 1,2 mm long., frecuentemente divididos 2-3 veces, ramas basales 


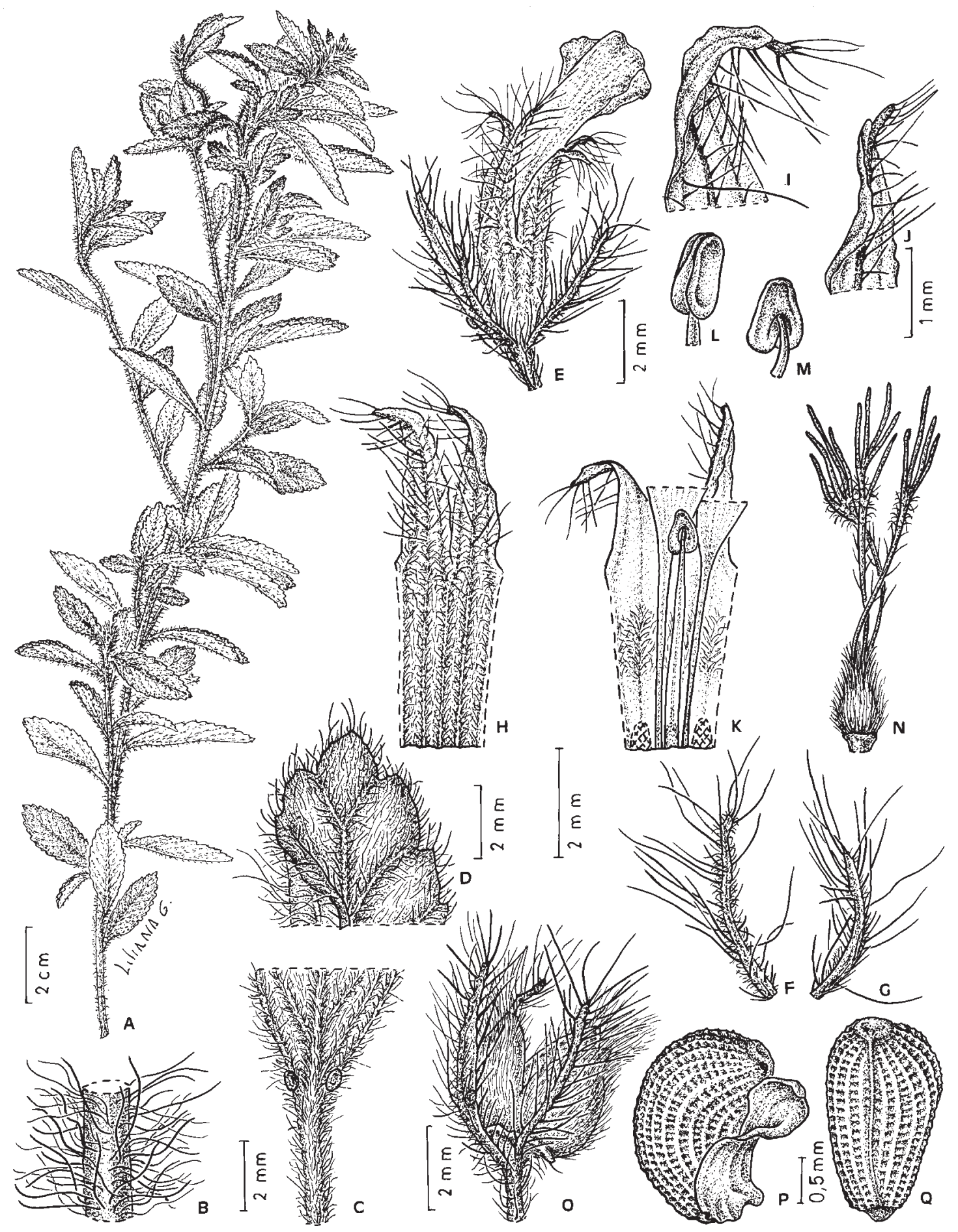

Fig. 15. Turnera dasytricha var. dasytricha. A: planta. B: porción del tallo. C: porción basal de la hoja, cara abaxial. D: ápice de la lámina foliar. E: flor. F-G: profilos. H: porción del cáliz, cara externa. I-J: ápice de los lóbulos del cáliz mucronados. K: flor longistila, porción del tubo calicino, cara interna, con pétalos y estambre adnatos; se han cuadriculado las cicatrices dejadas al desprender dos estambres. L-M: anteras, vistas ventral y dorsal. N: receptáculo y gineceo. O: bráctea con nectarios, fruto epifilo y profilos. P: semilla con arilo, vista lateral. Q: semilla, vista rafeal (AD: Solís Neffa \& al. 1222; E-Q: Nee 41273). Del. Liliana Gómez. 


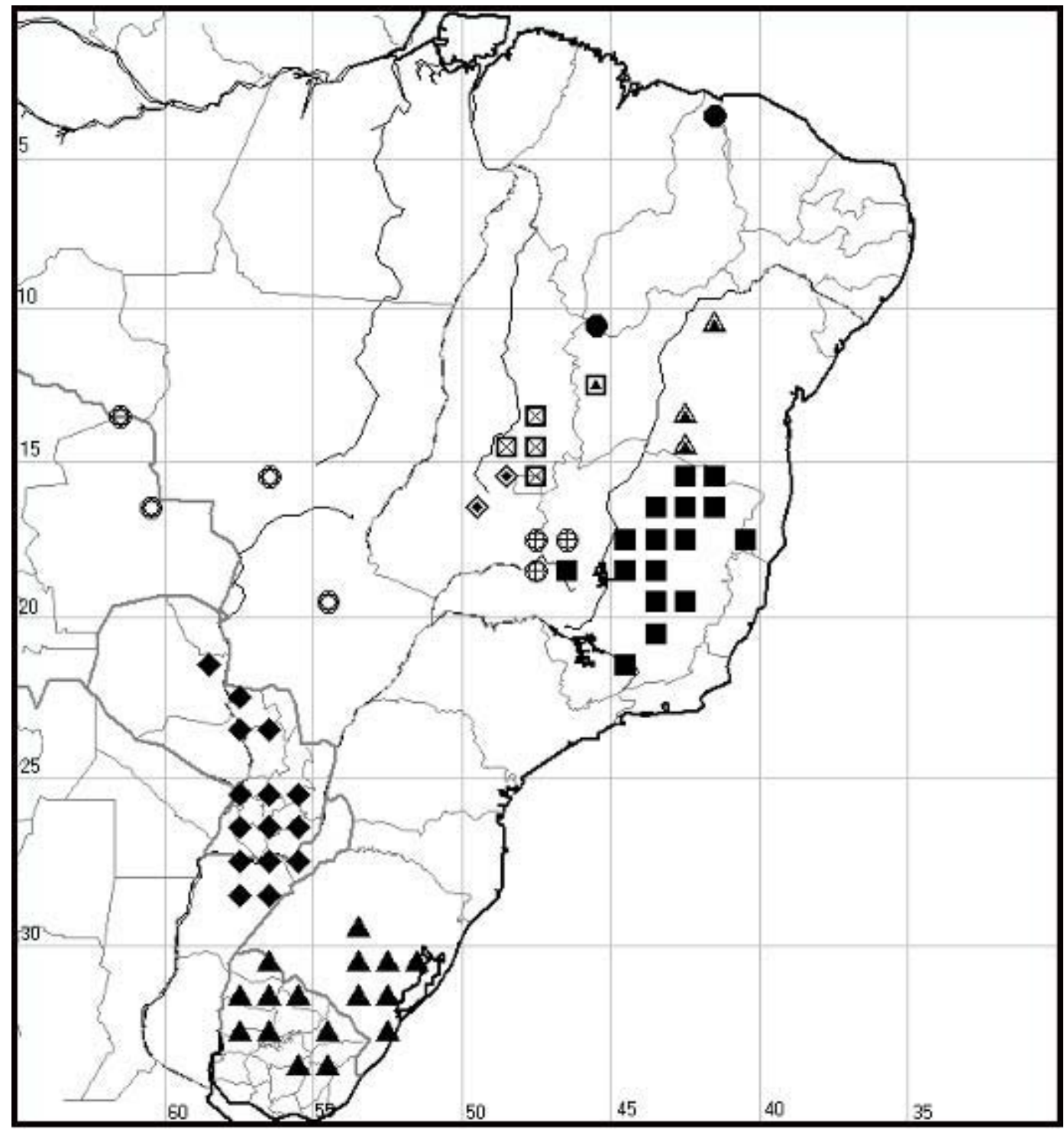

Fig. 16. Distribución de Turnera dasytricha var. dasytricha O; T. dasytricha var. crinita ; harleyi $\mathbf{\Delta}$; T. melochioides var. rugosa $\boldsymbol{\otimes} ;$ T. nervosa $\diamond ;$ T. opifera $\mathbf{\square} ;$ T. paradoxa $\boldsymbol{\boldsymbol { \theta }} ;$ T. patens $\operatorname{申}$; T. pinifolia $\diamond$; T. sidoides ssp. holosericea $\mathbf{\Delta}$.

glabras o pilosas. En flores longistilas, gineceo 1,2-1,5 mm más largo que el androceo, y en flores brevistilas, $1 \mathrm{~mm}$ más corto. Fruto ovoide, a veces deprimi-do, 2-2,5(-4,5) $\mathrm{mm}$ long., con reborde anular de 0,5 $\mathrm{mm}$ long. en la base dejado por el tubo floral al desprenderse; profilos más cortos o más largos que el fruto; valvas ovadas, pubescentes; cara externa de superficie irregular por la base cónica de los pelos simples, más largos hacia el ápi- ce, a veces entremezclados con pelos glandulares; cara interna glabra, ligeramente lustrosa, cara interna castaña o jaspeada. Semilla obovoide, curvada, 1,7-2 x 0,8-0,9 mm; exóstoma cónico, excéntrico; rafe linear apenas marcada, lado rafeal sigmoide o marcadamente cóncavo; cálaza algo saliente, pigmentada, a veces ligeramente deprimida. Episperma reticulado, aréolas cóncavas, más o menos cuadrangulares, epidermis papilosa. 
Arilo unilateral, angosto, igual o más corto que la semilla, de células papilosas.

Material estudiado: BOLIVIA. Santa Cruz: prov. Velasco, San Ignacio $10 \mathrm{~km} \mathrm{~N}$, aprox. 400 m, 15-IV-1988, Bruderreck 346 (CTES, LPB); J.M. de Velazco, a 4 km NE de San Ignacio, pasando $1 \mathrm{~km}$ el control policial, $16^{\circ} 22^{\prime} 47^{\prime \prime S}$ $60^{\circ} 55^{\prime} 41^{\prime \prime} \mathrm{W}, 395$ m, 25-I-2004, Solís Neffa \& al. 1222 (CTES). BRASIL. Mato Grosso do Sul: estrada para Rochedo, entrada a fazenda Novo Mundo, 25-I-1979, Heringer \& al. 780 (CTES).

Distribución: Especie de «cerradão», Brasil (Mato Grosso) y sabanas de Bolivia (Santa Cruz). Fue colectada en flor y fruto entre enero y junio.

Obs.: Variedad afín a Turnera melochioides. Las medidas máximas de flores y frutos corresponden al ejemplar Heringer \& al. 780.

\section{2b. Turnera dasytricha var. crinita Arbo, var. nov.}

Figs. 16 y 17

Fruticulus $30-50 \mathrm{~cm}$ altus, pilis crispulis brevibus et aliis curvato-erectis immixtis. Folia petiolata, subduplicato-crenata, subtus hirsuta, supra basin nectaria parvis gerentia. Flores dimorphi, apice caulium conferti, calyce 6-9 $\mathrm{mm}$ longo, petalis flavis; filamentis glabris base tubo tota facie adnatis. Fructus dorso laevi. Semina obovata, reticulata, arillo unilaterali, angusto.

Typus. Brasil. Piauí: mun. Buriti dos Lopes, a mais ou menos $110 \mathrm{~m}$ alt., 1-VII-1972, Sucre \& Silva 9472 (holotypus RB).

Subarbusto $30-50 \mathrm{~cm}$ alt.; cicatrices foliares prominentes; ramas $1,5 \mathrm{~mm}$ diám., densamente pilosas, com pelos largos amarillentos, 1,5 mm long. Hojas herbáceas. Pecíolo 3-5,5 mm long. Lámina elíptica u ovada, 28-46 x 10,5-22 mm, relación largo:ancho $=$ 1,5-3,5:1; haz con pelos simples largos 1,5 $\mathrm{mm}$ long., adpresos o antrorsos, dispuestos oblicuamente con respecto a la vena media; envés con pelos largos sin orientación defini- da, pelos cortos crespos y pelos glandulares microcapitados; venas secundarias rojizas, con pelos simples largos; ángulo de divergencia $30-50^{\circ}$. Nectarios $1+1$ o $2+2,0,5 \mathrm{~mm}$ diám, sobre el margen foliar. Hojas floríferas bracteiformes ovadas; pecíolo ca. $2 \mathrm{~mm}$; lámina muy reducida, $10-3,5 \mathrm{~mm}$, de margen aserrado, con un par de nectarios rojizos $0,7-0,8$ mm diám., asentados sobre el envés, junto al margen foliar. Flores heterostilas, agrupadas en el ápice de las ramas. Profilos 4,3-5 mm x 0,3 mm. Cáliz 6-9 mm long.; tubo calicino 2,5-4,5 mm long., por fuera con pelos simples más largos (1,3 mm long.) sobre las venas; lóbulos con pelos más largos que el tubo. Corola amarilla; pétalos con lámina obovada, ca. $5 \mathrm{~mm}$ long. Filamentos estaminales $7,7 \mathrm{~mm}$ long. en flores brevistilas; anteras $0,9 \times 0,4$ $\mathrm{mm}$. Ovario 2-3 mm long.; placentas 7-8ovuladas; estilos $3 \mathrm{~mm}$ long. en flores brevistilas; estigmas paucirramosos, ca. $1 \mathrm{~mm}$ long. En flores brevistilas androceo 1,5 mm mayor que el gineceo y casi tan largo como el cáliz. Fruto 3-4 mm long., profilos más largos que el fruto. Semilla 1,8-2,4 x 0,8-1,1 mm; lado rafeal incurvo. Arilo 1-2 mm long.

Paratypus: BRASIL. Piauí: 11 km N de Rio Corrente, BR-135, estrada Corrente-Gilbués, 490 m, 10²2'S 45¹3'W, 4-IV-1983, Krapovickas \& al. 38732 (CTES).

Distribución: Se conocen solamente el tipo y el paratipo, colectados en bosque abierto y borde del camino.

\section{Turnera diamantinae Arbo, sp. nov.}

Figs. 12 y 18

Fruticulus $30 \mathrm{~cm}$ altus, ramis lanosotomentosis. Folia stipulis rudimentariis; lamina discolora, subtus lanoso-tomentosa, subtus supra basin nectariis parvis gerentibus. Flores dimorphi, apice caulium conferti; calyce $9 \mathrm{~mm}$ longo; filamentis glabris, basi tubo tota facie adnatis; antheris brevissimis, 0,5 $\mathrm{mm}$ longis; placentis 2-3-ovulatis; stylis glabris. Fructus dorso laevis. Semina curvata, reticulata, arillo unilaterali, angusto. 


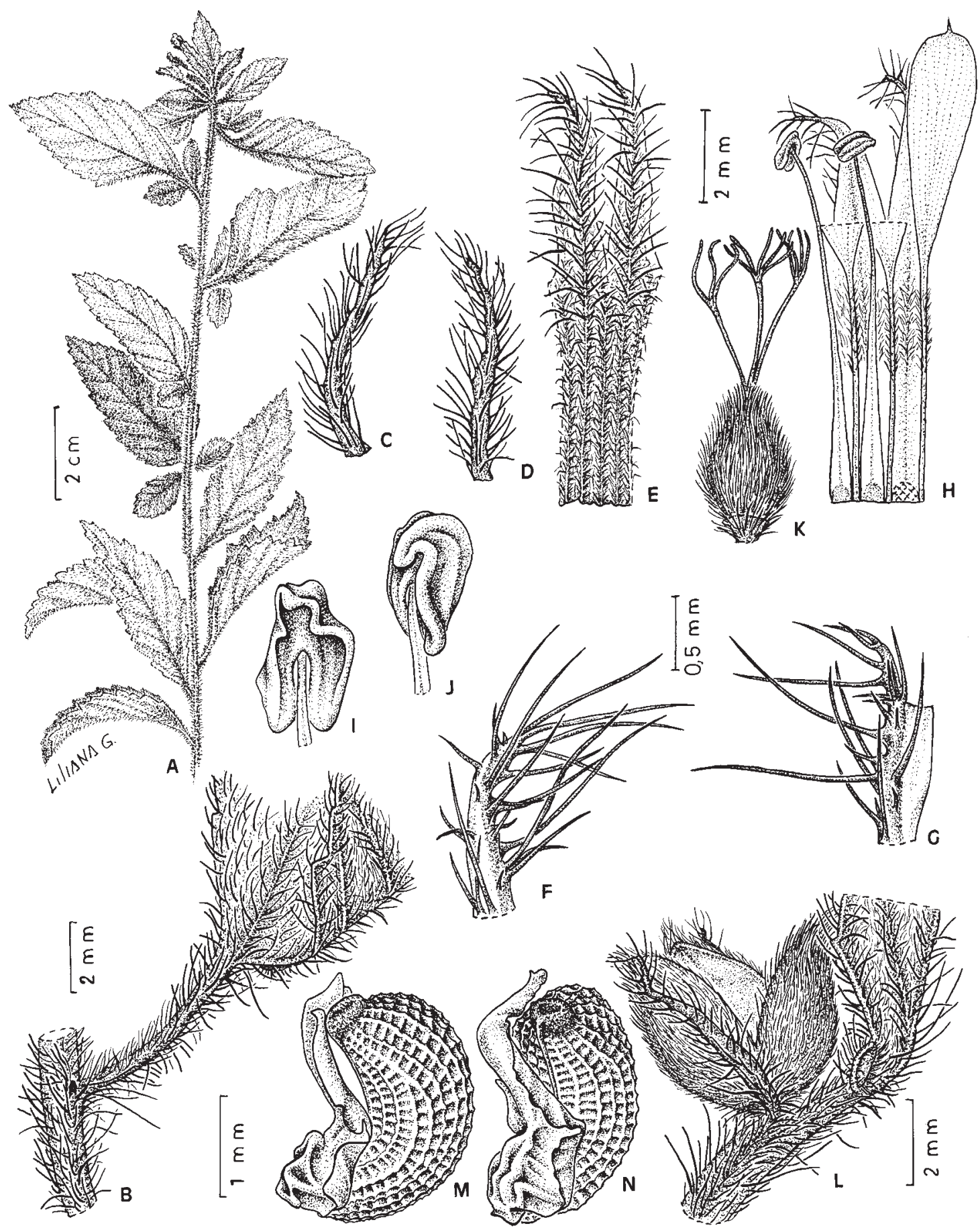

Fig. 17. Turnera dasytricha var. crinita. A: rama. B: nudo y base de la hoja. C-D: profilos. E: porción del cáliz, cara externa. F-G: ápice de los lóbulos del cáliz. H: flor brevistila, porción del tubo calicino, cara interna, con pétalos y estambres adnatos; se ha cuadriculado la cicatriz dejada al desprender un estambre. I-J: anteras, vistas dorsal y lateral. K: receptáculo y gineceo. L: base de una hoja florífera con nectarios, fruto epifilo y profilos. M-N: semilla con arilo, vistas lateral y rafeal (Krapovickas \& al. 38732). Del. Liliana Gómez. 


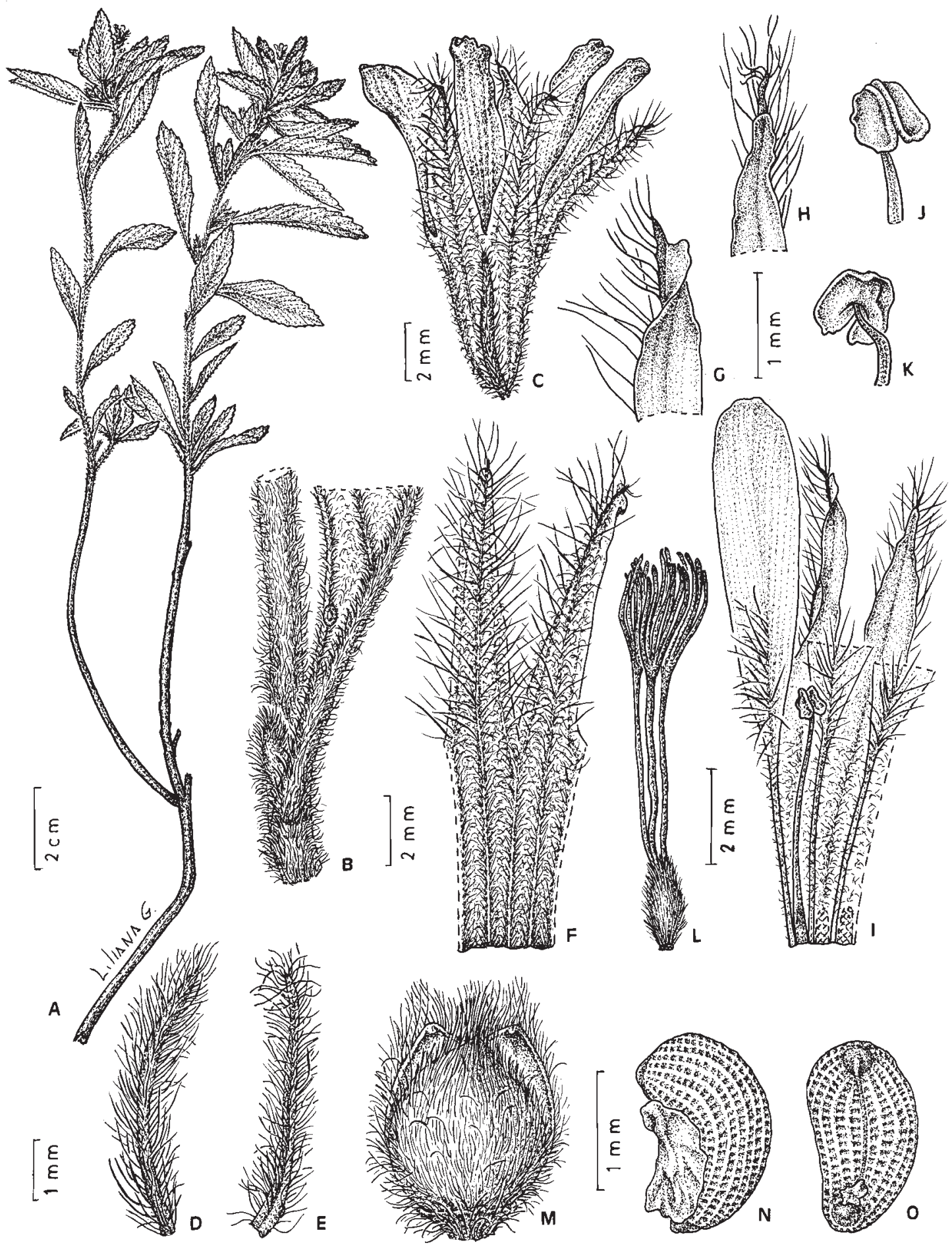

Fig. 18. Turnera diamantinae. A: planta. B: nudo, base de una hoja con nectario, cara abaxial y yema axilar. C: flor con profilo. D-E: profilos. F: porción del cáliz, cara externa. G-H: ápice de los lóbulos del cáliz. I: flor longistila, porción del tubo calicino, cara interna, con pétalos y estambre adnatos; se han cuadriculado las cicatrices dejadas al desprender dos estambres. J-K: anteras, vistas dorsal y ventral. L: gineceo. M: fruto. N-O: semillas con arilo, vistas lateral y rafeal (Hatschbach \& al. 41450). Del. Liliana Gómez. 
Typus. Brasil. Minas Gerais: Senador Mourão, mun. Diamantina, 24-I-1978, G. Hatschbach 41450 (holotypus MBM, isotypus CTES).

Subarbusto $30 \mathrm{~cm}$ alt., ramificado; tallos leñosos en la parte basal, corteza pardonegruzca, cicatrices foliares salientes; ramas del año lanoso-tomentosas al menos hacia el ápice, con pelos simples blandos y pelos crespos densísimos blanquecinos. Yemas axilares 2, ramas seriales desarrolladas. Hojas discoloras. Estípulas rudimentarias, con coléteres rojizos 0,1-0,2 mm long. Pecíolo semicilíndrico, 2-4,5 mm long., indumento como el del tallo. Lámina elíptica o angustiovada, 14-30 x 4-9 mm, relación largo:ancho 2,6-4,3:1; base cuneada o brevemente atenuada; ápice agudo; borde ligeramente revoluto, aserrado-crenado, dientes obtusos, terminados en coléteres; haz oscura en seco, grisáceo-tomentosa, envés blanquecino, lanoso-tomentoso; vena media y 9-10 pares de venas laterales alternas o subopuestas, rectas, de indumento muy denso: pelos blancos o rojizos antrorsos, hundidas en la haz, prominentes en el envés, terminando en las escotaduras o perdiéndose hacia los dientes, con ramas hacia las escotaduras; ángulo de divergencia $30-40^{\circ}$; venas terciarias y venación menor inconspicuas. Nectarios 2, 0,3-0,7 mm long., circulares o elípticos, negruzcos, borde angosto brevemente piloso, situados sobre el margen foliar, a 0,3-2,5 $\mathrm{mm}$ de la base, orientados hacia el envés. Hojas floríferas apicales acortándose rápidamente, formando un racimo apical abreviado. Flores epifilas, presumiblemente heterostilas (sólo se estudiaron flores longistilas). Pedúnculo 1,5-2 mm long., totalmente adnato al pecíolo. Profilos subulados, 5-6,5 x 0,4-0,5 mm, rojizos, densamente pilosos. Pedicelo nulo. Cáliz $9 \mathrm{~mm}$ long.; tubo calicino $4 \mathrm{~mm}$ long., cara externa densamente pilosa, pelos simples largos y pelos simples cortos crespos, cara interna vellosa; lóbulos triangulares, cara interna glabra, mucrón 0,5 mm long. Corola ca. $1 \mathrm{~mm}$ más larga que el cáliz, pétalos con uña pilosa, lámina obovada, $6,5 \times 1,5 \mathrm{~mm}$, vena media densamente pilosa en el tercio basal, pelos 0,6 $\mathrm{mm}$ long. Filamentos estaminales glabros, complanado-subulados en seco, 4,5 mm long. en flores longistilas; anteras dorsifijas, latiovadas, $0,5 \mathrm{x} \quad 0,4-0,5 \mathrm{~mm}$, base emarginada, ápice obtuso algo recurvado a la dehiscencia. Ovario ovoide, ca. $1 \mathrm{~mm}$ long., densamente piloso; placentas 2-3-ovuladas; estilos cilíndricos, glabros, $4 \mathrm{~mm}$ long. en flores longistilas; estigma penicilado, $2,5 \mathrm{~mm}$ long., numerosas ramas de diferente longitud. En flores longistilas, gineceo 2,7 $\mathrm{mm}$ más largo que el androceo. Fruto ovoide, 3,2 mm long., con reborde anular basal de 0,3 mm, dejado por el tubo floral al desprenderse; cara externa villosa, superficie irregular por la base abultada, rojiza de los pelos simples largos, cara interna glabra, lustrosa, castaña, vena placentaria saliente. Semilla obovoide, curvada, 1,5-1,6 x 0,7-0,9 mm; exóstoma hemisférico, 0,1-0,2 mm long.; rafe linear, lado rafeal incurvo; cálaza redondeada, con una protuberancia oscura formada por la prolongación de la rafe; epidermis lisa. Episperma suavemente reticulado, aréolas cóncavas. Arilo unilateral, angosto, más corto que la semilla, de células papilosas.

Distribución: Sólo se conoce el ejemplar tipo, colectado en «campo cerrado», de suelo rocoso.

Obs.: Especie similar a Turnera incana, de la que se diferencia por tener estípulas rudimentarias; anteras cortas de ápice obtuso y estigma multirramoso de 2,5 mm long.

\section{Turnera discolor Urb.}

Fig. 7 y 19

Urban, I., Bot. Jahrb. Syst. 17: 506. 1893. Typus: Brasil. Minas Gerais: Curalinho, près Diamantina, 6-IV-1892, Glaziou 19396 (holotypus $\mathrm{B}+$, fototipo $\mathrm{F} \mathrm{n}{ }^{\circ} 13578$ !, isotypi C!, K!, LY!, P!). La localidad del tipo es dudosa, es el único ejemplar de Minas Gerais, probablemente corresponde al mun. Diamantino de Mato Grosso.

Turnera chrysodoxa S. Moore, Trans. Linn. Soc. London, Bot. ser. 2, 4: 364. 1895. Typus: Brasil. Mato Grosso: Chapada plateau, 1800ft, elegant herb with yellow flowers, grows in small clumps, VIII-1891/1893, Moore 184 (holotypus $\mathrm{BM}$ ! fototipo $\mathrm{MO} \mathrm{n}^{\circ} 2793$, isotypi $\mathrm{NY}$ !, WU!). 


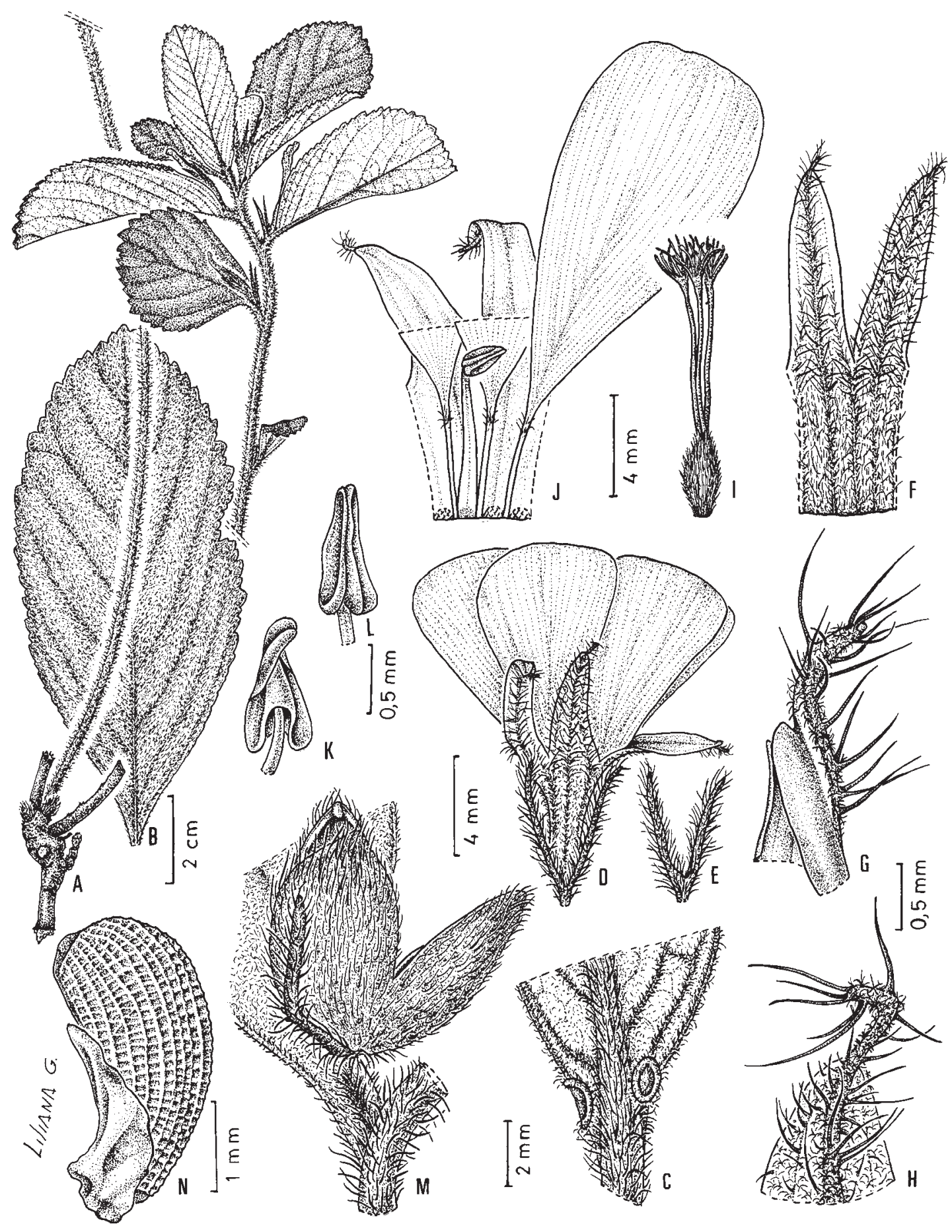

Fig. 19. Turnera discolor. A: planta. B: hoja, cara adaxial. C: parte basal de la hoja con nectarios, cara abaxial. D: flor con profilos. E: receptáculo y profilos. F: porción del cáliz, cara externa. G-H: ápice de los lóbulos del cáliz. I: gineceo. J: flor longistila, porción del tubo calicino, cara interna, con pétalos y estambre adnatos; se han cuadriculado las cicatrices dejadas al desprender tres estambres. K-L: anteras, vistas dorsal y ventral. M: base de una hoja florífera con fruto epifilo y profilo. N: semilla con arilo, vista lateral (A, D-L: Oliveira 82; B: Hatschbach \& al. 66901; C, M: Baldwin 3035; N: Hatschbach \& al. 63674). Del. Liliana Gómez. 
Hierba perenne hemicriptófita, 12-56 cm alt.; eje subterráneo grueso, recto o retorcido, hasta $20 \mathrm{~mm}$ diám.; uno a varios tallos simples o ramificados, porción basal con corteza rojiza, lustrosa, luego subglabros a hirsutos, con pelos simples largos erectos 1,5-2 mm long., pelos simples, tenues, cortos, crespos y pelos glandulares microcapitados. Yemas axilares 1-3, seriales, la basal florífera, ramas seriales floríferas desarrolladas. Hojas coriáceas, discoloras, más o menos abolladas, las basales bracteiformes, aumentando de tamaño hacia el ápice del tallo. Estípulas a veces desarrolladas, 0,6 mm long., escondidas en el indumento. Pecíolo 1-4,5 mm long., indumento igual o más denso que el del tallo, con 2-3 coléteres a cada lado en la base. Lámina elíptica, latielíptica, obovada, suborbicular, ovada o angustiovada, (0,6-)2,3-8,5(-11) x (0,5-)1,5$3,5(-5,4) \mathrm{cm}$, relación largo:ancho $=1,2-$ $3,5: 1$; base cuneada, redondeada o brevemente atenuada; ápice obtuso, a veces agudo o retuso; borde ligeramente revoluto, serrulado, dientes obtusos o agudos, a veces terminados en coléteres; haz oscura, a veces rojiza y lustrosa, lisa o rugosa, glabra a tomentosa, con pelos simples 0,5-1 mm long., blanquecinos, curvado-antrorsos entremezclados con pelos más cortos y delgados; envés lanosotomentoso, blanco-grisáceo; vena media y 4-8 pares de venas laterales hundidas en la haz, prominentes en el envés, rojo-oscuras, con pelos simples largos, antrorsos, laxos, perdiéndose hacia el margen y originando ramas hacia los dientes; ángulo de divergencia $20-40^{\circ}$; venas terciarias y venación menor conspicuas en el envés. Nectarios 1-2 pares, circulares o elípticos, 1-1,2 mm diám., borde glabro a piloso; situados en la unión de pecíolo y lámina, o desplazados sobre el envés, a veces sobre las venas laterales. Flores solitarias, epifilas, heterostilas, a veces dispuestas en ramas seriales floríferas con las hojas floríferas bracteiformes, 8-9 x 2,5-3 mm. Pedúnculo 2-5 $\mathrm{mm}$ long., totalmente adnato al pecíolo e incluso a la vena media. Profilos subulados, 59(-11) x 0,5-1 mm, glabros a hirsutos. Pedicelo nulo o subnulo (0,5 mm long.). Cáliz 11-18 mm long., sépalos coherentes $28-48 \%$ de su longitud; tubo calicino 4-6 mm long., cara externa glabra a densipilosa, con pelos simples largos 0,7-1 mm long., especialmente sobre las venas, pelos simples tenues y pelos microcapitados, cara interna vellosa; lóbulos angustiovados o triangulares, cara externa con pelos más largos que el tubo, hasta $1,5 \mathrm{~mm}$ long., pelos simples y a veces algunos pelos con 2-5 ramas (0,2 $\mathrm{mm}$ long.), cara interna glabra; lóbulos internos con bordes membranáceos y ápice cuculado, mucrón 0,5$1 \mathrm{~mm}$ long. Corola amarilla, 4,5-8 mm más larga que el cáliz; pétalos con la uña soldada al tubo calicino, lámina 13-16 x 8-9 mm. Filamentos estaminales glabros, complanadosubulados en seco, soldados $0,6-1 \mathrm{~mm}$ en la base al tubo calicino, $9 \mathrm{~mm}$ long. en flores brevistilas, 5-6 mm long. en flores longistilas; anteras angustiovadas, 1,2-1,6 x 0,5-0,7 mm, base emarginada, ápice obtuso, ligeramente recurvado a la dehiscencia, filamento inserto dorsalmente a 0,4-0,6 $\mathrm{mm}$ de la base. Ovario ovoide, hirsuto, $2 \mathrm{~mm}$ long.; placentas 3-7ovuladas; estilos cilíndricos, glabros o pilosos, $4 \mathrm{~mm}$ long. en flores brevistilas, $8-8,7$ $\mathrm{mm}$ long. en flores longistilas; estigma penicilado, 12-16 ramas, 1,2-2,5 $\mathrm{mm}$ long., más largo en flores longistilas. En flores longistilas gineceo 1,5-5 mm más largo que el androceo, y en flores brevistilas 1,5-6,5 mm más corto. Fruto 5-7 mm long.; profilos más cortos o más largos que el fruto; valvas ovadas, cara externa casi lisa, pelos simples largos y cortos, a veces de base cónica, rojiza, cara interna glabra o con pelos laxos, lustrosa, castaño claro. Semilla obpiriforme, curvada, voluminosa, 2,7-3 x 1,3-1,4 mm, base atenuada, exóstoma cónico $0,3 \mathrm{~mm}$ long.; rafe linear saliente, lado rafeal incurvo; cálaza redondeada, con una prominencia pigmentada, oscura, prolongación de la rafe. Episperma tenuemente reticulado, ca. 24 filas longitudinales de aréolas pequeñitas, transrectangulares o cuadrangulares; epidermis lisa, con bastoncillos de cera en la semilla inmadura. Arilo envolvente en la base, luego extendido sobre la rafe, más corto que la semilla, amarillento en seco, de células papilosas.

Material estudiado: BRASIL. Goiás: Mun. Jataí, $10 \mathrm{~km} \mathrm{~N}$ of Jataí, ca. $900 \mathrm{~m}, 15-\mathrm{X}-1968$, Eiten \& Eiten 9336 (US); $10 \mathrm{~km}$ ao N de Jatai, estrada Caiaponia-Jatai, 14-X-1968, Fonseca \& 
Onishi 1540 (UB). Mato Grosso: ca. $1 \mathrm{~km} \mathrm{~W}$ of Expedition Base Camp, 1249'S 514' 'W, 6-X1967, Argent \& al. 6681 (K, NY, UB); Braço, Rio Arinos, 26-IX-1943, Baldwin 3035 (US); Barra do Garças, Serra do Taquaral, 23-XI-1997, Bernacci \& Arbocz 2531 (ESA); Mun. Diamantino, BR163, Rod. Cuiabá-Sinop, $13^{\circ} 12^{\prime} \mathrm{S} 56^{\circ} 00^{\prime} \mathrm{W}, 17$ IX-1985, Cid Ferreira \& al. 6056 (NY); Chapada dos Guimaraes, 15²3'S 5550'W, 21-X-1977, Costa 24 (RB); Estrada Xavantina - São Felix, a $245 \mathrm{~km}$ ao NNE de Xavantina, Fonseca \& Onishi 1146 (UB); R.10, ca. 12 km SW of Base Camp, 1249'S 514'' W, 20-IX-1968, Harley \& Souza 10136 (K, MO, NY, RB, UB); mun. Chapada dos Guimarães, Rod. Chapa - Água Fria, Km 20 do trevo para Cuiabá, 13-VIII-1997, Hatschbach \& al. 66801 (C, CTES, K, MBM); ca. $75 \mathrm{~km} \mathrm{~N}$ of Xavantina, 300-400 m, 9-X-1964, Irwin \& Soderstrom 6696 (P); $10 \mathrm{~km} \mathrm{NW} \mathrm{do} \mathrm{Alto}$ Araguaia em direção a Rondonopolis, $700 \mathrm{~m}$, 22-IX-1988, Kral \& Wanderley 75022 (CTES, $\mathrm{SP})$; Sta. Ana da Chapada, 18-VII/10-VIII1902, y 6-VI-1903, Malme 1972 a-f (R, S); Chapada dos Guimarães, behind Colegio de Buriti, 720 m, 13-X-1973, Prance \& al. 18897 (P);

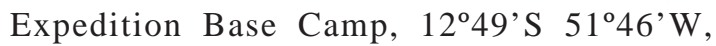
Square R 2, ca. $0.5 \mathrm{~km}$ E of road, 7-IX-1968, Richards 6858 (E, K, NY, P, RB); Sta. Anna da Chapada, 1-VIII-1902, Robert 459b (BM, K); Chapada dos Guimarães County, $\mathrm{S}$ of «Cacho-erinha» waterfall along the Indepedencia river, $15^{\circ} 25^{\prime} \mathrm{S} 55^{\circ} 50^{\prime} \mathrm{W}, 600-700$ m, 15-IX-1991, Schessl \& Gottsberger 2245 (CTES); Mun. Campo Verde, estrada Nova Brasilândia - Campo Verde, ca. 32 km de Nova Brasilândia, 1507'S 5506'W, 8-X-1997, Souza \& al. 20412 (CTES, ESA).

Distribución y fenología: Todos los ejemplares conocidos son de Mato Grosso, excepto el tipo (Minas Gerais?) y dos de Goiás. Vive en campo y «cerrado» con suelo laterítico o pedregoso, entre 300 y $900 \mathrm{~m}$ de altitud. Florece entre julio y noviembre.

Especie afín a Turnera lamiifolia, a la que se asemeja en el aspecto vegetativo y especialmente en la semilla. T. discolor presenta generalmente ejes simples, con las flores distribuidas a lo largo de los mismos, mientras los tallos de T. lamiifolia son ramificados y muestran las flores agrupadas en el ápice de las ramas, en inflorescencias capituliformes o racemiformes.

En los ejemplares secos el color de la haz foliar varía entre pardo-glaucescente y rojizooscuro; se puede observar toda la gama en especímenes de la Chapada dos Guimarães. En Prance 18897 se halló un fruto proveniente de un ovario 5-carpelar. El ejemplar Hatschbach \& al. 66801 se parece mucho a Turnera lamiifolia por sus hojas muy grandes (hasta $11 \mathrm{~cm}$ long.), y por su indumento inusualmente denso.

Se estudió la anatomía caulinar de esta especie (Gonzalez, 2000).

\section{Turnera dolichostigma Urb.}

Figs. 20 y 21

Urban, I., Jahrb. Königl. Bot. Bart. Berlin 2: 106. 1883, en parte; Urban, en Martius, C.F.P., Fl. Bras. 13(3): 128. 1883, en parte; Arbo, Bol.Soc.Argent.Bot. 24(3-4): 423-425. Fig. 1. Typus: Brasil, Minas Gerais, Serra da Lapa [Serra do Cipó], XI-1824, Riedel 941 (lectotypus LE!, isolectotypus $\mathrm{P}$ !)

Turnera pumileoides Urb., en Chodat \& Hassler, Bull. Herb. Boissier sér.2, 3: 1118. 1903. Typus: Paraguay, [Amambay], in regione cursus superioris fluminis Apa, II-1902, Hassler 8443 (lectotypus, aquí designado G!, isotypi BM!, G!, $\mathrm{K}$ !, LY!, NY!, P!, S!, W!, B+ fototipo $\mathrm{F} \mathrm{n}^{\circ}$ 13599).

Hierba perenne hemicriptófita ramosa o subarbusto 9-25(-50) cm alt.; base de 1,5-7 mm diám., glabrescente, rojiza; tallos raramente erectos, generalmente ascendentes o sinuosos, cilíndricos, estriados, 0,6-2 mm diám., con pelos simples hirsutos $1,5 \mathrm{~mm}$ long., y pelos cortos crespos, blanquecinos en la porción apical; entrenudos 9-37 mm long. Ramas seriales raramente desarrolladas. Hojas herbáceas. Estípulas rudimentarias, con coléteres 0,2-0,3 mm long., ocultos en el indumento. Yemas axilares 1-2. Pecíolo semicilíndrico, 2,5-6 mm long., indumento como el del tallo. Lámina 10-40 x 5-20 mm, obovada, elíptica u ovada, relación largo:ancho $=2,6-1,4: 1$; base cuneada o ate- 


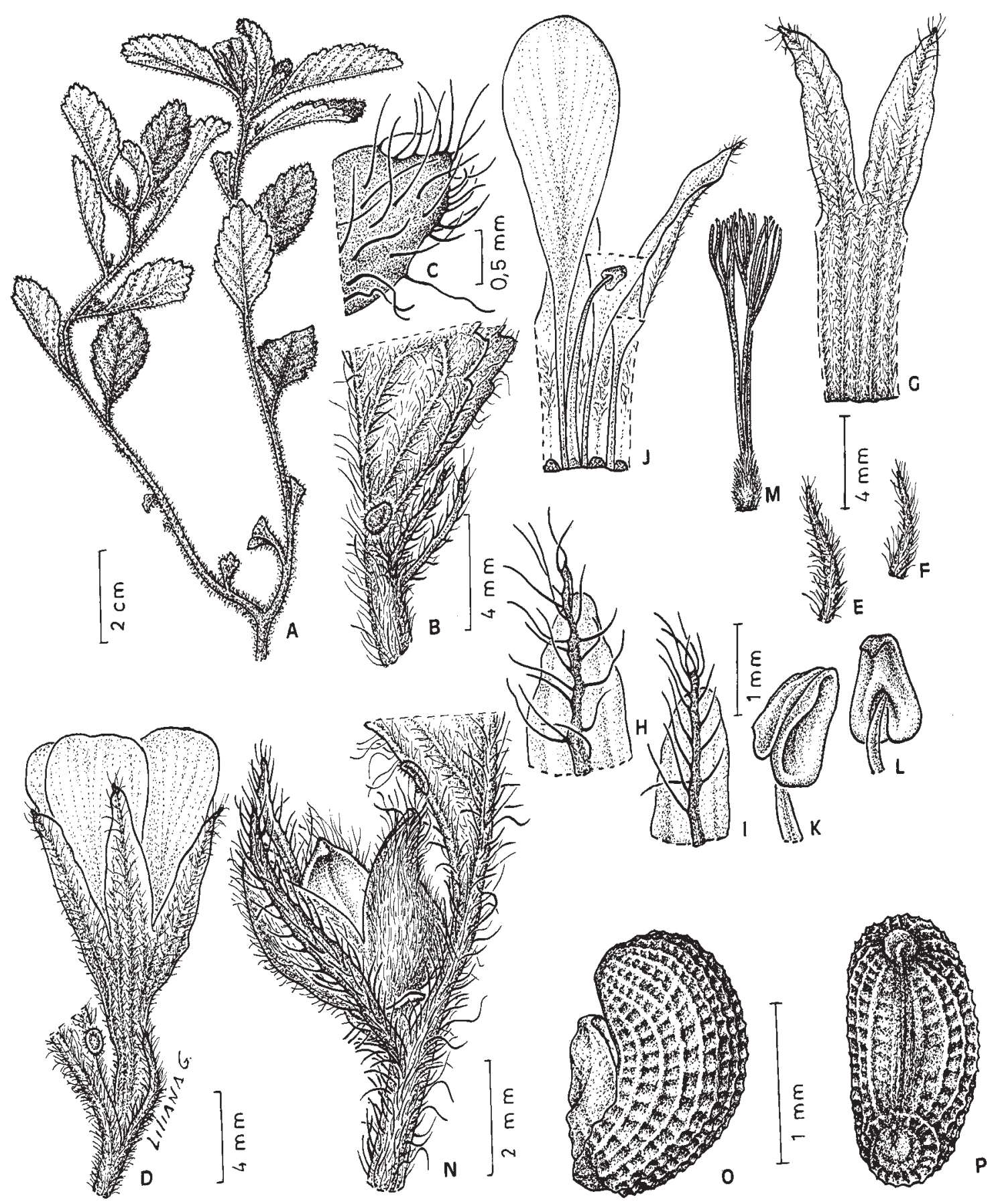

Fig. 20. Turnera dolichostigma. A: planta. B: hoja con nectarios, cara abaxial. C: ápice de la hoja, cara adaxial. D: flor epifila con profilo. E-F: profilos. G: porción del cáliz, cara externa. H-I: ápice de los lóbulos del cáliz. J: flor longistila, porción del tubo calicino, cara interna, con pétalos y estambre adnatos; se han cuadriculado las cicatrices dejadas al desprender tres estambres. K-L: anteras, vistas ventral y dorsal. M: gineceo. N: base de una hoja florífera con fruto epifilo y profilos. O: semilla con arilo, vista lateral. P: semilla, vista rafeal (A-N: Riedel 941; O-P: Hassler 8443). Del. Liliana Gómez. 


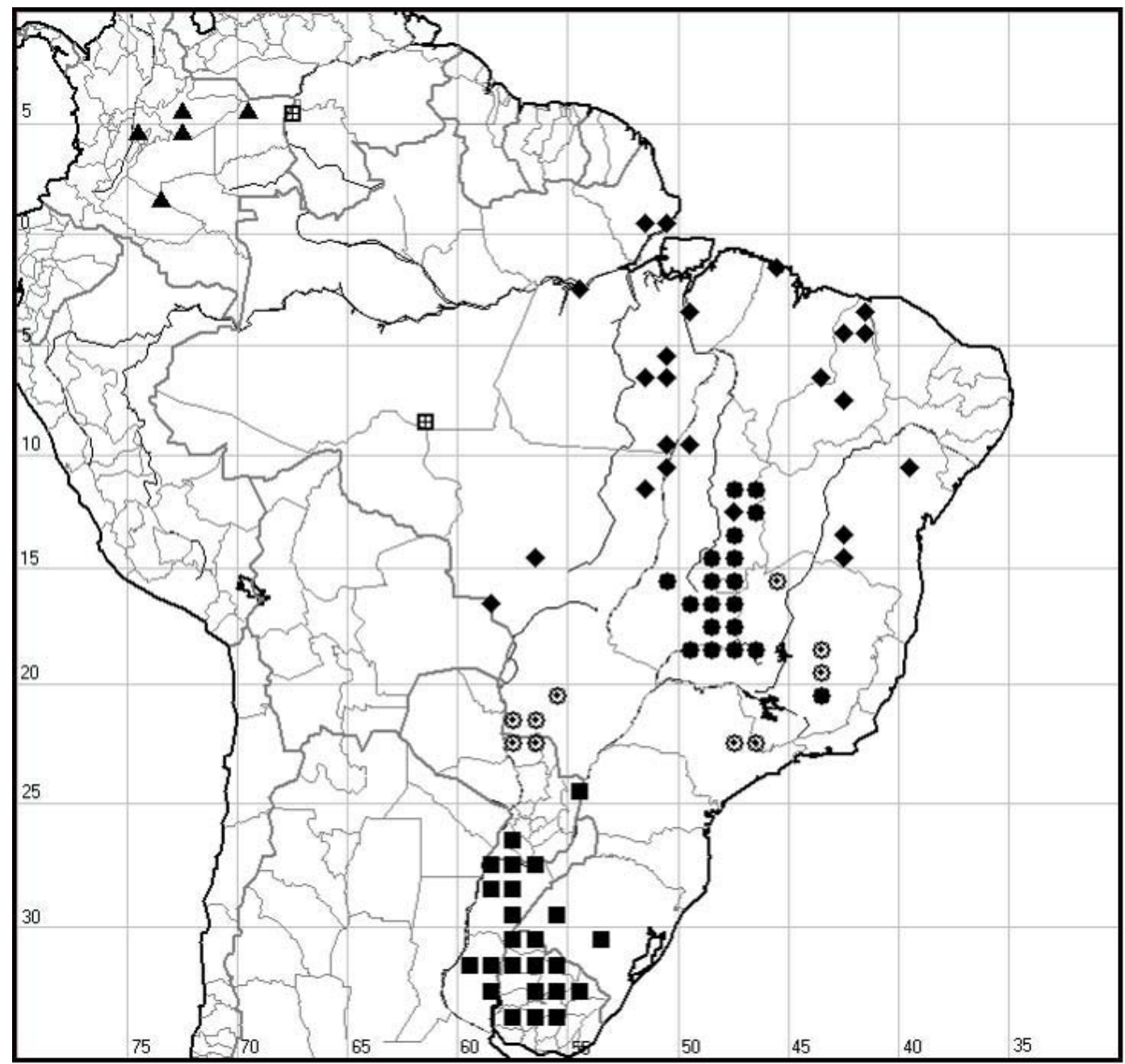

Fig. 21. Distribución de Turnera dolichostigma $₫$; T. huberi 田; T. longiflora $\bigcirc$; T. melochia var. melochia $\mathbf{\Delta}$;

nuada; borde crenado o doblemente crenado, dientes anchos, obtusos; ápice obtuso a veces agudo; haz punteada, con pelos simples largos, antrorsos, a veces adpresos, de base abultada, 1,4-2,5 mm long.; envés arenáceo o punteado, con pelos cortos crespos y pelos largos especialmente sobre las venas principales; 4-7 pares de venas laterales prominentes, dirigidas hacia las escotaduras del margen; ángulo de divergencia $25-40^{\circ}$; venas terciarias y venación menor inconspicuas. Nectarios 2, circulares, 0,3-0,6 mm diám., con reborde pubérulo, situados en la unión de pecíolo y lámina o desplazados hasta $2 \mathrm{~mm}$ sobre el margen foliar, a veces brevemente estipitados.
Hojas apicales frecuentemente dispuestas en roseta en los extremos de las ramas, y de tamaño bruscamente decreciente. Flores epifilas, heterostilas, agrupadas en los extremos de las ramas en racimos capituliformes hojosos. Pedúnculo 1,5-2,5 mm long., totalmente adnato al pecíolo o libre hasta $1 \mathrm{~mm}$ en la porción apical. Pedicelo ausente. Profilos 2, opuestos en la base del receptáculo, 2-3,5 mm long., subulados o lineares, pilosos por fuera, glabros por dentro en la base. Cáliz 9-14 mm long.; tubo calicino 4-4,5 mm long., cara externa con pelos cortos crespos, cara interna pilosa en la porción superior; lóbulos triangular-lanceolados, glabros por dentro, por fuera 
con pelos cortos crespos y pelos simples, largos, hirsutos sobre las venas, ápice agudo, a veces mucronulado. Corola cremosa o blanca; pétalos con la uña pilosa excepto en la base, lámina obovada 8-12 x 5-7 mm, glabra. Filamentos estaminales subulados, glabros, 4-5,5 $\mathrm{mm}$ long. en flores longistilas, 6,5-8 $\mathrm{mm}$ long. en flores brevistilas; anteras elípticas, 0,6-1 $\mathrm{mm}$ long., filamento inserto dorsalmente a 0,3-0,4 mm de la base, ápice retuso, curvado o no después de la dehiscencia. Ovario ovoide, 1-2 x 0,8-1,1 mm, hirsuto; placentas 6-7ovuladas; estilos cilíndricos glabros, 3,5-5 $\mathrm{mm}$ long. en flores longistilas, 2,5-3,5 mm long. en flores brevistilas; estigmas con 8-10 ramas glabras de 1,5-2,2 $\mathrm{mm}$ long. En flores longistilas el gineceo es 2-2,5 mm más largo que el androceo y 2-6 mm más corto que el cáliz; en flores brevistilas el androceo es 1,5 $\mathrm{mm}$ más largo que el gineceo, y 3-6 mm más corto que el cáliz. Fruto subesférico, 2-5 mm diám., con un reborde basal anular dejado por la absición del tubo floral; profilos más cortos que el fruto; valvas ovadas, por fuera lisas, pilosas, por dentro glabras, lustrosas, amarillentas con manchitas pardas. Semilla ligeramente curvada, $1,5-1,8 \times 0,7-1 \mathrm{~mm}$, negruzca a la madurez; exóstoma cónico; rafe linear, lado rafeal incurvo; cálaza poco saliente, oscura, a veces algo deprimida en el centro. Episperma reticulado, aréolas cuadrangulares o rectangulares pequeñitas. Arilo unilateral más corto que la semilla, 0,7-1,2 mm long., de células lisas.

Material estudiado: BRASIL. Mato Grosso do Sul: Estrada para o Rio Apa, Fazenda Milênio, mun. Porto Murtinho, 14-VI-2006, Barbosa \& Silva 1572 (CTES, MBM); Aquidauana, estrada para Rochedo, proximo ao rio Betina, Fazenda Marimbondo, 25-I-1979, De Grande \& Lopes 207 (CTES, SP); Rod. BR-267, Porto Murtinho-Bonito, próximo do Rio Perdido, mun. Porto Murtinho, 21-X-2003, Hatschbach \& al. 76592 (CTES, MBM); Rod. BR-267 Jardim-Porto Murtinho, próx. do Rio Perdido, mun. Porto Murtinho, 250 m, 15-III-2004, Hatschbach \& al. 77115 (CTES, MBM) y 77129 (CTES, MBM); Rod. Jardim-Porto Murtinho, prox. da Faz. Canadá, mun. Jardim, 15-III-2004, Hatschbach \& al. 77157 (CTES, MBM); Rio Capibara, 44 km E de Porto Murtinho,
29-IV-1977, Krapovickas \& Schinini 32803 (CTES); 83 km E de Pto. Murtinho, 29-VI-1977, Krapovickas \& Schinini 32966 (CTES); Rio Caracol, Mun. Caracol, 13-XI-2006, Silva \& Barbosa 5296 (CTES, MBM). Minas Gerais: mun. Formoso, Parque Nac. Grande Sertão Veredas: ca. $500 \mathrm{~m}$ da Vereda do Veado (nascente do Rio Preto), 1524'35"S 4555'07"W, 830 m, 6-XII1997, Alvarenga \& al. 1151 (CTES, IBGE); $13 \mathrm{~km}$ NW de Congonhas do Norte, camino a Gouveia, aprox. 18 $41^{\circ} \mathrm{S} 43^{\circ} 42^{\prime} \mathrm{W}$, ca. $900 \mathrm{~m}, 13-\mathrm{II}-1991$, Arbo \& al. 5013 (CTES, SPF); Serra do Espinhaço, ca. $27 \mathrm{~km} \mathrm{SW}$ of Diamantina on road to Gouveia, 1300 m, 17-I-1969, Irwin \& al. 22141 (P); Serra da Lapa [Serra do Cipo], Riedel s.n., p.p. (OXF). PARAgUAY. Amambay, In regione cursus superioris fluminis Apa, II-1902, Hassler 8443 a (G, sintipo de T.pumileoides); Estancia Santa Teresa, Potrero Guaraní, $12 \mathrm{~km}$ SE de Administración, 20-III-1991, Soria 4438 (CTES, FCQ, MO). Concepción: Trail from Ea. Lapuri to Ea. Arrecife, $22^{\circ} 17^{\prime} \mathrm{S} 57^{\circ} 26^{\prime} \mathrm{W}, 12-\mathrm{V}-2000$, Zardini \& Quintana 54535 (CTES).

Distribución y fenología: Especie del centro-sur de Brasil (Minas Gerais y Mato Grosso do Sul) y NE de Paraguay, entre 250 y $1300 \mathrm{~m}$ de altitud. Propia de campo y «cerrado» con suelo arenoso, también se adapta a sitios modificados como bordes de caminos. Florece y fructifica entre octubre y junio.

\section{Turnera elliptica Urb.}

Figs. 22 y 23

Urban, I., Jahrb.Königl.Bot.Gart.Berlin 2: 107. 1883; Urban, en Martius C.F.P., Fl. Bras. 13(3): 129. 1883. Typus: Brasil. Goiás. Chapada do Serra S.Marco, Pohl 2869 (holotypus W!).

Hierba de 30-35 cm alt., tallos cilíndricos o más o menos angulados hacia el ápice, $2 \mathrm{~mm}$ diám., indumento velutino, pelos simples amarillo-dorados. Hojas elípticas, velutinotomentosas, sésiles o subsésiles, 2-2,5 x 1,2$1,7 \mathrm{~cm}$, relación largo:ancho $=1,5-2,1: 1$, las apicales rápidamente decrecientes; base redondeada; ápice redondeado; margen serrulado hacia el ápice; vena media y 4-6 


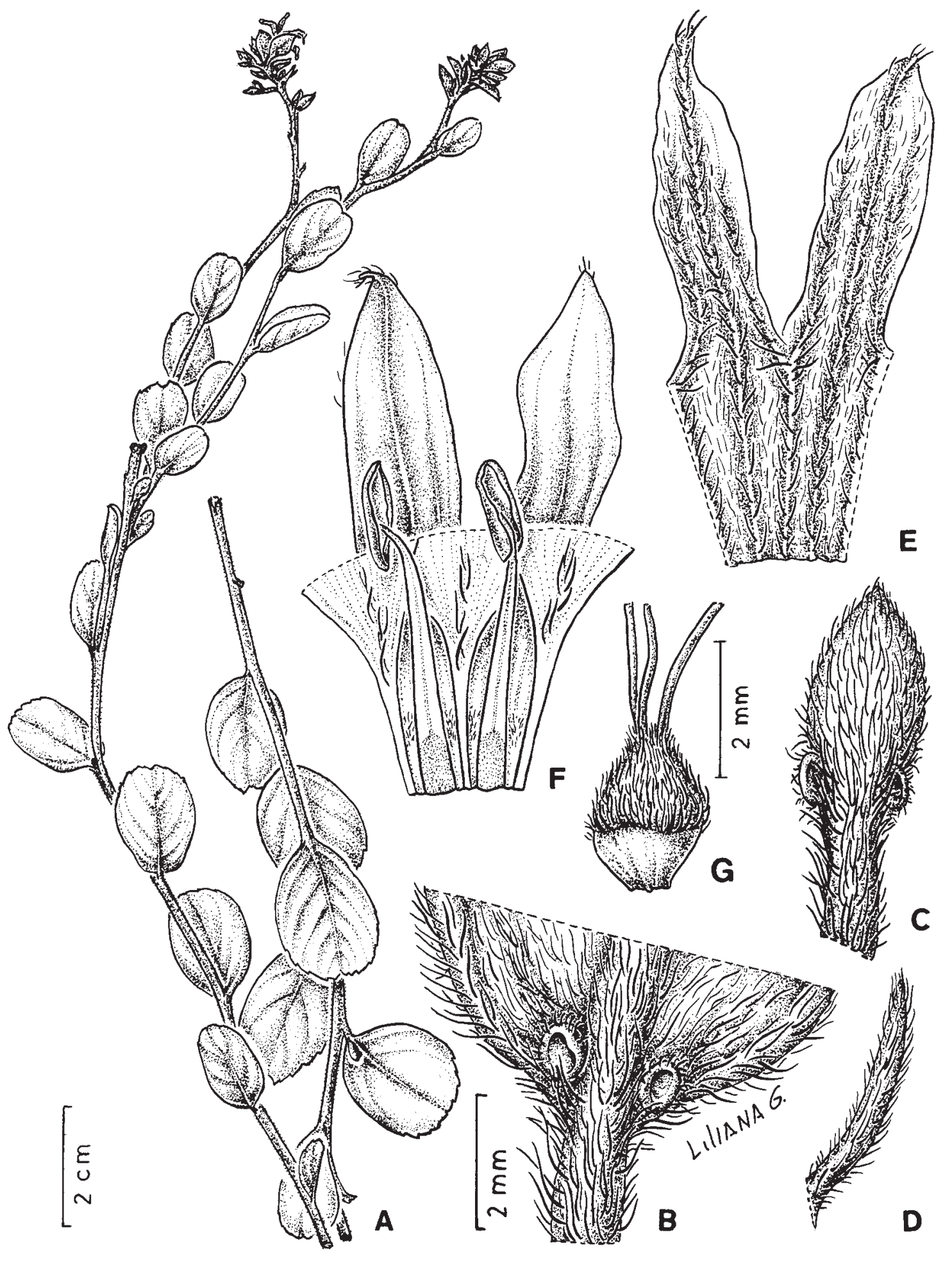

Fig. 22. Turnera elliptica. A: planta. B: porción basal de la hoja con nectarios, cara adaxial. C: bráctea, cara abaxial. D: profilo. E: porción del cáliz, cara externa. F: porción del tubo calicino, cara interna, con pétalos y estambre adnatos; se ha punteado la porción de los filamentos adherida al tubo floral. G: receptáculo, ovario y parte de los estilos (Pohl 2869). Del. Liliana Gómez. 


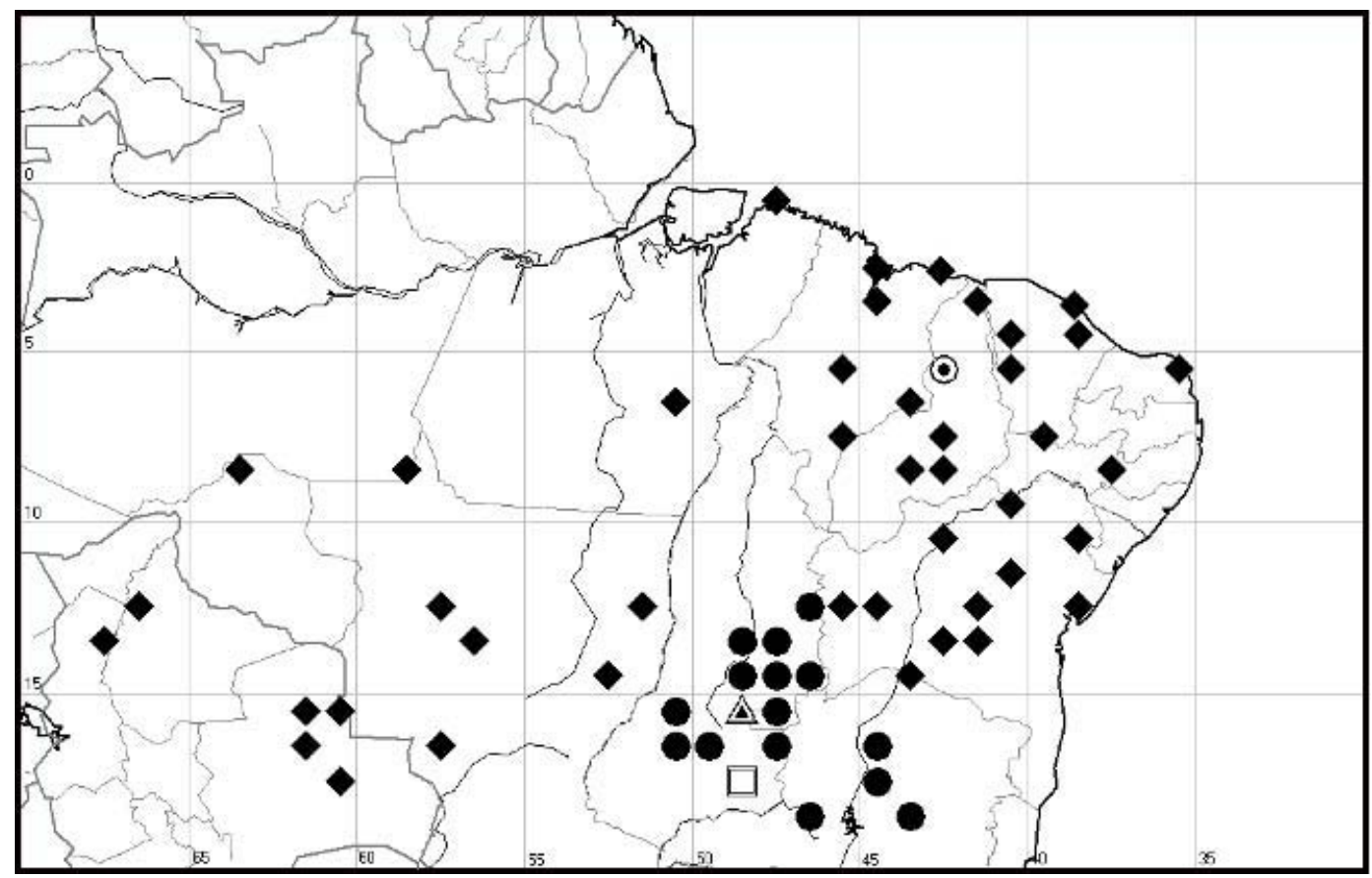

Fig. 23. Distribución de T. elliptica $\square ;$ T. glabrata $\Delta ;$. jobertii $\mathbf{O} ;$ T. melochioides var. latifolia $>$; T. trigona .

pares de venas laterales prominentes en el envés. Nectarios 2, circulares, ligeramente cóncavos, rojizos, situados en la base, a ambos lados de la vena media, asentados sobre el envés. Hojas floríferas 3-10 mm long. Flores epifilas, solitarias, agrupadas hacia el ápice. Pedúnculo adnato, 1,5-2 mm long. Profilos lineares o subulados, 2,5-3,5 x 0,4-0,6 mm. Cáliz $9 \mathrm{~mm}$ long., brevemente tomentoso por fuera; tubo calicino 3-3,6 mm long., pubescente por dentro en la parte superior; lóbulos 3-nervados, vena media terminada en un breve mucrón. Pétalos con la uña adnata al tubo calicino, lámina pilosa en la base. Filamentos estaminales glabros soldados al tubo $0,5 \mathrm{~mm}$, con nectarios en la unión, $4 \mathrm{~mm}$ long. en flores longistilas; anteras oblongas, $2 \times 0,7 \mathrm{~mm}$, base emarginada, filamento inserto dorsalmente a $0,7 \mathrm{~mm}$ de la base, algo recurvadas a la dehiscencia. Ovario globoso o cónico, hirsuto, con placentas 4-5-ovuladas; estilos glabros; estigma de aprox. 15 ramas ca. $2 \mathrm{~mm}$ long. Fruto inmaduro globoso, algo apiculado; valvas seríceo-pilosas por fuera, glabras por dentro.
Distribución: Se conoce solamente el ejemplar tipo.

\section{Turnera emendata Arbo, sp. nov.}

Figs. 10 y 24

Turnera nana Cambess. sensu Urb., Jahrb. Königl. Bot. Gart. Berlin 2: 103-104. 1883; Urban, en Martius C.F.P., Fl. Bras. 13(3): 127. 1883, excluyendo el tipo.

Herba 13-18 cm alta, pilis arcuato-antrorsis vel adpressis. Folia utrinque pubescentia, suprema tomentosa, nectariis basalibus. Flores magni, pedunculi supra medium vel toti adnati; calyx 10$17 \mathrm{~mm}$ longus, in 1/3 alt. coalitus; petala calycem dimidio superantia, aurea, glabra; filamenta glabra, basi tubo tota facie adnata; antherae 22,5 mm longae, in 1/3 alt. affixae; styli glabri.

Typus: Brasil. Goiás: ad Engenho Bernardino, J.B.E. Pohl 1272 (holotypus W, isotypi BR, F, M, $\mathrm{W})$. 


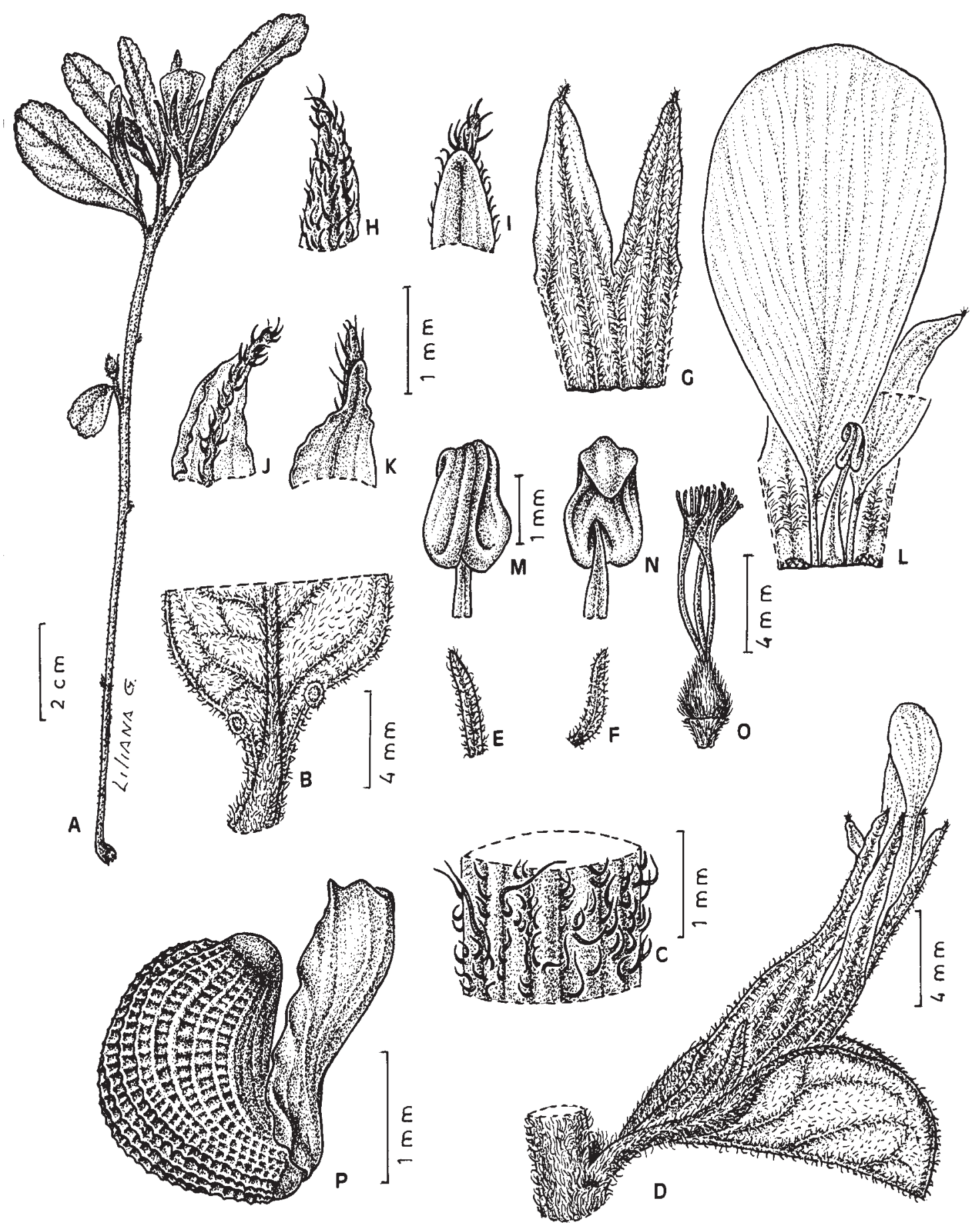

Fig. 24. Turnera emendata. A: planta. B: porción basal de hoja con nectarios, cara abaxial. C: porción del tallo. D: flor epifila con profilo. E-F: profilos. G: porción del cáliz, cara externa. H-I: ápice de un lóbulo externo del cáliz, caras externa e interna. J-K: ápice de un lóbulo interno del cáliz, caras externa e interna. L: flor brevistila, porción del tubo calicino, cara interna, con pétalos y estambre adnatos; se han cuadriculado las cicatrices dejadas al desprender dos estambres. M-N: anteras, vistas ventral y dorsal. O: gineceo. P: semilla con arilo, vista lateral (Pohl 1272). Del. Liliana Gómez. 
Hierba_13-18 cm alt., porción basal del tallo con pelos simples antrorsos o crespos 0,4 mm long.; ápice densamente piloso, con pelos adpresos o curvado-antrorsos, 0,6-0,9 mm long. y pelos simples crespos más cortos; entrenudos basales muy largos, acortándose hacia el ápice. Hojas aumentando de tamaño hacia el ápice, las basales obovadas, subsésiles, pequeñísimas. Estípulas rudimentarias, con coléteres oscuros 0,2-0,4 mm long. Pecíolo 2,5-4,5 mm long., indumento como el del tallo. Lámina foliar elíptica u obovada, a veces suborbicular,13-50 x 10-18 mm; base cuneada o brevemente atenuada; ápice obtuso $\mathrm{u}$ agudo; margen plano o apenas revoluto, aserrado-crenado, a veces doblemente; haz oscura, laxamente pilosa en hojas basales, las apicales estrigoso-tomentosas, pelos amarillos simples, gruesos, curvado-antrorsos o crespos; envés maculado (máculas diminutas rojizas) con pelos simples laxos y erectos en las hojas basales, en las hojas apicales tomentoso, con pelos crespos y glandulares microcapitados amarillos; venas laterales 4-5, hundidas en la haz, prominentes y rojizas en el envés, perdiéndose hacia el margen, a veces divididas, con ramas hacia los dientes o las escotaduras; ángulo de divergencia $25-35^{\circ}$. Nectarios en hojas floríferas, junto al borde la lámina, sobre el envés, distantes 2-3 mm de la base, rojizos, elípticos, 0,3-0,8 $\mathrm{mm}$ diám., borde piloso. Flores epifilas, heterostilas, solitarias. Pedúnculo floral 4-10 mm long., soldado totalmente al pecíolo, incluso a la base de la lámina, en las flores basales la porción apical libre 2-3 mm. Profilos lineares, 2,5-5,7 x 0,3-0,8 mm. Pedicelo 0-1 mm long. Cáliz 10-17 mm long.; tubo calicino 2,3-4,5 mm long., cara externa con pelos simples erectos $0,5 \mathrm{~mm}$ long., pelos cortos crespos y pelos glandulares microcapitados, cara interna vellosa; lóbulos triangulares, las venas con pelos algo más largos, cara interna glabra; ápice agudo. Corola amarilla, 4-7 $\mathrm{mm}$ más larga que el cáliz; pétalos con la uña soldada al tubo calicino, lámina glabra, obovada, 11-20 x 5-7 $\mathrm{mm}$, a veces con venas rojizas. Filamentos estaminales glabros, complanado-subulados, soldados $1 \mathrm{~mm}$ en la base al tubo calicino, 4,5-6,5 mm long. en flores longistilas, 7,5-9,5 $\mathrm{mm}$ long. en flores brevistilas; anteras 2-2,5 x
0,8-1 $\mathrm{mm}$, base emarginada, filamento inserto a $0,7 \mathrm{~mm}$ de la base, ápice recurvado a la dehiscencia. Ovario ovoide, hirsuto, $2 \mathrm{~mm}$ long.; estilos pilosos glabros, 4,5-6 mm long. en flores longistilas, 2,5-3 mm long. en flores brevistilas; estigma penicilado, amarillo, 1,5 mm long., ca. 16 ramas; gineceo 3-4,5 mm más largo que el androceo en flores longistilas, 3-4,5 mm más corto que el androceo en flores brevistilas. Fruto inmaduro densamente piloso, más largo o igual que los profilos. Semilla inmadura reticulada.

Paratypus: BRASIL. Goiás: between Goiás and Cavalcante, Burchell 7879 (K).

Distribución: Se conocen solamente el tipo y el paratipo.

Obs.: Especie de floración rápida, en los dos ejemplares conocidos, casi todas las hojas son floríferas. Una flor brevistila de Pohl 1272 presenta estambres de diferente longitud, 2 más largos (9-9,5 mm long.) y 3 más cortos (7,5-8 mm long.).

\section{Turnera fissifolia Arbo, sp. nov.}

Figs. 12 y 25

Herba $20 \mathrm{~cm}$ alta, pilis hirsutis. Folia paene usque ad nervum medium in lobos dissitos lineares dissecta, margine plano, ad petiolum nectaria stipitati gerentia. Flores dimorphi, pedunculo toti adnato, calyce 7-8 mm longo, in 2/5 altis coalitis, petalis roseo-purpurascentibus. Fructus dorso laevi. Semina quasi recta, reticulata, nodis reticuli non elevatis, chalaza prominula et arillo unilaterali, angusto.

Typus: Brasil. Goiás: Mun. Alto Paraíso de Goiás. Estrada para a Vila de São Jorge, ca. 26,5 $\mathrm{km}$ da GO-118, $14^{\circ} 08^{\prime} 09,8^{\prime \prime S} 47^{\circ} 43^{\prime} 56,7^{\prime \prime} \mathrm{W}$, 1130 m, 23-I-2005, Paula-Souza J., Ferrucci M.S., Duarte A.R., Rando J.G. \& Tsuji R. 4522 (holotypus ESA, isotypus CTES).

Hierba perenne hemicriptófita, ca. $20 \mathrm{~cm}$ alt., eje subterráneo grueso, vertical, 5-6 mm diám., base hasta $8 \mathrm{~mm}$ diám.; 6-10 tallos ci- 


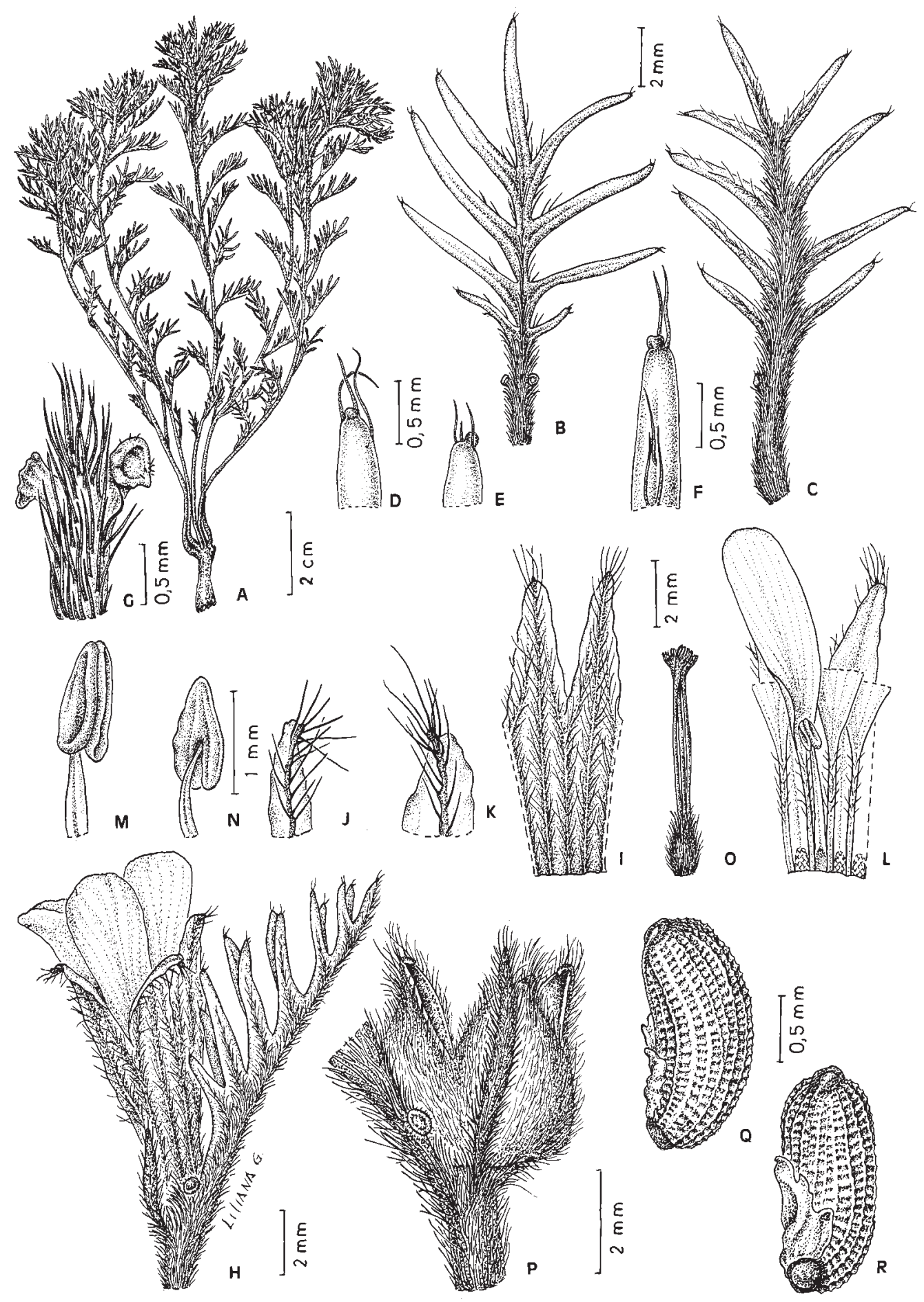

Fig. 25. Turnera fissifolia. A: planta. B-C: hojas, cara adaxial y abaxial. D-E: ápice de los lóbulos foliares, cara adaxial. F: ápice de un lóbulo foliar, cara abaxial. G: pecíolo con nectarios, cara adaxial. H: flor epifila con profilos. I: porción del cáliz, cara externa. J-K: ápice de los lóbulos del cáliz. L: flor longistila, porción del tubo calicino, cara interna, con pétalos y estambre adnatos; se han cuadriculado las cicatrices dejadas al desprender tres estambres. M-N: anteras, vistas ventral y dorsal. O: gineceo. P: base de una hoja florífera con fruto epifilo y profilos. Q-R: semilla con arilo, vistas lateral y rafeal (A, P-R: Paula-Souza \& al. 4522; B-O: Hatschbach \& al. 53893). Del. Liliana Gómez. 
líndricos, 1-1,5 mm diám., glabrescentes en la porción basal, luego hirsuto con pelos simples, largos, antrorsos, amarillentos, 1-1,5 mm long.; entrenudos 2-7 mm long., acortándose hacia el ápice. Hojas: herbáceas, patentes o recurvas. Estípulas ausentes, a veces con 1-2 coléteres cónicos, rojizos, 0,1 mm long. Pecíolo semicilíndrico, 3-4,5 mm long., indumento como el del tallo. Nectarios 2, opuestos o alternos sobre el pecíolo, circulares o elípticos, estipitados, 0,8-1 mm long., cara superior glabra, con «poro», borde pilósulo. Lámina impari-pinnatisecta, $10-13$ × 8-10 mm, grado de incisión de la hemilámina ca. 80\%, 3-5 lacinias a cada lado, el par basal más corto, subuladas, uninervadas, ápice terminado en un coléter; haz con pelos largos, densos, adpresos en la vena media, de base cilíndrica o ligeramente abultada, las lacinias generalmente glabras; envés glabro excepto las venas prominentes, densamente pilosas, ángulo de divergencia ca. $20^{\circ}$. Flores epifilas, heterostilas. Pedúnculo $2 \mathrm{~mm}$ long., soldado al pecíolo, indumento como el del tallo. Pedicelo ausente. Profilos 2, elípticos, 4-6 x 0,5-0,8 mm, insertos en la base del receptáculo, indumento como el de las hojas, margen aserrado o con 1-2 lacinias. Cáliz 7-8 mm long.; tubo calicino 2-3 mm long., por dentro velloso en la garganta, por fuera con pelos simples largos, antrorsos, $1 \mathrm{~mm}$ long., especialmente sobre las venas, y pelos más cortos; lóbulos angustiovados, trinervados, por dentro glabros, por fuera indumento como el del tubo calicino, márgenes internos membranáceos, ápice agudo. Corola rosadopurpurescente; pétalos unguiculados, uña pilosa, lámina obovada, 6,5 x $2 \mathrm{~mm}$. Filamentos estaminales subulados, glabros, $3,5 \mathrm{~mm}$ long. en flores longistilas; anteras ovadas, $1 \mathrm{x}$ $0,6 \mathrm{~mm}$, base emarginada, ápice obtuso, filamento inserto dorsalmente a $0,5 \mathrm{~mm}$ de la base. Ovario ovoide, $1 \mathrm{~mm}$ long., hirsuto; estilos cilíndricos, glabros, 4,2 mm long. en flores longistilas; estigmas multífidos, numerosas ramas de 0,5 $\mathrm{mm}$ long. En flores longistilas, el gineceo $1,5 \mathrm{~mm}$ más largo que el androceo. Fruto ovoide, 4,5 mm long., cara externa lisa, con pelos simples antrorsos, cara interna glabra, lustrosa. Semilla inmadura castaña, obovoide, 1,7-1,8 x 0,7 mm; exóstoma conoidal, asimétrico; rafe linear, lado rafeal recto o ligeramente incurvo; cálaza algo prominente, aguda. Episperma reticulado, nudos no prominentes, epidermis papilosa, aréolas transrectangulares. Arilo unilateral, angosto, más corto que la semilla, de células papilosas.

Paratypus: BRASIL. Goiás: Rod. GO-327, próx. ao Parque Nacional Chapada dos Veadeiros (mun. Alto Paraiso), 1200 m, 12-II-1990, Hatschbach \& al. 53893 (MBM).

Distribución: Aparentemente, se trata de una especie endémica de Goiás, se conocen sólo el tipo y el paratipo, colectados en «campo rupestre» y campo limpio con Velloziaceae, en enero y febrero.

Obs.: Esta es una de las pocas especies de Turnera con hojas pinatisectas, las otras son T. luetzelburgii, endémica de Bahia, con flores amarillas, y T. sidoides subsp. pinnatifida, que se diferencia por no presentar nectarios, por tener fruto tuberculado y semillas crestadas.

La epidermis foliar de esta especie presenta en sus células cristales visibles con la lupa, iguales a los que posee Turnera guianensis (Gonzalez A.M., com.pers.).

\section{Turnera foliosa Urb.}

Figs. 26 y 27

Urban, I., Bot. Jahrb. Syst. 25, Beibl. 40: 5. 1898. Typus: Brasil. Goiás: entre Burity Vermelho et Vargem, 28-VI-1895, Glaziou 21450 (holotypus $\mathrm{B}+$ fototipo $\mathrm{F} \mathrm{n}^{\circ} 13580$, isotypi BR!, C!, F!, K!, LY!, P!, R!, S!).

Subarbusto erecto o decumbente, 6-15 cm alt., base leñosa hasta de $5 \mathrm{~mm}$ diám., tallos 19, 1,5-3 mm diám., muy ramificados y foliosos, castaños o rojizos en seco, teretes o estriados longitudinalmente, hirsutos, con pelos simples setosos, patentes, 2-3 mm long. de base dilatada y rojiza, entremezclados con pelos simples cortos, curvados y antrorsos; entrenudos de 1-3,5 mm, los apicales más cortos; ramas patentes, las del año cilíndricas, 


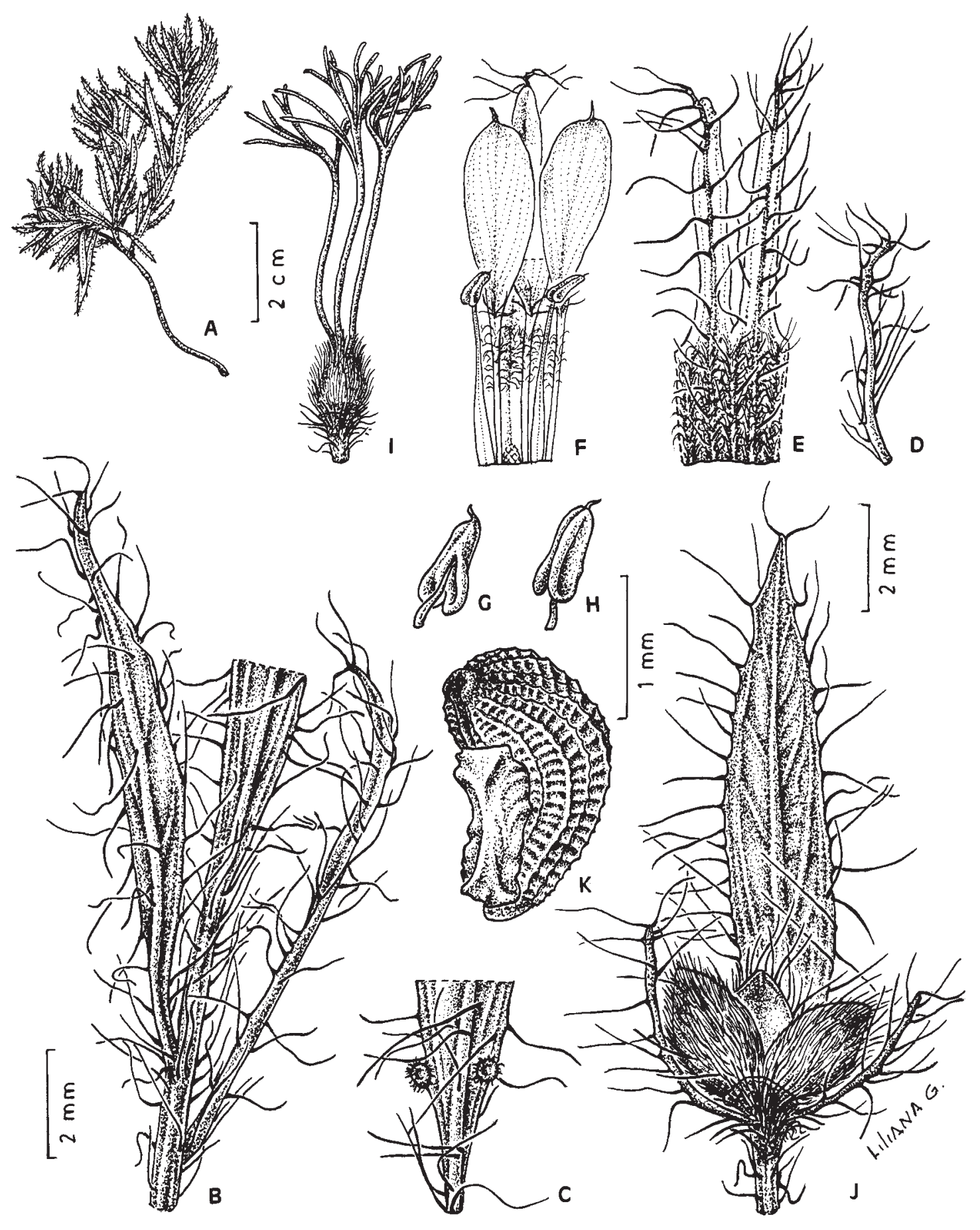

Fig. 26. Turnera foliosa. A: planta. B: porción de tallo y hojas, cara abaxial. C: porción basal de hoja florífera con nectarios, cara abaxial. D: profilo. E: porción del cáliz, cara externa. F: flor longistila, porción del tubo calicino, cara interna, con pétalos y estambres adnatos; se ha cuadriculado la cicatriz dejada al desprender un estambre. G-H: anteras, vistas dorsal y ventral. I: receptáculo y gineceo. J: hoja florífera con fruto epifilo y profilos. K: semilla con arilo, vista rafeal (Duarte 6487). Del. Liliana Gómez. 
densamente foliosas. Hojas erectas, coriáceas, lustrosas, generalmente castañas en seco. Estípulas ausentes o rudimentarias, con coléteres rojizos, 0,3 mm long. Pecíolo 0-1 mm long., en hojas floríferas hasta $2 \mathrm{~mm}$ long., con un fascículo de pelos setosos en la base. Lámina foliar elíptico-lanceolada a linear, 6-22 x 1-8,5 mm, relación largo:ancho = 2-13:1; base atenuada, margen plano, entero, glabro en las hojas inferiores, setoso en las apicales; haz y envés glabros, excepto las venas prominentes en ambas caras, con pelos simples setosos 2-3 mm long.; 2-4 pares de venas laterales opuestas o alternas, ángulo de divergencia $10-25^{\circ}$, venación menor a veces visible. Nectarios 2, marginales, circulares, 0,2-0,6 mm diám., sésiles o brevemente estipitados, de reborde pubérulo o hirsuto; situados a 1,5-4,5 $\mathrm{mm}$ de la base en hojas apicales y floríferas. Flores epifilas, heterostilas, agrupadas hacia el ápice de las ramas, poco conspicuas entre el follaje. Alabastro elipsoide, recto, mucrones libres en el ápice. Pedúnculo 1,8-3,5 mm long., soldado totalmente al pecíolo y vena media, o el ápice libre (0,2-1 mm), indumento como el del tallo. Profilos opuestos, insertos en la base del receptáculo, linear-subulados, 2-4,5 x 0,2-0,4 $\mathrm{mm}$, setosos excepto en la base. Cáliz 6-8,5(10) $\mathrm{mm}$ long.; tubo calicino $2-2,7 \mathrm{~mm}$ long., cara externa brevemente pilosa, cara interna glabra o pubescente; lóbulos triangularaes o angustiovados, glabros por dentro, setosos por fuera, 3-nervados, márgenes internos membranáceos, ápice brevemente mucronado (0,3-0,6 mm). Corola ligeramente más larga que el cáliz; pétalos amarillos, uña glabra a vellosa soldada al tubo calicino, lámina obovada, 5-8 x 1-3 mm, glabra o con algunos pelos en la base, ápice subtruncado o apiculado. Filamentos estaminales glabros, triangular subulados, 3,5-4 mm long. en flores longistilas, 4,2-6,5 $\mathrm{mm}$ en flores brevistilas, soldados 0,3-1 mm en la base al tubo calicino, con un nectario en la inserción; anteras angustiovadas, 0,6-1 $\mathrm{mm} \times 0,3-0,5 \mathrm{~mm}$, ápice obtuso o ligeramente apiculado, filamento inserto dorsalmente a $2 / 5$ de la base, curvadas después de la dehiscencia. Ovario ovoide o elipsoide, 0,7-1 mm long., hirsuto, pelos más largos en el ápice; placentas 2-4-ovuladas; es-

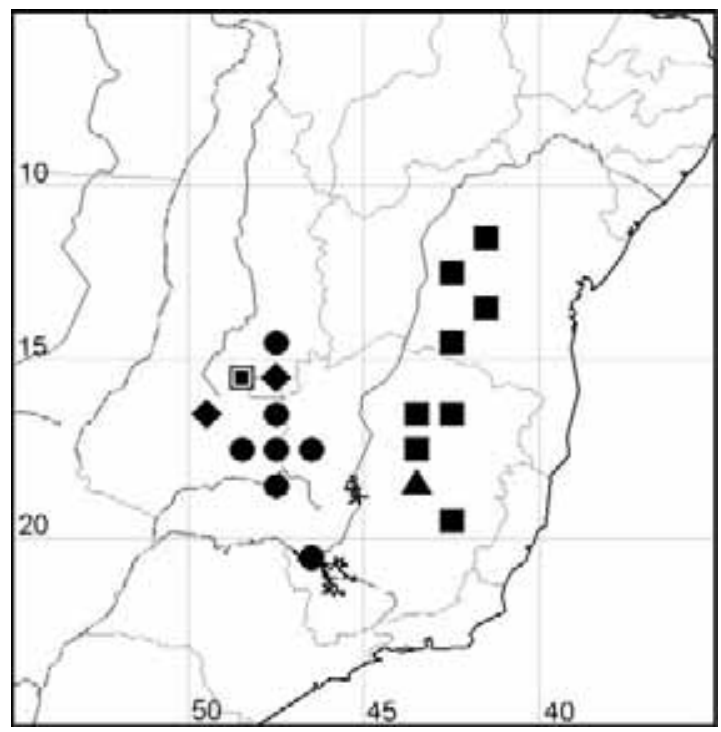

Fig. 27. Distribución de Turnera foliosa T. gouveiana $\boldsymbol{\Delta}$; T. iterata $\square$; T. luetzelburgii var. dubia $\mathbf{\square}$; T. oblongifolia var. goyazensis

tilos glabros o laxamente pilosos, 3,2-4 mm long. en flores longistilas, 1,7-2 mm long. en flores brevistilas; estigma 8-16 ramas, 1,2-2,5 $\mathrm{mm}$ long. En flores longistilas, el gineceo es 1,5-3 mm más largo que el androceo. Fruto latiovoide o subesférico, 1,5-3,5 mm long., con reborde anular basal de $0,3 \mathrm{~mm}$ dejado por el tubo floral al desprenderse; profilos más cortos que el fruto; valvas ovadas, cara externa lisa, castaña o amarillenta, con pelos simples más largos hacia el ápice, cara interna glabra, lustrosa, a veces jaspeada. Semilla obovoide, curvada, 1,7-2,1 x 1-1,2 mm; exóstoma semigloboso; rafe linear oscura, lado rafeal incurvo; cálaza poco prominente, oscura. Episperma reticulado, nudos algo prominentes. Arilo unilateral, más corto que la semilla, de células papilosas.

Material estudiado: BRASIL. Distrito Federal: 1 km N of Sobradinho, $1250 \mathrm{~m}, 8$-XI-1965, Irwin \& al. 10087 (NY, P); Morro da Igreginha, ca. $5 \mathrm{~km}$ SSE of Planaltina, $1000 \mathrm{~m}, 18-\mathrm{II}-1970$, Irwin \& al. 26362 (NY, P, UB). Goiás: So mmet du Morro da Canastra, 24-XI1894, Glaziou s.n. (P); Parananá, près de Cachoeirinha, 27-V-1895, Glaziou s.n. (P); Burity Vermelho, 28-VI1895, Glaziou 21455 (R). Minas Gerais: entre Unaí e Chupador, 25-X-1961, Duarte 6487 (RB). 
Distribución y fenología: Especie rara del Distrito Federal, Goiás y Minas Gerais, de campo y «cerrado» con suelo pedregoso. Los pocos ejemplares conocidos fueron colectados entre noviembre y junio.

Obs. En uno de los isotipos (P), una flor presenta dos estambres cortos y tres largos.

\section{Turnera genistoides Cambess.}

Figs. 28 y 29

Saint Hilaire, A., Jussieu, A. \& Cambessèdes, J., Fl. bras. merid. 2: 220, t. 121. 1830; Urban, Jahrb. Königl. Bot. Gart. Berlin 2: 113. 1883; Urban, en Martius, C.F.P., Fl. Bras. 13(3): 135. 1883. Typus: Brasil. Minas Gerais: Tijuco [Diamantina], Laruotte leg. Herb. Saint Hilaire 323 (holotypus $\mathrm{P}$ !, isotypi $\mathrm{F}$ !, $\mathrm{P}(2)$ !, US!).

Turnera procumbens Gardner ex Hook., Ic. Pl. 6, t. 522. 1843. Typus: Brasil. Minas Gerais. Diamantina, VIII-1840, Gardner 4696 (holotypus $\mathrm{K}$ !, isotypi BM!, CGE!, NY!, OXF!, P!, W!).

Subarbusto densamente ramoso $10-30 \mathrm{~cm}$ alt., ramas viejas glabrescentes, negruzcas; ramas del año cilíndricas, estrigosas; ramas seriales no desarrolladas. Hojas sin estípulas y sin nectarios. Pecíolo 0,5-1 $\mathrm{mm}$ long., estrigoso. Lámina linear, 6-12 x 0,5-1 mm, relación largo:ancho = 6-20:1; haz lustrosa, estrigosa, envés opaco, indumento denso; margen entero marcadamente revoluto. Flores heterostilas epifilas en racimos abreviados terminales 2-8-floros. Pedúnculo 0,5-1 mm long, totalmente adnato al pecíolo. Profilos lineares, 2-4,5 x 0,2-0,5 mm. Pedicelo ausente. Cáliz 6-7,5 mm long.; tubo calicino $3 \mathrm{~mm}$ long., densamente estrigoso por fuera, piloso por dentro en la parte superior; lóbulos angustiovados, 3-nervados, mucrón 0-0,4 mm long. Corola amarilla, igual o poco más larga que el cáliz; pétalos obovados, 4,5-6,5 x 2-3 $\mathrm{mm}$, glabros o con algunos pelos en la base. Filamentos estaminales adnados al tubo calicino 0,3-0,8 mm, pubescentes, $5 \mathrm{~mm}$ long. en flores brevistilas, 2,5-3 mm long. en flores longistilas; anteras ovadas, $1 \times 0,5-0,6 \mathrm{~mm}$, base emarginada, ápice obtuso o brevemente apiculado, filamento inserto a $0,5 \mathrm{~mm}$ de la base, casi rectas después de la dehiscencia. Ovario ovoide, estrigoso; placentas 1-2ovuladas; estilos hirsutos con pelos erectos o patentes, diferente pubescencia estilar en ambas formas, 4-5 mm long. e incurvos en flores longistilas, $2 \mathrm{~mm}$ long. en flores brevistilas; estigma paucirramoso, 1-1,5 mm long. En flores longistilas gineceo 2-3 mm más largo que el androceo, en flores brevistilas 1-2 mm más corto. Fruto ovoide o subtrigono, 4-4,5 x 3-3,5 $\mathrm{mm}$, obtuso o agudo, 1-6-seminado, con un reborde anular basal de $0,2 \mathrm{~mm}$ dejado por el tubo floral al desprenderse; valvas con cara externa pilosa, pelos de base cónica y abultada, cara interna glabra, parda o jaspeada. Semilla obovoide, casi recta, 2-2,5 x $1 \mathrm{~mm}$; exóstoma cónico o redondeado; rafe linear, lado rafeal recto o convexo; cálaza apical, ligeramente prominente, a veces algo deprimida en al centro. Episperma reticulado-estriado. Arilo amarillento, tan largo como la semi1la.

Material estudiado: BRASIL. Bahia: M. de Sincora, XI, Martius s.n. (M). Minas Gerais: Diamantina, 1400 m, VI-1934, Brade 13887 (RB); estrada Diamantina-Biri-Biri, 5-VI-1985, Cruz 86 (CTES, SP); Diamantina, 6-III-1892, Glaziou 19391 (C, K, LY, P, R); estrada Diamantina-BiriBiri, Km 5, 5-VI-1985, Martins \& al. 17432 (CTES, ESA, UEC); Serra de S.Antonio [entre los ríos Itacambiruçu y Jequitinhonha, al NE de Itacambira], VII, Martius s.n. (M); Diamantina, Agua Limpa, 22-V-1955, Pereira 1430 (RB); Diamantina, Toca, 6-VI-1955, Pereira 1703 (CTES, K, RB); estrada Diamantina-Biribiri, ca. 6 km de Diamantina, $18^{\circ} 13^{\prime} \mathrm{S} 43^{\circ} 37^{\prime} \mathrm{W}, 1200 \mathrm{~m}, 19$ VIII-1987, Pirani \& al. CFCR 11096 (CTES, SPF); sin localidad, Saint Hilaire s.n. (F, RB); inter Diamantina et Biribiry, 6-IV-1892, Schwacke 8214 (RB); estrada para Biribiri, 2-VIII-1989, Simão-Bianchini $89 \quad$ (CTES, SPF); Mun.Diamantina, estrada para Biribiri, 3,5 km da Rodovia em direcão a Biribiri, 6-VII-1996, Souza \& al. 11876 (CTES, ESA); Morro dos Cruzeiros (Cruzeiro das Almas e Cruzeiro do Anastacio), Diamantina, VIII-1949, Vidal s.n. (R).

Distribución y fenología: Especie propia de campo de altura y «campo rupestre», ha sido 


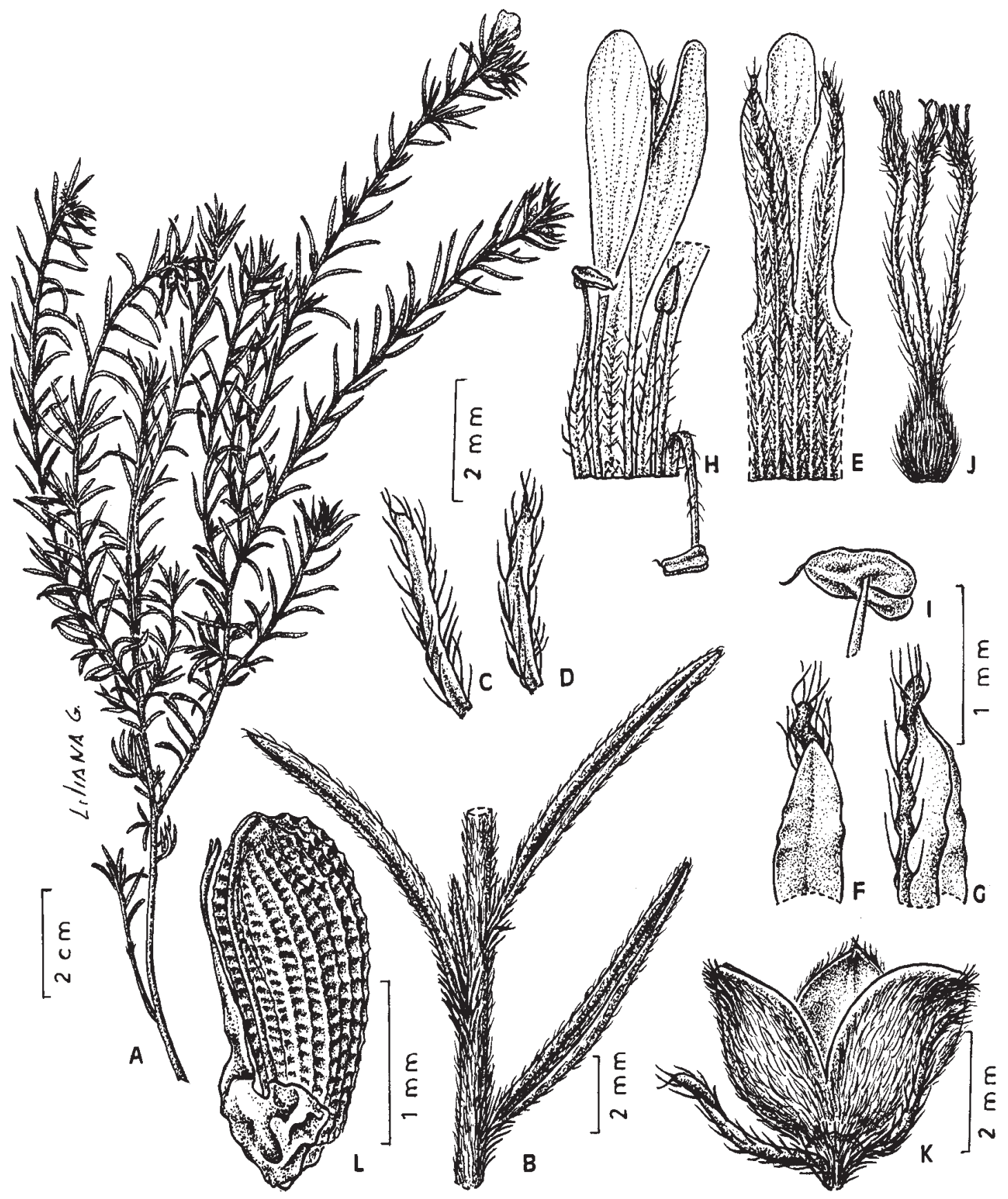

Fig. 28. Turnera genistoides. A: planta. B: porción de tallo con hojas revolutas, cara abaxial. C-D: profilos. E: porción del cáliz y pétalo, cara externa. F-G: ápice de los lóbulos del cáliz. H: flor longistila, porción del tubo calicino, cara interna, con pétalos y estambres adnatos; se ha cuadriculado la cicatriz dejada al desprender un estambre. I: antera, vista dorsal. J: gineceo. K: fruto y profilos. L: semilla con arilo, vista rafeal (A-B: Pereira 1703; C-L: Pirani \& al. CFCR 11096). Del. Liliana Gómez. 


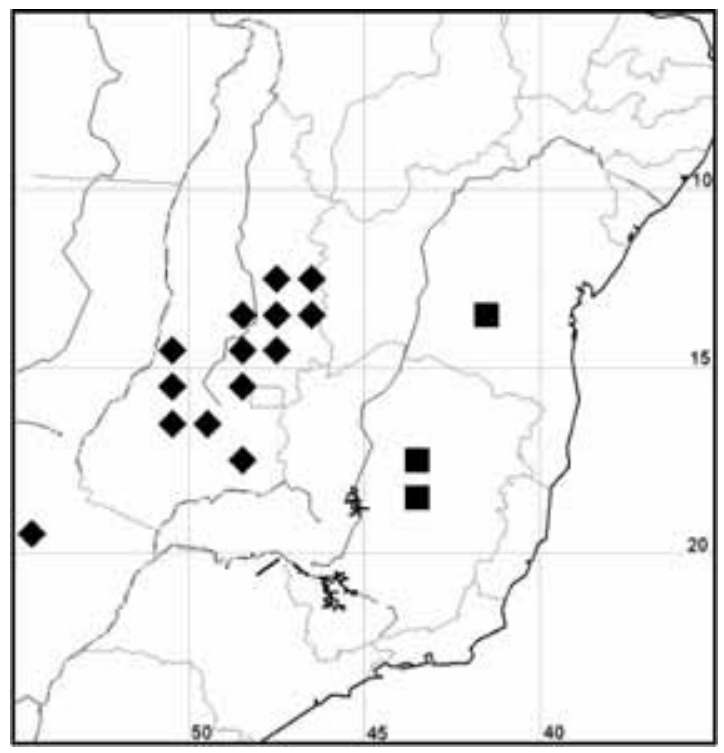

Fig. 29. Distribución de Turnera genistoides T. incana

colectada en el mun. Diamantina (Minas Gerais), desde marzo hasta agosto, entre 1200-1400 m alt. Martius la coleccionó en el mes de noviembre en la Serra do Sincorá (Bahia), donde hasta ahora no ha vuelto a ser encontrada.

Obs.: Spencer \& al. (1985) analizaron el ejemplar Saint Hilaire s.n. (F) y encontraron compuestos cianogénicos.

Gonzalez (2000) estudió la anatomía foliar de esta especie; es una de las pocas del género con hojas de tipo ericoide, angostas y marcadamente revolutas; los estomas se presentan solamente en la epidermis abaxial, donde también se observaron pelos glandulares microcapitados.

\section{Turnera glabrata Arbo, sp. nov.}

Figs. 23 y 30

Herba $20 \mathrm{~cm}$ alta, caulibus erectis, teretibus, glabris vel laxe pilosis. Folia stipulis rudimentaris, lamina lineari, glaberrima, supra basin subtus nectaria gerenti. Flores dimorphi, apice caulium conferti, pedunculo toti adnato, calyce glabro, $7 \mathrm{~mm}$ longo, in 2/5 alto coalito, filamentis glabris, base tubo tota facie adnatis, antheris $0,8 \mathrm{~mm}$ longis, dorso in $1 / 2$ affixis, placenta 4-ovulata, stylo glabro. Fructus dorso laevi. Semina curvata, reticulata, chalaza prominula, arillo unilaterali, angusto.

Typus. Brasil. Goiás. Serra dos Pireneus, Fazenda Solar dos Pireneus, mun. Pirenópolis, 1200-1300 m, 16-II-2000, Hatschbach G. \& M., Ribas O.S., Willberg G. 70240 (holotypus MBM, isotypus CTES)

Hemicriptófita herbácea, ca. $20 \mathrm{~cm}$ alt., con eje subterráneo leñoso de $8 \mathrm{~mm}$ diám.; tallos 1-3, cilíndricos, longitudinalmente estriados, erectos, simples o ramificados, densamente foliosos excepto en la base, glabros o con pelos simples cortos, laxos, curvadoantrorsos; entrenudos de 1-7,5 mm long., más cortos hacia el ápice. Hojas lineares, coriáceas, totalmente glabras, o con algunos pelos simples cortos en la inserción y en el margen. Estípulas rudimentarias, pilosas, con coléteres 0,1 mm long. Pecíolo 1-2 mm. Lámina lustrosa, 17-30 x 1,4-2,2 mm, relación largo:ancho = 12-16:1; venación prominente en ambas caras, vena media prolongada en un cordón sobre el tallo por debajo de la inserción; venas laterales 2-4, ángulo de divergencia 5-7º, incurvas, perdiéndose hacia el margen. Nectarios 1-2 pares, circulares o elípticos, de 0,3-1 mm long., reborde pubérulo, «poro» a veces visible, ubicados sobre el margen foliar a 0,7-2 $\mathrm{mm}$ de la base, orientados hacia el envés. Hojas floríferas con pecíolo más largo y lámina más corta, 11-12 x 1,3-1,7 mm, relación largo:ancho $=7-8,5: 1$. Flores epifilas, heterostilas, a la antesis agrupadas en el extremo del tallo, luego los frutos espaciados. Pedúnculo totalmente adnato al pecíolo, o el ápice brevemente libre. Profilos lineares, 2-4 x 0$3 \mathrm{~mm}$, insertos en la base del receptáculo, borde entero o con algunos dientes, con pelos simples esparcidos, uninervados. Pedicelo nulo. Cáliz $7 \mathrm{~mm}$ long., glabro por fuera; tubo calicino $2 \mathrm{~mm}$ long., velloso por dentro; lóbulos angustiovados o triangulares, glabros por dentro, márgenes internos membranáceos, ápice agudo, terminado en 1-2 pelos simples. Corola amarilla, 2,5 mm más larga que el cáliz; pétalos 7,5 x 2,5 mm, base cuneada, pilosa. Filamentos estaminales glabros, soldados en la base $0,5 \mathrm{~mm}$ al tubo calicino, 


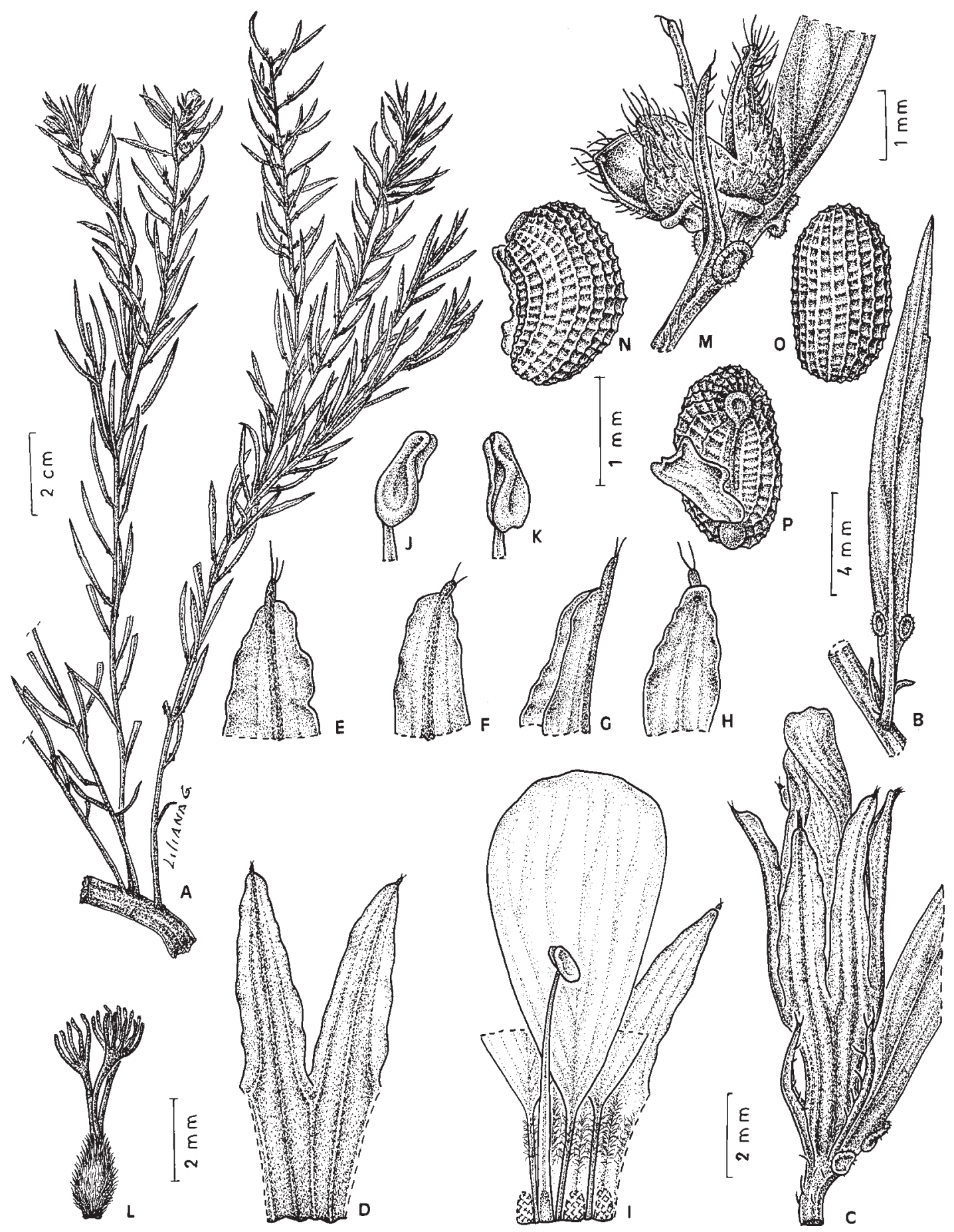

Fig. 30. Turnera glabrata. A: planta. B: hoja con nectarios, cara abaxial. C: flor epifila con profilos. D: porción del cáliz, cara externa. E-G: ápice de un lóbulo interno del cáliz, cara externa y vista lateral. F-H: ápice de un lóbulo externo del cáliz, caras externa e interna. I: flor brevistila, porción del tubo calicino, cara interna, con pétalos y estambre adnatos; se han cuadriculado las cicatrices dejadas al desprender tres estambres. J-K: anteras, vista lateral.L: gineceo. M: base de una hoja florífera con fruto epifilo y profilos. N-P: semilla con arilo, vistas lateral, dorsal y rafeal (A-N: Riedel 941; O-P: Hassler 8443). Del. Liliana Gómez. 
subulados, 3,5 mm long. en flores longistilas, $5,5 \mathrm{~mm}$ long. en flores brevistilas; anteras dorsifijas, $0,8 \times 0,5 \mathrm{~mm}$, base emarginada, ápice obtuso, curvadas después de la dehiscencia. Ovario cónico, 0,5-0,7 mm long., piloso; placentas 4-ovuladas; estilos glabros, 2,5 $\mathrm{mm}$ long. en flores longistilas, $1,5 \mathrm{~mm}$ long. en flores brevistilas; estigmas 1,5-2 $\mathrm{mm}$ long., con 8-10 ramas. En flores longistilas, gineceo $2 \mathrm{~mm}$ más largo que el androceo, y en flores brevistilas, 2,5 mm más corto. Fruto ovoide, 2-2,5 mm long., con un reborde $0,5 \mathrm{~mm}$ en la base, dejado por el tubo floral al desprenderse; profilos más largos que el fruto; valvas ovadas, cara externa lisa, con pelos simples laxos curvado antrorsos más densos en el ápice, cara interna lisa, lustrosa, amarillenta, jaspeada. Semilla curvada, 1,6 x 0,9-1,1 mm; exóstoma apenas saliente; rafe linear, lado rafeal incurvo; cálaza saliente y pigmentada, de orientación intermedia. Episperma reticulado con nudos prominentes, aréolas cuadrangulares o transrectangulares sin depresión punctiforme; epidermis ligeramente papilosa con cera epicuticular bastoniforme en la semilla inmadura. Arilo unilateral, más corto que la semilla, de células papilosas.

Paratypus: BRASIL. Goiás: Serra dos Pirineus, mun. Pirenópolis, 1350 m, 9-XII-1987, Semir \& al. 20615 (UEC).

Distribución y fenología: Se conoce solamente el material tipo, de los campos rupestres de la Serra dos Pirineus, Goiás, entre 1200-1350m de altitud, colectado en diciembre y febrero.

Obs.: Es una de las pocas especies de la serie con cáliz glabro. Turnera pinifolia, especie simpátrica, también con cáliz glabro y de aspecto vegetativo similar, se diferencia por sus hojas uninervadas, con relación largo:ancho muchísimo mayor.

\section{Turnera gouveiana Arbo, sp. nov.}

Figs. 27 y 31

Herba 10-20 cm alta, caulis erectis, teretibus, pilis brevibus densis et aliis curvato-erectis immixtis. Folia petiolata, stipulis rudimentaris; lamina elliptica vel obovata, laxe pilosa, supra basin subtus nectaria gerenti. Flores dimorphi, pedunculo supra medium vel toti adnato, calyce 8,5-10 mm longo, ca. 1/2 alto coalito, filamentis glabris, base tubo tota facie adnatis, antheris 1,3 $\mathrm{mm}$ longis, dorso in 2/5 altis affixis, ovario pluriovulato, stylo glabro. Fructus dorso laevi. Semina curvata, reticulata, chalaza prominula, arillo unilaterali, angusto.

Typus. BRASIL. Minas Gerais. Serra do Espinhaço, mun. Gouveia, 12-XI-1971, Hatschbach G. \& Pelanda P. 27791 (holotypus MBM, isotypus CTES).

Hierba hemicriptófita, 10-20 cm alt., base rojiza; tallo erguido, simple o ramificado, 1-2 mm diám., cilíndrico, longitudinalmente estriado, pelos simples cortos, densos, curvadoantrorsos, $0,2 \mathrm{~mm}$ long. y pelos simples más o menos patentes $0,7-0,8 \mathrm{~mm}$ long; entrenudos basales 1-2 cm long., los apicales 2-1 mm long. Yemas seriales presentes. Hojas herbáceas, algo discoloras, las de los nudos basales bracteiformes. Nomófilos aumentando de tamaño marcadamente hacia el ápice, los inferiores con ramas axilares adnatas al pecíolo, con profilos linear-elípticos 1-2 mm lat. Estípulas rudimentarias, pilosas, con un coléter oscuro 0,2-0,3 mm long. Pecíolo cilíndrico, 2-4 mm long., indumento como el del tallo. Lámina obovada en hojas basales, luego elíptica, 12-30 x 5-8 mm, relación largo:ancho = 2-3,8:1; base cuneada; ápice obtuso o agudo; borde plano o revoluto, crenado-aserrado, dientes obtusos; haz algo lustrosa, castaña en seco, con pelos simples largos $(0,5-0,6 \mathrm{~mm}$ long.) de base cónica y otros más cortos, antrorsos; envés opaco, con diminutas máculas rojizas, indumento laxo en hojas basales, denso en las apicales, de pelos simples largos y cortos y pelos glandulares microcapitados; vena media y 4-6 pares de venas laterales alternas o subopuestas, salientes en la haz en los nomófilos basales, prominentes en el envés, perdiéndose hacia el borde, con ramas hacia los dientes; ángulo de divergencia $35-40^{\circ}$; venas terciarias conspicuas en el envés. Nectarios 2, 0,3-0,5 mm diám., borde piloso, 


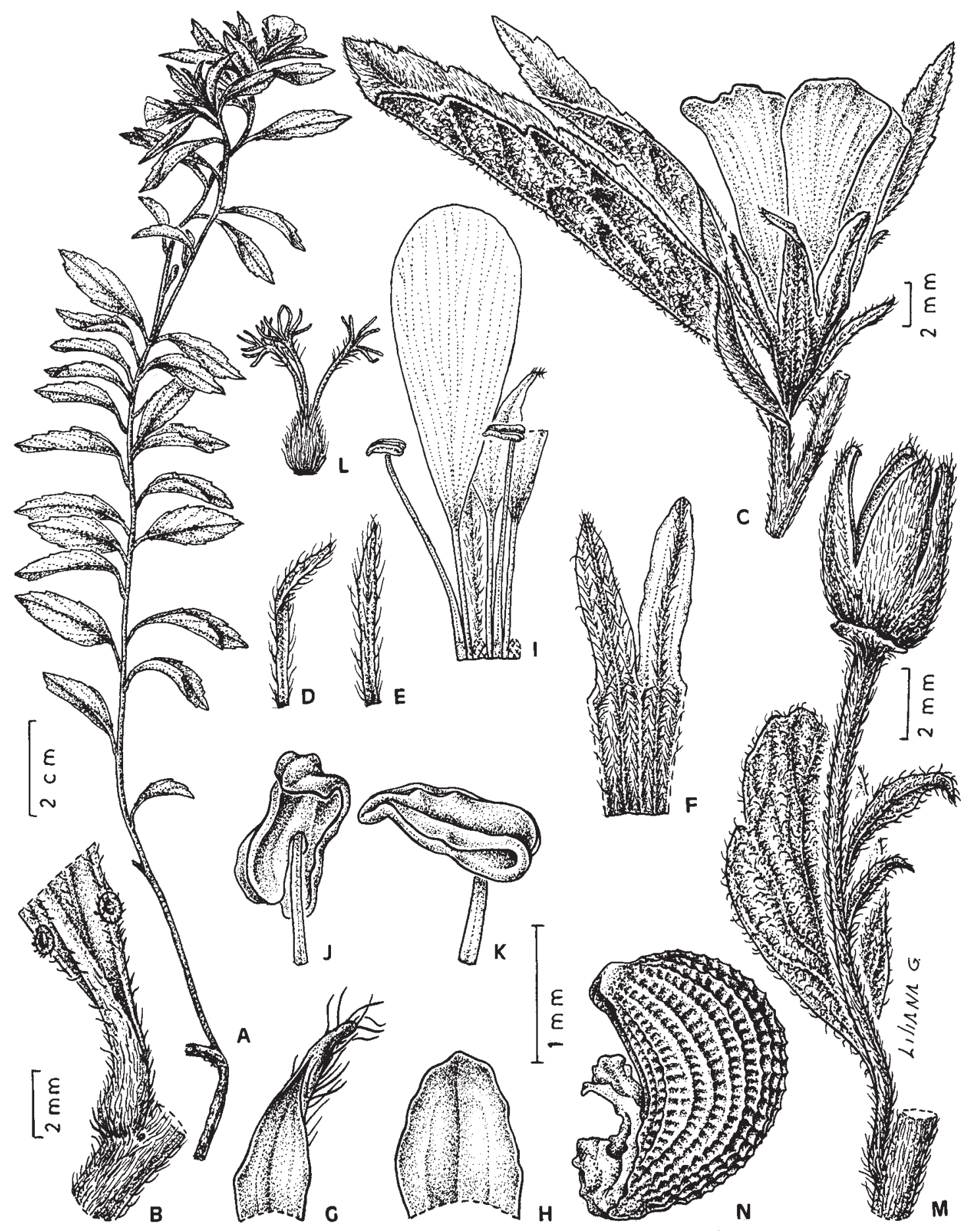

Fig. 31. Turnera gouveiana. A: planta. B: porción basal de hoja con nectarios, cara abaxial. C: flor epifila con profilo. D-E: profilos. F: porción del cáliz, cara externa. G: ápice de un lóbulo externo del cáliz, cara interna. H: ápice de un lóbulo interno del cáliz, cara interna. I: flor brevistila, porción del tubo calicino, cara interna, con pétalos y estambres adnatos; se han cuadriculado las cicatrices dejadas al desprender dos estambres. J-K: anteras, vistas dorsal y lateral. L: gineceo. M: hoja florífera con fruto y profilos, mostrando el pedúnculo adnato y el pedicelo desarrollado. N: semilla con arilo, vista lateral (Hatschbach \& al. 70240). Del. Liliana Gómez. 
situados sobre el margen a $1-4,5 \mathrm{~mm}$ de la base, orientados hacia el envés. Flores solitarias, epifilas, heterostilas. Pedúnculo 8-3,5 mm long., soldado al pecíolo o incluso a la vena media, la porción apical libre de (6-)2-0 mm long., indumento como el del tallo. Profilos opuestos o alternos en el ápice del pedúnculo, elípticos o subulados, 5,5-8,5 x 0,5-1,1 mm, borde entero. Pedicelo (4-)2-0 mm long. Cáliz 8,5-10 mm long.; tubo calicino (ca.1/2) 4,2-4,8 mm long., cara externa con pelos simples cortos, cara interna vellosa en la parte media; lóbulos triangulares o angustiovados, cara externa con pelos simples más largos sobre las venas; lóbulos internos con bordes membranáceos, ápice brevemente mucronado. Corola amarilla, 4-7 mm más larga que el cáliz; pétalos con la uña soldada al tubo calicino, vellosa en la parte media, lámina glabra, 11-12,5 mm long. Filamentos estaminales complanado-subulados en seco, glabros, soldados $0,3 \mathrm{~mm}$ en la base al tubo calicino, $7 \mathrm{~mm}$ long. en flores brevistilas; anteras $1,3 \times 0,5 \mathrm{~mm}$, base emarginada, ápice obtuso, recurvado a la dehiscencia, filamento inserto dorsalmente a $0,5 \mathrm{~mm}$ de la base. Ovario ovoide, hirsuto, $1,3 \mathrm{~mm}$ long., pluriovulado; estilos cilíndricos, pilosos en la parte superior, $2,5 \mathrm{~mm}$ long. en flores brevistilas; estigmas penicilados, 6-8 ramas de 1,1 mm long., gineceo 2,5 $\mathrm{mm}$ más corto que el androceo en flores brevistilas. Fruto ovoide, piloso, con un reborde anular basal de 0,5 $\mathrm{mm}$ dejado por la absición del tubo floral; profilos más cortos que el fruto; valvas con pelos simples largos y cortos y pelos glandulares microcapitados en la cara externa; cara interna glabra, lustrosa. Semilla inmadura obovoide, curvada, 2,4 x1,3 mm; exóstoma cónico; rafe linear, prominente, lado rafeal incurvo; cálaza saliente, oscura. Episperma reticulado, aréolas rectangulares pequeñitas, epidermis papilosa. Arilo unilateral más corto que la semilla, de células papilosas.

Distribución: Se conoce solamente el tipo, colectado en «cerrado».

Obs.: El fruto ilustrado (Fig. $31 \mathrm{M}$ ) presenta cuatro carpelos, y el pedicelo largamente desarrollado.

\section{Turnera guianensis Aubl.}

Figs. 5 y 32

Aublet, J. B. C., Hist. Pl. Guiane 1: 291, t.114. 1775; Urban, Jahrb. Königl. Bot. Gart. Berlin 2: 111; Urban, en Martius C.F.P., Fl. Bras. 13(3): 133. 1883. Typus: Guayana Francesa, Timoutou, Aublet s.n. (holotypus herb. J.J.Rousseau P!, isotypus $\mathrm{BM}$ !)

Turnera humboldtii Spreng., Syst.veg. 16 ed., 1: 941, 1825. Typus: Venezuela. [Guárico], Los Llanos, inter Calabozo \& Alto del Pyrital, Bonpland 793 (holotypus B-Willd. 6088 microficha IDC!, isotypus P-Humb.Bonpl. $\mathrm{n}^{\mathrm{o}} 1$ !).

Tribolacis juncea Griseb., Fl.Brit.W.Ind.Is.: 297. Typus: Trinidad, Piarco, VIII-1858, Crüger 15 (holotypus GOET!, isotypus $\mathrm{K}$ !).

Hierba perenne o sufrútice graminiforme, 20-42(-68) cm alt., erecto o decumbente, porción basal leñosa, 1-15 mm diám., con corteza pardo-grisácea; tallos numerosos, 0,8-1,5 mm diám., verdes en la porción apical, con estrías longitudinales, glabros o pubérulos en la base, simples o ramificados, entrenudos $1-3 \mathrm{~cm}$ long., los apicales acortándose rápicamente (3-1 mm). Hojas herbáceas, verdosas en seco, las vegetativas sésiles. Estípulas reducidas a coléteres. Lámina totalmente glabra, excepto algunos pelos en la base foliar o en el ápice; las basales largamente obovadas o lineares, 3,5-12 x 0,7-1,3 mm, relación largo:ancho = 4-16:1, las restantes lineares o angustielípticas, 9,5-61 x 0,5-5 mm, relación largo:ancho = 7-74:1; margen foliar glabro, plano o revoluto, entero o a veces serrulado hacia el ápice agudo; vena media prominente en ambas caras, prolongada debajo de la inserción foliar en una arista sobre el tallo; venas laterales poco conspicuas. Nectarios 0-2, redondeados, glabros, en la base. Hojas floríferas con pecíolo 0,5-4 mm long., lámina linear-lanceolada a triangular, de tamaño bruscamente decreciente, hasta $1,5 \times 0,4 \mathrm{~mm}$, con 1-2 pares de nectarios marginales, circulares, glabros, 0,3-0,8 mm diám. Flores epifilas, heterostilas, agrupadas en la porción apical de las ramas en racimos bracteosos de $1-8 \mathrm{~cm}$ long. Pedúnculo 1-4 mm long., adnado casi hasta el ápice al pecíolo y a veces a la lámina. 


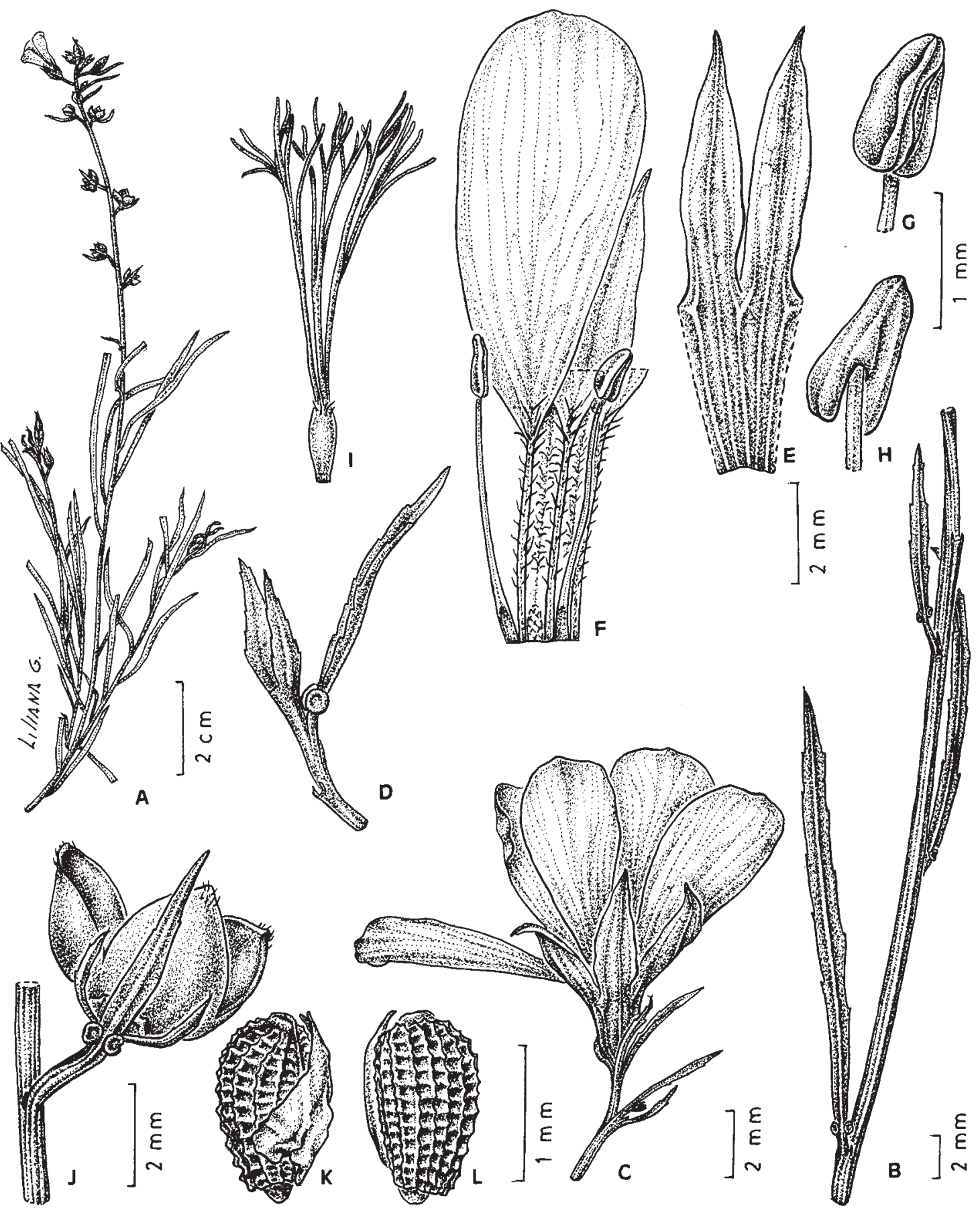

Fig. 32. Turnera guianensis. A: planta. B: porción de tallo, hojas con nectarios, cara abaxial. C: ápice del tallo, brácteas, flor epifila y profilo. D: bráctea con nectarios, receptáculo y profilos. E: porción del cáliz, cara externa. F: flor longistila, porción del tubo calicino, cara interna, con pétalos y estambres adnatos; se ha cuadriculado la cicatriz dejada al desprender un estambre. G-H: anteras, vistas ventral y dorsal. I: gineceo. J: bráctea con nectarios, fruto epifilo y profilos. K-L: semilla con arilo, vistas rafeal y lateral (A, J-L: Pittier 14869; B: Fernández, 2524; C: JansenJacobs 4038; D-I: Maas \& al. 5499). Del. Liliana Gómez. 
Profilos lineares, subulados o triangulares, 1,2-3 x 0,2-0,9 mm, insertos en la base del receptáculo, a veces con algunos pelos en el borde y en el ápice. Cáliz 5-10 mm long., glabro por fuera, excepto algunos pelos en el ápice de los lóbulos; tubo calicino 2-4 mm long., velloso por dentro; lóbulos triangulares o angustiovados, 3-nervados, márgenes internos membranáceos, ápice brevemente acuminado o mucronulado (0,1-0,3 $\mathrm{mm})$, a veces purpúreo. Corola más larga que el cáliz; pétalos amarillos o blanquecinos con venas rojizas, obovado-cuneados, 7-11 x 3-7,5 mm, glabros o pilosos en la base. Filamentos estaminales soldados al tubo 0,4-0,8 mm, triangular-subulados, glabros, 4-7 mm long. en flores brevistilas, 3-5 mm long. en flores longistilas; anteras ovadas o elípticas, 0,9-1,5 x 0,4-0,8 mm, subrectas después de la dehiscencia, base emarginada, ápice obtuso, filamento inserto dorsalmente, a 0,5-0,6 mm de la base. Ovario cónico, 0,7-1,2 x 0,6-1,2 mm, glabro o con algunos pelos en el ápice; placentas 3-7-ovuladas. Estilos cilíndricos, glabros, a veces pilosos, 1,5-2,5 $\mathrm{mm}$ long. en flores brevistilas, 4-7 mm long. en flores longistilas; estigma paucirramoso (4-10 ramas), 1-3 mm long., más largo en flores brevistilas. Fruto globoso o apiculado, 2-5 $\mathrm{mm}$ diám., con un reborde anular en la base de 0,3-0,5 $\mathrm{mm}$ dejado por el tubo floral al desprenderse; valvas de cara externa amarillenta, lisa, glabra o con algunos pelos en el ápice, que a veces es purpúreo, cara interna amarillenta o jaspeada, glabra. Semilla obovoide, casi recta, 1,2-2 x 0,8-1,1 mm; exóstoma poco notable; lado rafeal recto generalmente; cálaza apenas prominente, a veces cóncava. Episperma pardo-oscuro, reticulado, nudos del retículo prominentes, aréolas cóncavas, con cera epicuticular bastoniforme. Arilo angosto, amarillento, igual o más corto que la semilla, de células lisas o papilosas.

Material estudiado: COLOMBIA. Vichada: Maypures, VI-1854, Spruce 3645 (K). Parque Nacional Natural «El Tuparro», La Línea Roja, just $S$ of Río Tomo, 5³2'N 68³2'W, ca. 100m alt, 12III-1985, Zarucchi \& Barbosa 3662 (MO, NY, US). VENEZUELA. Caño Redito on Via a El Baballo, along bank, 7-VI-1967, Robertson \&
Austin 176 (MO). T.F.Amazonas: Dep. Atures, San Juan de Manapiare, margen E del rio Manapiare, 5 ${ }^{\circ} 18^{\prime} \mathrm{N} 66^{\circ} 02^{\prime} \mathrm{W}, 150 \mathrm{~m}, 13-\mathrm{X}-1977$, Huber 1105 (K, NY, US); Dep. Atures, alrededores de Puerto Ayacucho, ca. $30 \mathrm{~km} \mathrm{~N}$, al E de Rincones de Chacorro, $05^{\circ} 48^{\prime} \mathrm{N} 67^{\circ} 20^{\prime} \mathrm{W}$, aprox. 80 m, 24-V-1979, Huber 3804 (NY, US). Anzoátegui: Las Piedritas, 16-VII-1946, Burkart 17257 (SI); El Piñal, 3 km NE de San Diego de Cabrutica: 13-VIII-1984, Montes 2012-A (MO, US); Sabanas de Guaraguara, cerca de Santomé, 260 m, 22-III-1940, Pittier 14289 (US); Cabeceras del Guanipa, 23-VI-1941, Pittier 14869 (US, VEN); Ciénaga del morichal de El Tigrito, 21VIII-194?, Pittier 15085 (US); Rio Mapire, afluente $\mathrm{N}$ del río Orinoco Medio, $7^{\circ} 30^{\prime}-8^{\circ} 30^{\prime} \mathrm{N}$ $64^{\circ} 30^{\prime}-65^{\circ} \mathrm{W}, \mathrm{Pm} 1483 \mathrm{~mm}, \mathrm{Tm} .27^{\circ} 4^{\circ} \mathrm{C}$, Estación Musinacio, 22-IX-1987, Rosales \& Valles 141 (CTES). Apure: Dist. Pedro Camejo, ca. 7,5 km upstream from the mouth of the rio Cinaruco at its junction with the rio Orinoco, 6 $6^{\circ} 36^{\prime} \mathrm{N} 67^{\circ} 09^{\prime} \mathrm{W}, 35$ m, 4-V-1977, Davidse \& Gonzalez 12631 (MO, VEN). Bolívar: mun. Gran Sabana, ca. rio Aprada, al N de Urimán, $5^{\circ} 29^{\prime} \mathrm{N} 62^{\circ} 36^{\prime} \mathrm{W}, 460 \mathrm{~m}$, III-1986, Fernández 2524 (CTES); mun. Piar, Hato El Morichal, $10 \mathrm{~km} \mathrm{~S}$ de Sta. Rosa, 8 ${ }^{\circ} 54^{\prime} \mathrm{N}$ $62^{\circ} 29^{\prime} \mathrm{W}, 360$ m, V-1986, Fernández 3016 (MO); El Cristo, 290 m, 26-IV-1943, Killip 37708 (US); near El Pao de la Fortuna, $7^{\circ} 08^{\prime} \mathrm{N} 63^{\circ} 10^{\prime} \mathrm{W}$, ca. 200 m, 29-VII-1978, Liesner \& al. 5791 (MO, VEN); quebrada de Manare, río Paragua, a la altura del Campamento Auraima, 6 $222^{\prime} 30^{\prime \prime} \mathrm{N}$ $63^{\circ} 33^{\prime} 30^{\prime \prime} \mathrm{W}, 175 \mathrm{~m}$ alt, 13-V/13-VI-1987, Stergios 10514 (CTES); Dist. Cedeño, 14 km SW of Caicara del Orinoco, $7^{\circ} 35^{\prime} \mathrm{N} 66^{\circ} 15^{\prime} \mathrm{W}, 50 \mathrm{~m}, 2$ IX-1985, Steyermark \& al.131119 (MO); Rio Parguaza, $\quad 6^{\circ} 15^{\prime} \mathrm{N} \quad 67^{\circ} 07^{\prime} \mathrm{W}, \quad 10-\mathrm{IX}-1985$, Steyermark \& al.131694 (MO); 0.2-1.5 km N of lower Río Pargueni, 90-100 m, 11-XII-1955, Wurdack \& Monachino 39801 (CTES, NY); extreme N base of cerro Baraguan, 100 m, 12-I-1956, Wurdack \& Monachino 40205 (CTES). Guárico: Los Llanos, inter Calabozo \& Alto del Pyrital, Bonpland 793 (B, herb. Willdenow 6088; P, herb. $\mathrm{HB}$ ); $39 \mathrm{~km} \mathrm{~S}$ of Las Mercedes along Hwy 12 to Cabruta, 160 m, 20-XI-1973, Davidse 4261 (MO, VEN); Parque Nacional Aguaro-Guariquito, cabeceras del rio Agua Blanca, 152 m, IX-1981, Delascio \& al. 9882 (MO). Monagas: La Hormiga area, between La Pica and Caño Colorado E of Maturin, along shores of Laguna Grande, just $\mathrm{S}$ of 
La Pica, 70 m, 1955, Wurdack \& Monachino 39547 (NY). TRINIDAD. Piarco, S of Arouca, 12-XII-1919, Broadway s.n. (K, NY, US); íd., 24VIII-1977, Philcox \& Philcox 8205 (K, P); Aripo savanna, 100', 10-VIII-1961, Richardson 970 (K, US); Piarco, 12-VII-1891, Warming 845 (US). GUYANA. Sin localidad, VII-1866, Appun 1874 (K); N. Rupununi, Davis 871 (K, NY); Rupununi Dist., Rupununi Northern Savanna, 4.5mi N of Lethem, ca. 350ft, 28-IX-1963, Goodland 894 (NY, US); Kumana Road, 100 m, 29-IV-1977, Grewal \& al. 363 (U); Orealla Indian Reservation, Corentyne river, Berbice, 7-I-1955, Irwin 310 (US); Rupununi Distr., Mountain Point, 110 m, 12VI-1995, Jansen-Jacobs \& al. 4038 (CTES, P); Oreala, Corentyne river, X-1879, Jenman 537 (K); Savannah, camp river, IV-1884, Jenman 1884 (NY); Rupununi Dist., Manari, 0328'N 5941'W, 20-X-1979, Maas \& al. 3675 (CTES, K, NY); Rupununi Dist., Chaakoitou, near Mountain Point, just S of Kanuku Mts., $2^{\circ} 56 \mathrm{~N} 59^{\circ} 40 \mathrm{~W}, 25-\mathrm{X}-$ 1979, Maas \& al. 4006 (CTES, K, NY); W of Abary river, ca. 5 $55^{\prime} \mathrm{N} 57^{\circ} 54^{\prime} \mathrm{W}, 4-\mathrm{X}-1981$, Maas \& al. 5499 (CTES, K, NY); Rupununi River, Monkey Pond landing, SW of Mt. Makarapan, 353’'N 58 55'W, 10-IX-1988, Maas \& al. 7333 (CTES, K, NY, US); E Berbice-Corentyne Region: Canje River, ca. $1 \mathrm{~km} \mathrm{~N} \& \mathrm{~S}$ of Digitima creek, ca. $5 \mathrm{~km} \mathrm{~W}$ or river, $05^{\circ} 26^{\prime} \mathrm{N} 57^{\circ} 35^{\prime} \mathrm{W}, 1-20 \mathrm{~m}, 15$ IV-1987, Pipoly \& al. 11613 (US); Essequibo, 1836, Schomburgk 105 (BM, BR, CGE, E, FI, K, US, W); Komock, Takutu river, XI-1948, Wilson \& Browne 497 (K, NY). SURINAME. Sin localidad, Hostmann 633a (P) y Kappler 633a (S); ad r. Casawinica, VI-1846, Kappler 1880 (P, S). GUAYANA FRANCESA. Charvein, 28-X-1913, Benoist 114 (P); Pariacabo, 15-XII-1914, Benoist 1409 (P); Pointe Combi, E. Sinnamary, 29-IX1977, Cremers 4910 (P); Savane Onemark, Ile de Cayenne, 04'57'N 52²9'W, 0,50 m, 18-V-1990, Cremers \& Hoff 11465 (US); Savane de Corossony, Piste de St. Elie, 53 ${ }^{\circ} 00^{\prime} \mathrm{W} 05^{\circ} 23^{\prime} \mathrm{N}$, 27-XII-1986, Feuill\& 4035 (NY, P, US); Savane Macoua, region littorale, le long d'une piste allant de la R.N.1 vers la mer, 5.29N 53.33W, 10 m, 26V-1989, Hoff \& Cremers 5686 (P, US); Gros Ilêt Savane Matiti - Region littorale, 5.05N 52.37W, 10 m, 13-XII-1988, Hoff \& Granville 5469 (P, US); Km 4 Tonate-Cayenne road, 459'N 52²7'W, 19-II-1978, Leeuwenberg 11841 (NY) y Lindeman 1979 (P); sin localidad, Richard s.n. (C,
P); Savane route de Stoupan $1 \mathrm{~km}$ avant Crique Macrabo jusqu' au carregour route de Cayenne, 24II-1968, Sastre \& Sastre 19 (P, US); Cayenne region, near road (Hwy. D5) from Tonate to Montsinery and Tonnegrande, $05^{\circ} 01^{\prime} \mathrm{N} 52^{\circ} 28^{\prime} \mathrm{W}$, 1-10 m, 25-X-1986, Skog \& al. 7025 (NY, US). BRASIL. Roraima: Igarapé Caranã, 20-VIII1951, Black 51-12775 (UB, UEC); Conceição do Mahu, Alto Rio Branco, 26-IV-1937, Kuhlmann 143 (RB); Boa Vista, VI, Kuhlmann 474 (CTES, $\mathrm{RB})$; Rio Arraia, proximo da fronteira com a Guiana, 26-VI-1974, Pires \& Leite 14725 (RB); Limão, 21-IX-1927, Tate 79 (NY); São Marcos, VI-1909, Ule 7896 (K).

Distribución y fenología: Planta propia de las sabanas de Trinidad, Venezuela, Guayanas y $\mathrm{N}$ de Brasil. Florece y fructifica todo el año.

Nombres vulgares: Venezuela: «sauce» (Liesner \& Gonzalez 5791); «chanana» (Correa, 1931).

Usos: hojas emolientes, recomendadas para apresurar la maduración de forúnculos (Correa, 1931).

Obs.: El siguiente ejemplar parece pertenecer a esta especie, aunque está fuera del área: Brasil. Ceará: along Rio Ceará, $3 \mathrm{~km}$ E of Soure, 9-IX-1935, Drouet 2440 (F, MO, NY, R, S, US).

En el ejemplar Richard s.n. (P) una flor presentaba 4 estambres largos y uno corto.

Las hojas son dorsiventrales y anfistomáticas, y los haces vasculares presentan vaina tanífera (Gonzalez, 2000). La epidermis de esta especie presenta esferocristales (Gonzalez \& Arbo, 2000), que en algunos ejemplares como Zarucchi \& Barbosa 3662 son visibles incluso con la lupa. Cristales semejantes se encuentran en Turnera fissifolia.

\section{Turnera harleyi Arbo}

Figs. 16 y 33

Arbo, M. M., 1981. Bonplandia 5(14): 118-121. Fig. 3. Typus: Brasil. Bahia, Serra do Curral Feio, $8 \mathrm{~km} \mathrm{NW}$ of Lagoinha (5,5 km SW of Delfino) on 


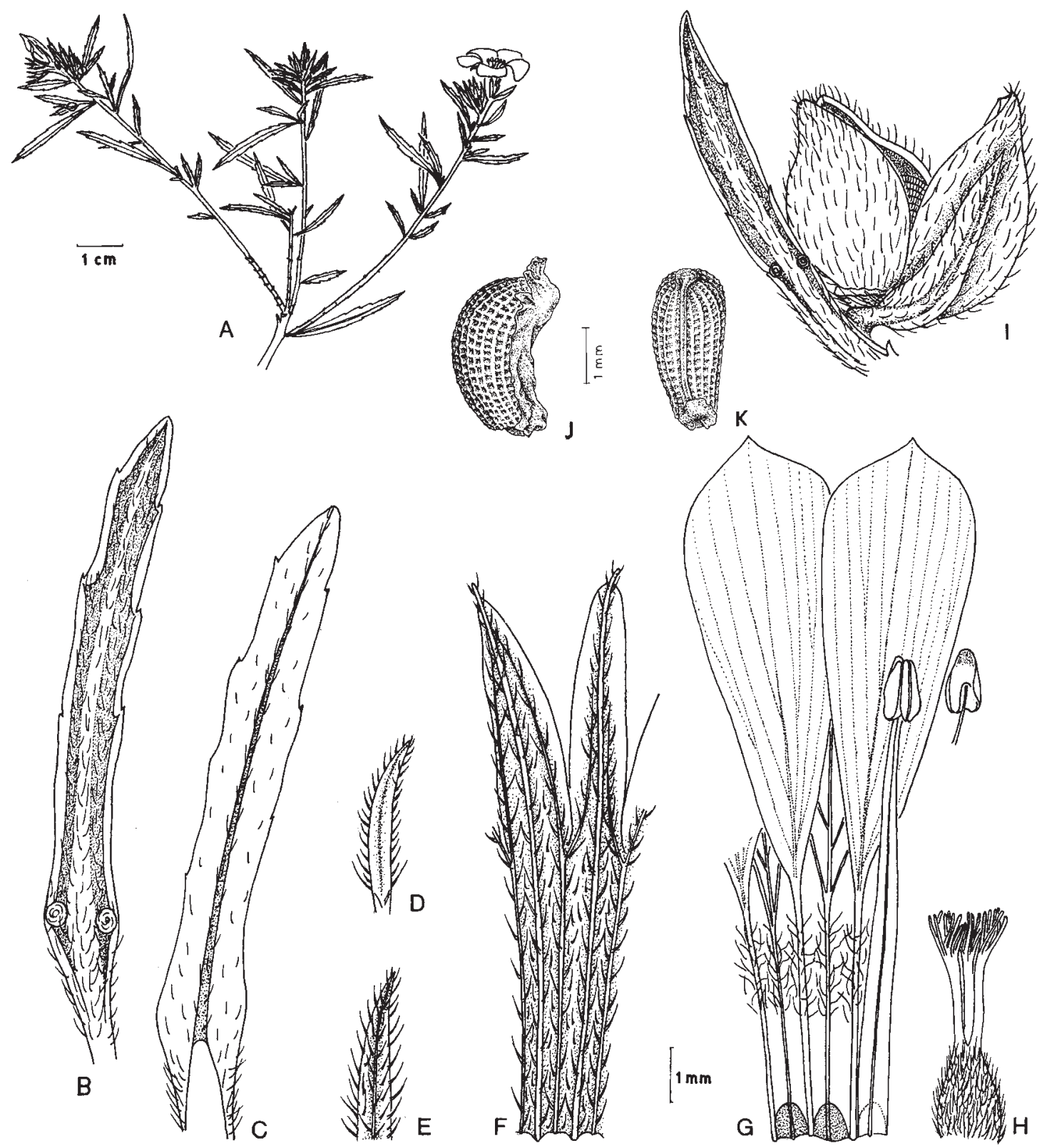

Fig. 33. Turnera harleyi. A: rama florífera. B-C: hoja florífera, caras abaxial y adaxial. D-E: profilo, haz y envés. F: porción del cáliz, cara externa. G: flor brevistila, porción del tubo calicino, cara interna, con pétalos y estambre adnato; se han punteado las cicatrices dejadas al desprender dos estambres. H: gineceo. I: hoja florífera con fruto epifilo y profilo. J: semilla con arilo, vista lateral. K: semilla, vista rafeal (A-H: Harley \& al. 16956; I: Harley \& al. 16807: J-K: Fiaschi \& al. 2487).

the road to Minas do Mimoso, approx. 10²4'S $41^{\circ} 17^{\prime} \mathrm{W}$, «caatinga/cerrado», frequently burnt and cut over, ca. 850m alt, 5-III-1974, Harley 16807 (holotypus CEPEC!, isotypi CTES!, IPA!, K!, NY!, RB!, U!, UEC!, US!).
Arbusto virgado, 0,8-1 m alt., ramas cilíndricas, longitudinalmente estriadas, lenticelas elípticas u oblongas, corteza parda; ramas jóvenes cilíndricas, delgadas, 0,6-1,2 mm diám., estrigosas, entrenudos hasta $16 \mathrm{~mm}$ 
long., cicatrices foliares salientes; yemas axilares 1-2 seriales, a veces ramas seriales desarrolladas. Hojas discoloras, las vegetativas generalmente sin nectarios. Base foliar prominente y persistente. Estípulas rudimentarias, con 1-2 coléteres rojizos $0,1-0,3$ $\mathrm{mm}$ long. Pecíolo estrigoso, 0,3-2,5 mm long., en hojas floríferas1,6-4 mm long. Lámina foliar linear, angustielíptica o angustiobovada, 4,5-34 x 0,7-3,5(-4,8) mm, relación largo:ancho $=(4,7-) 6-20: 1$; ápice agudo; margen marcadamente revoluto, la porción apical (22-71\% de su longitud) con 24 dientes a cada lado, con un coléter en el ápice; epifilo lustroso, estrigoso, en seco rugoso, pelos simples antrorsos brevísimos, 0,2$0,3 \mathrm{~mm}$ long., con la base abultada; envés con epidermis maculada, con pelos más largos, crespos y blanquecinos y pelos glandulares microcapitados, amarillentos, aprox. 0,04 $\mathrm{mm}$ diám. (Fig. 2A); venación pinnada, vena media hundida en la haz, prominente en el envés, ancha y plana, con pelos largos, blanquecinos, adpresos; 6-8 venas secundarias a cada lado, notables sólo en el envés, perdiéndose hacia el borde, con ramas hacia las escotaduras. Hojas floríferas pecioladas, de lámina más corta, con un par de nectarios circulares, sésiles, asentados en la base del hipofilo. Flores epifilas, heterostilas, solitarias o agrupadas en racimos bracteosos capituliformes en el ápice de las ramas, a veces en ramas seriales floríferas. Pedúnculo floral soldado al pecíolo, 1,5-2,5 $\mathrm{mm}$ long. Profilos angustitriangulares, 3-5,5 x 0,6-1 mm, opuestos en la base del receptáculo. Pedicelo nulo. Cáliz verde, a veces rojizo, (6)9-12 mm long.; tubo calicino subcampanulado, (3-)4,5-6 mm long., cara externa con pelos simples, curvados, antrorsos, cara interna glabra en la base, vellosa en la parte superior; lóbulos de prefloración quincuncial, triangulares o lanceolados, por fuera con pelos simples, cortos, curvados, antrorsos, por dentro glabros, márgenes internos membranáceos, ápice cortamente mucronado. Corola 0-3 mm más larga que el cáliz; pétalos unguiculados, uña soldada al tubo calicino, lámina amarillo intenso, rojiza por fuera, obovada, (4-)7-9 x (1,5-)3-5 mm, base cuneada, ápice ligeramente acuminado. Filamentos estaminales soldados $0,6 \mathrm{~mm}$ en la base al tubo calicino, triangular-subulados, (5,5-)7-9 mm long. en flores brevistilas, (3) $5,5 \mathrm{~mm}$ long. en flores longistilas, glabros; anteras dorsifijas, 0,8-1,2 x 0,4-0,9 mm, base emarginada, ápice obtuso o ligeramente apiculado, filamento inserto dorsalmente a 0,4-0,6 mm de la base. Ovario cónico, densamente cubierto de pelos simples, curvados, antrorsos, 1-1,5 x 1-1,2 mm; placentas 4-6ovuladas; estilos cilíndricos, glabros, 2-2,7 $\mathrm{mm}$ long. en flores brevistilas, $5 \mathrm{~mm}$ long. en flores longistilas; estigmas penicilados, 2-3 ramas basales a su vez divididas $0,7-2 \mathrm{~mm}$ long., con pelos brevísimos en la porción basal. En flores longistilas, gineceo $2 \mathrm{~mm}$ más largo que el androceo, y en flores brevistilas 2 $\mathrm{mm}$ más corto. Fruto ovoide, 4-6 mm long., con reborde anular basal de 0,4-0,5 mm dejado por la absición del tubo floral; valvas ovadas, cara externa lisa o punctulada, pelos simples, curvados, antrorsos, base hinchada, más abundantes en el ápice, cara interna lisa, jaspeada, pilosa. Semilla curvada, (2-)2,6-3,5 x 1-1,5 mm, parda; exóstoma cónico; rafe linear, lado rafeal incurvo; cálaza apical, saliente, pigmentada. Episperma reticulado, aréolas cuadrangulares o transrectangulares, epidermis papilosa, con bastoncillos de cera epicuticular en la semilla inmadura. Arilo membranáceo en seco, unilateral, tan largo como la semilla, de células papilosas.

Material estudiado: BRASIL. Bahia: mun. Caetité, Km 6 da estrada Caetité/Brejinho das Ametistas, 1100 m, 15-IV-1983, Carvalho \& al. 1731 (CEPEC, CTES); Umburanas: estrada de Umburanas para Delfino, ca. $31,3 \mathrm{~km}$, acceso a Serra da Empreitada, ca. $7 \mathrm{~km}$ do inicio, $10^{\circ} 26^{\prime} 28^{\prime \prime S} 41^{\circ} 17^{\prime} 39^{\prime \prime} \mathrm{W}, 925 \mathrm{~m}, 16-\mathrm{VII}-2004$, Fiaschi \& al. 2487 (CEPEC, CTES); Mun. de Sento Sé, $10^{\circ} 11^{\prime} \mathrm{S} \quad 41^{\circ} 25^{\prime} \mathrm{W}$, 9-IX-1981, Gonçalves 213 (CTES, HPR, RB); $16 \mathrm{~km} \mathrm{NW}$ of Lagoinha (5.5 km SW of Delfino) on side road to Minas do Mimoso, approx. $10^{\circ} 22$ 'S $41^{\circ} 20^{\prime} \mathrm{W}$, 950-1000 m, 8-III-1974, Harley 16956 (IPA, K, NY, RB, U, UEC, US); Serra Geral de Caitité, ca. $5 \mathrm{~km} \mathrm{~S}$ from Caitité along the Brejinhos das Ametistas road, $14^{\circ} 07^{\prime} \mathrm{S} 42^{\circ} 29^{\prime} \mathrm{W}$, ca. $1000 \mathrm{~m}, 9$ IV-1980, Harley \& al. 21127 (CTES, K); Rod. BR-430, trevo para Tanque Novo, mun. Igaporã, 1000 m, 5-IV-1992, Hatschbach \& al. 56642 
(CTES, MBM); Umburanas: Serra do Curral Feio (localmente referida como Serra da Empreitada) entrando para $\mathrm{W}$ a cerca de $20 \mathrm{~km} \mathrm{~S}$ de lfino, na estrada para Umburanas, $10^{\circ} 22^{\prime} \mathrm{S} 4^{\circ} 19^{\prime} \mathrm{W}, 1000$ 1200 m, 10-IV-1999, Queiroz \& al. 5237 (CTES, HUEFS); Caetité, 12-20 km da cidade em direção a Brejinho das Ametistas, entre $14^{\circ} 06^{\prime} 10^{\prime \prime S}$ $42^{\circ} 30^{\prime} 31^{\prime \prime W}$ e $14^{\circ} 11^{\prime} 19^{\prime \prime S} 42^{\circ} 29^{\prime} 48^{\prime \prime W}, 1100$ 1200 m, 8-III-1994, Souza \& al. 5377 (CTES, ESA, K, SPF).

Distribución y fenología: Aparentemente Turnera harleyi es una especie endémica de Bahia, se conocen pocos ejemplares colectados en «cerrado/caatinga», «carrasco»y «campos gerais» en la Serra do Curral Feio (Serra da Empreitada), y en la Serra de Caetité, a 950-1200 m, entre marzo y septiembre.

Obs.: Especie dedicada a Raymond M. Harley, quien coleccionó el ejemplar tipo. Es afín a Turnera opifera Mart., con hojas amplias y flores grandes. También tiene similitud con algunos ejemplares de T. melochioides Camb., que posee hojas opacas, con borde plano, y flores de menor tamaño.

Los ejemplares de la Serra de Caetité tienen hojas más anchas, con relación largo:ancho menor, y flores más pequeñas, con la corola igual o apenas más larga que el cáliz.

\section{Turnera hassleriana Urb.}

Figs. 12 y 34

Urban, I., Bull. Herb. Boissier sér. 2, 3: 1119. 1903. Typus: Paraguay, in dumeto Cordillera de Altos, II-1899, Hassler 3877 (lectotypus, aquí designado G!, isotypi BM!, K!, NY!, P!, B+ fototipo $\mathrm{F} \mathrm{n}^{\circ}$ 13583).

Turnera hassleriana var. lobulata Urb., Bull. Herb. Boissier sér. 2, 3: 1120. 1903. Typus: Paraguay, in regione superiore fluminis Apa, XI-1901, Hassler 7891 (holotypus G!).

Turnera dolichostigma Urb., Jahrb. Königl. Bot. Gart. Berlin 2: 106. 1883 (en parte, excluyendo el lectotipo), Arbo, M. M., Bol. Soc.Argent.Bot. 24(3-4): 423-425. Fig. 1. 1986.
Turnera ulmifolia $\mathrm{L}$. var. cuneiformis auct. non (Juss. ex Poir.) Urb., en Morong \& Britton, Contr. Dept. Bot. Columbia Univ. 35: 114. 1892.

Turnera weddelliana auct. non Urb. \& Rolfe en Molfino, Physis 8: 222. 1925.

Sufrútice 10-60 cm alt., corteza rojiza; tallos erectos a veces radicantes en la base, simples a muy ramificados, cilíndricos, estriados, con pelos simples, largos, antrorsos o patentes y pelos simples cortos, crespos, blanquecinos. Ramas seriales ascendentes generalmente desarrolladas. Yemas axilares seriales $1-5$, a veces todas desarrolladas. Hojas herbáceas. Estípulas cónicas o subuladas, 0,2-1,5 mm long., pilosas, a veces con coléteres. Pecíolo semicilíndrico, 3-13 $\mathrm{mm}$ long., indumento como el del tallo. Lámina ovada, elíptica u obovada, 29-72(-90) x 4-42 $\mathrm{mm}$, disminuyendo de tamaño bruscamente en hojas floríferas, relación largo:ancho $=(6,5-$ 2,9-1,5:1; base obtusa o cuneada, en hojas apicales atenuada; ápice agudo u obtuso; margen piloso, ligeramente revoluto, simple o doblemente crenado-aserrado; haz con pelos simples de base abultada, todos de longitud similar o a veces de diferente longitud, 0,2-1( 1,2) $\mathrm{mm}$ long., orientados oblicuamente hacia fuera; envés con pelos simples densamente dispuestos, a veces mezclados con pelos glandulares microcapitados; vena media y 5-11 pares de venas secundarias hundidas en la haz, prominentes en el envés, con pelos largos, 0,6-1,5 mm long.; venas terciarias visibles en el envés, venación menor inconspicua. Nectarios 2, situados en la unión de pecíolo y lámina o desplazados sobre el margen foliar, elípticos o circulares, con un reborde pubérulo de 0,1-0,2 $\mathrm{mm}$. Flores: epifilas, heterostilas, agrupadas en el ápice de las ramas en racimos hojosos capituliformes, luego los frutos distanciados. Pedúnculo de 2-6 mm long., adnato al pecíolo, a veces la porción apical brevemente libre. Profilos 2, subulados o lanceolados, 2-5(-7) mm long., opuestos en la base del receptáculo. Pedicelo nulo. Cáliz verdoso, 9-15(-18) mm long.; tubo calicino 3-5(5,5) x 0,4-0,6 mm, cara interna pilosa en la porción superior, cara externa con pelos simples, cortos, blanquecinos; lóbulos triangulares o lanceolados, 3nervados, glabros por dentro, por fuera como el tubo calicino, pero con pelos más largos 


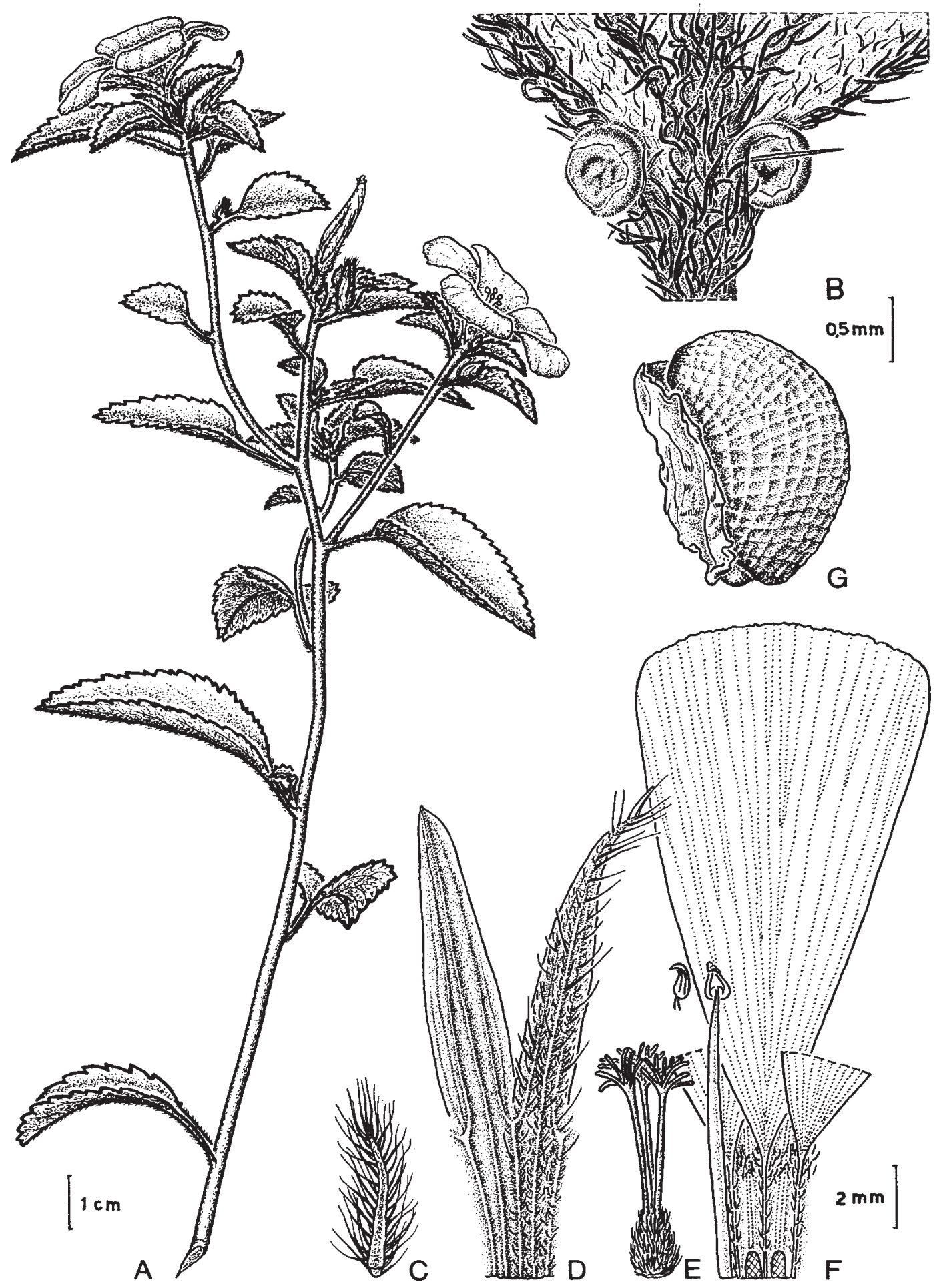

Fig. 34. Turnera hassleriana. A: rama florífera. B: porción basal de hoja con nectarios, cara abaxial. C: profilo, cara interna. D: porción del cáliz, cara externa. E: gineceo. F: flor brevistila, porción del tubo calicino, cara interna, con pétalos y estambres adnatos; se han cuadriculado las cicatrices dejadas al desprender dos estambres. G: semilla con arilo, vista lateral (A, C-F: Arbo 1735; B-G: Krapovickas 20762; C: Jansen-Jacobs 4038; D-I: Maas \& al. 5499). Del. A: Víctor Maruñak; B-G: Ricardo Vispo. 
sobre las venas; lóbulos internos con margen membranáceo, ápice brevemente mucronado. Corola 15-35 mm diám.; pétalos con uña pilosa adnata al tubo calicino, lámina obovada, blanca o cremosa con mácula amarilla en la base, 9-22 x 4-15 mm. Filamentos estaminales subulados, adnados en la base 0,5-0,8 $\mathrm{mm}$ al tubo calicino por su cara externa, con un nectario en la cara externa por encima de la inserción, 3,5-7 $\mathrm{mm}$ long. en flores longistilas, 5-9 $\mathrm{mm}$ long. en flores brevistilas; anteras ovadas, 1-1,3 x 0,5-1 mm, filamento inserto en una cavidad basi-dorsal a 0,4-0,6 mm de la base emarginada, ápice obtuso. Ovario cónico, 1-1,7 mm long., densamente cubierto de pelos simples largos; placentas 2-14-ovuladas; estilos cilíndricos, glabros, 4$8 \mathrm{~mm}$ long. en flores longistilas, 1,5-6 mm long. en flores brevistilas; estigmas con 6-12 ramas, 1,4-4 mm long. en flores longistilas, 0,5-1,5 mm long. en flores brevistilas. En flores longistilas el gineceo es 1-4 mm más largo que el androceo y 1-6 mm más corto que el cáliz. En flores brevistilas el androceo es 0,5$4 \mathrm{~mm}$ más largo que el gineceo y 1-5 mm más corto que el cáliz. Fruto ovoide, 3-7 mm long.; profilos más cortos que el fruto; valvas obtusas, por fuera lisas, pelos simples largos y cortos, por dentro glabras, lustrosas, jaspeadas o pardas. Semilla virguliforme, 1,5-2,3 x 0,7-1,2 mm, negruzca a la madurez; exóstoma breve, hemisférico; rafe linear, oscura, lado rafeal incurvo; cálaza pigmentada obtusa o ligeramente saliente. Episperma reticulado, muros verticales a veces más salientes que los transversales; aréolas rectangulares, a veces con cera epicuticular bastoniforme. Arilo 1-2 mm long., unilateral, borde entero o más o menos lobado, de células lisas.

Cromosomas: 2n=2x=14: Krapovickas 36444, 2n=4x=28: Arbo 1735 y Vanni 351 (Fernández, 1987; Solís Neffa \& Fernández, 1993 y 2000).

Material estudiado: BOLIVIA. Santa Cruz. Velazco: camino de Santa Ana a San Rafael, a 9 km S de Santa Ana, 16040'02"S 6041'27"W, 429 m, 26-I-2004, Solís Neffa \& al. 1246 (CTES); Chiquitos: $6 \mathrm{~km}$ W de Santiago, camino a Roboré, 1819'S 59³4'W, 23-IV-1980, Krapovickas \& al. 36444 (CTES). BRASIL. Mato Grosso do Sul:
Campo Grande, 1949, Amado \& al. 138 (RB); Estrada para a bacia do Apa, Rio Candelão, mun. Bela Vista, 12-XI-2006, Barbosa \& Silva 1856 (CTES, MBM); Jardim para Bela Vista, BR-060, ca. $8 \mathrm{~km}$ ao $\mathrm{N}$ da ponte sobre o rio Sobreiro, $21^{\circ} 55^{\prime} 23^{\prime \prime S} 56^{\circ} 22^{\prime} 52^{\prime \prime} \mathrm{W}, 294 \mathrm{~m}, 27-\mathrm{I}-2001$, Groppo Jr. \& al. 548 (CTES, SPF); Rod. BR-419, $11 \mathrm{~km} \mathrm{~S}$ de Anastacio, 11-II-1993, Hatschbach \& al. 58916 (C, MBM); $23 \mathrm{~km}$ E de Aquidauana, 3VII-1977, Krapovickas \& al. 32862 (CTES, WIS); Campo Grande, I-1979, Laclette 773 (R); 10-15 km W of Bela Vista, mun. Bela Vista, 16-II-1994, Pedersen 16051 (C, CTES, F, MBM); mun. Aquidauana, BR-262, proximo ao Km 464, entre Aquidauana e Campo Grande, $20^{\circ} 30^{\prime} \mathrm{S} 55^{\circ} 39^{\prime} \mathrm{W}$, 370 m, 15-X-1990, Pott 1514 (CTES); ad Rio Pardo, IX-1826, Riedel 503 (LE, B+, foto F $\mathrm{n}^{\circ}$ 13579); Salobra, XII-1941, Santos s.n. (R 91333); Fazenda Monte Alegre, rodovia Porto Murtinho a Bonito, mun. Porto Murtinho, 15-VI2006, Silva \& Barbosa 4890 (CTES, MBM); mun. Rio Verde, Fazenda Anhumas do Rio Negrinho, ca. 590 m, 27-XII-1973, Sucre 10471 (RB). PARAGUAY. in regione Yerbalium de Maracayú, XII-1900, Hassler 5641p.p. (BM). Amambay: Parque Nac. Cerro Corá, $1 \mathrm{~km}$ de la casa del guardaparque, $22^{\circ} 40^{\prime} \mathrm{S}, 56^{\circ} 03^{\prime} \mathrm{W}$, camino a cerro Muralla, 4-V-1989, Fortunato \& al. 1086 (CTES, FCQ, SI); Parque Nac. Cerro Corá, 22 40'S 560'', 1-XI-1983, Hahn 1779 (MO, PY); 20 km S de Bella Vista, 24-VI-1977, Krapovickas \& al. 32676 (BAA, C, UC, US); near Caballero, 20I-1889, Morong 608 (NY, US); ruta 3, $37 \mathrm{~km} \mathrm{~N}$ del cruce de ruta $5,22^{\circ} 35^{\prime} \mathrm{S} 56^{\circ} 17^{\prime} \mathrm{W}, 10-\mathrm{I}-2003$, Schinini \& Quintana 36363 (CTES); 9 km S de Bella Vista, camino a San Carlos, $22^{\circ} 15^{\prime} \mathrm{S}$ 56²30'W, 196 m, 11-I-2003, Schinini \& Quintana 36391 (CTES); Estancia Aramburu Cué, 11-XII1991, Soria 5217 (FCQ); Around Cerro Cora, 2239'53"S 5559'18"W, 27-II-2001, Zardini \& Acosta 56134 (BAB, CTES); around Lorito Picada, 2241'19"S 5600'25"W, 11-XI-1999, Zardini \& Baez 52428 (MO); Santa Rosa-Santa Barbara, 2350'26"S 56²3'47"W, 11-III-1998, Zardini \& Vera 48121 (CTES). Central: $1 \mathrm{~km}$ de la ruta 2, camino a San Bernardino, 14-X-1993, Krapovickas \& Cristóbal 44564 (CTES); Ñemby, 12-XII-1965, Pedersen 7531 (CTES). Concepción: Ea. Potrerito, orillas del rio Pitanoaga, potrero Ita, 8-VII-1991, Basualdo 3177 (FCQ); Rancho Z, Potrero Plantel, 12-XII-1991, Degen 
2515 (FCQ, MO); Estancia San Rafael, 140 km E de Concepción, 21-III-1991, Eliceche 123 (CTES, MO); Zwischen rio Apa und Rio Aquidaban, Centurion, XII-1908, Fiebrig 4409 p.p. (BM, E, M, W) y Fiebrig 4463 (BM, E); camino a Paso Mbutú, Karaza Bola, 238'S 5650’W, 18-XII1986, Fortunato \& al. 857 (CTES, PY); pr. Concepción, VIII-1901, Hassler 7171 (BM, G, NY, S, sintipo); In regione cursus superioris fluminis Apa, I-1902, Hassler 8425 (BM, G, NY, sintipo); Paso Barreto, $63 \mathrm{~km}$ NE de Concepción, 2305'S 570' 130 m, 19-IV-1995, Schinini \& al. 29345 (CTES); Ruta 5, 27 km E de Col. Memby, 2246'09"S 56²19'84"W, 8-XI-2001, Schinini \& al. 35543 (CTES); 19 km W de Concepción camino a Loreto, 140 m, XII-1983, Vanni \& al. 351 (CTES, TEX); Estancia Arrecife, 22¹0'28"S 57³1'08"W, 14-I-2000, Zardini \& Espinoza 53667 (CTES); Paso Horqueta: Rio Aquidaban, 230ㄱ'S 57²0’W, 18-XI-1993, Zardini \& Tilleria 37492 (CTES, MO); Around Sargento José E. Lopez, 22³3'06"S 5652'44"W, 11-V-2000, Zardini \& Vera 54410 (CTES). Cordillera: vicine lagunam Ypacaray, XII, Hassler 1712 (BM, G, K, NY, P, sintipo); prope Tobaty, IX-1900, Hassler 6450 (BM, G, NY, sintipo); Cordillera in regione lacus Ypacaray, IV-1913, Hassler 12588 (BAF, BM, E, F, MO, US). Guairá: Campo Mbuvevo, III-1931, Jorgensen 4069 p.p. (CTES, F, MO, US); Cnia. Independencia, 28-XII-1989, Mereles 3750 (FCQ) y Mereles 3754 (FCQ); San Salvador, [25.55S 56.30W], 22-II-1917, Rojas 2638 (MO); Cerro Nelville, $5 \mathrm{~km} \mathrm{~W}$ de Mbocayaty, $56^{\circ} 25^{\prime} \mathrm{W}$ 2542’ S, 280 m, 24-III-1993, Schinini \& al. 27892 (CTES). Misiones: San Ignacio, 1914, Chodat s.n. (G). Paraguarí: Salto de Pirareta, 14-XI-1978, Arbo \& al. 1735 (ANSM, CTES, EAC, MEXU, SI); 2 km E de la ruta Piribebuy-Paraguarí, sobre el desvío a Itá Morotí y Valenzuela, 25-XI-1993, Arbo \& al. 6082 (AAU, CTES, G, GH, LIL, MO, MBM, U); links vom Piribebuy und südlich vom Tobati, serranía nordlich vom Taldes Y-aguiguazú, 3-II-1903, Fiebrig 853 (BM, E, F, M, PR); vicine Cerro Hú, VI, Hassler 333 (G, K, NY, P, sintipos); in valle fluminis $\mathrm{Y}$-acá ad marginem silva prope Chololó, XII-1900, Hassler 6678 (BM, G, K, LY, MO, NY, P, S, W, sintipos); 17km de Paraguarí, camino a Piribebuy, 6-II-1966, Krapovickas \& al. 12469 (CTES); Parque Nacional Ybycu'i, $26^{\circ} 03^{\prime} \mathrm{S} 56^{\circ} 50^{\prime} \mathrm{W}, 5 \mathrm{~km} \mathrm{~N}$ of administration building on road to César
Barrientos, 14-XII-1988, Zardini 8716 (CTES, MO, MBM); $3 \mathrm{~km} \mathrm{~N}$ of Salto Cristal, Zardini 10207 (MICH, PY), NE area, 12-III-1992, Zardini \& Guerrero 31000 (BAB, CTES, SI); $1 \mathrm{~km} \mathrm{~S}$ of Arroyo Corrientes, 2600'S 5646’ W, 9-II-1991, Zardini \& Velázquez 26308 (CTES, MO, P, PY). Presidente Hayes: Gran Chaco, ad ripam occiden-talem flum. Paraguay $23^{\circ} 20^{\prime}-23^{\circ} 30^{\prime} \mathrm{S}, \mathrm{X}$ 1903, Hassler \& Rojas 2356 (BM); Puerto Militar, puente sobre el río Paraguay, frente a Concepción, 10-XII-1989, Vanni \& al. 1274 (CTES, K). San Pedro: Ruta 3, $10 \mathrm{~km} \mathrm{~S}$ del puente sobre el rio Aguaray Guazú, 2357'47"S 56²9'52"W, 31VIII-2001, Arbo \& al. 8897 (CANB, CTES); Ea. Santa Ana, Compañía San José, 10-XII-1992, Basualdo 4810 (FCQ). ARGENTINA. Misiones: ruta 105 , a $21 \mathrm{~km}$ del cruce de ruta 12 con Santa Ana, 19-I-1975, Cuezzo \& al. 11006 C (CTES); dep. Candelaria, Loreto, in campo arenoso, 31-I1908, Ekman 1972 (F, K, NY, P, S); Dep.Candelaria, Bonpland, 1900, Fiebrig s.n. (BAF); San Ignacio, V-1913, Hauman s.n. (BA); dep. Cande-laria, Loreto, ruta 12, 15-II-1971, Krapovickas \& al. 18274 (CTES, LPB); Loreto, 20-I-1972, Krapovickas \& al. 20762 (CTES, LIL, MBM, MICH); San Ignacio, 12-I-1976, Krapovickas \& al. 28675 (BAB, CTES, INPA); dep. Candelaria, Loreto, 230 m, 8-VI-1957, Montes 27268 (CTES, UB); camino desde San Ignacio hacia Parque Prov. Teyucuaré, ca. $3 \mathrm{~km}$ del pueblo, 2716'S 55³3'W, 120 m, 18-III-2002, Múlgura de Romero \& al. 3446 (CTES, SI); Teyucuaré, $7 \mathrm{~km} \mathrm{SW}$ de San Ignacio, 27¹6'03"S 55'33'28"W, 142 m, 2-III-2004, Schinini \& al. 36448 (CTES). Salta: Chaco salteño, 1902, Spegazzini s.n. (BAF).

Material cultivado: ARGENTINA. Corrientes: proc. de Paraguay, Paraguarí, Salto de Piraretá, III-1984, Arbo \& al. 1735 bis (CTES).

Distribución y fenología: Sudeste de Bolivia, Brasil (Mato Grosso do Sul), Paraguay y Argentina (Misiones y Salta). Vive en campo, sabana y «cerrado», frecuentemente con suelo arenoso o pedregoso. Florece durante todo el año, la mayor parte de los ejemplares se colectaron entre octubre y abril.

Obs.: Zardini 8716 presenta hojas angostas, relación largo:ancho $=6,5: 1$, el ejemplar es 
escaso, con flores viejas y no tiene semillas. El indumento varía en densidad y color, en algunos ejemplares como Fiebrig 853, Hassler 6678 y Krapovickas 12569, las hojas son grisáceas y casi velutinas. El tipo de Turnera hassleriana var. lobulata (Hassler 7891) presenta pelos de 1,5-1,8 mm long. en el haz foliar; el ejemplar corresponde a una planta joven y robusta, con hojas grandes y bien desarrolladas, de aspecto muy similar a otros como Hassler 2356 y Krapovickas 32676 , con pelos cortos en el epifilo.

La secuencia de sarrollo de las yemas seriales es acrópeta, pero aparecen nuevas yemas entre las ramas ya desarrolladas, y su secuencia de aparición es acrópeta o basípeta.

Normalmente cada pie tiene flores longistilas o brevistilas, pero una planta del ejemplar Krapovickas 34267 presenta 3 flores brevistilas y 1 longistila. En Krapovickas 32862 se encontraron flores longistilas normales y una flor brevistila con 3 estambres largos y 2 cortos con anteras indehiscentes, a la altura del estigma. En Morong 608 se halló una flor brevistila con 4 estambres largos y 1 estambre más corto que el gineceo.

Se mantuvieron bajo cultivo dos plantas brevistilas (Arbo 1735bis), que florecieron en abundancia durante el verano, sin fructificar. Sin embargo en otoño, se formaron algunos frutos con 1-2 semillas. Pareciera que la autoincompatibilidad disminuye al final de la estación. Los nectarios foliares son visitados por diferentes especies de hormigas.

Spencer \& al. (1985) revisaron el ejemplar Hassler 12588 (F) en busca de compuestos cianogénicos, con resultado negativo. En cambio Olafsdottir \& al. (1990) hallaron linamarina y compuestos cianohídricos ciclopentenoides en Vanni \& al. 347 (CTES)

La anatomía y vascularización floral de esta especie fueron estudiadas e ilustradas con todo detalle (Gonzalez, 1993), también la estructura de los nectarios extraflorales, comparada con la de los nectarios de la serie Turnera (Gonzalez, 1996). Se examinaron los coléteres, de tipo standard, emplazados en los dientes de los primordios foliares, en las estípulas rudimentarias y en los profilos jóvenes (Gonzalez, 1998). Se estudió la anatomía del tallo primario y secundario, las hojas son dorsiventrales y anfistomáticas, los haces vasculares poseen vaina fascicular tanífera; las semillas presentan aréolas pequeñas, determinadas por el tamaño de las células de la endotesta (Gonzalez, 2000).

\section{Turnera hilaireana Urb.}

Figs. 12 y 35

Urban, I., Jahrb. Königl. Bot. Gart. Berlin 2: 108-110. 1883, excluyendo Turnera lanceolata Cambess. y T. oblongifolia Cambess.; Turnera hilaireana Urb. var. minor Urb., Jahrb. Königl. Bot. Gart. Berlin 2: 109. 1883; Urban, en Martius, 1883, Fl. Bras. 13(3): 131, tab. 40, fig. II; Malme, Bih. Kongl. Svenska Vetensk.-Akad. Handl. 24 Afd. 3(6): 22. 1898; Glaziou, Bull. Soc. Bot. France 56, Mém. 3: 311. 1909. Typus: Brasil. Minas Gerais: Serra de Caldas, 30-IX-1864, Regnell I 100 (lectotypus, aquí designado S!, isotypi C!, CTES!, P!, US!).

Hierba perenne de 3-20 $\mathrm{cm}$ de alto, verde o castaña en seco, erecta, uni o pluricaule (1-11 ejes); base leñosa de hasta $8 \mathrm{~mm}$ diám. Tallos generalmente simples, a veces ramificados casi desde la base, 0,6-1,4 mm diám., generalmente castaño-rojizos en la base, rectos o sinuosos, cilíndricos, longitudinalmente estriados, con pelos simples crespos entremezclados con pelos patentes hasta $2 \mathrm{~mm}$ long. y a veces también con pelos glandulares microcapitados; entrenudos vegetativos de 1,5-48 mm long., generalmente tanto o más largos que las hojas, entrenudos floríferos más cortos, 12-0,6 mm long. Yemas axilares 1-2. Estípulas rudimentarias, con coléteres cónicos o cilíndricos, 0,2-0,3 mm long., amarillentos. Hojas herbáceas, generalmente erectas y opacas, verdosas o castañas en seco. Pecíolo de 01,5 mm long., en hojas floríferas hasta $3 \mathrm{~mm}$ long., raramente con un mechón de pelos largos en la base. Lámina elíptica, obovada, ovada o angustiovada, 7-28 x 4-15 mm, relación largo:ancho $=1,3-3: 1$, hojas basales reducidas, 2-10 x 1-5 mm, hojas floríferas de tamaño menor hacia el ápice; base atenuada o truncada, ápice agudo u obtuso, margen plano, excepcionalmente algo revoluto, piloso (pelos 


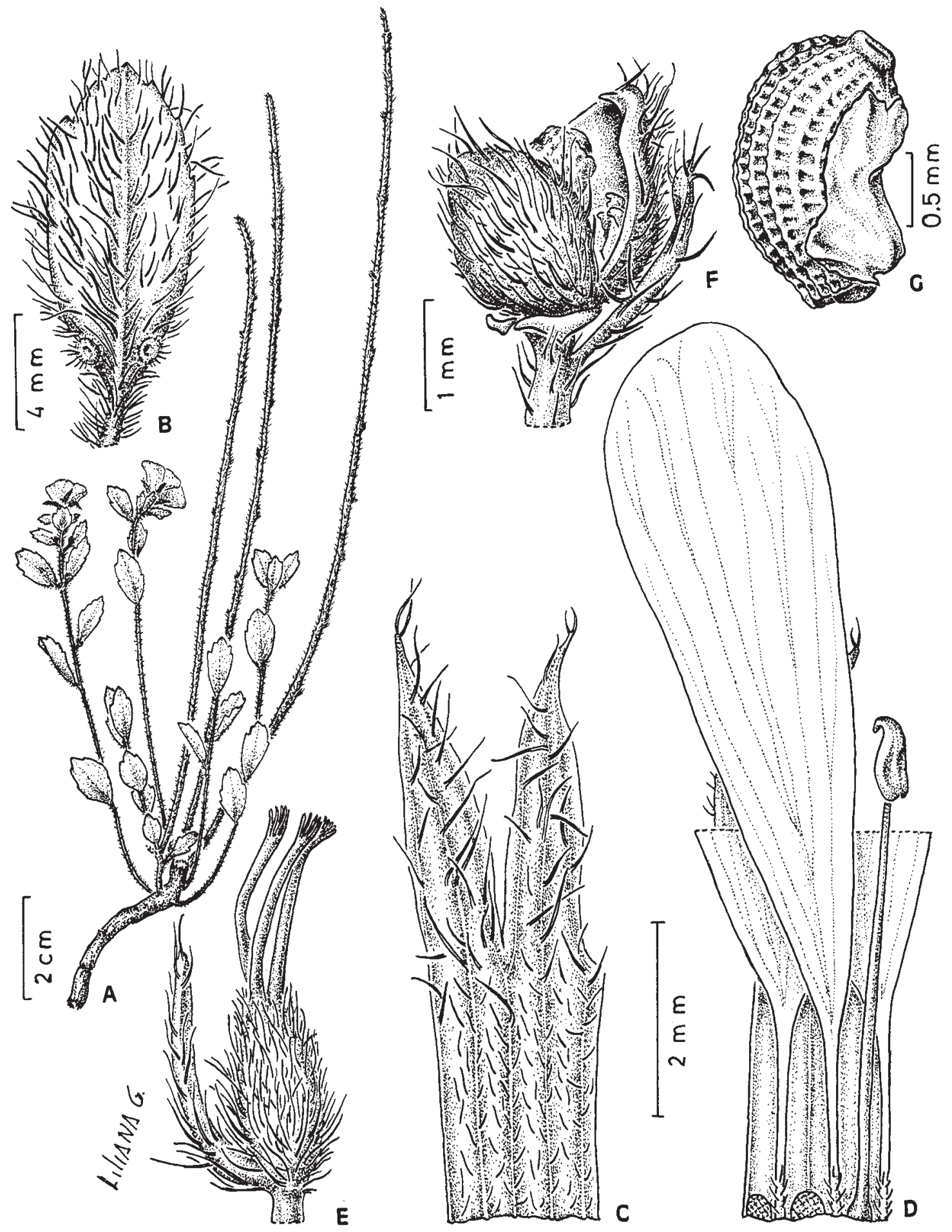

Fig. 35. Turnera hilaireana. A: planta. B: hoja con nectarios, cara abaxial. C: porción del cáliz, cara externa. D: flor brevistila, porción del tubo calicino, cara interna, con pétalos y estambre adnatos; se han cuadriculado las cicatrices dejadas al desprender dos estambres. E: receptáculo, profilo y gineceo. F: fruto y profilo. G: semilla con arilo, vista lateral (Mosen 529). Del. Liliana Gómez. 
simples largos y cortos), entero o aserrado, con 1-5 pares de dientes en la porción apical; haz punteada, raramente lustrosa; envés generalmente de aspecto arenáceo, raramente liso, ambas caras con pelos simples, curvados, antrorsos, a veces con la base cónica, laxamente dispuestos, ligeramente más largos sobre las venas, a veces también pelos glandulares microcapitados, a veces sólo las venas pilosas; vena principal y 2-3 pares de venas laterales prominentes en ambas caras, ángulo de divergencia $35^{\circ}-55^{\circ}$, venación menor inconspicua, raramente visible. Nectarios generalmente $1+1$ o $2+1$, circulares, $0,3-0,7 \mathrm{~mm}$ diám. , sésiles o estipitados, superficie cóncava en seco, borde piloso, situados en la unión de pecíolo y lámina o desplazados 0,5-3 mm sobre el margen foliar. Flores epifilas, heterostilas, solitarias. Alabastro elipsoide $\mathrm{u}$ obovoide, ápice obtuso o agudo, mucrones del cáliz apenas visibles. Pedúnculo 2-4,5 mm long., adnato al pecíolo y a veces a la base de la lámina excepto en la porción apical de 0,5-2 $\mathrm{mm}$ long., indumento como el del tallo. Profilos opuestos o ligeramente alternos, situados en la base del receptáculo (a veces alejados), subulados, 1-3,5 x 0,5-1 mm, haz glabra, envés piloso, borde piloso, serrulado, dientes glandulosos. Pedicelo 0-0,7 mm long. Cáliz 6-9 mm long.; tubo calicino 1,5-2,5 mm long., glabro o con pelos cortos simples, cara interna vellosa en la porción superior; lóbulos angustiovados o lanceolados, con pelos simples, largos, erectos, superficie frecuentemente maculada, cara interna glabra, bordes internos membranáceos, ápice mucronado $(0,1-0,3$ mm long.), a veces purpúreo. Corola amarilla; pétalos unguiculados, uña soldada al tubo calicino, lámina angustiobovada, 9-11 x 3,5$6,5 \mathrm{~mm}$, base brevemente atenuada, glabra o pilosa por dentro, ápice truncado. Filamentos estaminales triangular-subulados, brevemente soldados en la base al tubo floral $(0,3 \mathrm{~mm})$, glabros, 4-4,5 mm long. en flores longistilas, 5-6 mm long. en flores brevistilas; anteras 0,9$1,5 \times 0,4-0,8 \mathrm{~mm}$, ovado-elípticas, dorsifijas, filamento inserto a 0,3-0,6 $\mathrm{mm}$ de la base, ligeramente curvadas después de la dehiscencia. Ovario cónico, hirsuto, 0,6-1,5 mm long.; placentas 4-10-ovuladas; estilos cilíndricos, glabros o con algunos pelos simples, 2,4-4 $\mathrm{mm}$ long. en flores longistilas, 1,5-2,5 $\mathrm{mm}$ long. en flores brevistilas; estigmas penicilados, 4-18 ramas de 1,7-2,5 mm. Fruto subesférico, 3-4 mm diám., con un reborde anular de $0,4 \mathrm{~mm}$ en la base, dejado por el tubo floral al desprenderse; valvas ovadas, por fuera lisas, pelos simples cortos y largos, por dentro lustrosas, amarillentas o castañas o jaspeadas, glabras. Semilla ligeramente curvada, 1,6-2,3 x 0,8-1,2 mm, pardo-oscura; exóstoma cónico; rafe linear, lado rafeal incurvo; cálaza obscura, ligeramente saliente y a veces algo deprimida en el centro. Episperma reticulado, nudos algo prominentes, aréolas poligonales o cuadrangulares, con o sin depresión punctiforme, epidermis papilosa, con cera epicuticular bastoniforme. Arilo unilateral 1,5-2 mm long., membranáceo en seco, de células papilosas o no.

Material estudiado: BRASIL. Distrito Federal: Area do Cristo Redentor, 15 57'07's 475'ㄱ' $37^{\prime} \mathrm{W}, 19-\mathrm{X}-1988$, Azevedo 184 (IBGE, US); Fazenda Sucupira, Riacho Fundo,

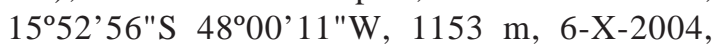
Cavalcanti \& al. 3552 (CEN, CTES); Reserva Ecologica do IBGE, prox. ao Córrego Taquara, 155' 55"S 4783'81"W, 1015 m, 13-IX-1999, Fonseca \& Alvarenga 2079 (CTES, IBGE); Brasília, Bacia do Rio São Bartolomeu, 9-VI1980, Heringer \& al. 5041 (IBGE); Lago Sul, proximidades do Corre-go Taquarí, 14-IX-1982, Heringer \& al. 7509 (CTES, IBGE); Córrego Jeriva, ca. $10 \mathrm{~km} \mathrm{E}$ of Brasília, $975 \mathrm{~m}, 15-\mathrm{IX}$ 1965, Irwin \& al. 8337 (CTES, P, UB); ca. $20 \mathrm{~km}$ $\mathrm{S}$ of Brasília on road to Goiania, near Rio Melchior, 1125 m, 25-IX-1965, Irwin \& al. 8645 (NY); Fazenda Agua Limpa, divisa com o Cristo Redentor (Jardim Botânico de Brasília) e o IBGE,

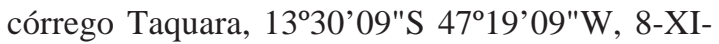
2000, Munhoz \& al. 2179 (CTES, IBGE); Reserva Ecologica do IBGE, perto do viveiro, 21-VII1994, Oliveira \& Fonseca 6 (IBGE); in the area of the Córrego Cabeça de Veado, ca. $9.5 \mathrm{~km} \mathrm{SSE}$ of Brasília TV tower, 3-VIII-1976, Ratter \& al. 3343 (E, UB, UEC); Mun. Samambaia, parque Boca da Mata na porcão norte, 30-IX-1995, Rezende 128 (CEN, CTES); mun. Brasília, Reserva Ecologica do Guará, $15^{\circ} 48 \mathrm{~S} 47^{\circ} 58 \mathrm{~W}, 1035 \mathrm{~m}, 26-\mathrm{VIII}-$ 1993, Silva 1734 (CEN, SP), ídem, campo de Murundum, 2-IX-1993, Silva 1777 (CEN, CTES, 
SP). Goiás: 7-20 km E de Pirenópolis, Serra dos Pirineus, ca. 1000 m, 7-II-1990, Arbo \& al. 3803 (CTES, HRCB, MBM); Pirenópolis, Rio Maranhão, 22-VII-1952, Macedo 3591 (S, US); Corumba- Pirineus, 17-XI-1956, Macedo 4311 (US). Minas Gerais: Hermillo Alves, Córrego Sujo, 26-XII-1949, Duarte 2319 (RB); Lima Duarte, Parque Estadual do Ibitipoca, Trilha para o Cruzeiro, 31-III-2004, Forzza \& al. 3344 (RB); Km 26, Estrada de Andradas para Pocos de Caldas, apos a Usina Nucleobras, 1300 m, 9-IX-1978, Freire de Carvalho 1054 (RB); Caldas, 27-VIII1854, Lindberg 359 en parte (C, S, sintipos); São João del Rey, 31-VIII-1892, Malme 22 (S); Poços de Caldas, VI-1896, Moraes 820 (SP); Caldas, 25IX-1875, Mosen 529 (CTES, S); Caete,-IX-1879, Motta s.n. (R); Sacramento, PARNA Serra da Canastra, proximo a guarita de Sacramento, 19VIII-1994, Nakajima \& al. 399 (CTES, HUFU); São Roque de Minas: proximo a sede administrativa, 19-XI-1995, Nakajima \& al. 1481 (CTES); Barbacena, Pohl 324 (W); Caldas, 17-VI-1938, Rombouts 2570 (SP); São Roque de Minas, PARNA Serra da Canastra, Cachoeira da Casca d'Anta, 20-IV-1994, Romero \& al. 940 (CTES, HUFU); estrada entre Piumhi e Araxa, $17 \mathrm{~km}$ de Piumhi, 850 m, 21-II-1978, Shepherd \& al. 7082 (SP, UEC); Tiradentes, XI-1896, Silveira 1879 (R); São Sebastião do Paraiso, Morro do Bau, 20VII-1993, Simão-Bianchini \& Bianchini 379 (SP); Conceição de Ibitipoca, entre 1100-1200 m, 16IX-1970, Sucre \& Braga 7104 (RB). Paraná: Vila Velha, 20-XI-1971, Occhioni s.n. (RFA 11370). São Paulo: near Ollaria [2049'S 51 ${ }^{\circ} 22^{\prime} \mathrm{W}$ ], VIII1827, Burchell 5342 (K); Serra de Cunha, 1200 m, 14-III-1939, Kuhlmann \& Gehrt s.n. (SP, R).

Distribución y fenología: Turnera hilaireana vive en campo, «cerrado», laderas y «campo rupestre» con suelos lateríticos, arcillosos o areno-pedregosos, también en terrenos periódicamente inundados, entre 600$1300 \mathrm{~m}$ de altitud, en el Distrito Federal, Goiás, Minas Gerais, São Paulo y Paraná. Florece y fructifica desde junio hasta abril.

Obs.: En el lectotipo, Regnell I 100, las estípulas están bien desarrolladas, son subuladas, de 0,7-2 mm long. La expresión de la heterostilia es variable, se observaron varias flores longistilas en las que las anteras alcanzan la base de los estigmas.

Especie afín a Turnera oblongifolia que se diferencia por su porte mayor, con entrenudos comparativamente más cortos y por las hojas coriáceas, con más venas laterales. Las flores marchitas de T. hilaireana presentan el tubo floral frecuentemente semitransparente en seco. En Lindberg 359 (S) hay una mezcla de las dos especies.

\section{Turnera huberi Arbo}

Figs. 21 y 36

Arbo, M. M., Ann. Missouri Bot. Gard. 77: 340-352, Fig. 2 F-K. 1990. Typus: Venezuela. Amazonas: Estación de Piscicultura de Puerto Ayacucho, entre la carretera hacia Samariapo y la pista de aterri-zaje de Puerto Ayacucho, aprox. $05^{\circ} 37^{\prime} \mathrm{N}$ 67³6'W, aprox. $75 \mathrm{~m}, 16-\mathrm{IV}-1977$, Huber 641 (holotypus VEN!).

Hierba o sufrútice $13-40 \mathrm{~cm}$ de alto, base leñosa, con xilopodio; tallos 1-varios, 0,8-1 mm diám.; ramas viejas con corteza rojiza o negruzca, longitudinalmente estriada, cicatrices foliares comúnmente salientes; ramas nuevas cilíndricas, con pelos simples crespos y otros más largos, antrorsos, muy densos hacia los ápices. Hojas herbáceas. Estípulas rudimentarias con 1-3 pares de coléteres $0,1-0,4$ mm long., cónicos, rojizos; yemas seriales 12. Pecíolo 1,5-3 mm long., semicilíndrico, indumento como el del tallo. Lámina foliar linear o angustielíptica, base cuneada o atenuada, 17-57x2-5 mm, relación largo:ancho $=8$ 23:1; ápice agudo; borde serrulado excepto en la base; haz punteada con algunos pelos simples especialmente sobre las venas y cerca del borde, o estrigosa, pelos de base abultada, vena principal prominente; envés con pelos simples y pelos glandulares microcapitados; 6-7(-11) pares de venas laterales prominentes; ángulo de divergencia muy agudo; venación menor inconspicua. Nectarios 2 en la unión de pecíolo y lámina o en la base de la lámina foliar sobre el envés, circulares o elípticos, 0,5-0,7 mm long., parte central glabra, con «poro», borde pubérulo o glabro. Hojas floríferas no bracteiformes. Flores epifilas, 


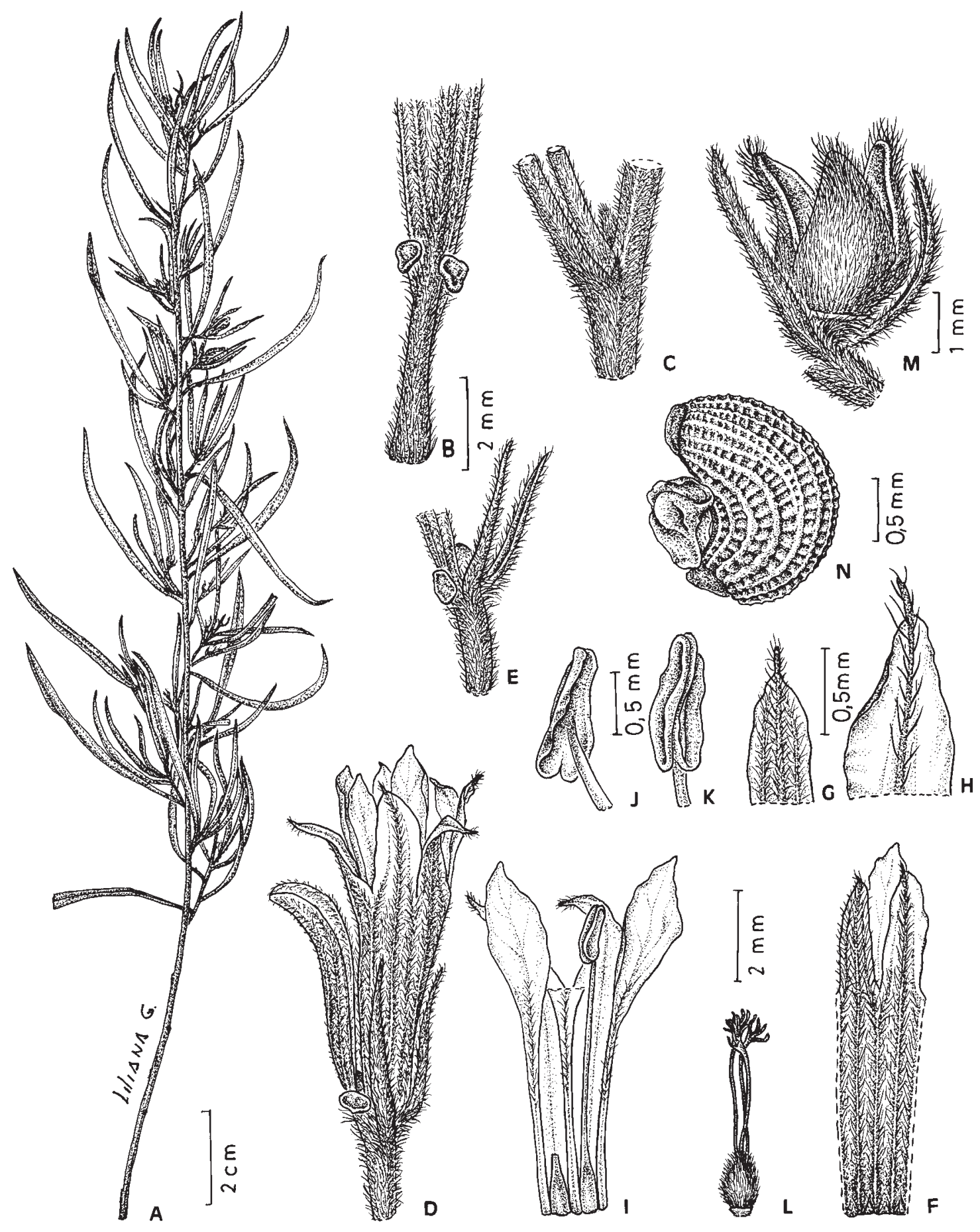

Fig. 36. Turnera huberi. A: planta. B: porción basal de hoja con nectarios, cara abaxial. C: nudo mostrando un pecíolo y estípula, una rama axilar y una yema serial. D: hoja florífera con flor epifila y profilos. E: base de hoja florífera con nectarios y profilos. F: porción del cáliz, cara externa. G-H: ápice de lóbulos externo e interno del cáliz, cara externa. I: flor brevistila, porción del tubo calicino, cara interna, con pétalos y estambres adnatos; se ha punteado la porción adherida del filamento estaminal. J-K: anteras, vistas dorsal y ventral. L: gineceo. M: fruto con profilos. N: semilla con arilo, vista lateral (Cid Ferreira 5602). Del. Liliana Gómez. 
heterostilas, solitarias o agrupadas hacia el extremo de las ramas. Pedúnculo floral 3-6 mm long., soldado al pecíolo, a veces la porción apical libre. Profilos 2, subulados, 2-6 mm long., 0,4-0,6 mm de ancho, borde entero o serrulado, pilosos en ambas caras. Pedicelo no desarrollado. Cáliz 7-10 mm long.; tubo calicino 3,5-5 mm long., 50-60\% de la long. del cáliz, cara interna con pelos blandos, cortos, por fuera con pelos cortos crespos; lóbulos triangulares o angustiovados, mucrón 0,5 mm long., cara interna glabra, cara externa con pelos simples crespos y pelos muy largos sobre las venas, bordes internos membranáceos. Corola amarilla; pétalos con la uña soldada al tubo calicino, lámina obovada angosta, 5-7x1,5-2,3 mm, generalmente con algunos pelos en la base y sobre la vena media. Filamentos estaminales glabros, soldados en la base $0,5-0,6 \mathrm{~mm}$ al tubo calicino, 5-9,7 mm long. en flores brevistilas, $4,5 \mathrm{~mm}$ long. en flores longistilas; anteras angustiovadas o elípticas, dorsifijas, 0,7-1,2 mm long. Ovario cónico 1-1,5 mm long., densamente piloso; placentas 3-4-ovuladas; estilos 3, cilíndricos, glabros, 3-5 $\mathrm{mm}$ long. en flores brevistilas, $5 \mathrm{~mm}$ long. en flores longistilas; estigmas 1,7-2 $\mathrm{mm}$ long., penicilados, ca. 12 ramas. En flores longistilas el gineceo es 1-2 mm más largo que el androceo, y en flores brevistilas es 0,7-2 mm más corto. Fruto 2-4 mm long., con un reborde anular basal de $0,3 \mathrm{~mm}$, dejado por el tubo floral al desprenderse; valvas ovadas, por fuera lisas, pilosas, castañas o amarillentas, por dentro lustrosas, jaspeadas. Semilla obovoide, 1,8-2,2 x 1-1,2 mm, ligeramente curvada; exóstoma cónico breve; cálaza pigmentada, ligeramente saliente, generalmente algo deprimida en el centro; rafe linear, lado rafeal casi recto, a veces incurvo. Episperma reticulado, pardo, aréolas cuadrangu-lares o rectangulares, nudos algo prominentes. Arilo unilateral casi tan largo como la semilla o ligeramente mayor, blanquecino en seco.

Material estudiado: VENEZUELA. Amazonas. Estación de Piscicultura de Puerto Ayacucho, entre la carretera hacia Samariapo y la pista de aterrizaje de Puerto Ayacucho, aprox. 05 $37^{\prime} \mathrm{N}$ 67³6'W, aprox. 75 m, 19-IV-1977, Huber 693
(VEN, paratipo); alrededores de Campo Florido, en carretera hacia El Sipapo, ca. 6 km después del cruce desde la carretera Puerto AyacuchoSamariapo, 22-III-1979, Trujillo \& Pulido 15152 (MY, paratipo; VEN); Puerto Ayacucho, $100 \mathrm{~m}$, 18-V-1940, Williams 12988 (US, paratipo) y Williams 12989 (VEN, paratipo). BRASIL. Amazonas. Mun. Novo Aripuanã, BR-230, 150 km L de Humaitá e $30 \mathrm{~km} \mathrm{~S}$ na Rod. do Estanho, 8²0'S 61ํํ' W, 16-IV-1985, Cid Ferreira 5602 (CTES, $\mathrm{RB}, \mathrm{UB})$.

Distribución y fenología: Especie amazónica, de Venezuela y NW de Brasil, crece en sabana y campo con suelo arenoso, en lugares sombreados. Se conocen unos pocos ejemplares colectados entre abril y mayo.

Obs.: En esta especie la expresión de la heterostilia es variable, en los ejemplares brevistilos especialmente; anteras y estigmas están parcialmente en contacto.

Taxón relacionado con Turnera argentea, que se diferencia por sus hojas seríceas, obtusas y de borde entero. También es afín a T. lanceolata Cambess. del centro de Brasil, que se diferencia por su tallo aristado, sus hojas con pecíolos cortos y venación conspicua en ambas caras.

Especie dedicada a Otto Huber quien coleccionó el ejemplar tipo y numerosos especímenes de Turneráceas.

\section{Turnera humilis Arbo, sp. nov.}

Figs. 37 y 38

Herba $5 \mathrm{~cm}$ alta, brevicaule, pilis simplicibus curvatis vel erectis.Folia rosulata, exstipulata, petiolata; lamina 2-4,5 mm, ovata vel elliptica, laxe pilosa, supra basin subtus nectaria gerentia.Prophylla lineares. Flores dimorphi, pedunculo fere ad prophylla vel toti adnato, calyce 6,5-8,3 mm longo, ca. 1/3 alto coalito, petalis flavis, filamentis glabris, base tubo tota facie adnatis, antheris 1,3 mm longis, dorso in 2/5 altis affixis, placenta 7-8-ovulata, stylo glabro. Fructus dorso laevi, prophyllum superatus. Semina vix curvata, reticulata, chalaza parum prominula, arillo unilaterali, angusto. 


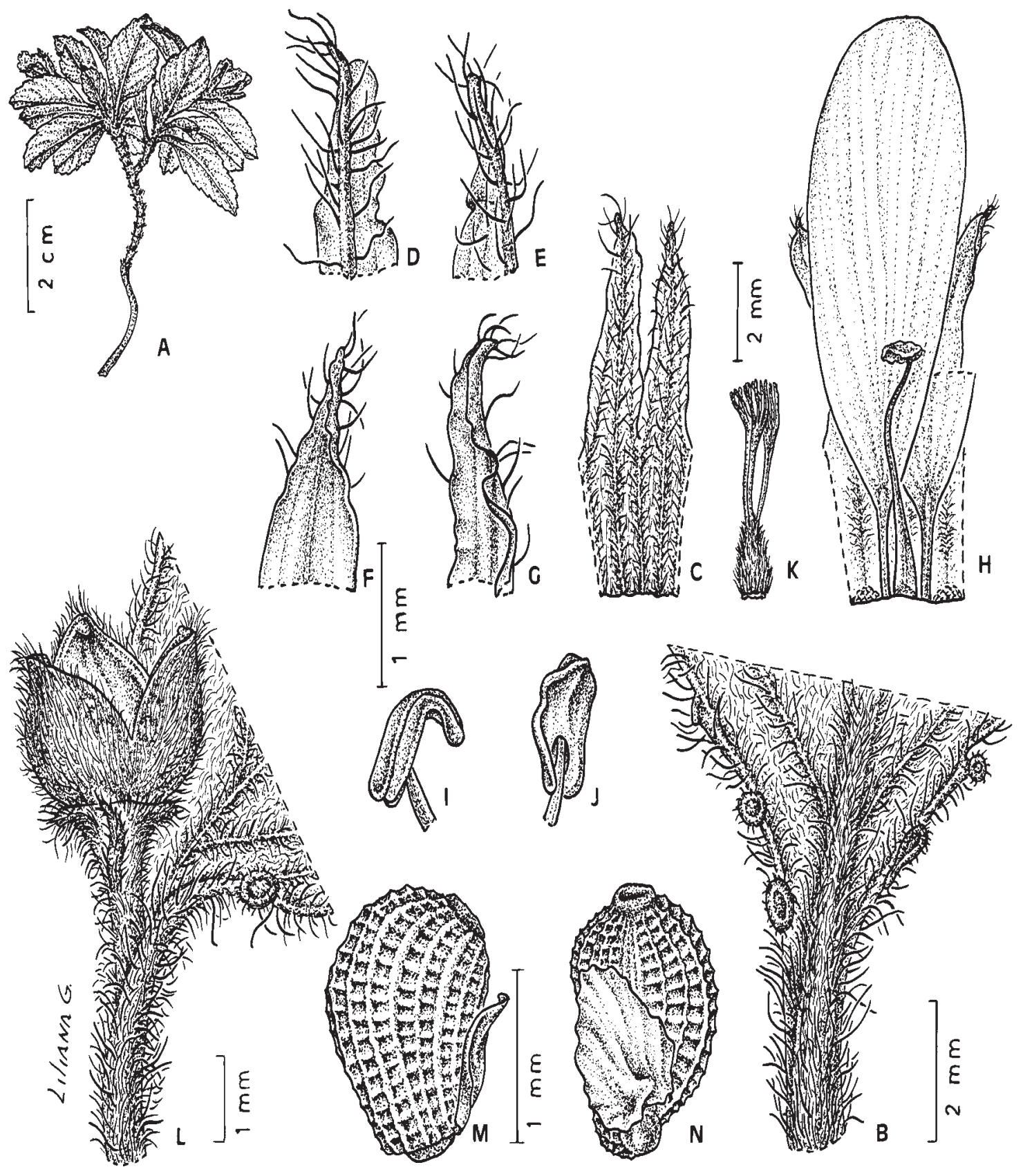

Fig. 37. Turnera humilis. A: planta. B: porción basal de hoja con nectarios, cara abaxial. C: porción del cáliz, cara externa. D y F: ápice de un lóbulo interno del cáliz, caras externa e interna. E y G: ápice de un lóbulo externo del cáliz, vistas lateral e interna. H: flor brevistila, porción del tubo calicino, cara interna, con pétalos y estambre adnatos; se han cuadriculado las cicatrices dejadas al desprender dos estambres. I-J: anteras, vistas lateral y dorsal. K: gineceo. J: porción basal de hoja florífera con nectario, fruto epifilo y profilo, nótese la porción apical del pedúnculo libre y el pedicelo. M-N: semilla con arilo, vistas lateral y rafeal (Guarino \& Pereira 9). Del. Liliana Gómez. 


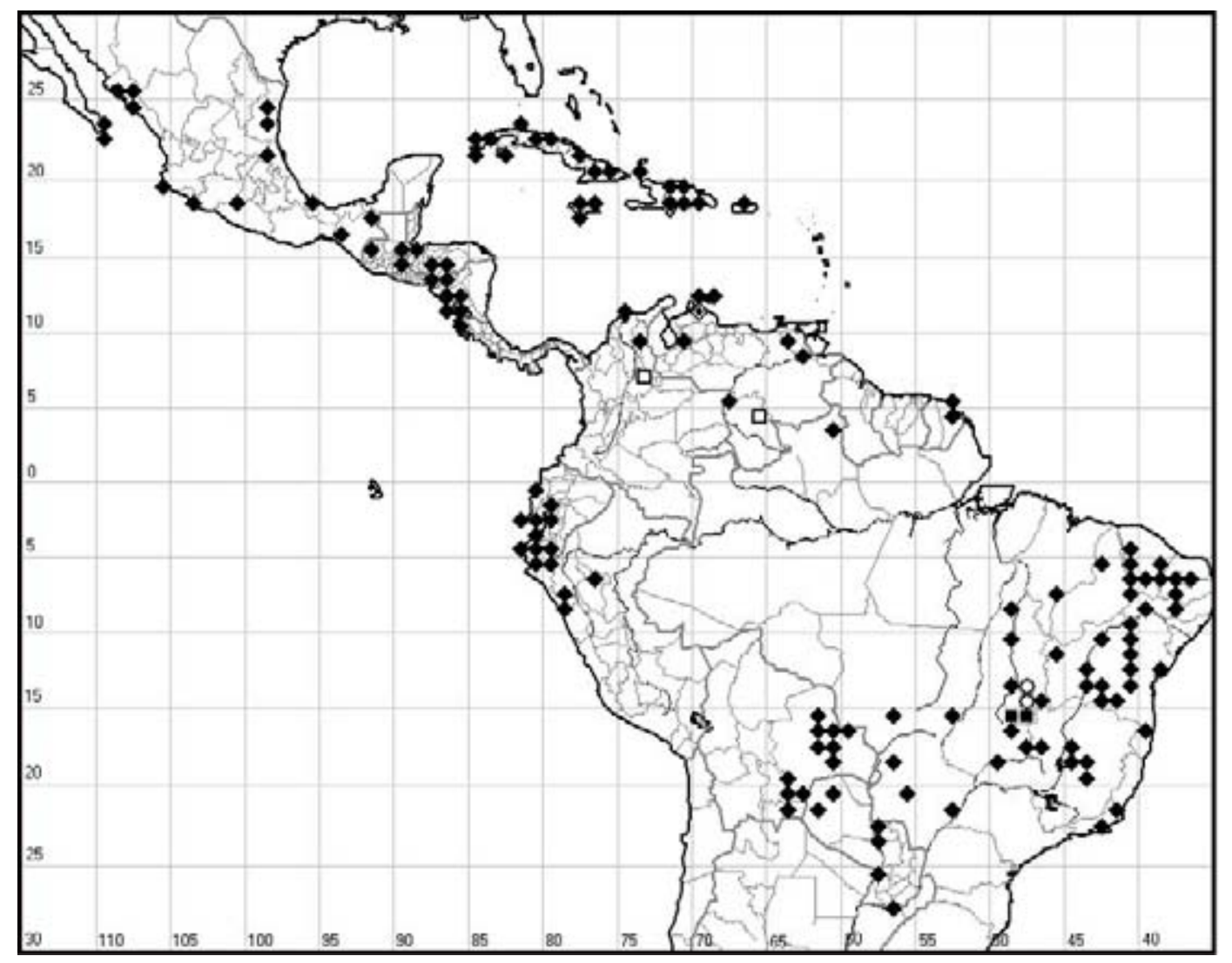

Fig. 38. Distribución de Turnera humilis $\boldsymbol{\Delta}$; T. pumilea var. pumilea $\diamond$; T. paruana $\square$; T. rosulata $\bigcirc$; T. venezuelana $\diamond$.

Typus. Brasil. Distrito Federal: mun. Brasília, lado direito da estrada que liga o Riacho Fundo ao restaurante da Fazenda Sucupira, 15 $52^{\circ} \mathrm{S} 48^{\circ} \mathrm{W}$, 1100 m, 8-XI-1999, Guarino E.S.G. \& Pereira J.B. 9 (holotypus CEN).

Hierba de $5 \mathrm{~cm}$ alt., tallo $1,5 \mathrm{~cm}$ long., simple o ramificado, apenas emergente, 1,5 mm diám., con pelos simples erectos o curvados 0,7-1,2 mm long., entrenudos cortísimos. Hojas dispuestas en roseta. Estípulas ausentes. Pecíolo 2-4,5 mm long., indumento como el del tallo; lámina extendida, ovada, elíptica, a veces obovada, 8-20 x 6-12 mm, relación largo:ancho $=1,3-$ 2,2:1; base anchamente cuneada o redondeada; margen plano, doblemente aserrado, con pelos crespos, cada diente con un coléter conspicuo rojizo o amarillento; ápice obtuso o agudo; epifilo arenáceo, piloso, pelos simples erguidos o crespos, ca. $1 \mathrm{~mm}$ long., glabrescente en hojas basales; envés arenáceo, pelos simples crespos más densos y pelos microcapitados, glabrescente en hojas basales; venas laterales 4-6 pares, opuestas o alternas, lineares en la haz, prominentes y pilosas en el envés; ángulo de divergencia $30-35^{\circ}$; venas terciarias y venación menor no visibles. Nectarios 2-4, 0,5-1 mm diám., dispuestos a 1-3 mm de la base, borde piloso. Flores epifilas, heterostilas. Pedúnculo totalmente soldado al pecíolo o con la porción apical libre hasta 0,6 mm. Profilos lineares, 1-1,5 x 0,2 mm, cara externa pilosa, cara interna glabra. Pedicelo ausente o hasta $1 \mathrm{~mm}$ long. Cáliz 6,5-8,3 mm long.; tubo calicino 2-2,5 mm long., con pelos simples cortos esparcidos por fuera, por dentro pelos simples laxos; lóbulos angustiovados con pelos simples largos y cortos entremezclados, más abundantes que 
en el tubo, los externos totalmente pilosos, los internos con márgenes membranáceos glabros; ápice terminado en mucrón 0,2-0,4 mm long. Corola amarilla; pétalos con uña pilosa 1,5 mm long., lámina obovada, $8,5 \mathrm{~mm}$ long. Filamentos estaminales subulados, glabros, adnatos $0,5 \mathrm{~mm}$ al tubo floral en la base, 4,5-4,7 mm long. en flores brevistilas; anteras 1,3 x 0,6 mm, anchamente ovadas, filamento inserto dorsalmente a $0,5 \mathrm{~mm}$ de la base emarginada, ápice obtuso. Ovario más o menos cónico, 0,8-1,3 mm long., hirsuto; placentas 7-8-ovuladas; estilos cilíndricos, glabros, 2-3 mm long. en flores brevistilas; estigmas penicilados 1,5-2 $\mathrm{mm}$ long., paucirramosos (ca. 8 ramas); gineceo $1 \mathrm{~mm}$ más corto que el androceo en flores brevistilas. Fruto ovoide, $2,5 \mathrm{~mm}$ long., con un reborde anular basal de $0,4 \mathrm{~mm}$, dejado por el tubo floral al desprenderse; profilos más cortos que el fruto; valvas latiovoides, ápice redondeado o en ángulo obtuso, cara externa densamente pilosa, cara interna glabra, lustrosa, jaspeada, vena placentaria prominente. Semilla casi recta, obovoide, $1,5 \times 1 \mathrm{~mm}$; exóstoma brevísimo, conoidal, asimétrico; rafe linear apenas visible, lado rafeal rectoconvexo; cálaza apical, ligeramente prominente, a veces algo deprimida en el centro. Episperma reticulado, aréolas cuadrangulares o transrectangulares; epidermis lisa, en la semilla inmadura con bastones de cera epicuticular. Arilo unilateral, angosto, $0,8 \mathrm{~mm}$ long., de células lisas.

Paratypus: BRASIL. Distrito Federal: Cristo Redentor, 2-VII-1990, Brochado \& Filgueiras 8 (CTES, IBGE).

Distribución: aparentemente endémica del Distrito Federal, se conocen sólo el tipo y el paratipo, colectados en campo con suelo arcilloso y en «campo rupestre» respectivamente.

Obs.: Especie afín a Turnera rosulata, que se diferencia por sus flores de color lila, sus nectarios extraflorales diminutos o ausentes y sus placentas 3-ovuladas; también es parecida a $T$. acaulis, endémica de Cuba, con flores homostilas de mayor tamaño.

\section{Turnera incana Cambess.}

Figs. 29 y 39

Saint Hilaire, A., Jussieu, A. \& Cambessèdes, J., Fl. bras. merid. 2: 158. 1830; Urban, Jahrb. Königl. Bot. Gart. Berlin 2: 120. 1883; Urban, en Martius, Fl. Bras. 13 (3): 140, tab. 42, 1883. Typus: Brasil. Goiás: au pied de la Serra Dorada, «sous arbris à tige droit 1-11/2 pieds, rameux des la base», Saint Hilaire C1 771 (lectotypus aquí designado $\mathrm{P}$ !).

Arbusto 30-90 cm alt., ramificado, tallos desnudos en la parte basal, corteza pardonegruzca, longitudinalmente estriada, cicatrices foliares salientes; ramas del año estriadas, lanoso-tomentosas al menos hacia el ápice, con pelos simples blandos y pelos crespos densísimos, grisáceos o amarillentos. Yemas axilares 2-4, la basal florífera, ramas seriales desarrolladas, a veces 2-3 en cada axila. Hojas cartáceas, discoloras. Estípulas filiformes, oscuras, 1-3 mm long., soldadas al pecíolo en la base, o insertas a ambos lados de la base foliar. Pecíolo semicilíndrico, acanalado en la cara superior, 4-8 mm long., indumento como el tallo. Lámina elíptica, ovada o angustiovada, (10-)16-100 × 6-35 mm, relación largo:ancho1,5-6:1; base cuneada, redondeada o brevemente atenuada; ápice agudo u obtuso; borde ligeramente revoluto, doblemente aserrado-crenado, dientes obtusos, terminados en coléteres; haz oscura en seco, rugosa, con pelos simples largos o cortos, curvado-antrorsos, orientados diagonalmente hacia fuera, a veces entremezclados con pelos crespos que pueden ser muy densos; envés blanquecino, amarillento o grisáceo, lanosotomentoso; vena media y 9-13 pares de venas laterales alternas o subopuestas, rectas, indumento muy denso, ligeramente prominentes o hundidas en la haz, prominentes en el envés, perdiéndose hacia los bordes, con ramas hacia los dientes; ángulo de divergencia $35-40^{\circ}$; venas terciarias a veces visibles en el envés, venación menor inconspicua. Nectarios 2-4 en la unión de pecíolo y lámina, circulares o elípticos, negruzcos, borde piloso, 0,4-1,2 $\mathrm{mm}$ long., a veces brevemente estipitados. Hojas floríferas apicales o de las ramas seriales 


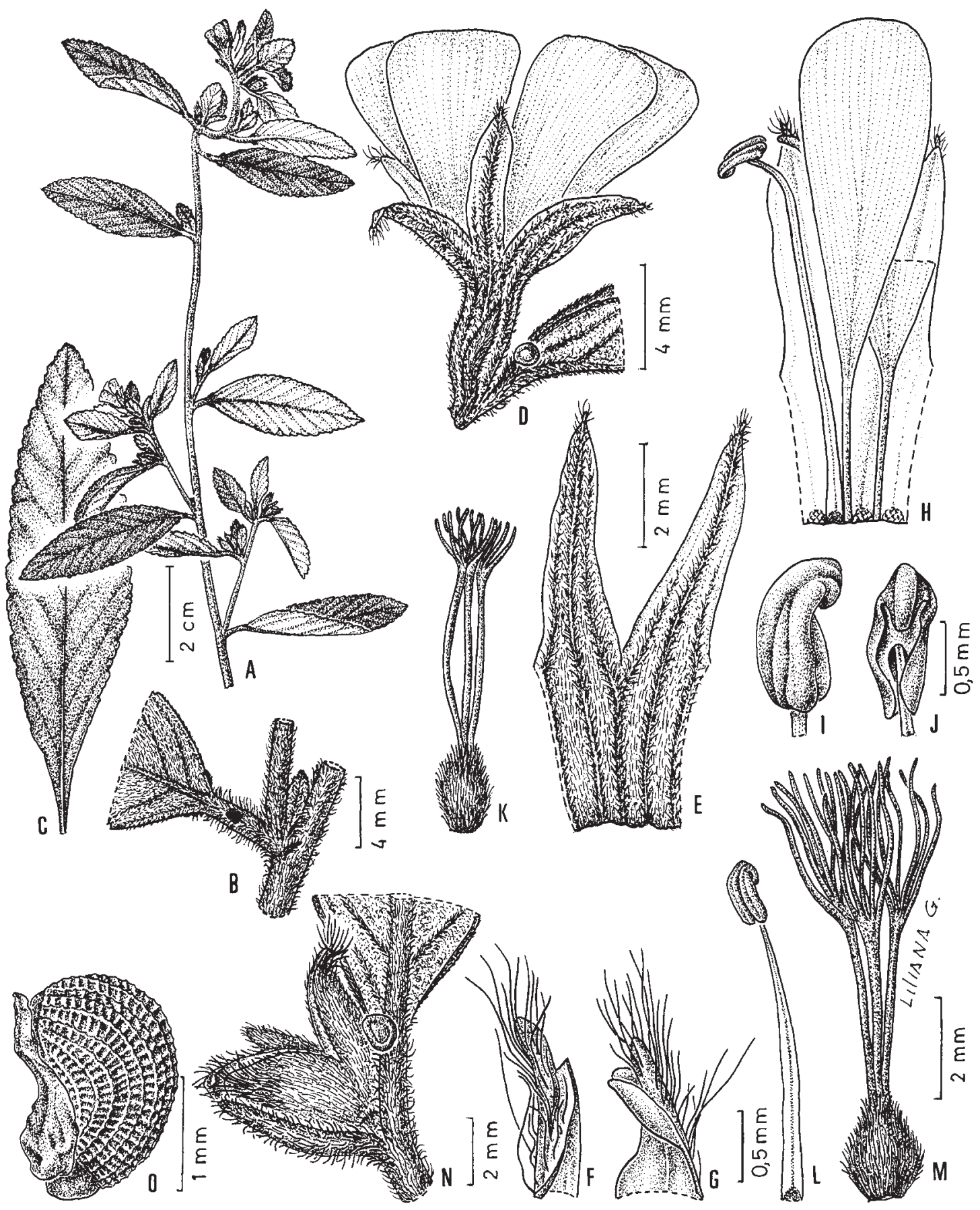

Fig. 39. Turnera incana. A: rama florífera. B: nudo con estípula, porción basal de una hoja mostrando la cicatriz floral, rama axilar, yema serial. C: hoja, cara adaxial. D: porción basal de hoja florífera con nectario, flor epifila y profilo. E: porción del cáliz, cara externa. F-G: ápice de lóbulos del cáliz externo e interno, vistas lateral y laterointerna. H: flor brevistila, tubo calicino, cara interna, con pétalos y estambre adnatos; se han cuadriculado las cicatrices dejadas al desprender tres estambres. I-J: anteras, vistas lateral y dorsal. K: gineceo. L-M: flor longistila, estambre y gineceo. N: porción basal de hoja florífera con nectario, fruto epifilo y profilos. O: semilla con arilo, vista lateral (A-B, E-K: Thomas \& al. 5772; C: Menezes 629; D, L-O: Assis \& al. 382). Del. Liliana Gómez. 
floríferas, a veces reducidas, bracteiformes, 48 x 3-4 mm. Flores epifilas, heterostilas, a veces agrupadas en racimos bracteosos capituliformes. Pedúnculo 1,5-4 mm long., totalmente adnato al pecíolo. Profilos subulados, 4-6,5 x 0,7-1,2 mm long., oscuros, lanoso-tomentosos. Pedicelo nulo. Cáliz 9-11 mm long.; tubo calicino 3,5-4,5 $\mathrm{mm}$ long., cara externa lanoso-tomentosa, cara interna con algunos pelos blandos; lóbulos triangulares, cara interna glabra, mucrón 0,3 mm long. Corola rosada, salmón, blanca, con centro amarillo o purpúreo, rosado-purpúrea cuando marchita, ca. 1-2 mm más larga que el cáliz; pétalos con uña glabra o con algunos pelos blandos, lámina obovada, 6-8 x 2-3,5 mm, a veces con algunos pelos largos en la base. Filamentos estaminales complanadosubulados en seco, 4-5,5 mm long. en flores longistilas, 5,5-8 $\mathrm{mm}$ long. en flores brevistilas, glabros; anteras angustiovadas, 0,7-1,2 x 0,4-0,5 mm, base emarginada, ápice agudo recurvado a la dehiscencia, filamento inserto dorsalmente a 0,3-0,4 $\mathrm{mm}$ de la base. Ovario ovoide, 1-1,5 mm long., lanoso-hirsuto; placentas 3-6-ovuladas; estilos cilíndricos, glabros, 4-5 mm long. en flores longistilas, 3$3,5 \mathrm{~mm}$ long. en flores brevistilas; estigma penicilado, aprox. 12 ramas ca. 1-2 mm long. En flores longistilas, gineceo 1,5-2 mm mayor que el androceo. En flores brevistilas, androceo 1,2-2,5 $\mathrm{mm}$ mayor que el gineceo. Fruto ovoide, 2,5-5 mm long., con un reborde anular de 0,3-0,5 $\mathrm{mm}$ dejado por el tubo floral al desprenderse; cara externa lisa, villosa, cara interna glabra, lustrosa, castaña, jaspeada, vena placentaria saliente. Semilla obovoide, curvada, 1,9-2,2 x 0,9-1,2 mm; exóstoma hemisférico o cónico, $0,3 \mathrm{~mm}$ long.; rafe linear ligeramente saliente, lado rafeal incurvo; cálaza redondeada, con una protuberancia oscura formada por la prolongación de la rafe. Episperma reticulado, nudos del retículo no elevados, ca. 16-20 filas longitudinales de aréolas transrectangulares, cuadrangulares o triangulares; epidermis papilosa. Arilo unilateral, angosto, más corto o tan largo como la semilla, de células papilosas.

Material estudiado: BRASIL. Sin localidad, Pohl s.n. (M), Pohl 989 (PR), Saint Hilaire s.n.
(F). Goiás: Serra Dourada, ca.15 km (straight line) S of Goias Velho, 1000 m, 10-V-1973, Anderson 10026 (NY, P, R, UB); Chapada dos Veadeiros, 21 $\mathrm{km}$ W de Alto Paraiso de Goias, camino a Niquelandia, ca. 1200 m, 4-II-1990, Arbo \& al. 3644 (C, CTES, F, G, GH, HRCB, K, M, MBM, $\mathrm{MICH}, \mathrm{MO}, \mathrm{NY}$ ); Chapada dos Veadeiros, $40 \mathrm{~km}$ W de Alto Paraiso de Goias, camino a Niquelandia, ca. 1000 m, 4-II-1990, Arbo \& al. 3658 (C, CTES, HRCB, K, WIS); alrededores de Colinas, sobre el camino a Cavalcante, 600-700 m, 5-II-1990, Arbo \& al. 3686 (C, CTES, F, GH, HRCB, K, LIL, MBM, MICH, MO, NY); 7-20 km E de Pirenopolis, Serra dos Pirineus, ca. 1000 m, 7-II-1990, Arbo \& al. 3806 (C, CTES, F, GH, HRCB, K, MBM, MICH, MO, NY); Mun. Minaçú, estrada Minaçú-Usina da Serra da Mesa, ca. $2 \mathrm{~km}$ para baixo da guarita, 28-I-1997, Assis \& al. 382 (CEN, CTES, SPF); near Goyaz, Burchell 7030 (K); Mun. Alto Paraiso de Goias, estrada Alto Paraiso-Teresina de Goias, a $37 \mathrm{~km}$ de Alto Paraiso, 13⒌'S 4723' W, 1480 m, 4-IV-1997, Cavalcanti \& al. 2207 (CEN CTES); Cabeceira du Rio Sta. Anna, 8-I-1895, Glaziou 21456 (BR, C, K, LY, P, R); Serra do Cabeludo, 20-IX-1894, Glaziou 21457 (BR, C, F, K, NY, P, RB, SP); Mun. Pirenopolis, Serra dos Pireneus, rodovia Pirenopolis-Cocalzinho de Goias, 13-II-2000, Hatschbach \& al. 70133 (C, CTES, MBM); Mun. Colinas do Sul, Rodovia Colinas do Sul a Niquelândia, entre Km 10-15, 500-600 m, 18-II2000, Hatschbach \& al. 70348 (CTES, MBM, W); su mmit of Serra Dourada, $14^{\circ} \mathrm{S}, 50^{\circ} \mathrm{W}, 20 \mathrm{~km} \mathrm{SE}$ of Goiás Velho, 800 m, 18-I-1966, Irwin \& al. 11714 (CTES, P, UB); Serra dos Pirineus, 20 km $\mathrm{N}$ of Corumbá de Goiás on road to Niquelândia, in valley of Rio Corumbá, ca. 1150 m, 18-I-1968, Irwin \& al. 18769 (HB, K, NY, P, UB, US); Serra dos Pireneus, Pico de Pireneus, ca. $20 \mathrm{~km} \mathrm{E} \mathrm{of}$ Pirenopolis, 1000 m, 14-I-1972, Irwin \& al. 34100 (MO, NY, P, UB, UEC); Encima de Serra Dourada, ca. $6 \mathrm{~km}$ NE de Mossâmedes, 1604'S, 50¹1'W, 7-II-1980, Kirkbride 3304 (UB); Corumbá, 17-II-1956, Macedo 4345 (K, RB, US); Colinas do Sul, Estrada Colinas/Alto Paraiso (15 km de Colinas do Sul), 21-X-1996, Marquete \& al. 2722 (RB); mun. Mossamedes, Serra Dourada, prox. ao portão Reserva Ecologica de Serra Dourada, 1604'45"S 50¹1'21"W, 001 m,29-XI2003, Mello-Silva \& al. 2217 (CTES, RB); Estr. Pirenópolis-Pirineus, 11-I-1981, Menezes CFCR 
629 (CTES, MBM, SPF); Serra Dourada, pr. Estrada para Goiás Velho, 600 m, 29-I-1966, Pabst \& al. 8837 (CTES, HB, UEC); Parque Nacional da Chapada dos Veadeiros, ca. $1 \mathrm{~km}$ da sede do Parque Nacional da Chapada dos Veadeiros, 7II-1987, Pirani \& al. 1741 (CTES, K, SPF); inter Montes Claros \& Rio S. Bartholomeo [seg. Urban], Pohl 1630 (K, P, W); dans la Serra dos Pyreneos, Saint Hilaire C1 $714\left(\mathrm{P}\right.$, foto $\mathrm{F} \mathrm{n}^{\circ}$ 38460 , sintipo); Chapada dos Veadeiros, $16 \mathrm{~km}$ de Alto Paraiso/Teresina de Goias, $14^{\circ} 00^{\prime} \mathrm{S} 47^{\circ} 31^{\prime} \mathrm{W}$, 29-VII-1994, Silva \& al. 2139 (CTES, RB); Serra dos Pirenéus, estrada de terra CocalzinhoPirenópolis, dentro do Santuário «Morro Cabeludo», 1549'S 48 53'W, 680-700 m, 16-II1995, Splett 713 (UB); Goiás Velho, Serra Dourada, reserva da UFG, $16^{\circ} 10^{\prime} \mathrm{S} 50^{\circ} 0^{\prime} \mathrm{W}, 29-\mathrm{X}$ 1993, Splett \& al. 156 (UB); mun. Goiás, Serra Dourada, 1,3 km NW of junctions with road to Mossamedes on GO-070 from Goiania to Goias, ca. 750-800 m, $15^{\circ} 57^{\prime} \mathrm{S} 50^{\circ} 02^{\prime} \mathrm{W}, 9-\mathrm{II}-1988$, Thomas \& al. 5772 (CTES, NY, SPF); subarbusto, Serra dos Pyreneos, XII-1892, Ule 486 (HBG, P, $\mathrm{R})$; mun. Minaçú, em frente ao antigo viveiro da Uhe Serra da Mesa, ca. $5 \mathrm{~km}$ da entrada $\mathrm{N}$ do canteiro de obras, $13^{\circ} 48^{\prime} \mathrm{S} 48^{\circ} 17^{\prime} \mathrm{W}, 500 \mathrm{~m}$, 9XII-1991, Walter \& al. 903 (CEN); sin localidad, IV-1844, Weddell 2617 (P); Region of the southern Serra Dourada at $13^{\circ} 45^{\prime} \mathrm{S} 48^{\circ} 50^{\prime} \mathrm{W}, 17$ km E of Formoso, 19-V-1956, Dawson 14980 (US). Mato Grosso do Sul: mun. São Gabriel do Oeste, estrada não pavimentada de São Gabriel a Rio Negro, 19²0'S 5448’ W, 450 m, 1-III-1994, Pott \& Pott 6776 (CTES). Tocantins: Between Cavalcante \& Conceição, Burchell 8040 (K); Campos Arrayas, III-1840, Gardner 3752 (BM, FI, K, OXF, W); mun. Arraias, Rod. TO-050, Km 415, $6 \mathrm{~km} \mathrm{O}$ de Arraias, $520 \mathrm{~m}, 10-\mathrm{V}-2000$, Hatschbach \& al. 70861 (C, CTES, MBM).

Distribución y fenología: Especie propia de Goiás, Tocantins y Mato Grosso do Sul. Vive en «cerrado» sobre laderas de colinas y en «campo rupestre» con rocas de cuarzo, suelo arenoso o pedregoso, entre 450 y $1700 \mathrm{~m}$ de altitud. Todos los ejemplares conocidos en flor o fruto fueron colectados entre septiembre y mayo, excepto uno en julio.

Obs.: El color de los ejemplares secos varía, el epifilo puede ser pardo-oscuro o ne- gruzco, y el envés puede tener indumento blanquecino, grisáceo o dorado. En Silva \& al. 2139 el epifilo seco es grisáceo. El espécimen Walter \& al. 903 tiene hojas con haz marrón, envés blanco, la flor seca es de color lila. El ejemplar Pott \& Pott 6776 presenta indumento seríceo-lanoso, y estípulas rudimentarias.

Spencer \& al. (1985) encontraron compuestos cianogénicos en el análisis de las hojas de Anderson 10026 (ILL) y Irwin \& al. 18769 (F).

\section{Turnera iterata Arbo, sp. nov.}

Figs. 27 y 40

Fruticulus $40 \mathrm{~cm}$ altus, cicatricibus foliorum prominentis, pilis simplicibus adpresis; stipulae rudimentariae, folia linearia vel angusti-elliptica, revoluta, subtus ad basin nectariis ornatis. Flores dimorphi, apice caulium conferti, pedunculi supra medium vel toti adnati, calyx 8,5-12,5 mm longus, in 1/3 vel 2/5 alt. coalitus, petala flava, filamenta glabra, basi tubo tota facie adnata, antherae $1 \mathrm{~mm}$ long., ovarium dense pilosum, styli pilosi.

Typus. Brasil, Distrito Federal: Brasília, Fazenda Sucupira, lado direito, antes da $1^{\mathrm{a}}$. Ponte na estrada principal da fazenda, $15^{\circ} 55^{\prime} 00^{\prime \prime} \mathrm{S}$ 4801'00"W, 1070 m, 9-VI-1999, Faria J.G., Walter B.M.T., Pereira J.B. \& Santos A.A. 171 (holotypus CEN, isotypus CTES).

Subarbusto ca. $40 \mathrm{~cm}$ alt., con rizoma grueso, horizontal o vertical, 7-12 mm diám.; base leñosa 1-3,5 cm diám.; varios tallos cilíndricos, 1-2 mm diám., cicatrices foliares salientes en los tallos quemados; indumento estrigoso, pelos simples adpresos 0,7-1 mm long.; entrenudos basales largos, hasta $6 \mathrm{~cm}$ long. Catáfilos oblongos, pilosos, 0,6-2 x 0,2$0,4(-0,9) \mathrm{mm}$ en los nudos basales. Hojas todas floríferas, las inferiores bracteiformes, oblongas, obovadas o angustiovadas, 1,2-4 x 0,5-0,8 $\mathrm{mm}$, aumentando de tamaño rápidamente en los nudos sucesivos. Estípulas rudimentarias, con coléteres oscuros $0,1 \mathrm{~mm}$ long. Pecíolo semicilíndrico, 1,5-3,5 mm long., indumento como el del tallo. Lámina linear, angustielíptica o angustiobovada, 8-23 x 0,8- 


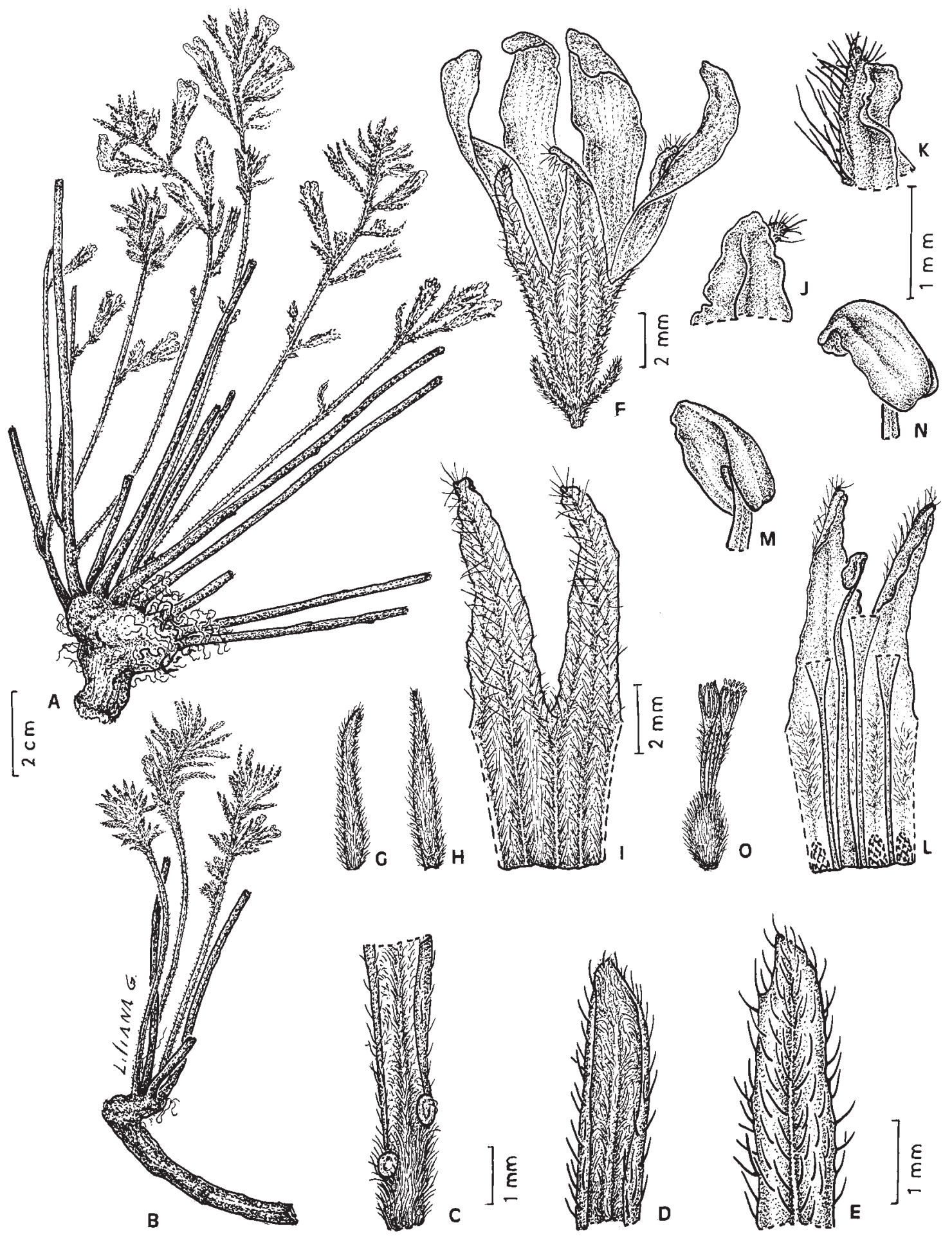

Fig. 40. Turnera iterata. A-B: plantas. C: porción basal de hoja con nectarios, cara abaxial. D-E: hoja, ápice, caras abaxial y adaxial. F: flor con profilos. G-H: profilos. I: porción del cáliz, cara externa. J-K: ápice de dos lóbulos del cáliz. L: flor brevistila, porción del tubo calicino, cara interna, con pétalos y estambre adnatos; se han cuadriculado las cicatrices dejadas al desprender tres estambres. M-N: anteras, vistas dorsal y lateral. O: gineceo. (A-B: Walter \& al. 3869; C-O: Faria \& al. 171). Del. Liliana Gómez. 
$1,8(-2,5) \mathrm{mm}$, relación largo:ancho $=7-15: 1$; ápice agudo u obtuso; margen marcadamente revoluto, serrulado, 3-4 dientes a cada lado terminados en coléteres; haz oscura en seco, superficie irregular por las bases abultadas de los pelos simples, antrorsos, 0,5 mm long., mezclados con pelos más cortos; envés con pelos crespos blanquecinos muy densos, y pelos glandulares microcapitados; vena media prominente en el envés, con pelos antrorsos largos muy densos, 2-3 pares de venas laterales a veces visibles; venación menor inconspicua. Nectarios $0-2$, circulares, rojizos, 0,5-0,8 mm diám., borde piloso, situados en la unión de pecíolo y lámina o desplazados ca. $1 \mathrm{~mm}$ sobre el margen foliar. Flores epifilas, heterostilas, agrupadas en el ápice en racimos hojosos 4-8 cm long. Pedúnculo 2,5-6 $\mathrm{mm}$ long., totalmente soldado al pecíolo e incluso a la base de la lámina, o la porción apical libre de 1-3,5 mm long., indumento como el del tallo. Profilos lineares, opuestos en la base del receptáculo, 2,2-3,5 x 0,2-0,3 $\mathrm{mm}$, pilosos. Pedicelo ausente. Cáliz 8,5-12,5 mm long.; tubo calicino $(1 / 3$ o $<1 / 2) 3-4 \mathrm{~mm}$ long., cara externa con pelos simples crespos y pelos antrorsos sobre las venas, cara interna glabra o vellosa; lóbulos triangulares o angustiovados, 3-nervados, por fuera con pelos más largos, 0,8 mm long., márgenes internos membranáceos, ápice agudo. Corola amarilla, 4-8 mm más larga que el cáliz; pétalos con lámina obovada, glabra, $12-15 \mathrm{~mm}$ long. Filamentos estaminales complanado-subulados, glabros, soldados brevemente en la base al tubo floral, 4-5 $\mathrm{mm}$ long. en flores longistilas, $8 \mathrm{~mm}$ long. en flores brevistilas; anteras $1 \times 0,5 \mathrm{~mm}$, base emarginada, filamento inserto dorsalmente a $0,5 \mathrm{~mm}$ de la base, ápice recurvado a la dehiscencia. Ovario densamente piloso, 1,2 mm long.; estilos 4,4-5 $\mathrm{mm}$ long. en flores longistilas, $3 \mathrm{~mm}$ long. en flores brevistilas, divididos en varias ramas pilosas en la porción apical; estigma penicilado, multirramoso, 1,5 $\mathrm{mm}$ long. Gineceo 2,5-3 mm más largo que el androceo en flores longistilas, 3-3,5 mm más corto que el androceo en flores brevistilas. Fruto y semilla desconocidos.

Paratypus: BRASIL. Distrito Federal: mun.
Brasília (Riacho Fundo), Fazenda Sucupira (EMBRAPA/CENARGEN), região entre Recanto das Emas e Riacho Fundo, 1554'09"S 4800'58"W, 1080 m, 19-IX-1997, Walter, Pereira \& Stancioli 3869 (CTES, SPF).

Distribución y fenología: Especie hemicriptófita propia del Distrito Federal, crece en «cerrado» y campo, en suelo arenoarcilloso con afloramientos rocosos. Los ejemplares conocidos fueron colectados entre junio y septiembre.

Obs.: Todos los ejemplares estudiados son rebrotes producidos después de la quema de la vegetación; la floración es precoz, ya que se observan flores abiertas en ejes de apenas 5 $\mathrm{cm}$ alt. El ejemplar Faria \& al. 171 muestra ejes quemados de $40 \mathrm{~cm}$ alt. Es necesario confirmar la altura de las plantas crecidas, corroborar si muestran hojas iguales a los rebrotes, y estudiar los frutos y semillas.

\section{Turnera jobertii Arbo, sp. nov.}

Figs. 23 y 41

Fruticulus $40 \mathrm{~cm}$ altus, rami densissime flavido-strigosi, stipulae rudimentariae; folia petiolata, elliptica vel ovata, subduplicato serrata, supra laxe pilosa, subtus pilis brevis densis et aliis curvato-erectis intermixtis, folia florifera supra basin subtus nectariis parvis gerentibus. Flores dimorphi, apice caulium conferti, calyx 7,8-8,5 mm long., ca. 1/2 alt. coalitus, petalis calycem paullo superantibus flavis; filamenta glabra, basi tubo tota facie adnata, placentae 6-7-ovulatae. Fructus dorso laeve. Semina nigra, obovata, reticulata, chalaza prominula, arillo unilaterali, angusto.

Typus: BRASIL. Piauí: S.Pedro de Alcântara, 1878, Jobert C. 979 (holotypus P, isotypus R, Jobert-Schwacke 979, flores incompletas, comidas por insectos).

Subarbusto ca. $40 \mathrm{~cm}$ alt., tallos erectos 2-3 mm diám., densamente estrigosos, con pelos amarillos, gruesos, curvado-antrorsos, 0,6-0,7 


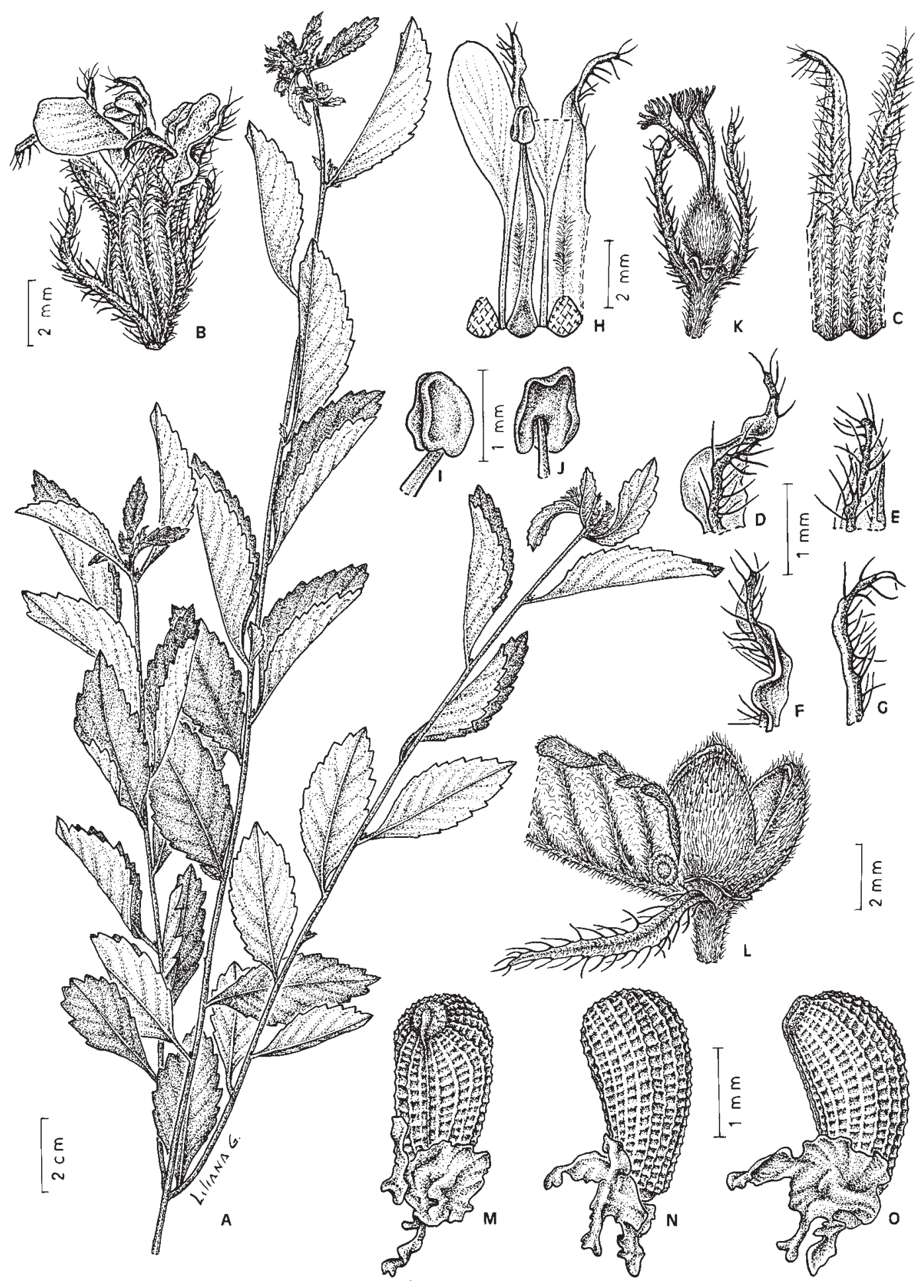

Fig. 41. Turnera jobertii. A: planta. B: flor con profilos. C: porción del cáliz, cara externa. D-E: ápice de lóbulos del cáliz, cara externa. F-G: ápice de lóbulos del cáliz, vista lateral. H: flor brevistila, porción del tubo calicino, cara interna, con pétalos y estambre adnatos; se han cuadriculado las cicatrices dejadas al desprender dos estambres. I-J: anteras, vistas ventral y dorsal. K: profilos, receptáculo y gineceo. L: bráctea con nectario, fruto epifilo y profilo. MO: semilla con arilo, vistas rafeal, dorsal y lateral (Glaziou 9646a). Del. Liliana Gómez. 
mm long., mezclados con pelos simples crespos más cortos y delgados; cicatrices foliares salientes. Hojas discoloras. Estípulas rudimentarias, con 3-4 coléteres negruzcos, cónicos, 0,2-0,3 mm long. Pecíolo 1-4 mm long., indumento como el del tallo. Lámina elíptica u ovada (en hojas basales obovada), 3-6,5 x 1,6-3,2 cm, relación largo:ancho $=1,8-2,4: 1$; base cuneada o brevemente atenuada; ápice agudo, en hojas basales obtuso; margen plano o ligeramente revoluto, doblemente aserrado excepto en la porción basal; haz oscura, con pelos simples curvado-antrorsos de base abultada, 0,3-0,7 mm long., laxamente dispuestos, venas ligeramente hundidas y carinadas; envés maculado, con pelos simples largos y cortos más densos y pelos microcapitados amarillentos entremezclados; 6-7 pares de venas secundarias prominentes, incurvas, anastomosadas antes del margen con la inmediata superior y dando ramas hacia los dientes y las escotaduras; ángulo de divergencia 40-48º venas terciarias más o menos perpendiculares a la vena media. Nectarios ausentes en hojas vegetativas. Hojas floríferas bracteiformes, ovadas o angustiovadas, de tamaño bruscamente decreciente, hasta $4,5 \times 1,5-2 \mathrm{~mm}$, con un par de nectarios asentados sobre el envés, pardos o negruzcos, 0,4-0,7 mm long., de borde piloso. Flores epifilas, dimorfas (sólo se estudiaron las flores brevistilas), reunidas en los ápices de las ramas en racimos bracteosos. Pedúnculo 1-2 mm, totalmente adnato al pecíolo. Profilos lineares o subulados, 3,5-5,3 x 0,3-0,5 mm, enteros, insertos en la base del receptáculo. Pedicelo ausente. Cáliz 7,8-8,5m long.; tubo calicino 3,8-4,5 mm, interiormente piloso en la porción apical, por fuera con pelos simples cortos y pelos simples más largos (0,4 mm long.) sobre las venas; lóbulos angustiovados o triangulares, con pelos más largos que el tubo (0,7 mm long.), 3-5 nervados, nervio medio prolongado en mucrón 0,5-1 mm long. Corola amarilla, apenas más larga que el cáliz; pétalos con uña pilosa en la mitad superior, lámina obovada, ca. $5 \mathrm{~mm}$ long., base subcuneada, con algunos pelos. Filamentos estaminales soldados en la base $0,4-0,5 \mathrm{~mm}$ al tubo calicino, con un nectario en la cara externa justo al separarse del tubo floral, los bordes del filamento reflexos en seco a la altura del nectario, glabros, subulados, $6,5 \mathrm{~mm}$ long. en flores brevistilas; anteras ovadas u ovado-oblongas, $0,8 \times 0,4 \mathrm{~mm}$, base emarginada, filamento inserto dorsalmente a $0,4 \mathrm{~mm}$ de la base, ápice obtuso. Ovario ovoide o cónico, densamente estrigoso, 1,2 $\mathrm{mm}$ long.; placentas 6-7-ovuladas; estilos cilíndricos, pilosos, 2,8-3,5 $\mathrm{mm}$ long. en flores brevistilas, tercio superior partido en 2-4 ramas, con pelos cortos; estigmas paucirramosos, $1 \mathrm{~mm}$ long. En flores brevistilas el androceo es tan largo como el cáliz, y 1,2 mm más largo que el gineceo. Fruto ovoide, 4-7 mm long., más largo que los profilos, con reborde anular basal de $0,5 \mathrm{~mm}$ dejado por el tubo floral al desprenderse; valvas maculadas por fuera, de superficie irregular por la base cónica de los pelos simples, adpresos, entremezclados con pelos simples más cortos y crespos; por dentro glabras, nítidas, parduzcas, con máculas amarillentas. Semilla negra, 2,1-2,6 x 1-1,1 mm, angusti-obovoide, curvada; exóstoma cónico; rafe linear algo prominente, lado rafeal incurvo a casi recto; cálaza de orientación apical, con una protuberancia que es continuación de la rafe, pigmentada en la semilla inmadura, a veces ligeramente deprimida en el centro. Episperma reticulado, nudos no prominentes, aréolas sin depresión punctiforme; epidermis lustrosa, papilosa en las aréolas. Arilo igual o más corto que la semilla, unilateral, lacerado o lobulado, amarillento en seco, de células papilosas.

Paratypi: Brasil. Rio de Janeiro: São João da Barra, prés Itabapoana (localidad dudosa), III, Glaziou 9646 (C, probablemente duplicado de Jobert-Schwacke 979); sin localidad, sin fecha, Glaziou 9646a (P, probablemente duplicado de Jobert-Schwacke 979).

Distribución: Probablemente endémica de Piauí, conocida por unos pocos ejemplares. El holotipo fue coleccionado en campo.

Obs.: Especie dedicada al botánico que coleccionó el ejemplar tipo: Clemens Jobert, quien acompañó a C. A. Schwacke en su expedición al norte de Brasil. 


\section{Turnera lamiifolia Cambess.}

Figs. 42 y 43

Saint Hilaire, A., Jussieu, A. \& Cambessèdes, J., Fl. bras. merid. 2: 213. 1830; Urban, Jahrb. Königl. Bot. Gart. Berlin 2: 119, tab. 1, fig. 27. 1883; Urban, en Martius, Fl. Bras. 13(3): 139, tab. 41, 1883. Typus: Brasil. Goiás: une queimada près Paracanjuba, fleurs jaunes, pétales oblongs cordiformes, tiges plusieurs [seg. catálogo], VIII, Saint Hilaire C1 862 (holotypus P! fototipo F $\mathrm{n}^{\circ}$ 38461, isotypi $\mathrm{F}$ !, $\mathrm{P}$ !).

Arbusto o subarbusto $0,2-1,5 \mathrm{~m}$ alt., eje subterráneo grueso, retorcido, hasta $13 \mathrm{~mm}$ diám.; uno a varios tallos simples o ramificados, ramas viejas con corteza rojiza, lustrosa, longitudinalmente estriada; ramas del año densamente hirsutas, a veces tomentosas hacia el ápice, pelos simples largos, 1,5-2 mm long., pelos simples cortos tenues y pelos bífidos a estrellados $0,5 \mathrm{~mm}$ long. Yemas axilares 2-3, la basal florífera, ramas seriales desarrolladas. Hojas coriáceas, abolladas, discoloras. Estípulas soldadas a la base del pecíolo, subuladas, rojizas 0 negruzcas, villosas, 0,5-3,5 mm long. Pecíolo semicilíndrico, 3-15 mm long., indumento como el del tallo, acanalado en la cara superior. Lámina ovada, latiovada, angustiovada, elíptica, latielíptica, suborbicular, orbicular, obovada, 2-15,7 x 1-8,5 cm, relación largo:ancho 1-2,5:1; base atenuada o cuneada; ápice truncado, redondeado o agudo; borde ligeramente revoluto, doblemente aserradocrenado, casi desde la base; haz oscura, con pelos simples largos y pelos estrellados, a veces solamente bífidos, trífidos o incluso simples laxos, con base abultada, a veces lustrosa y glabrescente; envés lanoso-tomentoso, blanquecino o ceniciento, con pelos simples y estrellados, a veces con pelos glandulares microcapitados amarillos; vena media y 6-7 pares de venas laterales, alternas o subopuestas, muy hundidas en la haz, prominentes en el envés; ángulo de divergencia ca. $50^{\circ}$; venas terciarias también hundidas en la haz y prominentes en el envés; venación menor a veces conspicua en el envés. Nectarios 1-3 pares, oscuros, circulares, 0,5-1 mm diám., borde glabro o densamente piloso, situados en la unión de pecíolo y lámina, desplazados sobre el margen foliar o sobre el envés. Hojas floríferas bruscamente reducidas, bracteiformes, lámina 2,5 x $2 \mathrm{~mm}$, con nectarios muy desarrollados, asentados sobre el envés. Flores heterostilas, epifilas, solitarias o dispuestas en ramas seriales floríferas en racimos hojosos abreviados. Pedúnculo 4-9 mm long., soldado al pecíolo. Profilos ovados, elípticos, subulados o espatulados, 5-9 x 0,5$2,5 \mathrm{~mm}$, indumento como el de las hojas, borde entero o dentado. Pedicelo nulo. Cáliz 9-10 mm long., villoso-hirsuto; tubo calicino 4-5 $\mathrm{mm}$ long., velloso por dentro en la mitad apical; lóbulos triangulares, glabros por dentro, mucrón 0,5-1 mm long. Corola amarilloanaranjada, 3-5 mm más larga que el cáliz; pétalos con la uña soldada al tubo calicino, vellosa en la parte superior, lámina obovada, 10-12 x 5-8 mm. Filamentos estaminales complanado-subulados en seco, soldados 0,6$1 \mathrm{~mm}$ en la base al tubo calicino, $5 \mathrm{~mm}$ long. en flores longistilas, 7-9 mm long. en flores brevistilas; anteras angustiovadas, 1,2-1,3 x 0,6-0,7 mm, base emarginada, ápice obtuso recurvado o no a la dehiscencia, filamento inserto dorsalmente a $0,4-0,5 \mathrm{~mm}$ de la base. Ovario $2 \mathrm{~mm}$ long., villoso-hirsuto; placentas 2-5 ovuladas; estilos rojizos, cilíndricos, glabros, $6 \mathrm{~mm}$ long. en flores longistilas, 3 $\mathrm{mm}$ long. en flores brevistilas; estigmas penicilados, ca. 15 ramas 1,2-3 mm long., amarillentas hacia el ápice. En flores longistilas el gineceo es 1,5-3 mm más largo que el androceo. En flores brevistilas el androceo es 2,5-3 mm más largo que el gineceo. Fruto ovoide, 4-5 mm long., con un reborde anular basal dejado por el tubo floral al desprenderse; valvas ovadas, cara externa ligeramente rugosa, densamente pilosa, cara interna glabra, lustrosa, castaña o rojiza, con máculas más oscuras, vena placentaria no prominente. Semilla obovoide, curvada, 3,5 x 1,6-2 mm; ápice voluminoso; base atenuada, con un reborde por encima del exóstoma hemisférico, reticulado, 0,6 mm long.; rafe linear, lado rafeal incurvo; cálaza apical, redondeada, obscura, a veces un poco prominente. Episperma finamente reticulado, aréolas transrectangulares pequeñas; epidermis lisa. 


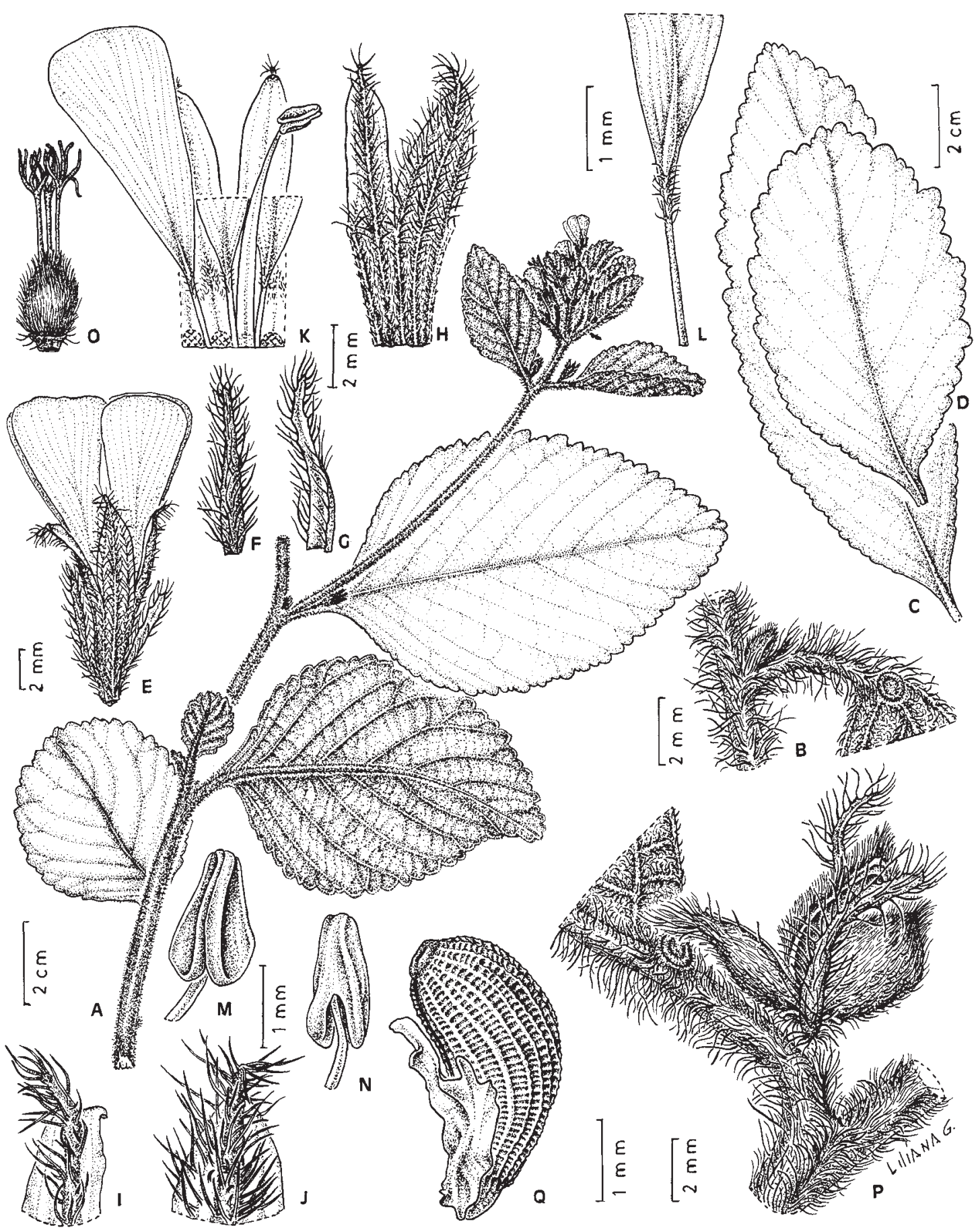

Fig. 42. Turnera lamiifolia. A: rama florífera. B: nudo, base de una hoja con nectario, cara abaxial, estípula y yema axilar. C-D: hojas, cara adaxial. E: flor y profilos. F-G: profilos, caras externa e interna. H: porción del cáliz, cara externa. I-J: ápice de lóbulos del cáliz interno y externo, cara externa. K: flor brevistila, porción del tubo calicino, cara interna, con pétalos y estambre adnatos; se han cuadriculado las cicatrices dejadas al desprender tres estambres. L: porción basal de un pétalo con pelos en la unión de uña y lámina. M-N: anteras, vistas ventral y dorsal. O: gineceo. P: porción basal de bráctea con nectario, fruto epifilo y profilos. Q: semilla con arilo, vista lateral (A: Silva 4682; B: Heringer \& al. 5146; C: Arbo \& al. 3435; D: Arbo \& al. 3847; E-P: Arbo \& al. 3127; Q: Hatschbach 37819). Del. Liliana Gómez. 


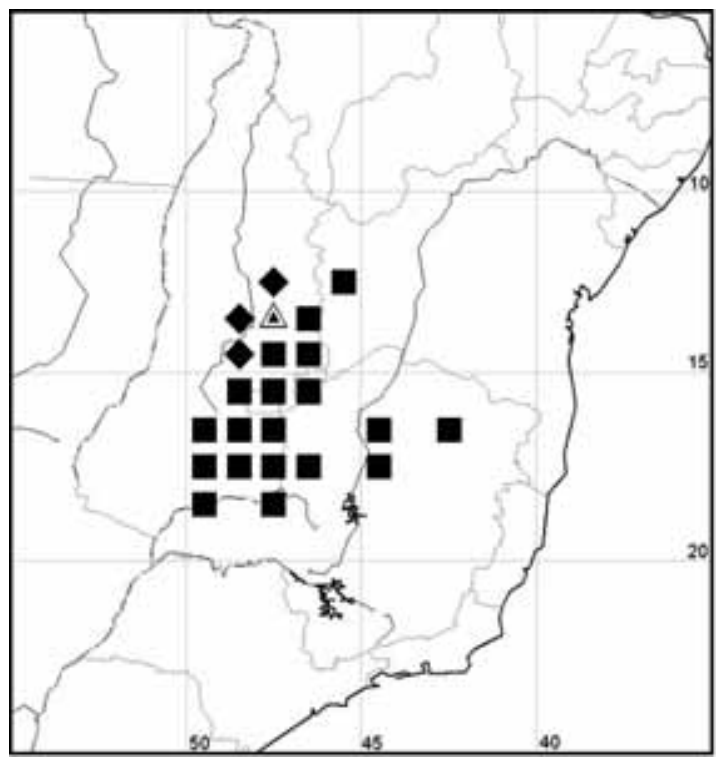

Fig. 43. Distribución de Turnera lamiifolia \%; T. pohliana f\&; T. vicaria

Arilo unilateral, amplio, lobulado, blanquecino o amarillo-rojizo en seco, más corto que la semilla, de células lisas cerca de la inserción, papilosas hacia los bordes.

Cromosomas: $2 \mathrm{n}=4 \mathrm{x}=28$, Krapovickas \& al. 33168 (Fernández, 1987).

Material estudiado: BRASIL. Alegre, VIII1834, Lund s.n. (C); sin localidad, Riedel s.n. (C, P); Brasil central, 1844, Weddell 2503 (P). Bahia: Rod.BR-020, $10 \mathrm{~km} \mathrm{~L} \mathrm{da} \mathrm{divisa} \mathrm{Goias/Bahia,}$ 1000 m, 10 III 1979, Hatschbach 42035 (C, CTES, MBM). Distrito Federal: Brasília, Patios do CENARGEN, 5-XI-1976, Allem 440 (CEN, UB); Fazenda Agua Limpa, UnB., 15 ${ }^{\circ} 58^{\prime} \mathrm{S}$ 4754'W, 9-I-1990, Alvarenga \& Oliveira 590A (CTES, IBGE); Brasília, Doremy, 4-IX-1960, Andrade 367 \& E mmerich 359 (R); Brasília, Campus Asa Norte-residencial, 21-VII-1967, Anhanguera 44 (NY, UB); BR 020, $5 \mathrm{~km} \mathrm{NE} \mathrm{de}$ Sobradinho, ca. 1000 m, 2-II-1990, Arbo \& al. 3413 (CTES, HRCB); Parque Nac. Brasília, 5-III1992, Barros \& al. 2279 (UB); Brasília, Campus da UnB, 3-II-1968, Belem 3931 (UB); Fazenda Agua Limpa, $15^{\circ} 57^{\prime}$ 'S 475' 'W, 22-I-1980, Cesar 45 (UB); Águas Emendadas, 15-V-1972, Ferreira 928 (HEPH); Reserva Ecologica do IBGE, prox. ao Corrego Taquara, 15⒌ $55^{\prime} 55^{\prime \prime} \mathrm{S} 47^{\circ} 83^{\prime} 81^{\prime \prime} \mathrm{W}$,
1015 m, 23-XII-1999, Fonseca \& Alvarenga 2218 (CTES, IBGE); mun. Brasília, Fazenda Sucupira, $15^{\circ} 52^{\prime} \mathrm{S} 48^{\circ} 00^{\prime} \mathrm{W}, 1100 \mathrm{~m}, 9-\mathrm{V}-2000$, Guarino \& al. 217 (CEN); Planaltina, lote 158, N. R. Rio Preto, 7-XI-1986, Guimarães s.n. (UB); Rod. BR020, $18 \mathrm{~km} \mathrm{~S}$ de Formosa, 17-III-1982, Hatschbach 44772 (CTES, MBM, MU); Rod. DF$345,5 \mathrm{~km}$ do trevo com Rod. BR-020, 7-II-1994, Hatschbach \& al. 59929A (CTES, MBM); Hôrto do Guará, Brasília, 7-I-1961, Heringer 7844 (HEPH, UB, UEC); Campo Experimental da Universidade Brasília, 20-V-1967, Heringer 11500 (NY, UB); area sede do IBDF, 21-IX-1976, Heringer 16238A (CTES, IBGE, UB, UEC); Brasília, SQ Sul 308, 28-II-1979, Heringer 17218A (CTES, IBGE, SP, UEC); Trevo de Unaí, 15-XI1980, Heringer 18018 (IBGE, K, NY); nascente do corrego Palmital, 27-XII-1978, Heringer 18385A (IBGE); Brasília, 25-VI-1980, Heringer \& al. 5146 (CTES, IBGE, K, MO, US); Brasília, Trevo de Unaí, 5-XI-1980, Heringer \& Salles 17923 (IBGE, R); ca. $10 \mathrm{~km}$ NE of Brasília, near Rio Torto, 1000 m, 16-IX-1965, Irwin \& al. 8358 (NY, P, UB); ca. 1,5 km E of Sobradinho, $1115 \mathrm{~m}$, 7-X-1965, Irwin \& al. 9021 (NY, P, UB, US); ca. $12 \mathrm{~km} \mathrm{~W}$ of Taguatinga on road to Brâslandia, 1250 m, 26-XI-1965, Irwin \& al. 10693 (F, NY, P, UB); inmediately $\mathrm{S}$ of Brasília, $975 \mathrm{~m}, 8$-XII1965, Irwin \& al. 11090 (NY, P, UB, US); between Taguatinga and Braslândia, 1100 m, 23II-1966, Irwin \& al. 13115 (MO, NY, P, UB); ca. 5 km E of Lagôa Paranoá, 1000 m, 25-II-1966, Irwin \& al. 13158 (E, NY, P, UB); Brasília Planalto, 700-1000 m, 27-VIII-1964, Irwin \& Soderstrom 5635 (NY); Brasília, Parque Nacional, 22-I-1978, Krapovickas \& al. 33168 (C, CTES, F, K, MBM, MO); $5 \mathrm{~km} \mathrm{~N}$ de Brasília, camino a Sobradinho, 27-I-1978, Krapovickas \& al. 33245 (CTES, K); Planaltina, Lote 95, N. Rural Taguatinga, 31-X1986, Melo s.n. (UB); Brasília, University Campus, 30-IX-1975, Oldenburger \& Mecenas 1673 (CTES, UB), along road parallel to Lago Paranoa, 20-X-1975, Oldenburger \& Mecenas 1736 (U); Reserva Ecologica do Guará, 1548'S 47058'W, 1035 m, 10-X-1993, Pereira-Silva 1981 (CEN); Area entre a rodoferroviaria e o viaduto Ayrton Senna, 1546'44"S 4756'23"W, $1180 \mathrm{~m}$, 6-X-2001, Pereira-Silva \& Guarino 5553 (CEN); Reserva Biologica de Aguas Emendadas, $40 \mathrm{~km}$ NE de Brasília, 1532'-38'S 47³3'-37'W, 10001150 m, 10-VI-1982, Proença 151 (HEPH), íd., 
corrego Vereda Grande, 13-VII-1982, Ramos 61 (CEN, HEPH); Parque Nacional de Brasília, novo setor Cascalheira Centro Oeste, $15^{\circ} 53^{\prime} \mathrm{S} 47^{\circ} 56^{\prime} \mathrm{W}$, 4-XII-1990, Ramos 361 (UB), íd., Lago do Suta, 1-II-1991, Ramos 607 (CTES, E, UB); Mun. Samambaia, parque Boca da Mata, 15²' S 4803'W, 10-XI-1995, Rezende 217 (CEN, CTES); Reserva Ecológica do Guara, mun. Brasília, 1548'S 4758’ W, 1035 m, 10-X-1993, Silva 1981 (CEN); Reserva Ecologica do IBGE, 1556'41"S 4753'07"W, 1100 m, 11-XII-2000, Silva 4682 (CTES, IBGE), Brasília, $\mathrm{S}$ side of campus of Universidade Brasília, $15^{\circ} 45^{\prime} \mathrm{S}$ 4751'W, 16-XI-1977, Taxonomy Class of Univ. Brasília 534 (MO). Goiás: BR 050, alrededores de Campo Alegre de Goiás, ca. 900 m, 31-I-1990, Arbo \& al. 3127 (C, CTES, F, GH, HRCB, K, MICH, MO, WIS); BR 040, 12 km N de Luziania, camino a Brasília, 800-1200 m, 1-II-1990, Arbo \& al. 3374 (CTES, HRCB, K, WIS); BR 020, entrada a Formosa, 800-1000 m, 2-II-1990, Arbo \& al. 3435 (CTES, HRCB, K, LP, U, WIS); BR 020, 26 km NE de Formosa, ca. 1000 m, 2-II-1990, Arbo \& al. 3464 (CTES, HRCB, G, K, LIL); GO 446, 7-8 km WSW de Posse, camino a Iaciara, ca. 800 m, 3II-1990, Arbo \& al. 3525 (CTES, HRCB); alrededores de Corumbá de Goiás, camino a Pirenopolis, ca. 900 m, 7-II-1990, Arbo \& al. 3847 (CTES, HRCB); inter Pe-da-Rocha \& Rio Corumba, 30IX-1827, Burchell 6048 (K, P); Mun. Anápolis, ramal no $\mathrm{Km} 8$ da estrada de Anápolis para Corumbá de Goiás, 2-4 km no ramal adentro, 8-II1986, Carvalho \& Delphim 2236 (CEPEC, K, UB); $11 \mathrm{~km} \mathrm{~S}$ de Alto Paraiso de Goias, 17-I-1967, Cristóbal \& Krapovickas 665 (CTES, MBM); Alexandre \& Antas, 29-VIII-1894, Glaziou 21458 (BR, C, K, P, R, S); Rod. BR-040, 3 km a leste de Luzia-nia, 14-X-1990, Hatschbach \& al. 54376 (CTES, MBM); Buriti Alegre, 23-I-1992, Hatschbach \& al. 56358 (CTES, MBM); mun. Campo Alegre, Rod.BR-050, próximo ao Rio Imburuçu, 29-XI-1992, Hatschbach \& al. 58276 (C, CTES, MBM); Mun. Agua Fria: Estação repetidora da Telebrasilia de Roncador, 1200 m, 12VI-1993, Hatschbach \& al. 59311 (CTES, MBM); mun. São João da Aliança, Córrego das Brancas, próximo a barra do Jacaré, 9-II-1994, Hatschbach \& al. 60207 (CTES, MBM); Serra dos Pirineus, $16^{\circ} \mathrm{S}, 49^{\circ} \mathrm{W}$, ca. $12 \mathrm{~km} \mathrm{~S}$ of Corumbá de Goiás, 1000 m, 1-XII-1965, Irwin \& al. 10862 (NY); Serra dos Cristais, $17^{\circ} \mathrm{S} 48^{\circ} \mathrm{W}$, ca. $15 \mathrm{~km} \mathrm{~W}$ of
Cristalina, 1200 m, 6-III-1966, Irwin \& al. 13634A (NY, P, UB); Serra Geral de Goiás, $14^{\circ} 46^{\circ} \mathrm{W}$, Rio Paraná, ca. $35 \mathrm{~km} \mathrm{~N}$ of Formosa, on road to São Gabriel, 950 m, 29-III-1966, Irwin \& al. 14228 (CTES, P, UB); Contraforte Central, Serra do Facão, ca. 35 km NE of Catalão, 900 m, 24-I-1970, Irwin \& al. 25287 (NY, P, UB); $20 \mathrm{~km} \mathrm{~N} \mathrm{de}$ Itumbiara, BR 153, 20-I-1978, Krapovickas \& al. 33106 (CTES, MBM); Serra de Chrystaes, Pohl 835 (BM, W); prope Chapadão de S. Marcos [seg. Urban], Riedel 2611 (K, P); estrada de Goiania a Anápolis, Km 42, 26-XI-1976, Sheperd \& al. 3587 (MBM, NY). Minas Gerais: Samambaia, mun. Morrinhos, 24-XI-1975, Hatschbach 37819 (CTES, MBM); Serra do Rio Preto, 25 km E de Cabeceiras (ca. $4 \mathrm{~km}$ E of Goiás-Minas border), $16^{\circ} \mathrm{S} 47^{\circ} \mathrm{W}, 1000 \mathrm{~m}, 19-\mathrm{XI}-1965$, Irwin \& al. 10529 (NY, P, UB); Serra do Espinhaço, $20 \mathrm{~km} \mathrm{~W}$ of Montes Claros, road to Agua Boa, 1000 m, 24II-1969, Irwin \& al. 23848 (NY, P); Serra da Anta, ca. 10 km NW of Paracatú, 900 m, 3-II-1970, Irwin \& al. 25855 (NY, UB); ca. $5 \mathrm{~km} \mathrm{~W}$ of Paracatú, Serra da Anta, 800 m, 4-II-1970, Irwin \& al. 26012 (E, F, NY, P, UB).

Distribución y fenología: Especie típica del «cerrado»y «campo cerrado» del Distrito Federal y Goiás, entre 700 y 1250 m de altitud, también presente en algunas localidades de Minas Gerais y Bahia. Florece y fructifica casi todo el año, la mayoría de los ejemplares se coleccionaron entre agosto y marzo.

Obs.: Las flores del ejemplar tipo, de Glaziou 21458 y de Irwin \& al. 25855 presentan un apéndice pistiliforme 2-4 mm long. en algunos pétalos. La flor estudiada en el ejemplar tipo, presentaba además un sépalo folioso. Urban (1883) destacó la similitud de estos apéndices con los estilos y estigmas.

El color de la planta seca varía, el epifilo puede ser pardo-obscuro, ocráceo o glauco (el tipo es glauco, con pelos brillantes). El indumento varía, hay ejemplares como Irwin \& al. 25855, Irwin \& Soderstrom 5635 y Sheperd \& al. 3587 en los que predominan los pelos simples; en algunos el indumento es dorado (Irwin \& al. 10862).

Los ejemplares Hatschbach \& al. 59311, 60260 , 60425 y 70650 son ramosos y presentan solamente hojas pequeñas, no más de $4 \mathrm{~cm}$ 
long., lo que les da un aspecto inusual, similar al de Turnera hassleriana. No obstante presentan el indumento y los nectarios característicos de T. lamiifolia.

Se encontraron compuestos cianogénicos (Spencer \& al., 1985) en el análisis de las hojas de Irwin \& al. 9021 y 25287 (ILL).

\section{Turnera lanceolata Cambess.}

Figs. 12 y 44

Saint Hilaire, A., Jussieu, A. \& Cambessèdes, J., Fl. bras. merid. 2: 214. 1830. Turnera hilaireana Urb. var. lanceolata (Cambess.) Urb. en parte, Jahrb. Königl. Bot. Gart. Berlin 2: 109. 1883; Urban, en Martius, Fl. Bras. 13(3): 130. 1883. Typus: Brasil. Goiás: Sitio do Ribeirão, Saint Hilaire C1 906 (lectotypus, aquí designado P!).

Hierba perenne graminiforme, de $9-45 \mathrm{~cm}$ alt., simple o ramificada, verdosa en seco, base leñosa 1-6 mm diám.; 1-4 tallos, 0,8-1,2 mm diám., a veces ligeramente en zig-zag, cilíndricos o angulados, estriados longitudinalmente, a veces aristados, con pelos simples largos, curvado-antrorsos o patentes, entremezclados con otros cortos y crespos; entrenudos 8-20 mm long., acortándose en la porción florífera. Ramas seriales no desarrolladas. Hojas generalmente patentes y excurvas, extendidas, a veces erectas. Estípulas rudimentarias, pilosas, con 1-3 coléteres 0,2-0,3 mm long., amarillentos o rojizos. Pecíolo 0,2-1,2 mm long., con pelos hirsutos a los lados en la unión con el tallo. Hojas basales sin nectarios, con lámina elíptica $\mathrm{u}$ obovada, 2,5-7,5 x 0,5-1,5 mm. Nomófilos con lámina linear o linear-lanceolada, a veces angustiovada, 15-65 x 3-8,5 mm, relación largo: ancho $=6-10(-17): 1$; base cuneada o redondeada; borde piloso, entero o serrulado, dientes diminutos; haz y envés con indumento formado por 2 estratos de pelos, uno de pelos largos y ergui-dos, el otro de pelos cortos, crespos, a veces entremezclados con pelos glandulares microcapitados; venación prominente en ambas caras, vena media prolongándose a veces sobre el tallo debajo de la inserción foliar en una arista; venas latera- les 4-5 a cada lado; ángulo de divergencia ca. $25^{\circ}$; venación menor conspicua en ambas caras. Nectarios 1+1 o 2+1, 0,4-1 mm diám., circulares, borde hirsuto, situados en la unión de pecíolo y lámina o desplazados hasta 1,5 $\mathrm{mm}$ sobre el margen foliar. Hojas floríferas acortándose rápidamente hasta ser bracteiformes, 10-3 x 2-1 mm, relación largo:ancho $=5-3: 1$. Flores epifilas, heterostilas, erectas, agrupadas en la porción apical del tallo en un racimo bracteoso, los primeros frutos espaciados. Alabastro elipsoide, ápice agudo, recto. Pedúnculo 2,24,5 mm long., densamente cubierto de pelos simples, crespos, soldado al pecíolo totalmente o porción apical libre $0,5-2,5 \mathrm{~mm}$. Profilos lineares, 2-4 x 0,2-0,5 mm, opuestos en la base del receptáculo, cara externa indumento como el del tallo, cara interna gla-bra, borde ligeramente dentado. Pedice-lo nulo. Cáliz 6,5-9 mm long., densamente cubierto de pelos cortos, crespos, en la parte apical de los lóbulos entremezclados con otros más largos, curvado-antrorsos; tubo calicino 2-3 mm long., internamente velloso; lóbulos triangulares o angustiovados, bordes a veces coloreados, los internos membranáceos, ápice mucronulado (0,1-0,2 mm). Corola amarilla; pétalos con uña soldada al tubo calicino, lámina obovada 7,5-11,5 x 2,5-3,5 mm, pilosa en la base de la cara interna. Filamentos estaminales glabros, soldados $0,3 \mathrm{~mm}$ en la base al tubo calicino, 3$4 \mathrm{~mm}$ long. en flores longistilas, 4,5-6 mm long. en flores brevistilas; anteras elípticas, $1,2-2 \times 0,5-0,8 \mathrm{~mm}$, base emarginada, filamento inserto dorsalmente a $0,4-0,6 \mathrm{~mm}$ de la base, rectas o lig-eramente curvadas después de la dehiscencia. Ovario cónico, 1,2-1,5 mm, hirsuto; placentas 7-10-ovuladas; estilos cilíndricos, glabros, 4-5 $\mathrm{mm}$ long. en flores longistilas, 1,5-2 $\mathrm{mm}$ long. en flores brevisti-las; estigmas 1-1,8 mm long., ca. 8 ramas. Fruto subesférico 2,5-5 mm long., con reborde anular basal de 0,2-0,3 $\mathrm{mm}$, dejado por el tubo floral al desprenderse; valvas ovadas, pelos crespos densos entremezclados con pelos curvado-antrorsos más largos hacia el ápice, verde-amarillenta, amarillenta o castaña por fuera, glabra o pilosa, a veces maculada por dentro. Semilla obovoide, ligeramente curvada, $1,5-2$ x 0,8-1,5 mm, pardo- 


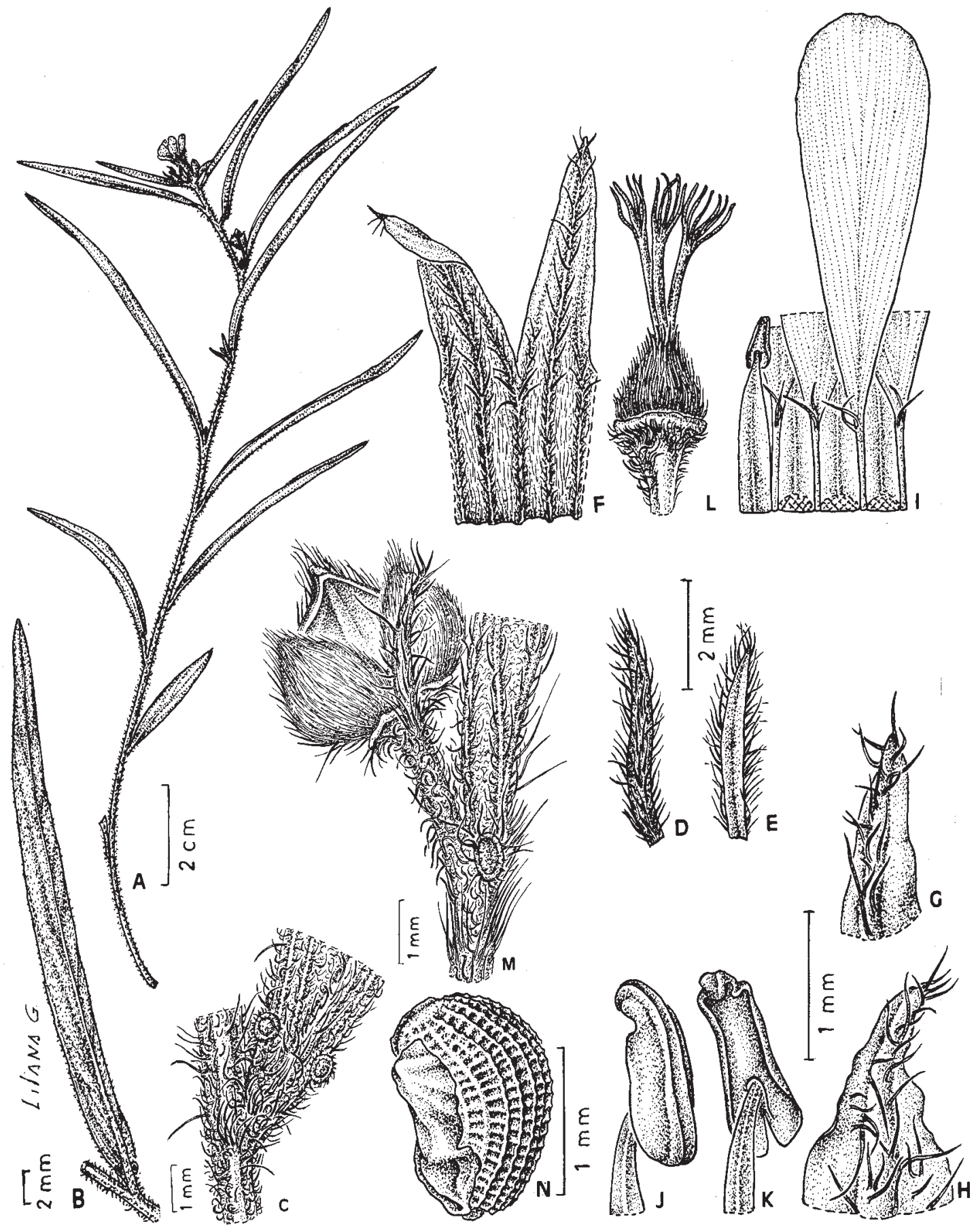

Fig. 44. Turnera lanceolata. A: planta. B: porción de tallo, hoja con nectarios, cara abaxial. C: inserción de hoja con nectarios. D-E: profilos, caras externa e interna. F: porción del cáliz, cara externa. G-H: ápice de lóbulos del cáliz externo e interno, cara externa. I: flor longistila, porción del tubo calicino, cara interna, con pétalos y estambre adnatos; se han cuadriculado las cicatrices dejadas al desprender tres estambres. J-K: anteras, vistas lateral y dorsal. L: receptáculo y gineceo. M: base de hoja florífera con nectario, fruto epifilo y profilos; nótese la porción apical del pedúnculo libre. N: semilla con arilo, vista lateral (Saint Hilaire 906). Del. Liliana Gómez. 
oscura; exóstoma redondeado poco prominente; rafe linear, a veces verdosa en la semilla inmadura, lado rafeal incurvo; cálaza oscura, ligeramente saliente, a veces ligeramente deprimida en el centro. Episperma reticulado con nudos a veces prominentes, aréolas transrectangulares o cuadrangulares cóncavas, con epidermis papilosa y bastones de cera epicuticular. Arilo unilateral, angosto, membranáceo en seco, borde lobulado, tan largo como la semilla o más corto, de células lisas.

Material estudiado: BRASIL. Goiás: $10 \mathrm{~km} \mathrm{E}$ de Corumbaiba, camino a Nova Aurora, ca. 800 m, 8II-1990, Arbo \& al. 3865 (C, CTES, GH, K, HRCB, MBM, MICH, MO); $30 \mathrm{~km}$ E de Corumbaiba, camino a Nova Aurora, ca. 800 m, 8-II-1990, Arbo \& al. 3867 (CTES, HRCB, MBM); mun. Caldas Novas, saindo de Caldas Novas virando a esquerda na estrada de acesso a UHE-Corumba, percorrer $13 \mathrm{~km}$, 17'58'S 48³5'W, 12-II-1993, Dias \& al. 379 (CEN); mun. Caldas Novas, pela estrada de acesso a UHE-Corumba a 2,7 km antes do Portão de acesso a obra, $18^{\circ} \mathrm{S} 48^{\circ} 34 \mathrm{~W}, 12-\mathrm{II}-1993$, Dias \& al. 416 (CEN); mun. Catalão, Rod. BR-050, divisa com Campo Alegre, 5-XII-1992, Hatschbach \& al. 58419 (C, MBM). Minas Gerais: $60 \mathrm{~km} \mathrm{SW}$ de Pirapora, 12-I-1989, Krapovickas \& Cristóbal 42904 (CTES); sin localidad, Saint Hilaire 331 P); Bom Jardin, Saint Hilaire $B_{1} 1558(\mathrm{P})$; près Pindaiba, Saint Hilaire $B_{1}$ 1758 (P, sintipo); Brasilândia de Minas, 6-I-2001, Soares 329b (BHCB, CTES). São Paulo: Estreito, perto do Rio Grande, 6-XI-1997, MarcondesFerreira \& al. 1568 (ESA, HRCB, SP, SPF, UEC).

Distribución: Especie poco frecuente, restringida a Goiás, Minas Gerais y São Paulo. Crece en «cerrado», en suelo pedregoso. Se adapta bien a lugares alterados como bordes de caminos.

Obs.: Turnera lanceolata y T. oblongifolia fueron consideradas por Urban como variedades de T. hilaireana, en la que describió además otras 2 variedades: var. minor y var. ovatifolia. Sin embargo, T. lanceolata se reconoce por sus hojas patentes y excurvas, más largas, y el indumento formado por dos tipos de pelos simples. Aparte del tipo, casi todo el material determinado por Urban como $T$. hilaireana var. lanceolata corresponde a T. oblongifolia Cambess.

\section{Turnera lineata Urb.}

Figs. 10 y 45

Urban, I. Repert. Spec. Nov. Regni Veg. 13: 157. 1914. Typus: Brasil. Amazonas: prope Manáos, Rio Negro, VI-1910, Ule 8901 (holotypus $\mathrm{B}+$ fototipo $\mathrm{F} \mathrm{n}^{\circ} 13587$ !, isotypi $\mathrm{K}$ !, MG, fototipo $\mathrm{n}^{\circ} 45258$ !).

Turnera ulmifolia L. f. serissima Killip, J.Wash.Acad.Sci. 24: 51. 1934. Typus: Colombia. Santander: Mesa de los Santos, Eastern Cordillera, 1500 m, 11/15-XII-1926, Killip \& Smith 15179 (holotypus US!, isotypi K!, NY!).

Hierba o sufrútice 0,10-1m alt., ramas viejas plicado-estriadas, pardo-negruzcas, a veces con grietas longitudinales, lenticelas ausentes; ramas del año cilíndricas, con pelos simples, cortos, crespos y otros largos o cortos, suberectos, muy densos, en la porción apical tomentosos o lanosos. Yemas seriales 2 , ramas seriales desarrolladas. Hojas generalmente concoloras, con estípulas 0,1-0,4 mm long., subuladas, pilosas. Pecíolo 1-5 mm long., indumento como el del tallo. Lámina obovada, elíptica o angustiovada, 1,1-6,1 x 0,4-1,6 cm, relación largo:ancho = 1-6:1; base obtusa, cuneada o atenuada; ápice agudo, a veces obtuso; margen piloso, plano o ligeramente revoluto, liso en la base, luego crenadoserrulado, a veces aserrado, cada diente generalmente terminado en un coléter; haz con epidermis generalmente oscura, con pelos crespos cortos y pelos antrorsos más o menos adpresos, densamente dispuestos, a veces largos y sedosos; envés tomentoso, con pelos crespos muy densos y pelos largos, curvadoantrorsos sobre las venas; 5-10 pares de venas laterales ligeramente hundidas en la haz, prominentes en el envés, rectas o ascendentes, frecuentemente bifurcadas, perdiéndose hacia el borde; ángulo de divergencia $30-35^{\circ}$. Nectarios 2, suborbiculares, 0,4-1,2 mm diám., en seco cóncavos, con reborde piloso; situados en la base de la lámina sobre el envés. Flores epifilas, heterostilas, a veces re- 

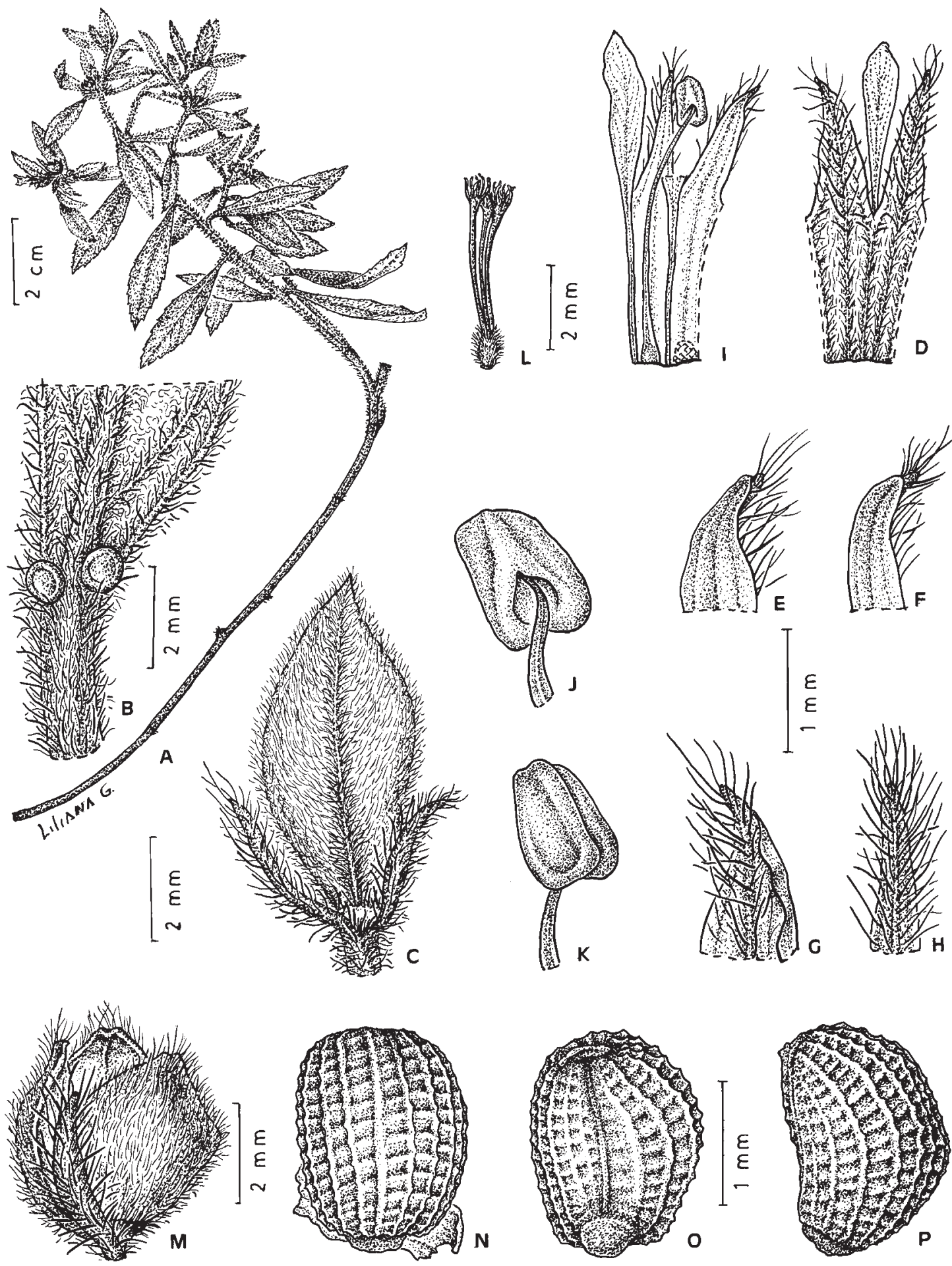

Fig. 45. Turnera lineata. A: planta. B: porción basal de hoja con nectarios, cara abaxial. C: bráctea, cara adaxial, con profilos. D: porción del cáliz, cara externa, y pétalo. E-F: ápice de lóbulos interno y externo del cáliz, cara interna. GH: cara externa. I: flor brevistila, porción del tubo calicino, cara interna, con pétalos y estambre adnatos; se ha cuadriculado la cicatriz dejada al desprender un estambre. J-K: anteras, vistas dorsal y lateral. L: gineceo. M: fruto y profilo. N: semilla con arilo, vista dorsal. O-P: semilla, vistas rafeal y lateral (Chaviel 854). Del. Liliana Gómez. 
unidas en racimos bracteosos apicales. Pedúnculo totalmente adnato al pecíolo o con el ápice brevemente libre, 4-6 mm long. en flores basales, 1-3 mm long. en flores apicales. Profilos subulados, 2,5-6 x 0,3-0,6 mm, con pelos 0,5-1(-2) mm long., cara interna a veces glabra en la porción basal. Pedicelo nulo. Cáliz (6-)9-12 mm long., sépalos soldados hasta la mitad o algo más; tubo calicino 3-6 mm long., 1,5 mm diám., pilósulo por dentro, por fuera con pelos cortos adpresos, raramente glabrescente o glabro en la base; lóbulos angustiovados o angusti-triangulares, ápice brevemente apiculado, 0-0,6 mm long., con pelos largos, curvado-antrorsos sobre las venas, 0,8-1,5(-2) mm long. Corola amarilla, 0-2 mm más larga que el cáliz; pétalos con la uña soldada al tubo calicino, lámina oblonga, amarilla, 4-10 x 1,2-4 mm, con pelos largos y antrorsos en la porción basal (1/3-1/2) de la vena media, raramente glabros. Filamentos estaminales soldados $0,5-0,7 \mathrm{~mm}$ al tubo calicino en la base, glabros, 5-8 mm long. en flores brevistilas, 4-7 mm long. en flores longistilas; anteras ovado-obtusas 1-1,3 mm long., dorsifijas. Ovario ovoide, con pelos breves erectos densamente dispuestos; placentas 3-6-ovuladas; estilos rectos, glabros, 3,5-7 mm long. en flores longistilas, 2,5-4,5 mm long. en flores brevistilas; estigma glabro penicilado 1,5-3 mm long. con ramas de diferente longitud. En flores longistilas el gineceo es 2-4 mm más largo que el androceo; en flores brevistilas el androceo es 1-3,5 mm mayor que el gineceo. Fruto ovoide o angustiovoide, 2,5-4 $\mathrm{mm}$ long., con la porción basal del tubo floral 0,4 $\mathrm{mm}$ long. persistente en la base; valvas ovadas, por fuera lisas, con pelos breves, tenues, cara interna lustrosa, glabra, jaspeada o castaña. Semilla obovoide breve, casi recta, 1,5-2,3 x 0,9-1,2 mm; exóstoma semigloboso, lado rafeal ligeramente incurvo, recto o convexo; cálaza ligeramente prominente. Episperma reticulado, aréolas transrectangulares o transelípticas; epidermis suavemente papilosa. Arilo unilateral blanquecino más corto o tan largo como la semilla, de células papilosas.

Material estudiado: PANAMA. Chiriqui, about $15 \mathrm{mi} \mathrm{N}$ of David towards Boqueta, 3-VIII-
1967, Duke 13641(3) (MO). Veraguas: ca. 5mi NE of La Mesa, 19-IX-1965, Blum \& Tyson 655 (MO); Yeguada, 16-V-1967, Hladik 384 (MO); vicinity of San José on Santiago-Santa Fe road, 18 km S of Santa Fe, 400 m, 18-XI-1973, Nee 8181 (MO). COLOMBIA. Caquetá: $\mathrm{N}$ de Chiribiquete, $0^{\circ} 56^{\prime} \mathrm{N} 72^{\circ} 42^{\prime} \mathrm{W}$, 800 m, 29-XI-1992, Velayos \& al. 6469 (MO); Meta: Villavicencio, 700-900 m, 26/31-VIII-1917, Pennell 1541a (NY). Santander: High of the SEfacing wall of Cañón de Chicamocha, near Hacienda de los Cacaos, Mesa de los Santos, ca. 1650-1675 m, 17-VI-1953, Langenheim 3034 (US). VENEZUELA. Amazonas. Dep. Atures, carretera Puerto Ayacucho-Sanariapo, Km 35, ca. 100 m, 6-19-VII1969, Bunting \& al. 3502 (MY, U, VEN); Dep. Atabapo, Cerro Parú, $4^{\circ} 30^{\prime} \mathrm{N}$ 65³0'W, 1160 m, II1992, Chaviel 454 (PORT); W base of Cerro Parú, Serranía Parú, rio Parú, 16-II-1951, Cowan \& Wurdack. 31488 (P); $25 \mathrm{~km} \mathrm{~S}$ of Sanariapo toward Rio Sipapo, ca. 125 m, 29-VI-1975, Gentry \& Berry 14599 (MO, NY); Dep. Atabapo, alred. Canariapo, margen $\mathrm{S}$ de rio Ventuari, ca. $20 \mathrm{~km}$ E de la confluencia con el rio Orinoco, $4^{\circ} 03^{\prime} \mathrm{N} 66^{\circ} 49^{\prime} \mathrm{W}, 98 \mathrm{~m}, 3$-III1979, Huber 1960 (NY, US); dep. Atabapo, Serranía del Parú (Aroko), sector N, 800 m, 4³2'N 65³1'W, 3-III-1979, Huber 3624 (VEN); Dep. Atabapo, Serranía del Parú (Aroko), meseta central en el sector centro-sur de la serranía, $4^{\circ} 27^{\prime} \mathrm{N} 6^{\circ} 32^{\prime} \mathrm{W}, 1100 \mathrm{~m}$, 7-X-1979, Huber 4423 (CTES, US); Dep. Atabapo, Serranía del Parú (Aroko), meseta central en el sector central de la serrania, $4^{\circ} 30^{\prime} \mathrm{N} 65^{\circ} 32^{\prime} \mathrm{W}, 1050 \mathrm{~m}, 7-\mathrm{X}$ 1979, Huber 4446 (CTES, US, VEN); Dep. Atabapo, Cerro Mahedi, ribera $\mathrm{N}$ del rio Ocamo Medio, $2^{\circ} 58^{\prime} \mathrm{N}$ 64²45'W, 600m aprox., 4-III-1980, Huber 4938 (MYF); Rio Atabapo, left bank, Caño Caname, $5 \mathrm{~km}$ below Guarinumo, $125 \mathrm{~m}, 8$-VI-1959, Wurdack \& Adderley 42863 (CTES). Bolívar: Dep. Heres, a lo largo del Rio El Trueno, al $\mathrm{N}$ de la base del Guaiquinima-Tepui, aprox. $6^{\circ} 14 \mathrm{~N} 63^{\circ} 27 \mathrm{~W}, 20-\mathrm{V}-$ 1987, Aymard 6130 (CTES, MO, VEN); Cerro Perro, Alto Paragua, VII-1943, Cardona 740 (VEN) y Cardona 757 (VEN); Campamento Auraima, río Paragua, 6²2'N 6333'W, hasta 300 m, V/VI-1987, Stergios 10084 (CTES, MO); alrededores del Campamento Auraima, río Paragua, 6²2'30"N 633'ㅇ"W, 330 m, 13-V/13-VI-1987, Stergios 10479 (CTES). GUYANA. Wabuwak, Kanuku Mts., 2000ft, XI-1948, Wilson-Browne 430 (K, NY). BRASIL. Amazonas: Rio Negro, margem direita, $50 \mathrm{~km}$ acima de Manaus. Campo Amelia (Faz. Belo Horizonte), $93^{\circ} 02^{\prime} \mathrm{S} 60^{\circ} 35^{\prime} \mathrm{W}, 18 / 19-\mathrm{VIII}-1985$, 
Nelson \& al. 1420 (CTES, NY); Campo Amélia, Faz. Belo Horizonte, entre ig. Acajatuva e margem a direita do rio Negro, $3^{\circ} 02^{\prime} \mathrm{S} 60^{\circ} 35^{\prime} \mathrm{W}, 20-\mathrm{IV}-1986$, Prance \& al. 29984 (CTES, K, NY), íd., 21-IV-1986, Prance \& 30064 (CTES, F, K, MO, NY). Para: Reserva Florestal de Gorotire (Kayapo Indian Reservation), Surroundings of Gorotire village at Rio Fresco, 747'S 51 $07^{\circ} \mathrm{W}$, ca. 200 m, 22-I-1983, Gottsberger \& Posey 318-22183 (CTES); perto do R.Xingu, ca. 8'S 52’W, 27-VI-1978, Pires 16065 (NY). Roraima: Estrada Boa Vista-Caracarai, perto da Colonia Fernando Costa, 11-IX-1951, Black 5113444 (UB).

Distribución y fenología: Vive en Panamá, Colombia, Venezuela (Amazonas y Bolívar), en Guyana (Kanuku Mts.) y Brasil (Amazonas, Pará, Roraima), en sabana húmeda, herbácea con suelo arenoso o pedregoso, entre aprox. 100 y $1650 \mathrm{~m}$ de altitud. Florece y fructifica todo el año.

Obs.: Generalmente el indumento foliar es blanco-grisáceo, pero en algunos ejemplares (Cardona 740 \& 757, y Huber 4938) es amarillento; Huber 4938 presenta hojas angustielípticas con relación largo:ancho $=6$ 7:1. Los especímenes Bunting 3502 y Pennell $1541 \mathrm{~A}$ tienen pelos cortos y densos con pelos crespos entremezclados, difícilmente visibles. En algunos ejemplares el indumento es seríceo-tomentoso, como en Pires 16065 cuyas hojas además están frecuentemente plegadas longitudinalmente, y sus anteras presentan mechones de pelos blancos en el borde inferior de cada teca y también en el ápice.

El espécimen Nee 8181, de Panamá, presenta hojas aserradas y pétalos glabros. Las hojas basales de Aymard 6130 y Chaviel 454 son algo discoloras. En Langenheim 3034 y Wilson \& Browne 430 el androceo es apenas más largo que el gineceo, estando anteras y estigmas en contacto.

\section{Turnera longiflora Cambess.}

Figs. 21 y 46

Saint Hilaire, A., Jussieu, A. \& Cambessèdes, J., Fl. bras. merid. 2: 157. 1830; Urban, Jahrb.
Königl. Bot. Gart. Berlin 2: 121. 1883; Urban, en Martius, Fl. Bras. 13(3): 141. 1883. Typus: Brasil. Minas Gerais: prope Mumquim haud longe à $\mathrm{Pa}-$ trocinio [seg. descr. orig.], campos d'arbres rabougris sur le chapadao, petales ovales cuneiformes rouges jaunes a la base, tige solitaire [seg. catálogo], V, Saint Hilaire c1 556 (holotypus $\mathrm{P}$ ! fototipo $\mathrm{F} \mathrm{n}^{\circ} 38462$, isotypi $\mathrm{F}$ !, $\mathrm{P}$ !).

Subarbusto virgado hasta $1 \mathrm{~m}$ alt., simple o ramificado, ramas viejas con corteza rojiza, lustrosa, con estrías y grietas longitudinales, cicatrices foliares a veces prominentes; ramas nuevas con pelos simples largos y pelos simples crespos cortos muy densos, a veces hirsuto-tomentosas. Yemas seriales 2, ramas seriales desarrolladas, a veces dos en la misma axila. Hojas coriáceas, discoloras, las basales a veces glabrescentes. Estípulas subuladas, 0,4-1 mm long., pilosas, con coléteres, escondidas en el indumento. Pecíolo 2-7 mm long., indumento como el del tallo. Lámina elíptica, angustielíptica, ovada, o angustiovada, 2,110,4 x 0,8-3,3(-4,1) cm, relación largo:ancho =1,8-3,6:1; base redondeada a cuneada; ápice agudo u obtuso; borde doblemente crenado, dientes obtusos, a veces terminados en coléteres cónicos; epifilo generalmente oscuro y rugoso en seco, a veces punteado, con pelos simples $1 \mathrm{~mm}$ long., más o menos antrorsos, a veces con base cónica rojiza; envés grisáceo-tomentoso, con pelos crespos densos y pelos glandulares microcapitados amarillentos; vena media y 6-9 pares de venas laterales alternas o subopuestas, rectas, perdiéndose hacia los bordes, visibles en la haz, prominentes e hirsutas en el envés; ángulo de divergencia $35-52^{\circ}$; venas terciarias visibles en el envés, venación menor inconspicua. Nectarios 1-3 pares, circulares, 0,5-1,2 mm diám., oscuros, borde piloso, a veces brevemente estipitados, situados en la unión de pecíolo y lámina, o desplazados hasta $3 \mathrm{~mm}$ sobre el margen, más desarrollados en hojas apicales y floríferas. Hojas floríferas reducidas, bracteiformes, 4-16 x 4-10 mm, con nectarios grandes. Flores epifilas, heterostilas, reunidas en el ápice de las ramas en racimos hojosos, a veces muy abreviados. Pedúnculo 1,5-3 mm long., totalmente soldado al pecíolo. Profilos subulados o angustiovados, 3-7,5 x 


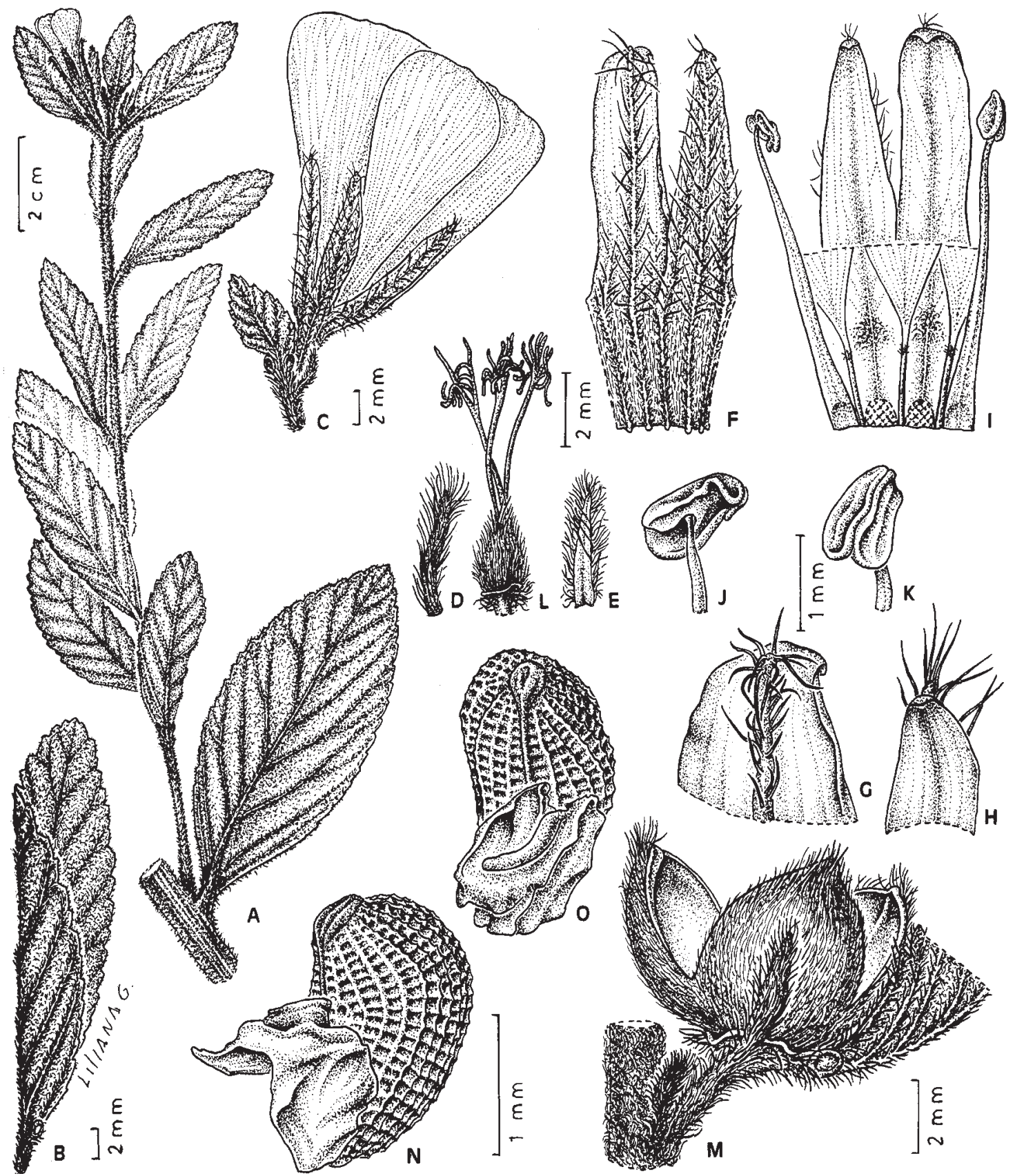

Fig. 46. Turnera longiflora. A: rama florífera. B: hojas con nectario. C: bráctea con flor epifila y profilo. D-E: profilos, caras externa e interna. F: porción del cáliz, cara externa. G: ápice de lóbulo interno del cáliz, cara exterior. H: ápice de lóbulo externo del cáliz, cara interna. I: flor brevistila, porción del tubo calicino, cara interna, con pétalos y estambres adnatos; se han cuadriculado las cicatrices dejadas al desprender dos estambres. J-K: anteras, vistas dorsal y ventral. L: receptáculo y gineceo. M: porción basal de bráctea con nectario, fruto epifilo y profilo. N-O: semilla con arilo, vistas lateral y rafeal (A-B: Fonseca \& al. 183; C-L, N-O: Hatschbach \& al. 60493; M: Arbo \& al. 3794). Del. Liliana Gómez. 
0,5-1,2 mm, hirsutos, frecuentemente oscuros, insertos en la base del receptáculo. Pedicelo ausente. Cáliz (7-)10-17(-22) mm long.; tubo calicino 4-6 mm long., cara externa con pelos cortos crespos, cara interna con pelos largos, blanquecinos; lóbulos triangulares, cara externa con pelos simples largos además de los pelos crespos, cara interna glabra, ápice brevemente cuculado en los internos, mucrón 0,3-0,8 mm long. Corola rojo bermellón 4-13 mm más larga que el cáliz, pétalos con la uña vellosa soldada al tubo calicino, lámina obovada, (11-)18-22 x (6-)9-13 mm. Filamentos estaminales complanado-subulados en seco, 6-7(-9) mm long. en flores longistilas, 9,5-12 mm long. en flores brevistilas; anteras dorsifijas, 1-1,5 x 0,5-0,6 $\mathrm{mm}$, base emarginada, ápice obtuso, ligeramente recurvado a la dehiscencia, filamento inserto a 0,5 $\mathrm{mm}$ de la base; androceo 2,5-5 $\mathrm{mm}$ mayor que el gineceo en flores brevistilas. Ovario piloso, 1,5 mm long.; placentas 3-6-ovuladas; estilos 8-9 mm long. en flores longistilas, 5 $\mathrm{mm}$ long. en flores brevistilas; estigma penicilado, 2,5-3,5 mm long.; gineceo $4 \mathrm{~mm}$ más largo que el androceo en flores longistilas. Fruto 3-7,5 mm long., con un reborde anular de $0,5 \mathrm{~mm}$ dejado por el tubo floral al desprenderse; valvas ovadas, cara externa villosa, pelos simples largos y cortos y pelos glandulares microcapitados $(0,15 \mathrm{~mm})$, cara interna glabra, lustrosa, castaña, jaspeada, o rojiza, a veces amarillenta. Semilla obovoide, algo curvada, 2,2-2,4 x 1,2-1,5 mm; exóstoma cónico $0,3 \mathrm{~mm}$ long; rafe linear, lado rafeal recto o curvo; cálaza oscura, ligeramente prominente. Episperma reticulado, ca. 20 filas longitudinales de aréolas más o menos cuadrangulares o hexagonales. Arilo unilateral, amplio, más corto, igual o más largo que la semilla, de células papilosas.

Material estudiado: BRASIL. Herb. Imp. Wien, ¿? 1318 (K); sin localidad, Pohl s.n. (BR, P). Distrito Federal: Imediações da Reserva de Aguas Emendadas, mun. Planaltina, 27-XI-1976, Allem A. 560 (CEN); road to Fercal, W of Sobradinho, $5 \mathrm{~km}$ by road N of Brasília-Fortaleza road, 29-III-1973, Anderson 7969 (NY, P, UB); Serra dos Pirineus, ca. $15 \mathrm{~km} \mathrm{~N}$ of Corumbá de Goiás, ca. 1250 m, 15-V-1973, Anderson 10314
(F, P, NY, UB); Brasília, 1-IV-1958, AndradeLima 58-2967 (IPA); BR 020, $5 \mathrm{~km} \mathrm{NE} \mathrm{de}$ Sobradinho, ca. 1000 m, 2-II-1990, Arbo \& al. 3414 (CTES, HRCB, K, MBM); BR 020, 20 km E de la entrada a Planaltina, ca. $1000 \mathrm{~m}$, 2-II-1990, Arbo \& al. 3427 (CTES, HRCB, K); Parque Nac. de Brasília, 5-III-1992, Barros \& al. 2280 (IBGE, UB); Brasília, Jardim Botânico de Brasília, Caminho da Horta, 1552'S 4751'W, 1025 m, 22V-1997, Boaventura 475 (HEPH); mun. Brasília, Bacia do Rio Maranhao, $15^{\circ} 30^{\prime}$ 'S $47^{\circ} 41^{\prime} \mathrm{W}, 900 \mathrm{~m}$, 16-VI-1999, Calago167 (CEN); Mun. Sobradinho, Fercal, Apa da Cafuringa, a $38 \mathrm{~km}$ do CENARGEN, 910 m, 9-VIII-1990, Cavalcanti \& al. 623 (CEN); Brasília, Reserva Ecologica do IBGE, perto da cabeceira do Corrego Tapera, ca. $15^{\circ} 05^{\prime} \mathrm{S} 47^{\circ} 05^{\prime} \mathrm{W}, 800-1000 \mathrm{~m}, 30-\mathrm{I}-1991$, FreireFierro \& Fonseca Vaz 3022 (CTES, SPF); Brasília, campus of the University, ca. $1000 \mathrm{~m}, 20$ I-1978, Gentry 21384 (MO, UB); Brasília, Horto do Guará, 12-I-1961, Heringer 7851 (HB, HEPH, UB, UEC); nascente do córrego Palmital, 27-XII1978, Heringer 18386 (IBGE, UEC); Bacia do Rio São Bartolomeu, 22-V-1980, Heringer \& al. 4856 (IBGE, K, MO); Chapada da Contagem, ca. $20 \mathrm{~km}$ E of Brasília, 700-1000 m, 17-VIII-1964, Irwin \& Soderstrom 5246 (NY, P, R, UB); i mmediately E of Lagôa Paranoá, 975 m, 10-XII-1965, Irwin \& al. 11171 (P, UB); near Planaltina, $950 \mathrm{~m}, 12-\mathrm{III}-$ 1966, Irwin \& al. 13909 (HB, NY, P, UB); Região

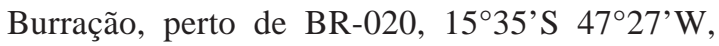
Kirkbride 3973 (UB); Vale do Amanhecer, 29-III1991, Melo \& França 545 (UB); Jardim Botânico de Brasília, 1552'S 4751'W, 1025-1150 m, 24II-1997, Nobrega \& al. 712 (HEPH); Chacara FTRC proximo ao Posto Colorado, $15^{\circ} 41^{\prime} \mathrm{S}$ 4752'W, 3-I-1996, Proença \& Almeida 1353 (UB); Reserva Ecologica do IBGE, entre Corrego Escondido e Cristo Redentor, 28-I-1987, Silva \& al. 356 (IBGE, SP). Goiás: Chapada dos Veadeiros, $9 \mathrm{~km}$ by road $\mathrm{S}$ of Terezina, $1100 \mathrm{~m}$, 18-III-1973, Anderson 7464 (NY, UB); BR 040, $12 \mathrm{~km}$ al $\mathrm{N}$ de Luziania, camino a Brasília, 8001000 m, 1-II-1990, Arbo \& al. 3375 (CTES, HRCB); 7-20 km E de Pirenopolis, Serra dos Pirineus, ca. 1000 m, 7-II-1990, Arbo \& al. 3794 (C, CTES, GH, HRCB, K, MBM, MO); alrededores de Corumbá de Goiás, camino a Pirenopolis, ca. 900 m, 7-II-1990, Arbo \& al. 3846 (CTES, HRCB, K, MBM); from Rio Paranahyba to Goyaz, Burchell 6034 (K, P); Mun.Teresina de Goias, 
estrada velha para Nova Roma, a $7 \mathrm{~km}$ do entroncamento com a GO-118, $13^{\circ} 47^{\prime} \mathrm{S} 47^{\circ} 13^{\prime} \mathrm{W}$, 894 m, 4-IV-1997, Cavalcanti \& al. 2215 (CEN, CTES); 45 km SW de Luziania, 12-I-1967, Cristóbal \& Krapovickas 659 (CTES, MBM); Rio Areias, 29-VII-1894, Glaziou 21455 (C, K, P, R); Mun. Itiquira, 8-II-1973, Gottsberger \& Gottsber-ger 11-8273 (ULM); São Gabriel, arredores, 7-XI-1991, Hatschbach \& al. 55871 (CTES, MBM); Rod. BR-050, divisa com Campo Alegre, mun. Catalão, 5-XII-1992, Hatschbach \& al. 58416 (C, CTES, HUEFS, MBM); near Rio Descoberto, on the Goiás-D.F. boundary between Anápolis and Brasília, 1010 m, 4-XII-1965, Irwin \& al. 11049 (P, R, UB); Serra dos Cristais, $17^{\circ} \mathrm{S}$ $48^{\circ} \mathrm{W}$ : ca. $3 \mathrm{~km}$ E of Cristalina, $1250 \mathrm{~m}$, 4-III1966, Irwin \& al. 13504 (CTES, P, UB); Serra dos Pirineus: $30 \mathrm{~km}$ N of Corumbá de Goiás on road to Niquelândia, in valley of Rio Corumbá, ca. 1150 m, 18-I-1968, Irwin \& al. 18819 (NY, UB, US), 75 $\mathrm{km} \mathrm{N}$ of Corumbá de Goiás on road to Niquelândia, in valley of Rio Maranhão, ca. 700 m, 22-I-1968, Irwin \& al. 18987 (F, NY, UB, US), Chapada dos Veadeiros, ca. $7 \mathrm{~km} \mathrm{~S}$ of Cavalcante, 1000 m, 9-III-1969, Irwin \& al. 24105 (P, NY, UB); Contraforte Central, Serra do Facão, 25 km NE of Catalão, 900 m, 24-I-1970, Irwin \& al. 25260 (P, UB); ca. 3 km S of São João da Aliança, ca. 850 m, 15-III-1971, Irwin \& al. 31818 (P, UB); ca. $15 \mathrm{~km} \mathrm{~S}$ of Niquelândia, $1000 \mathrm{~m}, 21-\mathrm{I}-1972$, Irwin \& al. 34628 (E, HB, P, UB); Morro da Cruz, 1603'S 47²8'W, 960 m, 25-I-1983, Kirkbride 5117 (UB); Mun. Pirenópolis, Morro do Frota, Mata Alto do Carmo, 26-I-1991, Lyra-Lemos \& Sugiyama 1707 (MAC); Caldas Novas, 20-III1951, Macedo 3531 (RB); Niquelândia, Km 31 ao 40 da estrada de terra a direita da Mina de Niquel, 14²3'S 48²4'W, 24-III-1995, Oliveira \& al. 263 (CTES, IBGE, RB); Luziana, 30-III-1963, Pereira 7459 (HB, NY, RB, UEC); Catalão, rodovia GO330 (GO-053) Catalão-Ipameri, ca. $24 \mathrm{~km}$ de Catalão, ca. 18 $18^{\circ} 10^{\prime} \mathrm{S} 47^{\circ} 57^{\prime} \mathrm{W}$, ca. $700 \mathrm{~m}, 23-\mathrm{I}-$ 1996, Pietrobom-Silva 2592 (CTES); Paranahyba, Pohl 640 (W); Serra de Christaes, Pohl 1019 (W); ad faz. do Parí, Pohl 2721 (W). Minas Gerais: MG-188, 42 km S de Paracatu, camino a Guarda Mor, Fazenda Santos Reis, Serra Branca, ca. 800 m, 31-I-1990, Arbo \& al. 3223 (CTES); Serra dos Pilões, 12 km SW de Guarda Mor, camino a Santo Antonio do Rio Verde, ca. 1000 m, 31-I-1990, Arbo \& al. 3276 (CTES, HRCB); Serra da Moeda,
BR-3, 4-IV-1963, Pereira 7552 (NY, RB). Tocantins: between Almas \& Natividade, X1839, Gardner 3201 (K); Arrayas, IV-1840, Gardner 3747 (K, OXF).

Distribución y fenología: Planta propia del Distrito Federal, Goiás y zonas limítrofes de Minas Gerais y Tocantins; vive en el «cerrado», en «campo cerrado», en campo y en campos rupestres, a 450-1250 m elev. Florece y fructifica desde julio hasta mayo, la mayoría de los ejemplares fueron colectados entre enero y marzo.

Obs.: Turnera longiflora es una de las pocas especies del género con flores de color rojo vivo. El ejemplar Pereira 7552 dice «flor amarela», pero los pétalos secos tienen el mismo color que en los demás ejemplares.

Spencer \& al. (1985) hallaron compuestos cianogénicos en Anderson 10134 (F!) y Plowman 1601 (ILL).

\section{Turnera luetzelburgii Sleumer}

Sleumer, H. O., Notizbl. Bot. Gart. Berlin 12: 70. 1934. Typus: Brasil. Bahia, Junco, 1400 m, V1913, P. Luetzelburg 186 (holotypus M!, isotypus $\mathrm{B}+)$.

\section{6a. Turnera luetzelburgii Sleumer var. luetzelburgii}

Figs. 47 y 48

Arbusto ramificado 0,20-1 m alt. Porción basal de los tallos con corteza negruzca, ramas del año cilíndricas, con pelos curvadoantrorsos densos. Hojas marcadamente recurvas, verde oscuras, a veces discoloras. Base foliar saliente y persistente. Estípulas rudimentarias, pilosas, 0,2 $\mathrm{mm}$ long. Pecíolo semicilíndrico 1,5-2 $\mathrm{mm}$ long. Lámina de 712(-20) x 9-16 mm, en el holotipo y algunos especímenes, profundamente (90\%) imparipinado-laciniada, con 2-4 pares de lacinias de 3-6 mm long., en otros ejemplares pinatífida, incisión de la hemilámina $22-81 \%$, con 2-4(-7) dientes triangulares, agudos, ter- 


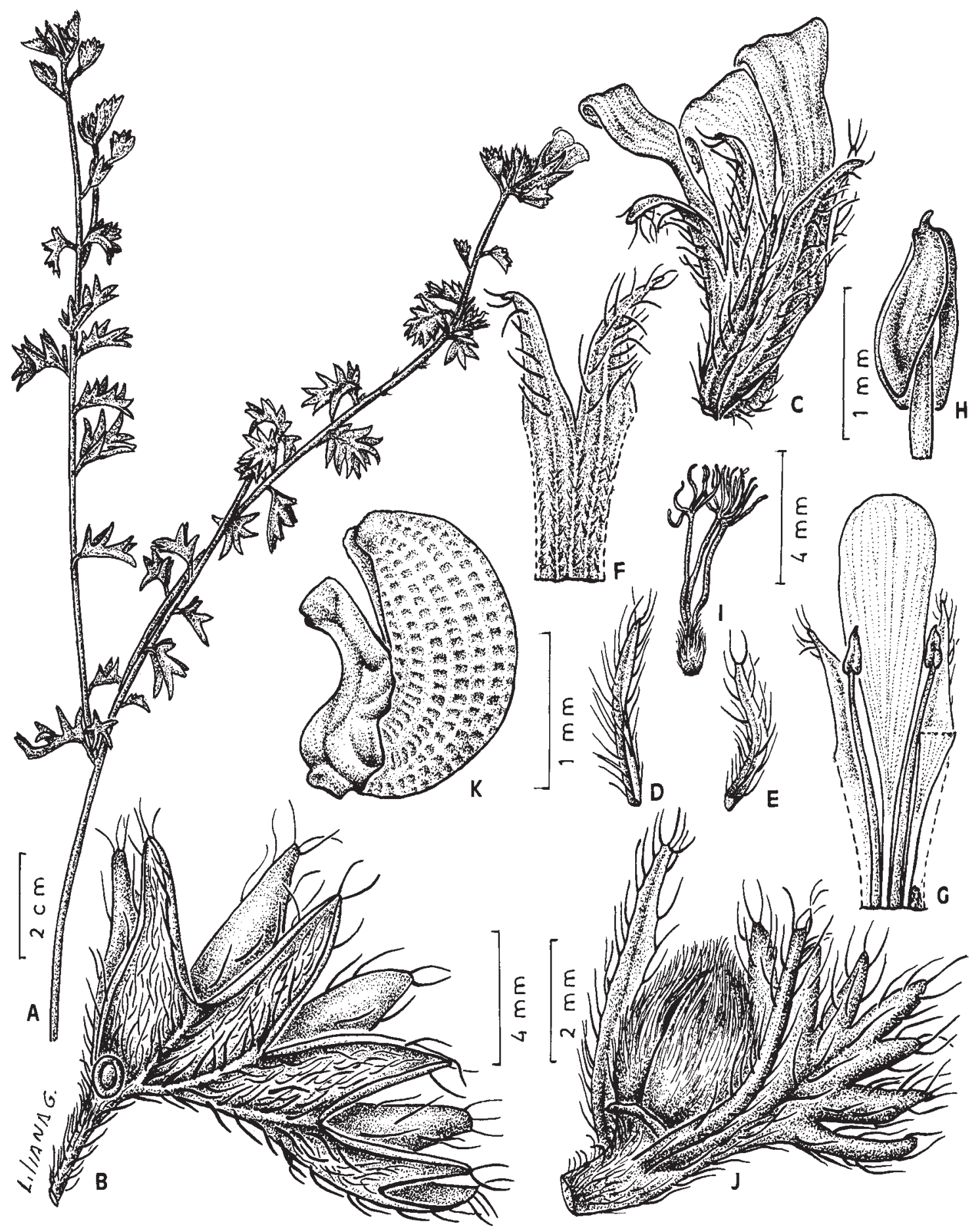

Fig. 47. Turnera luetzelburgii var. luetzelburgii. A: rama florífera. B: hojas plegada con nectario, cara abaxial. C: flor y profilo. D: profilos. F: porción del cáliz, cara externa. G: flor brevistila, porción del tubo calicino, cara interna, con pétalos y estambres adnatos; se ha cuadriculado la cicatriz dejada al desprender un estambre. H: antera, vista dorsal. I: gineceo. J: bráctea con fruto epifilo y profilos. K: semilla con arilo, vista lateral (A: Harley \& al. 25354; B-K: Hatschbach \& al. 56758). Del. Liliana Gómez. 


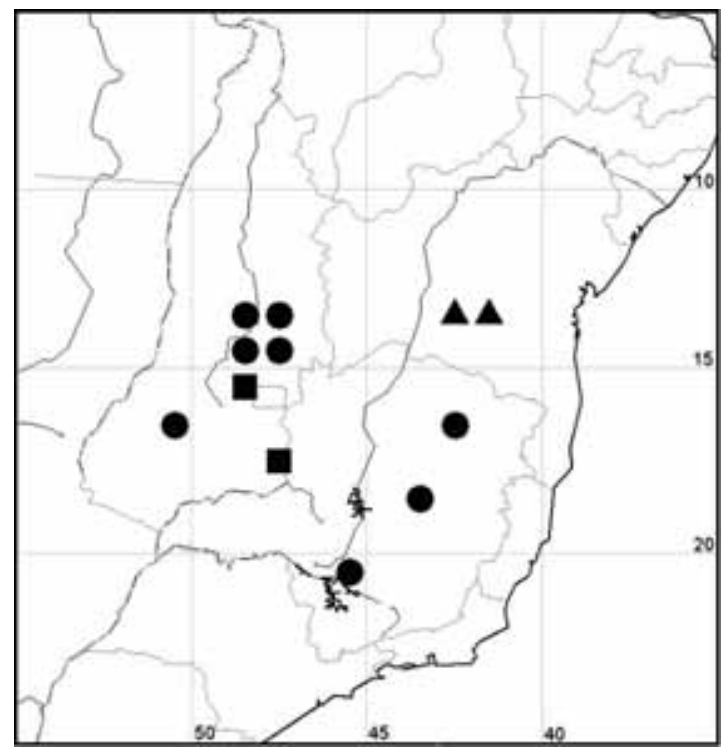

Fig. 48. Distribución de Turnera luetzelbur var. luetzelburgii $\boldsymbol{\Delta}$; T. riedeliana $\boldsymbol{\square}$; T. subnuda

minados en un coléter; margen revoluto; haz lustrosa, oscura y rugosa en seco, a veces punteada, con pelos simples largos a veces de base abultada; envés con pelos simples largos, antrorsos, laxos o densos, pelos crespos y pelos microcapitados; venas laterales rectas, cortas, terminando en las escotaduras del margen. Nectarios 2, discoideos, $1 \mathrm{~mm}$ diám., reborde pubérulo, asentados en el margen o desplazados sobre el envés foliar, cerca del pecíolo. Hojas floríferas de menor tamaño, con indumento cinéreo y con nectarios más desarrollados. Flores epifilas, heterostilas, reunidas en racimos apicales hojosos muy abreviados. Pedúnculo adnato al pecíolo. Profilos subulados, 2,5-5 mm long., insertos en la base del receptáculo, haz con pelos simples laxos, envés densamente piloso. Pedicelo no desarrollado. Cáliz 6 mm long.; tubo calicino 2,5 mm long., cara externa con pelos simples largos y cortos y pelos microcapitados, cara interna vellosa en la mitad superior; lóbulos con bordes internos membranáceos, glabros por dentro, ápice agudo o mucronado. Corola amarillo brillante; pétalos obovados, 8-12 x 2,5-6 mm, cara superior glabra o con algunos pelos simples en la base de la vena media, con venas rojizas en el envés. Filamentos estaminales glabros, soldados $0,8 \mathrm{~mm}$ al tubo floral, 4,5 mm long. en flores longistilas; anteras ovadas, $0,8 \times 0,6 \mathrm{~mm}$, base emarginada, ápice obtuso o apiculado, rectas después de la dehiscencia, filamento inserto dorsalmente, en la mitad. Ovario hirsuto, elipsoide, $1 \mathrm{~mm}$ long.; placentas 2-5ovuladas; estilos cilíndricos, glabros, $6 \mathrm{~mm}$ long. en flores longistilas, 3,5-3,7 mm long. en flores brevistilas; estigma asimétrico, 2-3 $\mathrm{mm}$ long, dividido en 8 ramas a su vez divididas, algunas ramas más largas que otras. Fruto ovoide, 2-4 mm long., con un reborde basal de $0,3 \mathrm{~mm}$ dejado por la absición del tubo floral; valvas ovadas, por fuera pilosas, por dentro glabras, amarillentas o castañas, con máculas oscuras. Semilla curvada, gruesa, 1,8-2,7 x 11,5 mm; exóstoma conoidal, asimétrico; rafe linear, lado rafeal incurvo; cálaza prominente, cónica, reticulada, a veces terminada en una protuberancia oscura, prolongación de la rafe. Episperma reticulado, aréolas transrectangulares pequeñas. Arilo unilateral más corto o igual que la semilla, de células papilosas.

Material estudiado: BRASIL. Bahia: Mun. Rio de Contas: Brumadinho, entre Faz. Brumadinho e Queiroz, ca. 1400 m, 21-II-1987, Harley \& al. 24650 (CTES, K, SPF); Mun. Rio de Contas, povoado de Mato Grosso, arredores, $13^{\circ} 28^{\prime} \mathrm{S}$ $41^{\circ} 50$ 'W, 1260 m, 24-X-1988, Harley \& al. 25354 (CEPEC, CTES, K, SPF); mun. Rio de Contas: Salto do Fragra, 1100 m, 6-IV-1992, Hatschbach \& al. 56712 (CTES, MBM), mun. Rio de Contas: Campo da Aviação, 1200 m, 6-IV-1992, Hatschbach \& al. 56733 (BR, C, CTES, MBM), Km 8-10 da estrada para Mato Grosso, 1100 m, 7IV-1992, Hatschbach \& al. 56758 (CTES, K, MBM); Barra do Brumado, 1100 m, 7-IV-1992, Hatschbach \& al. 56766 (CTES); Rio de Contas, rod. para Mato Grosso, 1100 m, 7-IV-1992, Hatschbach \& al. 56825-B (CTES); Mun. Rio de Contas, Aeroporto, arredores, 17-III-1998, Hatschbach \& al. 67858 (MBM); Rio de Contas, estrada para Livramento, em direção ao Rio Brumado, 13-XII-1984, Lewis \& al. CFCR 6811 (CTES, K); Rio de Contas, Junco, 1200 m, VIII1913, Luetzelburg 189 (CTES, M); Rio de Contas ca. $2 \mathrm{~km}$ da cidade, em direção a Marcolino Moura, 1100-1200 m, 4-III-1994, Sano \& al. CFCR 14854 (CTES, K, SPF); Rio de Contas, 
estrada para o Pico das Almas, entre os Km 11 e 19, 13-VII-1985, Wanderley \& al. 888 (SPF).

Distribución y fenología: La variedad típica aparentemente es endémica de Pico das Almas y adyacencias, Mun. Rio de Contas, Bahía, vive en campos rupestres y «carrasco» con suelo arenoso. Ha sido coleccionada en flor en casi todos los meses del año.

Se estudió la estructura anatómica de los nectarios extraflorales de esta especie, que son cupuliformes pero no presentan «poro» (Gonzalez \& Ocantos, 2006).

\section{6b. Turnera luetzelburgii var. dubia Arbo, nov. var.}

Figs. 27 y 49

Turnera aff. uleana Urb. en Arbo, M. M., Turneraceae en Flora de Grão-Mogol, Bol. Bot. Univ. São Paulo 24: 123-129. 2006.

Fruticulus 20-80 cm altus, pilis crispulis brevis et aliis curvato-erectis intermixtis; stipulae rudimentariae; folia discolora, petiolata, crenata vel profundiuscule dentata, supra obscura, subtus villosa vel ad nervos pilosa vel sericeo-lanosa, ad basin subtus nectariis gerentibus. Flores dimorphi, apice caulium conferti, pedunculi adnati, calyx 8,5-12,5 mm longus, in 1/3 vel 2/5 alt. coalitus, filamenta glabra, basi tubo tota facie adnata, placentae 4-6-ovulatae, styli pilosi. Fructus dorso laeve. Semina curvata, 2,4-3 mm longa, reticulata, nodis reticuli non elevatis, chalaza prominente, conica, minute reticulata; arillo angusto.

Typus. Brasil. Bahia. Caetité, 12-20 km da cidade em direção a Brejinho das Ametistas, 1100$1200 \mathrm{~m}$, entre $14^{\circ} 06^{\prime} 10^{\prime \prime} \mathrm{S} 42^{\circ} 30^{\prime} 31^{\prime \prime} \mathrm{W}$ e 14¹1'19"S 42²9'48"W, 8-III-1994, Souza \& al. 5374 (holotypus ESA, isotypi CTES, K, SPF).

Subarbusto erecto o tortuoso, a veces decumbente, $20-80 \mathrm{~cm}$ alt. Porción basal de los tallos con corteza negruzca; ramas del año cilíndricas, con pelos simples curvadoantrorsos densos y pelos simples crespos. Hojas patentes o incurvas, a veces recurvadas, extendidas o plegadas longitudinalmente en seco, discoloras, generalmente pinatífidas, a veces apenas crenuladas. Base foliar algo saliente y persistente. Estípulas rudimentarias, pilosas, con coléteres 0,1-0,2 mm long. Pecíolo semicilíndrico, 2-7 mm long. Lámina elíptica, angustiovada, 1,7-4,5 x 0,5-2 cm, relación largo:ancho $=1,5-3(-4,2): 1$; margen revoluto, crenado a marcadamente dentado, 3-15 dientes a cada lado, grado de incisión de la hemilámina 8-48(-60)\%; haz lustrosa, verde oscura, con pelos simples laxos o densos, 11,3 mm long., a veces con base cónica; envés verde grisáceo a plateado, desde glabro excepto las venas pilosas, hasta densamente seríceo-lanoso, con pelos crespos densísimos y pelos microcapitados; venas secundarias rectas, 3-11(-15), prominentes en el envés, terminando en las escotaduras del margen (venación mayor craspedódroma), a veces originando muy cerca del margen una vena que inerva un diente; ángulo de divergencia 20$50^{\circ}$. Nectarios 2, en la base, sobre el envés, reborde glabro o pilósulo, poro a veces visible. Hojas floríferas disminuyendo rápidamente de tamaño hasta brácteas, con indumento cinéreo y nectarios más desarrollados. Flores epifilas, heterostilas, reunidas en racimos hojoso-bracteosos muy abreviados. Pedúnculo soldado al pecíolo. Pedicelo nulo. Profilos 3,5-6 x 0,5-1,2 mm, enteros o dentados. Cáliz amarillo 8,5-12,5 mm long.; tubo calicino 3-5 mm long., cara externa con pelos simples largos y cortos y pelos microcapitados, cara interna vellosa en la mitad superior; lóbulos con bordes internos membranáceos, glabros por dentro, ápice agudo o mucronado. Corola amarillo vivo, 4-6 mm más larga que el cáliz; pétalos obovados, 1014 x 6-10 mm, con venas anaranjadas en la cara externa o con mancha vinosa en la base. Filamentos estaminales amarillos, 7-9,5 mm long. en flores brevistilas, 4-5 mm long. en flores longistilas; anteras ovadas, 1,5 x 0,6 $\mathrm{mm}$, apiculadas, filamento inserto dorsalmente a 0,6 $\mathrm{mm}$ de la base. Ovario 1-1,2 $\mathrm{mm}$ long, hirsuto; placentas 4-6-ovuladas. Estilos amarillos, pilosos, $4 \mathrm{~mm}$ long. en flores brevistilas, $5 \mathrm{~mm}$ long. en flores longistilas; estigma penicilado paucirramoso 1,3-1,5 mm long., ramas divididas. En flores longistilas el 

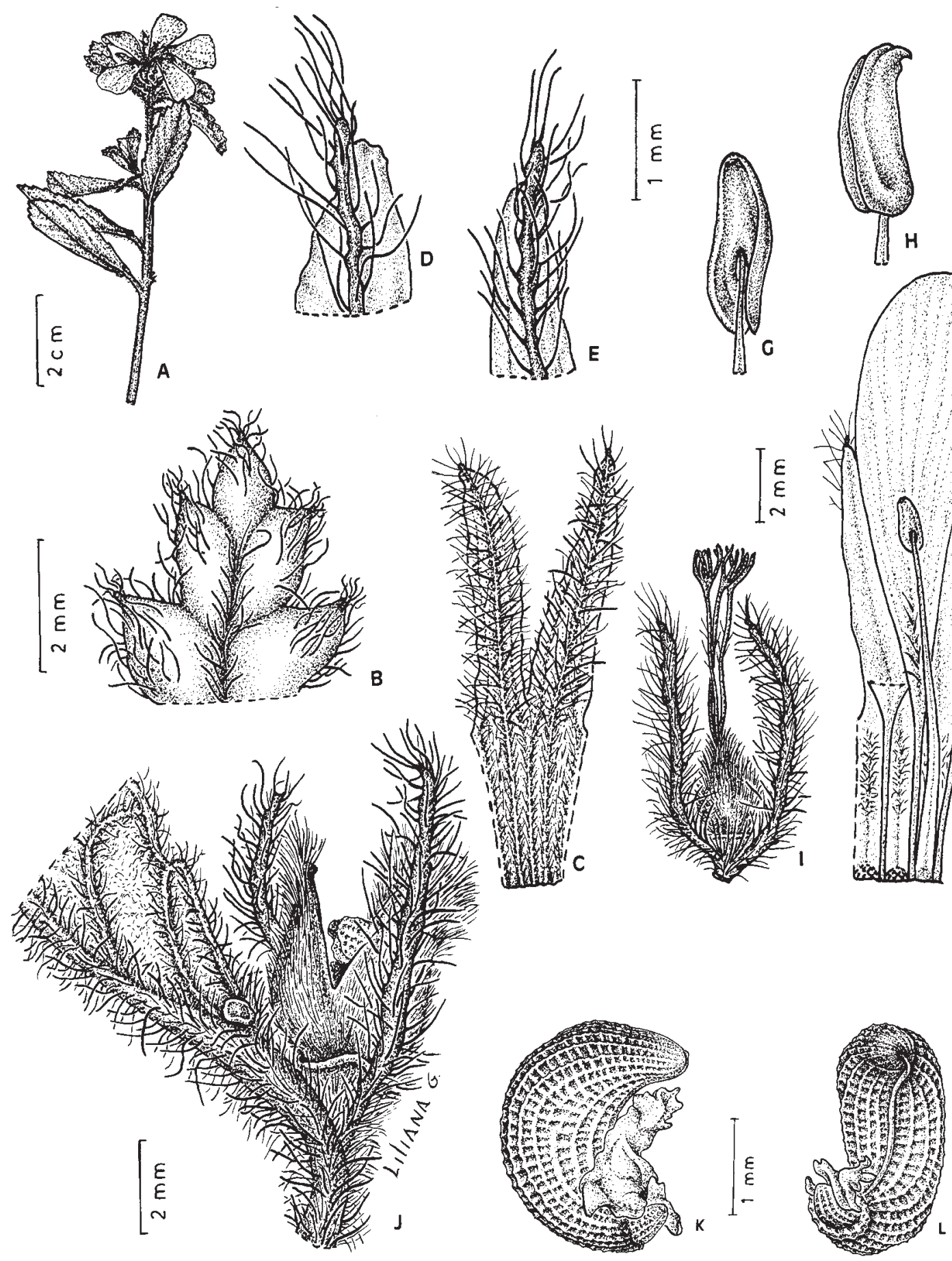

Fig. 49. Turnea luetzelburgii var. dubia. A: rama florífera. B: ápice foliar, cara adaxial. C: porción del cáliz, cara externa. D-E: ápice de lóbulos del cáliz interno y externo, cara externa. F: flor brevistila, porción del tubo calicino, cara interna, con pétalos y estambre adnatos; se han cuadriculado las cicatrices dejadas al desprender dos estambres. G-H: anteras, vistas dorsal y latero-ventral. I: gineceo y profilos. J: porción basal de hoja florífera con nectario, fruto epifilo y profilos. K-L: semillas con arilo, vistas lateral y rafeal (A: Harley 27845; B-J: Souza \& al. 5374; K-L: Ganev 1783). Del. Liliana Gómez. 
gineceo es 1,5-2,3 mm más largo que el androceo, y en flores brevistilas es 1,7-3,5 mm más corto. Fruto ovoide, 3,5-5-5 mm long., con un reborde basal de 0,5-0,6 $\mathrm{mm}$ dejado por la absición del tubo floral; valvas pilosas por fuera, lisas, por dentro glabras, lustrosas. Semilla curvada, 2,4-3 x 1,1-1,3 mm; exóstoma conoidal y asimétrico; rafe linear, lado rafeal incurvo; cálaza más o menos cónica, 0,2 mm long., con la superficie diminutamente reticulada, a veces terminada en una protuberancia oscura, prolongación de la rafe. Episperma reticulado, epidermis lisa, aréolas con cera epicuticular bastoniforme en la semilla inmadura. Arilo unilateral, angosto, de células papilosas.

Paratypi: BRASIL. Bahia: Mun. Abaíra, Km 12 estrada Abaíra/Catolés, $13^{\circ} 10^{\prime}$ 'S 41 ${ }^{\circ} 49^{\prime} \mathrm{W}, 28$ III-1985, Araújo \& Fonseca 427 (HRB); Mun. Morro do Chapéu, Morrão al S de Morro do

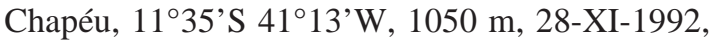
Arbo \& al. 5409 (CTES, SPF); Mun. Caetité, 6 km $\mathrm{S}$ de Caetité camino a Brejinho das Ametistas, aprox. 1402'S 42³2'W, ca. 1090 m, 20-XI-1992, Arbo \& al. 5634 (CTES, MBM, K, NY); Mun. Morro do Chapéu, Morrão $8 \mathrm{~km}$ al S de Morro do Chapéu, aprox. $11^{\circ} 35^{\prime} \mathrm{S} 41^{\circ} 13^{\prime} \mathrm{W}, 1170 \mathrm{~m}, 18$-I1997, Arbo \& al. 7456 (CEPEC, CTES); mun. Barra da Estiva, torre da Telebahia, 13\%41'S $41^{\circ} 19^{\prime} \mathrm{W}, 1130 \mathrm{~m}, 16-\mathrm{II}-1997$, Atkins \& al. PCD 5754 (K); mun. Caetité, Km 2-8 camino a Brejinho das Ametistas, $14^{\circ} 04^{\prime} 40$ " $\mathrm{S}$ 42³0'50"W, 8-VIII-1996, Ferrucci \& al. $983 a$ (CEPEC, CTES); Mun. Oliveira dos Brejinhos, Serra da Água Quente, 16-IV-1999, Forzza \& al. 1249 (SPF); Mun. Abaíra: Catolés de CimaBem Querer, $13^{\circ} 17^{\prime} \mathrm{S} 41^{\circ} 53^{\prime} \mathrm{W}, 1350 \mathrm{~m}$, 5-I1993, Ganev 1783 (CTES, HUEFS, K, SPF); ca. $6 \mathrm{~km} \mathrm{~N}$ of Barra da Estiva on Ibicoara road, aprox. $13^{\circ} 35^{\prime} \mathrm{S} 41^{\circ} 18^{\prime} \mathrm{W}, 1100 \mathrm{~m}, 28-\mathrm{I}-1974$, Harley \& al. 15524 (CEPEC, CTES); ca. $10 \mathrm{~km}$ $\mathrm{N}$ of Barra da Estiva on Ibicoara road, by the Rio Preto, aprox. $13^{\circ} 35^{\prime} \mathrm{S} 41^{\circ} 18^{\prime} \mathrm{W}, 1100 \mathrm{~m}, 2$ II-1974, Harley \& al. 15827 (CEPEC, CTES, $\mathrm{RB})$; ca. $14 \mathrm{~km} \mathrm{~N}$ of Barra da Estiva, near the Ibicoara road, aprox. $13^{\circ} 35^{\prime} \mathrm{S} 41^{\circ} 18^{\prime} \mathrm{W}, 1100$ m, 2-II-1974, Harley \& al. 15849 (CEPEC, CTES, RB); Serra do Sincorá, 3-13 km W of Barra da Estiva on the road to Jussiape, $13^{\circ} 40^{\prime} \mathrm{S}$ $41^{\circ} 25^{\prime} \mathrm{W}, 1000-1300 \mathrm{~m}, 23-\mathrm{III}-1980$, Harley \& al. 20792 (CEPEC, CTES, K); Mun. Piatã, Quebrada da Serra do Atalho, $13^{\circ} 13^{\prime} \mathrm{S} 41^{\circ} 50^{\prime} \mathrm{W}$, 1600-1700 m, 26-XII-1992, Harley \& al. 50418 (SPF); Mun. Piatã, Estrada Piatã-Abaíra, 4 km

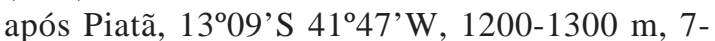
I-1992, Harley \& al. 50674 (CTES, K, SPF); Mun. Mucugê, Vereda Grande, 18-VI-1984, Hatschbach \& Ku mmrow 48041 (C, CTES, MBM); Mun. Abaíra, Campo de Ouro Fino

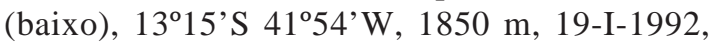
Hind \& Queiroz H50905 (CEPEC, CTES, K, SPF); Mun. Abaíra, base da encosta da Serra da Tromba, $13^{\circ} 17^{\prime} \mathrm{S} 41^{\circ} 48^{\prime} \mathrm{W}, 1000-1200 \mathrm{~m}, 2-\mathrm{II}-$ 1992, Pirani \& al. H51430a (CTES, K, SPF). Minas Gerais: $11 \mathrm{~km}$ de Francisco Sá, na estrada para Grão Mogol, Serra do Calixto, 1050 m, 26-XI-1984, Harley \& al. CFCR 6421 (CTES, K, SPF); Mun. Grão Mogol, Rio Itacambiruçu, 21-IV-1978, Hatschbach 41241 (CTES, MBM); Grão Mogol, arredores, 1000 m, 12-VI-1990, Hatschbach \& al. 54164 (MBM, MU); $23 \mathrm{~km} \mathrm{NW}$ de Botumirim, camino hacia Adão Colares y Barrocão, aprox. 16 $40^{\circ}$ 'S $43^{\circ} 07^{\prime} \mathrm{W}, 1000$ m, 20-XI-1992, Mello-Silva \& al. 741 (CTES, SPF); Estrada Grão Mogol Virgem da Lapa, 14-IV-1981, Pirani \& al. CFCR 897 (CTES).

Distribución y fenología: Vive en Bahía y Minas Gerais, en campos gerais, «campo rupestre», «carrasco»y «cerrado», con suelo arenoso o pedregoso; también se adapta a terrenos alterados como bordes de caminos. Florece y fructifica desde noviembre a agosto.

Obs. 1: La mayoría de los ejemplares de los municipios Abaíra y Piata (Bahia) presenta hojas casi glabras, concoloras, 4-8 dientes a cada lado, porcentaje de incisión de la hemilámina 20-36\%; algunos especímenes, con el envés piloso, tienen hojas discoloras. En Arbo \& al. 7456 las hojas basales son pinatisectas (incisión 88\%).

Obs. 2: El ejemplar Hatschbach \& al. 67305 (C, CTES, MBM) de Minas Gerais, mun. Bocaiúva, Rod. BR-367, descida para o Rio Jequitinhonha, 20-XI-1997, presenta algunas diferencias: las hojas son notoriamente discoloras, crenadas, el indumento lanoso en el envés y en la región apical de los tallos. 


\section{Turnera melochia Triana \& Planch.}

Triana, J.J. \& Planchon, J.E., Ann. Sci. Nat., Sér. 5, 17: 187. 1873. Typus: Colombia, Llano de San Martín, 250 m, I-1856, Triana 5056 (holotypus $\mathrm{BM} !)$.

Distribución: Especie nativa en Colombia, Venezuela y $\mathrm{N}$ de Brasil.

\section{7a. Turnera melochia var. melochia}

Figs. 21 y 50

Hierba o subarbusto ramificado, $5-40 \mathrm{~cm}$ alt., pardo-obscuro en seco, ramas viejas con corteza pardo-negruzca con estrías longitudinales, cicatrices foliares salientes; ramas del año con pelos simples largos, hasta $1 \mathrm{~mm}$ long., erectos entremezclados con pelos cortos, a veces crespos, tomentosas hacia el ápice; entrenudos de longitud variable: porciones con entrenudos largos alternan con otras de entrenudos breves, yemas seriales 2 . Hojas algo discoloras. Estípulas rudimentarias, pilosas, con coléteres rojizos o negruzcos $0,3 \mathrm{~mm}$ long. Pecíolo semicilíndrico, indumento como el del tallo. Pecíolo 2-3 mm long. Lámina elíptica, angustiovada u obovada, 1135 x 5,5-13 mm, relación largo:ancho $=1,6-$ 3,2:1; base atenuada o cuneada; ápice obtuso o agudo; borde crenado-aserrado, ligeramente revoluto, dientes obtusos terminados en un coléter cónico; haz pardo-oscura en seco, rugosa, con pelos más o menos laxos oblicuos, blanquecinos, de base hinchada; envés maculado (células taníferas dispuestas en grupos irregulares), con pelos simples largos, erectos, pelos más cortos, crespos, y pelos glandulares microcapitados, amarillos; 5-6 pares de venas laterales, opuestas o alternas, deprimidas arriba, prominentes abajo, rojizas, con pelos simples, largos, antrorsos, terminando en las escotaduras o perdiéndose hacia el margen; ángulo de divergencia $35-40^{\circ}$; venas terciarias y venas menores inconspicuas. Nectarios 0,5-0,7 mm diám., circulares o elípticos, rojizos, a veces la membrana cuticular amarillenta, reborde angosto, pubérulo, situados en la unión de pecíolo y lámina o sobre el envés, junto al margen foliar, a 1-2,5 mm de la base. Hojas floríferas apicales muy cortas, bracteiformes, 7-4 x 4-3 mm. Flores epifilas, heterostilas, las basales distanciadas, sobre nomófilos, las apicales reunidas en racimos hojosos. Pedúnculo totalmente adnato al pecíolo, 1,5-2 mm long. Profilos insertos en la base del receptáculo, angustiovados 0 lanceolados, 2,5-7 x 0,5 mm; borde entero o con algunos dientes, cara externa con pelos simples blanquecinos, cara interna glabra excepto en el ápice. Pedicelo nulo. Cáliz 7-10,5 $\mathrm{mm}$ long.; tubo calicino 3,5-5,5 mm long., por dentro velloso desde la base o sólo en la parte apical, por fuera piloso desde la base, con pelos simples, cortos y laxos; lóbulos triangulares con pelos un poco más largos $(0,4-0,5$ mm long.), mucrón $0,1 \mathrm{~mm}$ long., piloso. Corola poco más larga que el cáliz; pétalos de lámina glabra o pilosa hasta la mitad. Filamentos estaminales complanado-subulados, soldados en la base al tubo calicino; 4,5 mm long. en flores longistilas, $8 \mathrm{~mm}$ long. en flores brevistilas; anteras $0,9-1 \times 0,5 \mathrm{~mm}$, dorsifijas, ápice obtuso ligeramente recurvo después de la dehiscencia. Ovario hirsuto, 1,2 mm long.; placentas 4-5-ovuladas; estilos cilíndricos, glabros, $5 \mathrm{~mm}$ long. en flores longistilas, 3,7 mm long. en flores brevistilas; estigmas amarillentos 1-2 mm long., con ca. 12 ramas de diferente longitud. En flores longistilas el gineceo es $2 \mathrm{~mm}$ mayor que el androceo, y en flores brevistilas es $2 \mathrm{~mm}$ menor. Fruto 2,5-4 mm long., más largo o más corto que los profilos; porción inferior del tubo floral 0,4-0,5 mm long. persistente en la base; valvas castañas, lisas por fuera, superficie arenácea, con máculas diminutas, pelos largos, antrorsos, blanquecinos y otros cortos, crespos; cara interna glabra, lisa, jaspeada, más o menos lustrosa. Semilla obovoide, casi recta, 2 x $1 \mathrm{~mm}$; exóstoma hemisférico, corto; rafe linear, lado rafeal recto o ligeramente convexo; cálaza ligeramente saliente, plana o ligeramente deprimida en el centro, pigmentada, oscura. Episperma reticulado, muros longitudinales más salientes que los transversales, aréolas cóncavas, epidermis papilosa. Arilo membranáceo y blanquecino en seco, unilateral, tan largo como la semilla, de células lisas. 


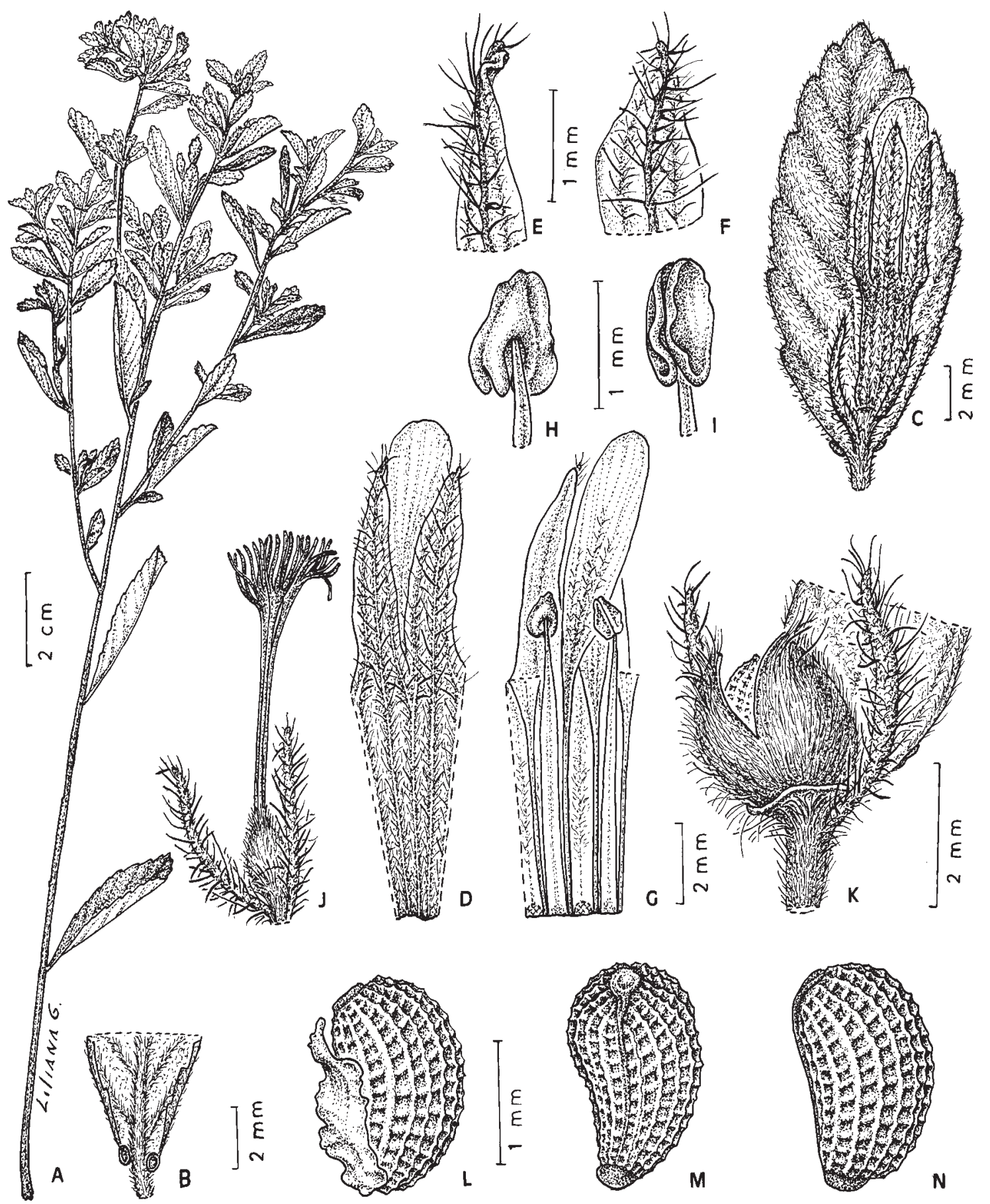

Fig. 50. Turnera melochia var. melochia. A: planta. B: porción basal de hoja con nectarios, cara abaxial. C: bráctea con flor epifila y profilos. D: porción del cáliz, cara externa y pétalo. E-F: ápice de lóbulos del cáliz, externo e interno, cara externa. G: porción del tubo calicino, cara interna, con pétalos y estambres adnatos; se han cuadriculado las cicatrices dejadas al desprender dos estambres. H-I: anteras, vistas dorsal y ventral. J: receptáculo, profilos y gineceo. $\mathrm{K}$ : parte basal de bráctea con fruto epifilo y profilos. L: semilla con arilo, vista lateral. M-N: semilla, vistas rafeal y lateral (A, L-N: Sprague 39; B-K: Sastre 807). Del. Liliana Gómez. 
Material estudiado: COLOMBIA. Boyaca: Estero de las Garzas, 9 km SE de Mani, 22-II1971, Sastre 807 (P). Caquetá: mun. San Vicente del Caguán, Sabanas del Yari, Vereda Yaguara, Hato Montecarlo, 151.0N 7348.9' W, 240 m, 27I-1990, Betancur \& Velásquez 1575 (HUA). Casanare: Rio Casanare, Esmeralda, 130 m, 19/ 20-X-1938, Cuatrecasas 3837 (US). Meta: Cabuyaro, Rio Meta, 8-I-1899, Sprague 39 (K, US). Vichada: Parque Nac. Natural El Tuparro, ca. $11 \mathrm{~km} \mathrm{NE}$ of El Tapon on road to centro administrativo, 5'12'N 6904'W, ca. $115 \mathrm{~m}, 18$-III1985, Zarucchi \& Barbosa 3753 (CTES, MO).

Distribución y fenología: Variedad endémica de las llanuras orientales de Colombia. Los pocos ejemplares conocidos se han colectado entre octubre y marzo

\section{7b. Turnera melochia var. ramosissima} (Urb.) Arbo, comb. nov.

Figs. 7 y 51

Turnera melochioides Cambess. var. ramosissima Urb., Jahrb. Königl. Bot.Gart. Berlin 2: 116. 1883; Urban, en Martius C.F.P., Fl. Bras. 13(3): 138. 1883. Typus: Brasil. Amazonas: Janauari, [03ำ'S 6004'W], I-1851, Spruce 1278-2 (lectotypus, aquí designado $\mathrm{P}$ !, isotypus $\mathrm{K}$ !).

Hojas notoriamente discoloras, estípulas con 1-2 coléteres 0,3-0,6 mm long. Pecíolo 3$5 \mathrm{~mm}$ long. Lámina 20-62 x 5-11(-22) mm, relación largo:ancho $=2,5-6,6: 1 ; 5-8$ pares de venas laterales, ángulo de divergencia 20-35 . Hojas floríferas apicales 8-11 x 3,4-5 mm. Flores heterostilas, epifilas. Pedúnculo 2-4 mm long. Profilos 4-5 x 0,7-1 mm. Cáliz 8-10 mm long.; tubo calicino 3-4,5 mm long., por dentro velloso desde la base, por fuera piloso o glabro en la base. Corola de igual longitud que el cáliz; pétalos con pelos en la vena media. Filamentos estaminales 6-8 mm long. en flores brevistilas. Ovario 0,9 mm long.; estilos rojizos, 4,5 $\mathrm{mm}$ long. en flores brevistilas; estigmas 1-2 mm long. En flores longistilas el gineceo es 2,5 $\mathrm{mm}$ más largo que el androceo, y en flores brevistilas es 1-1,5 mm más corto. Fruto 2-4 mm long., más corto que los profilos; parte basal del tubo floral $0,5 \mathrm{~mm}$ long. persistente en la base; valvas con cara externa de superficie irregular por la base abultada de los pelos simples largos, cara interna lisa, vena placentaria poco prominente en la parte basal. Semilla obovoide, casi recta, 1,7-1,8 x 1,2-1,3 mm; exóstoma brevísimo, redondeado; rafe linear, lado rafeal convexo, cálaza apenas prominente. Episperma reticulado, muros longitudinales más gruesos que los transversales, aréolas transrectangulares, cóncavas, con epidermis papilosa. Arilo unilateral, más corto que la semilla, de células lisas.

Material estudiado: COLOMBIA. Santander: Mun. Los Santos, mesa de Los Santos, Vereda El Tabacal, 1600-1890 m, 6²45.231' -6º 47.861'N 73⒍026-73⒊430'W, 19-IX-2004, Betancur \& al. 10948 (HUA); mun. Piedecuesta, mesa de los santos, Vereda El Duende-El Guayabal, 653'N 7303'W, 1710 m, Betancur \& al. 10963 (COL, HUA). VENEZUELA. Amazonas: Dep. Atabapo, Cerro Parú, 4³0'N 6530'W, 1160 m, II-1992, Chaviel 452 (PORT); Dep. Atures, Rincones de Chacorro, a unos $30 \mathrm{~km}$ de Puerto Ayacucho y a unos $5 \mathrm{~km}$ NE de Galipero, 5\%48' N 67²0'W, 80m aprox., 22-VIII-1979, Huber 4246 (VEN); dep. Atures, Rincones de Chacorro, a unos $30 \mathrm{~km} \mathrm{~N}$ de Puerto Ayacucho y $5 \mathrm{~km} \mathrm{NE} \mathrm{de}$ Galipero, 548'N 67²0'W, 80 m, 18-VI-1980, Huber 5260 (US, VEN), íd., 5-XI-1980, Maas \& Huber 5132 (VEN); Cerro Moriche, Rio Ventuari, 1250 m, 15-I-1951, Maguire \& al. 30949 (NY). BRASIL. Amazonas: in vicinibus Barra, prov. Rio Negro [Manaus], XII-1850/III-1851, Spruce 1075 (CGE, M, OXF, K, W, sintipo).

Distribución y fenología: Variedad de Colombia, Venezuela y Brasil, coleccionada en pradera, «cerrado» y «caatinga» a 80-1710 m de altitud. Florece y fructifica entre agosto y febrero.

Obs.: Los duplicados de Spruce de CGE, OXF, K y W no tienen número, pero evidentemente son parte de la misma colección que Spruce 1075. Las hojas del ejemplar Betancur \& al. 10948 no son marcadamente discoloras, sin embargo los demás caracteres foliares corresponden a esta variedad. 


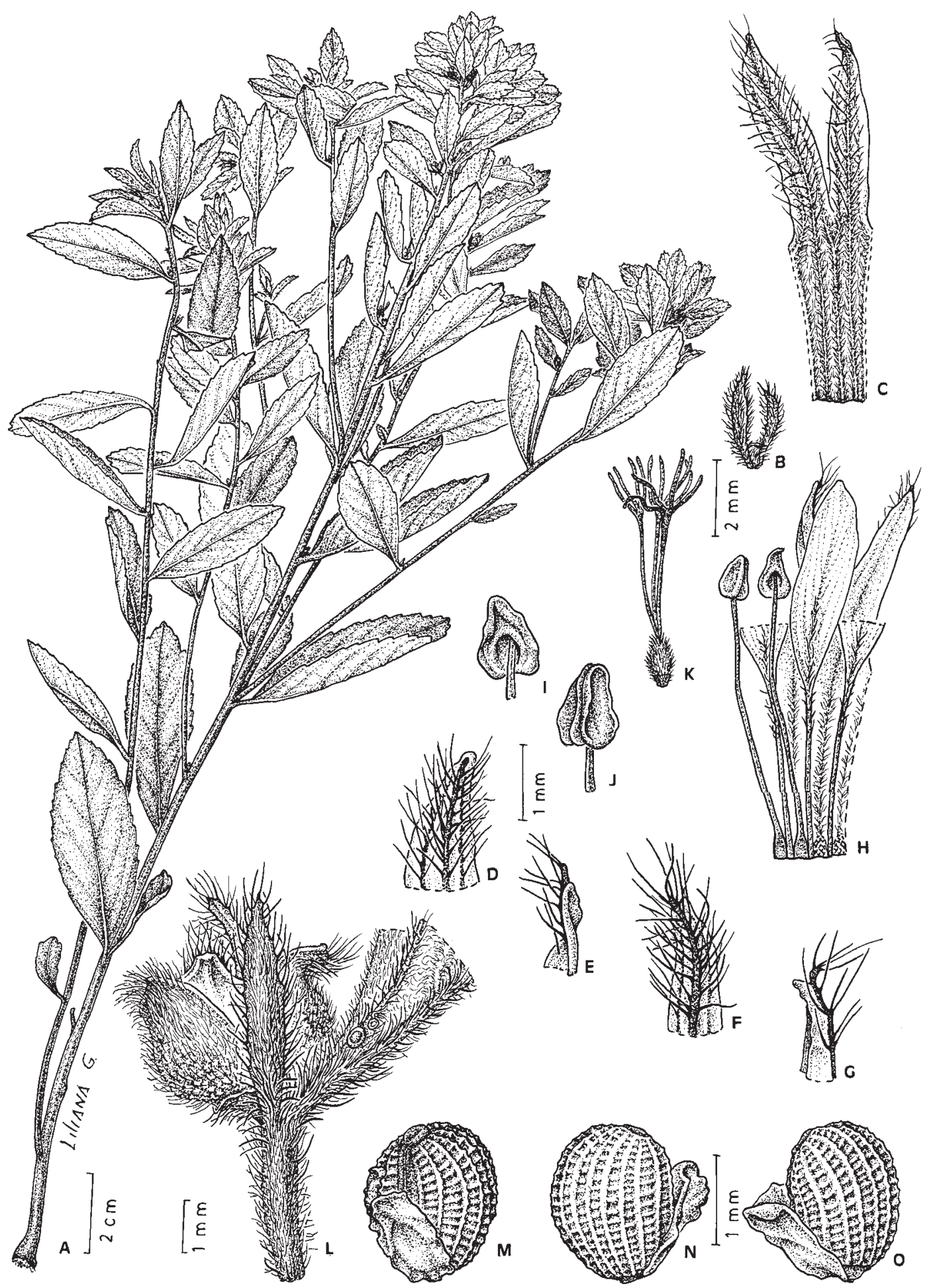

Fig. 51. Turnera melochia var. ramosissima. A: planta. B: receptáculo y profilos. C: porción del cáliz, cara externa. D-G: ápice de los lóbulos del cáliz. H: flor brevistila, porción del tubo calicino, cara interna, con pétalos y estambres adnatos; se han cuadriculado las cicatrices dejadas al desprender dos estambres. I-J: anteras, vistas dorsal y ventral. K: gineceo. L: porción basal de bráctea con nectarios, fruto epifilo y profilos. M-O: semilla con arilo, vistas rafeal y laterales (Spruce 1278). Del. Liliana Gómez. 


\section{Turnera melochioides Cambess.}

Fig. 52

Saint Hilaire, A., Jussieu, A. \& Cambessèdes, J., Flor. bras. merid. 2: 159 (219). Turnera melochioides var. genuina Urb. [nom. inval.], Jahrb. Königl. Bot. Gart. Berlin 2: 116. 1883; Urban, en Martius C.F.P., Fl. Bras. 13(3): 138. 1883. Typus: Brasil. Minas Gerais, Olho d'Agua, haud longe á vico Contendas, Laruotte s.n. (holotypus $\mathrm{P}$ !, isotypi $\mathrm{F}$, $\mathrm{P} !)$.

Subarbusto o arbusto ramoso hasta $1 \mathrm{~m}$ alt., erecto o procumbente, tallo cilíndrico, porción basal leñosa, corteza rojiza o pardonegruzca, con estrías longitudinales, cicatrices foliares salientes; entrenudos bien desarrollados. Yemas axilares de sarrollo acrópeto o acrópeto-basípeto; 1-2 ramas seriales floríferas desarrolladas en cada nudo. Hojas herbáceas, a veces coriáceas, a veces obscuras en seco, frecuentemente discoloras, extendidas o (cuando angostas) plegadas longitudinalmente. Estípulas rudimentarias, con coléteres. Pecíolo semicilíndrico, indumento como el del tallo. Lámina angustielíptica, elíptica, latielíptica, ovada, angustiovada, raramente obovada o suborbicular 13-75 x 2,5$33 \mathrm{~mm}$, relación largo:ancho $=1,6-15,6: 1$; venas laterales hundidas en la haz, a veces formando una cresta en el surco, prominentes en el envés, con pelos largos o cortos, venas terciarias a veces visibles o conspicuas en el envés, venación menor a veces visible en el envés. Nectarios circulares, marginales, reborde piloso, a veces ligeramente estipitados. Hojas floríferas súbitamente reducidas, bracteiformes, con nectarios sésiles sobre el envés y generalmente conspicuos. Flores heterostilas, epifilas, las basales en la axila de nomófilos, las apicales reunidas en racimos bracteosos compuestos, los racimos axilares originados por las yemas seriales de las hojas floríferas. Pedúnculo floral totalmente adnato al pecíolo, o con una porción apical libre. Profilos filiformes a veces subulados, o lanceolados, insertos en la base del receptáculo. Pedicelo nulo. Cáliz 3,2-10,5mm long., sépalos coherentes entre sí cerca de la mitad, raramente más. Corola ligeramente más corta,

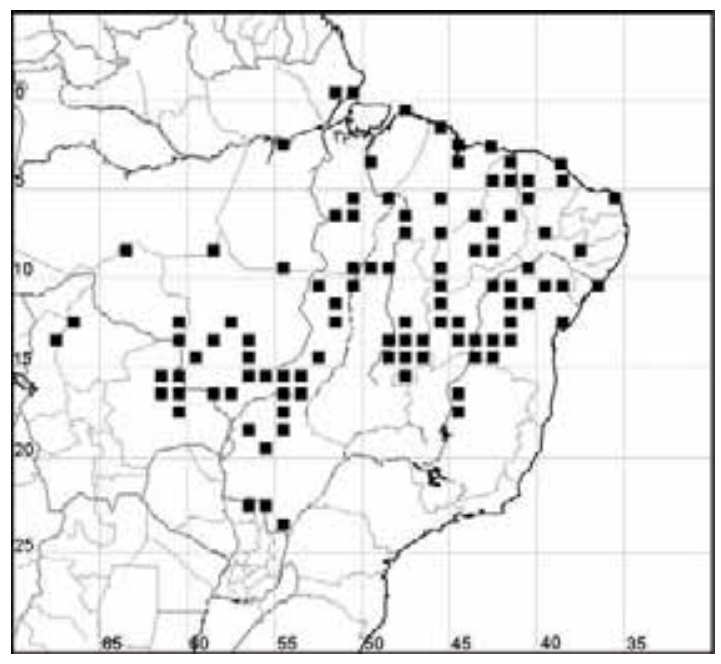

Fig. 52. Distribución de Turnera melochioides.

igual o hasta $4 \mathrm{~mm}$ más larga que el cáliz; pétalos amarillos o amarillo-anaranjados. Filamentos estaminales subulados, glabros, soldados brevemente al tubo calicino en la base; anteras ovadas, dorsifijas, base emarginada, ápice obtuso, ligeramente recurvado después de la dehiscencia. Ovario piloso, ovoide; estilos cilíndricos, pilosos, a veces glabros, porción superior dividida en ramas pilosas; estigma penicilado, ramas frecuentemente pilosas en la base. Fruto globoso, ovoide o cónico, porción inferior del tubo floral $0,2-0,5 \mathrm{~mm}$ long. persistente en la base; profilos más cortos o más largos que el fruto; valvas ovadas, lisas o a veces rugosas por fuera. Semilla obovoide, curvada, pardo-oscura cuando madura; exóstoma cónico u obtuso, excéntrico; rafe linear apenas marcada, lado rafeal ligera o marcadamente cóncavo; cálaza saliente, pigmentada, a veces ligeramente cóncava. Episperma reticulado, aréolas diminutas, más o menos cuadrangulares, con una depresión punctiforme, epidermis papilosa, con cera epicuticular bastoniforme en las semillas inmaduras. Arilo unilateral, angosto, blancoamarillento, igual o más largo que la semilla, borde rasgado, de células papilosas.

Cromosomas: $2 \mathrm{n}=14$, Krapovickas \& Schinini 36653, Krapovickas \& al. 38621, 38695 y 38754 (Fernández, 1987). Cariotipo: Krapovickas \& Schinini 36653 (Solís Neffa, 1996). 
Distribución: Especie de amplia distribución en el centro y Este de Brasil (Alagoas, Amapá, Amazonas, Bahia, Ceará, Goiás, Maranhão, Mato Grosso, Mato Grosso do Sul, Minas Gerais, Pará, Paraíba, Pernambuco, Piauí, Rio Grande do Norte, Rondonia y Tocantins) norte y este de Bolivia y noreste de Paraguay. Vive en «cerrado», campo-cerrado y «campo rupestre», ocasionalmente en «caatinga», también en lugares arenosos inundables a orillas de ríos, en lugares rocosos y en dunas marítimas. Prospera bien en la vegetación secundaria y en lugares alterados como los bordes de caminos.

Nombres vulgares: «malvavisco da costa» (Maranhão: Froes 1827); «chanana» (RGN: $P P D-152$ ), «alfazema de periquito» (RGN: Fonseca 11); «malva» (Miranda 155); «carrapicho» (Piaui, Barroso \& Elsie 8); «vassourinha» (Mato Grosso: Guimarães $328)$.

Usos: En los especímenes Carvalho \& Bona Nascimento 463, 1103 y 1104 se indica que la planta es consumida por ganado bovino. En el ejemplar $P P D-152$, se dice que tiene uso medicinal como cicatrizante.

Obs.: Especie de antesis matutina, las flores se cierran alrededor de las 15 hs. Su morfolo- gía es muy variable, Urban (1883) describió seis variedades sobre los escasos ejemplares conocidos en la época; con el abundante material disponible en la actualidad, se constata que los caracteres se solapan de manera que se reconocen 3 de las variedades de Urban y se agrega una, con frutos rugosos, carácter excepcional en la serie.

Los profilos son acrescentes, los que se encuentran sobre los frutos son más largos y anchos que los que acompañan las flores. Urban (1883) describe profilos de hasta 0,8 $\mathrm{mm}$ lat. Los más anchos encontrados en frutos miden $0,6 \mathrm{~mm}$ lat.

Se encontraron compuestos cianogénicos (Spencer \& al., 1985) en el ejemplar Froes $1132(\mathrm{~F})$.

En la var. melochioides se analizó la estructura de los coléteres, de tipo standard, presentes en los dientes de los primordios foliares, en las estípulas rudimentarias y en los profilos jóvenes (Gonzalez, 1998). Se estudió la anatomía caulinar y foliar, los haces caulinares no presentan casquetes fibrosos; las hojas son dorsiventrales e hipostomáticas, los haces vasculares muestran vaina parenquimática; en la semilla la endotesta está formada por células pequeñas (Gonzalez, 2000). La vascularización floral y los nectarios florales fueron estudiados en las vars. melochioides y latifolia (Gonzalez, 2001).

\section{Clave para las variedades de Turnera melochioides}

1. Planta oscura en seco, hojas generalmente coriáceas y discoloras. Lámina elíptica, latielíptica, a veces ovada, raramente obovada, ápice obtuso o agudo, simple o doblemente aserrado-crenada

2. Lámina 20-55(-66) x (8-)11-20(-33) mm, relación largo:ancho = 1,6-3(-4,5):1. Cáliz (3,7-)5-6(-9,5) mm long.; tubo calicino (1,6-)2-3(-4,7) mm long. Fruto liso, 1,8-5,7 mm long.; placentas 2-11ovuladas. Semilla 2-2,5 x 0,8-1,2 mm. Bolivia, Paraguay, Brasil: AL, BA, CE, GO, MA, MT, MS, MG, PA, PE, PI, RO, TO.

T. melochioides var. melochioides

2'. Lámina 1,3-4 x 0,5-1,2 mm, relación largo:ancho = 1,9-3,5:1. Cáliz 3,2-7,3 mm; tubo calicino 1,6$4,1 \mathrm{~mm}$. Fruto rugoso, a veces liso y rugoso en la misma rama; placentas 2-3-ovuladas. Semilla 1,32,7 x 1,2-1,5 mm. Brasil: GO.

T. melochioides var. rugosa

1'. Planta no oscura en seco, hojas herbáceas concoloras o algo discoloras

3. Hojas ovadas u ovado lanceoladas, herbáceas, simple o doblemente crenadas, extendidas, 20-60 
(-73) x 8-25 mm, relación largo:ancho = (1,6-)2-4(-5):1, epifilo piloso. Bolivia, Brasil: AM, BA, CE, MA, PA, PE, PI, RN.

T. melochioides var. latifolia

3'. Hojas angustielípticas o lineares, subenteras, serruladas o aserradas, extendidas o plegadas longitudinalmente, (13-)23-56(-75) x 2,5-10 mm, relación largo:ancho = 4,1-15,6:1, epifilo glabro o piloso. Bolivia, Brasil: BA, MA, MT, PA, PI, TO.

T. melochioides var. arenaria

118a. Turnera melochioides Cambess. var. melochioides

Figs. 10 y 53

Turnera melochioides var. oblongifolia Urb., Jahrb. Königl. Bot. Gart. Berlin 2: 116, 1883, Lectotypus: Arbo (1993) seleccionó erróneamente como lectotipo Gardner 1247; la descripción original de la variedad indica «obscure colorata», cualidad que el ejemplar indicado no posee. Se designa aquí el ejemplar adecuado: Brasil. Ceará: Serra de Araripe, X-1838, Gardner 1667 (P!, isotypi BM!, CGE!, K!, NY!, OXF!, S!, US!, W!).

Subarbusto o arbusto ramoso hasta $1 \mathrm{~m}$ alt., tallos con pelos largos curvado-antrorsos, curvado-erectos o patentes mezclados con pelos cortos crespos, a veces estrigosos o sólo con pelos crespos. Hojas oscuras en seco, generalmente coriáceas y discoloras, extendidas. Lámina elíptica, latielíptica, ovada, algunas veces obovada, 20-55(-66) x (8-)11-20(-33)mm, relación largo:ancho = 1,6-3(-4,5):1; ápice agudo u obtuso; margen ligera o marcadamente revoluto, aserrado-crenado, a veces doblemente; haz oscura en seco, estrigosa, con pelos más o menos erectos, de base cónica abultada, o con pelos cortos crespos y pelos largos entremezclados, a veces con pelos esparcidos sobre las venas; envés con pelos simples más o menos erectos, a veces con pelos largos y cortos mezclados, a veces muy densos, generalmente con pelos glandulares microcapitados; venas terciarias recurvas visibles en el envés. Nectarios 0-2, situados cerca de la base de la lámina. Flores reunidas en racimos bracteosos (braquiblastos) terminales o axilares, el eje puede alcanzar $3 \mathrm{~cm}$. Cáliz (3,7-)5-6(-9,5)mm long.; tubo calicino (1,6)2-3(-4,7)mm long., por fuera con pelos cor- tos; lóbulos con pelos más largos. Corola más corta $(0,6 \mathrm{~mm})$, igual o más larga $(1,5 \mathrm{~mm})$ que el cáliz; pétalos glabros o con pelos en la base o sobre la vena media en el tercio basal. Fruto 1,8-5,7mm long.; placentas 2-11-ovuladas. Semilla 2-2,5 x 0,8-1,2mm.

Material escogido: BOLIVIA. Santa Cruz, prov. Velasco, $6 \mathrm{~km} \mathrm{~N}$ de San Miguel, camino a San Ignacio de Velasco, 16³1'17"S 6059'19"W, 455 m, 3-IV-2006, Ferrucci \& al. 2472 (CTES); Velasco: Pque. Nac. Noel Kempff M., meseta de Caparuch, 1,5 km S de la pista Noel Kempff, $13^{\circ} 54^{\prime} 22 \mathrm{~S} 60^{\circ} 48^{\prime} 52 \mathrm{~W}, 190 \mathrm{~m}, 12-\mathrm{V}-1994$, Mostacedo \& al.1681 (CTES, F, MO); prov. Velasco, Campamento Las Torres, margen del Rio Iténez (Guaporé), frontera con Mato Grosso, lado NE de la Serranía Huanchaca, 24 km S de Flor de Oro, ca. $50 \mathrm{~km} \mathrm{~N}$ del Rio Verde, 13\%39'S $60^{\circ} 48^{\prime} \mathrm{W}, 200-400$ m, 26-V-1991, Peña \& Foster 332 (CTES, F, LPB, NY). BRASIL. Alagoas: near Piaçabaçu, III-1838, Gardner 1247 (BM, CGE, F, FI, K, NY, OXF, P, S, US, W, sintipo de var. oblongifolia). Bahia: mun. Ibotirama, BR-242

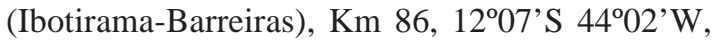
830 m, 7-VII-1983, Coradin \& al. 6628 (CEN, CTES); Mun. Correntina, ca. $17 \mathrm{~km} \mathrm{~W}$ de Correntina en la ruta BA-349 a Brasília, 13⒉ $5^{\prime} \mathrm{S}$ 444ㄴ'W, 10-VIII-1996, Ferrucci \& al. 995 (CEPEC, CTES, K, MBM) y Ferrucci \& al. 996 (CEPEC, CTES, K, MBM); $19.5 \mathrm{~km}$ SE of the town of Morro do Chapeu on the BA-052 road to Mundo Novo, by the Rio Ferro Doido, ca. 900 m, approx. $11^{\circ} 38^{\prime} \mathrm{S} 41^{\circ} 02^{\prime} \mathrm{W}, 2-\mathrm{III}-1977$, Harley \& al. 19291 (CTES, E, IPA, K, NY, US); Formosa do Rio Preto, $24 \mathrm{~km}$ de Formosa do Rio Preto, na

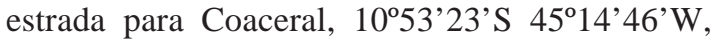
737 m, 28-III-2000, Harley \& al. 53740 (CTES, HUEFS); Rio de Contas, prox. a Barragem, nos arredores da cidade, na estrada para o Pico das Almas, 13³4'16"S 41²4ㄴㄱ"W, 1016 m, 4-III- 
2004, Harley \& Giulietti 55020 (CTES, HUEFS); Rod. BR-020, $30 \mathrm{~km} \mathrm{~W}$ of Barreiras, 12-I-1977, Hatschbach 39473 (C, CTES, HB, MBM, MO); Mun. Rio de Contas, Campo da Aviação, 1200 m, 04-VI-1992, Hatschbach \& al. 56725 (C, CTES, MBM, SP); mun. Igapora, Rod.BR-430, proximo do trevo para Tanque Novo, 10-III-1998, Hatschbach \& al. 67584 (CTES, MBM); ca. $5 \mathrm{~km}$ $\mathrm{S}$ of Rio Roda Velha, ca. $150 \mathrm{~km}$ SW of Barreiras, 900 m, 15-IV-1966, Irwin \& al. 14896 (CTES, NY, P, UB); Licinio de Almeida: Rod. para Urandi, ca. $3,8 \mathrm{~km}$ da cidade, $14^{\circ} 42^{\prime} 47 \mathrm{~S}$ 4230'33W, $860 \mathrm{~m}$, 31-III-2001, Jardim \& al. 3313 (CEPEC, CTES, NY); Mun. Riachão das Neves, BR-135, estrada Barreiras-Corrente, $3 \mathrm{~km}$ $\mathrm{N}$ de Rch.Caripare, $11^{\circ} 30^{\prime} \mathrm{S} 45^{\circ} 00^{\prime} \mathrm{W}, 1-\mathrm{IV}-1983$, Krapovickas \& al. 38713 (C, CTES, F, K, MBM); Barra: Ibiraba (=Icatú), em frente a vila de Ibiraba no caminho para os Brejos, $10^{\circ} 48^{\prime} \mathrm{S} 42^{\circ} 50^{\prime} \mathrm{W}, 26-$ II-1997, Queiroz 4876 (CTES, HUEFS, MBM); Umburanas: Serra do Curral Feio (localmente referida como Serra da Empreitada), Cachoeirinha, a beira do rio Tabuleiro, ca. $10 \mathrm{~km} \mathrm{NW}$ de lfino, $10^{\circ} 21^{\prime} \mathrm{S} 41^{\circ} 13^{\prime} \mathrm{W}, 11-\mathrm{IV}-1999$, Queiroz \& al. 5378 (CTES, HUEFS); Bahia, Bom Jesus da Lapa, ca. $14 \mathrm{~km} \mathrm{~S}$ do entroncamento para Bom Jesus da Lapa na estrada para Malhada, $13^{\circ} 24^{\prime} 14^{\prime} \mathrm{S}$ $43^{\circ} 21^{\prime} 43^{\prime} \mathrm{W}, 11-\mathrm{II}-2000$, Queiroz \& al. 5863 (CTES, HUEFS); Bahia, Correntina: ca. 43 km W de Santa Maria da Vitoria na estrada para

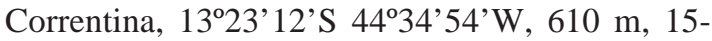
II-2000, Queiroz \& al. 6041 (CTES, HUEFS); Barra, Ibiraba, $10^{\circ} 32^{\prime} \mathrm{S} 52^{\circ} 00^{\prime} \mathrm{W}$, 4-II-2000, Rodarte 65 (CTES, HRB); Licinio de Almeida, estrada de terra para Caetité, $14^{\circ} 36^{\prime} 31^{\prime \prime S} 42^{\circ} 31^{\prime} 55^{\prime \prime} \mathrm{W}, 852$ m, 3-XI-2006, Scuza-Silva \& al. 221 (CTES, HUEFS). Ceará: Chapada da Serra do Araripe, 4VIII-1948, Duarte \& Ivone 1291 (CTES, RB); Mun. Crato, Floresta Nac. do Araripe, próximo a sede da floresta, 6-V-1991, Esteves \& Barros 2582 (CTES, MAC, SPF); Serra de Ibiapaba, Guaraciaba do Norte, 15-VI-1979, Fernandes \& al. s.n. (CTES); near Crato, IX-1838, Gardner 1664 (BM, K, sintipo de var. oblongifolia); mun. Crato, $12 \mathrm{~km} \mathrm{SW}$ of Crato on road to Exú, Serra do Araripe, $7^{\circ} 14^{\prime} 55.6^{\prime \prime} \mathrm{S} 39^{\circ} 29^{\prime} 53.8^{\prime \prime} \mathrm{W}$, ca. $700 \mathrm{~m}$, 30-VII-1997, Thomas \& al. 11670 (CTES, NY). Goiás: GO 446, $7 \mathrm{~km}$ NW de Iaciara, camino a Nova Roma, ca. 500 m, 3-II-1990, Arbo \& al. 3538 (C, CTES, F, GH, HRCB, K, LIL, MBM, MO, NY); Mun.São Domingos, Rod.GO-110,
Serra Geral de Goias, 700 m, 13-V-2000, Hatschbach \& al. 71061(C, CTES, MBM); Rodovia Alto Paraíso de Goiás-Teresina de Goiás, 12-III-2007, Pastore \& al. 1800 (CTES, HUEFS); Mun. Minaçu, região de Agua Quente, corrego Bateias, proximo a obra do AHE Serra da Mesa, futuro reservatorio do AHE Serra da Mesa, $390 \mathrm{~m}$, 21-X-1996, Walter \& al. 3508 (CEN, CTES). Maranhão: inter S. João \& S. Anna [seg. Urban, 1883), Burchell 9247 (K, P, US, sintipo de var. oblongifolia) y Burchell 9250 (K, P, sintipo de var. oblongifolia); Mun. Loreto, ca. $40 \mathrm{~km} \mathrm{~S}$ of Loreto, ca. $7^{\circ} 26^{\prime} \mathrm{S} 45^{\circ} 07^{\prime} \mathrm{W}$, ca. $250 \mathrm{~m}, 23-\mathrm{III}-$ 1962, Eiten \& Eiten 3845 (SP); BR-230, estrada para Barão de Grajau, São João dos Patos, 19-IV1980, Fernandes \& Nunes s.n. (CTES); Mun. Carolina, Transamazonian Highway BR-230 \& BR010, Pedra Caida, $35 \mathrm{~km} \mathrm{~N}$ of Carolina, 400-500 m, 14-IV-1983, Taylor \& al. E1218 (CTES, NY). Mato Grosso: Rondonópolis, arredores, 16-V1973, Hatschbach 31998 (C, CTES, MBM); Rod. MT-160 km 44, mun. Arenapolis, 12-V-1995, Hatschbach \& al. 62654 (C, MBM); Água Fria, mun. Chapada dos Guimaraes, 13-VIII-1997, Hatschbach \& al. 66836 (CTES, MBM); Mun. Jaciara, Rio Amaral, Cachoeira da Fumaça, 21VIII-1997, Hatschbach \& al. 67045 (CTES, $\mathrm{MBM}$ ); ca. $20 \mathrm{~km} \mathrm{~S}$ of Xavantina, $400 \mathrm{~m}$, 9-VI1966, Irwin \& al. 16825 (CTES, UB); BR-070, 170 km W de Barra do Garças, 550 m, 4-VI-1985, Krapovickas \& al. 40237 (C, CEN, CTES, K); 41 km E de Cuiabá, BR-163, 3-VI-1985, Krapovickas \& al. 40270 (CTES); Serra da Pacca Norea, extremo N de M.Grosso, cob. do Cantaño, III-1917, Rondon en Kuhlmann 2185 (SP); Mun. Alto do Garça, ca. $58 \mathrm{~km}$ da cidade, sentido Alto do GarçaDiamantina, ca. 16²56'S 5330'W, 19-XII-1992, Rodrigues \& Silva 361 (SJRP); Mun.Diamantino, Fazenda Pequeno Figueiredo, ca. 4 km (em linha reta) de Diamantino $14^{\circ} 20^{\prime} \mathrm{S} 56^{\circ} 27^{\prime} \mathrm{W}, 22-\mathrm{V}$ 1997, Souza \& al. 16835 (CTES, ESA); Rod. Cuiabá-Mimoso, 25-V-1982, Vasconcellos \& Cunha 13533 (UEC). Mato Grosso do Sul: 7 Quedas, mun. Rio Verde, 27-VIII-1973, Hatschbach 32427 (CTES, MBM, Z); Rio Corrente, mun. Itaquira, 11-II-1974, Hatschbach 34051 (CTES, MBM); Rio Verde, 5 km S, 11-XI1975, Hatschbach \& al. 37413 (CTES, MBM, NY, W); Mun. Aquidauana, Correo São João, 25 $\mathrm{km}$ de Rio Negro e $25 \mathrm{~km}$ de Cipolandia, 1956'08S 55²19'27W, 31-VIII-1998, Pott \& 
Foster 3674 (CTES, F); Mun. Coxim, Km 0,6 Rodovia Coxim-Silviolândia, Area do Exercito, 26-II-1994, Pott \& Pott 6631 (CTES); mun. Corumbá, Fazenda Nhumirim, subregião de Nhecolândia, 1859'S 56³9'W, 3-X-1984, Pott 1461 (CTES). Minas Gerais: Serra do Cabral, subida Buenópolis-Estrada Real, mun. Buenópolis, 24-VIII-2002, Hatschbach \& al. 73822 (CTES, MBM). Pará: Mun. Itaituba, estrada Santarem-Cuiabá, BR-163 km 171, prox. a div. Pará-MT, 09³5'S 54³5’ W, 22-IV-1983, Amaral \& al. 870 (CTES, K, MO, RB, UB); approx. $18 \mathrm{~km}$ E of Tucurui and Rio Tocantins, by BR 263, approx. 3³0'S 49³2'W, 28-X-1981, Daly \& al. 983 (NY). Pernambuco: Exu: Chapada do Araripe, Serra do Inga. Projeto Exu $7^{\circ} 21^{\prime} 32 \mathrm{~S}$ 3946’34W, 4-IV-2001, Harley \& Giulietti 54165 CTES, HUEFS). Piauí: São Raimundo Nonato, 7 IV-1978, Fernandes s.n. (CTES); between the Rio Caninde \& Oeiras, IV-1839, Gardner 2180 (BM, CGE, K, OXF); Serra do Santana, mun. Granja, 3'21'S 4112'W, 21-XI-1977, Lima 22 (HRB, RB); Serra do Uruçuí, 9²0'S 4504'W, 23-III1978, Miranda 155 (RB); S.Filomena, 11-VII1925, Snethlage 667 (F); Serra Branca, I-1907, Ule 7509 (HBG, K). Rio de Janeiro: cult., Glaziou 9649 (BR, C, K, P, sintipo de var. oblongifolia); Rio de Janeiro, Glaziou 10879 (P, sintipo de var. oblongifolia, localidad dudosa). Rondonia: Mun. Colorado do Oeste, BR-364, Porto Velho-Cuiabá, estrada para Colorado do Oeste, Km 25, 12¹3'S 6051'W, 7-VI-1984, Cid \& al. 4305 (CTES, F, K, MO, RB); mun.Vilhena, BR-364, rodovia Porto Velho-Cuiaba, Km 39, $12^{\circ} 13^{\prime} \mathrm{S} 60^{\circ} 61^{\prime} \mathrm{W}, 10-\mathrm{VI}-1984$, Cid \& al. 4458 (CTES, K, RB). Tocantins: inter Porto Imperial \& Funil [Mares, Cachoeira dos Marcos? seg. Smith \& Smith 1967], V, Burchell 8860 (K, P, sintipo de var. oblongifolia); inter Funil \& S.João [Sobradinha, on the left bank, opposite Barra do R.Farinha seg. Smith \& Smith, 1967], Burchell 8979 (K, P, sintipo de var. oblongifolia) y Burchell 8983 (K, P, sintipo de var. oblongifolia); Rod. Belem-Brasília, mun. Babaçulandia, 26-III1976, Hatschbach \& Ku mmrow 38385 (C, CTES). PARAGUAY. Amambay: Colonia Santa Clara, ca. Cerro Corá, 18-XII-1999, Ferrucci \& al. 1685 (CEPEC, CTES, K); 35 km W de Pedro Juan Caballero, 10-XII-1992, Nicora \& al. 9803 (CTES); Ruta $5,3 \mathrm{~km} \mathrm{~W}$ del Parque Nacional Cerro Corá, 7-XI2001, Schinini \& al. 35536 (CTES).
Distribución y fenología: variedad extendida desde los estados nordestinos de Brasil hasta Bolivia (Santa Cruz) y Paraguay (Amambay), en «cerrado», «caatinga», sabana arbolada, bosque abierto, matorrales, también en «campo rupestre», frecuentemente en suelo arenoso o pedregoso; se adapta bien a lugares alterados como bordes de caminos; florece y fructifica todo el año. Hay dos ejemplares de Glaziou, indicando Rio de Janeiro como localidad; en uno se indica que es cultivado, tal vez el otro también sea cultivado, la especie nunca fue encontrada en el sur de Minas Gerais, ni en Espirito Santo ni en Rio de Janeiro.

Obs.: El ejemplar Kuhlmann 2835 presenta semillas más cortas y gruesas $(1,8 \times 1,1 \mathrm{~mm})$, con el lado rafeal convexo. El espécimen Lima 22 presenta flores grandes, el cáliz de 9,5 mm long., los filamentos estaminales largamente adheridos $(1,8 \mathrm{~mm})$ al tubo calicino $\mathrm{y}$ semillas grandes, curvas, 2,5 x 1,2 mm. El ejemplar Harley \& al. 19291 tiene gineceo y androceo de la misma longitud, sólo las ramas más largas del estigma sobrepasan las anteras. El espécimen Hatschbach \& al. 67584 tiene hojas muy angostas, su aspecto vegetativo es similar a Turnera harleyi, pero presenta flores pequeñas con corola poco más larga que el cáliz.

\section{8b. Turnera melochioides var. arenaria Urb.}

Figs. 21 y 54

Urban, I., Jahrb. Königl. Bot. Gart. Berlin 2: 115. 1883; Urban, en Martius C.F.P., Fl. Bras. 13(3): 135. 1883; Turnera arenaria Spruce ex Urb. pro syn. Turnera arenaria (Urb.) Arbo, Bonplandia 7: 98. 1993. Typus: Brasil. Pará: Santarem, XI-1849/III1850, Spruce s.n. [743 seg. Urban] (lectotypus P!, select. Arbo, 1993, isotypi FI!, P!, W!).

Turnera melochioides var. angustifolia Urb., Jahrb. Königl. Bot. Gart. Berlin 2: 116, 1883; Urban, en Martius C.F.P., Fl. Bras. 13(3): 137. 1883. Lectotypus, seleccionado por Arbo (1993): Brasil. Piauí. Gardner 2171 (P!, isotypi BM!, CGE!, G!, K!, NY!, OXF!, P!, US!, W!). 


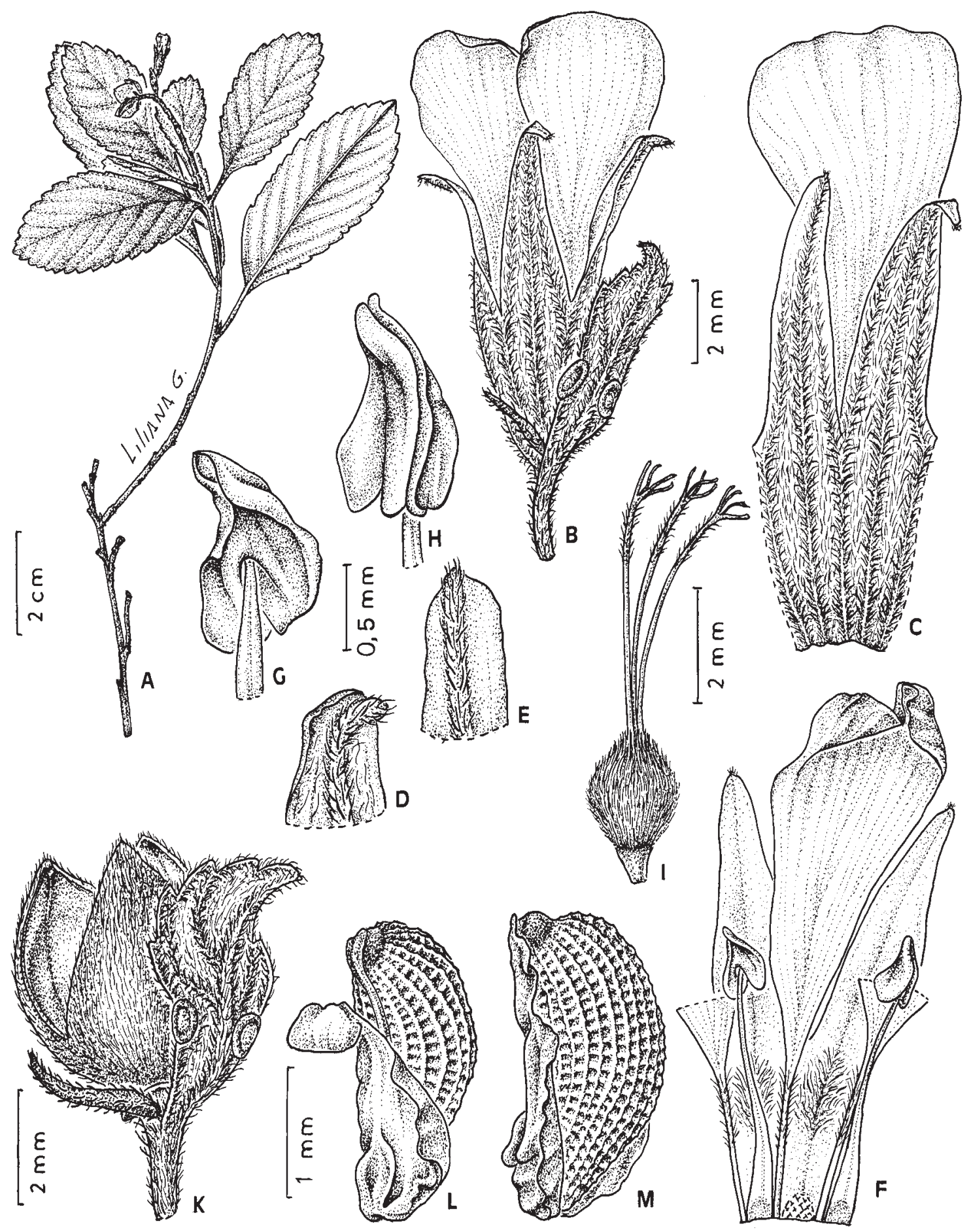

Fig. 53. Turnera melochioides var. melochioides. A: rama florífera. B: bráctea con flor epifila y profilo. C: porción del cáliz, cara externa y pétalo. D-E: ápice de lóbulos del cáliz externo e interno. F: flor longistila, porción del tubo calicino, cara interna, con pétalos y estambres adnatos; se ha cuadriculado la cicatriz dejada al desprender un estambre. G-H: anteras, vistas dorsal y ventral. I: receptáculo y gineceo. K: bráctea con nectarios, fruto epifilo y profilo. L-M: semillas con arilo, vistas rafeal y lateral (Peña \& Foster 332). Del. Liliana Gómez. 
Subarbusto o arbusto ramoso hasta $1 \mathrm{~m}$ alt., tallos con pelos largos curvado-antrorsos mezclados con pelos cortos crespos, a veces sólo con pelos crespos o hirsuto, con pelos largos. Hojas herbáceas, a veces algo discoloras, extendidas o plegadas longitudinalmente. Lámina angustielíptica o linear, algunas veces angustiobovada, (13-)23-56(-75) x 2,5-10 mm, relación largo:ancho $=4,1-$ 15,6:1; margen revoluto, subentero, serrulado o aserrado; ápice agudo u obtuso; haz y envés totalmente glabros, con algunos pelos sobre las venas o con pelos esparcidos o uniformemente pilosos, a veces con pelos largos de base cónica o cilíndrica y pelos cortos mezclados, generalmente con pelos glandulares microcapitados en el envés. Nectarios 0-2, situados cerca de la base de la lámina. Flores reunidas en racimos bracteosos muy abreviados, a veces los entrenudos inferiores alargados de manera que el racimo puede alcanzar 10-12 cm. Cáliz (4-)5-7( 9) mm long.; tubo calicino (2-)2,5-3(-3,7) $\mathrm{mm}$ long., por fuera con pelos cortos; lóbulos con pelos más largos al menos sobre las venas. Corola más larga que el cáliz; pétalos glabros o con pelos sobre la vena media en la porción basal. Fruto 2,5-4,2 mm long.; placentas 2-9-ovuladas. Semilla $1,7-2$ x $0,8-1 \mathrm{~mm}$.

Material escogido: BOLIVIA. Santa Cruz: prov. Sandoval, camino de San Matías a Las Petas, a $38,3 \mathrm{~km}$ W de San Matías, 16 22'15"S

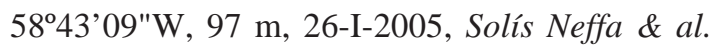
1637 (CTES). BRASIL. Amapá: Highway BR156, opposite EMBRAPA research station, $0^{\circ} 37 \mathrm{~N}$ 5105W, 01-VIII-1993, Bridgewater \& al. S72 (E); Macapa, campo experimental (Km 44 da BR156) da UEPAT de Macapá/EMBRAPA, $50 \mathrm{~m}$, 14-VII-88, Pott \& al. 4272 (CPAP, CTES). Bahia. Montem Sanctum, IV, Martius s.n. (M, sintipo de var. angustifolia); Mun. Igaporã, Rod. BR-430, proximo ao trevo para Tanque Novo, 950 m, 18-III-1995, Hatschbach \& al. 62022 (CTES); Mun. Brejinho das Ametistas, estrada Brejinho das Ametistas-Caetité, 22-V-1999, Souza \& al. 23048 (CTES, ESA). Maranhão: entre Barão de Grajaú e S.José dos Patos, 3-VIII-1964, Castellanos 25355 (CTES). Mato Grosso: São Felix do Araguaia, Beira do Rio Araguaia, entre São Felix do Araguaia e o encontro com o Rio das Mortes,
Praia do Gado, $11^{\circ} 40^{\prime} 22 \mathrm{~S} 50^{\circ} 40^{\prime} 14 \mathrm{~W}, 130 \mathrm{~m}, 16-$ III-1997, Souza \& al. 14249 (CTES, ESA). Pará: Mun. Santarém, estrada do Aeroporto, Km 2, $02^{\circ} 25^{\prime} \mathrm{S} 54^{\circ} 45^{\prime} \mathrm{W}, 21-\mathrm{V}-1983$, Amaral \& al. 1391 (CTES, K, MO, NY, RB, UB); «N 1», 25 km NW of camp at Serra Norte, approx. $05^{\circ} 54^{\prime} \mathrm{S} 50^{\circ} 27^{\prime} \mathrm{W}$, 13-XII-1981, Daly \& al. 1980 (CTES, F, K, NY, US); Mun. Obidos, Campos do Ariramba, campos prox. ao Rio Ariramba, 5-XII-1987, Farney \& Batista 2098 (CTES, K, RB); Mun. Tucuruí, Km 25 S of Represa Tucuruí on road BR-422 to Breu Branco, approx. $03^{\circ} 52^{\prime} \mathrm{S} 49^{\circ} 44^{\prime} \mathrm{W}, 90 \mathrm{~m}, 15$-III1980, Plowman \& al. 9601 (CTES, HPR, NY, US); Serra dos Carajás, 26-VI-1976, Ribeiro 1361 (CTES); prope Santarem, XI-1828, Riedel 1544 (K, M, NY, P, sintipo de var. arenaria); São Felix do Xingú, ponto 8, folha SC 22 VD, 12-VI-1978, Rosário 66 (UEC); Marabá, Serra dos Carajás, N4, 17-III-1984, Silva \& al. 1867 (CTES, NY); AMZA cap N.1, $06^{\circ} 01^{\prime} \mathrm{S} 50^{\circ} 18^{\prime} \mathrm{W}, 650 \mathrm{~m}, 18$-V1982, Sperling \& al. 5724 (CTES, F, K, MO, NY). Piauí: mun. Piracuruca, Serra Negra, Parque Nac.

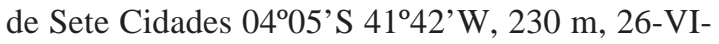
1999, Alencar 655 (CTES, TEPB); mun. Piripiri, Parque Nac. de Sete Cidades, Descoberta (7a.cidade) $04^{\circ} 05^{\prime} \mathrm{S} 41^{\circ} 44^{\prime} \mathrm{W}, 200 \mathrm{~m}, 27-\mathrm{VI}-1999$, Alencar 663 (CTES, TEPB); mun. Piracuruca, Parque Nac. de Sete Cidades, Baixa do Bacuri (1a.cidade), $04^{\circ} 05^{\prime} \mathrm{S} 41^{\circ} 40^{\prime} \mathrm{W}, 120 \mathrm{~m}, 23-\mathrm{VII}-$ 1999, Alencar 723 (CTES, TEPB); mun. Campo Maior, Fazenda Sol Posto 04'49'S 42 ${ }^{\circ} 10^{\prime} \mathrm{W}, 125$ m, 9-VII-1989, Bona Nascimento \& Carvalho 1102 (CTES); Floriano, 0645'S, 43ํW, 170 m, 7IV-1983, Krapovickas \& al. 38621 (CTES); $7 \mathrm{~km}$ E de Nazaré do Piauí, BR-230, $07^{\circ} \mathrm{S} 42^{\circ} 38^{\prime} \mathrm{W}$, 300 m, 7-IV-1983, Krapovickas \& al. 38754 (CEN, CTES). Tocantins: Rod. TO-050, $5 \mathrm{~km}$ ao $\mathrm{S}$ de Conceição do Tocantins, Fazenda Cartão de Visita, $400 \mathrm{~m}, 11-\mathrm{V}-2000$, Hatschbach \& al. 70927 (CTES, MBM); Ilha do Bananal, Parque Nac. do Araguaia, Mun. Pium, Base Fisica do Rio Javaés, Antigo Acampamento do Projeto Quelônios do Amazônia, 0959'59"S 5007'12"W, 145 m, 27-III-1999, Silva \& al. 4185 (CTES); sueRio Araguaia, Caseara, 17-VIII-1978, Silva 4942 (CTES, F, NY); Ilha do Bananal, Parque Nac. do Araguaia. Mun. da Lagoa da Confusão, Praia do Gado, 10²4'02S 50²9'07W, 180 m, 23-III-1999, Silva \& al. 4090 (CTES).

Ejemplares cultivados: ARGENTINA. Co- 
rrientes, proc. Brasil, Piauí, Floriano, $06^{\circ} 45^{\prime} \mathrm{S}$ 4300'W, 25-IV-1984, Krapovickas \& al. 38621 bis (CTES).

Distribución y fenología: variedad extendida desde Amapá y Pará hasta Bahia, Tocantins, Mato Grosso y Bolivia (Santa Cruz); vive en campo y «cerrado», «campo rupestre», «capoeira», «varzea», matorrales, tanto en suelos arenosos como en suelos rojos $\mathrm{y}$ en afloramientos rocosos. Florece y fructifica casi todo el año, pero la mayoría de los ejemplares fueron colectados entre marzo y agosto.

Obs.: En Bona Nascimento \& Carvalho 1102 el tubo calicino es piloso en la base y los lóbulos son glabros.

En el ejemplar Hatschbach \& al. $62022 \mathrm{el}$ indumento es como el de Turnera harleyi, pero las hojas más anchas $(0,7-0,8 \mathrm{~mm})$, de borde algo revoluto, y el tamaño menor de las flores (cáliz de 5,5 mm long.), corresponden a T. melochioides.

\section{8c. Turnera melochioides var. latifolia Urb.}

Figs. 23 y 54

Urban, I., Jahrb. Königl. Bot. Gart. Berlin 2: 116, 1883, Lectotypus, designado por Arbo (1997): Brasil. Maranhão, Shady woods, Gardner 6031 (W!, isotypi BM!, CGE!, FI!, K!, OXF!, W!).

Subarbusto o arbusto ramoso $30-90 \mathrm{~cm}$ alt., tallos erectos o decumbentes, con pelos largos curvado-antrorsos, mezclados con pelos cortos crespos, a veces sólo con pelos crespos. Hojas herbáceas, extendidas, a veces algo discoloras. Lámina elíptica, latielíptica, ovada, angustiovada, algunas veces obovada o suborbicular, 20-60(-73) x 8-25 mm, relación largo:ancho $=(1,6-) 2-4(-5): 1 ;$ margen plano o revoluto, serrulado, aserrado, doblemente aserrado-crenado; ápice agudo u obtuso; haz a veces oscura en seco, estrigosa, o con pelos cortos crespos y pelos largos de base cónica o cilíndrica entremezclados; envés con pelos simples más o menos erectos, a veces con pelos largos y cortos mezclados, generalmente con pelos glandulares microcapitados; venas terciarias recurvas visibles en el envés. Nectarios 0-4, situados cerca de la base de la lámina. Flores reunidas en racimos bracteosos terminales o axilares, el eje puede alcanzar 13 $\mathrm{cm}$ por alargamiento de los entrenudos basales. Cáliz (4,6-)5-8( 10,5) mm long.; tubo calicino 2-4,5 mm long., por fuera con pelos cortos; lóbulos con pelos más largos, hasta 1,2 $\mathrm{mm}$ long. Corola 1-3,5 mm más larga que el cáliz; pétalos glabros o con pelos en la base o sobre la vena media en el tercio basal; ovario con placentas 3-9-ovuladas. Fruto 2-6 mm long.; profilos 0,2-0,7 mm lat. Semilla 1,7-2,1 x $0,7-1 \mathrm{~mm}$.

Material escogido: BOLIVIA. Beni: Vaca Diez, along road between Rurrenabaque and Riberalta, between Puerto Yata and jct. of hwy. to Cobija, 30,8 km S of border with Vaca Diez Province, $176,9 \mathrm{~km} \mathrm{~S}$ of jct. to Cobija, $12^{\circ} 47^{\prime} 34 \mathrm{~S}$ 663'07W, $190 \mathrm{~m}, 13-\mathrm{VIII}-2000$, Croat \& al. 84861 (MO). La Paz: Prov. Iturralde, Luisita, $13^{\circ} 05^{\prime} \mathrm{S} 67^{\circ} 15^{\prime} \mathrm{W}, 180 \mathrm{~m}, \mathrm{~W}$ del rio Beni, 5-III1984, Beck \& Haase 10204 (CTES) y Haase 862 (CTES). Santa Cruz, prov. Velazco, Taperas, ca. $95 \mathrm{~km} \mathrm{~N}$ of San Ignacio and ca. $32 \mathrm{~km} \mathrm{~S}$ of San Simón, 15²4'’ 6058'W, ca. 370 m, Hopkins \& al. 108 (LPB, NY); Velasco, VII-1892, Kuntze s.n. (NY); prov. Chiquitos, $10 \mathrm{~km} \mathrm{~S}$ de San José, $17^{\circ} 47^{\prime} \mathrm{S} \quad 60^{\circ} 67^{\prime} \mathrm{W}, \quad 400 \mathrm{~m}, \quad 29-\mathrm{IV}-1980$, Krapovickas \& al. 36653 (CTES); prov. Velasco, $15^{\circ} 30^{\prime} \mathrm{S} 61^{\circ} 00^{\prime} \mathrm{W}$, aprox. $400 \mathrm{~m}, 11-\mathrm{V}-1986$, Seidel 538 (CTES). BRASIL. Amazonas: Mun. Humaitá, estrada Humaitá-Porto Velho, Km 38, $8^{\circ} 00^{\prime} \mathrm{S}, 63^{\circ} 00^{\prime} \mathrm{W}, 6-\mathrm{V}-1982$, Teixeira 271 (CTES, K, NY, RB). Bahia: BR-101, $20 \mathrm{~km} \mathrm{~S}$ de Feira de Santana, camino a Cachoeira, aprox. $12^{\circ} 26^{\prime} \mathrm{S}$ $38^{\circ} 56^{\prime} \mathrm{W}$, ca. $250 \mathrm{~m}, 3$-XII-1992, Arbo \& al. 5525 (CTES, SPF); $6 \mathrm{~km} \mathrm{SW} \mathrm{de} \mathrm{Mucujé,} \mathrm{camino} \mathrm{a}$ Barra da Estiva, aprox. $13^{\circ} 01^{\prime} \mathrm{S} 41^{\circ} 26^{\prime} \mathrm{W}$, ca. 950 m, 25-XI-1992, Arbo \& al. 5765 (CTES, SPF); Serra do Tombador, $19 \mathrm{~km}$ al NW de Jacobina, BR-324, aprox. $11^{\circ} 05^{\prime} \mathrm{S} 40^{\circ} 40^{\prime} \mathrm{W}, 17-\mathrm{I}-1997$, Arbo \& al. 7396 (CEPEC, CTES K); Rio Paraguaçu , $3 \mathrm{~km}$ al $\mathrm{S}$ de Andaraí, camino a

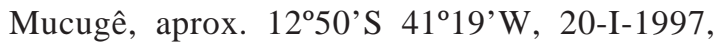
Arbo \& al.7536 (CEPEC, CTES, K); Mun. Tucano, Kms. 7-10 na estrada de Tucano para Ribeira do Pombal, 21-III-1992, Carvalho \& al. 


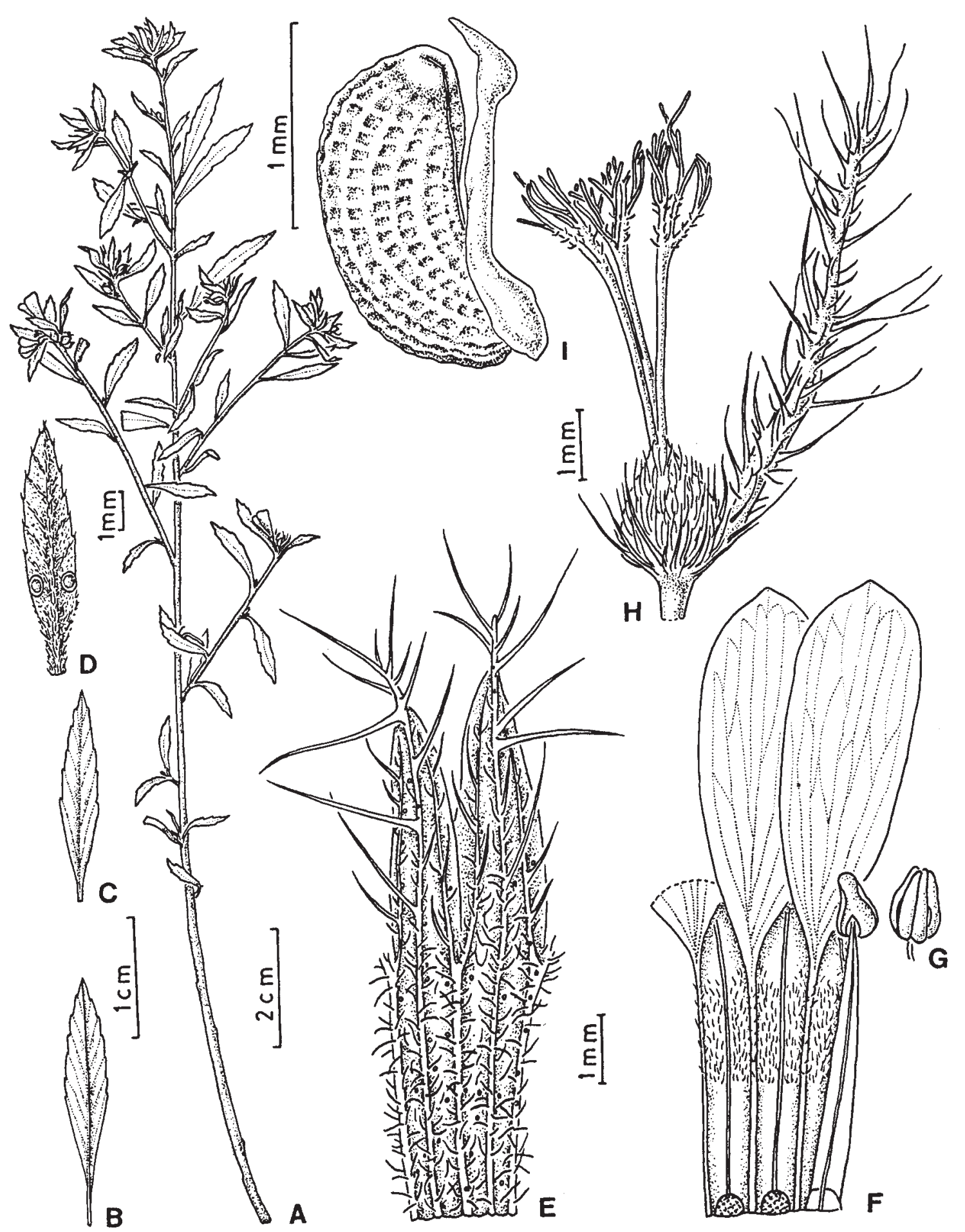

Fig. 54. Turnera melochioides var. arenaria. A: planta. B-C: hojas, cara adaxial. I: semilla con arilo, vista laterorafeal. T. melochioides var. latifolia. D: hoja, cara abaxial mostrando los nectarios. E: porción del cáliz, cara externa. F: porción del tubo calicino, cara interna, con pétalos y estambre adnatos; se han cuadriculado las cicatrices dejadas al desprender dos estambres. G: antera, vista ventral. H: receptáculo, profilo y gineceo. (A, B-C, I: Amaral \& al. 1391; D-H: Eiten \& Eiten 3665). Del. Liliana Gómez [@ Conservatoire et Jardin botaniques de la Ville de Genève. Reproducida con permiso]. 
3895 (CTES, NY); $8 \mathrm{~km} \mathrm{~S}$ of Andaraí, on road to Mucugé, just $\mathrm{N}$ of turning to Itaeté, ca. $400 \mathrm{~m}$, approx. $12^{\circ} 51^{\prime}$ S $41^{\circ} 19^{\prime} \mathrm{W}, 13-\mathrm{II}-1977$, Harley \& al. 18605 (CTES, IPA, K, NY, US); Mun. Rio de Contas, Barra do Brumado, 1100 m, 7-IV-1992, Hatschbach \& al. 56767 (CTES); Mun. Palmeiras, Rod. BR-242, trevo para Palmeiras, 9-IV-1992, Hatschbach \& al. 56925 (CTES, MBM); Valley of the Rio das Ondas: ca. $10 \mathrm{~km}$ W of Barreiras, ca. 500 m, 2-III-1971, Irwin \& al. 31286 (E, MO, NY, P); Carinhanha: Rod. para Cocos, $13 \mathrm{~km} \mathrm{~W} \mathrm{da}$ cidade, $14^{\circ} 13^{\prime} 45 \mathrm{~S} 43^{\circ} 52^{\prime} 01 \mathrm{~W}, 480 \mathrm{~m}, 16-\mathrm{IV}$ 2001, Jardim \& al. 3553 (CEPEC, CTES, NY); 60 $\mathrm{km}$ E de Barreiras, $12^{\circ} 05^{\prime} \mathrm{S} 44^{\circ} 30^{\prime} \mathrm{W}, 18$-III-1982, Krapovickas \& al. 37879 (CEN, CTES, K); 65 km W de Barreiras, $12^{\circ} 03^{\prime} \mathrm{S} 45^{\circ} 36^{\prime} \mathrm{W}, 30$-III-1983, Krapovickas \& al. 38695 (CEN, CTES); Caxoeira, II, Martius s.n. (M, sintipo de var. latifolia); Lençois, $12^{\circ} 34^{\prime} \mathrm{S}$ 41 ${ }^{\circ} 23^{\prime} \mathrm{W}, 400-450 \mathrm{~m}, 3-\mathrm{IV}$ 1980, Noblick 1794 (ALCB, CTES, HUEFS); mun. Palmeira, estrada para o povoado de Cercado, 12²6'00"S 41²8'09"W, 725 m, 29-I-2005, Paula-Souza \& al. 4969 (CTES); Conceição de Jacuipe, IV-1974, Pinto 42269 (ALCB, CTES, IPA). Ceará: Mun. Lençóis, Serra da Chapadinha, 12¹7’35"S 41²6’25"W, 950 m, 31-VIII-1994, Poveda \& al. PCD 682 (ALCB, CTES); Barra, Ibiraba, $10^{\circ} 47^{\prime} \mathrm{S}$ 42 $49^{\prime} \mathrm{W}, 27-\mathrm{X}-2000$, Rodarte 130 (CTES); Fortaleza, sitio São José, 6-VI-1946, Bezerra s.n. (CTES); $20 \mathrm{~km}$ de Crato, Barbalha, sitio da Barreira, 22-VII-1964, Duarte \& Castellanos 469 (CTES, HB, M); mun. Crateús, Ibiapaba Sur, Mambira, 460 m, 20-V-1997, Lima-Verde 772 (CTES); Andrade, Guaraciaba do Norte, 5-III1981, Martins s.n. (EAC 9850). Maranhão: ca. $45 \mathrm{~km}$ due NNE of Balsas or $45 \mathrm{~km}$ due WSW of São Raimundo das Mangabeiras, on road between these two cities, ca. $7^{\circ} 10^{\prime} \mathrm{S} 45^{\circ} 50^{\prime} \mathrm{W}$, ca. $300 \mathrm{~m}, 15$ III-1962, Eiten \& Eiten 3665 (SP, US); ca. 1,5 km S of main house of Fazenda «Morros», about $35 \mathrm{~km} \mathrm{~S}$ of Loreto, Chapada das Traíras, ca. $7^{\circ} 24^{\prime} \mathrm{S} 45^{\circ} 04^{\prime} \mathrm{W}$, ca. 300 m, 27-IV-1962, Eiten \& Eiten 4421 (US); Barra do Corda, 27-VIII-1973, Fernandes s.n. (CTES); São Luis, Cidade Universitária Paulo VI, Reserva Botânica Rosa Mochel, 10-XII-1987, Fernandes 39 (C, CTES); Ilha de São Luis, $02^{\circ} 30^{\prime} \mathrm{S} 44^{\circ} 15^{\prime} \mathrm{W}$, Calhau, 6 km NNE of São Luis, 20-X-1982, Gottsberger \& Gottsberger 11 201082 A (CTES); Itapecuru Mirim, along the road to the village Chapadinha, $3^{\circ} 30^{\prime} \mathrm{S} 44^{\circ} 15^{\prime} \mathrm{W}$, 16-VII-1982, Gottsberger \& Gottsberger 19-
16782 (CTES); Mun. Barreirinhas, Barra do Rio Preguiças, opposite of the village of Mandacurú, 0236'S 4242'W, 7-XI-1982, Gottsberger 1971182 (CTES); BR-316, $10 \mathrm{~km} \mathrm{~W}$ del puente a Teresina, Fazenda Bandeirante, 31-I-1981, Krapovickas \& Cristóbal 37218 (CTES); mun. Grajaú, estrada do Arame, 15-IV-1983, Rosa \& al. 1141 (CTES); S.Luiz, Olho d'Agua, Strand, 31-VII-1923, Snethlage 153 (F). Mato Grosso: ca. $4 \mathrm{~km} \mathrm{~S}$ of Base Camp, 12 $49^{\prime} \mathrm{S} 51^{\circ} 46^{\prime} \mathrm{W}, 4$ X-1967, Argent \& al. 6639 (CTES); Mato Grosso, $12^{\circ} 36^{\prime} \mathrm{S} \quad 57^{\circ} 55^{\prime} \mathrm{W}, \quad 12-\mathrm{X}-1978$, Guimarães 328 (RB); Gleba Facão, rodovia para o Rio Jacobina, mun. Cáceres, Hatschbach \& al. 62292 (CTES); drainage of the upper Rio Araguaia, Xavantina, 400 m, 8-VI-1966, Irwin 16783 (CTES, NY, UB); R. Juruena, Cachoeira São Simão, 21-V-1977, Rosa \& Santos 1958 (CTES, HPR, NY); mun. São José do Rio Claro, Fazenda Arinos 1351'S 56²9'W, 14-VI-1997, Souza \& al. 18027 (CTES, ESA). Pará: Município de Marapanim, Praia, 3-XII-1999, Bovini \& Kajima 1734 (RB); Serra Norte, Carajás, 4-VII-1987, Silva 2347 (CTES). Pernambuco: prope Joazeiro, IV, Martius s.n. (M, sintipo de var. latifolia); Buique, Catimbau, 4-IX-1999, Schlindwein \& al. CS948 (UFP). Piauí: mun. Luiz Correa, Lagoa Sobradinha, 6-X-1973, Araujo \& al. 476 (RB); mun. S. João do Piauí, Porfirio, 08²1'S 4214'W, 222 m, 14-IV-1994, Carvalho \& Bona Nascimento 463 (CTES); $5 \mathrm{~km} \mathrm{~S}$ de Eliseu Martins, BR-135, 08¹4'S 4345'W, 4-IV-1983, Krapovickas \& al. 38619 (CTES); $3 \mathrm{~km} \mathrm{~W} \mathrm{de}$ Oeiras, BR-230, 200 m, 0702'S 42 $08^{\circ} \mathrm{W}, 8-\mathrm{IV}-$ 1983, Krapovickas \& al. 38761 (CEN, CTES). Rio Grande do Norte: Base física do Jiquí (IBDF), mun. Natal, 10-II-1981, Fonseca 11 (UEC).

Material cultivado: ARGENTINA. Corrientes, proc. Brasil, Piauí, $3 \mathrm{~km}$ de Oeiras, $7^{\circ} 02^{\prime} \mathrm{S}$ 420' 'W, 26-IV-1984, Krapovickas \& al. 38761 bis (CTES). CANADA. Ontario, York University, Biology Department, proc. Brasil, Pará, V-2003, Bovini \& Kajima 1734bis (CTES).

Distribución y fenología: Se extiende sde Amazonas, Pará y los estados nordestitos de Brasil hasta Bahía, Maranhão, Mato Grosso y Bolivia (Beni, La Paz y Santa Cruz). Florece y fructifica todo el año. 
Obs.: En plantas cultivadas en Ontario se pudo constatar experimentalmente que son autocompatibles (Shore \& al. 2006).

En Teixeira \& al. 271 el tubo calicino es glabro.

\section{8d. Turnera melochioides var. rugosa Arbo, var. nov.}

Figs. 16 y 55

Frutex vel fruticulus 0,3-1m altus, pilis crispulis brevis et aliis curvato-erectis intermixtis, cicatricibus foliorum prominentis; stipulae rudimentariae; folia coriacea, elliptica vel ovata, interdum obovata, margine revoluto, supra strigosa, subtus pilis brevis densis et pilis glandularibus micro-capitatis intermixtis, supra basin subtus interdum nectariis parvis gerentibus. Flores dimorphi, apice caulium in racemum bracteosum conferti, calyx 3,2-7,3 $\mathrm{mm}$ long., ca. 1/2 alt. coalitus, petalis calycem paullo superantibus flavis; filamenta glabra, basi tubo tota facie adnata, placentae 2-3-ovulatae. Fructus dorso tuberculatus vel laevis. Semina curvata, chalaza prominula, arillo unilaterali, angusto.

Typus. Brasil. Goiás: Mun. Niquelandia, Macedo velho, perto do local de movimentacão das maquinas, 2-VI-1999, Filgueiras \& al. 3568 (holotypus IBGE, isotypi CTES, RB).

Subarbusto o arbusto ramoso 0,3-1 m alt., tallos erectos, con pelos largos curvadoantrorsos, mezclados con pelos cortos crespos, a veces sólo con pelos crespos. Hojas coriáceas, extendidas, discoloras. Lámina elíptica, latielíptica, ovada, algunas veces obovada, 13-40 x 5-12 $\mathrm{mm}$, relación largo:ancho $=1,9-3,5: 1 ;$ margen revoluto, serrulado, simple o doblemente aserradocrenado; ápice agudo u obtuso; haz oscura en seco, estrigosa, pelos simples de base cónica; envés castaño, con pelos simples curvadoantrorsos, pelos simples crespos y pelos glandulares microcapitados; venas terciarias oblicuas visibles en el envés. Nectarios 0-2, marginales, situados cerca de la base de la lámina. Flores reunidas en racimos bracteosos terminales abreviados, a veces el eje puede alcanzar $4 \mathrm{~cm}$. Cáliz 3,2-7,3 mm long.; tubo calicino 1,6-4,1 mm long., por fuera con pelos cortos; lóbulos con pelos más largos. Corola 4,1-7,5 mm long.; pétalos glabros. Ovario con placentas 2-3-ovuladas. Fruto 2-5 mm long., con reborde basal de $0,2 \mathrm{~mm}$ dejado por la absición del tubo floral; valvas con cara externa rugosa o a veces lisa y rugosa en el mismo pie. Semilla 2,3-2,7 x 1,2-1,5 mm.

Paratypi: BRASIL. Goias, Chapada dos Veadeiros, 5-9 km N de Alto Paraíso de Goiás, ca. 1200 m, 4-II-1990, Arbo \& al. 3619 (CTES, HRCB, K); Macedo, ca. $15 \mathrm{~km} \mathrm{~N}$ of Niquelandia,

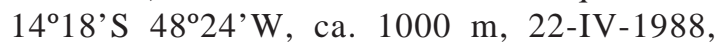
Brooks \& al. Braspex 158 (CTES, NY) y Brooks \& al. Braspex 181 (CTES, NY); Mun. Niquelândia, morro ca. $4 \mathrm{~km}$ de Macedo Velho para a mina de niquel, perto de bica d'agua, $14^{\circ} 21^{\prime} 34 \mathrm{~S}$ 48²4’38W, 30-V-1996, Fonseca \& al. 979 (CTES, IBGE, RB); Alto Paraíso, rod. para Nova Roma, Rio Bartolomeu, 13-VI-1993, Hatschbach \& al. 59479 (CTES); Mun. Niquelândia, Jacuba, 24-II-1956, Macedo 4416 (HB, RB, US); mun. Niquelândia, Companhia de Níquel Tocantins, 1 $\mathrm{km}$ após a mina de níquel, $14^{\circ} 21^{\prime} 29 \mathrm{~S} 48^{\circ} 23^{\prime} 11 \mathrm{~W}$, 12-IV-1996, Marquete \& al. 2433 (CTES, IBGE, RB); Chapada dos Veadeiros, $2 \mathrm{~km}$ from Veadeiros, 18-VII-1964, Prance \& Silva 58201 (CTES, NY); Niquelândia, Southernmost ultramafic hill of Tocantins complex, $850 \mathrm{~m}, 29$ IV-1988, Reeves \& al. BRASPEX 227 (CTES, NY); Mun. Niquelândia, Macedo, ca. $1 \mathrm{~km}$ da mina de níquel, $14^{\circ} 21^{\prime} 29 \mathrm{~S}$ 4823'11W, 29-V1996, Silva \& Nunes de Jesus 2984 (CTES, IBGE); Mun. Niquelândia, morro ão lado esquerdo do trevo para Macedo Velho, $14^{\circ} 21^{\prime}$ 'S 48²5'W, 30-V-1996, Silva \& Oliveira 2990 (CTES, IBGE).

Distribución y fenología: Variedad aparentemente endémica de Goiás, saxícola, todos los ejemplares conocidos proceden de los municipios Niquelandia, donde crece en suelo serpentino, y Alto Paraíso de Goiás, entre 850 y $1200 \mathrm{~m}$ de altitud. Vive en campo, «cerrado» $\mathrm{y}$ «campo rupestre».

Obs.: En algunos ejemplares, por ejemplo Arbo \& al. 3619, las hojas vegetativas no presentan nectarios, y las hojas floríferas los tienen diminutos, 0,3 mm diám. 


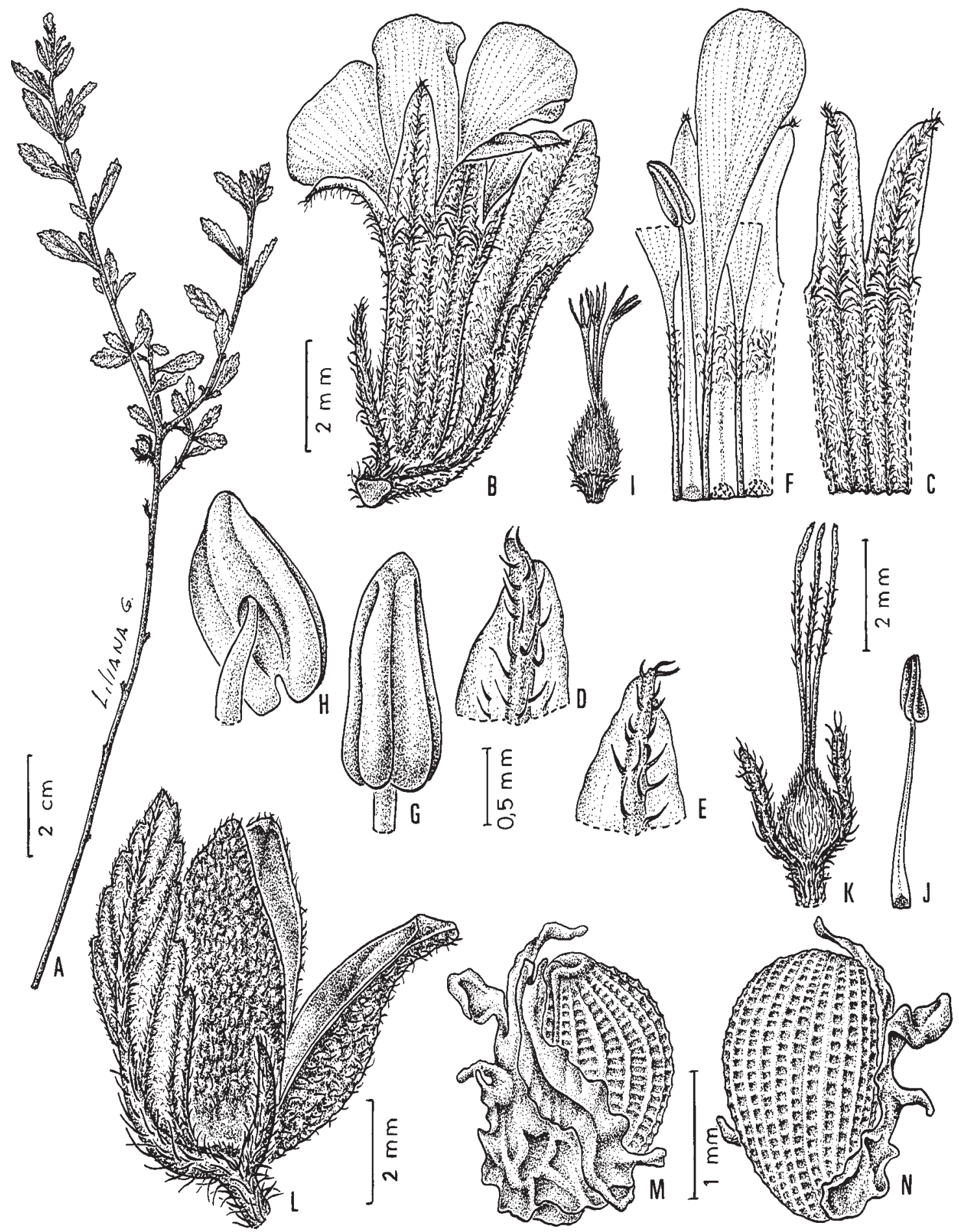

Fig. 55. Turnera melochioides var. rugosa. A: rama florífera. B: bráctea con flor epifila y profilos. C: porción del cáliz, cara externa. D-E: ápice de lóbulos del cáliz. F: flor brevistila, porción del tubo calicino, cara interna, con pétalos y estambre adnatos; se han cuadriculado las cicatrices dejadas al desprender dos estambres. G-H: anteras, vistas dorsal y ventral. I: gineceo. J-K: flor longistila, estambre y gineceo con profilos. L: bráctea con fruto epifilo y profilo. M-N: semilla con arilo, vistas rafeal y dorsal (A, J-L: Macedo 4416; B-I: Filgueiras \& al. 3568; M-N: Silva \& Oliveira 2990). Del. Liliana Gómez. 


\section{Turnera nervosa Urb.}

Figs. 16 y 56

Urban, I. Jahrb. Königl. Bot. Gart. Berlin 2: 108. 1883; Urban, en Martius, Fl. Bras. 13 (3): 130. 1883. Typus: Paraguay. Guairá, Villa Rica, dans les prairies humides, fl. blanches, 10-XII1874, Balansa 2341 (holotypus $\mathrm{B}+$ fototipo $\mathrm{F} \mathrm{n}^{\circ}$ 13594, isotypi $\mathrm{F}$ !, G!, K!, P!).

Hemicriptófita herbácea, 13-48 cm alt., base leñosa, corteza castaña o negruzca; tallos 1-6, simples o poco ramificados, cilíndricos o angulados, sinuosos, 1-4 $\mathrm{mm}$ diám., estrigosos, con pelos simples de base cilíndrica y pelos microcapitados. Entrenudos 13-35 $\mathrm{mm}$ long., los apicales acortándose rápidamente hasta $0,5 \mathrm{~mm}$ long. Ramas seriales a veces desarrolladas. Hojas coriáceas, lustrosas, erectas. Estípulas ausentes o reducidas a prominencias pilosas, a veces con un coléter $0,1 \mathrm{~mm}$ long. Yemas axilares 1-2. Pecíolo estrigoso 0,5-4 $\mathrm{mm}$ long. Lámina elíptica, lanceolada, linear o angustiovada, 2-6,5 x 0,2$2 \mathrm{~cm}$, glabras o con algunos pelos sobre las venas en el envés; margen glabro, plano, aserrado en la porción apical, dientes terminados en coléteres; venación prominente en ambas caras, venas laterales rectas o incurvas, formando arcos marginales que se anastomosan con la vena siguiente; ángulo de divergencia 20-40 ; venación menor conspicua. Nectarios $1+1$, en la unión de pecíolo y lámina, orientados hacia el envés, circulares o elípticos, 0,61,2 mm diám., reborde pubérulo, con «poro», a veces ausentes en hojas basales. Hojas floríferas reduciéndose rápidamente hasta brácteas linear-subuladas de 3,5 mm long., con 2 nectarios grandes en la unión de pecíolo y lámina. Flores: heterostilas, epifilas, agrupadas en el ápice de las ramas en racimos abreviados bracteosos. Pedúnculo estrigoso, soldado al pecíolo y en parte a la vena media, porción apical libre de 1-6(-13) mm long. Profilos opuestos, lineares, 2-6,5 x 0,2-0,5 $\mathrm{mm}$, estrigosos en la cara externa, glabros por dentro, insertos en la base del receptáculo, a veces con nectarios. Pedicelo no desarrollado. Cáliz 10-16 mm long., estrigoso por fuera; tubo calicino 2-4 mm long., velloso por den- tro; lóbulos lanceolados o triangulares, márgenes internos membranáceos, ápice mucronulado. Corola blanco-cremosa; pétalos con uña pilosa, lámina obovada, 15-22 x 8-17 $\mathrm{mm}$, con mácula amarilla en la base y a veces algunos pelos, venas purpúreas en la cara externa. Filamentos estaminales 5-6 mm long. en flores longistilas, 7,5-11 mm long. en flores brevistilas, glabros, soldados $0,7-1 \mathrm{~mm}$ en la base al tubo calicino; anteras ovadas o elípticas, 1,5-2,5 x 0,4-0,8 mm, base emarginada, ápice recurvo después de la dehiscencia, filamento inserto dorsalmente en el tercio inferior, a 0,5-0,7 $\mathrm{mm}$ de la base. Ovario cónico densamente estrigoso, 1,5-2 mm long.; placentas 6-18-ovuladas; estilos cilíndricos glabros o con algunos pelos simples, 5-6 mm long. en flores longistilas, $2 \mathrm{~mm}$ long. en flores brevistilas; estigmas con 10-16 ramas glabras de 1,5-3,1 mm long. Fruto ovoide, 3,5$10 \mathrm{~mm}$ long., con reborde basal de $0,5 \mathrm{~mm}$ dejado por la absición del tubo floral; profilos más cortos que el fruto; valvas lisas, estrigosas por fuera, glabras y jaspeadas por dentro. Semilla obovoide, 2,2-2,6 x 1-1,5 mm, pardo-oscura, ligeramente curvada; exóstoma conoidal, excéntrico; rafe linear, poco marcada, lado rafeal recto o incurvo; cálaza apenas prominente. Episperma reticulado, nudos del retículo elevados, aréolas poligonales, con una depresión punctiforme, epidermis papilosa. Arilo 1,5-2,4 mm long., de células lisas.

Cromosomas: 2n=14, Arbo \& al. 2076 (Fernández, 1987).

Material estudiado: PARAGUAY. Caaguazú: between Coronel Oviedo and Caaguazú, Route 2, Km 140, 2529'S 56²0’W, 9-XI-1993, Zardini \& Tilleria 37211 (CTES, MO). Caazapá: Estancia San Agustín entre las compañías de Boquerón y San Agustín, potrero Espinillo, 26-X-1993, Basualdo 5098 (FCQ); Ruta 8, 25 km NE de Yuty, camino a Yegros, 24-III-1993, Schinini \& al. 27849 (C, CTES). Concepción: prope Concepción in campo Aguaguigo, X-1902, Hassler 7685 (BM, MO). Guairá: Campo Mbuvevo, II-1930, Jorgensen 4071 (F, GH, MO, US). Itapúa: 9 km SE de General Delgado, 26-XI-1993, Arbo \& al. 6156 (CTES); Parque Nacional San Rafael, San Pedro mi, dep. Itapúa, 14-XI-2001, Caballero 


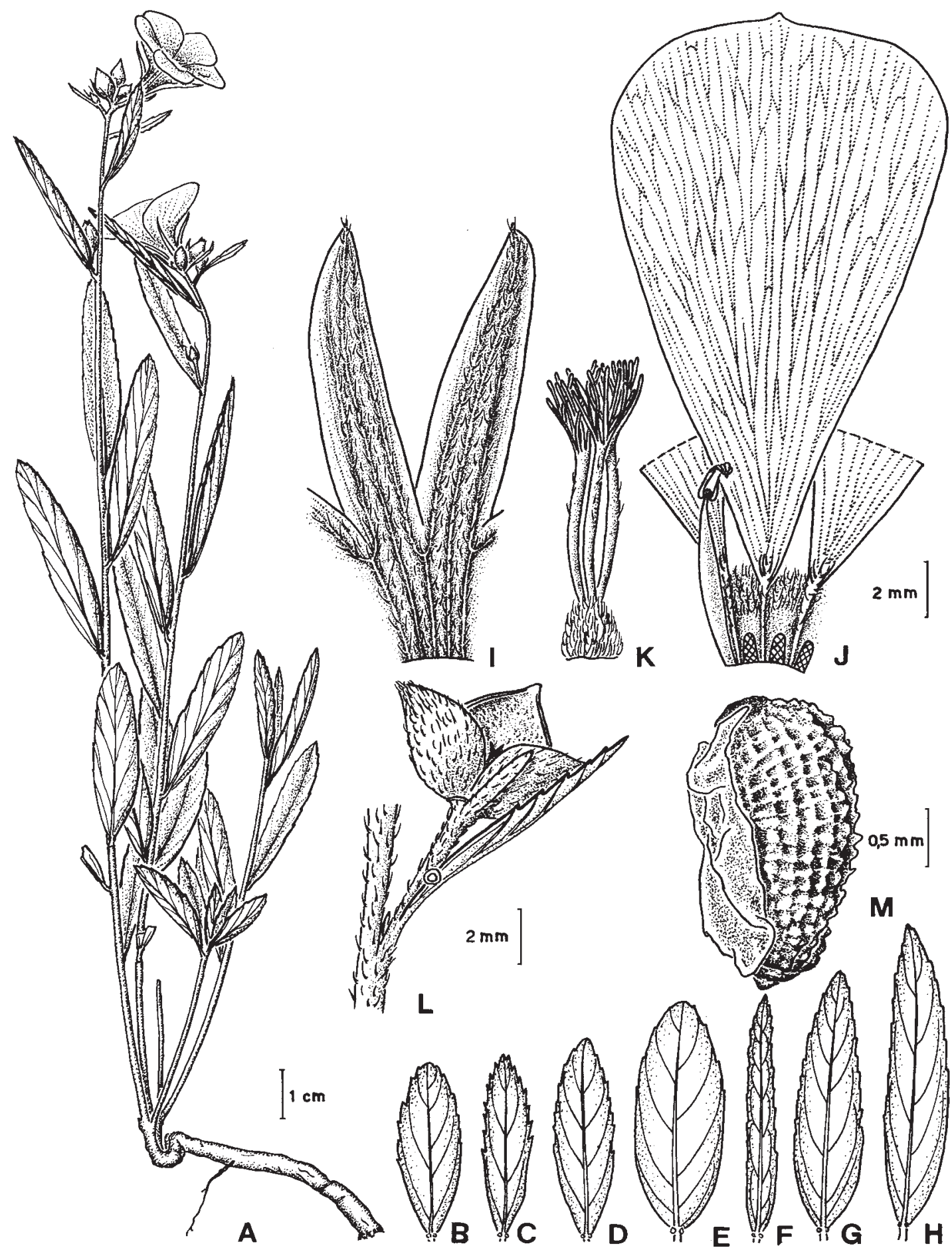

Fig. 56. Turnera nervosa. A: planta. B-H: hojas con nectarios, cara abaxial. I: porción del cáliz, cara externa. J: flor longistila, porción del tubo calicino, cara interna, con pétalos y estambre adnatos; se han cuadriculado las cicatrices dejadas al desprender 3 estambres. K: gineceo. L: bráctea con fruto epifilo y profilo; nótese la porción apical libre del pedúnculo. M: semilla con arilo, vista lateral (A, L: Balansa 2341; B: Quarin \& al. 1821; C, I-K, M: Quarin \& al. 2711; D: Krapovickas \& al. 24442; E, H: Arbo \& al. 2076; F: Krapovickas \& al. 24815; G: Ahumada 2306). Del. AL: Víctor Maruñak; M: Ricardo Vispo. 
Marmori 3963 (CTES, MBM). Misiones: Santiago, Estancia «La Soledad», 17-XI-1956, Pedersen 4334 (CTES). Paraguarí: Caballero, 20-I-1889, Morong 609 (SI). Presidentes Hayes: Camino entre Chaco-i y Benjamin Aceval, X-1974, Arenas 1017 (CTES). San Pedro: Colonia Nueva Germania, XII-1916, Rojas 2083 p.p. (AS, CTES, SI). ARGENTINA. Corrientes: dep. Ituzaingó, 16 km NE de Ituzaingó, costa del río Paraná, 9-IV1978, Ahumada 2306 (CTES, ICN, MBM); dep. Ituzaingó: Rincón Ombú Chico, 17-XI-1978, Arbo \& al. 2076 (BAB, C, CTES, MO, SI, WIS); dep. Ituzaingó, Ruta 41, en la intersección con ruta 37,

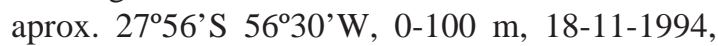
Arbo \& al. 6457 (AAU, CANB, CTES, GH, ICN, $\mathrm{U})$; Ituzaingó, $8 \mathrm{~km} \mathrm{~S}$ de R.12, Macrosistema Iberá, 23-XI-1999, Arbo \& al. 8401 (CTES); dep. San Miguel, 15-20 km al E de San Miguel, 21-XI1979, Carnevali 4879 (CTES); dep. Ituzaingó, Rincón de Santa María, aprox. 15 km E de Ituzaingó, 22-III-1982, Carnevali 5648 (CTES); dep.Ituzaingó, Ea. Don Andrés de Urrutia, 23-II1982, Carnevali 6134 (CTES); dep. Ituzaingó: Puerto Valle, Ituzaingó, sin fecha, Heinonen \& al. 125 (CTES); dep. Berón de Astrada, Santa Isabel, 19-XII-1945, Ibarrola 3985 (LIL, S); dep. Ituzaingó: isla Apipé Grande, Puerto Mora, 11-XII-1973, Krapovickas \& al. 24442 (CTES); dep. Berón de Astrada, Ruta Nac. 12 y Arroyo Santa María, 31-III1974, Krapovickas \& al. 24815 (CTES); dep. Ituzaingó: Ea. Puerto Valle, 24-XI-1962, Partridge 34 (BA); dep. Concepción, Ea. Buena Vista, 12-XII1972, Pedersen 10266 (C, CTES); 10 km NNE de Ituzaingó, camino a Guardia Cué, 13-XII-1973, Quarín \& al. 1821 (CTES); dep. Ituzaingó: 40 km NE de Galarza, ruta 41, 8-XII-1974, Quarín \& al. 2711 (CTES); dep. Ituzaingó, San Borgita, ruta 12, 1 km del desvío a San Carlos, 19-I-1993, Schinini 27560 (CTES); $35 \mathrm{~km} \mathrm{~W}$ de Posadas, por ruta 12, 22 XI-1993, Schinini \& al. 28349 (CTES); dep. Ituzaingó, río Aguapey y ruta 38, 6-XII-1981, Tressens \& al. 1689 (CTES); dep. Ituzaingó, destacamento Prefectura Ayo.Garape, 41 km E de Ituzaingó, costa rio Paraná, 9-XII-1984, Tressens \& al. 2649 (CTES); Dep. San Miguel: 12 km NE de San Miguel, Ea. Toro-y, 4-III-1990, Vanni \& al. 1708 (CTES). Misiones: prope Posadas, X-1897, Spegazzini s.n. (BAF 108227).

Distribución: Especie exclusiva de Paraguay y NE argentino (Misiones y Corrientes).
Vegeta en campos, frecuentemente con suelos arenosos, a veces en terrenos bajos, inundables. Rebrota después de las quemazones. Florece y fructifica desde noviembre hasta febrero.

Obs.: Se estudió la anatomía de los nectarios extraflorales de Turnera nervosa, comparada con la de otras especies de la serie Leiocarpae y de la serie Turnera (Gonzalez, 1996). Los coléteres, de tipo standard, están ubicados en los dientes de los primordios foliares, en las estípulas rudimentarias y en los profilos jóvenes (Gonzalez, 1998). El tallo no presenta células taníferas ni casquetes fibrosos perifloemáticos; las hojas son dorsiventrales y anfistomáticas, los haces vasculares presentan vaina fascicular esclerenquimática; las semillas presentan endotesta formada por células pequeñas (Gonzalez, 2000). Además se examinaron la vascularización floral y los nectarios florales (Gonzalez, 2001).

\section{Turnera oblongifolia Cambess.}

Saint Hilaire, A., Jussieu, A. \& Cambessèdes, J., Fl. bras. merid. 2: 215. 1830. Typus: Brasil. Minas Gerais, paturages herbeux près la fazenda dos vertentes do Jacaré [Serra de Galga, ca. Olivera] Saint Hilaire C1 250 (lectotypus, aquí designado $\mathrm{P}$ ! fototipo $\mathrm{F} \mathrm{n}^{\mathrm{o}} 38464$ !).

\section{0a. Turnera oblongifolia var. oblongifolia}

Figs. 7 y 57

Turnera hilaireana Urb. var. oblongifolia (Cambess.) Urb., Jahrb. Königl. Bot. Gart. Berlin 2: 109. 1883; Urban, en Martius, Fl. Bras. 13 (3): 131. 1883; Turnera hilaireana Urb. var. lanceolata (Cambess.) Urb., Jahrb. Königl. Bot. Gart. Berlin 2: 109. 1883; Urban, en Martius, Fl. Bras. 13 (3): 130. 1883, excluyendo el tipo.

Turnera hilaireana Urban var. ovatifolia Urb., Bot. Jahrb. Syst. 25, Beibl. 60: 5. 1898. Typus: Brasil. Goiás: Bomdium, entre Barreira do Veado \& Morro Redondo, dans le campo pierreux, fleur jaune pále, 4-X-1895, Glaziou 20652a (holotypus P!). 


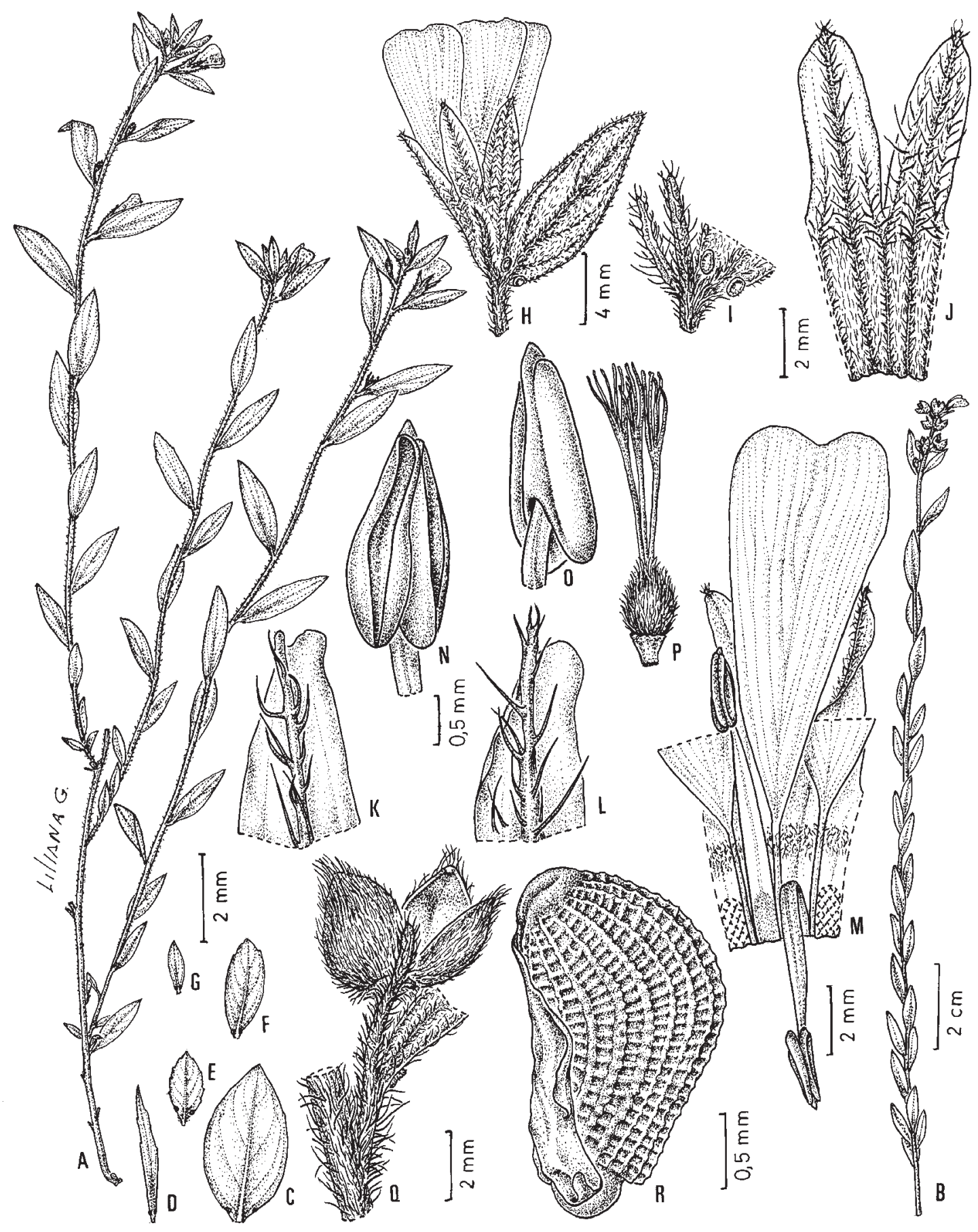

Fig. 57. Turnera oblongifolia var. oblongifolia. A-B: plantas. C-G: hojas con nectarios, cara abaxial. H: bráctea con nectarios, flor epifila y profilo. I: bráctea, parte basal y profilos. J: porción del cáliz, cara externa. K-L: ápice de lóbulos del cáliz. M: porción del tubo calicino, cara interna, con pétalos y estambres adnatos; se han cuadriculado las cicatrices dejadas al desprender 2 estambres. N-O: anteras, vistas ventral y dorsal. P: gineceo. Q: bráctea con fruto epifilo y profilo; nótese la porción apical libre del pedúnculo. R: semilla con arilo, vista lateral (A, H-P: Souza 5084; B: Arbo \& al. 3275; C: Hensold \& al. 2073; D, Q-R: Hoehne \& Gert s.n.; E: Souza \& al. 22443; F: Joly \& al. 552; G: Sakuragui \& al. 15258). Del. Liliana Gómez. 
Hierba perenne de 7-60 $\mathrm{cm}$ de alto, erecta, frecuentemente castaña en seco, con una base leñosa de hasta $10 \mathrm{~mm}$ diám.; tallos 1-10, simples o ramificados generalmente en la porción media o apical, 0,7-3,5 mm diám., castaño-rojizos generalmente, rectos o sinuosos, cilíndricos, longitudinalmente estriados, raramente aristados, completamente vestidos con pelos simples desde cortos, antrorsos y adpresos a crespos, blanquecinos o amarillentos, a veces con pelos largos, curvado erectos o patentes entremezclados, o solamente con pelos largos; entrenudos 3-50 mm long., los apicales más cortos. Yemas axilares 1-2, a veces ramas seriales desarrolladas. Hojas generalmente erectas, coriáceas, lustrosas. Estípulas nulas o rudimentarias, pilosas, con coléteres rojizos, 0,1-0,3 mm long. a cada lado de la base foliar. Pecíolo 0-1 mm long., en hojas floríferas hasta $4 \mathrm{~mm}$ long., con un mechón de pelos hirsutos en la base. Lámina elíptica, angustielíptica, ovada, angustiovada, a veces lanceolada, en hojas basales 2-8 x 1$2,7 \mathrm{~mm}$, relación largo:ancho $=1,8-5,8: 1$, en las siguientes 7-60 x 1,5-19 mm, relación largo:ancho $=1,5-8: 1$; base atenuada, bruscamente atenuada, cuneada o truncada; ápice generalmente agudo, a veces obtuso o acuminado; margen piloso, plano, a veces ondulado, entero o serrulado (25-80\% desde el ápice); haz y envés con puntos claros muy notables cuando la planta es castaña en seco, con un estrato de pelos simples desde cortos y completamente adpresos hasta muy largos, 1$2 \mathrm{~mm}$ long., curvado-erectos o patentes, a veces con la base cónica, a veces entremezclados con pelos glandulares microcapitados; venación prominente en ambas caras, venas laterales 4-6 a cada lado, ángulo de divergencia $15-50^{\circ}$, venación menor conspicua en ambas caras. Nectarios presentes excepto en hojas basales, $1+1$, a veces $2+1$ o $3+1$, situados en la unión de pecíolo y lámina o desplazados 0,5-3 $\mathrm{mm}$ sobre el margen foliar, circulares, 0,3-1,3 mm diám., opuestos o subopuestos, borde piloso. Hojas floríferas disminuyendo rápidamente de tamaño, las apicales bracteiformes. Flores epifilas, heterostilas, extendidas a lo largo del tallo o agrupadas en los extremos de las ramas en racimos bracteosos abreviados. Alabastro elipsoide u ovoide, agudo, recto.
Pedúnculo 2-7 mm long., totalmente adnato al pecíolo y vena media, o parcialmente, con una porción apical libre de hasta $4 \mathrm{~mm}$ long., o adherido sólo en la porción basal 0,2-0,5 mm long., indumento como el del tallo. Profilos lineares o subulados, opuestos o subopuestos, 1,2-7 x 0,2-0,7 mm, situados en la base del receptáculo o distantes $0,2-1 \mathrm{~mm}$, a veces con un par de nectarios, cara externa con indumento como el de las hojas, cara interna glabra o pubérula, margen piloso, serrulado, dientes de aspecto glanduloso. Cáliz 6-12 mm long., con pelos simples, cortos, crespos, entremezclados con otros más largos y erguidos especialmente en los lóbulos, éstos raramente glabros; tubo calicino campanulado, 2-3 mm, cara interna vellosa o pubérula en la porción superior; lóbulos elíptico-lanceolados, bordes maculados, a veces purpúreos, los internos membranáceos, ápice frecuentemente purpúreo, con mucrón piloso de 0,1-0,4 mm long. Corola amarilla; pétalos con lámina obovada, a veces con venación purpúrea en la cara externa, 7-12(-17) x 2,5-6,5 mm, base redondeada, a veces pilosa, ápice obtuso. Filamentos estaminales complanados en seco, amarillos, glabros, subulados o angustiovados, 3,5-6 mm long.en flores longistilas, 4,5-8 mm long. en flores brevistilas, soldados al tubo calicino en la porción basal 0,4-0,6 mm long.; anteras 1-2 x 0,3-0,9 mm, rectas o con el ápice ligeramente curvado después de la dehis-cencia, filamento inserto dorsalmente a $0,4-0,5 \mathrm{~mm}$ de la base. Ovario cónico o hemisférico, 1-1,6 x 1,2 $\mathrm{mm}$, densamente cubierto de pelos simples, gruesos, curvados, antrorsos; placentas 6-10ovuladas; estilos cilíndricos, 2,5-4 mm en flores longistilas, $1,5-3 \mathrm{~mm}$ en flores brevistilas, glabros o con algunos pelos simples; estigmas de 1,5-3,5 mm long., divididos en (4 )6-8(-16) ramas. En flores longistilas, gineceo 2,7-3 mm más largo que el androceo y en flores brevistilas, 1,2-2,5 mm más corto. Fruto ovoide o subesférico, ápice umbonado, 2,5-7 x 2,2-6 mm; absición del tubo floral a 0,3-0,6 $\mathrm{mm}$ de la base, dejando un reborde alrededor de la base del fruto; valvas ovadas, dehiscentes hasta la mitad o hasta la base, cara externa pilosa, cara interna lustrosa, amarillenta o jaspeada, totalmente glabra o con pelos especialmente en la base, borde y ápice 
frecuentemente purpúreos. Semilla 1,5-2,2 x 0,7-1,3 mm, ligeramente curvada, castaña; exóstoma cónico, apenas a muy prominente; rafe linear, lado rafeal incurvo; cálaza apical, oscura, saliente. Episperma reticulado, aréolas transrectangulares o cuadrangulares, nudos no prominentes. Arilo membranáceo en seco, 1,2-2,1 mm long., células aparentemente lisas.

Material estudiado: BrasiL. Sin localidad: Ferreyra 25 (P), Glaziou 9856a (P); Riedel s.n. (NY), Riedel 1453 (F); Weddell s.n. (P). Bahia: Espigão Mestre, ca. $10 \mathrm{~km} \mathrm{~N}$ of Rio Roda Velha, ca. $100 \mathrm{~km}$ WSW of Barreiras, ca. $800 \mathrm{~m}$, 9-III1972, Anderson \& al. 36891 (NY, UB); Serra de Sincora, XI, Martius s.n. (M). Distrito Federal: Brasília, X-1964, Barroso 675 (RB); Jardim

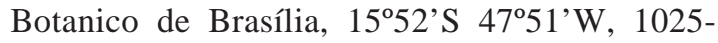
1150 m, 10-IX-1996, Boaventura 331 (HEPH); mun. Brasília, Fazenda Sucupira, area ao lado da antiga sede do clube da EMBRAPA, a direita da entrada da Faz., $15^{\circ} 52^{\prime} \mathrm{S} 48^{\circ} \mathrm{W}, 1100 \mathrm{~m}, 5-\mathrm{X}-$ 2000, Guarino \& Pereira 475 (CEN); Brasília, 1III-1979, Heringer 17212-A (IBGE, P, SP, US); Brasília, Trevo de Unaí, 12-XI-1980, Heringer 17981 (IBGE, NY); Chapada da Contagem, 1000 m, 4-IX-1965, Irwin \& al. 7934 (NY; P); Chapada da Contagem, ca. $20 \mathrm{~km}$ NE de Brasília, $1000 \mathrm{~m}$, 5-IX-1965, Irwin \& al. 7993 (NY); 1,5 km E of Sobradinho, 1115 m, 7-X-1965, Irwin \& al. 9020 (CTES, NY, P, UB); ca. 5 km NE of Planaltina, on road to São Gabriel de Goiás, 1200 m, 16-X-1965, Irwin \& al. 9246 (NY); Brasília, 700-1000 m, 7IX-1964, Irwin \& Soderstrom 6113 (CTES, NY, $\mathrm{P})$; in the area of the Córrego Cabeça de Veado ca. 9,5 km SSE of Brasília TV tower, 27-VIII-1976, Ratter \& al. 3489 (E, UB); mun. Samambaia, Parque Boca da Mata, $15^{\circ} 52^{\prime} \mathrm{S} 48^{\circ} 03^{\prime} \mathrm{W}, 1150 \mathrm{~m}, 4-$ V-1996, Rezende 468 (CEN); em frente ao Zoobotanico, 26-X-1965, Sucre 865 (RB, UB). Goiás: Serra Geral do Paraná, $13 \mathrm{~km}$ by road $\mathrm{S}$ of São João da Aliança, 1120 m, 21-III-1973, Anderson 7566 (P, UB); $17 \mathrm{~km} \mathrm{~N}$ of Alto Paraiso, 1480 m, 1-III-1982, Anderson 12495 (C, CTES, MBM, MU); BR 020, entrada a Formosa, 8001000 m, 2-II-1990, Arbo \& al. 3438 (CTES); Chapada dos Veadeiros, 22-25 km N de Alto Paraiso de Goiás, ca. 1500 m, 4-II-1990, Arbo \& al. 3603 (CTES, HRCB); 7-20 km E de Pirenópolis, Serra dos Pirineus, ca. 1000 m, 7-
II-1990, Arbo \& al. 3807 (CTES, F, GH, HRCB, K, MBM, MICH); alrededores de Corumbá de Goiás, camino a Pirenópolis, ca. 900 m, 7-II1990, Arbo \& al. 3845 (CTES, HRCB, MBM); estrada Alto Paraido de Goias-Teresina de Goias, a $25 \mathrm{~km}$ de Alto Paraiso, 1359's 47³0'W, 1642 m, 4-IV-1997, Cavalcanti \& al. 2202 (CEN, CTES); Alto Paraiso de Goias, $14^{\circ} 09^{\prime} \mathrm{S} 47^{\circ} 35^{\prime} \mathrm{W}, 1155 \mathrm{~m}, 6-\mathrm{V}-2005$, Chaves \& al. 286 (CTES, UB); Chapada dos Veadeiros, estrada de Chao entre Goianesia e Vila Propicio, ca. $38 \mathrm{~km}$ de Goianesia, parcelas 1 e 2,15⒉ 2 'S $48^{\circ} 53^{\prime} \mathrm{W}, 7-\mathrm{VI}-1995$, Fonseca \& al. 313 (CTES, IBGE); Mun.Niquelandia, estrada de chao com entrada no $\mathrm{Km} 8$ da rodovia Niquelandia/ Uruaçu, Fazenda Trairas, $14^{\circ} 29^{\prime} \mathrm{S} 48^{\circ} 33^{\prime} \mathrm{W}, 13-$ IV-1996, Fonseca \& al. 872 (CTES, IBGE); 5 $\mathrm{km}$ E of Alto Paraiso, $1500 \mathrm{~m}$, Gates \& Estabrook 66 (MICH, UB); Chico Lobo, dans la vallée du Rio Paranana, 10-XI-1894, Glaziou 21453 (BR, C, K, P); Pouso Alto, Serra dos Veadeiros, I-II, Glaziou 21454 p.p. (BR, C, K, $\mathrm{P}, \mathrm{R})$; São João da Aliança, arredores, 11-II1990, Hatschbach \& al. 53835 (C, CTES, MBM, MU); mun. Agua Fria de Goiás, Estação Repetidora da Telebrasília de Roncador, 1200 m, 8-II-1994, Hatschbach \& al. 60028 (CTES, HUEFS, K, MBM, UB); Rod. GO-118, 10 km N de Alto Paraiso, mun. Alto Paraiso de Goias, 8V-2000, Hatschbach \& al. 70696 (C, CTES, MBM); Serra do Rio Preto, ca. $10 \mathrm{~km} \mathrm{E} \mathrm{of}$ Cabeceiras, $16^{\circ} \mathrm{S} 47^{\circ} \mathrm{W}, 1000 \mathrm{~m}, 19-\mathrm{XI}-1965$, Irwin \& al. 10500 p.p. (UB); Chapada dos Veadeiros, $14^{\circ} \mathrm{S} 47^{\circ} \mathrm{W}$, ca. $15 \mathrm{~km} \mathrm{~W}$ of Veadeiros, $1000 \mathrm{~m}, 14-\mathrm{II}-1966$, Irwin \& al. 12787 (CTES, NY, P); Serra dos Pirineus: 20 km $\mathrm{N}$ of Corumbá de Goiás, on road to Niquelandia, in valley of Rio Corumbá, ca. 1150 m, 18-I-1968, Irwin \& al. 18758 (CTES, MO, NY, UB), Pico dos Pirineus, ca. $20 \mathrm{~km} \mathrm{NW}$ of Corumbá de Goiás, near road to Niquelandia, ca. 1400 m, 28-I-1968, Irwin \& al. 19353 (MO, NY, UB, US); prox. a Anapolis, 16 $14^{\circ} \mathrm{S} 4^{\circ} \mathrm{W}$, 11-III-1978, Maguago 178 (RB); mun. Pirenopolis, Serra dos Pireneus, $15,5 \mathrm{~km}$ do trevo de Anapolis e Goiania em direção ao Parque, 15⒋'S 48 50'W, 1170 m, 19I-2005, Paula-Souza \& al. 4160 (CTES, ESA); mun. Alto Paraiso de Goias, arredores da estação de tratamento de agua, ca. $3 \mathrm{~km}$ da entrada lateral ao posto na margen da GO- $118,14^{\circ} 08^{\prime} \mathrm{S} 47^{\circ} 32^{\prime} \mathrm{W}$, 1150 m, 22-I-2005, Paula-Souza \& al. 4400 
(CTES, ESA); Serra dos Pirineus, mun. Pirenópolis, $1350 \mathrm{~m}, 8-X I I-1987$, Semir \& al. 20573 (UEC); Chapada dos Veadeiros, Mun.Alto Paraiso, $12 \mathrm{~km}$ da cidade, na estrada que da acesso a Nova Roma, 1359'S 47²1'W, 21-V-1994, Silva \& al. 1939 (CTES, IBGE); estrada UruaçuNiquelândia, margen do Rio Maranhão, proximo a ponte sobre este rio, 12-IX-1998, Souza \& al. 21576 (CTES, ESA). Minas Gerais: Serra de São José, half up slope of the hill to $\mathrm{W}$ above Cachoeira do Mangue Falls (the one with the stone road), $21^{\circ} 05^{\prime} \mathrm{S} 44^{\circ} 10^{\prime} \mathrm{W}$, aprox. $1100 \mathrm{~m}, 24-\mathrm{IV}$ 1992, Alves 4001 (RB); BR-050, 5 km S del río Paranahyba, límite estadual Minas Gerais-Goiás, 29-I-1990, Arbo \& al. 3044 (C, CTES, HRCB, K); Serra dos Pilões, 12 km SW de Guarda Mor, camino a San Antonio de Rio Verde, ca. 1000 m, 31-I1990, Arbo \& al. 3275 (CTES, HRCB); Serra de

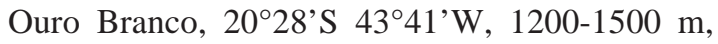
12-V-1990, Arbo \& al. 3912 (C, CTES, F, GH, K, MBM, MO, MICH, NY, SPF, UB, WIS); Serra do Cipo, 10-20 km NE de Cardeal Mota, camino a Conceição do Mato Dentro, 19²0'S 433' W, 1000-1320 m, 15-V-1990, Arbo \& al. 4121 (C, CTES, K, MBM, MO, SPF); Mun. Diamantina, 20-26 km WSW de Diamantina, camino a Conselheiro Mata, MG-220, ca. $18^{\circ} 17^{\prime} \mathrm{S}$ 434' W, 1270-1300 m, 18-V-1990, Arbo \& al. 4406 (CTES, K, MBM, MICH, MO, SPF); Serra do Cabral, ca. $15 \mathrm{~km} \mathrm{~W}$ de Joaquim Felicio, cami-

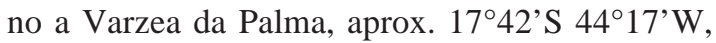
1180 m, 20-V-1990, Arbo \& al. 4583 (CTES, K, SPF); Serra do Cipo, 7 km NE de Cardeal Mota, camino a Conceicão do Mato Dentro, 19²0'S 433'ㄴ, $1000-1320$ m, 8-II-1991, Arbo \& al. 4632 (CTES, GH, K, SPF); 22 km NE de São José de Almeida, camino a Santana do Riacho, ca. $19^{\circ} 18^{\prime}$ 'S 4346'W, ca. 950 m, 11-II-1991, Arbo \& al. 4910 (CTES, SPF); Alrededores de Gouveia, 18²6'S 4343'W, ca. 1100 m, 16-II-1991, Arbo \& al. 5231 (CTES, MICH, SPF); Rodrigo Silva, 1932, Badini s.n. (EM); Falção, 7-XI-1971, Badini s.n. (EM); Serra da Caveira, Ouro Preto, 8-X1978, Badini s.n. (EM); Cachoeira do Campo, 19III-1980, Badini s.n. (EM); mun. Sta. Luzia, Serra do Cipó, Km 139, estrada de Conceição, 16-IV1935, Barreto 1016 (F, RB); Mun. Belo Horizonte, Serra do Taquaril, 31-III-1933, Barreto 8178 (F, RB); Chapada do Couto, 20-XI-1937, Barreto 9903 (F, R); Serra do Cipo, Retiro do Alto do Palácio, ca. 1300 m, 1-V-1993, Barros 2780 (SP); between Tejuco and Rio Paranahyba, Burchell 5910 (K); Ouro Branco, Campos do Alto, 26-XI1922, Campos Porto 1223 (RB); Km 109 ao longo da rodovia Belo Horizonte - Conceição, estrada da Usina Cachoeira de São Nicolau, 3-III-1981, Castro \& Mayo CFSC 7197 (CTES, SP, SPF); Gouveia, Fazenda do Sr. Everaldo, Estrada para o Garimpo, 11-IX-1986, Cavalcanti \& al. CFCR 10321 (SPF); Santa Barbara, Serra da Caraça, 18II-1977, Cruz \& al. 6366 (UEC); Miguel Burnier, X-1906, Damazio 1811 (RB); Carandai Crespo, 18-XI-1946, Duarte 551 (CTES, RB); Hermillo Alves, Morro Grande, 1100 m, 26-XII-1949, Duarte 2305 (RB); Carandaí, 5-XI-1952, Duarte 4071 (RB); Serra do Cipó, Chapéu de Sol, XII1958, Duarte 4623 (HB); Varzea da Palma, Fazenda Mae d'Agua, 21-XI-1962, Duarte 7544 (NY, RB); Serra do Cipó, surroundings of a small road near the Córrego Brauna ca. $2 \mathrm{~km} \mathrm{~N}$ Pensâo Chapéu-de-Sol (NNE Cardeal Mota), 37,5 km E de Baldim, ca. 1050-1100 m, 19¹7'S 4336'W, 22-IX-1990, Esteves \& al. CFCR 15497 (SPF, W); Itabira do Campo, Glaziou 17014 (C, K, P, R); Faria, 27-I-1891, Glaziou 18259 (C, K, P); Francisco Sá na estrada para Grão Mogol, 11 km de Francisco Sá, Serra do Calixto, 1050 m, 26-XI1984, Harley \& al. CFCR 6420 (CTES, K, SPF); Belo Horizonte, 3000ft, IV-1921, Harris s.n. (K); mun. Joaquim Felício, Serra do Cabral, 14-III1997, Hatschbach \& al. 66209 (BM, C, CTES, MBM, SPF); Serra do Cabral, entre o Rio Embaiassaia e o Rio Preto, 7-VI-2004, Hatschbach \& al. 77511 (CTES, MBM); estrada Varzea da Palma a Joaquim Felicio, mun. Varzea da Palma, 1000 m, 5-XII-2004, Hatschbach \& al. 78871 (CTES, MBM); Estr. Diamantina-Gouveia, a $73 \mathrm{~km}$, em direção a Sete Lagoas, 4-XII-1981, Hensold \& al. CFCR 2703 (CTES, MBM, SPF); Imbiruçú, Paraopeba, 2-III-1955, Heringer 3761 (UB, US); Faz. da Serra Jaquitibá, 6-VII-1957, Heringer 5855 (UB); Serra do Itabirito, ca. $50 \mathrm{~km}$ SE of Belo Horizonte, ca. 1500 m, 10-II-1968, Irwin \& al. 19751 (NY, UB, US); ca. $27 \mathrm{~km} \mathrm{SW}$ of Diamantina on road to Gouveia, $1300 \mathrm{~m}, 17-\mathrm{I}-$ 1969, Irwin \& al. 22143 (NY); Serra do Espinhaço, ca. $31 \mathrm{~km} \mathrm{NE}$ of Francisco Sá, road to Salinas, 1100 m, 11-II-1969, Irwin \& al. 23048 (NY, P); ca. $10 \mathrm{~km} \mathrm{NE} \mathrm{of} \mathrm{Francisco} \mathrm{Sá,} \mathrm{road} \mathrm{to}$ Salinas, 1100 m, 12-II-1969, Irwin \& al. 23144 (NY, P); ca. $12 \mathrm{~km} \mathrm{~W}$ of Barão de Cocais, base of Serra da Caraça, ca. 1500 m, 28-I-1971, Irwin \& 
al. 29304 (UB); ca. 18 km E of Pirenópolis, 1000 m, 18-II-1972, Irwin \& al. 34477 ; Serra do Cipó, Mun. Jaboticatubas: Km 116-117 ao longo da rodovia Lagoa Santa - Conceição do Mato Dentro, 7-VI-1970, Joly \& al. 207 (SP, SPF, UEC), ao longo da estrada da Usina, 16-IV-1972, Joly \& al. 1752 (SP, SPF), Km 138-139, 8-IX-1972, Joly \& al. 3444 (SP, SPF), Estrada da Usina, ca. $10 \mathrm{~km} \mathrm{da}$ entrada da estrada principal, 21-VIII-1972, Joly \& Semir 3016 (SP, SPF), Mun. Santana do Riacho, m 105 ao longo da rodovia Belo Horizonte Conceição do Mato Dentro, 7-X-1981, Kawasaki \& al. CFSC 7552 (SP, SPF); São Gonçalo do Abaete, 7-I-1989, Krapovickas \& Cristóbal 42823 (CTES); Pirapora, 11-I-1989, Krapovickas \& Cristóbal 42886 (CTES, MBM); sin localidad, Langsdorff s.n. (CTES, P, US); Mun. Sta. Barbara, Serra do Caraça, 13-XII-1978, Leitão Filho \& al. 9696 (UEC); Mun. Santana do Riacho, Km 106 ao longo da rodovia Belo Hori-zonte - Conceição do Mato Dentro, Estrada da Usina, $8 \mathrm{~km}$ da Pousada, 940-1000 m, 16-II-1982, Lewis \& al. CFSC 7751 (CTES, SP, SPF); Serra da Moeda, Moeda, $10^{\circ} 17^{\prime} \mathrm{S} 4^{\circ} 3^{\circ} 57^{\prime} \mathrm{W}, 28-\mathrm{V}-1997$, Lombardi 1822 (BHCB, CTES); S. Lucía de Sabará, 21-XI-1893, Magalhaes Gomes 1568 (EM); Montes Claros, serra do Cattoni, 9-XI-1938, Markgraf 3223 (RB); Brumadinho, $20^{\circ} 08^{\prime} \mathrm{S} 44^{\circ} 13^{\prime} \mathrm{W}$, Serra da Calçada (da Moeda), Retiro das Pedras, 1400 m, 2-III1990, Martens 281 (SPF); Contendas, IV, Martius s.n. (M); Serro Frio, V, Martius s.n. (M); Formigas, VII, Martius s.n. (M); Carmo do Rio Claro, Fazenda Alegría, 15-XI-1947, Mello Filho 585 (R); Mun. Buenópolis, Curimataí, a 15 km del lugar, aprox. $17^{\circ} 52^{\prime} \mathrm{S} 44^{\circ} 04^{\prime} \mathrm{W}$, ca. $500 \mathrm{~m}, 18$-XI1992, Mello-Silva \& al. 603 (CTES, F, SPF); Cachoeira de Macacos, 1935, Moreira s.n. (EM); São Roque de Minas, PARNA Serra da Canastra: 2 $\mathrm{km}$ da sede administrativa, estrada para Sacramento, 15-X-1994, Nakajima \& al. 515 (CTES, HUFU), estrada para a Cachoeira da Casca d'Anta, 12-V-1995, Nakajima \& al. 1033 (CTES, HUFU); Itabirito, Serra de Itabirito, Km 14 da rodovia $\mathrm{BH}-$ Itabirito, 20¹4'S 4348' W, 1300 m,14-XI-1987, Oliveira s.n. (BHCB, CTES); Km 421 viae BR-3 pr. Lago Grande, 4-XI-1962, Pabst \& al. 7199 (HB, UEC); Engenheiro Correia a Ouro Preto, 1000 m, 19-IV-1957, Pereira 3021 (HB, RB); Serra da Moeda, BR-3, 4-IV-1963, Pereira 7533 (HB, NY, RB, UEC); Mun. Santana do Riacho, Serra do Cipó, em frente a estátua do Juca, 16-II-
1988, Piliackas \& al. CFSC 10903 (CTES, SPF); Chapada S.Marcos, Pohl 2523 (W); sin localidad, Riedel 811 (BR, F, K, M, P, S); prope Paracatu, IX-1834, Riedel 2609 (C, P, W, WU); São Roque de Minas, PARNA Serra da Canastra: $5 \mathrm{~km}$ da sede administrativa, estrada para Sacramento, 16X-1994, Romero \& al. 1264 (CTES, HUFU), estrada para Cachoeira Casca D'Anta, 28-IX1995, Romero \& al. 2959 (CTES, HUFU), estrada para Sacramento, apos a entrada para o Retiro de Pedras, Romero \& Nakajima 1514 (CTES, HUFU); Serra da Carassa, Saint Hilaire s.n. (P, sintipo de T. oblongifolia); près Pindaiba seg. catálogo, Saint Hilaire B1 1758 (P); mun. Augusto de Lima, Serra do Cabral, ca. $12 \mathrm{~km}$ da cidade em direção a Fazenda Serra do Cabral, 1800'40"S 44¹9'41"W, 1000 m, 20-III-1994, Sakuragui \& al. CFCR 15258 (CTES, ESA, SPF); Conceição de Ibitipoca, Pq. Fl. Est. Ibitipoca, 29-VI-1991, Salimena-Pires \& al. s.n. (CESJ); São Julião, 9III-1891, Schwacke s.n. (R); prope Valle da Serra, 28-X-1818, Sellow C.1566 (K); Serra da Pitangui, 18-XII-1818, Sellow 1570 (K); Serra de S.José del Rei (p.a.), XI-1896, Silveira 1924 (R); Morro do Ferro, ca. $7 \mathrm{~km}$ da cidade em direção ao observatório, 2045'38"S 44³3’23"W, 1109 m, 15-I-1994, Souza \& al. 5084 (CTES, ESA, K, $\mathrm{SPF})$ mun. Lagoa Dourada, $8 \mathrm{~km}$ de Lagoa Dourada em direcão a Entre Rios de Minas,

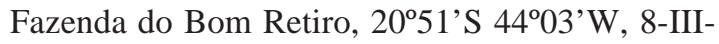
1995, Souza \& al. 7986 (ESA); Mun. Joaquim Felício, Serra do Cabral: 17²4'29"S 44¹1'31"W, 16-V-1999, Souza \& al. 22443 (CTES, ESA); Perdizes, Cerrado Ceu do Cavalo, Unidade Conservação do Galheiro, CEMIG, 27-X-1994, Tameirão Neto \& Werneck 1718 (BHCB, CTES); Itabirito, Pico do Itabirito, na Serra dos Inconfidentes, 21-V-1994, Teixeira s.n. (BHCB, CTES); C. do Batatal, S. do Capanema, 19-IX1893, Thomas \& Magalhaes Gomes 1206 (EM); Serra de Caraça, III-1892, Ule 2696 (HBG, R); Belo Horizonte, Serra do Curral, 1100 m, 25-X1997, Vasconcelos s.n. (BHCB, CTES); Mun. Santa Rita de Cassia, Morro da Furna, prox. Fazenda do Morro Redondo, III-1945, Vidal I-506 (R); Lagoa Santa, Warming s.n. (C, US); Piedade, Warming s.n. (C); Joaquim Felicio, Serra do Cabral, Fazenda da Onca, ca. 1100 m, 1-IX-1985, Zappi \& al. CFCR 8110 (CTES, SPF). Paraná: Capão Bonito, 29-III-1915, Dusén 16909 (MO, S); Jaguariaiva, Barra Rio das Mortes, 810 m, 5-XII- 
1964, Hatschbach 11955 (MBM, US); Jaguariaiva, Fda. Cajuru, 4-III-1966, Hatschbach \& al. 13993 (CTES, MBM, US). Santa Catarina: Cachambu, 1861-2, Weir 333 (BM, FI, K). São Paulo: Ipiranga, 18-II-1912, Brade 5922 (BM, CTES, R, S, SP); Saude, 11-II-1912, Brade 5923 (S); S. Bernardo, XII-1911, Brade 5924 (S); Villa E mma, XII-1932, Brade 12413 (R); Campos de Jordão, X-1937, Campos Porto 3401 (RB); Ibiúna, ca. $2 \mathrm{~km}$ da estrada que sai a esquerda (sentido São Paulo-Ibiúna) da Rodovia Sp-250, Km 63, 9-XII1998, Cordeiro \& al. 1828 (CTES, SP); Santo Amaro, I-1898, Edwall s.n., C.G.G.SP 3939 (SP, $\mathrm{R})$; mun. Itapetininga, Km 180, Rod. Raposo Tavares, 3-XII-1974, Freire de Carvalho \& al. 112 (RB); Campo Congonhas, Cap., 29-I-1942, Hoehne 1018 (CTES); Caiciras, 25-I-1945, Hoehne 1666 (CTES); São Paulo, Parque Jabaquara, 24-I-1924, Hoehne \& Gehrt s.n. (CTES, R, SP); Rod. SP-Parana, Brigadeiro Talhías, 10-XI-1936, Hoehne \& Gehrt s.n. (R, SP); Tatuhy, 1-XII-1936, Hoehne \& Gehrt s.n. (CTES, SP); França, 16-I-1893, Löfgren \& Edwall 2170 (BM, SP); Mugi, XI-1833, Lund s.n. (C); Pedregulho, 12-XI-1994, Marcondes-Ferreira \& al. 962 (CTES, SP); 3 km N de Casa Branca, na Fazenda Ribeirão do Açude, 8-XI-1967, Mattos \& Mattos 14218 (SP); São José dos Campos, 29VIII-1962, Mimura 530 (SP); São Paulo, linha do S. Amaro, 28-I-1940, Pickel 4525 (IPA, SP); Campos de Sn. Bernardo, 18-IX-1902, Puttermans s.n. (SP); camp. Hytu, II-1834, Riedel s.n. (C); in campis siccis prope Mugi [seg. Urban], XI, Riedel 1403 (BR, C, FI, K, M, P, S, US, W, WU); près le Rio Jaguariahiba, Saint Hilaire C2 1428 (P, sintipo de T. oblongifolia); près de St Paul, Saint Hilaire D 676 (P, sintipo de T. oblongifolia) y Saint Hilaire s.n. (P, sintipo de T. oblongifolia); Mun. Itararé, estrada Itararé-Bomsucesso, Fazenda Ibiti (Ripasa), 13-XI-1994, Souza \& al. 7150 (ESA, SP); Villa Mariana, 7-XI-1905, Usteri 19 (BM, CTES, G, SP).

Distribución y fenología: Variedad propia de campo y «cerrado» de suelo arenoso o pedregoso de las regiones montañosas de Bahía, Goiás, Minas Gerais, São Paulo y Paraná. Crece entre los 800 y 1600 m de elevación. Existe un ejemplar colectado en el estado de Santa Catarina, Cachambu, donde no ha vuelto a ser encontrada. Florece durante todo el año, la mayor parte de los ejemplares fueron colectados en los meses más cálidos, desde septiembre a abril.

Obs.: En esta variedad la expresión de la heterostilia es variable, en muchas flores longistilas las anteras alcanzan la base de los estigmas, y en muchas flores brevistilas los estigmas alcanzan las anteras (Fig. $57 \mathrm{M}$ y P). La antesis se produce en horas de la mañana, las flores se cierran hacia el mediodía. En el ejemplar Irwin \& al. 9020 ciertas flores presentan un apéndice flageliforme 4-5 mm long. en la base de algunos pétalos, con granos de polen adheridos en la porción apical.

Es una entidad polimorfa, pertenece al grupo de taxones con venas laterales salientes en ambas caras de la lámina foliar. El tamaño, la forma y el indumento de la lámina son muy variables, así como la ramificación del tallo. Algunos ejemplares tienen pelos simples casi tan largos como los de Turnera foliosa, que se caracteriza por su foliación densa y por sus hojas vegetativas generalmente eglandulosas. Ciertos ejemplares son similares a $T$. hilaireana, que se caracteriza por sus hojas herbáceas, cuyo envés tiene aspecto arenáceo, y la longitud de sus entrenudos, algunos notablemente largos en relación con la corta altura de la planta.

Los ejemplares Irwin 7934 y Irwin \& Soderstrom 6113 tienen aspecto similar a Turnera riedeliana. En algunos especímenes como Anderson \& al. 7566 y Irwin \& al. 19353 el indumento es intermedio con el de la var. goyazensis. Las hojas de Krapovickas \& Cristóbal 42901 recuerdan las de T. lanceolata, pero su relación largo:ancho es menor. El ejemplar Arbo \& al. 3807 presenta una gran variabilidad en forma y tamaño de hojas, así como de indumento. En Irwin \& al. 23144 las hojas tienen margen serrulado casi hasta la base.

Se examinó la anatomía de los nectarios extraflorales de esta entidad, comparada con la de otras especies de la serie y de la serie Turnera (Gonzalez, 1996). Los coléteres, de tipo standard, están presentes en los dientes de los primordios foliares, en las estípulas rudimentarias y en los profilos jóvenes (Gonzalez, 1998). Las hojas son dorsiventrales y 
anfistomáticas, los haces vasculares con vaina parcialmente esclerenquimática; en la semilla, la endotesta está constituida por células pequeñas (Gonzalez, 2000). Se estudiaron además la vascularización floral y los nectarios florales (Gonzalez, 2001).

\section{0b. Turnera oblongifolia var. goyazensis (Urb.) Arbo comb. nov.}

Figs. 27 y 58

Turnera goyazensis Urb., Bot. Jahrb. Syst. 25, Beibl. 40:4. 1898. Typus: Brasil. Goiás, sin localidad, Glaziou $21450 b$ (holotypus $\mathrm{B}+$ fototipo $\mathrm{F} \mathrm{n}^{\circ}$ 13582; no se han hallado isotipos en los herbarios consultados). Neotypus, aquí designado: Brasil. Goiás, próximo ao Rio São Bartolomeu, 35 km O de Cristalina, 7-II-1994, Hatschbach \& al. 59941 (MBM, isotypus CTES).

Hierba perenne de $12-50 \mathrm{~cm}$ de alto, verde o castaña en seco, base leñosa de 1-7 mm diám.; tallos 1-5, sinuosos, desnudos en la porción inferior, 1-2,5 mm diám., cilíndricos, a veces estriados, con pelos simples, cortos y crespos entremezclados con otros largos, y curvado-antrorsos; entrenudos 2-38 mm long., entre hojas floríferas más cor-tos, 5-1 mm long. Yemas axilares 1, raramente 2, ramas seriales no desarrolladas. Hojas vegetativas erguidas o extendidas. Estípulas rudimentarias, con coléteres 0,1-0,3 mm long., cónicos, rojizos. Pecíolo 0-2 mm long., con un mechón de pelos hirsutos en la base. Lámina elíptica, elíptica, ovada, angustiovada o angustielíptica, en hojas basales obovada o suborbicular, (5-)13-61 x (3-)4,5-20(-30) mm, relación largo:ancho $=1,7-7,6: 1$; base redondeada, brevemente atenuada o raramente cuneada; ápice agudo, a veces obtuso; margen plano, entero o serrulado, con pelos simples cortos y largos; haz y envés a veces punteados y lustrosos, densamente cubiertos de pelos simples, cortos, crespos, entremezclados con pelos largos, antrorsos o erectos; 3-6 pares de venas secundarias incurvas, salientes en la haz, más prominentes en el envés, generalmente no formando arcos marginales prominentes; ángulo de divergencia $20-35^{\circ}$; vena- ción menor conspicua. Nectarios $1+1$ o $2+2$, situados en la unión de pecíolo y lámina o desplazados hasta $1,5 \mathrm{~mm}$ sobre el margen, circulares o elípticos, 0,4-0,8 mm diám., hasta de $1,2 \mathrm{~mm}$ en hojas floríferas, rojizos, con «poro», borde eriza-do de pelos cortos. Hojas floríferas acortándose rápidamente hasta ser bracteiformes, 29-2 x 11-1 mm, relación largo:ancho $=4,6-1,3: 1$. Flores epifilas, heterostilas, agrupadas en la porción apical, a veces los frutos espaciados hasta $2-7 \mathrm{~cm}$ del ápice. Alabastro elipsoide, apiculado, mucrones libres en el extremo. Pedúnculo 23,5 mm long., soldado al pecíolo totalmente o con una porción apical libre de 0,9-1,5 mm long. Profilos subulados, 2,5-6 x 0,3-0,7 mm, opuestos en la base del receptáculo o ligeramente más abajo, cara externa con indumento como el de las hojas, cara interna glabra, borde ligeramente serrulado, a veces con nectarios. Pedicelo nulo. Cáliz 6,5-10 mm long., densamente cubierto de pelos cortos, crespos y otros más largos, curvado-antrorsos, especialmente en los lóbulos; tubo calicino 23,5 mm long., cara interna vellosa en la parte superior; lóbulos ovado-lanceolados o triangulares, bordes membranáceos, a veces purpúreos; lóbulos internos cuculados, mucrón 0,2-0,4 mm long. Corola amarilla, pétalos de lámina obovada, 6,5-11 x 3-7 mm, base cuneada, pilosa por dentro. Filamentos estaminales glabros, 3-5 $\mathrm{mm}$ long. en flores longistilas, 4,5-6,5 $\mathrm{mm}$ long. en flores brevistilas, soldados en la base por 0,3-0,5 $\mathrm{mm}$ al tubo calicino; anteras elípticas, 1-1,6 x 0,5-0,7 mm, base emarginada, ápice obtuso, a veces ligeramente apiculado, revoluto después de la dehiscencia, filamento inserto dorsalmente a $0,3-0,5 \mathrm{~mm}$ de la base. Ovario subesférico, 1-1,5 x 1-1,7 mm, hirsuto; placentas 6-12-ovuladas; estilos cilíndricos, 3-5 mm long. en flores longistilas, 2-2,5 mm long. en flores brevistilas, glabros o pilosos; estigmas 1,2-2 mm long., divididos en 6-10 ramas. En flores longistilas el gineceo es 1,5-2 $\mathrm{mm}$ más largo que el androceo, y en flores brevistilas $1,5-2 \mathrm{~mm}$ más corto. Fruto subesférico, ligeramente apiculado, 4-6,5 mm long., con un reborde basal de $0,3 \mathrm{~mm}$ dejado por la absición del tubo floral; cara externa con pelos simples cortos y largos, cara interna 


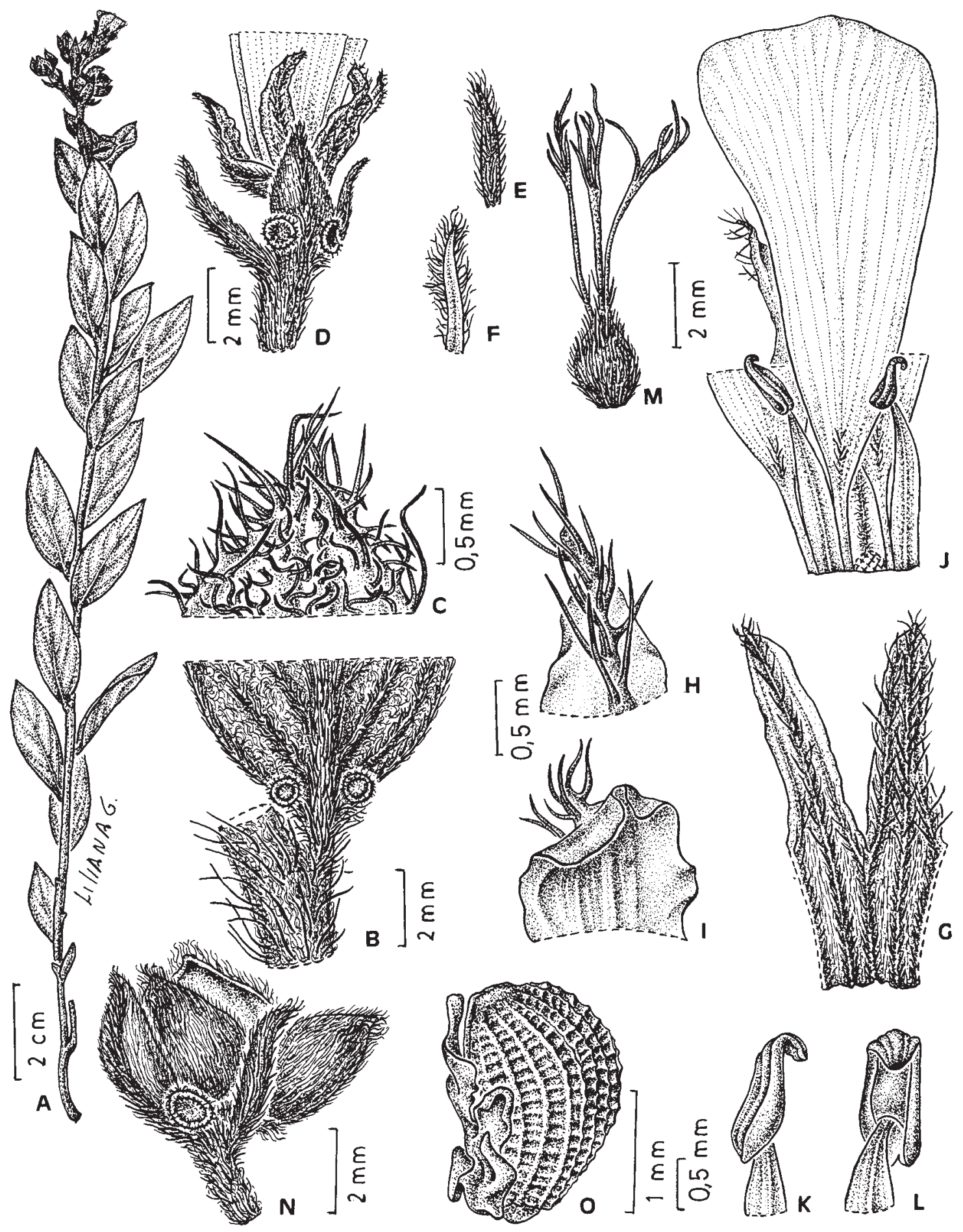

Fig. 58. Turnera oblongifolia var. goyazensis. A: planta. B: porción basal de hoja con nectarios, cara abaxial. C: ápice foliar, cara abaxial. D: bráctea con nectarios, flor epifila y profilos. E-F: profilos. G: porción del cáliz, cara externa. HI: ápice de lóbulos del cáliz, caras externa e interna. J: flor longistila, porción del tubo calicino, cara interna, con pétalos y estambres adnatos; se ha cuadriculado la cicatriz dejada al desprender un estambre. K-L: anteras, vistas lateral y dorsal. M: gineceo. N: bráctea con nectario, fruto epifilo y profilo. O: semilla con arilo, vista lateral (A-D, O: Irwin \& al. 26142; E-M: Irwin \& al. 25955). Del. Liliana Gómez. 
lustrosa, maculada, totalmente glabra o con algunos pelos en la base. Semilla ligeramente curvada, obpiriforme, 1,7-2,8 x 1-1,5 $\mathrm{mm}$, pardo-oscura; exóstoma cónico y prominente; rafe linear oscura, lado rafeal recto, a veces incurvo; cálaza saliente, oscura, a veces ligeramente deprimida en el centro. Episperma reticulado, nudos algo prominentes, aréolas transrectangulares, epidermis papilosa, con cera epicuticular bastoniforme. Arilo 1,3-2 mm long., angosto, unilateral, de células lisas.

Material estudiado: BRASIL. Sin localidad, Pohl s.n. (BM, BR, W). Distrito Federal: APA de Cafuringa, Mumunhas, 27-I-1994, Silva \& al. 1884 (IBGE). Goiás: Rod. GO-118, 10-15 km S de Alto Paraiso, Chapada dos Veadeiros, $1000 \mathrm{~m}$, 15-X-1990, Hatschbach \& al. 54550 (CTES, MBM); Rod. BR-040, próximo ao Rio São Barto-lomeu, 35 km W de Cristalina, 7-II-1994, Hatschbach \& al. (CTES, MBM); Serra dos Cristais, $17^{\circ} \mathrm{S} 48^{\circ} \mathrm{W}$, ca. $2 \mathrm{~km} \mathrm{~N}$ of Cristalina, 1250 m, 5-XI-1965, Irwin \& al. 9933 (NY); Contraforte Central, ca. $25 \mathrm{~km} \mathrm{NE}$ de Catalão, 875 m, 21-I-1970, Irwin \& al. 25022 (NY); Caldas Novas, Pohl 2626 (W) y Pohl 2633 (W). Minas Gerais: MG-188, 28 km S de Paracatú, cerca del río Escurinho, camino a Guarda Mor, 600 m, 31-I1990, Arbo \& al. 3201 (CTES); Delfinópolis, complexo do Claro, proximo a Cachoeira do Claro, 10-VI-1999, Filliettaz \& al. 60 (UEC); Serra da Anta, ca. 5 km NW of Paracatú, 800 m, 4-II1970, Irwin \& al. 25955 (CTES, NY, P, UB), ca. 10 km N of Paracatú, 900 m, 6-II-1970, Irwin \& al. 26142 (CTES, P, UB); Serra de Itabira do Campo, 11-IX-1887, Schwacke s.n. (R).

Distribución y fenología: Variedad propia del «cerrado» y «campo rupestre» del Distrito Federal, Goiás y de la región occidental de Minas Gerais, entre 600 y 1250 m de altitud. Florece y fructifica entre septiembre y febrero.

Turnera oblongifolia var. goyazensis se diferencia principalmente por su indumento más denso, constituido por pelos simples dispuestos en dos estratos: uno de pelos cortos y otro de pelos largos. Es afín a T. lanceolata, con el mismo indumento, que se distingue por sus hojas vegetativas largas, generalmente lineares y extendidas, y hojas floríferas bien desarrolladas. Según Urban es afín a T. elliptica. En varios ejemplares el indumento presenta características intermedias con la var. oblongifolia.

\section{Turnera opifera Mart.}

Figs. 16 y 59

Martius, C.F.P., en Martius C.F.P. \& Spix J.B., Reise Bras. 2: 552. 1828; Urban, Jahrb. Königl. Bot. Gart. Berlin 2: 117. 1883; Urban, en Martius C.F.P., Fl. Bras. 13(3): 138, tab. 48, 2. 1883. Typus: Brasil. Minas Gerais: campis ad Arraial das Barreiras, Serro Frio [Serro], in indigestione decortum pumitur, VII-1818, Martius 1405 (holotypus M!).

Turnera lutescens Cambess., en St.Hilaire, Juss. \& Cambessedes, Fl. bras. merid. 2: 217. 1830; Urban, Jahrb. Königl. Bot. Gart. Berlin 2: 117; Urban, en Martius C.F.P., Fl. Bras. 13(3): 139. 1883. Typus: Brasil. Minas Gerais: Roca do Contrato, Saint Hilaire s.n. (lectotypus, aquí designado $\mathrm{P}$ !, isotypus $\mathrm{F}$ !).

Turnera nana Cambess., en St. Hilaire, Juss. \& Cambessedes, Fl. bras. merid. 2: 219. 1830; Urban, Jahrb. Königl. Bot. Gart. Berlin 2: 103. 1883; Urban, en Martius C.F.P., Fl. Bras. 13(3): 127. 1883. Typus: Brasil. Minas Gerais: Catonio, Certão, campos dont on a rece mment brulé les herbes, fleurs d'un jaune doré, IX, Saint Hilaire $B_{1}$ 1956 (holotypus $\mathrm{P}$ ! fototipo $\mathrm{F} \mathrm{n}^{\circ}$ 38465).

Subarbusto o arbusto hasta $1,5 \mathrm{~m}$, rebrotes florecidos desde $5 \mathrm{~cm}$; tallos erectos 2,5-4 mm diám., en los rebrotes hirsutos, pelos simples curvado-antrorsos o patentes, 0,8-1,2 mm long., a veces mezclados con pelos cortos erectos o crespos; tallos jóvenes de plantas crecidas densamente estrigosos, pelos amarillos, gruesos, adpresos, a veces tomentosos hacia el ápice. Hojas discoloras. Base foliar saliente y persistente. Estípulas 0,2-0,6 mm long., pardas o negruzcas, más o menos cónicas o subuladas. Pecíolo 2-12 mm long., indumento como el del tallo. En los rebrotes: lámina obovada o angustiobovada, a veces elíptica u ovada, 6,5-16 x 3,5-11 mm, relación largo: ancho $=1,2-3$, margen aserrado o 


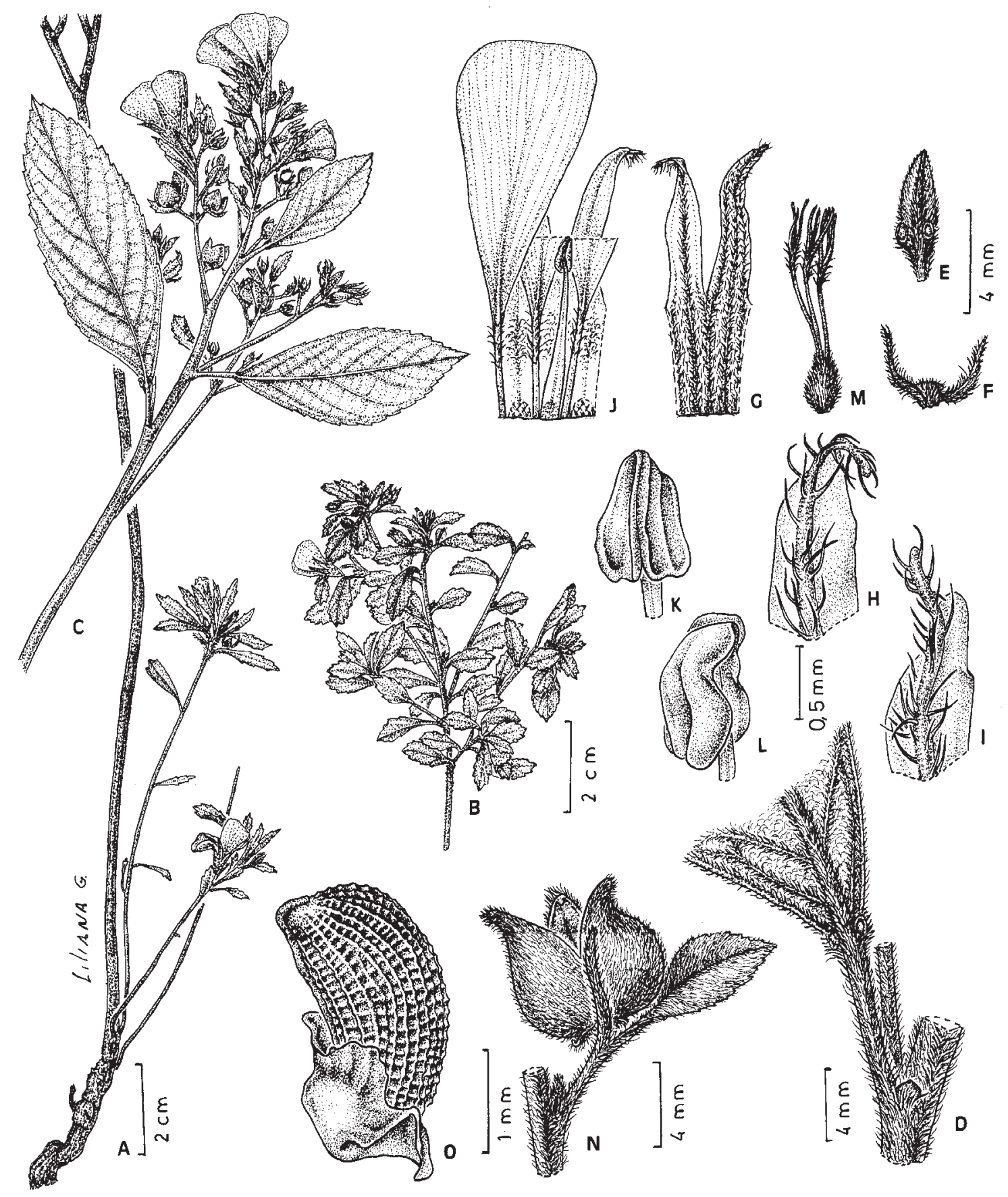

Fig. 59. Turnera opifera. A: planta rebrotando. B-C: ramas floríferas. D: nudo, porción basal de una hoja, cara abaxial, estípula y rama axilar. E: bráctea con nectarios. F: receptáculo y profilos. G: porción del cáliz, cara externa. H-I: ápice de lóbulos del cáliz, cara externa. J: flor longistila, porción del tubo calicino, cara interna, con pétalos y estambre adnatos; se han cuadriculado las cicatrices dejadas al desprender 2 estambres. K-L: anteras, vistas ventral y lateral. M: gineceo. N: bráctea con fruto epifilo y profilo. O: semilla con arilo, vista lateral (A: Arbo \& al. 4408; B, NO: Mello-Silva \& al. 641; C-M: Hatschbach 29039). Del. Liliana Gómez. 
crenado-aserrado, plano o algo revoluto, ápice agudo u obtuso, haz con pelos simples curvado-antrorsos de base cónica y pelos simples más cortos, envés con pelos iguales sin orientación definida, y pelos glandulares microcapitados, hojas basales a veces glabrescentes. En plantas crecidas: lámina elíptica, obovada, obovado-oblonga, lanceolada o angustilanceolada, 1,7-11 x 0,5$4 \mathrm{~cm}$, relación largo:ancho $=(1,4-) 2,5-4,8: 1$; base cuneada o brevemente atenuada; ápice agudo u obtuso; margen plano o ligeramente revoluto, regular o irregularmente crenadoaserrado excepto en la porción basal; haz oscura, lustrosa, con pelos simples curvadoantrorsos de base abultada, venas ligeramente hundidas; envés a veces maculado, con pelos simples más densos y pelos microcapitados amarillos entremezclados; 5-7(-9) pares de venas secundarias prominentes, incurvas, anastomosándose antes del margen con la inmediata superior; ángulo de divergencia (25 )30-35(-45) ${ }^{\circ}$. Nectarios circulares o elípticos, 0,5-1 mm long., insertos en la parte basal del margen foliar, orientados hacia el envés, a veces ausentes en las hojas vegetativas. Hojas floríferas bracteiformes, de tamaño bruscamente decreciente, hasta 6-2 mm long., con un par de nectarios grandes asentados sobre el envés, pardos o negruzcos, elípticos, 0,4-1,5 mm diám., de reborde piloso, a veces glabro. Flores epifilas, dimorfas, reunidas en los ápices de las ramas en racimos bracteosos compuestos paniculiformes, los racimos axilares 8-15-floros originados por las yemas seriales de las primeras hojas floríferas. Pedúnculo 4,5-2 $\mathrm{mm}$, el ápice libre 0,5-1,5 $\mathrm{mm}$ en las flores basales de los rebrotes, en las flores apicales muy breve, totalmente adnato. Profilos lineares o subulados, 2-6,5 x 0,3-0,7 $\mathrm{mm}$, enteros, insertos en la base del receptáculo. Pedicelo ausente. Cáliz 7-13 mm long., estrigoso, a veces tomentoso o con pelos erectos ásperos; tubo 3,5-5,2 mm long., interiormente piloso o pubescente en la porción apical; lóbulos lanceolados o linearlanceolados, con pelos más largos que el tubo, 3-5 nervados, nervio medio prolongado en mucrón 0,3-1 mm long. Corola amarilla, rotácea, 2,5-8,5 mm más larga que el cáliz; pétalos con uña pilosa, lámina obovada, 8-15 mm long., base subcuneada, glabra o con algunos pelos. Filamentos estaminales soldados en la base $0,3-1 \mathrm{~mm}$ al tubo calicino, glabros, subulados, 5-7 mm long. en flores longistilas, 6,5-10 mm long. en flores brevistilas; anteras ovadas u ovado-oblongas, $0,8-2 \times 0,5-1 \mathrm{~mm}$, base emarginada, filamento inserto dorsalmente a 0,4-0,6 $\mathrm{mm}$ de la base, ápice obtuso o apiculado, ligeramente recurvado después de la dehiscencia. Ovario ovoide o cónico, densamente estrigoso, 1,2-2 mm long.; placentas 5-12-ovuladas; estilos cilíndricos, 3,5-8 mm long. en flores longistilas, 2,5-4,5 mm long. en flores brevistilas, tercio superior partido en 2-4 ramas, generalmente con pelos breves, rígidos, patentes laxos o densos; estigmas paucirramosos, 1-2 mm long. En flores longistilas el gineceo es 1-3 $\mathrm{mm}$ más largo que el androceo y en flores brevistilas es 1-3,5 mm más corto. Fruto 5-8 mm long., subesférico, cónico o piramidal; absición del tubo floral a 0,4-0,5 $\mathrm{mm}$ de la base, dejando un reborde anular persistente; valvas pardas por fuera, con pelos cortos, adpresos, densos o laxos, entremezclados con pelos cortos, erectos o crespos, por dentro glabras, nítidas, amarillentas, a veces con máculas rojizas. Semilla negruzca, (2 )2,3-3 x 1$1,6 \mathrm{~mm}$, obovoide u oblongo-obovoide, curvada, base atenuada; exóstoma brevemente cónico; rafe linear algo prominente, lado rafeal incurvo; cálaza redondeada, con una protuberancia pigmentada que es continuación de la rafe, a veces ligeramente deprimida en el centro. Episperma reticulado, nudos no prominentes, muros verticales más prominentes que los transversales, aréolas con epidermis lisa, en la semilla inmadura con bastoncillos de cera epicuticular. Arilo igual o más largo que la semilla, envolvente, borde lacerado o lobulado, amarillento o blanquecino en seco especialmente en la zona de inserción, de células papilosas.

Cromosomas: $2 \mathrm{n}=10 \mathrm{x}=70$, Fernández y Arbo 370 (Fernández, 1987)

Material escogido. BRASIL. Sin localidad, Neuvoied s.n. (BR). Bahia: Rod. BR-116, 3 km S de Candido Sales, 19-I-1984, Hatschbach 47352 (C, CTES, MBM, MO, US). Minas Gerais: Mun. 
Tiradentes, Serra de São José, 1200 m, 7-X-1998, Alves 6501c (CTES, R); Rio Jequití, $2 \mathrm{~km}$ from Mendanha, ca. 800 m, 13-IV-1973, Anderson 8824 (NY, UB); Serra do Espinhaço, ca. $17 \mathrm{~km}$ SW of Gouveia, mun. Gouveia, Km 258 on MG 259, 1000-1050 m, 7-II-1972, Anderson \& al. 35613 (CTES, P, UB); Mun. Diamantina: 20-26 km WSW de Diamantina, camino a Conselheiro Mata, MG-220, ca. $18^{\circ} 17^{\prime}$ S 4349' W, 1270-1300 m, 18-V-1990, Arbo \& al. 4408 (C, CTES, GH, K, MBM, MICH, MO, SPF), mun. Diamantina, 8-15 km S de São João da Chapada, camino a Diamantina, $18^{\circ} 11^{\prime} \mathrm{S} 43^{\circ} 45^{\prime} \mathrm{W}$, ca. $1100 \mathrm{~m}, 19-\mathrm{V}-$ 1990, Arbo \& al. 4443 (C, CTES, K, MBM, MICH, MO, SPF), 2-4 km S de São João da Chapada, $18^{\circ} 07^{\prime} \mathrm{S} 4^{\circ} 46^{\prime} \mathrm{W}, 1270 \mathrm{~m}, 19-\mathrm{V}-1990$, Arbo \& al. 4460 (CTES, SPF); Serra dos Crystaes, 6-XI-1937, Barreto 9541 (F); Diamantina: estrada Belo Horizonte-Diamantina, Km 499, 21-IX-1998, Braga \& al. (BHCB, CTES); Mun. Turmalina, Peixe Cru, 2-XII-1991, Carvalho 847 (BHCB, CTES); Grão Mogol, 13-IV-1981, Cordeiro \& al. CFCR 818 (CTES, MBM, SPF); Mun. Cristália, Mórro do Chapéu, ca. 1200 m, 6-I-1986, Cordeiro \& al. CFCR 8898 (CTES, SPF); Estrada CorintoVarzea da Palma, 2-X-1965, Ferreira \& Marques 57 (SP); Carandahy, 14-VI-1882, Glaziou 13913 (C, K, P, R); Diamantina, estrada para Biri-Biri a $13 \mathrm{~km}$ da cidade, 18-XI-1984, Harley \& al. CFCR 6139 (CTES, K, MBM, SPF); mun. Buenópolis, Serra do Cabral, a 6-7 km da cidade, $17^{\circ} 53$ ' S 44'15'W, 760 m, 12-X-1988, Harley \& al. 24858 (K); Mun. Grão Mogol, ca. 5-15 km N da cidade, $16^{\circ} 32$ ' S, 42 $47^{\prime} \mathrm{W}, 900 \mathrm{~m}, 16-\mathrm{X}-1988$, Harley \& al. 25096 (CTES, K, SPF); Serra do Espinhaço, mun. Gouveia, 6-IX-1971, Hatschbach 27320 (CTES); Grão Mogol, rod. para Cristália, 22-IV1978, Hatschbach 41404 (CORD, CTES, MBM, MU, SPF, US); mun. Diamantina, Serra do Espinhaço, 16-II-1973, Hatschbach \& Ahumada 31646 (CTES, MBM); mun. Felisberto Caldeira, Curtidor, 16-II-1973, Hatschbach \& Ahumada 31683 (CTES, MBM); Mun. Grão Mogol, Ribeirão, 11-VI-1990, Hatschbach \& al. 54194 (C, CTES, DAV, MBM, MO); mun. Cristália, Bem Querer, 850 m, 10-II-1991, Hatschbach \& al. 54993 (CTES, MBM, MO, W); Mun. Bocaiuva, Rod. Bocaiuva-Diamantina, prox. do rio Jequitinhonha, 17-III-1997, Hatschbach \& al. 66430 (CTES, ESA, MBM); Grão Mogol, estrada para Josenopolis, 17-VII-1998, Hatschbach \& al.
67966 (C, CTES, MBM); mun. Cristália, Soberbo, 18-VII-1998, Hatschbach \& al. 68006 (CTES, MBM); Barão do Guaçui, mun. Diamantina, 24-X1999, Hatschbach \& al. 69662 (CTES, MBM)); Serra do Cabral, subida Buenópolis para Estrada Real, Mun. Buenópolis, 23-VIII-2002, Hatschbach \& al. 73785 (CTES, MBM); mun. Berilo, Leliveldia, 26-XI-1985, Hatschbach \& Silva 50172 (BR, CTES, MBM, MU, US); Grão Mogol, margem da estrada Grão Mogol - Montes Claros em direção sudoeste, aprox. $16^{\circ} 35^{\prime} \mathrm{S} 42^{\circ} 53^{\prime} \mathrm{W}$, 23-V-1982, Hensold \& al. CFCR 3509 (CTES, F, $\mathrm{SPF}$ ); ca. $27 \mathrm{~km} \mathrm{SW}$ of Diamantina on road to Gouveia, 1300 m, 17-I-1969, Irwin \& al. 22142 (NY); ca. $12 \mathrm{~km} \mathrm{NE}$ of Diamantina, road to Mendanha, 1300 m, 28-I-1969, Irwin \& al. 22780 (CTES, P); Serra do Espinhaço, ca. $30 \mathrm{~km} \mathrm{NE}$ of Francisco Sá, road to Salinas, 1100 m, 10-II-1969, Irwin \& al. 22972 (CTES, NY, P, UB); ca. $15 \mathrm{~km}$ W of Grão Mogol, road to Cristália, 950 m, 20-II1969, Irwin \& al. 23596 (NY, P, UB); ca. 15 km N of São João da Chapada, 975 m, 23-III-1970, Irwin \& al. 28109 (CTES, P, UB); Serra do Calixto, IX1945, Lanstyak s.n. (RB); Mun. Diamantina, estrada para Biribiri, 8-XII-1992, Leitão Filho \& al. 27483 (MBM, UEC); Parque Estadual do Rio Preto, São Gonçalo do Rio Preto junto ao corrego da Lapa, $18^{\circ} 05^{\prime} 28^{\prime \prime S} 43^{\circ} 20^{\prime} 32^{\prime \prime W}$, 7-IV-2000, Lombardi \& al. 3749 (BHCB, CTES); Serra do Grão Mogol, 900-1000 m, 12-XI-1938, Markgraf \& al. 3427 (F, R, RB); Mun. Itacambira, camino de Juramento a Itacambira, $16 \mathrm{~km}$ W de Itacambira, aprox. $17^{\circ} 01^{\prime} \mathrm{S} 43^{\circ} 24^{\prime} \mathrm{W}$, aprox. $700 \mathrm{~m}, 18-\mathrm{XI}-$ 1992, Mello-Silva \& al. 636 (CTES, K, SPF); Extremo $\mathrm{N}$ de Serra da Canastra, proximo al camino hacia Itacambira, Tinoco, aprox. $16^{\circ} 55^{\prime} \mathrm{S}$ 4303'W, 970 m, 19-XI-1992, Mello-Silva \& al. 641 (CTES, K, MBM, SPF); 14 km NW de Botumirim, camino hacia Adão Colares y Barrocão, aprox. $16^{\circ} 45^{\prime} \mathrm{S} 43^{\circ} 05^{\prime} \mathrm{W}, 850 \mathrm{~m}, 20$ XI-1992, Mello-Silva \& al. 734 (CTES, SPF); Mun. Grão Mogol, BR-251, 2 km NE de Barrocão, camino hacia Salinas, aprox. $16^{\circ} 21^{\prime} \mathrm{S} 43^{\circ} 13^{\prime} \mathrm{W}$, 900 m, 20-XI-1992, Mello-Silva \& al. 749 (CTES, SPF, UB); BR-251, 53 km E de Caveira, a $23 \mathrm{~km}$ de Serra de Bocaina, Vale das Cancelas, aprox.

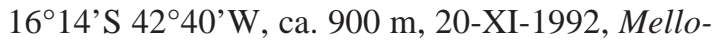
Silva \& al. 764 (CTES, SPF); Grão Mogol: montanha a esquerda do riacho Ribeirão, Trilha da Tropa, 16³3'S 4254'W, 850-1000 m, 3-XI-1987, Mello-Silva \& al. CFCR 11396 (CTES, SPF); Km 
938 da BR-4 entre Medina e Limeira, 16-I-1965, Pabst 8345 - Pereira 9456 (CTES, HB, R, RB, UEC); Capelinha, $17^{\circ} 28^{\prime} \mathrm{S}$ 42 $36^{\prime} \mathrm{W}, 11-\mathrm{XI}-$ 1981, Pinto 381/81 (HRB, MBM, RB); Estr. Grão Mogol - Virgem da Lapa, 14-IV-1981, Pirani \& al. CFCR 896 (CTES, F, SPF); Cristália: Vale do Corrego Jacuba, entre Cristália e Botumirim, 700 m, 28-IX-1997, Rapini \& al. 349 (CTES, SP, SPF); Salinas: estrada Salinas/Aeroporto a $2 \mathrm{~km}$ do entroncamento, $16^{\circ} 11^{\prime} 46^{\prime \prime S} 42^{\circ} 20$ ' $18^{\prime \prime} \mathrm{W}, 704$ m, 7-IV-2002, Ribeiro \& al. 290 (HUEFS); sin localidad, 1816-1821, Saint Hilaire B1 1362 (P, sintipo de T. lutescens); Rio Preto [probablemente São Sebastião do Rio Preto], Saint Hilaire C554 (P, sintipo de T. lutescens); divisa entre os Mun. Espinosa e Montezuma, a $35 \mathrm{~km}$ Serra do Pau D’Arco, 1504'55"S 4208'27"W, 1300-1400 m, 15-III-1994, Sakuragui \& al. CFCR 15079 (CTES, ESA, SPF); Grão Mogol. Vale do rio Itacambiruçu, entre a fazenda Jambeiro e estrada para Cristália, 700 m, 26-II1986, Semir \& al. CFCR 9703 (CTES, SPF, UEC); Grão Mogol, estreito do Riacho Ribeirão, ca. 950-1100 m, ca. 16 33's 42 54'W, 16-VI1990, Simão-Bianchini \& al. CFCR 13145 (CTES, SPF); Mun. Itacambira, estrada Itacambira-Juramento, ca. $2 \mathrm{~km}$ de Itacambira, 1300 m, 22-II-2002, Souza \& al. 28188 (CTES, ESA).

Material cultivado. ARGENTINA. Corrientes: proc. de Grão Mogol, semillas de Cordeiro \& al. 818, 10-III-1983, Fernández y Arbo 370 (CTES).

Distribución y fenología: Especie propia del «cerrado»y «campo rupestre», a veces también en borde bosque y en transición con «caatinga». Crece bien en terrenos modificados como bordes de caminos. Vegeta en suelos pedregosos o arenosos, a veces arcillosos. Vive en Minas Gerais y zona limítrofe de Bahia, entre los 750 y 1300 m de elevación, siendo una especie frecuente. Florece desde septiembre a julio.

Usos: Según Correia (1931) su nombre vulgar es «damiana», y tiene acción tónica especial inmediata sobre los órganos genitourinarios. Martius, quien coleccionó el ejem- plar tipo, indica que se utiliza en caso de indigestión.

Obs.: Se trata de una especie de floración muy rápida, después de la quema del campo o del «cerrado», se encuentran rebrotes de apenas $5 \mathrm{~cm}$ long. ya florecidos, en los cuales las flores se hallan sobre nomófilos cuya forma, tamaño e indumento son diferentes. El tipo de Turnera nana y los siguientes ejemplares corresponden a estos rebrotes: Alves 6501c, Anderson \& al. 35613, Braga \& al. s.n., Ferreira \& Marques 57, Harley \& al. 24858, Hatschbach 27320, Hatschbach \& al. $69662 \mathrm{y}$ 73785. En los ejemplares Arbo \& al. 4408 y 4460 y en Irwin \& al. 22142 se pueden observar rebrotes y ejes desarrollados con nomófilos.

El ejemplar Barreto 9451 (F) dio resultados positivos para cianogénesis (Spencer \& al. 1985, sub Turnera stachydifolia, Barreto 954)

Se estudió la estructura de los nectarios extraflorales de Turnera opifera, comparada con la de otras especies de la serie y de la serie Turnera (Gonzalez, 1996). Los coléteres, de tipo standard, se hallan en los dientes de los primordios foliares, en las estípulas rudimentarias y en los profilos jóvenes (Gonzalez, 1998). Se estudió la anatomía foliar y caulinar; en las semillas, las células de la endotesta son pequeñas, y la epidermis calazal está constituida por células taníferas (Gonzalez, 2000). Además se analizó la vascularización floral y la estructura de los nectarios florales (Gonzalez, 2001).

\section{Turnera paradoxa Arbo, nov. sp.}

Figs. 16 y 60

Herba $10 \mathrm{~cm}$ alta, caules strigosi, stipulis rudimentariis; folia praeter nervis pilosis glabra, petiolata, suprema flores et nectariis gerentia.Flores dimorphi, apice caulium conferti, calyx 6 mm long., in 1/2 alt. coalitus, petala flava, filamenta glabra, basi tubo tota facie adnata, antherae 0,7 mm longae, in 1/2 alt. affixae, placentae 2-ovulatae, styli glabri. Fructus dorso laeve. Semina curvata, reticulata, chalaza prominula. 


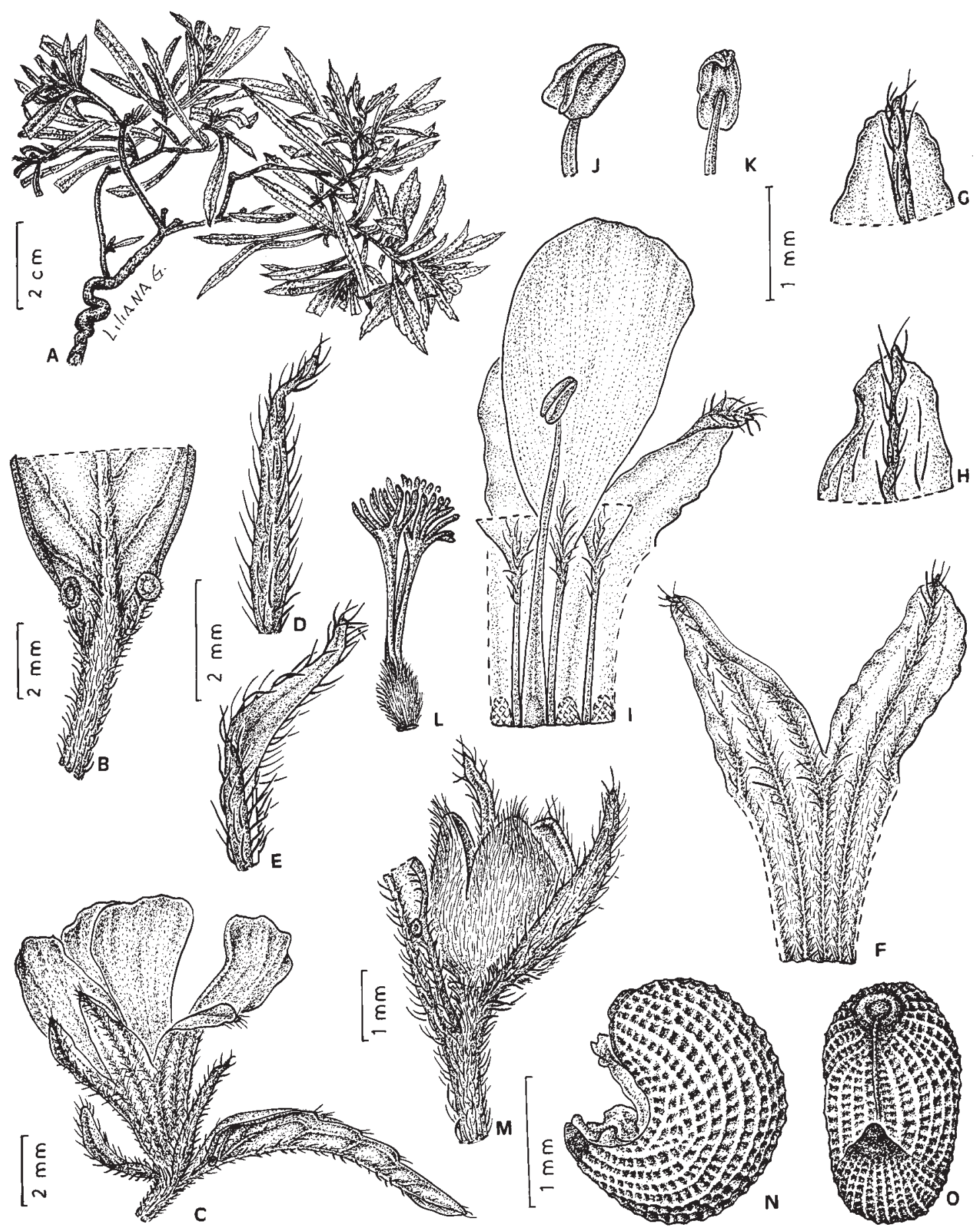

Fig. 60. Turnera paradoxa. A: planta. B: porción basal de hoja con nectarios, cara abaxial. C: bráctea con nectarios, flor epifila y profilos. D-E: profilos. F: porción del cáliz, cara externa. G-H: ápice de lóbulos interno y externo del cáliz. I: flor brevistila, porción del tubo calicino, cara interna, con pétalos y estambre adnatos; se han cuadriculado las cicatrices dejadas al desprender 3 estambres. J-K: anteras, vistas ventral y dorsal. L: gineceo. M: parte basal de hoja florífera con nectario, fruto epifilo y profilos. N: semilla con arilo, vista lateral. O: semilla, vista rafeal (Irwin \& al. 31354B). Del. Liliana Gómez. 
Typus: Brasil. Bahia: Valley of the Rio das Ondas, slopes of Espigão Mestre, ca. $25 \mathrm{~km} \mathrm{~W}$ of Barreiras, ca. 600 m, 3-III-1971, Irwin, Harley \& Smith 31354 B (holotypus NY).

Hierba perenne de $10 \mathrm{~cm}$, base leñosa $2 \mathrm{~mm}$ diám., corteza oscura, con estrías longitudinales; tallos cilíndricos, estrigosos, con pelos simples, cortos, adpresos; entrenudos cortos; cicatrices foliares salientes. Hojas herbáceas, extendidas. Estípulas rudimentarias, con coléteres $0,1 \mathrm{~mm}$ long., cónicos, negruzcos. Pecíolo 1-5 mm long., indumento como el del tallo. Lámina angustiovada, angustielíptica o linear, 22-35 x 2,6-4 mm, relación largo:ancho=7-10:1; base cuneada, ápice agudo, margen recurvo, serrulado en la porción distal, con algunos pelos en cada diente; haz y envés glabros, el envés con diminutas máculas castañas; vena media y 4 a 6 pares de venas secundarias hundidas en la haz, la vena media con algunos pelos en la porción basal, prominentes, rojizas y laxamente pilosas en el envés, perdiéndose hacia el margen o formando arcos con la superadyacente; ángulo de divergencia 25$30^{\circ}$; venas terciarias y venación menor inconspicuas. Hojas floríferas más cortas, ovadas, con un par de nectarios situados sobre el envés, junto al margen, a ca. $2 \mathrm{~mm}$ de la base, con poro, borde pilosiúsculo. Flores epifilas, heterostilas, agrupadas en la porción apical. Pedúnculo totalmente adnato al pecíolo. Profilos rojizos, lineares, 3-6,5 x 0,5 mm, opuestos en la base del receptáculo, cara externa pilosa, cara interna subglabra. Pedicelo nulo. Cáliz $6 \mathrm{~mm}$ long.; tubo calicino $3 \mathrm{~mm}$ long., cara externa con pelos simples cortos, cara interna con pelos simples blandos en la porción apical; lóbulos ovado-lanceolados, con pelos simples más largos especialmente sobre las venas, bordes internos membranáceos, ápice agudo. Pétalos amarillos, lámina obovada, 5 x 2,5 mm, base cuneada, con algunos pelos, ápice obtuso. Filamentos estaminales complanado-subulados en seco, glabros, $5 \mathrm{~mm}$ long. en flores brevistilas, brevemente soldados al tubo calicino en la base; anteras oblongas, $0,7 \times 0,3$ $\mathrm{mm}$, base emarginada, ápice obtuso, recto a la dehiscencia, filamento inserto dorsalmente a $0,4 \mathrm{~mm}$ de la base. Ovario ovoide, $0,8 \mathrm{~mm}$ long., piloso; placentas 2-ovuladas; estilos cilíndricos, 2,5 $\mathrm{mm}$ long. en flores brevistilas, glabros; estigma penicilado $0,8 \mathrm{~mm}$ long. En flores brevistilas, el androceo 1,8 $\mathrm{mm}$ más largo que el gineceo. Fruto ovoide, $3 \mathrm{~mm}$ long., con un reborde basal de $0,3 \mathrm{~mm}$ dejado por la absición del tubo floral; cara externa amarillenta, lisa, brevemente pilosa, cara interna jaspeada, lustrosa, glabra. Semilla inmadura obovoide, curvada, 1,9x1 mm; exóstoma cónico; rafe linear, oscura, lado rafeal cóncavo; cálaza oscura, prominente, orientada hacia el ápice. Episperma reticulado, aréolas más o menos cuadrangulares, cóncavas, epidermis papilosa con bastones de cera epicuticular.

Distribución: Solamente se conoce el ejemplar tipo, coleccionado en «cerrado», en las laderas del Espigão Mestre.

\section{Turnera paruana Arbo}

Figs. 38 y 61

Arbo, M. M., Ann.Missouri Bot.Gard. 77: 340352, Fig. 2 L-Q. 1990. Typus: Venezuela. T.F. Amazonas: Dep. Atabapo, Serranía del Parú (Aroko), sabanas sobre colinas onduladas en el sector centro-nororiental de la serranía, al $\mathrm{S}$ del Río Parú, aprox. 4³3'N 65³1'W, 710 m, 5/6-X1979, Huber 4386 (holotypus VEN!).

Arbusto de $50 \mathrm{~cm}$ alt., ramificado, tallo cilíndrico, corteza rojiza en la parte basal, con grietas longitudinales, cicatrices foliares no salientes, pelos simples crespos cortos y pelos simples largos antrorsos o erectos. Yemas seriales 2. Hojas oscuras en seco. Estípulas 0,5 $\mathrm{mm}$ long., subuladas. Pecíolo semicilíndrico 2-4 mm long. Lámina elíptica 15-30 x 6-11 $\mathrm{mm}$, relación largo:ancho $=2,5-3: 1$; base brevemente atenuada, ápice agudo, borde piloso plano, serrulado, dientes agudos terminados en un coléter alargado; haz verde mediano en vivo, lustrosa y pardo-rojiza en seco, glabra excepto algunos pelos sobre la vena media y cerca del borde; envés verde claro en vivo, castaño en seco, vena principal y 6-9 pares de venas laterales prominentes, con pelos largos, 


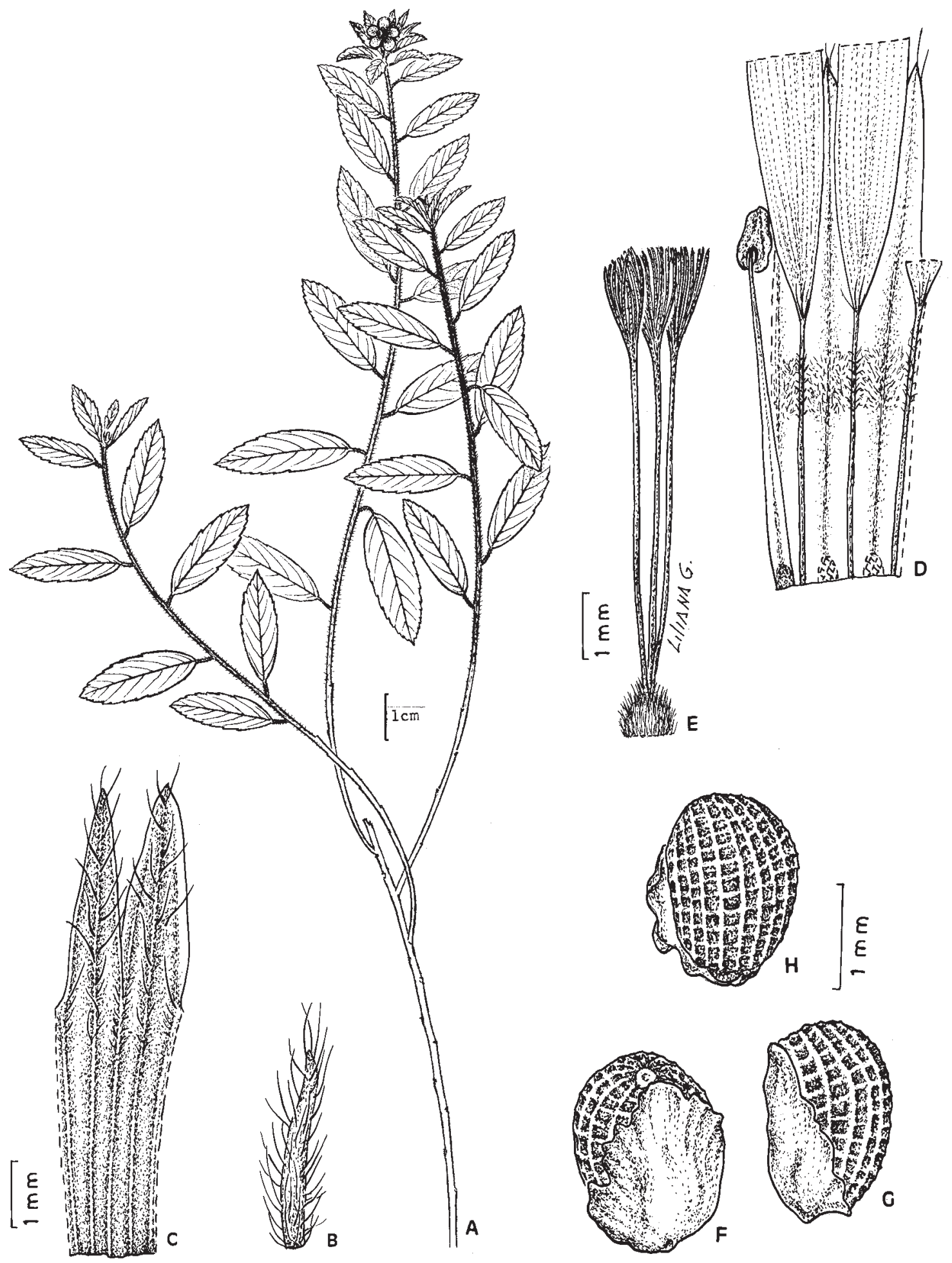

Fig. 61. Turnera paruana. A: planta. B: profilo. C: porción del cáliz, cara externa. D: flor longistila, porción del tubo calicino, cara interna, con pétalos y estambre adnatos; se han cuadriculado las cicatrices dejadas al desprender 2 estambres. E: gineceo. F-H: semilla arilada, vistas rafeal, lateral y dorsal (A-H: Huber 4386; A: (C) Missouri Botanical Garden, reproducida con permiso, del. Bruno Manara, B-H: Liliana Gómez, sobre dibujos a lápiz de la autora). 
simples, antrorsos; ángulo de divergencia 45$50^{\circ}$; venas terciarias visibles, no prominentes, venación menor inconspicua. Nectarios 2, situados en la base del envés foliar, elípticos, 0,6-0,9 mm long., parte central blanquecina, borde rojizo glabro. Hojas floríferas apicales bracteiformes, obovadas u romboidales, 7-12 $\mathrm{x}$ 3-5 mm. Flores presumiblemente heterostilas, agrupadas en racimos apicales hojosos, flores basales alejadas. Pedúnculo floral totalmente soldado al pecíolo, 1,2-2,5 $\mathrm{mm}$ long. Profilos insertos en la base del receptáculo, subulados, rojizos, uninervados, 2,5-3,5 x 0,3-0,4 mm, con pelos largos, simples, en los bordes y en la cara externa. Pedicelo ausente. Cáliz 7,5 mm long.; tubo calicino 4,3 mm long., glabro por fuera en la base, con algunos pelos cortos sobre las venas en la parte superior, por dentro velloso en la porción media; lóbulos triangulares, glabros por dentro, por fuera con pelos simples largos especialmente sobre las venas. Corola amarilla; pétalos con la uña soldada al tubo calicino, lámina con algunos pelos en la base, en la cara interna. Filamentos estaminales subulados, glabros, soldados en la base 0,3 $\mathrm{mm}$ al tubo calicino, $5 \mathrm{~mm}$ long. en flores longistilas; anteras ovadas, $1 \times 0,6 \mathrm{~mm}$, dorsifijas, base emarginada, ápice agudo. Ovario cónico, 0,7 mm long., densamente piloso; placentas 3-4 ovuladas; estilos 3, cilíndricos, glabros, 4,5 $\mathrm{mm}$ long. en flores longistilas; estigma 1,7 mm long., penicilado, ca. 10 ramas. Gineceo 1,7 mm más largo que el androceo en flores longistilas. Fruto ovoide, 2-3 mm diám.; valvas ovadas, lisas, pilosas por fuera, por dentro lustrosas, castaño claro, vena placentaria prominente. Semilla elipsoide, casi recta, 1,8 x 1,2 mm; exóstoma cónico, pequeño; rafe linear; cálaza no prominente, ligeramente deprimida en el centro. Episperma reticulado, aréolas más o menos hexagonales. Arilo unilateral, ovado, casi tan largo como la semilla, membranáceo y blanquecino en seco, borde eroso.

Material estudiado: COLOMBIA. Santander: Alrededores de Lebrija, [07.07N 73.13W], 300m aprox., 28-VIII-1948, Araque Molina 378 (US).

Distribución: Especie rara de la que se co- nocen sólo dos ejemplares, uno de Colombia, colectado en suelos secos y pedregosos, y el tipo, de Venezuela.

Obs.: Turnera paruana es parecida a T. lineata Urb. var. ramosissima, que se diferencia por tener hojas pilosas, hojas floríferas no bracteiformes y nectarios con borde piloso. También se asemeja a T. melochioides Cambess. var. arenaria Urb. que se diferencia por sus ramas estigmáticas pilosas en la base y por sus semillas más grandes y curvadas.

\section{Turnera patens Arbo, sp. nov.}

Figs. 16 y 62

Fruticulus $25 \mathrm{~cm}$ altus, caules tereti, pilis brevibus antrorsis simplicibus interdum aliis curvato-erectis intermixtis; stipulae rudimentariae; folia elliptica,angustiovata, interdum lanceolata, glabra vel laxe pilosa, supra basin subtus nectariis gerentibus. Flores dimorphi, pedunculi supra medium vel toti adnati, calyx laxe pilosi,6-7,5 mm longus, in 2/5 alt. coalitus, filamenta glabra, basi tubo tota facie adnata, antherae $1 \mathrm{~mm}$ long., dorso in $1 / 2$ affixae, placentae 4-ovulatae, styli glabri. Fructus dorso laeve. Semina curvata, reticulata, nigrescens, chalaza prominula, arillo unilaterali.

Typus. Brasil. Minas Gerais. Serra da Anta, ca. $12 \mathrm{~km}$ N of Paracatú, 950 m, 6-II-1970, Irwin H.S., Onishi E., Fonseca S.F., Souza R., Santos R.R. \& Ramos J. 26174 (holotypus UB, isotypus NY).

Subarbusto ca. $25 \mathrm{~cm}$ alt., castaño en seco, tallos 1-3, erectos o ascendentes, simples o ramificados, 1-1,2 mm diám., castaño-rojizos, rectos o sinuosos, cilíndricos, con pelos simples cortos, antrorsos, amarillentos, de 0,3-0,4 mm long., a veces con pelos largos, curvado erectos o antrorsos entremezcladosm de 0,60,7 mm long.; entrenudos 3,5-7,5 mm long., los apicales más cortos. Yemas axilares 1-2, a veces ramas seriales desarrolladas. Hojas patentes o recurvas, coriáceas, pardo-rojizas en seco. Estípulas nulas o rudimentarias, pilosas, con coléteres amarillentos, 0,1 mm long. a cada lado de la base foliar. Pecíolo 2-2,5 mm 


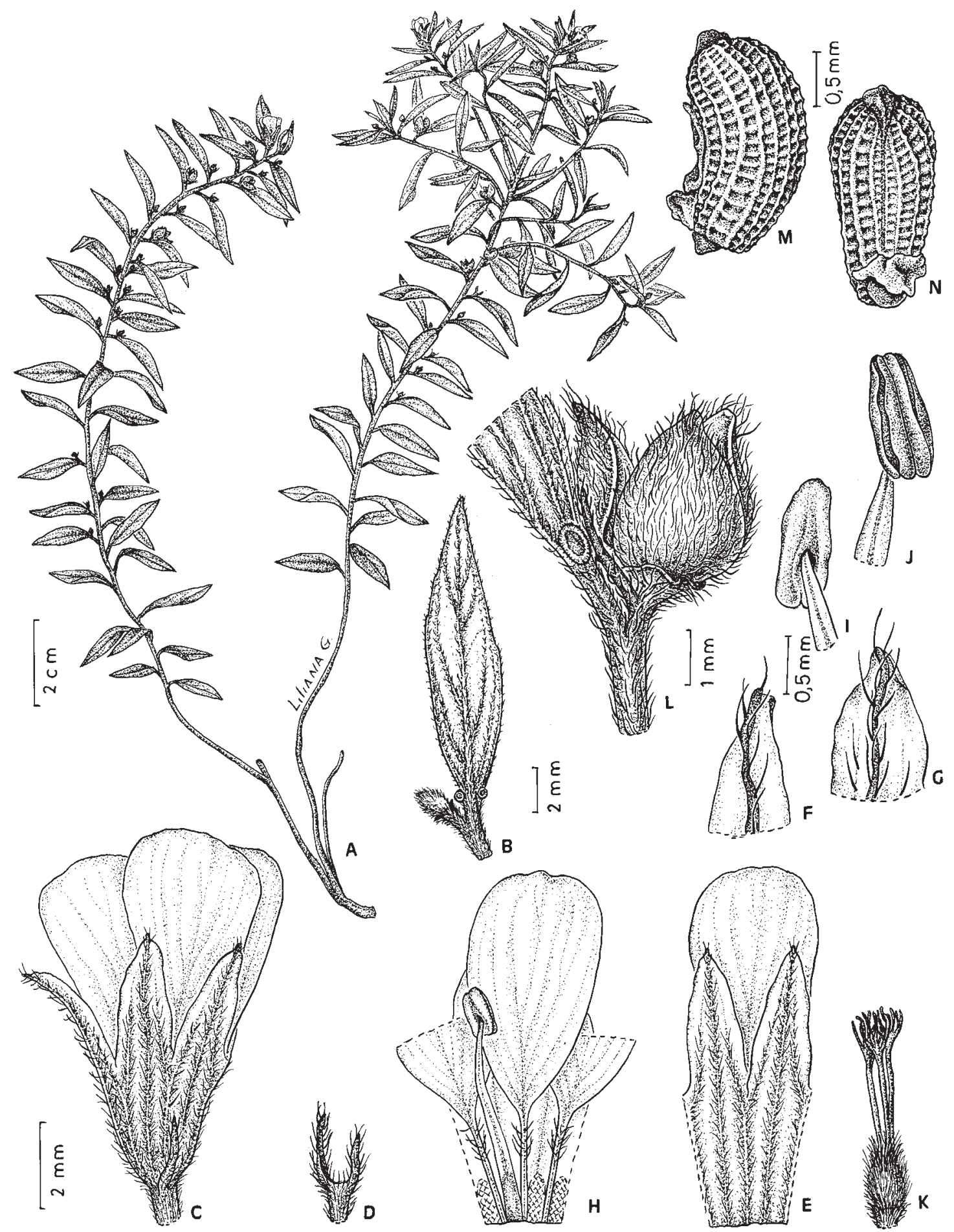

Fig. 62. Turnera patens. A: planta. B: hoja con nectarios, cara abaxial y fruto joven, nótese la porción apical libre del pedúnculo. C: flor y profilo. D: receptáculo y profilos. E: porción del cáliz, cara externa. F-G: ápice de lóbulos del cáliz, cara externa. H: flor brevistila, porción del tubo calicino, cara interna, con pétalos y estambre adnatos; se han cuadriculado las cicatrices dejadas al desprender 3 estambres. I-J: anteras, vistas dorsal y ventral. K: gineceo. L: porción basal de hoja con nectario, fruto epifilo y profilo. M-N: semillas con arilo, vistas lateral y rafeal (Irwin \& al. 26174). Del. Liliana Gómez. 
long. Lámina elíptica, angustielíptica, angustiovada, a veces lanceolada, 12-35 x 3-7 $\mathrm{mm}$, relación largo:ancho $=2,8-5,8: 1$; base cuneada, atenuada o redondeada; ápice generalmente agudo, a veces obtuso; margen piloso, plano, entero o serrulado, plano o en partes apenas revoluto; haz y envés glabros o con pelos simples cortos y antrorsos laxamente dispuestos; 3-4 pares de venas laterales prominentes en ambas caras, ángulo de divergencia $15-25^{\circ}$, perdiéndose hacia el margen, venación menor inconspicua en ambas caras. Nectarios 1+1, situados en la unión de pecíolo y lámina o desplazados $0,5-1,5 \mathrm{~mm}$ sobre el margen foliar, circulares, 0,3-0,7 mm diám., opuestos o subopuestos, borde piloso, a veces con «poro». Flores epifilas, extendidas a lo largo del tallo. Alabastro elipsoide, recto. Pedúnculo 2-2,5 mm long., totalmente adnato al pecíolo y vena media, o con una porción apical libre de hasta $0,5 \mathrm{~mm}$ long., indumento como el del tallo. Profilos lineares o subulados, opuestos o subopuestos, 2-2,5 x $0,2-0,3 \mathrm{~mm}$, insertos en la base del receptáculo. Pedicelo nulo o hasta 0,4 mm. Cáliz 6-7,5 mm long., con pelos simples, laxos, curvadoantrorsos; tubo calicino 2,5-3,5 mm long., cara interna glabra; lóbulos angustiovados, bordes internos glabros, membranáceos, ápice emucronado. Corola amarilla; pétalos con uña pilosa, lámina obovada, 5,5 x 3,2 mm, base cuneada, ápice obtuso. Filamentos estaminales complanados en seco, amarillos, glabros, subulados, 4,5 mm long. en flores longistilas y brevistilas, soldados al tubo calicino $1 \mathrm{~mm}$ en la porción basal; anteras 1$1,1 \times 0,5 \mathrm{~mm}$, rectas después de la dehis-cencia, filamento inserto dorsalmente a $0,5 \mathrm{~mm}$ de la base. Ovario ovoide, $1,1 \mathrm{x} 1 \mathrm{~mm}$, densamente cubierto de pelos simples, curvado-antrorsos; placentas 4-ovuladas; estilos cilíndricos, glabros, 3,5 $\mathrm{mm}$ en flores longistilas, $2 \mathrm{~mm}$ en flores brevistilas; estigmas penicilados de 1-1,5 mm long. Fruto ovoide, 3,5-5 mm long., más largo que los profilos; absición del tubo floral a $0,5 \mathrm{~mm}$ de la base, dejando un reborde anular persistente; valvas ovadas, dehiscentes casi hasta la base, cara externa pilosa, cara interna lustrosa, amarillenta, jaspeada, totalmente glabra. Semilla curvada, negruzca, 2 x $1 \mathrm{~mm}$; exóstoma cóni- co; rafe linear, lado rafeal incurvo; cálaza apical, negra, saliente. Episperma reticulado, aréolas transrectangulares, nudos no prominentes, epidermis papilosa, aréolas cóncavas. Arilo membranáceo en seco, más corto que la semilla, de células lisas.

Paratypi: BRASIL. Goiás: estrada entre Catalão e a divisa com MG, ca. 8 km de Catalão, 18¹4'54"S 4759'40"W, 8-IX-1998, Souza \& al. 21286 (CTES, ESA). Minas Gerais: MG-188, 28 $\mathrm{km}$ al S de Paracatú, cerca del río Escurinho, camino a Guarda Mor, 600 m, 31-I-1990, Arbo \& al. 3181 (CTES); MG-188, 42 km S de Paracatú, camino a Guarda Mor, Fazenda Santos Reis, Serra Branca, ca. 800 m, 31-I-1990, Arbo \& al. 3217 (CTES, HRCB); MG-188, 42 km S de Paracatú, camino a Guarda Mor, Fazenda Santos Reis, Serra Branca, ladera oriental; ca. 800 m, 31-I-1990, Arbo \& al. 3220 (CTES).

Distribución y fenología: Especie conocida sólo a través de unos pocos ejemplares colectados en «cerrado» y «campo rupestre», a 600$950 \mathrm{~m}$ de elevación, en enero y febrero.

\section{Turnera pinifolia Cambess.}

Figs. 16 y 63

Saint Hilaire, A., Jussieu, A. \& Cambessèdes, J., Fl. bras. merid. 2: 220. 1830; Urban, Jahrb. Königl. Bot. Gart. Berlin 2: 112. 1883; Urban, en Martius C.F.P., Fl. Bras. 13(3): 134. 1883. Typus: Brasil. Goiás: in parte australi prov. Goyaz, in monte Serra dos Pyreneos prope urbem Meia Ponte [seg. descrip. orig.], VI, Saint Hilaire s.n. (holotypus $\mathrm{P}$ ! fototipo $\mathrm{F} \mathrm{n}^{\circ}$ 38466!).

Hierba 13-40 cm alt., erguida, verde o castaña en seco, base leñosa de 2-13 mm diám; ejes 1-15, simples o ramificados en la porción apical, densamente foliosos excepto la porción basal desnuda; tallos angulado-estriados, glabros o con pelos simples en la base y en el ápice; entrenudos de 1-4,5 mm, más cortos hacia el ápice. Yemas axilares seriales 1-2. Hojas aciculares, sésiles. Estípulas rudimentarias, con 


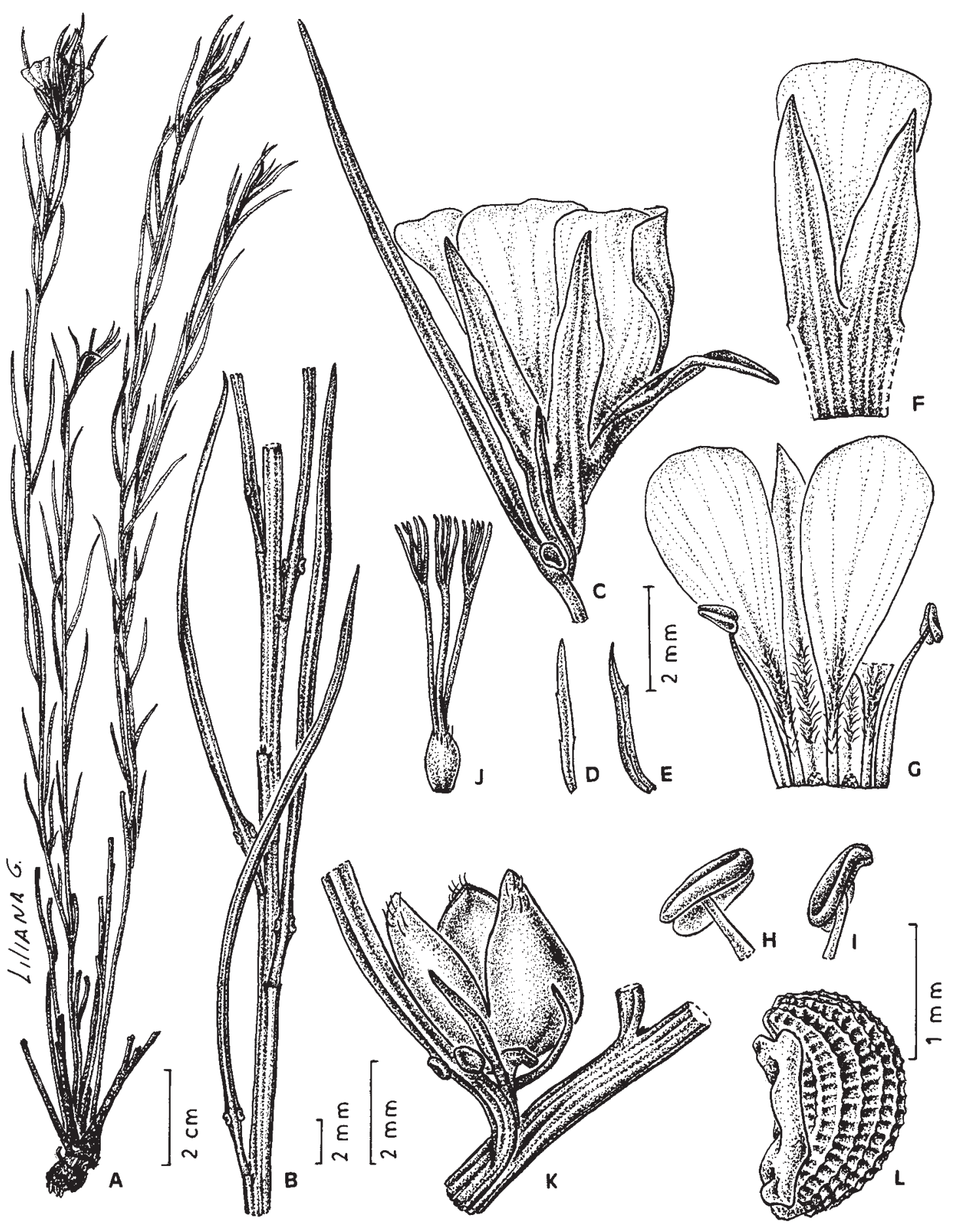

Fig. 63. Turnera pinifolia. A: planta. B: porción de tallo y hojas con nectarios, cara abaxial. C: hoja florífera con nectarios, flor epifila y profilo. D-E: profilos. F: porción del cáliz, cara externa, y pétalo. G: flor longistila, porción del tubo calicino, cara interna, con pétalos y estambres adnatos; se han cuadriculado las cicatrices dejadas al desprender dos estambres. H-I: anteras, vistas dorsal y lateral. J: gineceo. K: porción basal de hoja florífera con nectario, fruto epifilo y profilos. L: semilla con arilo, vista lateral (A: Menezes 1235; B, K-L: Onishi \& al. 53; G-J: Arbo \& al. 3817 ). Del. Liliana Gómez. 
coléteres 0,1-0,2 mm long. Hojas basales 5$13 \times 0,4-0,9 \mathrm{~mm}$, relación largo:ancho $=7$ 17:1; nomófilos 13-40 x 0,4-1,2 mm, relación largo:ancho $=19-75: 1 ;$ totalmente glabras o con algunos pelos en la base; margen plano o ligeramente recurvado, glabro, entero o serrulado, ápice agudo; vena media prominente en ambas caras, prolongada en una arista sobre el tallo por debajo de la inserción; venas laterales inconspicuas. Nectarios 0-2 pares, circulares, raramente elípticos, de 0,3-1,1 mm long., glabros o con el borde pubérulo, ubicados sobre el margen foliar a 1-2 mm de la base, y orientados hacia el envés. Hojas floríferas pecioladas y de lámina más corta, 8-28 x 0,5-1 mm, relación largo:ancho $=16-40: 1$. Flores epifilas, heterostilas, agrupadas en el extremo de las ramas, luego los frutos espaciados. Pedúnculo 1-2,5 mm long., piloso en la cara superior, totalmente adnato o el ápice brevemente libre. Profilos lineares, 2-4 x 0,2-0,4 mm, opuestos o subopuestos, borde entero o con algunos dientes, glabros o pilosos, uninervados. Pedicelo nulo. Cáliz 5,5-8 mm long., glabro por fuera; tubo calicino 1,7-3 mm long., velloso por dentro; lóbulos angustiovados o triangulares, glabros por dentro, márgenes internos membranáceos, ápice cortamente mucronado $(0,1-0,2 \mathrm{~mm})$. Corola amarilla; pétalos de 5-6 x 1,5-3 mm, base cuneada, ápice obtuso o ligeramente acuminado. Filamentos estaminales glabros, soldados en la base $0,5 \mathrm{~mm}$ al tubo calicino, subulados, 3,5-3,7 mm long. en flores longistilas, 5-5,7 $\mathrm{mm}$ long. en flores brevistilas; anteras dorsifijas, 0,6-1,1 x 0,3-0,7 mm, base emarginada, ápice obtuso, curvadas después de la dehiscencia. Ovario cónico u ovoide, 0,6-1 mm long., glabro excepto el ápice con algunos pelos simples; placentas 2-3ovuladas. Estilos glabros, $4 \mathrm{~mm}$ long. en flores longistilas, 1-2 $\mathrm{mm}$ long. en flores brevistilas; estigmas 1-1,5 mm long., con 414 ramas. Fruto ovoide, 2-4,5 mm long.; profilos más cortos que el fruto; tubo floral desprendiéndose a $0,5 \mathrm{~mm}$ de la base, dejando un reborde anular persistente; valvas ovadas, cara externa lisa, glabra, excepto algunos pelos simples en el ápice, cara in- terna lisa o jaspeada. Semilla curvada, 1,5-2 x 0,7-1,1 mm; exóstoma hemisférico; rafe linear, lado rafeal incurvo; cálaza saliente, pigmentada, a veces ligeramente deprimida en el centro. Episperma reticulado con nudos prominentes, aréolas cuadrangulares, rectangulares o ligeramente hexagonales, con cera epicuticular bastoniforme. Arilo unilateral, más corto que la semilla, de células lisas.

Material estudiado: BRASIL. Goiás: Ca. 15 km (straight line) N of Corumbá de Goiás, 1230 m, 16-V-1973, Anderson 10440 (NY, UB); 7-20 km E de Pirenópolis, Serra dos Pirineus, ca. 1000 m, 7-II-1990, Arbo \& al. 3817 (C, CTES, F, GH, HRCB, K, LIL, MBM, MICH, MO, NY); Serra dos Pyreneos, 20-VII-1894, Glaziou s.n. (P); Cachoeira do Abbade, 17-VII-1894, Glaziou 21460 (BR, C, F, K, LY, P, R, S); Pirenópolis, caminho da Cachoeira do Abade, Irnaldo \& al. s.n. (UB); $15 \mathrm{~km} \mathrm{~N}$ of Corumbá de Goiás on road to Niquelandia, in valley of Rio Corumbá, 1150 m, 15-I-1968, Irwin \& al. 18627 (NY); Pirineus, estrada de Corumbá de Goiás a Brasília, próximo do Salto de Corumbá, caminho da Cachoeira, 26-I-1991, Menezes 1235 (CTES, SPF); Cocalzin-ho, prox. à Corumbá, 27-I-1991, Menezes 1252 (CTES, SPF); Pirenópolis, caminho da Cachoeria do Abade, 25-V-1968, Onishi \& al. 53 (CTES, UB); Serra dos Pirineus, Mun. Pirenópolis, 1350 m, 8-XII-1987, Semir \& al. 20541 (UEC), íd., 9XII-1987 Semir \& al. 20614 (UEC).

Distribución y fenología: Endémica de la Serra dos Pirineus, Goiás. Se conocen unos pocos ejempolares, colectados en «campo rupestre», «campo cerrado» y «cerrado», en suelos arenosos o pegregosos, entre diciembre y julio, a 1000-1350m elev.

Obs.: El tallo presenta haces vasculares con casquetes perifloemáticos de fibras; las hojas son anfiestomáticas y tienen mesófilo isobilateral, los haces vasculares presentan vaina esclerenquimática (Gonzalez, 2000).

La floración es matutina, las flores se cierran hacia el mediodía; en días nublados la antesis se produce más tarde, y las flores permanecen abiertas hasta las 16 horas. 


\section{Turnera pohliana Urb.}

Figs. 43 y 64

Urban, I., Jahrb. Königl. Bot. Gart. Berlin 2: 104. 1883; Urban, en Martius C.F.P., Fl. Bras. 13 (3): 128. 1883. Typus: Brasil. Tocantins: Engenho de Donna Feliciana [entre Rio Paraná y Rio Manoel Alves hacia Porto Nacional seg. Urban, 1906], VII-1819, Pohl 5148 (holotypus $\mathrm{B}+$ fototipo $\mathrm{F} \mathrm{n}^{\circ} 13597$ !, isotypi $\mathrm{W}$ !, fragmento $\mathrm{P} !)$.

Hierba hemicriptófita, $20-25 \mathrm{~cm}$ alt., varios tallos 1-3 mm diám., con entrenudos basales muy largos, hasta $6 \mathrm{~cm}$ long., hirsutos, pelos simples erectos amarillentos, $1 \mathrm{~mm}$ long., a veces entremezclados con pelos simples más cortos, incurvos. Yemas axilares 2, la basal florífera, ramas seriales no desarrolladas. Hojas herbáceas, algo discoloras, aumentando de tamaño marcadamente hacia el ápice, las de los nudos basales bracteiformes. Estípulas rudimentarias, con coléteres 0,2-0,3 mm long. Pecíolo cilíndrico, 2-5 mm long., indumento como el del tallo. Lámina obovada o elíptica, 23-50 x 9-30 mm, relación largo:ancho $=1,5-$ $2: 1$; base cuneada, ápice obtuso, a veces agudo; borde plano o apenas revoluto, doblemente crenado-aserrado, dientes obtusos; haz algo lustrosa u opaca, verde oscura en seco (tipo), con pelos simples largos (1-1,4 mm long.) a veces con la base cónica y otros cortos; envés arenáceo, a veces con diminutas máculas rojizas, indumento laxo en hojas basales, villosohirsuto en las apicales, pelos simples largos (0,7-1,2 mm long.) y cortos y pelos glandulares microcapitados; vena media y 4-6 pares de venas laterales alternas o subopuestas, apenas salientes en la haz, prominentes en el envés, más pilosas que la lámina, perdiéndose hacia el borde, con ramas hacia la escotaduras o los dientes; ángulo de divergencia $30-40^{\circ}$; venas terciarias y venación menor conspicuas en el envés. Nectarios 2 o 4, 0,5-1 mm diám., borde glabro o piloso, situados a $2 \mathrm{~mm}$ de la base de la lámina, en el margen foliar. Flores solitarias, epifilas, heterostilas. Pedúnculo 24-15 mm long., soldado al pecíolo o incluso a la vena media, la porción apical libre de 16-3($0,2) \mathrm{mm}$ long., indumento como el del tallo.
Profilos opuestos o alternos en el ápice del pedúnculo, angustiobovados, elípticos o subulados, 3-12,5 x 0,4-4,5 mm, borde entero, a veces dentado hacia el ápice, a veces con nectarios. Pedicelo 0-1 mm long. Cáliz 11,5$19 \mathrm{~mm}$ long.; tubo calicino (1/4) 2,8-4,5 mm long., cara externa con pelos simples cortos, 0,6-0,8 mm long., cara interna vellosa en la parte media; lóbulos triangulares o angustiovados, cara externa hirsuta, pelos 1,2$1,4 \mathrm{~mm}$ long. especialmente sobre las venas; lóbulos internos con bordes membranáceos, ápice cuculado, mucrón 0,2-0,7 mm long. Corola amarilla, 6-10 $\mathrm{mm}$ más larga que el cáliz, uña de los pétalos soldada al tubo calicino, vellosa en la parte media, lámina glabra, 19$25 \mathrm{~mm}$ long. Filamentos estaminales complanado-subulados en seco, glabros, soldados 0,4-0,7 $\mathrm{mm}$ en la base al tubo calicino, $8 \mathrm{~mm}$ long. en flores brevistilas, 5-6 mm long. en flores longistilas; anteras 1,6-3 x 0,9-1,3 $\mathrm{mm}$, base emarginada, ápice obtuso, recto o recurvado a la dehiscencia, filamento inserto dorsalmente a 0,4-0,7 $\mathrm{mm}$ de la base. Ovario ovoide, hirsuto, 1,5-2 $\mathrm{mm}$ long., multiovulado; estilos cilíndricos, rojizos, glabros o pilosos, 5-8 $\mathrm{mm}$ long. en flores longistilas, $2 \mathrm{~mm}$ long. en flores brevistilas; estigmas penicilados, ca. 12 ramas de 1,2-2 mm long., gineceo 3-3,5 mm más largo que el androceo en flores longistilas y $2 \mathrm{~mm}$ más corto en flores brevistilas. Fruto inmaduro, hirsuto, pelos simples largos y pelos glandulares microcapitados.

Material estudiado: BRASIL. Goiás: $32 \mathrm{~km}$ W de Niquelandia, camino a Uruaçú, entrada al camino a Rio Vermelho, ca. 800 m, 6-II-1990, Arbo \& al. 3764 (CTES, HRCB); mun. Minaçu, a $7 \mathrm{~km}$ da entrada norte do canteiro de obras, $13^{\circ} 28^{\prime} \mathrm{S} \quad 48^{\circ} 23^{\prime} \mathrm{W}, 920 \mathrm{~m}, 10$-III-1992, Cavalcanti \& al. 1097 (CEN, RB); Cocal, W de Trairas [Niquelandia], VI-1819, Pohl 1858 (W).

Distribución y fenología: Vive en los estados de Goiás y Tocantins, crece en campos de suelo arenoso, entre gramíneas y en «cerrado» con afloramientos rocosos. Se conocen solamente unos pocos ejemplares, colectados entre febrero y julio. 


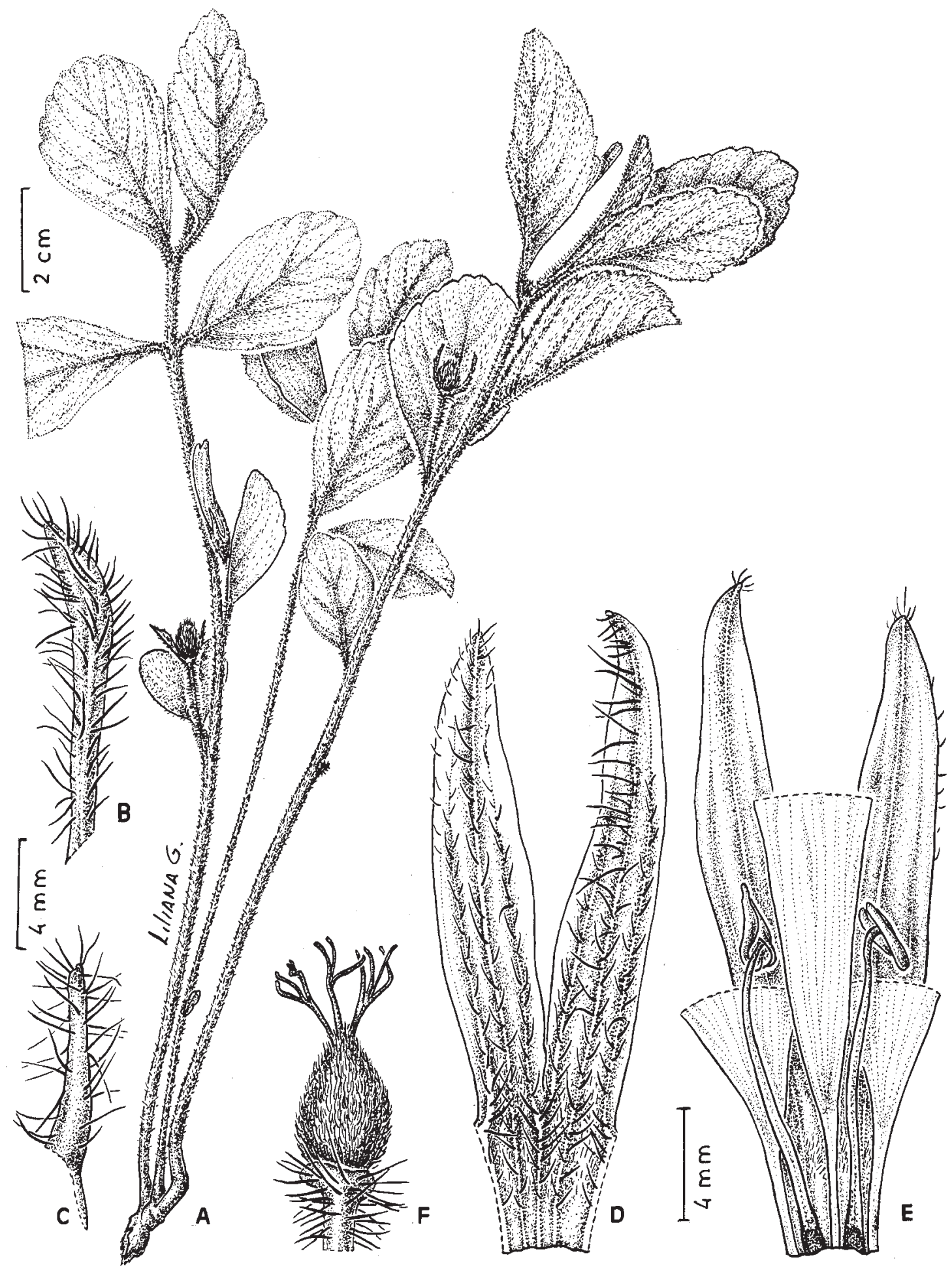

Fig. 64. Turnera pohliana. A: planta. B-C: profilos. D: porción del cáliz, cara externa, y pétalo. E: flor brevistila, porción del tubo calicino, cara interna, con pétalos y estambres adnatos; se ha sombreado la porción adherida. F: gineceo (Pohl 5148). Del. Liliana Gómez. 


\section{Turnera prancei Arbo}

Figs. 12 y 65

Arbo, M.M., Bonplandia 7: 63-99. Fig. 6. 1993. Typus: Brasil. Mato Grosso, BR-163, Km 768.5, 10 km S of Mato Grosso-Pará border, elev. 490 m, 12XI-1977, Prance \& al. 25281 (holotypus CTES, isotypi NY, US).

Turnera riedeliana auct. non Urb. en Hoehne, Hist. Nat. Bot. 6: 53. 1915. Hoehne, Ind. Com. Rondon: 290, 1951.

Hierba erecta, graminiforme, perenne, 25$45 \mathrm{~cm}$ alt., base leñosa de 1-3 mm diám.; tallos 1-varios, poco ramificados, cilíndricos, sinuosos, grises o castaños en la base, luego verdosos en seco, longitudinalmente estriados, punteados, 0,7-1,2 mm diám., glabros o con pelos simples adpresos en la base o hacia el ápice, o dispuestos en filas debajo de la inserción de las hojas; entrenudos 4-35 mm long. Yemas y ramas seriales no observadas. Hojas cartáceas, extendidas, lustrosas, verdes en seco. Estípulas rudimentarias, con coléteres rojizos o amarillentos, 0,1 $\mathrm{mm}$ long. Pecíolo 0-1 mm long. Lámina linear o lanceolada, 1546 x 0,7-2,5(-5) mm, relación largo:ancho (6)9-30:1; base cuneada, ápice agudo, borde plano, entero o denticulado, glabro excepto el ápice con 2-3 pelos; haz punteada, glabra; envés glabro excepto algunos pelos simples en la base y sobre la vena media; 3-4 pares de venas laterales prominentes en ambas caras, decurrentes; ángulo de divergencia 10-12% venación menor visible en ambas caras. Nectarios 1-2, discoideos, 0,3-0,7 mm diám., situados sobre el margen foliar, a 1-2,5 mm de la base, reborde glabro o apenas pubérulo, membrana cuticular con «poro» central. Hojas floríferas apicales acortándose bruscamente hasta brácteas de pocos mm long., pecíolo 1-2 mm long., nectarios 2 en la unión de pecíolo y lámina. Flores epifilas, heterostilas, solitarias, agrupadas en la región apical. Alabastro elipsoide, ápice agudo, mucrones libres en el ápice. Pedúnculo 2-6 mm long., glabro o estrigoso, totalmente soldado a la vena media o con una porción apical libre de 0,5-2,5 mm long. Profilos situados en la base del receptáculo o ligeramente distantes, subulados, 2,5-3 x 0,3-0,5 mm, glabros o con algunos pelos. Pedicelo ausente. Cáliz 6,5-7,5 mm long., con pelos simples, adpresos, en la base, venas y ápice de los lóbulos; tubo calicino velloso por dentro, 2-3 mm long.; lóbulos angustiovados, ápice acuminado, a veces purpúreo, mucrón $0,2-0,4 \mathrm{~mm}$ long. Pétalos amarillos con la uña vellosa, lámina obovada, 8-10,5 x 3-6 mm, base atenuada, ápice obtuso o apiculado. Filamentos estaminales subulados, glabros, 3,5$5,5 \mathrm{~mm}$ long. en flores longistilas, $6 \mathrm{~mm}$ long. en flores brevistilas, base soldada $0,5-0,6 \mathrm{~mm}$ al tubo calicino; anteras ovado-elípticas, 1-1,2 x 0,4-0,6 mm, base emarginada, ápice obtuso, ligeramente curvadas después de la dehiscencia, filamentos insertos dorsalmente a 0,3-0,5 $\mathrm{mm}$ de la base. Ovario cónico, $1 \mathrm{~mm}$ long., hirsuto; placentas 4-5-ovuladas; estilos cilíndricos, glabros o con algunos pelos 3,5-4,5 $\mathrm{mm}$ long. en flores longistilas, $2 \mathrm{~mm}$ long. en flores brevistilas; estigmas divididos en 4-6 ramas 1,2-2 mm long. En flores longistilas el gineceo es 0,5-2 $\mathrm{mm}$ más largo que el androceo; en flores brevistilas el androceo es 2,5 $\mathrm{mm}$ más largo que el gineceo. Fruto ovoide, 4$5 \mathrm{~mm}$ long.; tubo floral desprendiéndose a $0,5 \mathrm{~mm}$ de la base, dejando un reborde anular persistente; valvas con cara externa lisa, pilosa, pelos simples largos, antrorsos, de base ligeramente abultada; cara interna lustrosa, glabra, amarillenta. Semilla obovoide, 2,12,4 x 1,3-1,4 mm; exóstoma cónico, asimétrico; rafe linear apenas marcada, lado rafeal incurvo; cálaza oscura, algo prominente. Episperma reticulado, nudos algo prominentes, aréolas cóncavas, epidermis papilosa, con cera epicuticular bastoniforme en la semi1la inmadura. Arilo angosto, unilateral, más corto que la semilla, de células papilosas.

Material estudiado: BRASIL. Mato Grosso: Cuiabá, Chapada Km 34, 10-IX-1981, Monteiro 21 (UEC); Mun. Barra do Garças, lado E da cidade Barra do Garças, 4-X-1968, Fonseca \& Onishi 1093 (UB, paratipo); mun. Chapada dos Guimarães, Salgadeira, 12-VIII-1997, Hatschbach \& al. 66751 (CTES); Cuyabá, 3-XI-1902, Malme s.n. (S, paratipo), íd., 4-XII-1902, Malme s.n. (S, paratipo). Rondonia: Vilhena, Campos de Comemoração de Floriano, alem de Campos Novos da Serra do Norte, XI-1911, Hoehne 5539 (CTES, R, paratipos). 

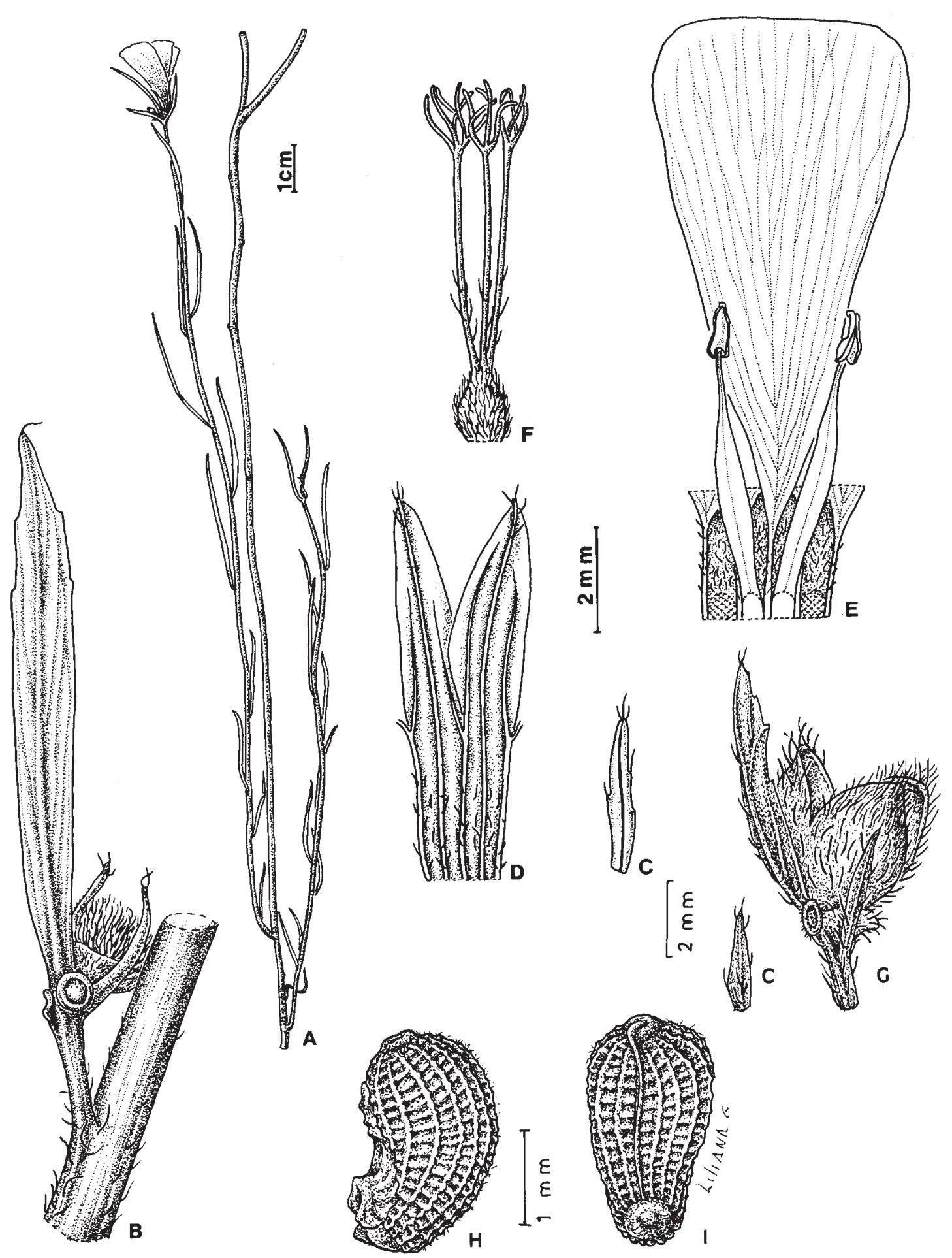

Fig. 65. Turnera prancei. A: planta. B: porción de tallo y hoja con nectarios, fruto joven y profilos, cara abaxial. C: profilo. D: porción del cáliz, cara externa. E: flor longistila, porción del tubo calicino, cara interna, con pétalos y estambres adnatos; se han cuadriculado las cicatrices dejadas al desprender dos estambres. F: gineceo. G: hoja florífera con nectario, fruto epifilo y profilo. H: semilla inmadura con arilo, vista lateral. I: semilla inmadura, vista rafeal (A-F: Prance \& al. 25281; G-I: Monteiro 21). Del. Liliana Gómez. 
Distribución: Especie encontrada en los estados de Mato Grosso y Rondonia, en «cerrado», entre agosto y diciembre.

Obs.: Especie muy afín a Turnera subnuda, que se distingue por sus hojas muy angostas, uninervias, y a $T$. guianensis, que se diferencia por tener ovario y cáliz glabros. $T$. tenuicaulis, especie de aspecto vegetativo similar, se diferencia por sus tallos cilíndricos completamente pilosos y hojas uninervias, $\mathrm{y}$ T. trigona por sus tallos más robustos, de sección angular. Dedicada al Prof.Dr. Ghillean T. Prance, quien coleccionó el ejemplar tipo.

\section{Turnera pumilea $\mathrm{L}$.}

Linneo, C., Syst. Nat. ed. 10, 2: 965. 1759; Urban, Jahrb. Königl. Bot. Gart. Berlin 2: 114. 1883; Urban, en Martius C.F.P., Fl. Bras. 13(3): 136. 1883. Lectotypus, aquí designado: Jamaica. Browne s.n., Linn. Herb. 384-4 (LINN!), seleccionado con el asesoramiento de William Stearn. Linneo tomó el epíteto específico usado por Browne (1756), cuyo herbario adquirió en 1758; describió la planta en Pl. Jam. Pug.: 10, 1759, y en Fl. Jam.: 15, 1759, y transcribió dicha descripción en Amoen. Acad. 5: 395, 1760.

Turnera hirsutissima Wright in Sauvalle F. A., Anales Acad. Ci. Méd. Habana 6:77. 1869; Sauvalle, Fl. Cub.: 55. 1873, «en los pinares arenosos de la Vuelta Abajo, cerca de La Grifa». Typus: Cuba, Wright 3569 (holotypus GH!. isotypi NY!, US!). Según Urban (1898), Wright trabajó en GH, y los resultados de su trabajo se publicaron en la obra de Sauvalle.

\section{Polinomios:}

Chamaecistus urticaefolio, flore luteo Sloane, Catalogus plantarum quae in insula Jamaica sponte proveniunt: 87. 1696; Sloane, Voyage to Madeira, Barbadoes, Nevis, St.... 1: 202. 1707.

Pumilea minima subhirsuta foliolis angustis profunde serratis Browne, Civil \& Nat. Hist. Jamaica: 188. 1756.

Los autores prelinneanos e incluso el mismo Linneo citan como sinónimo el siguiente polinomio: Chamaecistus luteus, foliis parvis serratis, Petiver J., Gazophylacii naturae \& artis decas quartus, 8, t.38, f.9. 1704. La planta ilustrada parece ser Piriqueta cistoides (L.) Griseb., y por otra parte, no hay ningún ejemplar de Turnera pumilea en el Herb. Sloane 162: Petiver, Hortus siccus Jamaica (BM).

\section{8a. Turnera pumilea L. var. pumilea}

Figs. 38 y 66

Hierba anual erguida, ramosa, $6-40 \mathrm{~cm}$ alt., raíz pivotante; tallos cilíndricos 1-4 mm diám., vestidos con pelos cortos muy crespos y pelos largos, erectos, blanquecinos, 1,5-2,5 $\mathrm{mm}$ long. Ramas ascendentes, frecuentemente las basales más largas que el tallo principal. Entrenudos basales largos, los apicales muy cortos, 1-0,1 mm long. Yemas seriales 2-3, con desarrollo acrópeto, ramas seriales frecuentemente desarrolladas. Hojas herbáceas. Estípulas rudimentarias, con coléteres 0,2-0,4 $\mathrm{mm}$ long. Pecíolo semicilíndrico, 2,5-8 mm long., indumento como el del tallo. Lámina herbácea, ovada o elíptico-lanceolada, 20-51 x 9-21 mm, relación largo:ancho $=2-2,7: 1$; base cuneada, ápice agudo, borde simple o doblemente dentado; haz con pelos simples sedosos, largos, antrorsos, adpresos, de base cilíndrica o ligeramente abultada; envés igual con 6-9 pares de venas prominentes densamente cubiertas de indumento incano como el del tallo, terminando en las escotaduras del borde; ángulo de divergencia $25-40^{\circ}$. Nectarios 0-2, discoideos, brevemente estipitados, 0,3-0,5 mm diám., sin reborde, con pelos largos hirsutos en la cara inferior, insertos en el margen o en el hipofilo, a 1-7 $\mathrm{mm}$ de la base de la lámina. Hojas floríferas formando rosetas en el ápice de las ramas, tamaño bruscamente decreciente: $17-5 \mathrm{~mm}$ long., las externas con nectarios pequeños en la unión de pecíolo y lámina, las internas romboidales, sin nectarios, porción apical de la lámina profundamente dentada. Flores epifilas, homostilas, reunidas en racimos capituliformes. Pedúnculo totalmente adnato al pecíolo y a veces a la vena media. Pedicelo nulo. Profilos 2, subulados, 4-8(-10) $\mathrm{mm}$ long., opuestos en la base del receptáculo. Cáliz 4-6(-9) long.; tubo calicino 2,5-3 mm long., glabro por fuera, velloso en la mitad superior por dentro; lóbulos triangulares $\mathrm{o}$ 


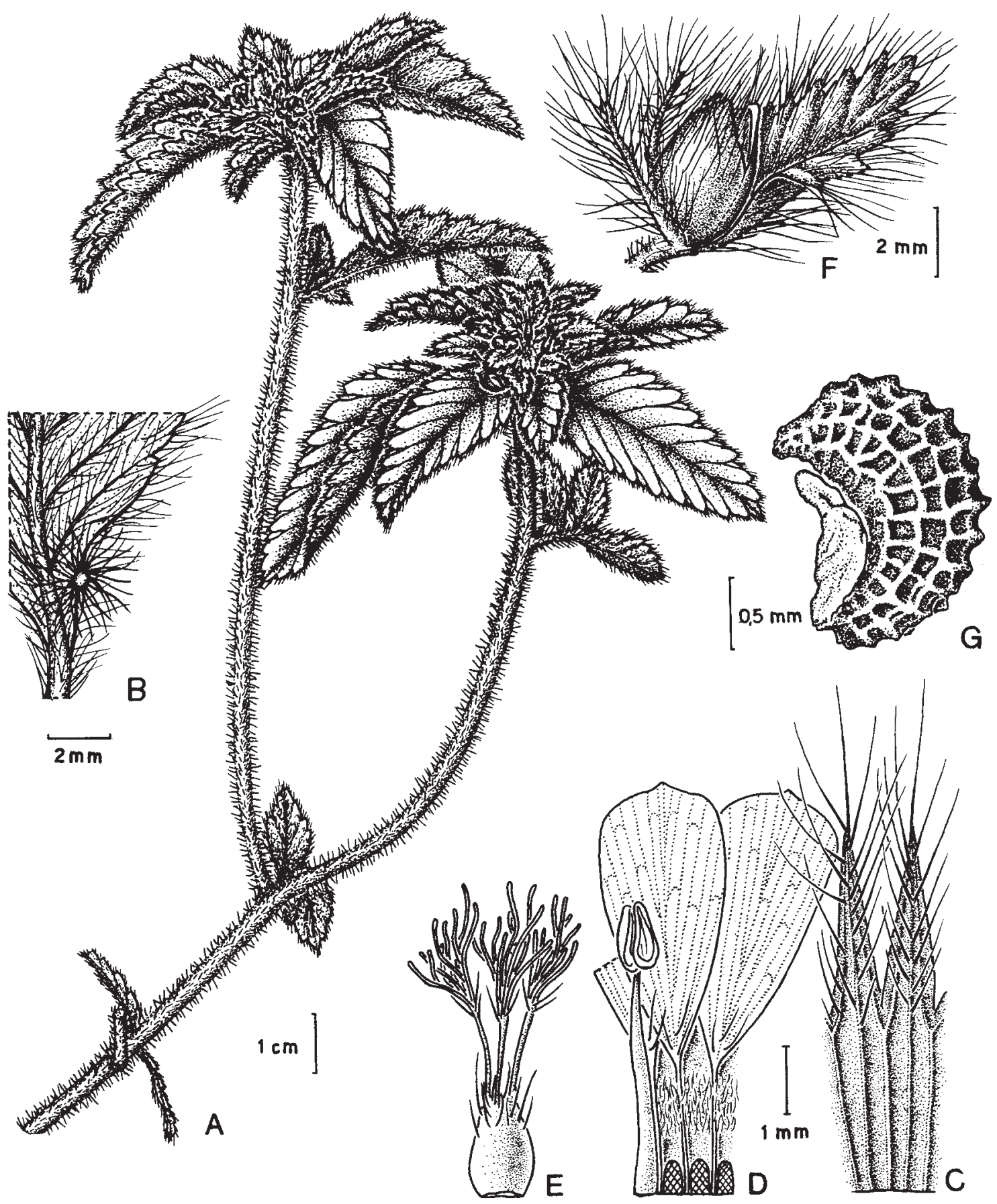

Fig. 66. Turnera pumilea var. pumilea. A: planta. B: porción basal de hoja con nectario, cara abaxial. C: porción del cáliz, cara externa. D: flor homostila, porción del tubo calicino, cara interna, con pétalos y estambre adnatos; se han cuadriculado las cicatrices dejadas al desprender tres estambres. E: gineceo. F: hoja florífera sin nectario, fruto epifilo y profilos. G: semilla con arilo, vista lateral (A: Menezes 1235; B, K-L: Onishi \& al. 53; G-J: Arbo \& al. 3817). A-F: Del. Víctor Maruñak. G: Del. Ricardo Vispo. 
lanceolados, glabros por dentro, con pelos largos sedosos y pelitos crespos por fuera. Corola poco más larga que el cáliz, amarilla; pétalos con uña pilosa; lámina obovada 3,5-5 mm long. con algunos pelos largos, sedosos, en la base y a veces con mácula oscura, ápice redondeado o acuminado. Filamentos estaminales adnatos al tubo calicino en la base, 3,5-4 mm long., glabros; anteras ovadas, base emarginada, ápice obtuso, frecuentemente oscuras en vivo. Ovario ovoide $0,9-1,5 \mathrm{~mm}$ long., glabro en la porción basal, con pelos largos sedosos en el ápice; placentas 2-5 ovuladas; estilos cilíndricos, 1,5-2 mm long., glabros o con pelos simples largos; estigma con 8-12 ramas 1,5-2,5 mm long. Fruto ovoide, 4,5-5(-6,5) x 2,5-3,5 mm; parte basal del tubo floral persistente, formando un reborde anular; valvas ovadas, cara externa lisa, glabra en la porción basal, con pelos largos, sedosos en el ápice, cara interna lisa, glabra, lustrosa. Semilla virguliforme, 1,5-2,3 x 0,7-1,1 mm, negruzca a la madurez; exóstoma pequeño; rafe linear apenas prominente, lado rafeal curvo; cálaza apical, prominente, cónica, reticulada. Episperma reticulado, muros longitudinales más notables, a veces con nudos prominentes; aréolas muy amplias poligonales, frecuentemente rectangulares o cuadrangulares. Arilo unilateral, angosto, 11,2 mm long., de células lisas.

Cromosomas: 2n=14, Arbo \& al. 2120; Krapovickas \& al. 37189 (Fernández, 1987); Arbo \& al. 4079 (Solís Neffa \& Fernández, 1993).

Material escogido. América septentrional, sin localidad, Herb. Maille (P) y Herb. Poiteau (P). MEXICO. Baja California: San José del Cabo, 2-VIII-1890, Brandegee 226 (F, GH); Cape St Lucas, VIII-1859-I-1860, Xantus 37 (F, GH, US). Chiapas: Monserrate, IV-1925, Purpus 250 (US); Sierra de Tonala, IX-1913, Purpus 6632 (BM, F, MO, NY, US). Jalisco: $8 \mathrm{~km} \mathrm{~N}$ de Cruz de Loreto, sobre el camino a Tomatlan, 50 m, 26-VIII-1976, Rzedowski \& McVaugh 1326 (MEXU). México: Temascaltepec, Ixtapan, Hinton 8451 (K, US). Sinaloa: San Ignacio, San Juan, Cerro del Potrerillo, 300 m, Gonzalez Ortega 145 (MEXU); San Ignacio, C. del Potrerillo, V-1921, González Ortega 609 (F, K); Mun.Culiacan, Tacuichamona ca. 6-7 $\mathrm{km}$ al SE del pueblo, 60m aprox, 28-VII1984, Valverde 117 (MEXU). Tabasco: mun. Huimanguillo, camino a ejido Mecatepec, 29-X1978, Cowan 1667 (CAS). Tamaulipas: Sierra de Tamaulipas, region of Rancho Las Yucas, ca. 40 $\mathrm{km}$ NNW of Aldama, mun. Aldama, ca. $23^{\circ} 14^{\prime} \mathrm{N}$ $98^{\circ} 10^{\prime} \mathrm{W}$, near Juan Tomás, E of Las Yucas, 16-X1957, Dressler 2422 (GH); Morales, 15-II-1939, Le Sueur 574 (F). Veracruz: Wartenberg, near Tantoyuca, prov. Huasteca, 1858, Ervendberg 134 (GH); Zacuapán, Corral de Piedras, VIII-1917, Purpus 7896 (GH, HBG, MO, NY, US); La Ceiba, mun. de Puente Nacional, 250 m, 27-VII-1974, Ventura 10410 (MEXU). CUBA. sin localidad, 1860-1864, Wright 2606 (BM, CTES, F, GH, K, MO, NY, P, S, US, W, WU-Keck). Camagüey: near Camagüey, 2-7-IV-1912, Britton \& al. 13180 (NY, US). Isla de Pinos: near Nueva Gerona, 17V-1904, Curtiss 503 (BM, E, F, HBG, K, LY, M, MO, NY, P, PR, US); Columbia, 26-XI-1920, Ekman 12412 (S); Santa Isabel, 6-I-1956, Killip 45332 (US). Las Villas: San Marcos, Amaro, 22VII-1920, [Bro.] León 9192 (GH). Matanzas: E of Matanzas, 9-IX-1903, Britton \& Wilson 426 (NY). Oriente: sin localidad, 4-VIII-1914, Ekman 2424 (F, S); Sierra de Nipe, 13-VIII-1915, Ekman 6371 (S); prope Alto Cedro, 26-X-1919, Ekman 10047 (S); Sierra Maestra, 21-VIII-1922, Ekman 14925 (S). Pinar del Rio: near Cajálbana, La Palma, 15-VII-1950, [Bros.] Alain \& Clemente 1473 (GH); Arroyo Mantua, Damuje, 28-V-1920, Ekman 10953 (K, S, US); La Grifa, 19-XI-1923, Ekman 18161 (NY, S); Laguna Jovero and vicinity, 5-7-XII-1911, Shafer 10703 (A, NY, US). Santa Clara: dist. Cienfuegos, Cieneguita, 14-VI1895, Combs 165 (F, GH, K, MO, NY, P, US); Herradura, 9-VIII-1907, Earle 680 p.p. (NY); 10 km E of Cascajal, VII-1941, Howard 5533 (GH). HAITI. Ile La Tortue, near Mare-Rocher, 24-V1925, Ekman 4130 (F, S, US). REPÚBLICA DOMINICANA. Las Brujas, 14-VIII-1938, Canela s.n. (P); Valle de San Juan, prov. Azua, San Juan, 22-VIII-1929, Ekman 13397 (A, GH, NY, S, US); Cerros de los Peralta al S de Santiago, 200 m, 24XII-1981, Jiménez 9083 (CTES); Jarabacoa, 25VII-1966, Lavastre 2255 (NY, US); Azua, Monte Rio, about 50 m, 10-X-1970, Liogier 17550 (F); St. Domingue, Poiteau s.n. (P); Cordillera Central, prov. Santiago, Caobamito, 9,17 km W de la plaza central de San José de Las Matas y $1 \mathrm{~km} \mathrm{~N}$ en el camino a Caimito, $19^{\circ} 22^{\prime} \mathrm{N} 71^{\circ} 02^{\prime} \mathrm{W}, 425 \mathrm{~m}, 19$ - 
II-1983, Zanoni \& Pimentel 25395 (MO, NY); Valle Cibao, prov. Santiago Rodríguez, 6,4 km E de Sgo. Rodríguez en carretera a Mao, 19²9’ N $71^{\circ} 18^{\prime}$ W, 215 m, 6-XI-1984, Zanoni \& al. 32028 (NY). JAMAICA. St.Catherine: Two mile Wood Pen, 8-VI/6-VIII-1915, Harris 12066 (BM, C, F, GH, K, MO, NY, P, US); St.Andrews, Liguanea, X-1848, McNab s.n. (BM, K, P); Clarendon: Harris savanna, $350 \mathrm{ft}$, 13-XI-1974, Proctor 34297 (BM, C, F, GH, MO, NY, P, US); sin localidad, Herb. Sloane IV, f. 5 (BM), Swartz s.n. (BM, M, S) y Wullschlaëgel 1399 (W). PUERTO RICO. Punta Casaba, 26-II-1915, Britton \& al. 4659 (NY); Coamo, inter Serillos et Salinas, 9XII-1885, Sintenis 2995 (C, CORD, GH, K, M, S, US); pr. Vega baja, VI-1884, Stahl 57 (S). ANTILLAS HOLANDESAS. Aruba: 1913, Boldingh 6543 (NY). Bonaire, 22-I-1947, Arnoldo 384 (K). Curação: Macao to Playa Grande, 20-27-III1913, Britton \& Shafer 3049 (F, NY, US). GUATEMALA. Chiquimula: Mount Tojás, near village of Sasmo, about 1mi NW of Chiquimula, 420-520 m, 21-X-1939, Steyermark 30194 (F). Huehuetenango: along Rio Cuilco, between Cuilco and aldea of San Juan, 2.5mi of Cuilco, 1200-1300 m, 18-VIII-1942, Steyermark 50864 (F, NY, US). Jalapa: along the road between Jalapa and San Pedro Pinu-la, 1400-1800 m, 12XI-1940, Standley 77111 (F). Jutiapa: between Jutiapa and Plan de Urrutia, N of Jutiapa, 9001200 m, 28-X-1940, Standley 75597 (F). Zacapa: near divide on road between Zacapa and Chiquimula, 500-660 m, 9-X-1940, Standley 73777 (F); between Rio Hondo and Santa Cruz, about 200 m, 11-X-1940, Standley 74077 (F). HONDURAS. Santa Barbara, $4 \mathrm{~km}$ NE of La Arada, 13-VIII-1970, Harmon \& Dwyer 3836 (MO). Comayagua: Valle Comayagua entre Las Mercedes y Villa de Flores, 650 m, 28-VI-1964, Molina 14359 (F); Zambrano, 45 km NO de Tegucigalpa, camino a la quebrada Mata de Caña desde svío hacia El Coyolar, entrando por Los Acantilados, 1000 m, 12-X-1991, Nelson \& Andino 12935 (TEFH). El Paraiso: Rastrojos vegas del Rio Mata Indio, entre San Francisco y Lizapa, 900 m, 8-VII1964, Molina 14445 (F, NY, US); region of Quebrada de Dantas, $5 \mathrm{~km} \mathrm{~S}$ of Ojo de Agua, about 750 m, 11-XII-1946, Standley \& al. 1240 (F). Morazán: Santa Clara creek, drainage of the rio Yeguare, about $14^{\circ} \mathrm{N} 87^{\circ} \mathrm{W}, 2600 '$, 14-VII-1948, Glassman 1894 (F, NY); vicinity of El Zamorano,
780-900 m, 3-17-VIII-1947, Standley 11635 (F); along road from El Zamorano toward San Antonio de Oriente, 825-950 m, IX/XI-1948, Standley 14258 (F); región of Rio de la Orilla, SE of El Zamorano, 900-950 m, 2-VIII-1949, Standley 22147 (F); W of Chagüite, near Rio Yeguare, about 850 m, 21-VIII-1949, Standley 22941 (F). Valle: mun. Nacaome, 1 mi NE of Jícaro Galán, along main highway to Tegucigalpa, $13^{\circ} 32^{\prime} \mathrm{N}$ 87²5' W, 80 m, 18-VI-1994, Davidse \& al. 35106 (CTES, MO); San Lorenzo, 20 m, 14-IX-1945, Rodríguez 3489 (F). NICARAGUA. Chontales: E facing slopes of Cerro Pedernal, $2 \mathrm{~km} \mathrm{~W}$ of Hacienda Corpus, $13.5 \mathrm{~km} \mathrm{~W}$ of Juigalpa, $12^{\circ} 07^{\prime} \mathrm{N} 85^{\circ} 29^{\prime} 30^{\prime \prime} \mathrm{W}, 200 \mathrm{~m}, 27-\mathrm{VIII}-1983$, Nee \& Miller 27555 (CTES, MO). Granada: Near Granada, 2-VII-1923, Maxon \& al. 7578 (US). León: carretera a León, Hacienda «El Chacal», a 2 km hacia León del empalme León-La Paz Centro, 26-IX-1982, Grijalva \& al. 1267 (MO); along Hwy. 12 (Carretera vieja a León), ca. 4 km SE of intersection with Hwy. 52 (to Puerto Somoza), ca.Km 53 , ca. $12^{\circ} 11^{\prime} \mathrm{N} 86^{\circ} 40^{\prime} \mathrm{W}$, ca. $80 \mathrm{~m}, 8$-VIII1978, Stevens 9756 (CTES, MO). Masaya: su mmit of Volcán Ma-saya, NE of crater, 500 m, 12XI-1977, Neill 2944 (MO); Parque Nacional Volcán Masaya, N slope of Volcán Santiago, ca. 31 $\mathrm{km} \mathrm{S}$ of original park entrance, ca. $11^{\circ} 59^{\prime} \mathrm{N}$ 86¹0’W, ca. 375 m, 25-XI-1977, Stevens 5229 (CTES, MO). COSTA RICA. Guanacaste: Parque Nac. Santa Rosa, near «laguna», 11-VIII1975, Haithaus 604 (F); $30 \mathrm{~km} \mathrm{NW}$ of Liberia, ca. $10^{\circ} 50^{\prime} \mathrm{N} 85^{\circ} 35^{\prime} \mathrm{W}, 0-300 \mathrm{~m}, 16-\mathrm{VII}-1979$, Janzen 11770 (MO); Guanacaste, ca. 1051'N 85³7' W, 200-300 m, 26-VI-1977, Liesner \& Lockwood 2561 (MO). COLOMBIA. Chiriguana, near Lake Sapatora, Magdalena Valley, 22-VII-1924, Allen 139 (K, MO); Santa Marta, 3 mi S of Gaira, 8-XI1898, Smith 1338 (K, NY); Vichada: pr. Maypures, ad flumen Orenoco, VI-1854, Spruce 3574 (BR, CGE, K, OXF, NY, P, W). VENEZUELA. Bolívar: Distr. Páez, Laguna Larga, 8 km SE de Upata, 350 m, VII-1978, Delascio \& Liesner 6905 (MO, VEN); Guayana, cantón de Upata, Guacaima, 1864, Grosourdy 13 (P). Monagas: Maturín, 5-I-1941, Pittier 14914 (US). Zulia: vicinity of Mene Grande, 27-X-1922, Pittier 10567 (NY). GUYANA. Rupununi Distr., Mountain Point, 110 m, 13-VI-1995, JansenJacobs 4045 (CTES, P). GUAYANA FRANCESA. La Roche Elisabeth, II-1901, Lemée s.n. (P); 
Cayenne, 1840, Leprieur s.n. (P); sin localidad, II, Richard s.n. (C, P). ECUADOR. Isla Puna, 1852, Andersson s.n. (S); Insula Puna, I-1892, Eggers 14777 (M). El Oro: Arenillas, 15-III-1955, Asplund 15756 (K, NY, R, S). Guayas: Salinas, 19-II-1939, Asplund 5059 (K, R, S, US); Capeira,Km 21, Guayaquil to Daule, 20-200 m, 15-II-1982, Dodson \& Gentry 12458 (F); N slope of Puntilla, Salinas, $2^{\circ} 13$ 'S $81^{\circ} \mathrm{W}, 4-\mathrm{IV}-1941$, Svenson 11241 (NY). Loja: Hacienda Comunidades, S Vilcabamba, 1600 m, 14-V-1967, Sparre 16089 (S). Manabi: Manta, 6-IV-1955, Asplund 15973 (NY, S, US). PERU. Cajamarca: prov. Cajamarca, dist. Ichocan, en el Arboretum Ichocan II de CICAFOR, entre Chancay y Valle de Condebamba, 29-III-1981, Sanchez Vega \& al. 2417 (BR). La Libertad: Huamachuco, Cangau Sartimbamba, 3500 m, 26-I-1952, Infantes Vera 4009 (LIL); prov. Trujillo, Puente Pedregal (Trujillo-Shirán), 250 m, 21-X-1973, López 8069 (NY); Prov. San Marcos, 6 km above San Marcos on road to Cajamarca, 2600-2700 m, 5-II-2-IV1997, Weigend \& al. 97/333 (F, K, M). Lambayeque: Olmos, 280-300m alt, 31-V-1972, Ferreyra 17984 (MO); El Porvenir, Olmos, 100 m, 10-IV-1984, Llatas Quiroz 1092 (F, RB). Piura: al S de Piura, desvío a Chulucanas, 100-200 m alt, 18-IV-1949, Ferreyra 5920 (MO); Cabo Blanco, IV-1927, Haught F-53 (F); Tablazo, 30-III-1929, Haught 219 (NY, RB, US); Prov. Chulucanas, Cerro Vicus, $52 \mathrm{~km}$ de la carretera Piura-Morropon, 120 m, 24-V-1992, Sanchez Vega \& Guevara 6202 (F, MO); Serran, 1909-1914, Weberbauer 5948 (F, US); San Martín: pr. Tarapoto, 1855-56, Spruce 4075 (BR, CGE, K, NY, OXF, P, W). Tumbes: nordlich Tumbes, ca. $50 \mathrm{~m}, 7-\mathrm{V}-1957$, Ellenberg 1309 (GOET); La Peña a 16 km SE de Tumbes, 30-40 m, 22-IV-1949, Ferreyra 5981 (MO); prov. Contralmirante Villar, Bocapan, cerca a Cancas, 10-20 m, 17-V-1965, Ferreyra 16262 (MO); plain SE of Hacienda La Choza, 28-II/3-III1927, Weberbauer 7732 (F). BRASIL. Lower Amazon, Traill s.n. (K). Bahia: $2 \mathrm{~km} \mathrm{~S} \mathrm{de}$ Itaberaba, camino a Milagres, 23-I-1980, Arbo \& al. 2537 (CTES); BR-407, 4-9 km N de Filadelfia, camino a Senhor do Bomfin, aprox. 10 40-42'S 4008'W, ca. 450 m, 1-XII-1992, Arbo \& al. 5456 (CTES, SPF); Mun. Urandi, $7 \mathrm{~km} \mathrm{~N}$ de Urandi, aprox. 1448'S $42^{\circ} 38^{\prime} \mathrm{W}$, ca. $600 \mathrm{~m}, 20-\mathrm{XI}-1992$, Arbo \& al. 5611 (CTES, SPF); Serra do Tombador, 19 km al NW de Jacobina, BR-324, ca.

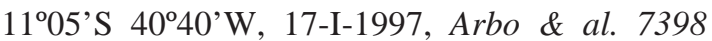
(CEPEC, CTES, K); $15 \mathrm{~km} \mathrm{~S}$ de Xique-Xique, camino a Santo Inacio, aprox. 10 $0^{\circ} 58^{\prime} \mathrm{S} 42^{\circ} 41^{\prime} \mathrm{W}$, 19-I-1997, Arbo \& al. 7523 (CEPEC, CTES, K, MBM); $30 \mathrm{~km}$ al $\mathrm{W}$ de Brumado, camino a Caetité, aprox. $14^{\circ} 08^{\prime} \mathrm{S} 41^{\circ} 57^{\prime} \mathrm{W}$, ca. 600 m, 21-I1997, Arbo \& al. 7625 (CEPEC, CTES); entre Ajuda e Porto Seguro, 28-V-1962, Duarte 6630 (RB); Rod. BR-242, mun. Ibotirama, 13-I-1977, Hatschbach 39515 (CTES, MBM); Bom Jesus da Lapa, Km 5-10 da rodovia para Malhada, 500 m, 5-IV-1992, Hatschbach \& al. 56602 (CTES); Mun. Rio de Contas, aeroporto, arredores, 17-III1998, Hatschbach \& al. 67851 (CTES, MBM); 12 km N de Riachão das Neves, BR-135, 11²4'S 4500'W, 480 m, 1-IV-1983, Krapovickas \& al. 38606 (CTES); Vila Nova da Rainha, IV, Martius s.n. (M); Campus da UEFS, Feira de Santana, $12^{\circ} 15^{\prime} \mathrm{S} 38^{\circ} 58^{\prime} \mathrm{W}, 25-\mathrm{V}-1983$, Noblick 2678 (HUEFS, MBM); Anage: Estrada para Vitoria ca.

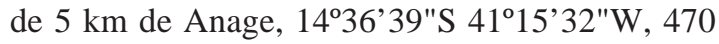
m, 19-III, Queiroz \& al. 9209 (CTES, HUEFS); Caetité: Brejinho das Ametistas, $14^{\circ} 15^{\prime} 22^{\prime \prime S}$ 42³1'20"W, 880 m, 13-III-2002, Roque \& al. 631 (HUEFS); Chacara Provisão a $4 \mathrm{~km}$ E de Jequié, 25-I-1980, Santos 3508 (CEPEC, CTES, HUEFS); Catinga de Moura, 1890, Schreiner s.n. (R); Caetité, ca. $13 \mathrm{~km}$ da cidade em direcão a Paramirim localidade Cachoeirinha, 135' $35^{\prime \prime S}$ 42²7'16"W, 900 m, 9-III-1994, Souza \& al. 5392 (CTES, K, SPF). Ceará: Grajal - Serra das Almas - Crateus, 280 m, 27-II-2002, Araujo 1336 (HUEFS); Fazenda Itatiaia, Santa Quitéria, 26-IV1984, Fernandes \& al. s.n. (CTES); between as Difuntos \& Varzea da Vaca, Gardner 2415 (BM, CGE, K, OXF, W); Mun. Morada Nova, Faz. Serraria, Baixo Jaguaribe, 100 m, 25-IV-1997, Lima-Verde 689 (CTES); Cedro, 27-II-1910, Löfgren 66 (S); Mun. Arneiroz, 20 km de Taua em direcão a Arneiroz, 609'S 40²' W, 500 m, 20III-2002, Souza \& al. 28764 (CTES, ESA). Goiás: GO-446, $9 \mathrm{~km}$ NE de Iaciara, camino a Posse, ca. 800 m, 3-II-1990, Arbo \& al. 3534 (CTES); 20 km $\mathrm{N}$ de Itumbiara, BR-153, Krapovickas \& al. 33103 (CTES); 80 km SE de Brasília camino a Anapolis, 28-I-1978, Krapovickas \& al. 33264 (CTES); mun. Minaçú, em frente ao antigo viveiro da Uhe. Serra da Mesa, ca. $5 \mathrm{~km}$ da entrada N do canteiro de obras, $13^{\circ} 48^{\prime} \mathrm{S} 48^{\circ} 17^{\prime} \mathrm{W}, 500 \mathrm{~m}$, 9-XII-1991, Walter \& al. 918 (CEN, CTES). Maranhão: Mun. Loreto, Ilha de Balsas region between the Ríos 
Balsas and Parnaíba, about $35 \mathrm{~km} \mathrm{~S}$ of Loreto, Fazenda Morros, approx. $07^{\circ} 22^{\prime} \mathrm{S} 45^{\circ} 04^{\prime} \mathrm{W}$, ca. 300 m, 24-III-1962, Eiten \& Eiten 3767 (SP, US); Maranhão, Moju, Gardner 6031 p.p. (BM, K); Timón, 7 km W del puente a Teresina, 28-I-1981, Krapovickas \& Cristóbal 37189 (C, CTES). Mato Grosso: BR 158, 89 km N de Barra do Garças, camino a Nova Xavantina, 16-I-1989, Krapovickas \& Cristóbal 42965 (CTES, K, MBM); Cuyabá, 18-XI-1902, Malme 2608 (S). Mato Grosso do Sul: Porto XV, mun. Bataguaçú, 21-X-1970, Hatschbach 24980 (CTES, MBM, US); mun. Aquidauana, Serra de Maracaju, $10 \mathrm{~km}$ E de Piraputanga, 500 m, 12-II-1993, Hatschbach \& al. 58984 (CTES, MBM); Mun. Corumba, Invernada 2, area da Estacão Meteorologica, Faz. Nhumirim, Nhecolandia, Pantanal, 1859'S 56³9'W, 90 m, 14-III-1996, Salis \& al. 858 (CPAP); mun. Aquidauana, Rio Taboco, 21-XI2006, Silva \& Barbosa 5388 (CTES, MBM). Minas Gerais: BR-040, alrededores de Paracatú, ca. 700 m, 31-I-1990, Arbo \& al. 3302 (CTES, HRCB, K, MBM); Serra do Cipó, vertiente oriental, 10-20 km WSW de Morro do Pilar, hacia Cardeal Mota, ca. $19^{\circ} 13^{\prime} \mathrm{S} 43^{\circ} 27^{\prime} \mathrm{W}$, ca. $1100 \mathrm{~m}$, 12-II-1991, Arbo \& al. 4926 (CTES, SPF); 5-7 km NE de Diamantina, camino a Mendanha, ca. $18^{\circ} 12^{\prime} \mathrm{S} 43^{\circ} 34^{\prime} \mathrm{W}$, ca. 1100 m, 14-II-1991, Arbo \& al. 5079 (CTES, SPF); Rod. BR-135, mun. Corinto, 21-I-1978, Hatschbach 40767 (CTES, MBM); Serra da Anta, ca. $10 \mathrm{~km} \mathrm{NW}$ of Paracatú, 900 m, 3-II-1970, Irwin \& al. 25891 (NY, P, UB); Pirapora, terraplén del camino sobre la costa del río São Francisco, 11-I-1989, Krapovickas \& Cristóbal 42868 (C, CTES); Belo Horizonte, Campus UFMG, 6-II-1980, Oliveira 412 (BHCB, CTES); prope Campos, VII-1832, Riedel s.n. (P); ad Lapa prope Sabara, I-1865, Warming 25 (C). Paraíba: Cruzeiro, Condado, 4-V-1933, Luetzelburg 23510 (IPA, M); Condado, V-1933, Luetzelburg 23648 (IPA, M); S. Gonçalo, 1-II-1936, Luetzelburg 27034 (IPA, K, M). Pernambuco: mun. Sertânia, margem da BR-232 próximo à base da Serra do Pereiro, 29-VII-1981, Andrade-Lima \& al. 95 (IPA); Parnamirim, Km 5 da estrada ParnamirimPetrolina, 28-IV-1984, Araújo 30 (F, IPA); em Baixada, 6-IV-1983, Fotius 3396 a (K); Petrolina, 26-I-1958, Heringer 5869 (HB, HBG, UB); Tapera, 11-VIII-1936, Pickel 4188 (IPA, US); Piauí: Boqueirão Grande, São Raimundo Nonato, 31-I-1984, Emperaire 2225 (CTES). Rio de
Janeiro: prope Campos, VII-1832, Riedel s.n. (K, M, P); near Iguaba Grande, 7-9-VIII-1915, Rose \& Russell 20721 (NY, US); Restinga de Cabo Frio, 18-XI-1967, Sucre 1910 (CTES). Rio Grande do Norte: Cerro Corá, ca. 600 m, 3-IX-1959, Andrade-Lima 59-3373 (IPA); Região do Seridó, 1986, Costa Lima s.n. (IPA). Roraima: San Marcos, VI-1909, Ule 7877 (K, U). Tocantins: Porto Real, Burchell 8480 (K); between Funil \& São João, Burchell 8914 (K, OXF, P, US). BOLIVIA. Chuquisaca, Pcia. L. Calvo, entrada al Valle Itangua, 20²7'S 6340’ W, 1310 m, 11-IV-1993, Saravia Toledo \& al. 11683 (CTES). Santa Cruz: prov. Cordillera, $34 \mathrm{~km} \mathrm{~N}$ de Boyuibe, $20^{\circ} 15^{\prime} \mathrm{S}$ 6329'W, 896 m, 29-III-2006, Dematteis \& al. 1967 (CTES); Nuflo de Chavez Prov., Ea. San Miguelito, $200 \mathrm{~km}$ al NE de la ciudad de Santa Cruz: al E de puesto Montana, 290 m, 28/29-XII1995, Fuentes \& Rojas 1515 (USZ); prov. Velazco, $27 \mathrm{~km} \mathrm{~S}$ de San Ignacio, camino a San Miguel, $16^{\circ} 36^{\prime} \mathrm{S} 61^{\circ} \mathrm{W}$, ca. $400 \mathrm{~m}, 7-\mathrm{V}-1977$ Krapovickas \& Schinini 32361 (CTES); 2 km W de San José, Km 263 del ferrocarril, 300 m, $17^{\circ} 47^{\prime} \mathrm{S} 60^{\circ} 47^{\prime} \mathrm{W}, 25-\mathrm{IV}-1980$, Krapovickas \& Schinini 36530 (CTES); a $113 \mathrm{~km}$ E de Concepción y $57 \mathrm{~km} \mathrm{NW}$ de San Ignacio, 1559'50"S 61²3'23"W, 359 m, 24-I-2004, Solís Neffa \& al. 1200 (CTES); Velazco, San Ignacio, peaje, $16^{\circ} 12^{\prime} 32^{\prime \prime S ~ 6058 ’ 43 " W, ~} 403$ m, 24-I-2004, Solís Neffa \& al. 1218 (CTES); Chiquitos, a $29 \mathrm{~km} \mathrm{~W} \mathrm{de}$ San José camino hacia Roboré, 17²52'50"S 60²9’11"W, 390 m, 28-I-2004, Solís Neffa \& al. 1293 (CTES); prov. Velasco, a 38,3 km NE de Santa Rosa, rumbo a San Ignacio, arroyo Aragua,

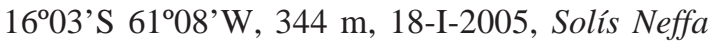
\& al. 1528 (CTES); prov. Sandoval, a $31 \mathrm{~km} \mathrm{NW}$ de Candelaria proximidades a Natividad, 16³8'32"S 5909'21"W, 126 m, 29-I-2005, Solís Neffa \& al. 1692 (CTES); Camino de Roboré a Fortín Ravelo, a $81,3 \mathrm{Km} \mathrm{S}$ de Roboré, 1845'58"S 60¹2’30"W, 336 m, 6-II-2005, Solís Neffa \& al. 1902 (CTES); prov. Chiquitos, a 57,4 $\mathrm{km}$ W de San José camino a Santa Cruz, 17² '42S 61ำ'12W, 262 m, 8-II-2005, Solís Neffa \& al. 1928 (CTES); Cordillera, camino de Camiri a Santa Cruz (ruta 9) a $6 \mathrm{~km} \mathrm{~N}$ de Los Husos y a 27,6 km N del desvío a Lagunillas, 3-IV2004, Solís Neffa \& Seijo 1488 (CTES). Tarija: 2 $\mathrm{km}$ N de Palmar Grande, $38 \mathrm{~km}$ S de Villa Montes, $21^{\circ} 27^{\prime} \mathrm{S} \quad 63^{\circ} 30^{\prime} \mathrm{W}, 400 \mathrm{~m}, 10-\mathrm{IV}-1977$, Krapovickas \& al. 31119 (CTES, LPB). PARA- 
GUAY. Boquerón: Ruta Transchaco, 7 km NW de Nueva Asunción, 14-V-1994, Krapovickas \& al. 45453 (CTES). Central: Asunción, 26-V1876, Balansa 2633a (P). Chaco: Cerro León (Lagerenza), 20²0'S 60²3' W, centro del cerro, 380-500 m, 17-XI-1992, Ramella \& al. 3072 (G). Concepción: San Salvador, 20-II-1917, Rojas 2635 (AS). Cordillera: Cerros de Tobaty, IX1900, Hassler 6340 (BM). Nueva Asunción: 7 km NW de Nueva Asunción, 20³8'S 6205'W, 12 XII-1987, Schinini \& Palacios 25690 (CTES). Presidente Hayes: Loma Porá, Estancia Alegría, 26-V-1917, Rojas 2637 (AS, CTES). ARGENTINA. Corrientes: dep. Ituzaingó, Villa Olivari, ruta 12, 24 km W de Ituzaingó, barranca del río Paraná, 17-XI-1978, Arbo \& al. 2120 (CTES).

Material cultivado. Argentina. Corrientes, proc. de Brasil, Piaui, $3 \mathrm{~km}$ W de Oeiras, BR-230, 702'S 4208'W, Krapovickas \& al. 38624 bis (CTES).

Distribución y fenología: Especie de área muy amplia, desde México y el Caribe hasta el $\mathrm{N}$ de Argentina. En el hemisferio norte vive en bosque de pino y encino, sabanas, matorrales y llanuras, en suelos arenosos o pedregosos, también a orillas de ríos. En Brasil crece en «campo rupestre», «cerrado», «caatinga»y campo; en Perú en bosque de algarrobo entre la vegetación herbacea; se adapta a lugares alterados como bordes de caminos. Florece y fructifica todo el año.

Nombres vulgares: Costa Rica: «lidio» (Haithaus 604); Puerto Rico: «mari-lopez»; Mexico: «bruja», (Gonzalez Ortega 609). Guayana venezolana: «conejito»

Obs.: En Gonzalez Ortega 145 se observó una flor con uno de los estambres más corto. Spencer \& al. (1985) encontraron compuestos cianogénicos en Glassman 1894 (ILL) de Honduras, y Haught F-53 (F), de Perú, pero no en Weberbauer 7732 (F), también de Perú.

Las semillas de Turnera pumilea son inconfundibles, se reconocen entre todas las especies del género por su marcada curvatura, por las aréolas grandes, los nudos del retículo salientes y la cálaza cónica, diminutamente reticulada. $\mathrm{Su}$ anatomía y ontogenia fueron estudiadas por Gonzalez (2000).

La anatomía de los nectarios extraflorales de esta especie fue estudiada y comparada con la de otras especies de la serie Leiocarpae y de la serie Turnera (Gonzalez, 1996). Los coléteres, de tipo standard, se hallan en los dientes foliares y en las estípulas rudimentarias (Gonzalez, 1998). El tallo no presenta células taníferas, y los haces vasculares carecen de fibras perifloeméticas; se analizaron la ontogenia y estructura seminal (Gonzalez, 2000). Se investigó la vascularización floral y los nectarios florales (Gonzalez, 2001), y se estudió la anatomía caulinar, foliar y la del fruto (Gonzalez \& Arbo, 2005).

\section{8b. Turnera pumilea var. piauhyensis Urb.}

Figs. 7 y 67

Urban, I., Repert. Spec. Nov. Regni Veg. 4: 133. 1907. Typus: Brasil. Piauí: in Serra da Lagoa, I-1907, Ule 7510 (holotypus HBG!).

Hierba anual o perennizante, $25-40 \mathrm{~cm}$ alt., ramosa. Raíz pivotante. Hojas subduplicadocrenadas. Flores heterostilas, epifilas. Cáliz 9,5-11 mm long.; tubo calicino 4,3-5 mm long. Corola amarilla; pétalos 10-12 x $8 \mathrm{~mm}$, a veces con la base y/o venas oscuras. Filamentos estaminales $6 \mathrm{~mm}$ long. en flores longistilas, 8-8,5 $\mathrm{mm}$ long. en flores brevistilas; estilos $3,5 \mathrm{~mm}$ long. en flores brevistilas; estigma penicilado 1,5 $\mathrm{mm}$ long. En flores longistilas, gineceo 1,3 mm más largo que el androceo. En flores brevistilas, androceo 0,6-3 $\mathrm{mm}$ más largo que el gineceo. Semilla obovoide, curvada, 1,7-2 x 0,7-0,9 $\mathrm{mm}$; exóstoma hemisférico y cálaza cónica diminutamente reticulados. Episperma reticulado, nudos del retículo salientes, aréolas grandes, cóncavas. Arilo unilateral, de células lisas.

Material estudiado: BRASIL. Bahia: $14-19 \mathrm{~km}$ W de Itiuba, camino a Filadelfia, $10^{\circ} 42^{\prime} \mathrm{S} 40^{\circ} \mathrm{W}$, ca. 600 m, 1-XII-1992, Arbo \& al. 5463 (CTES, HUEFS, SPF); Mina Caraiba, 17-II-1966, Castellanos 25819 (HB, HBG, K, LP, M); Remanso: 


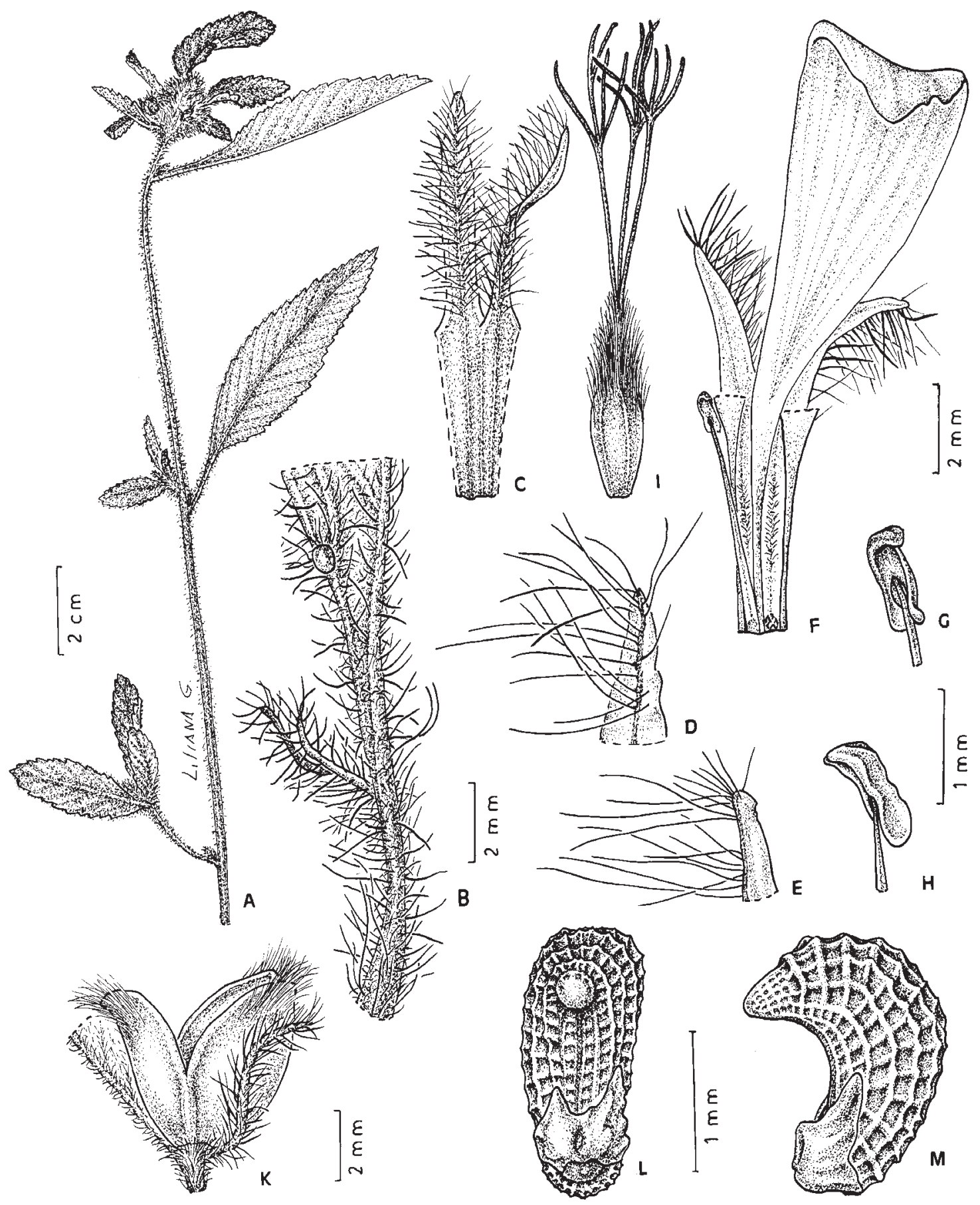

Fig. 67. Turnera pumilea var. piauhyensis. A: planta. B: porción basal de hoja con nectario y profilos, cara abaxial. C: porción del cáliz, cara externa. D-E: ápice de los lóbulos del cáliz. F: flor longistila, porción del tubo calicino, cara interna, con pétalos y estambre adnatos; se ha cuadriculado la cicatriz dejada al desprender un estambre. G-H: anteras, vistas dorsal y lateral. I: gineceo. K: fruto y profilos. L-M: semilla con arilo, vistas rafeal y lateral (Ule 7510). Del. Liliana Gómez. 
caminho para Pau Ferro, entrada a esquerda para subir a Serra, 944'17"S 42²3'49"W, 28-II-2000, Cavacanti \& al. 15 (RB); Juazeiro, 8-II-1970, Costa s.n. (ALCB, CTES); Rod. Oliveira dos Brejinhos a Macaúbas, $\mathrm{Km} \mathrm{8,} \mathrm{mun.} \mathrm{Oliveira} \mathrm{dos}$ Brejinhos, 20-IV-1996, Hatschbach \& al. 65099A (C, CTES, MBM); Rodovia Paramirim a Caetité, próximo a Grama, mun. Paramirim, 21-IV-1996, Hatschbach \& al. 65163 (MBM); Nova Casa Nova, Caraíba dos Bragas, 10-II-1988, Moruz 154 (HRB). Pernambuco: Parnamirim, Km 27,8 da estrada Parnamirim-Petrolina, 21-V-1984, Araújo 68 (F, IPA); Petrolina, CPATSA, 6-IV-1983, Fotius 3396 (IPA, R, UB); Petrolina, campos do CPATSA, 1976, entre Petrolina e Afranio, 19-IV1971, Heringer \& al. 169 (IPA, R, UB); Afranio, em direção ao Piauí, 23-IV-1971, Heringer \& al. 312 (IPA, R, RB, UB); entre Serra Talhada e Salgueiro, 10-V-1971, Heringer \& al. 651 (IPA, R, RB, UB); Petrolina, campos do CPATSA, Lima s.n. (IPA); Mun. Santa Maria da Boa Vista, estrada que liga Barra Bonita, na BR-122 a Cristália, a 3 km de Barra Bonita, 380 m, 2-VI-1984, Salgado \& al. 397 (ALCB, CTES, GUA, HRB, MAC, MBM). Piauí: Teresina, 28-I-1981, Arbo 2409 (CTES); Serra da Capivara, 1979, Emperaire 544 (IPA); 3 $\mathrm{km}$ W de Oeiras BR-230, 0702'S 4208'W, 200 m, 8-IV-1983, Krapovickas \& al. 38624 (CTES); Brionia, mun. Oeiras, 19-I-2008, Oliveira \& al. 237 (CTES, TEPB).

Distribución y fenología: Turnera pumilea var. piauhyensis vive en la «caatinga», en los estados nordestinos de Brasil: Bahia, Pernambuco y Piauí. Se la coleccionó en flor $\mathrm{y}$ fruto desde enero hasta junio.

Nombre vulgar: «ranca-estrepe» (Oliveira \& al. 237).

Obs.: En plantas cultivadas se pudo constatar experimentalmente que son autocompatibles (Shore \& al. 2006).

\section{Turnera riedeliana Urb.}

Figs. 48 y 68

Urban, I., Jahrb.Königl.Bot.Gart.Berlin 2: 110. 1883; Urban, en Martius, Fl. Bras. 13(3): 132, tab.
40, fig. 1. 1883. Typus: Brasil. Goiás [actualmente Minas Gerais], «in campis lapidosis prope Chapadão de S. Marcos», VIII-1834, Riedel 2539 (P, W).

Turnera melanorhiza Urb., Bot. Jahrb. Syst. 25, Beibl. 60: 7. 1898; Glaziou, Bull. Soc. Bot. France 56 Mém. 3: 311. 1909. Typus: Brasil. Goiás. Serra dos Pirineus, 20-IX-1894, Glaziou 21449 (holotypus $\mathrm{B}+$, isotypi BR!, K!, P!).

Turnera melanorhiza Urb. var. latifolia Urb., Bot. Jahrb. Syst. 25, Beibl. 60: 8. 1898. Typus: Brasil. Goiás. Sin localidad ni fecha, Glaziou 21450 e (holotypus $\mathrm{B}+$, no se han encontrado duplicados en los herbarios consultados).

Hierba perenne 5,5-12 cm alt., erecta, castaña en seco, base leñosa de 1-7 mm diám., originando 1-8 ejes, simples o ramificados desde la base. Tallos cilíndricos, 0,5-1 mm diám., glabrescentes en la base, luego con pelos simples, curvados, antrorsos; entrenudos 0,5-10 mm long., más cortos hacia el ápice. Hojas patentes o erguidas. Estípulas rudimentarias, pilosas, con coléteres cónicos, amarillentos, 0,1-0,4 mm long. Yema axilar 1, vegetiva o florífera. Pecíolo 0-2 mm long. Lámina linear o angustielíptica, 5-20 x 0,7-4 $\mathrm{mm}$, relación largo:ancho $=1,5-5(-11): 1$; base cuneada o atenuada, ápice agudo, margen revoluto, entero o con algunos dientecillos pilosos en la porción apical (7-50\%); haz y envés glabros o con algunos pelos simples en la base; vena principal y 2-3 pares de venas laterales prominentes en ambas caras, decurrentes, ángulo de divergencia ca. $25^{\circ}$. Nectarios 0-2, situados sobre el borde a 0,6$1,5 \mathrm{~mm}$ de la base, orientados hacia el envés, 0,3-0,5 mm diám., borde piloso. Flores epifilas, solitarias, heterostilas. Alabastro elipsoidal, agudo, recto. Pedúnculo 0,9-1,8 $\mathrm{mm}$ long., en las flores inferiores casi libre, en las superiores soldados al pecíolo excepto el ápice $(0,2-1 \mathrm{~mm})$, indumento como el del ta1lo. Profilos 1,2-2,5 x 0,1-0,2 mm, subulados, opuestos, borde entero, con pelos como los del tallo, insertos en la base del receptáculo. Pedicelo nulo. Cáliz 4-7,5 mm long., por fuera con pelos simples, curvados, antrorsos; tubo calicino 1,2-2 mm long, velloso por dentro; lóbulos con pelos más largos y escasos, mucronulados $(0,1 \mathrm{~mm})$, a veces el ápice pur- 


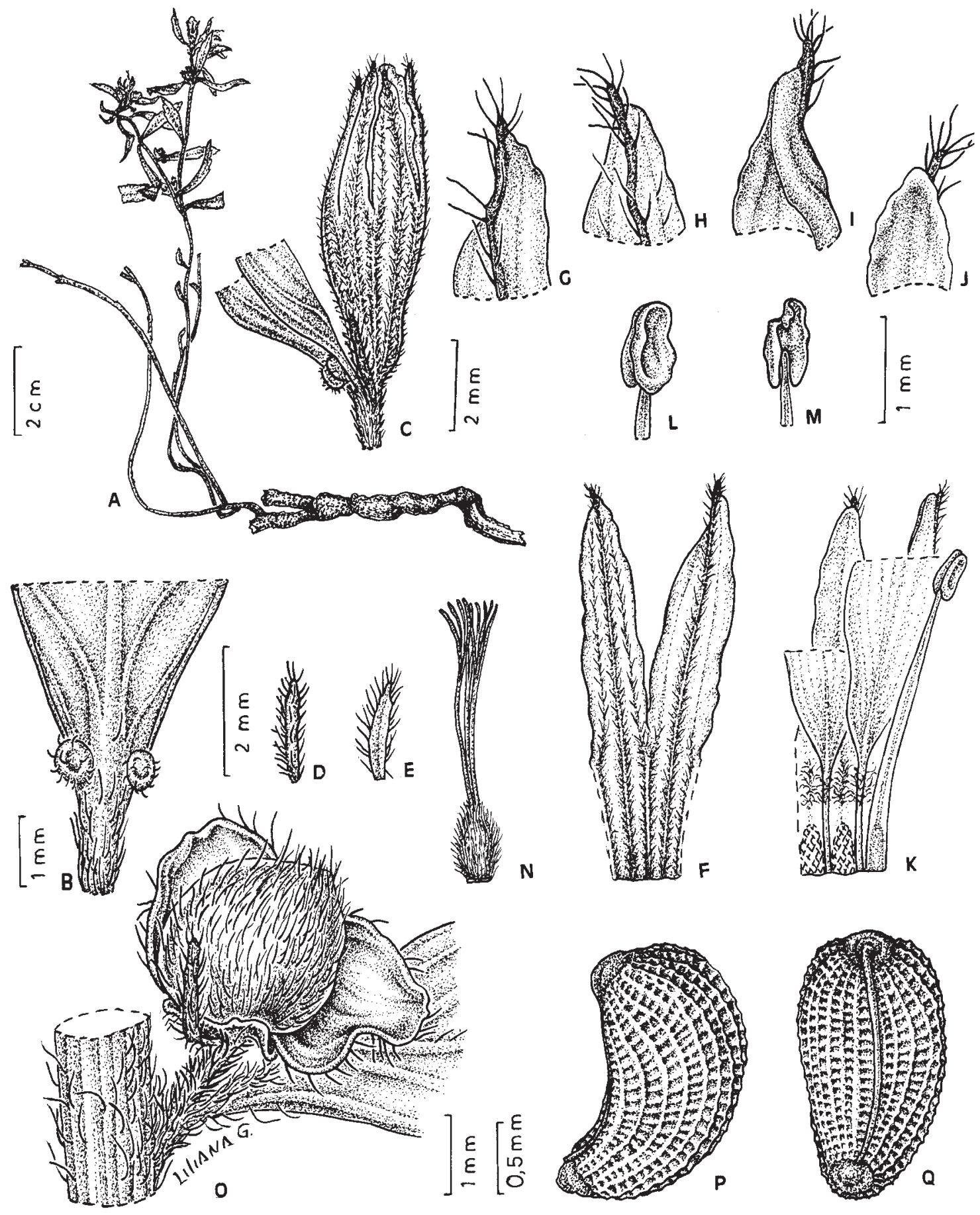

Fig. 68. Turnera riedeliana. A: planta. B: porción basal de hoja con nectarios, cara abaxial. C: porción basal de hoja florífera con nectarios, flor epifila y profilo. D-E: profilos, caras interna y externa. F: porción del cáliz, cara externa. G-J: ápice de los lóbulos del cáliz, vistas externa e interna. K: flor brevistila, porción del tubo calicino, cara interna, con pétalos y estambre adnatos; se han cuadriculado las cicatrices dejadas al desprender dos estambres. L-M: anteras, vistas ventral y dorsal. N: gineceo. O: porción basal de hoja florífera con fruto epifilo y profilos; nótese la porción apical del pedúnculo libre. P-Q: semilla, vistas lateral y rafeal (A: Glaziou 21449; B-Q: Bernacci \& al. 19957). Del. Liliana Gómez. 
púreo, terminado en 2-3 pelos. Pétalos unguiculados, uña soldada al tubo calicino, lámina amarilla, 5-7 x 3-3,5 mm, totalmente glabra o con algunos pelos en la base de la cara interna. Filamentos estaminales glabros, soldados $0,2-0,5 \mathrm{~mm}$ en la base al tubo calicino, 2,8-3,5 $\mathrm{mm}$ long. en flores longistilas, 4,5-6 $\mathrm{mm}$ long. en flores brevistilas; anteras 0,7-1,2 x 0,3-0,5 mm, ovadas, base emarginada, ápice obtuso ligeramente curvado después de la dehiscencia, filamento inserto dorsalmente a $0,2-0,5 \mathrm{~mm}$ de la base. Ovario cónico, densamente estrigoso, 0,6-1 x 0,6-0,9 mm; placentas 1-3-ovuladas; estilos cilíndricos, glabros, $4 \mathrm{~mm}$ long. en flores longistilas, 2-3 $\mathrm{mm}$ long. en flores brevistilas; estigmas 1-2 mm long, con 6-7 ramas. En flores brevistilas los estigmas alcanzan la base de las anteras. Fruto ovoide, 2$4 \mathrm{~mm}$ long.; valvas ovado-elípticas, cara externa con pelos simples, curvados, antrorsos, de base ligeramente dilatada, cara interna lisa, jaspeada, glabra, a veces el ápice purpúreo, absición del tubo floral a 0,2 $\mathrm{mm}$ de la base, dejando un reborde persistente. Semilla curvada, 1,8-2 x 0,7-1 mm; exóstoma redondeado o conoidal; rafe linear, lado rafeal incurvo; cálaza saliente, oscura, ligeramente deprimida en el centro. Episperma reticulado, nudos del retículo algo prominentes, aréolas cuadrangulares o rectangulares, epidermis tenuemente papilosa. Arilo unilateral, angosto, $1 \mathrm{~mm}$ long., de células papilosas.

Material estudiado: BRASIL. Goiás. Serra dos Pirineus, Pirenópolis, ca. 1350 m, 8-XII-1987, Bernacci \& al. 19957 (UEC).

Distribución: Especie rara, coleccionada en un área restringida, en la Serra dos Pirineus, Goiás y en el Chapadão de San Marcos, Minas Gerais, casi en el límite con Goiás.

\section{Turnera rosulata Arbo, sp. nov.}

Figs. 38 y 69

Herba brevicaule, pilis simplicibus curvatis vel erectis; stipulae nullae; folia rosulata, $4-9 \mathrm{~mm}$ petiolata, ovata vel suborbicularia, supra glabra vel pilosa, nectariis nullis. Flores dimorphi, pedunculi toti adnati, prophylla linearia, calyx 8,5 mm longus, ca. 2/5 alt. coalitus, petala rosea, filamenta glabra, basi tubo tota facie adnata, antherae 0,7 mm long., placentae 3-ovulatae, styli glabri. Fructus dorso laeve, prophyllis superante. Semina quasi recta, reticulata, chalaza parum prominula, concaviuscula, arillo unilaterali, angusto.

Typus. Brasil. Goiás, mun. Alto Paraíso de Goiás, estrada Alto de Goiás-Colinas, ca. 14 km da entrada do Parque Nacional da Chapada dos Veadeiros, 20-XI-1987, Mamede \& al. 54 (holotypus SP, isotypus CTES).

Hierba brevicaule, tallo 0-3 cm long., enterrado o postrado, 0,5-2 mm diám., con pelos simples erectos o curvados ca. $1 \mathrm{~mm}$ long., entrenudos cortísimos. Hojas dispuestas en roseta. Estípulas ausentes. Pecíolo aplanado en seco, 4-9 mm long., indumento como el del tallo. Lámina extendida, ovada o suborbicular, elíptica en hojas basales, 11-26 x 8-14 mm, relación largo:ancho = 1-2:1; base redondeada o anchamente cuneada; margen crenulado o crenado, plano o apenas revoluto, con pelos crespos; ápice obtuso o agudo; epifilo glabro, generalmente oscuro, arenáceo, con pelos simples hacia el margen o completamente piloso (pelos simples blandos, delgados, más o menos erectos, con base cónica); envés arenáceo, piloso o lanoso; venas laterales 4-5 pares, opuestas o alternas, ligera o marcadamente hundidas en la haz, prominentes y densamente pilosas en el envés; ángulo de divergencia $45-50^{\circ}$; venas terciarias y venación menor no visibles. Nectarios ausentes. Hojas floríferas reduciéndose rápidamente hasta $4 \times 3 \mathrm{~mm}$. Flores epifilas, heterostilas. Pedúnculo totalmente soldado al pecíolo. Profilos lineares, 1,5-2 x 0,2 mm, cara externa pilosa, cara interna glabra. Pedicelo ausente. Cáliz 8,5 mm long.; tubo calicino 3,5 $\mathrm{mm}$ long., piloso o glabrescente, pelos simples cortos esparcidos por fuera, por dentro pelos simples largos laxos; lóbulos angustiovados con pelos simples largos y cortos entremezclados, más abundantes que en el tubo, los externos con pelos hasta el borde, los internos con bordes membranáceos glabros. Pétalos 

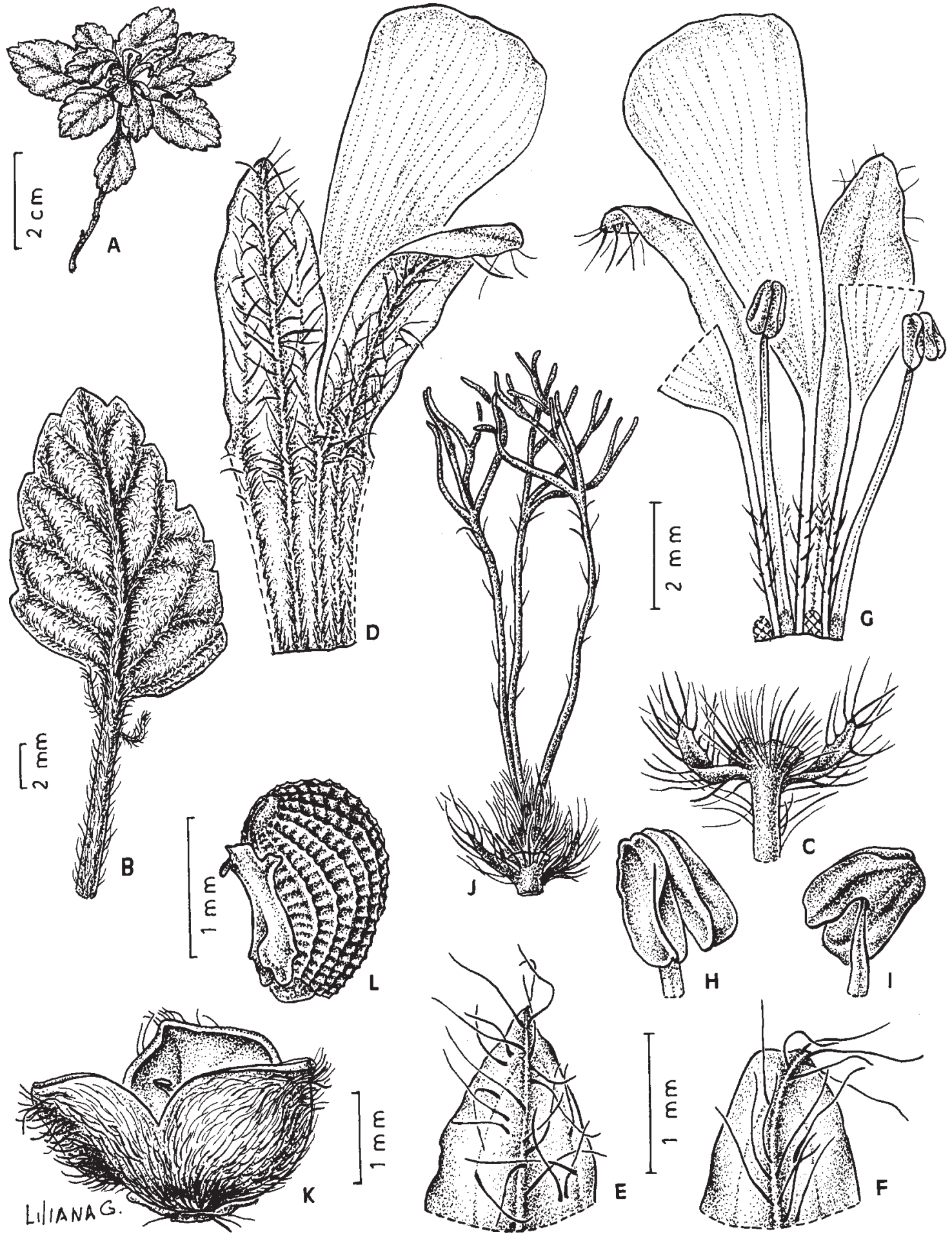

Fig. 69. Turnera rosulata. A: planta. B: hoja con profilos, cara abaxial. C: ápice del pedúnculo, profilos y receptáculo. D: porción del cáliz, cara externa, y pétalo. E-F: ápice de los lóbulos del cáliz, cara externa. G: flor longistila, porción del tubo calicino, cara interna, con pétalos y estambres adnatos; se han cuadriculado las cicatrices dejadas al desprender dos estambres. H-I: anteras, vistas ventral y dorsal. J: receptáculo, profilos y gineceo. K: fruto. L: semilla con arilo, vista lateral (Barbosa \& Castro 174). Del. Liliana Gómez. 
color lila, uña pilosa $3 \mathrm{~mm}$ long., soldada al tubo calicino, lámina obovada, 8,5-9 x $3 \mathrm{~mm}$, ápice obtuso. Filamentos estaminales subulados, glabros, adnatos $0,7 \mathrm{~mm}$ al tubo floral en la base, $5 \mathrm{~mm}$ long. en flores longistilas; $7 \mathrm{~mm}$ long. en flores brevistilas; anteras anchamente ovadas, 0,7 x 0,5 mm, filamento inserto a $0,2 \mathrm{~mm}$ de la base emarginada, ápice obtuso. Ovario más o menos cónico, 0,7 mm long., hirsuto; placentas 3-ovuladas; estilos cilíndricos, glabros, 4,5 $\mathrm{mm}$ long. en flores longistilas, $3 \mathrm{~mm}$ long. en flores brevistilas; estigmas penicilados 2-3 mm long., paucirramosos (ca. 8 ramas). En flores longistilas el gineceo es 1-1,5 mm más largo que el androceo; en flores brevistilas el androceo es $2 \mathrm{~mm}$ más largo que el gineceo. Fruto globoso, 2-3 mm diám., 3-seminado; tubo floral desprendiéndose a $0,3 \mathrm{~mm}$ de la base, dejando un reborde anular persistente; valvas latiovoides, ápice redondeado o en ángulo obtuso, cara interna glabra, lustrosa, vena placentaria prominente, llegando hasta la mitad de la valva. Semilla casi recta, obovoide, 1,5-1,6 x 1-1,2 mm; exóstoma brevísimo, redondeado; rafe linear apenas visible, lado rafeal recto o ligeramente incurvo; cálaza ligeramente prominente, a veces deprimida en el centro. Episperma reticulado, epidermis lisa, aréolas transrectangulares o poligonales con una depresión punctiforme. Arilo unilateral, angosto, 0,7-1,5 mm long., de células lisas.

Paratypus: BRASIL. Goiás: Goiás: mun. Alto Paraíso, próximo a entrada Sul do Parque Nacional Chapada dos Veadeiros, 19-XI-1987, Barbosa \& Castro 174 (CTES).

Distribución: aparentemente endémica de Goiás, los dos ejemplares conocidos fueron coleccionados en la vecindad del Parque Nacional Chapada dos Veadeiros, en campo recién quemado.

Obs.: Especie afín a Turnera acaulis, endémica de Cuba, con flores homostilas de mayor tamaño y a Turnera humilis, con flores amarillas, 2-4 nectarios foliares y placentas 8ovuladas.

\section{Turnera sidoides $L$.}

Fig. 70

Linneo, C., Mantissa Pl.: 58. 1767. Typus: Herb. Linn. 384-5 (holotypus LINN!). Según Smith (Rees, 1817, Cyclop. 36,2) dicho ejemplar fue coleccionado en Brasil por el Padre Panegai, y enviado a Linneo por Pietro Arduino (1728-1805), quien está mencionado en el protólogo.

Urban, Jahrb. Königl. Bot. Gart. Berlin 2: 101103.1883; Urban, en Martius C.F.P., Fl. Bras. 13(3): 124-127. 1883; Arbo, Candollea 40: 183190. Fig. 3, Mapa 1. 1985.

Arbo (1985) reconoció 5 subespecies en Turnera sidoides, sobre la base de 480 especímenes estudiados; en el lapso transcurrido se han analizado 610 especímenes más, lo que ha permitido confirmar la validez de las subespecies. En este taxón la expresión de la heterostilia es variable, en las subespecies integrifolia y pinnatifida se encontraron solamente flores longistilas y brevistilas; en las otras subespecies una alta proporción de las flores estudiadas mostraba androceo y gineceo de igual longitud o con anteras y estigmas parcialmente en contacto. Sin embargo, se ha constatado en plantas cultivadas de todas las subespecies que son autoincompatibles, no producen frutos por autopolinización.

Los estudios citológicos realizados han demostrado que esta especie es un complejo autopoliploide con niveles de ploidía entre $2 \mathrm{x}$ y $8 x$, siendo el nivel $4 x$ el prevaleciente; las poblaciones diploides y hexaploides muestran distribución disyunta; en la subsp. integrifolia se han detectado cuatro citotipos $(2 \mathrm{x}, 4 \mathrm{x}, 6 \mathrm{x}$ y $8 \mathrm{x})$, en las subespecies carnea y pinnatifida tres citotipos $(2 \mathrm{x}, 4 \mathrm{x}$ y $6 \mathrm{x})$, en la subsp. holosericea se conocen dos $(4 \mathrm{x}$ y $6 \mathrm{x})$ y solamente en la subsp. sidoides se ha observado un solo citotipo: $4 \mathrm{x}$, aunque también se han encontrado algunas plantas aneuploides con números cercanos a $5 \mathrm{x}$ (Fernández 1987; Solís Neffa \& Fernández, 2000, 2001 y 2002). Se ha constatado, en plantas de la mayoría de las poblaciones estudiadas, la producción de microsporas no reducidas, cuya intervención en los cruzamientos sería uno de los mecanismos de poliploidización en este complejo (Panseri \& al. 2008). 
Se han realizado estudios comparativos entre los cariotipos de varias especies de la serie Turnera $(\mathrm{x}=5)$, una de Papilliferae $(\mathrm{x}=13)$, una especie de Salicifoliae, tres especies de Leiocarpae y todas las subespecies de T. sidoides $(\mathrm{x}=7)$. El análisis de componentes principales indica que los dos primeros componentes dan cuenta del $58 \%$ de la variación; el primero marca las diferencias en número cromosómico básico y asimetría del cariotipo, y el segundo acentúa la variación en la longitud de los cromosomas. Es interesante destacar que en el gráfico bidimensional elaborado sobre estos componentes, los cariotipos de $T$. sidoides aparecen agrupados, y separados claramente de las restantes especies con $\mathrm{x}=7$.

Se analizó la cianogénesis en 38 poblaciones del complejo Turnera sidoides, constatándose que las 5 subespecies son cianogénicas, pero la expresión del carácter es variable entre subespecies y dentro de cada entidad. En la subsp. pinnatifida, la de distribución geográfica más amplia, tres poblaciones diploides correspondientes a tres provincias fitogeográficas diferentes presentan niveles distintos de cianogénesis, y esta variación es mayor que la detectada entre las poblaciones diploide y tetraploide la misma área. La variación en la subsp. pinnatifida podría estar relacionada con la presión de selección ejercida por diferentes regímenes climáticos (Solís Neffa \& al. 2003).

La estructura de los coléteres fue estudiada en tres subespecies: carnea, integrifolia y pinnatifida. En el margen de los profilos se encontraron coléteres de tipo standard, mientras en los dientes foliares y en las estípulas rudimentarias o en su lugar, se hallaron coléteres sésiles (Gonzalez, 1998). En todas las subespecies el tallo carece de células taníferas y los haces caulinares no presentan fibras perifloemáticas; las hojas son dorsiventrales y anfistomáticas, y los haces vasculares presentan vaina parenquimática; se estudió la ontogenia y estructura de las semillas en 3 subespecies: carnea, integrifolia y pinnatifida, se comprobó que el diseño característico de las semillas crestadas es determinado por la exotesta, a diferencia de las restantes especies de Leiocarpae, de las otras series del género, y de Piriqueta, en las que el

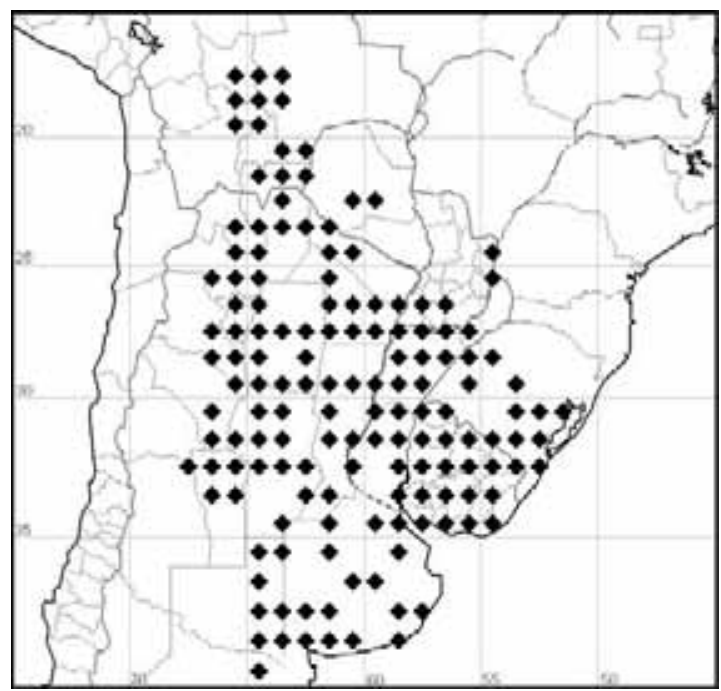

Fig. 70. Distribución de Turnera sidoides.

diseño de la cubierta seminal es el resultado de la interacción de las células de la endotesta y las esclereidas del exotegmen (Gonzalez, 2000).

Turnera sidoides es la especie de la serie con distribución más amplia, se extiende desde Bolivia, Paraguay y Brasil hasta el N de la Patagonia en Argentina (Fig. 70). Los límites conocidos de su distribución son: al NW, el Cerro Punata, situado al $\mathrm{N}$ de Cochabamba,

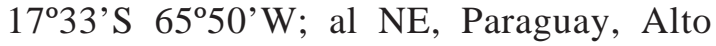

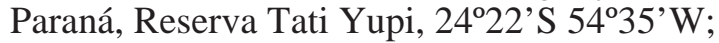
al E, el Cerro da Gloria, Porto Alegre, $30^{\circ} 04^{\prime} S$ $51^{\circ} 12^{\prime} \mathrm{W}$; al W, Divisadero, San Luis, $32^{\circ} 24^{\prime} \mathrm{S} 67^{\circ} 15^{\prime} \mathrm{W}$; al S, $50 \mathrm{~km}$ al S de Rio Colorado, prov. Rio Negro, aprox. 39²3'S $64^{\circ} 11^{\prime} \mathrm{W}$. Por su vasta distribución, que abarca varias provincias fitogeográficas, crece en una variedad de ambientes y climas, desde la alta montaña en Cochabamba, hasta el nivel del mar, tanto en bosques abiertos como en pastizales.

\section{1a. Turnera sidoides L. subsp. sidoides}

Figs. 12 y 71

Turnera sidoides L. var. hispida Urb., Jahrb. Königl.Bot.Gart.Berlin 2: 102. 1883; Urban, en Martius C.F.P., Fl. Bras. 13(3): 125. 1883. Nom- 


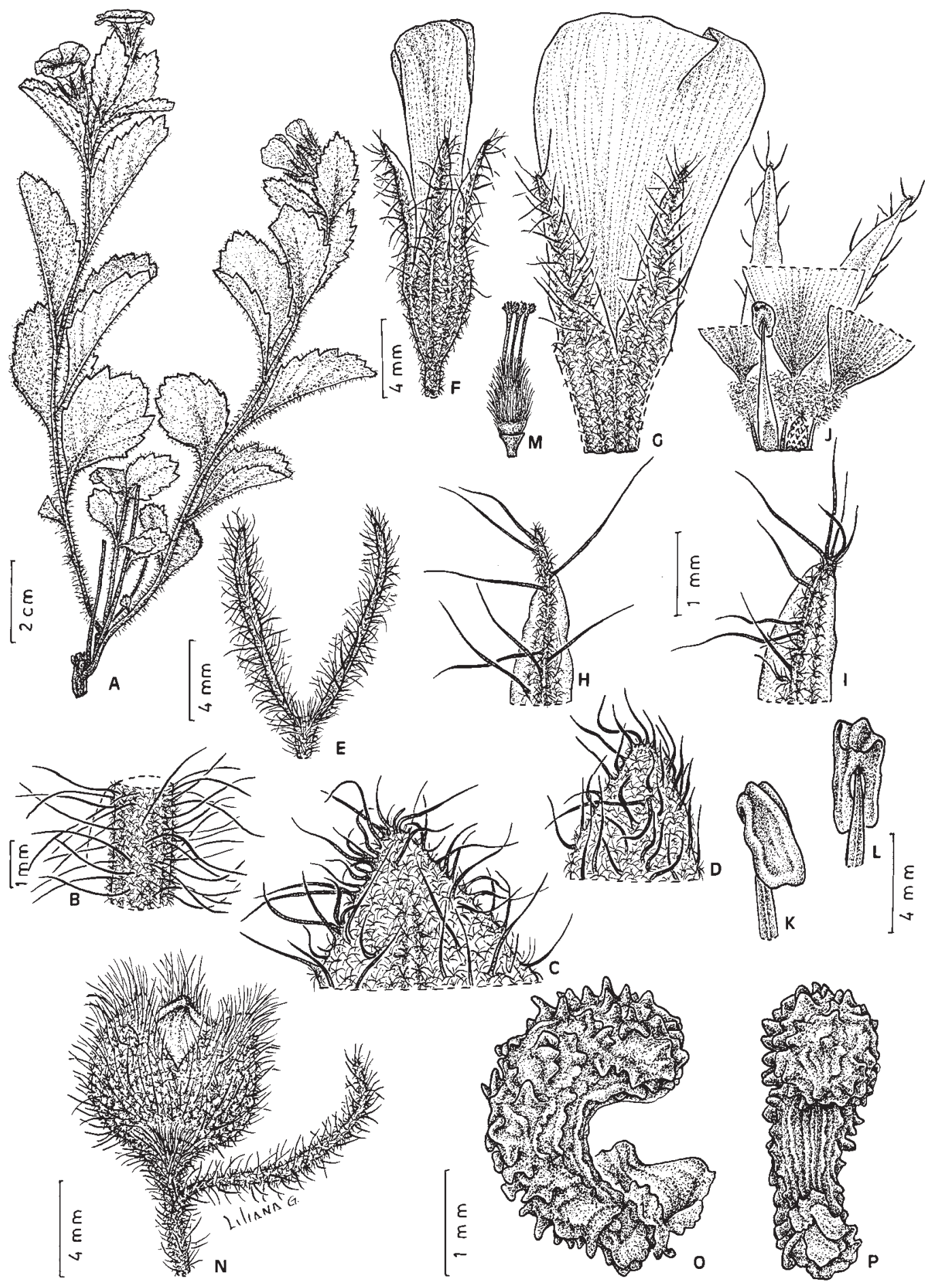

Fig. 71. Turnera sidoides subsp. sidoides. A: planta. B: porción de tallo. C-D: ápice de la lámina foliar, envés y haz. E: ápice del pedúnculo y profilos. F: flor. G: porción del cáliz, cara externa, y pétalo. H-I: ápice de 2 lóbulos del cáliz. J: flor brevistila, porción del tubo calicino, cara interna, con pétalos y estambre adnatos; se ha cuadriculado la cicatriz dejada al desprender un estambre. K-L: anteras, vistas lateral y dorsal. M: receptáculo y gineceo. N: fruto y profilo. O: semilla con arilo, vista lateral. P: semilla, vista rafeal (A: Krapovickas \& Cristóbal 16311. B-F, K-N: Solís Neffa \& al. 540. G-J, O-P: Arbo \& Schinini 2515). 
bre superfluo por incluir al tipo de la especie.

Turnera sedoides L. en DC., Prod. 3: 347. 1828. Error.

Turnera pinnatifida auct. non Juss. ex Poir. en Saint Hilaire, A., Jussieu, A. \& Cambessèdes, J., Fl. bras. merid. 2: 161. 1830.

Turnera sidoides L. var. herteriana Urb. ex Herter G., Repert. Spec. Nov. Regni Veg. 15:396. 1919. Typus: Uruguay. Maldonado: Cerro de los Gigantes, Herter 10423. Ejemplar no encontrado en $\mathrm{G}$, donde se conserva la colección Herter, ni en los otros herbarios consultados. Según la breve descripción y considerando la localidad tipo, corresponde a esta subespecie.

Turnera herteri (Urb.) Herter, 1957 , Fl.Il.Uruguay 14: Lám. 2227, combinación no válida, art. 33.

Hierba de 9-26 cm., muy ramificada desde la base de 5-7 mm diám. Tallos de 1-1,5 mm diám., entrenudos de 9-20 mm long., los apicales más cortos, con pelos simples hirsutos 0,8-2 mm long. y pelos estrellados cortos. Ramas seriales no desarrolladas. Hojas herbáceas sin nectarios. Estípulas ausentes o rudimentarias, con coléteres 0,2-0,3 mm long. Pecíolo 0,5-6 mm long., indumento como el del tallo. Lámina 17-53 x 7-25 mm, relación largo:ancho $=1,6-3: 1$, grado de incisión de la hemilámina 10-40\%; haz y envés con tomento muy denso, de pelos estrellados, pelos simples escasos en el envés, sobre las venas principales; venas laterales 4-5 pares, apenas visibles en el envés, ángulo de divergencia $25-30^{\circ}$, incurvas. Flores solitarias. Pedúnculo 0,2-6 $\mathrm{mm}$ long., soldado en la base 0,2-2 $\mathrm{mm}$ al pecíolo. Profilos lanceolados, 8-14 x 0,5-3 $\mathrm{mm}$, base atenuada, ápice agudo. Pedicelo 2-4 mm long. Cáliz 8,5-14 mm long.; tubo calicino 2,5-4 mm long., cara externa con pelos estrellados, cara interna vellosa en la garganta; lóbulos emucronados, con pelos simples de 1-2 mm long. Pétalos rosados, uña vellosa, lámina de 12-18 x 6-13 mm, con una mancha oscura en la base. Filamentos estaminales pilosos, 4,5-5,5 mm long. en flores longistilas, 5-6 $\mathrm{mm}$ long. en flores brevistilas; anteras de 1,2-2,2 x 0,6-1 mm, filamento inserto dorsalmente $0,5-0,8 \mathrm{~mm}$ de la base. Ovario 1,5-1,7 mm long, densamente cubierto de pelos simples largos; placentas 7- 9-ovuladas; estilos glabros, 4,5-6 mm long. en flores longistilas, 1,5-4 mm long. en flores brevistilas; estigma lobulado, 0,3-0,5 mm long. En flores longistilas el gineceo es 1-3 mm más largo que el androceo, y en flores brevistilas, 1,5-3 mm más corto. Fruto ovoide, 4-8 mm long.; valvas ovadas, cara externa tuberculada y pilosa, cara interna lisa, glabra, lustrosa, con algunas máculas oscuras. Semilla 4 x $1 \mathrm{~mm}$. Episperma crestado, crestas de $0,3 \mathrm{~mm}$ long. Arilo más corto que la semilla, de células lisas.

Cromosomas: $2 \mathrm{n}=2 \mathrm{x}=28$, Arbo \& Schinini $2497 y$ 2515, Krapovickas \& Cristóbal 16173, Solís Neffa s.n., 407, 408, 501 y 502; 2n=32, 34, 37, Arbo \& Schinini 2435 (Fernández, 1987; Solís Neffa \& Fernández, 2001); cariotipo: Solís Neffa 501 (Solís Neffa \& Fernández, 2002).

Material estudiado: BRASIL. Rio Grande do Sul: 10 km E de Alegrete, BR-290, 18-XII-1981, Arbo \& Schinini 2435 (CTES). URUGUAY. Canelones: R.8, Km 58, Ayo. Mosquitos, 3440’00"S 5540’41"W, 54 m, 1-XII-2001, Solís Neffa \& al. 548 (CTES). Florida, camino de Casupa a Barrancas, 3408'49"S 55³9'14"W, 159 m, 30-XI-2001, Solís Neffa \& al. 544 (CTES). Lavalleja: alrededores de Cerro Verdún, NW de Minas, 20-XII1981, Arbo \& Schinini 2500 (CTES); Villa Serrana, 12-XI-1959, Arrillaga 826 (MVFA); Cerro Arequita, 11-X-1970, Krapovickas \& al. 16173 (CTES); R.14, camino de J.P.Varela a J.Batlle y Ordoñez, 3334'52"S 5448'02"W, 187 m, 29-XI2001, Solís Neffa \& al. 540 (CTES). Maldonado: Punta Ballena, 5-IX-1970, Del Puerto \& Codina 9307 (MVFA); Sierra de las Ánimas, 28-X-1962, Marchesi 272 (MVFA); près de Montevideo, a Maldonado, Neé s.n. (C); Abra Perdomo, 22-X1969, Olano \& al. s.n. (MVFA); Solís, 2-XI-1929, Osten 21662 (S); Piriápolis, Cerro Pan de Azúcar, 12-XII-1997, Solís Neffa \& al. 407 (CTES); Piriápolis, Cerro San Antonio, 6-XII-1997, Solís Neffa \& al. 501 (CTES); R.12, camino de San Carlos a Minas, 34³0'49"S 5508'13"W, 348 m, 1-XII-2001, Solís Neffa \& al. 547 (CTES). Minas: Co. Arequita, 3-X-1937, Rosengurtt B 2159 (MVFA). Montevideo: Granja Facultad, II-1955, Arrillaga 77 (MVFA); Cerro de Montevideo, X1986, Crosa s.n. (CTES, K); S. Pedro de Rio Grande, jusq. A Maldonado, Saint Hilaire C2 
2068 (P). Tacuarembó: 10 km NW de Tacuarembó, camino a Gruta de los Helechos, 22II-2005, Dematteis \& Schinini 1778 (CTES); camino a Gruta de los Cuervos, 31 $37^{\circ} 42^{\prime \prime S}$ 5602'15"W, 225 m, 3-XII-2001, Solís Neffa \& al. 555 (CTES).

Material cultivado: ARGENTINA, Corrientes: proc. de Uruguay, $17 \mathrm{~km} \mathrm{NW}$ de Tacuarembó, 2-I-1984, Arbo \& Schinini 2515 (CTES); proc. de Uruguay, R.3, 17 km NW de Tacuarembó, 14-IX1998, Solís Neffa 502 (CTES).

Distribución y fenología: Turnera sidoides subsp. sidoides es exclusiva de Rio Grande do Sul (Brasil) y Uruguay, donde vive en campos y laderas de cerros, entre 54 y $225 \mathrm{~m}$ de altitud. Los pocos ejemplares conocidos han sido colectados entre septiembre y marzo.

Obs.: En las flores estudiadas de esta subespecie, $66 \%$ son heterostilas y $34 \%$ poseen androceo y gineceo de igual longitud o en contacto. El ejemplar Solís Neffa \& al. 544 presenta pelos simples, bífidos, trífidos y algunos estrellados.

\section{1b. Turnera sidoides subsp. carnea (Cambess.) Arbo}

Figs. 7 y 72

Arbo, M. M., Candollea 40: 182, 1985. Typus: Brasil. Rio Grande do Sul, pâturages près le ruisseau Itapuitataocai [Itapitocaí, ca. Uruguayana], Saint Hilaire C2 2577 (holotypus $\mathrm{P}$ !, isotypi $\mathrm{F}$ !, $\mathrm{P}$ !).

Turnera pinnatifida Juss. var. carnea Cambess., Fl. bras. merid. 2: 222, 1830.

Turnera sidoides var. incisa Urb., Jahrb. Konigl. Bot. Gart. Berlin 2: 102, 1883; Urban, en Martius C.F.P., Fl. Bras. 13(3): 126. 1883, en parte.

Hierba de 6-27 $\mathrm{cm}$ alt., base de $2-5 \mathrm{~mm}$ diám. Tallo erecto, 1-2 mm diám., con pelos simples curvado-antrorsos gruesos y pelos simples cortos, entrenudos de 4-27 mm long.; a veces ramas largas apoyantes, con los ápices erguidos. Ramas seriales a veces desarrolladas. Hojas herbáceas sin nectarios. Estípulas ausentes o rudimentarias, $0,2 \mathrm{~mm}$ long. Pecíolo 1-5 mm long. Lámina entera, elíptica u obovada, en hojas basales latiobovada, en hojas apicales romboidal, 12-47 x 6-25 mm, relación largo:ancho $=1,1-2,7: 1 ;$ base cuneada o atenuada, ápice agudo o redondeado, borde simple o doblemente aserrado, grado de incisión de la hemilámina 16-50\%; haz con pelos simples curvados, antrorsos, con la base cónica y rojiza, generalmente orientados diagonalmente con respecto a la vena media, pelos cortos crespos, pelos glandulares microcapitados, y algunas veces pelos bífidos o trífidos; envés con indumento igual, generalmente más denso; 4-6 pares de venas laterales prominentes, por lo general incurvas o rectas; ángulo de divergencia $23-28^{\circ}$; venas terciarias a veces visibles en el envés. Flores rosa pálido a rosado intenso. Pedúnculo con indumento como el del tallo, 2,5-7 mm long., libre o soldado $0,5-3 \mathrm{~mm}$ al pecíolo. Profilos subulados, opuestos o alternos en el ápice del pedúnculo, 6-11 x 0,2-0,7 mm. Pedicelo 1-3 $\mathrm{mm}$ long., ligeramente más grueso y con indumento más denso. Cáliz 7-12 mm long., con pelos simples largos, generalmente antrorsos, y pelos cortos; tubo calicino 2-4 mm long., velloso por dentro en la garganta; lóbulos glabros en la cara interna, cara externa con pelos simples 1-2 mm long., a veces ligeramente mucronados. Pétalos con la uña pilosa en la porción apical, lámina 10-18 x 7-12 mm, con mácula purpúrea en la base. Filamentos estaminales vellosos, soldados $0,2 \mathrm{~mm}$ al tubo calicino, 3,2-4,5 $\mathrm{mm}$ long. en flores longistilas, 5,5-6,5 $\mathrm{mm}$ long. en flores brevistilas; anteras $1,5-2 \times 0,5-1 \mathrm{~mm}$, con la base emarginada, ápice obtuso, recurvado a la dehiscencia, filamento inserto dorsalmente a 0,5-0,9 $\mathrm{mm}$ de la base. Ovario piloso, $1,5 \mathrm{~mm}$ long.; placentas 6-10-ovuladas; estilos amarillos o rojizos, cilíndricos, pilosos o glabros, 4$5,5 \mathrm{~mm}$ long. en flores longistilas, 1,2-3 mm long. en flores brevistilas; estigma amarillo, lobulado a penicilado, 12-24 ramas de 0,4-1 $\mathrm{mm}$ long. Fruto ovoide, a veces suborbicular, 5-10 mm long.; valvas con cara externa tuberculada, pelos simples largos y cortos; cara interna lisa, lustrosa, reticulada, amarillenta. Semilla virguliforme, 3,5-4 x 1-1,5 $\mathrm{mm}$; exóstoma cónico, borde superior marca- 


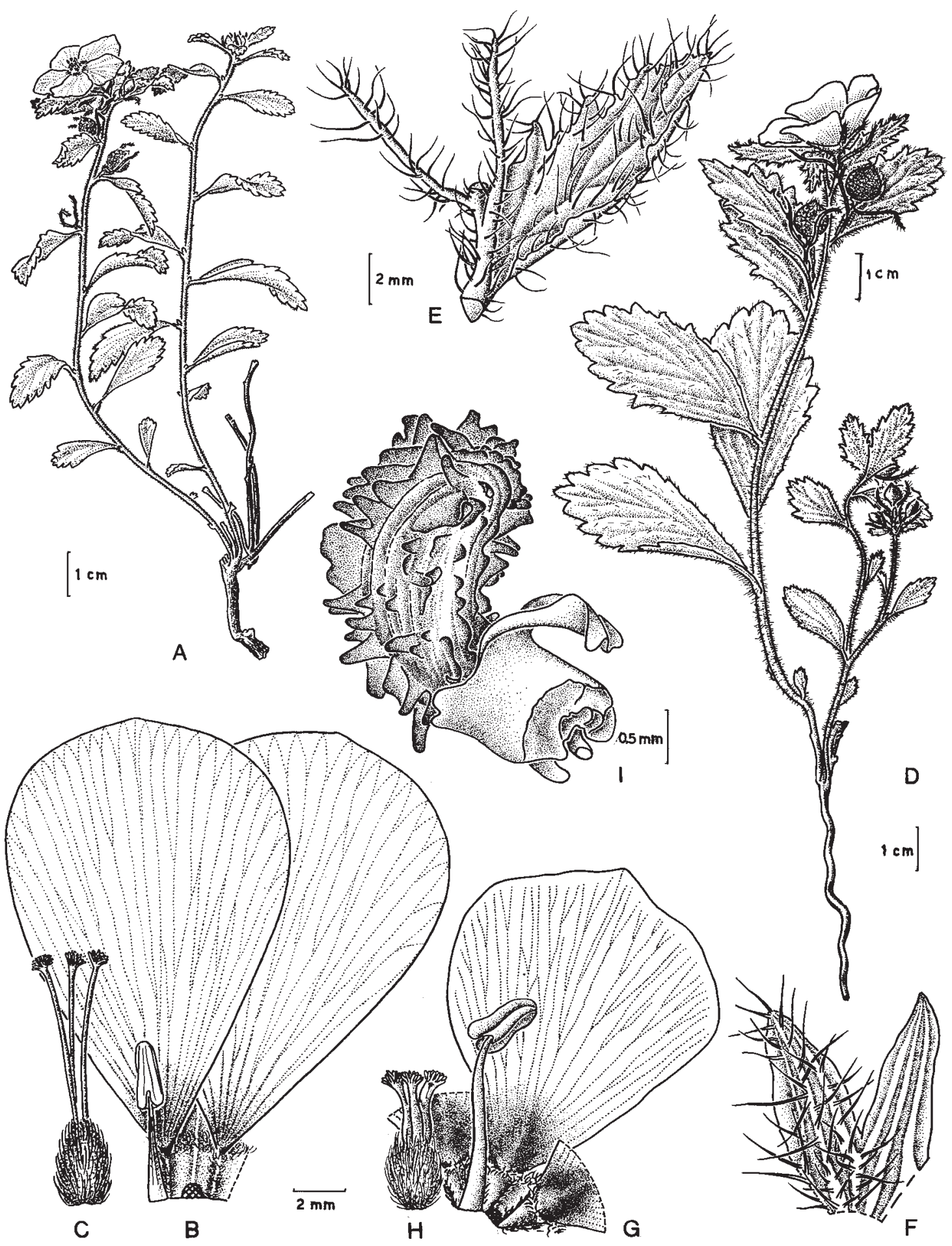

Fig. 72. Turnera sidoides subsp. carnea. A: planta. B: flor longistila, porción del tubo calicino, cara interna, con pétalos y estambre adnatos; se ha cuadriculado la cicatriz dejada al desprender un estambres. C: gineceo. T. sidoides subsp. integrifolia. D: planta. E: hoja con pedúnculo y profilos, cara adaxial. F: porción del cáliz, cara externa. G: flor brevistila, porción del tubo calicino, cara interna. H: gineceo. I: semilla con arilo, vista lateral (A: Schinini 21711; BC: Saint Hilaire C2 2577; D: Lorentz, 257; E-I: Arbo 385). Del. Ricardo Vispo. 
do por las crestas; rafe linear, ligeramente prominente, lado rafeal curvado; cálaza redondeada, levemente deprimida. Episperma crestado, crestas longitudinales $0,3-0,6 \mathrm{~mm}$ y transversales irregulares. Arilo unilateral, más corto que la semilla, de células lisas.

Cromosomas: $2 \mathrm{n}=2 \mathrm{x}=14$, Schinini \& al. 21711, Solís Neffa \& al. 504; $\mathrm{n}=4 \mathrm{x}=28$, Arbo \& Schinini 2510, Gonzalez \& al. 31, Solís Neffa s.n., 271 y 278, Solís Neffa \& al. 271, 278 y 395; 2n=6x=42, Cristóbal \& Krapovickas 1782, Krapovickas \& al. 25847, Solís Neffa 508, Solís Neffa \& Dematteis s.n., 312, (Fernández, 1987; Solís Neffa \& Fernández, 2000, 2001 y 2002).

Material estudiado: PARAGUAY. Itapúa: Colonia Alborada, 225 m, 24-XI-1948, Montes 3253 (K, SI, US). Guairá: Iturbe, IX-1952, Montes 12433 (CTES). Misiones: San Juan Bautista, 21XI-1981, Lurvey 388 (PY). ARGENTINA. Corrientes: Dep. Paso de los Libres, Parada Pucheta, ruta nac. 127, 17-II-1979, Ahumada 2565 (CTES); dep. Santo Tomé, R.38 y rio Aguapey, 24-II-1986, Cáceres \& al. 384 (CTES); Dep. Ituzaingó: 10 km W de Colonia Liebig, camino a Playadito, 11-IX1978, Cristóbal \& Krapovickas 1782 (CTES, K); Dep.Ituzaingó: San Carlos, 30-IV-1997, Dematteis 677 (CTES); Ruta 12 y entrada al camino a San Carlos, 18-XI-1996, Gonzalez \& al. 31 (CTES); Dep. Santo Tomé: $23 \mathrm{~km}$ E de ruta 14, camino a Colonia Garabí, 3-XII-1970, Krapovickas \& al. 16937 (CTES); Dep. Santo Tomé: arroyo Chimiray, 6-II-1972, Krapovickas \& al. 21180 (CTES), Garruchos, estancia San Juan Bautista, costa del rio Uruguay, 20-IX-1974, Krapovickas \& al. 25847 (CTES), Colonia Garabi, 21-IX-1974, Krapovickas \& al. 25943 (CTES); Ea. Santa Rita, $27^{\circ} 03^{\prime} \mathrm{S} 5^{\circ} 04^{\prime} \mathrm{W}, 2-\mathrm{III}-1987$, Krapovickas \& al. 41011 (CTES); dep. Santo Tomé: $15 \mathrm{~km}$ de Gobernador Virasoro, camino a Garruchos, 5-II-1972, Krapovickas \& Cristóbal 20975 (CTES); dep. Santo Tomé: 36 km al N de Santo Tomé, R.Prov. 40, 2-II-1976, Krapovickas \& Cristóbal 29095 (CTES); dep. Santo Tomé, Cuay Grande, 20-XI-1973, Lourteig \& al. 2880 (CTES); Dep.Mercedes, Ea. Ita-Caabi, 18-X1961, Pedersen s.n. (CTES); dep. Mercedes: R.23, rio Miriñay, 17-IX-1979, Schinini \& al. 18688 (CTES); rio Miriñay, Paso Rosario, camino entre Mercedes y Paso de Los Libres, 13-XI-1981,
Schinini \& al. 21711 (CTES); dep. Santo Tomé,

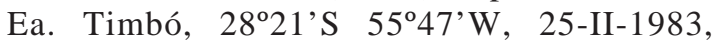
Schinini \& al. 23389 (CTES); dep. Santo Tomé, Ayo. Ciriaco y Ruta 40, 27-II-1983, Schinini \& al. 23481 (CTES, K, MBM); dep. Mercedes, R.123, $\mathrm{km}$ 184, X-1999, Solís Neffa 504 (CTES); Dep.Santo Tomé, Ea. Vuelta del Ombú, 3 km SW de Gobernador Virasoro, 12-III- 1982, Tressens \& al. 2005 (CTES). Misiones: Misiones, Dep. Capital, Zaiman, 4-IX-1945, Bertoni 1906 (F, K, LIL); Candelaria, Santa Ana, 19-IV-1944, Bertoni s.n. (LIL); Campiña Bonita, 16-II-1945, Burkart 15412 (SI); Apóstoles: R.203, entre R.14 y R.201, 25-VIII-1978, Cabrera \& al. 29483 (SI); dep. Concepción, aldea aborigen Yraka Miri, 27 $52^{\prime} 54^{\prime \prime S} 55^{\circ} 26^{\prime} 59^{\prime \prime W}$, 17-VII-2008, Keller 5611 (CTES); $5 \mathrm{~km}$ de ruta 12, camino a Profundidad, 19-IX-1974, Krapovickas \& al. 25687 (CTES); Dep. Candelaria, Cerro Santa Ana, 10XI-1979, Martínez Crovetto 11423 (CTES); dep. Iguazú, Puerto Istueta, IX-1950, Montes 9370 (CTES); Posadas, X-1911, Muniez 26 p.p. (BAF); San José, Escuela Agrotécnica Don Bosco, 200 m, 12-X-1978, Renvoize \& al. 3053 (K); Dep. Candelaria, ruta 12, $3 \mathrm{~km} \mathrm{~W}$ de Arroyo San Juan, 25-IX1972, Schinini 5539 (CTES); Dep. Candelaria, Arroyo Santa Ana, 19-I-1945, Schwarz 540 (LIL). BRASIL. Rio Grande do Sul: Granja Sodal, Giruá, 12-X-1966, Hagelund 4662 (CTES); Lagoa Urubú, Santo Angelo, 9-XI-1973, Hagelund 7254 (CTES); mun. Uruguayana, 24-I-1948, PalaciosCuezzo 217 (LIL); São Gabriel, 29-II-1948, Palacios-Cuezzo 2460 (LIL); mun. São Sepe, propriedade Jorge A. Simões,10-X-1973, Santos \& al. 3269 (R); Cabana de Palmira, Uruguaiana, margem do rio Uruguai, 22-X-1947, Vidal 1371 (R); Belem Velho, 31-X-1897, Reineck \& Czermak 723 (G). URUGUAY. Artigas: Cuarein, 29-IX-1901, Berro 1615 (MVFA). Cerro Largo: Sierra de Aceguá, ca. $13 \mathrm{~km}$ E de Aceguá, 19-XII1981, Arbo \& Schinini 2492 (CTES); Bañado de Medina, Esc. de Agronomia, 6-X-1961, Del Puerto 200 (MVFA); Ayo. Malo, Ruta 26, 22-XI-1968, Lema \& al. 7869 (MVFA); Bañado Medina, R. 44, Km 409, 12-XII-1995, Solís Neffa \& al. 271 (CTES); Ruta 8, 20 km N de Melo, 12-XII-1995, Solís Neffa \& al. 278 (CTES); Ea. La Alborada, 34²2’09"S 54²7’42"W, 20-XII-1996, Solís Neffa \& al. 397 (CTES); R.44, Km 49, frente a la

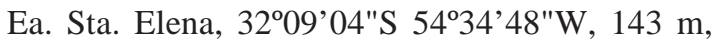
28-XI-2001, Solís Neffa \& al. 535 (CTES). Du- 
razno: Quinta of the Estancia del Cerro San Jorge, XI-1867, Christison s.n. (E); R.5, Km 196, 3316’22"S 56²8'56"W, 136 m, 3-XII-2001, Solís Neffa \& al. 550 (CTES). Flores: Ayo. Maciel, R.141, Km 168, 3323'49"S 56³7'19"W, 20-XII-1996, Solís Neffa \& al. 400 (CTES). Florida: entre ayo. Timote y Mansavillagra, 1-XI-1946, Castellanos 16917 (LIL); R.7, Km 162, ayo. Mansavillagra, 334' $51^{\prime \prime S} 55^{\circ} 27^{\prime} 12^{\prime \prime} \mathrm{W}, 173 \mathrm{~m}$, 30-XI-2001, Solís Neffa \& al. 542 (CTES). Montevideo: Montevideo, 6-VIII-1867, Fruchart 754 (P); Quinta Varela, VI-1874, Fruchart s.n. (P); Atahualpa, X-1925, Herter 164 (F, MO, SI); Montevideo, 1838, Isabelle $65 \mathrm{~A}(\mathrm{~W})$; près Montevideo, IX-1826, Orbigny 32 (P). Paysandú: R.3, Km 467, ayo. Chapicuy Chico, $31^{\circ} 37^{\prime} 40^{\prime \prime S}$ 5752'57"W, 62 m, 4-XII-2001, Solís Neffa \& al. 559 (CTES). Rivera: Ruta 30, Km 111, 31 08'59'S 5553'46W, 12-XII-1997, Solís Neffa 454 (CTES). Salto: Ruta 3 de Salto a Paysandú, 2/ 4-XI-1963, Arrillaga \& al. 1631 (MVFA); camino de acceso a la Represa Salto Grande y R.31, 10-I2006, Solís Neffa 1999 (CTES). San José: Mal Abrigo, Sierras de Mahoma, R.23, Km 126, 3407'11"S 55²5'48"W, 265 m, 2-XII-2001, Solís Neffa \& al. 549 (CTES). Soriano: Vera, 9-X1898, Berro 2235 (MVFA). Tacuarembó: Salto, XI, Felippone 5065 (K).

Material cultivado: ARGENTINA. Corrientes: proc. de Uruguay, dep. Tacuarembó, Cerro de las Ánimas, 32 km NE de Paso de los Toros, R.5, camino a Tacuarembó, 21-X-1983, Arbo \& Schinini 2510 (CTES); proc. de Mercedes, rio Miriñay, camino entre Mercedes y Paso de los Libres, III-1984, Schinini 21711bis (CTES); proc. de Misiones, dep. Candelaria, camino a Profundidad, a $5 \mathrm{~km}$ de ruta 12, 18-XII-2003, Solís Neffa 986 (CTES).

Distribución, hábitat y fenología: Habita en el S de Paraguay, NE de Argentina (Misiones y Corrientes), Brasil (Rio Grande do Sul) y Uruguay. En Paraguay crece en campos y lomadas de suelo arenoso-gredoso, hasta los $265 \mathrm{~m}$ de altitud. Se adapta a lugares modificados como bordes de caminos. Florece y fructifica de septiembre a febrero.

Obs.: Los ejemplares coleccionados en $\mathrm{Pa}-$ raguay presentan flores longistilas $\mathrm{O}$ brevistilas, pero en el material argentino se encontró un $18 \%$ de flores con anteras y estigma en contacto, o con androceo y gineceo de igual longitud, por ejemplo Bertoni s.n., Burkart 15412, Solís Neffa 986. Las hojas de los ejemplares Solís Neffa \& al. 278 y 400 presentan indumento intermedio con el de la subsp. integrifolia. En el ejemplar Schinini \& al. 18688 se observaron ramas desarrolladas a partir de yemas seriales.

\section{1c. Turnera sidoides subsp. holosericea (Urb.) Arbo}

Figs. 16 y 73

Turnera sidoides var. holosericea Urb., Jahrb. Königl. Bot. Gart. Berlin 2: 101. 1883 ; Urban, en Martius C.F.P., Fl. Bras. 13(3): 125, tab. 39. 1883; Arbo, Candollea 40: 186, 1985. Lectotypus: Brasil. Rio Grande do Sul: desde Encruzilhada hasta Caçapava y el río Santa Bárbara, Sellow 3043 (P!, isotypi $\mathrm{K}$ !, $\mathrm{W}$ !).

Turnera holosericea (Urb.) Herter, Fl. Il. Uruguay 14: Lám. 2229, combinación inválida, art. 33.

Hierba de $8-28 \mathrm{~cm}$ alt., base hasta $10 \mathrm{~mm}$ diám.; tallos 1 o varios, 0,8-2,5 mm diám., erguidos, simples o ramificados en los nudos basales; entrenudos 7-50 mm long., los apicales más cortos; pelos simples unicelulares de 1-2,5 mm long., pelos simples más cortos y crespos muy abundantes y pelos glandulares microcapitados. Hojas enteras sin nectarios, lanoso-seríceas, indumento amarillo-rojizo, a veces glauco. Estípulas rudimentarias, con coléteres rojizos $0,1-0,6 \mathrm{~mm}$ long. Pecíolo 0-4 mm long. Lámina 13-50 x 8-24 $\mathrm{mm}$, relación largo:ancho $=1,3-3,2: 1 ;$ margen aserrado, grado de incisión de la hemilámina 12-37\%; envés lanoso, a veces glabrescente en hojas basales; 3-4 pares de venas laterales incurvas, prominentes en el envés, con pelos simples amarillentos; ángulo de divergencia $10-27^{\circ}$; venas terciarias a veces visibles, excurvas. Flores solitarias. Pedúnculo 3,5-13 $\mathrm{mm}$ long., soldado al pecíolo 2-4 $\mathrm{mm}$. Profilos 6-15 x 0,3-0,6 mm, opuestos en el ápice del pedúnculo, o desplazados hasta $3 \mathrm{~mm}$ hacia abajo. Pedicelo 1-6 mm long. Cáliz 7,5-11 


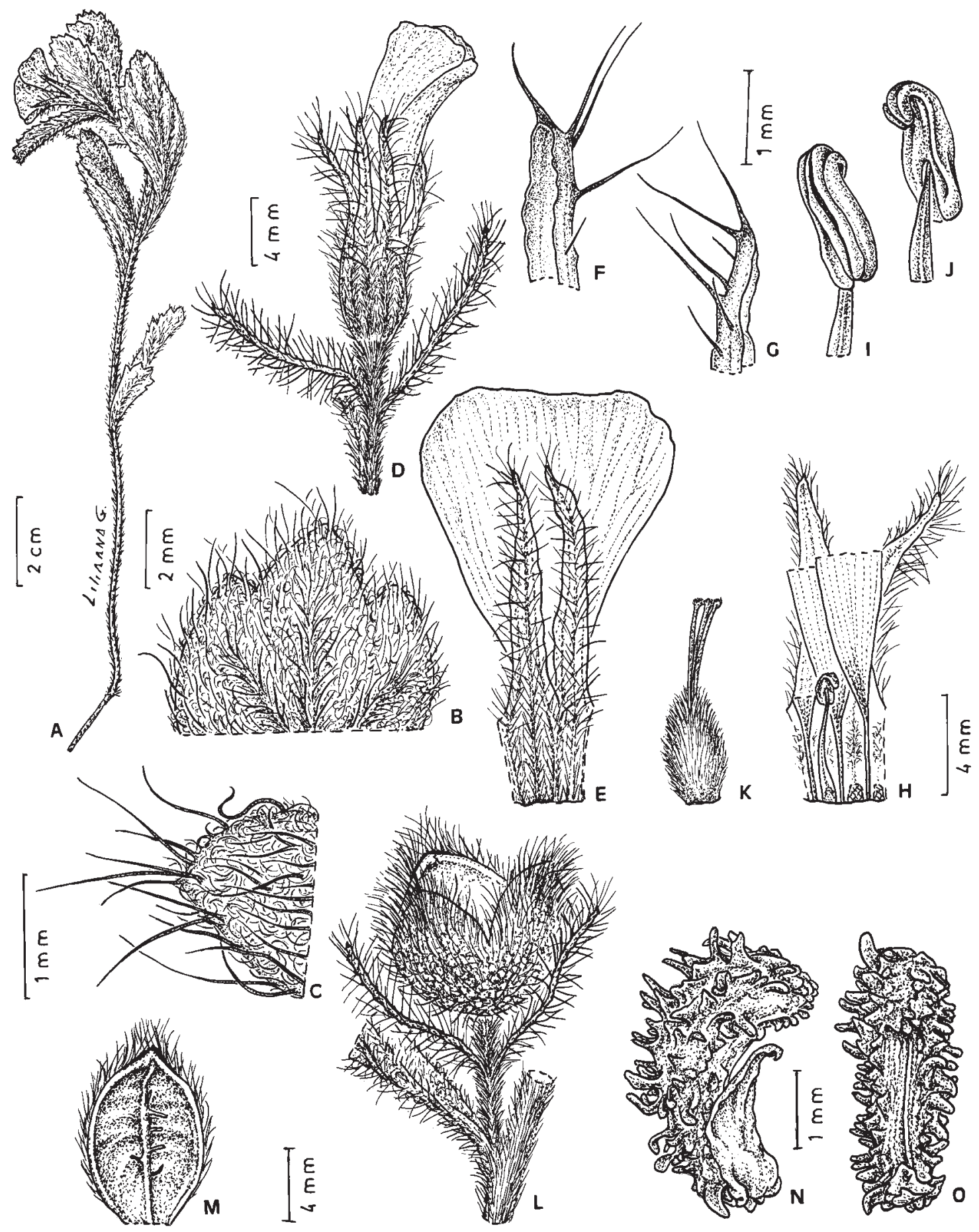

Fig. 73. Turnera sidoides subsp. holosericea. A: planta. B: porción apical de la hoja, cara abaxial. C: detalle del indumento. D: flor con profilos. E: porción del cáliz, cara externa y pétalo. F-G: ápice de los lóbulos del cáliz. H: flor longistila, porción del tubo calicino, cara interna, con pétalos y estambre adnatos, se han cuadriculado las cicatrices dejadas al desprender dos estambres. I-J: anteras, vistas ventral y dorsal. K: gineceo. L: base de una hoja florífera y fruto con profilos. M: valva del fruto, cara interna. N: semilla con arilo, vista lateral. O: semilla, vista rafeal (A-C: Pedersen 11435; D-O: Arbo \& Schinini 2495). 
mm long.; tubo calicino 1/3 o menos, 2-3 mm long., velloso en la cara interna; lóbulos emucronados, con abundantes pelos cortos crespos y pelos simples largos sobre las venas. Corola color rosado intenso o rojiza; pétalos 9-13 x 6-8,5 mm, base vellosa con mácula purpúrea, a veces con venas purpúreas. Filamentos estaminales glabros, soldados $0,5 \mathrm{~mm}$ al tubo calicino, 4-4,5 mm long. en flores longistilas, 5,5-6 $\mathrm{mm}$ long. en flores brevistilas; anteras 1,8-2 x 0,4-1 mm, base emarginada, ápice obtuso, filamento inserto dorsalmente a $0,5-0,6 \mathrm{~mm}$ de la base. Ovario densamente piloso, 1,5-2 mm long.; placentas 6-12-ovuladas; estilos glabros, rojizos, 3-4,5 $\mathrm{mm}$ long. en flores longistilas, 1,5-2 mm long. en flores brevistilas; estigma lobulado, 0,3-0,4 $\mathrm{mm}$ long. En flores longistilas el gineceo es 12,5 $\mathrm{mm}$ más largo que el androceo, y en flores brevistilas es 1-2,5 mm más corto. Fruto ovoide, 6-7 mm long., cara externa tuberculada, lanosa, cara interna glabra, lustrosa, irregular. Semilla 3 x 1-1,2 mm; exóstoma cónico; rafe linear, saliente, lado rafeal incurvo. Episperma crestado, crestas $0,2 \mathrm{~mm}$, epidermis con papilas filiformes. Arilo unilateral.

Cromosomas: $2 \mathrm{n}=4 \mathrm{x}=28$, Arbo \& Schinini $2461,2478,2513$ y 2525; $2 \mathrm{n}=6 \mathrm{x}=42$, Arbo \& Schinini 2492, 2494 y 2495, Solís Neffa \& al. 506 (Fernández, 1987; Solís Neffa \& Fernández, 2001). Cariotipo: Arbo \& Schinini 2495 (Solís Neffa \& Fernández 2002).

Material estudiado: BRASIL. Rio Grande do Sul: ca. 70 km E de São Gabriel, BR-290, 18-XII1981, Arbo \& Schinini 2461 (CTES); entre Porto Alegre y Encruzilhada, Gaudichaud 2946 (P, sintipo); desde Encruzilhada hasta Caçapava y el río Santa Bárbara, Gaudichaud 3043 (P, sintipo); Embrapa - UEPAE, former Faz. 5 Cruzes, $10 \mathrm{~km}$ SE of Bagé, 7-I-1981, Lindeman 6908 (U); Pedras Brancas, prope Porto Alegre, 8-X-1892, Malme 150 (S); Cachoeira do Sul, 18-II-1948, PalaciosCuezzo 1126 (LIL); mun. Pinheiro Machado, Coxhilho Pedras Altas, 11-XI-1976, Pedersen 11435 (C, CTES); Porto Alegre, Morro da Gloria, 12-XII-1945, Rambo 33141 (LIL); Camaqua, ruta a Porto Alegre, Km 111, 11-XI-1962, Rosengurtt \& Del Puerto 9184 (MVFA); Pelotas, Sacco \& Rambo 688 (F, HB, NY); sin localidad, Sellow
3034 (W); entre Porto Alegre y Encruzilhada, Sellow 2946 (P, sintipo); Rio Grande, Tweedie s.n. (K, sintipo). URUGUAY. Artigas: R.30, Km155, puente sobre el ayo. Catalancito, 30 37'52"S $56^{\circ} 22^{\prime} 45^{\prime \prime W}, 147$ m, 26-XI-2001, Solís Neffa \& al. 526 (CTES). Cerro Largo: $15 \mathrm{~km} \mathrm{~S}$ de Melo, ruta 8, camino a Treinta y Tres, 19-XII-1981, Arbo \& Schinini 2494 (CTES); Ruta 7, Km 285, entre Santa Clara del Olimar y Tupambaé, 32 54 '47"S 545'ㄷ' 'W, 1-XI-2005, Bonifacino \& al. 1785 (CTES); Camino a Sierra de Rios, próximo a escuela 115, 23-X-1991, Ziliani \& al. s.n. (MVFA). Florida: R.7, a 1m de la entrada a la Ea. La Palma, 333'ㄹ' $24^{\prime \prime S} 55^{\circ} 13^{\prime} 22^{\prime \prime} \mathrm{W}, 182 \mathrm{~m}, 30-\mathrm{XI}-2001$, Solís Neffa \& al. 541 (CTES). Paysandú: al O de Algorta, $32^{\circ} 25^{\prime} \mathrm{S} 57^{\circ} 28^{\prime} \mathrm{W}$, ayo.Negro y Cañada del Sarandizal, campo Schneider, vecino Est. Sta. Matilde, 6-XI-1991, Marchesi \& Armand-Ugon s.n. (MVFA); R.3, Km 417, ayo. Quebracho, 31 58'29"S 5751'00"W, 66 m, 4-XII-2001, Solís Neffa \& al. 557 (CTES). Rivera: R.30, Bajada de

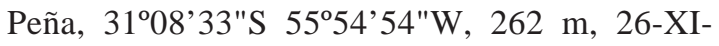
2001, Solís Neffa \& al. 527 (CTES). Tacuarembó: Valle Edén, 19-II-1947, Castellanos 17869 (LIL); camino a Paso del Medio, 3-XI1990, Marchesi \& Bayce 19978 (MVFA); Ruta 5,

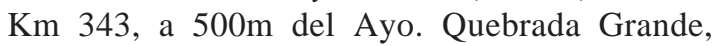
$32^{\circ} 05^{\prime} 41 \mathrm{~S} 56^{\circ} 06^{\prime} 23 \mathrm{~W}, 12-\mathrm{XII}-1997$, Solís Neffa \& al. 418 (CTES). Treinta y Tres: ca. $40 \mathrm{~km} \mathrm{~N} \mathrm{de}$ Treinta y Tres, ruta 8, 19-XII-1981, Arbo \& Schinini 2495 (C, CTES, K); 12 km NW de Treinta y Tres, Cuchilla de Los Ladrones, 19-II-2005, Dematteis \& Schinini 1632 (CTES); Ruta 8, Km 320-321, 20-X-1992, Izaguirre \& al. 21026B (MVFA); arroyo Parao, puente sobre ruta 8, 24XI-1968, Lema \& al. 7980 (MVFA).

Material cultivado. ARGENTINA, Corrientes, proc. de Brasil, Rio Grande do Sul, ca. $70 \mathrm{~km}$ E de São Gabriel, BR-290, 9-IX-1982, Arbo \& Schinini 2461 (CTES); proc. de Brasil, Rio Grande do Sul, $27 \mathrm{~km} \mathrm{~S}$ de Caçapava do Sul, camino a Baje, 4-XI-1983, Arbo \& Schinini 2478 (CTES); proc. de Uruguay, Tacuarembó, $43 \mathrm{~km} \mathrm{SSW} \mathrm{de}$ Tacuarembó, ruta 5, arroyo Quebrada Chica, 28III-1983, Arbo \& Schinini 2513 (CTES); proc. de Uruguay, Artigas, $6 \mathrm{~km}$ SE de Arroyo Catalán Grande, 64 km SW de Artigas, ruta 30, 6-IX-1982, Arbo \& Schinini 2525 (CTES); proc. De Uruguay, dep. Cerro Largo, $15 \mathrm{~km} \mathrm{~S}$ de Melo, R.8, 1-XI1982, Arbo \& Schinini 2494(CTES). 
Distribución: Esta subespecie es exclusiva de Rio Grande do Sul (Brasil) y Uruguay. Vive en serranías, en terreno pedregoso, la elevación máxima registrada es de $262 \mathrm{~m}$. Los ejemplares conocidos han sido colectados entre octubre y marzo.

Obs.: Entre las flores estudiadas de la subsp. holosericea, $43 \%$ son heterostilas y $57 \%$ poseen androceo y gineceo de igual longitud o con anteras y estigmas en contacto.

En Solís Neffa \& al. 418 y Pedersen 11435 algunas plantas son intermedias con la subsp. carnea, tienen el indumento más laxo.

\section{1d. Turnera sidoides subsp. integrifolia (Griseb.) Arbo}

Figs. 21 y 72

Turnera setosa Sm. var. integrifolia Griseb., Symb. F1. Arg.: 138. 1879; Arbo, Candollea 40: 188. 1985; Turnera sidoides L. var. grisebachiana Urb., Jahrb. Konigl. Bot. Gart. Berlin 2: 102. 1883; Urban, en Martius C.F.P., Fl. Bras. 13(3): 125. 1883. Lectotypus: Argentina. Entre Rios, Concepción del Uruguay, X-1857, Lorentz 257 (GOET!).

Turnera grisebachiana Urb. ex Herter G., Fl. Il. Uruguay 14, Lám. 2226. 1957. Nomen.

Hierba de 4-31 cm (en plantas cultivadas, ramas decumbentes hasta de $55 \mathrm{~cm}$ long.), base de 2,5-4 mm diám.; tallos 1 o varios de 0,6-2 mm diám., raramente ramificados; entrenudos de 7-44 mm long., pelos simples unicelulares de 1-3,2 mm long. y pelos simples más cortos también erguidos. Hojas herbáceas, aserradas, sin nectarios. Estípulas ausentes o rudimentarias, con coléteres $0,3 \mathrm{~mm}$ long. Pecíolo 0-6 $\mathrm{mm}$ long. Lámina suborbicular u obovada en hojas basales, luego elíptica, ovada o romboidal, 13-50(-72) x 6-28(-32) mm, relación largo:ancho $=1-3: 1$; grado de incisión de la hemilámina $8-40 \%$; haz punteada, con pelos simples, 1,5-2,5 mm long. de base abultada, dispuestos sin orientación definida; envés arenáceo, a veces casi glabro, con pelos largos especialmente sobre las venas y a veces pelos cortos entre las mis- mas y pelos glandulares microcapitados; 4-5 pares de venas laterales prominentes, a veces decurrentes; ángulo de divergencia 20-35 . Flores rosadas, salmón, lila o fucsia. Pedúnculo 3-21 mm long., soldado parcialmente al pecíolo (1-6 mm), con pelos hirsutos. Profilos 8-13(-19) x 0,3-1 mm, insertos en el ápice del pedúnculo, indumento como el de las hojas. Pedicelo 1-5 mm long., con pelos hirsutos y pelos cortos crespos. Cáliz 6-12 mm long.; tubo calicino $1 / 3$ o $1 / 4$ de su longitud, 2-3 mm long., velloso por dentro especialmente en la garganta, cara externa con pelos 1,7-3 mm long., curvados, dispuestos especialmente sobre las venas, orientados en todas direcciones, y pelos cortos; lóbulos con márgenes internos membranáceos y ápice mucronulado (0,3-0,6 $\mathrm{mm})$. Corola más larga que el cáliz; pétalos de 10-18 x 6-15 mm, uña y base de la lámina vellosa, con mácula basal purpúrea. Filamentos estaminales pilosos en la cara externa, de 3,5-5,5 mm long. en flores longistilas, 6,5-8 $\mathrm{mm}$ long. en flores brevistilas; anteras de 1-2 x 0,5-1 mm, base emarginada, ápice obtuso recurso a la dehiscencia, filamento inserto dorsalmente a $0,5-0,8 \mathrm{~mm}$ de la base. Ovario hirsuto, 1,5-2 mm long.; placentas 7-12ovuladas; estilos cilíndricos, rojizos, glabros, 3,5-6 mm long. en flores longistilas, 1,7-3,5 $\mathrm{mm}$ long. en flores brevistilas; estigma lobulado a penicilado, 12-24 ramas 0,4-1 mm long. En flores longistilas el gineceo es 1-3,5 mm más largo que el androceo, y en flores brevistilas, 1,5-4,5 mm más corto. Fruto ovoide, 6,5-10 mm long., tuberculado, con un reborde formado por la base del tubo floral. Semilla curvada, 3,5-4,5 x 0.9-1,5 mm; exóstoma prominente, limitado por crestas; rafe linear saliente, lado rafeal incurvo; cálaza redondeada. Episperma crestado, crestas irregulars, longitudinales y transversales de 0,3-0,6 mm, epidermis con papilas filiformes. Arilo 1,5-2 mm long., de células lisas.

Cromosomas: $2 \mathrm{n}=2 \mathrm{x}=14$, Arbo $385 ; 2 \mathrm{n}=4 \mathrm{x}=28$, Arbo \& Schinini 2418 y 2506, Arbo \& Tressens 2562bis, Solís Neffa \& al. 310 y 456; 2n=6x=42, Arbo \& Schinini 2421, y 2487; $2 \mathrm{n}=8 \mathrm{x}=56$, Arbo \& Schinini 2419 (Fernández, 1987; Solís Neffa \& Fernández, 2001). Cariotipo: Arbo \& Schinini 2418 (Solís Neffa \& Fernández, 2002). 
Material escogido: PARAGUAY. Alto Paraná: 4-5 km NE de Hernandarias, Reserva Biológica Tati Yupi, 543' $\mathrm{W} 24^{\circ} 22^{\prime}$ 'S, 13-X1990, Schinini \& Caballero Marmori 27279 (CTES, K). Misiones: $12 \mathrm{~km}$ W de San Ignacio, camino a Pilar, 15-XI-1978, Arbo \& al. 1804 (CTES). ARGENTINA. Corrientes: dep. Paso de los Libres, Estancia El Recreo, $21 \mathrm{~km} \mathrm{E} \mathrm{de}$ Bonpland, costa del rio Uruguay, 12-XI-1980, Ahumada \& Schinini 3992 (CTES); Dep. Concepción, Tabay, 8-X-1972, Arbo 385 (CTES); Dep. San Miguel, $21 \mathrm{~km} \mathrm{~S}$ de Loreto, 7-III-1974, Arbo 514 (MBM); Estancia Caaguazú, $11 \mathrm{~km} \mathrm{NE} \mathrm{de}$ Chavarría, camino a Tacuaritas, aprox. $2 \mathrm{~km}$ al N del casco, 22-X-1996, Arbo \& al. 6704 (CTES); Estancia Tranquera de Hierro, $66 \mathrm{~km}$ al NE de Chavarría, camino a Concepción; ca. $8 \mathrm{~km}$ al E de la ruta, aprox. 2835'S 5804-05'W, 3-XII-1996, Arbo \& al. 6974 (CTES); Paso de los Libres, Laguna Mansa, 17-XII-198, Arbo \& Schinini 2418 (CTES); SE de Saladas, pasando el arroyo Santa Lucía, 14-X-1983, Beck s.n. (LPB); dep. San Miguel, R.117, 24 km S de R.12, Cnia. San Antonio, 23-X-1979, Carnevali 4069 (CTES); P.N.Mburucuyá, 9-X-2004, Dematteis \& al. 1320 (CTES); Dep. Mercedes, Arroyo Medina, camino desde ruta 23 a San Roquito, 5-I-1975, Irigoyen \& Schinini 173 (CTES); Dep. Mburucuyá, 10 km W de Mburucuyá, 29-X-1967, Krapovickas \& Cristóbal 13260 (CTES); Dep. Concepción, entre Santa Rosa y Rio Santa Lucia, 5-II-1968, Krapovickas \& Cristóbal 13776 (CTES); Dep. Monte Caseros, La Cachuera, 21-IV-1952, Nicora 6183 (SI); dep. Concepción, Colonia Tatacuá, Ea. San Francisco, 21-X-1993, Nuñez 1209 (CTES); Estancia Santa Teresa, dep. Mburucuyá, 2-IV-1947, Pedersen 17 (US); Dep. Concepción, Estancia Santa Rosalía, 4I-1955, Pedersen 3106 (C, CTES); dep. Paso de los Libres, pr. Bonpland, ca. Tres Cerros, 20-XI1990, Pedersen s.n. (CTES); Capital, Riachuelo, 15-II-1996, Schinini 30432 (CTES); Dep. Saladas, San Lorenzo, rio San Lorenzo, 20-IV-1973, Schinini \& al. 6326 (CTES); Dep. Concepción, 28 km SE de Concepción, Estancia El Tránsito, 20-V1976, Schinini \& al. 13056 (CTES); Dep. Monte Caseros, Km 173, Campo Gral. Avalos, Arroyo Curupí, 21-II-1979, Schinini \& al. 17539 (CTES); dep. Ituzaingó, Villa Olivari, 22-XI-1993, Schinini \& al. 28348 (CTES). Entre Ríos: Villaguay, II1918, Baez 188 (BA); Dep. Colón, Palmar, 2-XII1941, Biraben 5060 (LP); Dep. Colón, Colón, 15-
XII-1963, Burkart 24857 (CTES, SI); Dep. Colón, Ubajay, Estancia Los Monigotes, 13-X-1968, Cabrera \& al. 19319 (LP); Dep. Concordia, Yeruá, 10-X-1950, Hunziker 4441 (BAB); camino de Chajarí a Gualeguaychú, I-1945, Job 218 (LP); Dep. Concordia, Yuquerí Grande, 2-XI-1949, Job s.n. (LP); Concepción del Uruguay, X-1875, Lorentz 959 (GOET, sintipo); Rio Molino, 25-XI1946, Meyer 10501 (LIL); Dep. Federación, Santa Ana, 20-X-1984, Muñoz 2052 (Herb. Muñoz); Dep. Concordia, Concordia, Spegazzini s.n. (BAB, CTES). BRASIL. Rio Grande do Sul: $6 \mathrm{~km}$ E de Uruguayana, BR-290 camino a Alegrete, 17-XII1981, Arbo \& Schinini 2419 (CTES); Arroyo Capivarí, 14 km W de Alegrete, 26-X-1982, Arbo \& Schinini 2421 (CTES); Mun. São Gabriel, some $20 \mathrm{~km}$ E of Rosario do Sul, on road to Porto Alegre, 9-XI-1976, Pedersen 11402 (C, CTES); sin datos, Tweedie s.n. (K). URUGUAY. Artigas: Tomas Gomensoro, 16-I-1971, Marchesi 101230 (MVFA); R.30, Km 30, ayo. Yacutiya Miní, $30^{\circ} 28^{\prime} 53^{\prime \prime S ~} 57^{\circ} 20^{\prime} 53^{\prime \prime} \mathrm{W}, 89$ m, 25-XI-2001, Solís Neffa \& al. 522 (CTES). Durazno: Ruta 5, Km 196, 33¹6’26S 56²9'12W, 12-XII-1997, Solís Neffa \& al. 410 (CTES). Florida: Estancia Rincón de Sta. Elena, Picada Castro, Arroyo Mansavillagra, XI-1946, Rosengurtt Gallinal 5809 (BR, MVFA, S). Rio Negro: R.3, Km 283, 17-II-1959, Carambula 2688 (MVFA). Rivera: Cerro Chato Dorado, Ruta 29, Km 15-16, $31^{\circ} 03$ '59S 5527'27'W, 12-XII-1997, Solís Neffa 483 (CTES); R.29, Km 10, ayo.Capivari, 3131'52"S 55³5'07"W, 151 m,4-XII-2001, Solís Neffa \& al. 560 (CTES). Salto: rio Arapey y Ayo. Valentín, 28-I-1937, B 982 (MVFA); Salto, 17-I-1931, Castellanos s.n. (BA); Ayo. Espinillar, 29-XI-1975, Del Puerto 12657 (MVFA); área a inundar por Represa Salto Grande entre Ayo. Espinillar y Rio Arapey, 2226-XI-1977, Del Puerto 14554 (MVFA); Ayo. Ceibal, entre ruta 3 y rio Uruguay, 29-X-1978, Del Puerto \& Marchesi 15923 (MVFA); 4 km de bifurc. Est. Sta. Ana hacia B. Brum (camino Termas), 19-X-1961, Millot 516 (MVFA); Termas del Arapey, 15-I-1967, Rosengurtt \& al. 10552 (MVFA). Soriano: Santa Elena, X-1892, Aplin s.n. p.p. (BM); Juan Jackson, MonzónHeber, XII-1937, Gallinal \& al. PE-650 (MO, MVFA, US). Tacuarembó: La California, Tac. Chico, 31-I-1962, Millot \& Del Puerto 1112 (MVFA); Valle Edén, 20-XII-1996, Solís Neffa 
\& al. 399 (CTES); R.26, 3202'12"S $55^{\circ} 21^{\prime} 49^{\prime \prime} \mathrm{W}, 138$ m, 28-XI-2001, Solís Neffa \& al. 534 (CTES).

Ejemplares cultivados: ARGENTINA. Corrientes: proc. de Paso de los Libres, Laguna Mansa, 23-II-1983, Arbo \& Schinini 2418bis (CTES, K); proc. de Brasil, RGS, BR-153, camino a Baje, 18-XII-1982, Arbo \& Schinini 2487 (CTES); proc. de Concepción, R.17, 5 km NE de Tabay, 2-XI-1984, Arbo \& Tressens 2562bis (CTES); proc. de Concepción, ruta 117, Km 54, 27-XI-2003, Solís Neffa \& Seijo 973 (CTES); proc. de Concepción, Tabay, $5 \mathrm{~km}$ NO de Tabay, 27-XI-2003, Solís Neffa \& Seijo 974 (CTES); proc. de Concepción, ruta 117, Km 54, 28-XI-2003, Solís Neffa \& Seijo 979 (CTES).

Distribución y fenología: Habita en el S de Paraguay, Brasil (Rio Grande do Sul), Argentina (Corrientes y Entre Ríos) y en Uruguay. Vegeta en praderas y campos altos con Butia yatay o isletas de bosque higrófilo, en tierra colorada, suelo arenoso o pedregoso. La altitud máxima registrada es de $217 \mathrm{~m}$. Se adapta a lugares modificados como bordes de caminos y céspedes urbanos. Florece desde septiembre a mayo. 17).

Nombre vulgar: «lamacelita» (Pedersen

Obs.: Todas las flores estudiadas fueron heterostilas. En Job s.n. (Yuquerí Grande) se observó una flor con 4 estambres largos y uno corto; en Ahumada 3992 se encontró una flor con 6 pétalos, 6 estambres y 4 estilos.

En los siguientes ejemplares, el indumento y la incisión foliar son intermedios entre las subespecies carnea e integrifolia:

URUGUAY. Rivera: Ea. El Miriñaque, Ruta

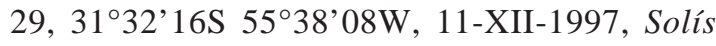
Neffa \& al. 424 (CTES). Salto: Salto, 9-III1994, Izaguirre \& al. 23120 (MVFA). San José: Sierra Mahoma, 21-X-1966, Izaguirre \& al. 2611 (MVFA); íd., 27-X-1963, Marchesi 517 (MVFA). Tacuarembó: Ruta 5, Km 257, $32^{\circ} 45^{\prime} 09 \mathrm{~S} 56^{\circ} 30^{\prime} 05 \mathrm{~W}, 11-\mathrm{XII}-1997$, Solís Neffa \& al. 414 (CTES). 131e. Turnera sidoides subsp. pinnatifida (Juss. ex Poir.) Arbo

Figs. 10 y 74

Turnera pinnatifida Juss. ex Poir., en Lam., Encycl. 8: 144, 1808; Arbo, Candollea 40: 189. 1985. Typus: Uruguay. Montevideo, Commerson s.n. (holotypus P-JU 13574!, isotypi C!, F!, P!)

Turnera pinnatifida Juss. ex Poir. var. $\beta$ en Lam., Encycl. 8: 144, 1808; Arbo, Candollea 40: 189. 1985. Typus: Uruguay. Montevideo, Commerson s.n. (holotypus P-JU 13574, planta superior!).

Turnera setosa Sm. in Rees, Cyclop. 26(2). 1817. Lectotypus: Uruguay. Montevideo, Commerson s.n., Herb. Smith 540-3 (LINN!), posible isotipo de T. pinnatifida var. $\beta$ (Arbo, 1985).

Turnera pinnatifida Juss. ex Poir. var. angustiloba DC., Prodr. 3: 347. 1828. Turnera sidoides L. var. angustiloba (DC.) Urb., Jahrb. Königl.Bot.Gart.Berlin 2: 102. 1883; Urban, en Martius C.F.P., Fl. Bras. 13(3): 124. 1883. Typus: Uruguay. Montevideo, [Commerson?], (holotypus G-DC microficha 552!).

Turnera pinnatifida Juss. ex Poir. var. lycopifolia DC., Prodr. 3: 347. 1828; Turnera sidoides L. var. lycopifolia (DC.) Urb., Jahrb. Königl. Bot. Gart. Berlin 2: 102. 1883; Urban, en Martius C.F.P., Fl. Bras. 13(3): 126. 1883. Typus: Argentina. Buenos Aires, [Commerson?], (holotypus G-DC microficha $552 !)$.

Turnera setosa Sm. var. entreriana Griseb., Symb.fl.arg.: 138. 1879. Typus: Argentina. Entre Rios: Concepción del Uruguay, X-1875, Lorentz 960 (holotypus GOET!).

Turnera sidoides L. var. incisa Urb., Jahrb. Königl.Bot.Gart.Berlin 2: 102. 1883, en parte.

Turnera pinnatifida Juss. var. $\beta$ angustifolia DC., error en Gibert J. E., Enum. Pl. Agro Montev.: 80. 1873.

Turnera sidodes L., error en Kuntze, Rev. Gen. Pl.: 101. 1898.

Turnera sidoides L. var. lycopodifolia Urb., error en Arechavaleta, Fl. Uruguaya 2: 120. 1898.

Hierba perenne hemicriptófita, con raíces gemíferas, 5-37 cm alt., simple a muy ramificada; base hasta $1 \mathrm{~cm}$ diám.; tallos cilíndricos, 1-2 mm diám., glabrescentes en la por- 


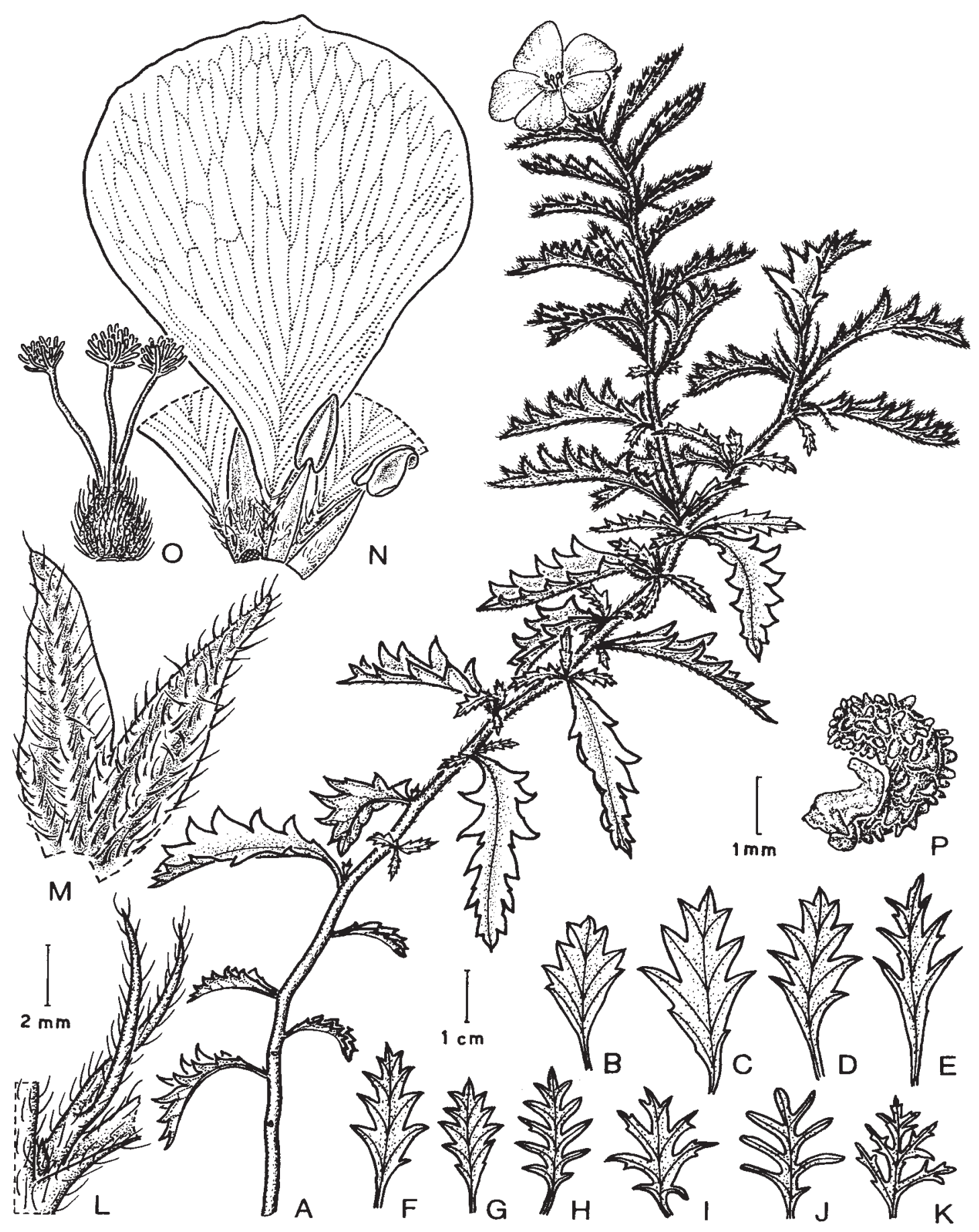

Fig. 74. Turnera sidoides subsp. pinnatifida. A: planta. B-K: hojas, cara adaxial. L: inserción de hoja florífera, pedúnculo con profilos y yema axilar; nótese la porción apical libre del pedúnculo. M: porción del cáliz, cara externa. $\mathrm{N}$ : flor longistila, porción del tubo calicino, cara interna, con pétalos y estambres adnatos; se ha cuadriculado la cicatriz dejada al desprender un estambre. O: gineceo. P: semilla con arilo, vista lateral (A, F, P: Arbo 2411; B, D: Krapovickas 28592; C: Ahumada 3793; E: Ahumada 3911; G: Ibarrola 2496; H: Cristóbal 1953; I: Schinini 21648; J: Ahumada 1340; K: Krapovickas 27757; L-O: Krapovickas 24476). Dels. Víctor Maruñak y Ricardo Vispo. 
ción basal, luego con pelos simples, largos, antrorsos y pelos cortos, crespos; entrenudos 6-25 mm long. Yemas axilares seriales 1-3, a veces ramas seriales desarrolladas. Hojas herbáceas, sin nectarios. Estípulas ausentes o rudimentarias, con coléteres cónicos 0,1-0,4 mm long. Pecíolo 0,5-8 $\mathrm{mm}$ long., indumento como el del tallo. Lámina pinnatifida a pinnatisecta, $12-58 \times 6-28 \mathrm{~mm}$, relación largo:ancho $=1,2-5,1: 1$, grado de incisión de la hemilámina $37-95 \%$, 2-6 lóbulos a cada lado, lanceolados, triangulares o subulados, con pelos largos, adpresos de base cónica y a veces pelos cortos erectos; 3-4 pares de venas laterales excurvas, prominentes en el envés; ángulo de divergencia $15-35^{\circ}$; venación menor inconspicua. Flores solitarias, heterostilas. Pedúnculo 2,5-11 mm long., soldado 0-8 $\mathrm{mm}$ al pecíolo, indumento como el del tallo. Pedicelo cilíndrico 1-4 mm long. Profilos 2, subulados, 6-12 x 0,3-0,6 mm, insertos en la articulación pedúnculo-pedicelo, indumento como el de las hojas. Cáliz 6-12 mm long.; tubo calicino $1 / 4-1 / 3$, de 1,5-3,5 mm long., por dentro velloso en la garganta, por fuera con pelos simples largos, antrorsos, 1-2 $\mathrm{mm}$ long., especialmente sobre las venas, $\mathrm{y}$ pelos muy cortos erectos; lóbulos triangulares, trinervados, por dentro glabros, por fuera indumento como en el tubo calicino, márgenes membranáceos, ápice agudo, mucrón 00,6 mm. Corola amarilla, rosa pálido, salmón, rosado-lila o anaranjado-rojiza; pétalos unguiculados, uña pilosa, lámina obovada, 1018 x 6-14 mm. Filamentos estaminales subulados, 3-5 mm long. en flores longistilas, 6-8 mm long. en flores brevistilas, con pelos simples; anteras ovadas, 1,2-2,2 x 0,5-1,2 mm, base emarginada, ápice obtuso, filamento inserto dorsalmente a $0,4-0,7 \mathrm{~mm}$ de la base. Ovario ovoide, 1,5-2 mm long., hirsuto; placentas 8-14 ovuladas; estilos cilíndricos, rosados, glabros, 4-6 $\mathrm{mm}$ long. en flores longistilas, 1,5-2 $\mathrm{mm}$ long. en flores brevistilas; estigmas lobulados a multífidos, numerosas ramas 0,4-1,1 mm long., amarillas. Diferencia en longitud entre androceo y gineceo 1-5 mm. Fruto ovoide, 4,5-11 mm long., cara externa tuberculada, pelos largos entremezclados con pelos cortos y crespos, cara interna lustrosa, amarillenta, lisa o impreso- reticulada. Semilla negruzca, virguliforme, 34,2 x 0,8-1,3 mm; exóstoma cónico; rafe linear, lado rafeal incurvo; cálaza redondeada. Episperma con crestas longitudinales, a veces transversales. Arilo 1,2-2 mm long., unilateral, de células lisas.

Cromosomas: $2 \mathrm{n}=2 \mathrm{x}=14$, Krapovickas \& Cristóbal 46241 (Solís Neffa \& Fernández, 2002); Solís Neffa \& al. 500 (Solís Neffa \& Fernández, 2001); $2 \mathrm{n}=4 \mathrm{x}=28$, Arbo 2697 y 2729, Arbo 2411, Schinini 21648 y 29142, Solís Neffa 22 y 486, Solís Neffa \& al. s.n., 44, 307, 309, 316, 356 y 384 (Fernández, 1987; Solís Neffa \& Fernández, 2001 y 2002); $2 \mathrm{n}=6 \mathrm{x}=42$, Aguirre 454, Solís Neffa 388, Solís Neffa \& al. 311 (Solís Neffa \& Fernández, 2001 y 2002). Cariotipos en Solís Neffa \& Fernández, 2002.

Material estudiado: BOLIVIA. Chuquisaca. Oropeza, Sucre, $1 \mathrm{~km}$ del barrio de Santo Domingo bajando hacia el rio Quirpinchaca, 1902'21"S 6516’26"W, 2744 m, 1-IV-2003, Huaylla 1181 (CTES); prov. Azero, Est. Exp. Zootecn. «El Salvador», $26 \mathrm{~km} \mathrm{NW}$ de Carandaytí, 2045'S $63^{\circ} 13^{\prime} \mathrm{W}$, ca. $500 \mathrm{~m}, 13-\mathrm{IV}-1977$, Krapovickas \& Schinini 31265 (CTES); sin localidad, II, Orbigny 1253 (P); Zudanez, a 85 km SE de Sucre rumbo a Padilla, desvío hacia la comunidad Sarupay, 1904'36"S 6448’23"W, 2638 m, 3-II-2004, Solís Neffa \& al. 1405 (CTES); Camino desde Boyuibe a Fortín Villazón, a 2,9 km E de Boyuibe, $20^{\circ} 27^{\prime} 29^{\prime \prime S ~} 63^{\circ} 15^{\prime} 24 " \mathrm{~W}, 874$ m, 11-II- 2005, Solís Neffa \& al. 1938 (CTES); prov.Azero, camino de Boyuibe a Fortín Villazón, a 20,2 km E de Boyuibe, $20^{\circ} 26^{\prime} 41^{\prime \prime S} 62^{\circ} 44^{\prime} 36^{\prime \prime} \mathrm{W}, 520 \mathrm{~m}, 11-\mathrm{II}-$ 2005, Solís Neffa \& al. 1962 (CTES); prov. Tomina, Corso, a $8 \mathrm{~km}$ de Tomina, $2000 \mathrm{~m}, 10$ XII-1993, Terán s.n. (BM, LPB); ca. 2 km from Sucre towards Tarabuco, $19^{\circ} 10^{\prime} \mathrm{S} 64^{\circ} 57^{\prime} \mathrm{W}, 2800$ m, 19-XII-1993, Wood 7719 (K, LPB). Cochabamba: Siaco, a 73 km, 2720 m, 19-XII1959, 123 (US); Campero, a 8 km de Peña Colorada hacia Pasorapa, $18^{\circ} 20^{\prime} \mathrm{S} 65^{\circ} 00^{\prime} \mathrm{W}, 1820 \mathrm{~m}, 14-$ II-1999, Antezana 1012 (CTES); Cochabamba, ca.

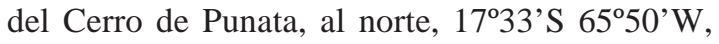
2700 m, XII-1947, Cardenas 4074 (CORD, US); prov. Tirquipina, alred. de Cochabamba, 17-III2003, Schinini \& al. 36428 (CTES); prov. Mizque, Canton Molinero, Mizquepampa, 2800 m, 1-XII1986, Sigle 169 (CTES); Carrasco, 100 km W de 
Comarapa, 1744'32"S 64'51'41"W, 2295 m, 2II-2004, Solís Neffa \& al. 1363 (CTES). Santa Cruz: Florida, camino viejo de Santa Cruz a Cochabamba, aprox. a $5 \mathrm{~km} \mathrm{~W}$ de Samaipata, 1809'43"S 6354'52"W, 1359 m, 30-I-2004, Solís Neffa \& al. 1327 (CTES); Caballero, 2 km de Comarapa, camino a Cochabamba, $18^{\circ} 01^{\circ} 03^{\prime \prime S}$ 64³2’50"W, 1964 m, 31-I-2004, Solís Neffa \& al. 1355 (CTES). Tarija: prov. Méndez, Tomatas grande, campo experimental, ca. $1950 \mathrm{~m}$, 8-XII1985, Bastian 67 (CTES); prov. Cercado, Tarija 29 km hacia Palos Blancos, 2350 m, 14-XI-1993, Beck \& al. 22165 (LPB); dep.Gran Chaco, 14 km E del camino de Villa Montes a Paraguay, 21ำ17'32"S 6320'55"W, 374 m, 17-I-2004, Solís Neffa \& al. 1025 (CTES); a 95,9 km E de Villa Montes y $26,9 \mathrm{~km}$ E de Ibibobo rumbo a Paraguay, 213' 13"S 6245'03"W, 317 m, 12-I-2005, Solís Neffa \& al. 1510 (CTES); desvío hacia el E del camino Camiri-Boyuibe (1 $\mathrm{km} \mathrm{N}$ del río Machareti) rumbo a Carandaity, $27,5 \mathrm{~km} \mathrm{E}$ del cruce, $20^{\circ} 45^{\prime} 46^{\prime \prime S} 63^{\circ} 07^{\prime} 55^{\prime \prime} \mathrm{W}, 675 \mathrm{~m}, 12-\mathrm{II}-$ 2005, Solís Neffa \& al. 1968 (CTES); Gran Chaco, camino a Saladillo, $9 \mathrm{~km} \mathrm{~N}$ de Carapari, 214'07"S 6343'43"W, 591 m, 2-IV-2004, Solís Neffa \& Seijo 1481 (CTES); Arce, ca. $5 \mathrm{~km} \mathrm{~N}$ of Padcaya on road to Tarija, $21^{\circ} 53^{\prime}$ 'S $64^{\circ} 43^{\prime} \mathrm{W}, 2200$ m, 20-I-2000, Wood \& Goyder 15813 (K, LPB); alrededores de Tarija, ca. 1700 m, 17-II-1929, Zelada s.n. (LIL). PARAGUAY. Boquerón: 7 km S de Filadelfia, 7-XII-1992, Krapovickas \& Cristóbal 44236 (CTES); Campo Aroma, Km 10 NO, 22-X-1992, Mereles \& Degen 4833 (FCQ). ARGENTINA. Buenos Aires: entre Bahía Blanca y San Blas, X/XI-1903, Ameghino s.n. (BA); alrededores de La Plata, City Bell, 4-XI-1922, Cabrera 2458 (LP, R); Gral. Pintos, Media Luna, 20-I1925, Castellanos s.n. (BA); Sierra Baya, Boca del Diablo, 10-XI-1924, Castellanos s.n. (BA); El Toro, Rosas F.C.S., 27-XI-1925, Daguerre 218 (BA); El Hinojo, 2-XII-1917, Estrada s.n. (BAB); G.E.Hudson R.R.Station, ca. halfway between La Plata and Buenos Aires, 3-XII-1938, Eyerdam \& Beetle 23151 (K); Saavedra, Sa. de Currumalán, 25-III-1918, Hauman s.n. (BA); Punta Chica a San Isidro, 2-XII-1900, Hicken s.n. (SI); Ituzaingó, 7I-1914, Holmberg 116 (MO); Campana, 28-X1945, Hunziker 1041 (CORD); pdo. Carlos Casares, Carlos Casares, R.5, 30-X-1972, Krapovickas \& al. 22297 (CTES); Nacurutu, in delta flum. Parana, 1895, Kullberg s.n. (P); Macedo, XI-1926,
Link s.n. (BA); Tandilewir, 27-II-1882, Lorentz s.n. (CORD); partido Luján, Molfino s.n. (BAF); pdo. Balcarce, Ea. El Volcán, 27-I-1960, Nicora 6927 (BAA, CTES); Médano, 16-XI-1944, O’Donnell 1484 (P, W); Tandil: Los Leones, 22XI-1937, Pastore 1191 (F, K, SI); Otamendi, 26X-1928, Pérez Moreau s.n. (BA); partido Tres Arroyos, S.Fr. de Bellocq, Esc.Agr.Elemental, 15 $\mathrm{m}, 26-\mathrm{XI}-1953$, Petersen \& Hjerting 1815 (C); Azul, XII-1908/I-1909, Puyssegur s.n. (CORD); Gral. Villegas, XII-1944, Schulz 4051 (CTES); Bahia Blanca, campus depto. Agronomía, 24-II1994, Solís Neffa 22 (CTES); Cnel. de Marina Leonardo Rosales, Punta Alta, 26-II-1945, Soriano 1587 (CTES); pdo. Cnel. Suárez, Cura-Malal, 15-XII-1899, Spegazzini 37 (BAB, CTES); Pdo. Tornquist, alrededores Sierra de la Ventana, 27XI-1962, Tell s.n. (CTES, LP); Buenos Aires, 1837, Tweedie s.n. (K, SI); Mar del Plata, Sierra La Peregrina, 7-XII- 1924, Valentini 222 (SI). Catamarca: 7 km de El Rodeo, 1800 m, 12-XII1949, Araque \& al. 620 (LIL); dep. La Paz, El Quebracho, 7-XII-1946, Brizuela 370 (BR, LIL, MO, P, R); La Brea, 14-I-1950, Brizuela 462 (CTES, LIL); Las Tejas, 8-II-1947, Brizuela 822 (LIL); El Suncho, 26-XII-1915, Jörgensen 1615 (BA, BAF, F, MO, SI, US); Sierra del Alto, Abra de los Guayacanes, 28-I-1944, Castellanos s.n. (BA); Pomancillo, 12-I-1940, Castellanos s.n. (BA); Dep. Andalgala, Ea. Las Rosas, 1700 m, 30XI-1948, Filipovich 54 (LIL); Capital: Choya, 11II-1974, Guaglianone \& Ulibarri 843 (SI); dep. Ambato, Cumbres de Narváez (Falda O): dep. La Paz: entre San Antonio de La Paz e Icaño, 25-III1964, Hunziker \& Cocucci 17162 (CORD); Dep. Ancasti, Sa. de Ancasti, Falda E, a 9 km al S de El Alto, Dique de Coyogasta, ca. 770 m, 27-III-1964, Hunziker \& Cocucci 17264 (CORD); Dep. Paclin, pasando rio Huacra $3 \mathrm{~km}$ más o menos, 16-XII1963, Legname \& al. 4293 (C, LIL); camino de Alijilan a El Alto, próximo a El Alto, 17-XI-1972, Menéndez Sevillano \& al. 9357 (C, LIL); camino del Durazno al Dique Sumampa, 14-XI-1972, Menéndez Sevillano \& al. 9419 (C, LIL); Dep. Capital, Valle de Catamarca, 600 m, II-1941, Parodi 13973 (LP); Capayan, Los Angeles, Villa Santo Domingo (Los Morteros), 11-I-1947, Risso 835 (R); Dep. Ambato, La Rinconada, 9 km S de Los Varela, Sierra de Graciana, 1150-1250 m, 27III-1995, Saravia Toledo \& al. 12856 (CTES); Dep.Ambato, La Puerta, 900 m, 29-III-1995, 
Saravia Toledo \& al. 13047 (CTES). Chaco: Pdo. $1^{\circ}$ de mayo: Margarita Belén, 16-II-1945, Aguilar 325 (BM, NY); Pdo. Mayor L. J. Fontana: Villa Angela, II-1940, Boffa 1006 (LP); dep. Presidencia de la Plaza, $32,5 \mathrm{~km}$ O de Col. Unidas, Bordón s.n. (CTES); O’Higgins, 8,5 km ONO La Tigra, 9X-1972, Bordón s.n. (CTES); Maipú, 5 km SO Tres Isletas, 25-X-1972, Bordón s.n. (CTES); Pdo. Comandante Fernández: Las Cuchillas (Cnia. J. Mármol), 15-I-1947, Buratovich 712 (LIL); Pdo. 25 de mayo: Tres Palmas, 16-III- 1973, Caplán 27 (CTES); dep. Bermejo, Puerto Las Palmas, 5-XII1981, Krapovickas \& Schinini 37565 (CTES); Pdo. Chacabuco: Charata, VIII-1965, Martínez Crovetto 10432 (CTES), Pdo. Gral. Güemes: 19 km W de Fuerte Esperanza, en el llamado Impenetrable, ca. $25^{\circ} 08^{\prime} \mathrm{S}, 61^{\circ} 59^{\prime} \mathrm{W}, 22-\mathrm{I}-1980$, Piccinini \& Hilfer 4200 (BAB); Enrique Urien, Campo Bonazzola, XI-1940, Rodrigo 2610 (LP); Pdo. Independencia: 4 km SE de Avia Terai, 7-XII-1979, Schinini 19475 (CTES); Colonia Benítez, IX1929, Schulz 21 (BAF, CTES); Pdo. 12 de octubre: Gral. Pinedo, 15-III- 1955, Schulz 8910 (CTES); Pdo. 9 de julio, Las Breñas, EEA-INTA, 4-XI-2005, Solís Neffa 1994 (CTES); Pampa del Infierno, de R.16, $\mathrm{Km}$ 255-256 (a $1,7 \mathrm{~km}$ de la

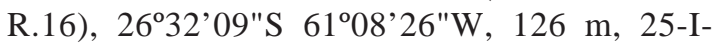
2002, Solís Neffa \& al. 935 (CTES). Córdoba: Rio Cuarto: Estac. Corral de Bustos, 22-XI-1909, Autran 23 (BAF, CORD); Sierras de Córdoba, Potrero de Calmayo, XI-1895, Bodenbender s.n. (BAF); Mina Clavero, 9-XI-1950, Capurro s.n. (BA); Valle de los Reartes, 14-XI-1919, Castellanos s.n. (SI); San Javier: La Paz, 19-IX-1927, Castellanos s.n. (BA); dep. Unión, Bell Ville, Parque Francisco Tau, 13-X-1992, Ferrucci 827 (C, CTES); Córdoba, 19-XI-1880, Galander s.n. (CORD, E); Cumbres de los Comechingones, I1945, Gavio-Zotta s.n. (BA); dep. Calamuchita, campo Los Morteritos, entre Santa Rosa y Yacanto, 750 m, 2/10-XI-1945, Gutiérrez 39 (CORD); Chivilqui, Potrero de Losa, Sierra de Córdoba, 23-XII-1975, Hieronymus 129 (CORD); dep. Punilla: Sa.Chica, Cerro Uritorco, frente a Capilla del Monte, ca.1500 m, 19-XII-1950, Hunziker 8537 (CORD); dep. Rio Segundo: R.N. 9, Km 668, entre Toledo y Rio Segundo, 22-XI1963, Hunziker y Cocucci 16574 (CORD, F, MBM, MO); dep.Gral. Roca: entre las Estaciones Burmeister y Onagoity (F.C.Gral.S.Martín), 3-XI1971, Hunziker \& Di Fulvio 21380 (CORD); dep.
Sobremonte, Sa. del Norte, ca. $6 \mathrm{~km} \mathrm{~W}$ de San Francisco del Chañar, rumbo a Lucio V. Mansilla, ca. 700 m, 30-I-1987, Hunziker \& Subils 24980 (CORD); Cruz del Eje, 1898, Isler 139 (BA, US); Santa María: Despeñaderos, 3-XI-1949, Krapovickas 6521 (BAB, CORD, CTES, LIL, SI); dep. San Martín, Cárcano, 14-XI-1950, Krapovickas 7364 (CTES, (LIL); Falda de San Esteban, Sierra Chica, 11-XII-1885, Kurtz 2817 (CORD); Córdoba, 25-I, Lossen 40 (F, M, MO); ca. Las Chacras, entre Salsacate y Los Gigantes, Sas. Grandes, 26-X-1949, Luti 1255 (CORD); Dep. Rio Seco, Cerro Colorado, 30-I-1942, Maldonado 1036 (LP); dep. Colón, Ascochinga, 25-XI-1936, Nicora 1225 (CTES, SI); Leones, 13XI-1965, Partridge 16 (BA); dep. Punilla, Los Cocos, 1500-1600 m, 17-X-1971, Pedersen 9935 (C, CTES, MBM); dep. Punilla, Santa María, 20XI-1947, Ragonese \& Piccinini 6113 (BAB, CTES); Cuchi, Corral cerca de La Cumbre, 25XII-1950, Rentzell s.n. (US); dep. Punilla, Villa Carlos Paz, 15-XII-1997, Solís Neffa 486 (CTES); Totoral: Totoral, 20-II-1900, Stuckert 8541 (CORD); Achala: punta Sierra, 18-XII-1901, Stuckert 10716 (CORD); Ischilín: Ongamira, 15XII-1906, Stuckert 16557 (CORD); Marcos Juárez, 20-X-1907, Stuckert 17856 (CORD); dep. Tercero Arriba: Villa Ascasubi, en el Rio Tercero, 26-X-1980, Subils \& al. 2798 (CORD); dep. Unión, proximidades de Idiasabal, 22-XI-1977, Subils \& Bernardello 2489 (CORD); Dep. Punilla, Tanti, 900 m, 17-X-1974, Tirel 229 (P). Corrientes: dep. Monte Caseros, Mocoretá, río Mocoretá, 10-XI-1980, Ahumada \& Schinini 3911 (CTES, F); dep. Sauce, Chacra El Timbó, 3 km N de Sauce, 22-X-1977, Ahumada \& al. 1340 (CTES); Dep. Capital, Molina Punta, 16-III-1981, Arbo 2411 (CTES); dep. Curuzú Cuatiá, 5 km SE de Curuzú Cuatiá, 10-III-1985, Cáceres \& Zamudio 295 (CTES); Corrientes, II-1883, Gulich s.n. (BAF); Dep. Monte Caseros, Libertad, costa Arroyo Curuzú, 23-II-1945, Ibarrola 2496 (CTES, LIL, NY, S); Dep. Curuzú Cuatiá, cercanías de Curuzú Cuatiá, 1-III-1945, Ibarrola 2535 (NY, S); San Luis del Palmar, Estación Herlitzka, 28-IX1945, Ibarrola 3356 (BM, F, K); Dep. Esquina, 26 km SE de Libertador, Ea. La Blanca, 30²0'S 59²0'W, 12-III-1975, Krapovickas \& al. 27425 (CTES); dep. San Cosme, 4 km E de Paso de la Patria, 20-III-1969, Krapovickas \& Cristóbal 28592 (CTES); Dep. Monte Caseros, Estancia La 
Horqueta, próxima a Parada Acuña, 10-II-1949, Nicora 5326 (SI); Dep. Empedrado, Estancia La Yela, 28-XI-1961, Pedersen 6409 (C, CTES); Dep. Curuzú Cuatiá, Arroyo Avalos, $31 \mathrm{~km} \mathrm{~S} \mathrm{de}$ Perugorría, 12-XI-1981, Schinini \& al. 21648 (CTES); Dep. Lavalle, Yataity, ruta 120, $10 \mathrm{~km} \mathrm{~W}$ de ruta 12, 5850'W 2900'S, 55 m, 8-III-1995, Schinini \& al. 29142 (CTES); dep. Mercedes, R.119, Km 89, 17-XI-1996, Solís Neffa 388 (CTES); dep. Mercedes, camino a Yofre, Km 65, 4-IV-1994, Solís Neffa \& al. 44 (CTES); Dep. Mercedes, arroyo Pay-Ubre Grande y camino a Itá Corá, 21-II-1984, Tressens \& al. 2274 (CTES); Dep. Mercedes, $11 \mathrm{~km} \mathrm{~S}$ de Mercedes, antiguo camino a Curuzú Cuatiá, cerro Pajarito, 23-II1984, Tressens \& al. 2410 (CTES). Entre Ríos: Feliciano: S. José de Feliciano, Ayo. Feliciano, Ea. La Emilia, 20-XI-1988, Bacigalupo \& al. 685 (SI); Dep. Villaguay, FCER, 26-XII-1916, Baez 27 (BAB); La Paz: Santa Elena, 14-III-1962, Burkart \& al. 23412 (SI); Concordia: arroyo Robledo a Redomón, 8-XI-1965, Burkart 25998 (SI); Dep. Federación, Chajarí, 16-XII-1957, Cabrera 12366 (LP); prope Paraná, 1888, Fro mmel \& Lefebre s.n. (P); Dep. Gualeguaychú, Estancia Rincón de Landa, 19-IV-1943, Krapovickas 191 (LIL); Concepción del Uruguay, X-1875, Lorentz s.n. (BAF); Estancia La Mechita, sembrado de lino, 26-XII1941, Nicora 3224 (SI); Dep. Federación, Estancia Buena Esperanza, 25-X-1961, Pedersen 6272 (C, CTES); dep. Colón, Colón, puerto, 5-IV-1994, Solís Neffa \& al. 309 (CTES); Diamante: Diamante, suburbios, 27-I-1981, Troncoso \& Bacigalupo 3010 (SI). Formosa: dep. Laishí, ruta 11, 18 km NE del río Bermejo, entre arroyos Mbiguá y Lindo, 22-XII-1984, Arbo \& al. 2697 (CTES); Km 83, IV-1919, Jorgensen 3350 (BA, MO, SI); dep. Ramón Lista, El Quebracho (alrededores), 2320'S, 6153'W, 11-II-1986, Maranta 999 (CTES). dep. Patiño: 3-5 km SW de Las Lomitas, por ruta 81, 13-XI-1984, Schinini \& Bernardello 24138 (CTES); dep. Bermejo: $2 \mathrm{~km} \mathrm{~N}$ de Laguna Yema, 140 m, 12-XII-1984, Schinini \& Pire 24251 (CTES); Matacos, R. 81, Km 1591, 24³3'50"S 61 03'00"W, 171 m, 14-I-2002, Solís Neffa \& al. 583 (CTES). Jujuy: dep. Capital, Termas de Reyes, 7-I-1975, Arbo 695 (CTES); El Potrerillo, San Antonio, nr. Jujuy, 4300ft, 6-II-1939, Balls 5928 (K); dep. Capital, camino al aeropuerto El Cadillal, Ayo. Palo Marcado, 23-I-1976, Cabrera \& al. 27490 (SI); Dep. Tumbaya, Chilcayo, 2300 m, 5-I-1966, Fabris 6119 (BAA, CTES); Dep. Tumbaya, Volcán, 11-I-1947, Garolera Romero s.n. (LIL, W); dep. San Antonio, Los Ávalos, R.9, 22 km S de Jujuy, 13-XII-1985, Krapovickas \& Cristóbal 40289 (CTES); dep. Ledesma, 1 km antes de Fraile Pintado, 28-I-1969, Legname \& al. 5959C (LIL); Cerro del Espíritu Santo, 1300 m, Rial Alberti \& al. 403 (BAB); Dep. El Carmen, Pampa Blanca, 9-XII-1979, Schinini 19532 (CTES); dep. Capital, camino de Lozano a Tiraxi, ruta 29, 3-XI-1974, Schinini \& al. 10242 (CTES); Cerro de Zapla 1300-1400 m, 14-XI-1925, Schreiter 119 (BA, BAF, F, LIL); dep. Capital, Yala, 1450 m, 27-I-1940, Schreiter 11114 (LIL, SI); Ledesma: Calilegua, 234' $22^{\prime \prime S}$ 6446’33"W, 491 m, 18-I-2002, Solís Neffa \& al. $717 B$ (CTES); Sta. Bárbara, R.23, rumbo a Santa Clara, a $3 \mathrm{~km} \mathrm{~S}$ de El Fuerte, 2416'02"S 64²6'00"W, 1391 m, 19-I-2002, Solís Neffa \& al. 779 (CTES); Capital, Palpalá, autopista de acceso a Jujuy, $24^{\circ} 16^{\prime} 42^{\prime \prime S} 65^{\circ} 11^{\prime} 42^{\prime \prime} \mathrm{W}, 1113 \mathrm{~m}, 20-\mathrm{I}-$ 2002, Solís Neffa \& al. 823 (CTES); Tumbaya, R.9, rumbo a Tumbaya, a $18 \mathrm{~km}$ de Lozano, 2359'30"S 65²7'08"W, 1849 m, 20-I-2002, Solís Neffa \& al. 833 (CTES); Tumbaya: Volcán, Cerro Abra del Paraguay, 2300 m, 14-II-1927, Venturi 4933 (BA, BAB, SI, US). La Pampa: Parque Luro, 28-XI-1959, Boelcke \& Nicora 7946 (BAA); La Maruja, 11-XI-1939, Burkart 9890 (SI); La Pampa, XI-1948, Crovetto \& Piccinini s.n. (BAB, CTES); General Acha, ca. 200 m, 8-I1944, Hunziker 4147 (K); Est. Exp. Anguil, potrero 15, II-1960, Legaspi s.n. (BAA); alred. de Conhelo F.C.O., 29-XII-1933, Pereyra s.n. (BA); Dep.Calev-Calev, camino de Guatrache a Rio Colorado, a 93 km S de Abramo, 6-II-1969, Rúgolo de Agrasar 624 (BAA); Cuchillo-Co, 15-XII1951, Solbrig 171 (SI); Jacinto Arauz, 13-XII1951, Solbrig s.n. (SI); Guatraché, 1925, Williamson s.n. (SI). La Rioja: dep. Gral. Belgrano, R.N.38, Km 996, entre Chamical y Chañar, Paraje La Llanura, Campo Exp. Las Vizcacheras del INTA, 18-II-1985, Aguirre 454 (CTES); Dep. San Martín: La Diana, 26-II-1907, Stuckert 17038 (CORD). Rio Negro: dpto. Pichi Mahuida: ruta 22, Km 890 al W del Rio Colorado, 11-II-1948, Burkart 15852 (K, SI); ca. 40 km antes de Rio Colorado, 7-XI-1948, Correa \& Nicora 3155 (BAA, BAB); Juan de Garay, XI-1948, Martinez Crovetto \& Piccinini 7033 (BAB, CTES). Salta: Dep. La Viña, Coronel Moldes, La 
Hoyada, 14-XI-1942, Burkart 13155 (SI); Dep. Molinos, Seclantas, 21-I-1947, Garolera Romero s.n. (LIL); Campo Durán, 1930, Horovitz 579 (BAA); Campo Quijano, 4-II-1941, Hunziker s.n. (US); Dep. Guachipas, Guachipas, Estancia Patrón Costa, I-1937, Job 1458 (LP); Capital: Limache, sobre el canal que divide el Barrio Tribuno del intersindical, 1200 m, 26-XII-1995, Juárez de Varela 2177 (MCNS); Dep. Metan, 20 km S de Metan, ruta 34, 3-I-1971, Krapovickas \& Cristóbal 17407 (C, CTES); dep. Rosario de la Frontera, 4 km W de Antilla, 23-III-1977, Krapovickas \& Schinini 30479 (CTES); La Caldera: El Gallinato, a 2 km de R.N. 9, 1500 m, 5-XII-1995, Martínez 221 (MCNS); alrededores de Pampa grande y Cerro Cristal, 1740-2700 m, 1900, Nelson s.n. (CORD); dep.Vaqueros: ayo. Chaile, 1400 m, 21X-1986, Nuñez 124 (MCNS); between La Merced \& El Carril, dep. Cerrillos/Chicoana, 5-XI-1984, Pedersen 13951 (BR, C, CTES, MBM); about 20 $\mathrm{km}$ from La Candelaria on road to La Tranquera, provincial road 35, dep. La Candelaria, 7-XI-1993 Pedersen 15818 (BR, C, CTES, F, MBM); Güemes: ruta $51,10 \mathrm{~km}$ al $\mathrm{W}$ del cruce rutas $51 \mathrm{y}$ 34, 350 m, 28-XI-1988, Saravia Toledo 1721 (CTES, MCNS); Dep. Anta, 20 km W de Joaquín V. González, 8-XII-1979, Schinini 19519 (CTES); Dep. Rivadavia, ruta 81, $21 \mathrm{~km}$ SE de Coronel Juan Solá (Morillo), 10-XII-1979, Schinini 19573 (CTES); dep. Rosario de Lerma, R.36, 3 km NW de Rosario de Lerma, 11-III-1982, Schinini \& Vanni 22240 (CTES); dep. Rosario de la Frontera, R.9, 18-IV-1996, Solís Neffa \& al. 356 (CTES); dep. Metán, R.16, Km 657, entre El Galpón y El Tunal, 22-IV-1996, Solís Neffa \& al. 384 (CTES); Cachi, La Zanja, 2509'27"S 6545'51"W, 2332 m, 22-I-2002, Solís Neffa \& al. 852A (CTES); Metán: R. 5 aprox. a 7 km NE del desvío al Parque Nac. El Rey, 2500'30"S 64³1'21"W, 644 m, 23I-2002, Solís Neffa \& al. 918 (CTES); Dragones, 2314'58"S 6320'47"W, 259 m, 13-II-2005, Solís Neffa \& al. 1979 (CTES); Estación Murillo, 2328'23"S 6253'29"W, 222 m, 13-II-2005, Solís Neffa \& al. 1988 (CTES); camino de Salta a Cafayate, XII-1896, Spegazzini 101743 (BAF); Dep. Orán, Orán, 30-I-1906, Spegazzini s.n. (BAB, CTES); Salta, 4-XII-1946, Wall \& Sparre s.n. (S). San Luis: Desvío Chischaca, 16-XII1925, Castellanos s.n. (BA); Villa Mercedes, 1-I1926, Castellanos s.n. (BA); Sierras de San Luis, Peñón Colorado, 18-XII-1929, Castellanos s.n.
(BA); Cuesta del Palmar, 26-XI-1926, Castellanos s.n. (BA); Nogoli, 25-II-1925, Castellanos s.n. (BA); Divisadero, 14-II-1886, Galander 3686 (CORD); Los Corrales, 15-II-1886, Galander 3699 (CORD); dep. Cnel. Pringles, ca. Fraga, unos $40 \mathrm{~km}$ antes de Villa Mercedes, R.7, yendo desde San Luis, 14-XI-1956, Hunziker 13137 (CORD); dep. Belgrano, Sa. del Gigante, en las inmediaciones de La Calera, 700-750 m, 31-I-1963, Hunziker \& Maldonado16242 (CORD); dep. Gral. Pedernera, R.P. 17, tramo secundario, ca. $1 \mathrm{~km} \mathrm{E}$ de San José del Morro, Sierra del Morro, S del Cerro Mogote, 3313'S 65²8'W, 1100 m, 13-I2004, Pozner \& Belgrano 178 (CTES); Entre Pescadores y ciudad de San Luis, 30-X-1945, Ruiz. Leal 10436 (C, M); San Martín, 1000 m, 12-XI1944, Varela 528 (R); dep. C. Pringles, Trapiche, 1040 m, 27-II-1944, Varela 657 (DAV, NY, S); El Volcán, I-1934, Vignatti 77 (LP). Santa Fe: Gral. López: Entre María Teresa y Christophersen, 14XI-1939, Covas \& Ragonese 4182 (BA); dep. Castellanos, Sunchales, 27-XI-1998, Cristóbal \& Krapovickas 2491 (CTES); Dep. 9 de Julio, Tostado, Rio Salado, I/II-1936, Job 1075 (LP); Estancia La Guasuncha entre Hersilia y E. Rams, 28-XII1944, Krapovickas 759 (LIL); Estancia Las Novias, Logroño FCE, 30-XII-1944, Krapovickas 801 (LIL); Dep. Vera, Margarita, 2940'S $60^{\circ} 15^{\prime} \mathrm{W}, 26-\mathrm{IX}-1982$, Krapovickas 38176 (CTES); Ceres, X-1892, Kuntze s.n. (CORD, F, NY, US); E.E.R.A. de Rafaela, León 973 (SI); Dep. Caseros, San José de la Esquina, cabaña Los Molles, XII-1917, Puleston 36 (BAB); Dep. Gral. Obligado, bords du rio Las Garzas, 100 m, 20-XI1902, Wagner s.n. (P). Santiago del Estero: Dep. Belgrano: camino entre Bandera y Fortín Inca, 29X-1964, Alonso \& al. 576 (SI); Dep. Capital: alrededores de Santiago del Estero, 12-III-1939, Argañaraz 3 (LP); Dep. Gral. Taboada: camino a La Nena, 2 km E de Los Juríes, 22-X-1972, Elisetch \& Cano 118 (BAB); Coronel Barros, 11XI-1946, Huidobro 3135 (C); Dep. Aguirre, Pinto, 14-XI-1946, Huidobro 3185 (BR, MO, P, R, W); dep. Rivadavia, unos $10 \mathrm{~km}$ W de La Isleta (WSW de Ceres), 11-XI-1954, Hunziker 10453 (CORD); Dep. Rio Hondo: Termas de Rio Hondo, Aeropuerto, ruta 9, 1-I-1971, Krapovickas \& Cristóbal 17378 (CTES); Dep. Guasayán, Sierra de Guasayán, Ruta 64, Km 79, 1 km E de Puerta Chiquita, 600 m, 17-XI-1994, Krapovickas \& Cristóbal 46217 (CTES); Jiménez: R. 34, 4 km N 
de Las Cejas, 300 m, 30-III-1996, Krapovickas \& Cristóbal 46606 (CTES); Dep. Robles: Beltrán, 12-XI-1940, Maldonado 515 (LP), Sierra de Sumampa, ruta prov. 13, a $7 \mathrm{~km}$ desde Ojo de Agua hacia Sumampa, ca. 29²9'S 63²0'W, 520 m, 12-X-1979, Piccinini \& Hilfer 3790 (BAB); Dep. Ojo de Agua, $2 \mathrm{~km}$ E de Pozo Grande, ca. 2918'S 6401'W, 18-X-1979, Piccinini \& Hilfer 3966 (BAB); Dep. Banda: ruta prov. 40, 3 km NE de Huyamampa hacia Salina Lomas Coloradas, ca. $27^{\circ} 22^{\prime}$ S $64^{\circ} 16 \mathrm{~W}, 17-\mathrm{II}-1977$, Piccinini \& Petetin 2856 (BAB); Dep. Choya: Sol de Mayo, ruta 24 km 22 entre Santa Catalina y La Punta, ca. $28^{\circ} 16^{\prime} \mathrm{S}$ 6446'W, 18-XI-1978, Piccinini \& Petetin 3336 (BAB); Dep. Silipica: Arraga, II-1982, Renolfi 182 (CTES); dep. Moreno, R. 89, Km 369, camino a Quimilí, 16-IV-1996, Solís Neffa \& al. 316 (CTES); Dep. Copo: Pampa de los Guanacos, 7-I1948, Spegazzini 10565 (BAF). Tucumán: circa Tapia, XII-1902, Baer 120 (BA, BAB, BAF, LY, SI); Dep. Cruz Alta, $4 \mathrm{~km}$ antes de llegar a Las Cejas, finca La Ponderosa, 21-XII-1970, Cuezzo 7903 (LIL); Dep. Tafí, Tafí Viejo, 9-XII-1900, Holmberg 1220 (BAB); dep. Leales, La Florida, R.N. 9, 1-I-1971, Krapovickas \& Cristóbal 17361 (CTES); dep. Capital, El Cadillal, Parque de las Américas, 29-XII-1974, Krapovickas \& Cristóbal 27136 (CTES, MBM); dep. Leales, Los Puestos, 2-I-1975, Krapovickas \& Cristóbal 27146 (CTES); Dep.Trancas, Ruta 9, ayo. Potro Yaco, 7 km S del acceso a Trancas, 21-XI-1994, Krapovickas \& Cristóbal 46241 (CTES); Dep. Graneros, rio Graneros, Lamadrid, 14-XI-1946, Malvarez 71 (LIL); La Invernada, 450 m, 11-XI1962, Neuman 2 (LIL); Las Mesadas, 1600 m, 1954, Pierotti s.n. (LIL); Tafí, Cerro San Agustin, 20 IX 1950, Rocha 3608 (K); Dep. Tafí, Tipa, 30XI-1950, Rocha 3664 (LIL); Tafí del Valle, Sleumer s.n. (B); Burruyacu, 8-I-1903, Stuckert 12581 (CORD); Dep. Leales, Chañar Pozo, 300 m, IX-1919, Venturi 468 (BA, SI); Rio Sali, XII1920, Venturi 468a (BAB); Alto de Medina, 1000 m, 12-I-1924, Venturi 2688 (BA, SI, US); El Puestito, 600 m, 14-XI-1928, Venturi 7501 (LIL, US); camino a San Pedro de Colalao, 10-IV-1968, Villa \& al. 3159 (LIL). URUGUAY. Artigas: Bella Unión ,28-I-1948, Castellanos 18380 (LIL); Costa del rio Uruguay, Colonia España, 2-X-1972, Del Puerto \& al. 11436 (MVFA); R.30 y Ayo.Cuaró, 30²6'13"S 57¹7'41"W, 61 m, 25XI-2001, Solís Neffa \& al. 524 (CTES). Canelo- nes: La Torre, 14-XI-1908, Berro 5413 (MVFA); Pando, X-1948, Herter $717 f(\mathrm{MO})$; près Sta. Lucia Montevideo a la frontiere par la riviere del'Uruguay, Saint Hilaire C 2284 (P); R.8, 14XII-1995, Solís Neffa \& al. 500 (CTES). Colonia: Colonia Suiza, I-1910, Rua 66 (SI); Punta Gorda, 30-X-1969, Del Puerto \& Marchesi 8932 (MVFA); Colonia, II-1920, Molfino s.n. (BA). Durazno: Bords de 1'Yi, 1888, Alvares \& al. s.n. (P). Florida: Ayo. Arias, 21-II-2005, Dematteis \& Schinini 1688 (CTES); R.7, Km 114, $3 \mathrm{~km}$ al N de Casupa, 3404'25"S 55³9'14"W, 159 m, 30-XI2001, Solís Neffa \& al. 543 (CTES). Montevideo: Cuchilla Pereyra, Felippone 3310 (SI); Montevideo, Felippone 3376 (FI, SI); Carrasco, 28-II1875, Fruchart s.n. (P); Quinta Varela, I-1874, Fruchart s.n. (P); Atahualpa, XI-1925, Herter 717 (NY, SI); prope Montevideo, Sellow d.68 (K). Paysandú: 15 km E del rio Queguay, 24-II-2005, Dematteis \& Schinini 1847 (CTES); Est. Exp. Fac. Agr., 15-XI-1977, Marchesi \& Ferres 14208 (MVFA). Rio Negro: Playa Ubisi al N. de Fray Bentos, 22-XII-1965, Del Puerto \& Marchesi 5678 (MVFA). Salto: Espinillar, 18-II-1965, Del Puerto \& al. 2155 (MVFA). San José: Rincón del pino, 10-XI-1970, Izaguirre \& al. 9572 (MVFA). Soriano: Santa Elena, X-1892, Aplin s.n. p.p. (BM); Daca, 2-XII-1914, Berro 7490 (MVFA); Playa Agraciase, 31-X-1969, Del Puerto \& Marchesi 8955 (MVFA); Mercedes, 12-II-1918, Doello-Jurado s.n. (BA).

Material cultivado: ARGENTINA. Corrientes: proc. de Chaco, Colonia Benítez, 22-II-1985, Arbo 2729 (CTES); proc. de Salta, R.9, 1 km N de La Caldera, 25-X-1985, Arbo 2759 (CTES); proc. de Argentina, La Rioja, Quebrada de Cibila, 10-II-2004, Seijo \& Solís Neffa 3106 (CTES); proc. de San Luis, San Francisco, 10-II-2004, Seijo \& Solís Neffa 3107 (CTES); proc. de Corrientes, Mercedes, ruta 123, Km 89, 5 km E de la entrada a Yofre, 4-IV-1994, Solís Neffa \& al. 307 (CTES); proc. de Uruguay, dep. Rio Negro, Grecco, 6-IV-1994, Solís Neffa \& al. 311 (CTES); proc. de Ctes., Mercedes, ruta 119, Km 97, 27-XI-2003, Solís Neffa \& Seijo 978 (CTES); proc. de Uruguay, dep. Artigas, ruta 30 y arroyo Cuaró, 28XI-2003, Solís Neffa \& Seijo 980 (CTES); proc. de Salta, dep. Rivadavia, R.81, a 1 km SE de Solá, 4XII-2003, Solís Neffa \& Seijo 983 (CTES); proc. de Córdoba, dep. Capital, Ciudad Universitaria, 18-XII2003, Solís Neffa \& Seijo 985 (CTES). 
Distribución fenología: Sur de Bolivia (Chuquisaca), Chaco paraguayo, Argentina (hasta el norte de la Patagonia) y Uruguay, de 15 a $2800 \mathrm{~m}$ de altitud. Crece en el chaco serrano, en el bosque chaqueño, en laderas y en campos, en suelos arcillosos, arenosos o pedregosos. Se adapta a lugares modificados. Florece casi todo el año, pero la mayor parte de los ejemplares fueron colectados entre octubre y marzo.

Nombres vulgares: Argentina: «amapolita», «yerba del ciervo» (Hunziker 20784, Schikendantz 140), «malvita crespa» (Bordón s.n.); Bolivia: «verbenita» (Teran BM109).

Obs.: Todas las flores estudiadas fueron heterostilas. En los ejemplares Fruchard s.n. (XI-1876) y Ahumada 3973 se observaron flores con 4 estilos.

Seigler (1979) encontró compuestos cianogénicos en hojas del ejemplar Seigler \& Vervoorst 10121 (ILL), también Spencer \& al. (1985) en Kuntze s.n. (F), en cambio el resultado fue negativo en Cabrera \& Fabris 16432 (F).

Se estudió la variación del color de las flores en relación con el número cromosómico de la subsp. pinnatifida en Bolivia; se analizaron 41 poblaciones -5 con flores color salmón, 35 con flores amarillas- y se obtuvo el número cromosómico de 14 poblaciones (1 salmón 13 amarillas) siendo todas diploides; la distribución está asociada con variables climáticas y espaciales: las poblaciones con flores salmón viven en la Provincia biogeográfica del Chaco boreal, y las de flores amarillas en la Provincia Biogeográfica BolivianoTucumana (Solís Neffa \& al., 2004).

En esta subespecie se estudiaron la vascularización floral y la estructura de los nectarios florales; es interesante señalar que los filamentos estaminales presentan sección semilunar al separarse del tubo floral, los bordes quedan brevemente soldados al tubo, dejando una ligera depresión rodeada de tejido nectarífero (Gonzalez, 2001). Esta estructura podría ser la precursora de los bolsillos nectaríferos característicos de las series Anomalae y Turnera.

\section{Turnera stachydifolia Urb. \& Rolfe}

Urban, I., Jahrb. Königl. Bot. Gart. Berlin 2: 122. 1883; Urban, en Martius C.F.P., Fl. Bras. 13 (3): 142. 1883. Typus: Brasil. Piauí: dry rocky places near Oeiras, shrub about 3ft high, V-1839, Gardner 2176 (holotypus K!, isotypi F!, K!, NY!, P!, S!, US!, W!, G fototipo F 24131!).

\section{2a. Turnera stachydifolia Urb. \& Rolfe var. stachydifolia}

Figs. 12 y 75

Arbusto ca. $1 \mathrm{~m}$ alt., ramas viejas con corteza parda, con estrías y grietas longitudinales, cicatrices foliares salientes; ramas del año tomentosas, pelos crespos densísimos y pelos glandulares capitado-sésiles rojizos salpicados, 0,1 mm diám. (Fig. 2B). Yemas axilares 2-4, ramas seriales con secuencia de desarrollo variable (1-2-3; 1-3-4-2). Hojas abolladas, patentes o recurvadas, grisáceo-amarillentas en seco. Estípulas rudimentarias, pilosas, con coléteres 0,3-0,6 mm long., escondidos en el indumento. Pecíolo cilíndrico, 1,5-5 mm long. Lámina elíptica u obovada, 16-51 x 8-14 mm, relación largo:ancho 2-4,3:1; base cuneada o atenuada, ápice obtuso, a veces agudo, borde ligeramente revoluto, doblemente aserradocrenado, dientes obtusos; haz tomentosovelutina; envés ligeramente más claro, lanosovelutino, con pelos glandulares capitadosésiles rojizos salpicados; vena media y 5-7 pares de venas laterales alternas 0 subopuestas muy hundidas en la haz y prominentes en el envés, perdiéndose hacia el borde; ángulo de divergencia $20-40^{\circ}$; venas terciarias hundidas en la haz, prominentes en el envés, venación menor inconspicua. Hojas floríferas apicales bracteiformes, elípticas, ovadas o espatuladas, 3-6 x 2-4 mm, con 2 nectarios diminutos, rojizos, circulares, 0,3$0,5 \mathrm{~mm}$ diám. en el borde, asentados sobre el hipofilo, a 1-2 mm de la base. Flores epifilas, heterostilas, reunidas en los ápices de ramas y ramas seriales en racimos abreviados. Pedúnculo totalmente soldado al pecíolo, 1,5-2,5 $\mathrm{mm}$ long. Profilos lineares, 2,5-5 mm long., indumento como el envés. Pedicelo nulo. Cá- 


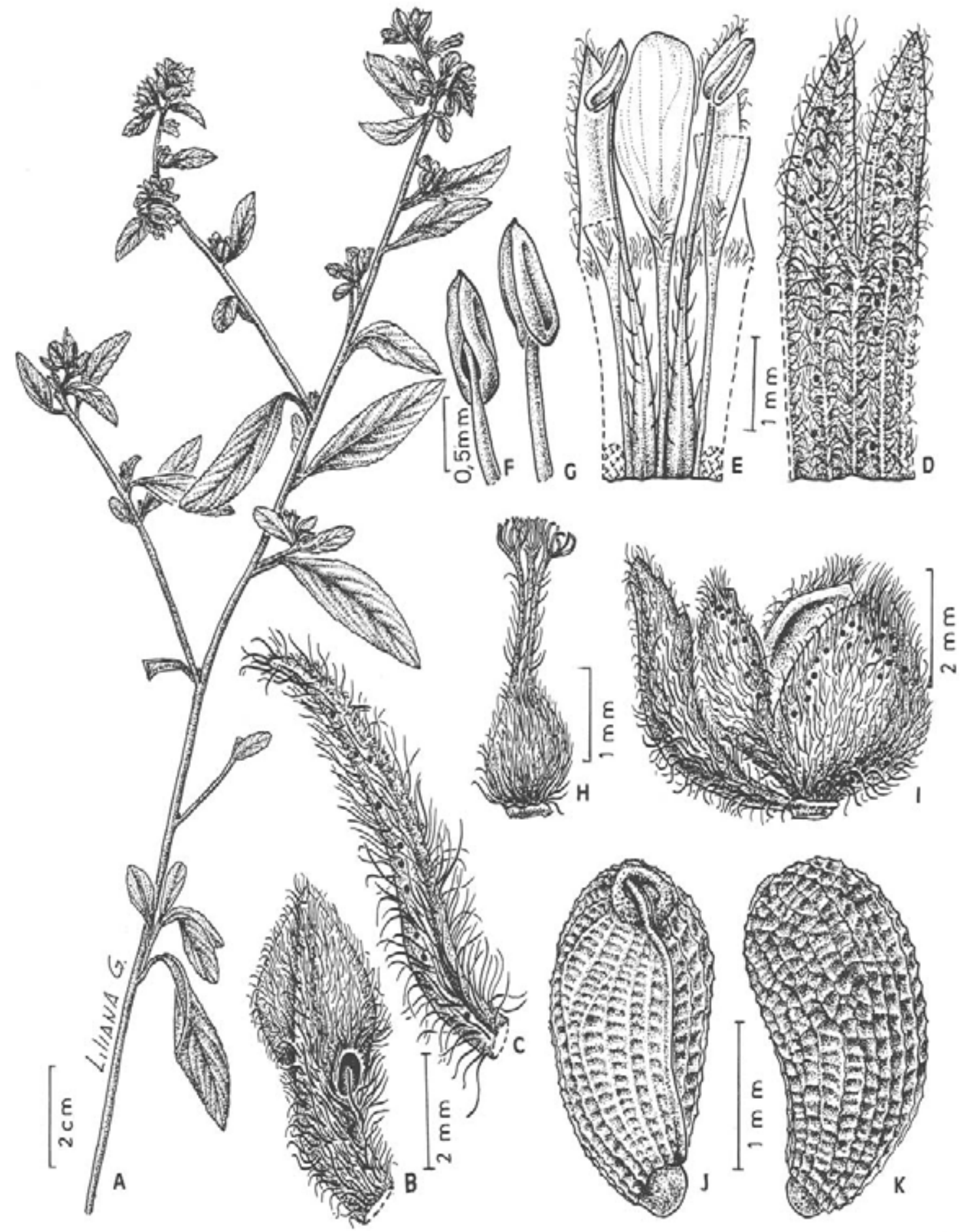

Fig. 75. Turnera stachydifolia var. stachydifolia. A: planta. B: bráctea con nectarios, cara abaxial. C: profilo. D: porción del cáliz, cara externa. E: flor brevistila, porción del tubo calicino, cara interna, con pétalos y estambres adnatos; se han cuadriculado las cicatrices dejadas al desprender dos estambres. F-G: anteras, vistas dorsal y ventral. H: receptáculo y gineceo. I: fruto y profilo. J-K: semilla, vistas rafeal y lateral (Gardner 2176). Del. Liliana Gómez. 
liz $5 \mathrm{~mm}$ long., cara externa lanoso-tomentosa, con pelos glandulares; tubo calicino $2,5 \mathrm{~mm}$ long., cara interna vellosa; lóbulos triangulares, cara interna, emucronados. Corola tan larga como el cáliz o $1 \mathrm{~mm}$ más larga; pétalos con uña soldada al tubo calicino, glabra en la parte basal, luego vellosa, lámina obovada 2,5 x 1 $\mathrm{mm}$, pilosa en la mitad basal en ambas caras, en la externa con pelos glandulares rojizos. Filamentos estaminales complanadosubulados en seco, hirsutos en los 2/3 basales, soldados $0,5 \mathrm{~mm}$ en la base al tubo calicino, $3,2 \mathrm{~mm}$ long. en flores brevistilas; anteras angustiovadas, $0,7-0,8 \times 0,3-0,4 \mathrm{~mm}$, base emarginada, ápice obtuso no recurvado a la dehiscencia, filamento inserto dorsalmente a 0,3 $\mathrm{mm}$ de la base. Ovario ovoide, $1 \mathrm{~mm}$ long., hirsuto; placentas 3-4-ovuladas; estilos cilíndricos, pilosos, 1,2-1,5 $\mathrm{mm}$ long. en flores brevistilas; estigma penicilado, pauciramuloso, 0,5 $\mathrm{mm}$ long. En flores brevistilas el androceo es $1,5 \mathrm{~mm}$ más largo que el gineceo. Fruto $4 \mathrm{~mm}$ long., cara externa lisa, con pelos simples y pelos glandulares, rojizos, cara interna. Semilla 1,9-2 x 0,9 mm; exóstoma cónico; rafe linear, lado rafeal incurvo; cálaza con una prominencia oscura, ligeramente deprimida en el centro, prolongación de la rafe. Episperma reticulado, ca. 24 filas longitudinales de aréolas más o menos cuadrangulares, con una depresión punctiforme; epidermis papilosa. Arilo unilateral.

Distribución: Se conoce solamente el material tipo.

Obs.: En un ejemplar de P se halló una flor con 4 estambres largos 3,5 mm long., un estambre más corto, estéril, y gineceo 3,5 mm long.

\section{2b. Turnera stachydifolia var. flexuosa Urb.}

Figs. 12 y 76

Urban, I., Jahrb. Königl. Bot. Gart. Berlin 2: 122. 1883; Urban, en Martius C.F.P. Fl. Bras. 13(3): 143. 1883. Typus: Brasil. Bahia: Marais d'Itabira, Rio São Francisco, [tal vez Ibiraba, sobre el río San Francisco, frente a Xique-Xique] 1838,
Blanchet 2873 (holotypus $\mathrm{B}+$ fototipo $\mathrm{F}^{\circ}{ }^{\circ} 13603$, isotypi $\mathrm{F}$ !, $\mathrm{K}$ !, $\mathrm{M}$ !, $\mathrm{P}$ !, $\mathrm{SP}$ !, $\mathrm{W}$ !).

Arbusto con ramas en zig-zag, pelos glandulares capitado-sésiles amarillos. Estípulas soldadas a la base del pecíolo, 1-3-laciniadas, las más desarrolladas 0,9-1,2 mm long., rojizas, pilosas. Pecíolo 3-7 mm long. Venas laterales formando arcos cerca del borde al unirse con las superadyacentes o con las ramas derivadas de ellas. Flores epifilas. Profilos lineares 1,5-2 mm long. Cáliz 6-6,5 mm long.; tubo calicino $4 \mathrm{~mm}$ long., cara interna vellosa en la mitad superior. Corola ligeramente más larga que el cáliz, uña de los pétalos pilosa, soldada al tubo calicino, lámina obovada, $3 \mathrm{x}$ $1 \mathrm{~mm}$, con algunos pelos en la base en la cara interna, cara externa glabra. Filamentos estaminales complanado-subulados en seco, pilosos en la porción media, $6 \mathrm{~mm}$ long. en flores brevistilas; anteras $0,9 \times 0,3 \mathrm{~mm}$, filamento inserto en una cavidad basi-dorsal a 0,5 $\mathrm{mm}$ de la base. Estilos 2,5 $\mathrm{mm}$ en flores brevistilas. Fruto 3-4 mm long., con pelos simples blanquecinos largos y cortos y pelos glandulares capitados amarillos que no se destacan, cara interna lisa, lustrosa, amarillenta o jaspeada. Semilla obovoide, curvada, 2,2-2,5 x 1-1,1 mm; exóstoma pequeño; rafe linear, lado rafeal incurvo; cálaza oscura, prominente. Episperma reticulado, aréolas cóncavas, epidermis papilosa. Arilo unilateral amplio, tan largo como la semilla, de células papilosas.

Distribución: Sólo se conoce el material tipo.

\section{Turnera subnuda Urb.}

Figs. 48 y 77

Urban, I., Bot. Jahrb. Syst. 25 Beibl. 40: 8. 1898; Glaziou, Bull. Soc. Bot. France, 56 mém. 3: 311. 1909. Typus: Brasil. Goiás, Guariroba, dans le camp, 18-X-1894, Glaziou 21446 (holotypus $\mathrm{B}+$ fototipo $\mathrm{F} \mathrm{n}^{\mathrm{o}} 13605$ !, isotypi $\mathrm{BR}$ !, C!, F!, K!, LY!, P!, R!, S!, SP!).

Hierba graminiforme, perenne, erecta, 30- 


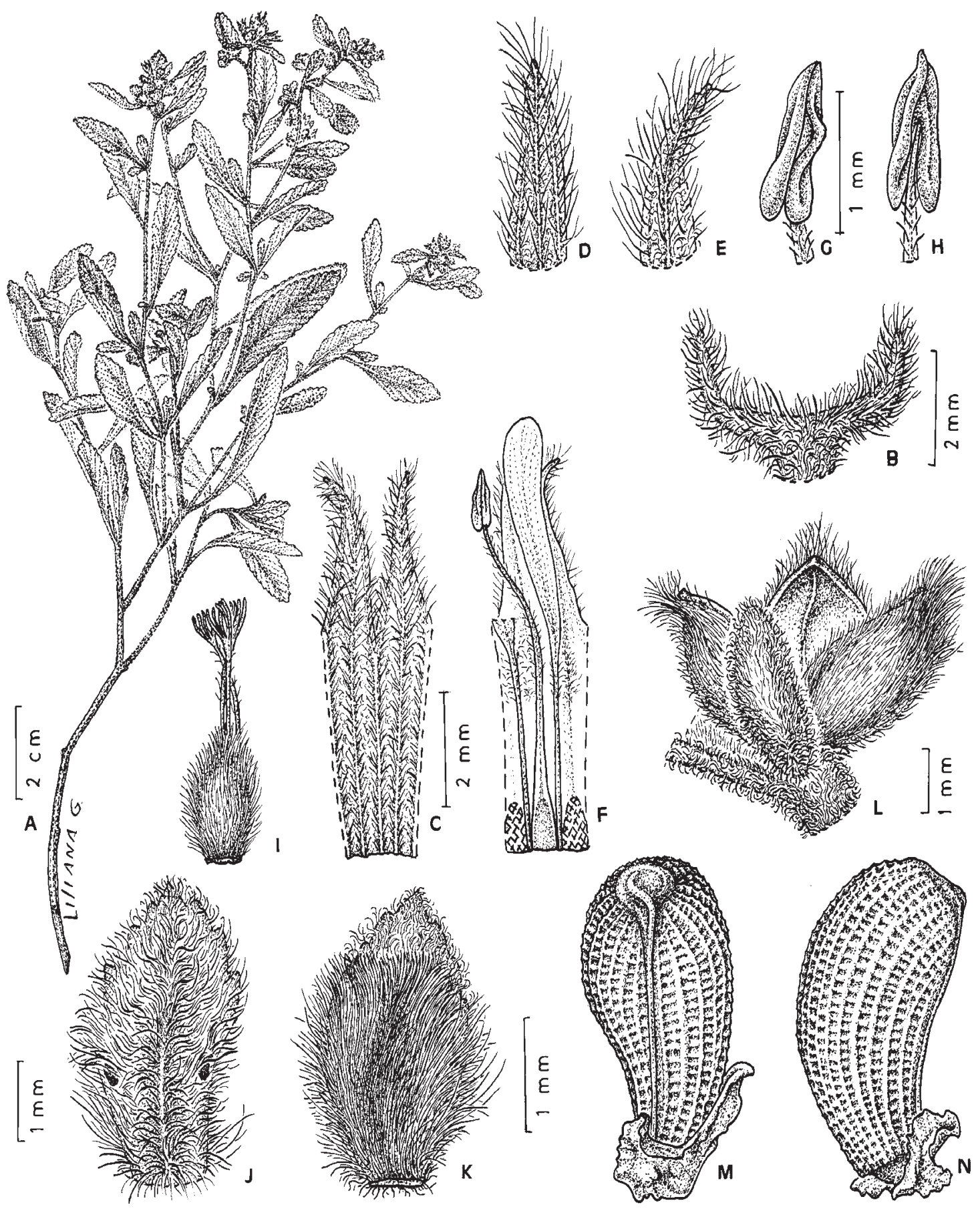

Fig. 76. Turnera stachydifolia var. flexuosa. A: planta. B: ápice del pedúnculo con profilos. C: porción del cáliz, cara externa. D-E: ápice de los lóbulos del cáliz, cara externa. F: flor brevistila, porción del tubo calicino, cara interna, con pétalos y estambre adnatos; se han cuadriculado las cicatrices dejadas al desprender dos estambres. G-H: anteras, vistas ventral y dorsal. J-K: bráctea, caras abaxial y adaxial. L: porción basal de bráctea con fruto epifilo y profilo. MN: semilla con arilo, vistas rafeal y lateral (Blanchet 2873). Del. Liliana Gómez. 


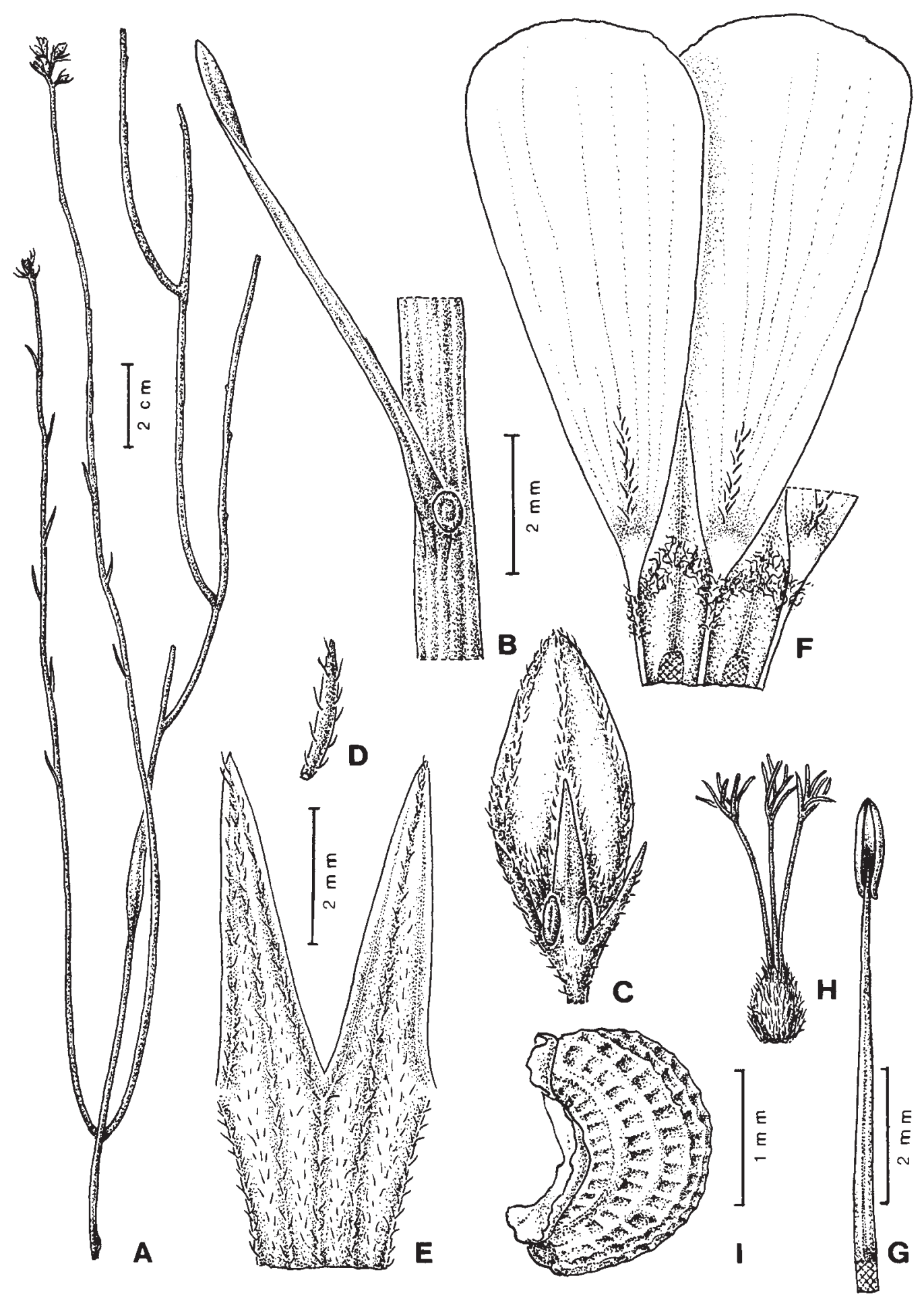

Fig. 77. Turnera subnuda. A: planta. B: porción de tallo y hoja con nectario, cara abaxial. C: bráctea con nectarios, botón floral epifilo y profilos; D: profilo. E: porción del cáliz, cara externa. F: porción del tubo calicino, cara interna, con pétalos adnatos; se han cuadriculado las cicatrices dejadas al desprender dos estambres. G-H: flor brevistila, estambre y gineceo. I: semilla con arilo, vista lateral (A-H: Hatschbach \& al. 54229; I: Glaziou 21446). Del. Liliana Gómez. 
$75 \mathrm{~cm}$ alt., base leñosa 3-8 mm diám.; tallos 17 cilíndricos, 1-1,5 mm diám., simples o poco ramificados, rectos, castaños, punteados, longitudinalmente estriados, pubérulos en la base, luego glabros o con pelos simples adpresos debajo de la inserción de cada hoja; entrenudos 3-20 mm long., acortándose rápidamente en la región florífera. Hojas erectas, verdes o castañas en seco. Estípulas nulas, a veces algunos pelos simples y un coléter 0,1 $\mathrm{mm}$ long. Yema axilar 1. Pecíolo 0-0,5 mm long. en hojas vegetativas, 0,9-1,5 mm long. en hojas floríferas, estrigoso. Lámina filiforme, linear o angustiovada en hojas vegetativas, 3-15 x 0,3-1,5 mm, relación largo:ancho = 3-18:1; margen glabro, entero o con 1-2 pares de dientes en la mitad apical, plano o ligeramente revoluto, glabro o con algunos pelos hacia el ápice; haz y envés totalmente glabros o con algunos pelos en la base, o con el envés estrigoso; vena media conspicua en ambas caras, venas laterales ausentes generalmente. Nectarios generalmente ausentes en hojas vegetativas. Hojas floríferas reducidas a brácteas subuladas, 2-6 x 0,4-1 mm, relación largo:ancho $=3-6: 1$, con 2 nectarios en la base de la lámina o desplazados 1-2 mm sobre su borde, circulares o elípticos, 0,4-0,6 mm diám., reborde glabro o ligeramente pubérulo, con «poro». Flores epifilas, heterostilas, agrupadas en el extremo de las ramas en un racimo bracteoso de $2-3 \mathrm{~cm}$ long. Alabastros elipsoides, ápice agudo con los mucrones diminutos libres en el ápice. Pedúnculo floral estrigoso, 1-2 mm long., totalmente adnato al pecíolo o porción apical libre $0,2-$ $0,5 \mathrm{~mm}$ long. Profilos subulados de 1,2-2,5 $\mathrm{x}$ 0,3-0,5 mm, estrigosos, situados en la base del receptáculo. Pedicelo nulo. Cáliz 5-8 mm long., estriguloso por fuera; tubo subcilíndrico 1,5-3 mm long., velloso en la cara interna; lóbulos elípticos o triangulares, ápice frecuentemente purpúreo, mucrón 0,1 $\mathrm{mm}$ long. Pétalos amarillos, lámina angustiobovada, 5,5-9 × 2,5-5 mm, base atenuada, pilosa en la cara interna, ápice redondeado. Filamentos estaminales glabros, subulados, soldados por $0,5 \mathrm{~mm}$ al tubo en la base, 3,5-5 mm long. en flores longistilas; an-teras 1-1,2 x 0,4-0,5 mm, base emarginada, ápice obtuso, filamento inserto en una cavidad dorsal 0,4-0,5 mm long. Ovario ovoide o cónico, 0,6-0,7 mm long., hirsuto; placentas 3-9ovuladas; estilos cilíndricos, glabros, 3,5-5 $\mathrm{mm}$ long. en flores longistilas, $3 \mathrm{~mm}$ long. en flores brevistilas; estigmas 1-1,5 mm long., divididos en 6-10 ramas. En flores longistilas, gineceo 1-1,5 mm más largo que el androceo y en flores brevistilas, 2,5-3 mm más corto. Fruto ovoide, 3-7 mm long.; tubo floral desprendiéndose a 0,1-0,2 $\mathrm{mm}$ de la base, dejando un reborde anular persistente; valvas ovadas, ápice generalmente purpúreo, cara externa lisa, estrigosa, cara interna glabra, lisa, amarillenta con manchitas castañas. Semilla curvada, obovoide, 1,5-2 x 0,9-1,1 mm; exóstoma cónico o hemisférico; rafe linear, lado rafeal incurvo; cálaza saliente, oscura, a veces ligeramente deprimida en el centro. Episperma reticulado, muros longitudinales más marcados que los transversales, nudos prominentes, aréolas rectangulares o cuadrangulares, a veces con depresión punctiforme, con cera epicuticular bastoniforme en la semilla inmadura. Arilo membranáceo en seco, unilateral, 1,3 mm long., de células lisas.

Material estudiado: BRASIL. Goiás: Chapada dos Veadeiros, $40 \mathrm{~km}$ W de Alto Paraíso de Goiás, camino a Niquelandia, ca. 1000 m, 4-II-1990, Arbo \& al. 3660 (CTES); alrededores de Colinas, sobre el camino a Cavalcante, 600-700 m, 5-II1990, Arbo \& al. 3677 (CTES); Niquelândia, southermost ultramafic hill of Tocantins complex, ca. $14^{\circ} 18^{\prime} \mathrm{S} 48^{\circ} 23^{\prime} \mathrm{W}, 800 \mathrm{~m}, 17-\mathrm{V}-1988$, Brooks \& al. BRASPEX 308 (CTES); Chapada dos Veadeiros, ca. $16 \mathrm{~km} \mathrm{~S}$ of Alto do Paraíso (formerly Veadeiros), $1000 \mathrm{~m}, 20-\mathrm{III}-1969$, Irwin \& al. 24730 (P, UB); ca. $10 \mathrm{~km} \mathrm{~W}$ of Alto do Paraiso, 1000 m, 24-III-1969, Irwin \& al. 24984 (NY, P); mun. Alto Paraiso, Reserva Particular do Patrimonio Natural (RPPN), Mata Funda, propriedade Sr. Angelo/Solange, $14^{\circ} 08^{\prime} \mathrm{S}$ 47043'W, 1190 m, 5-VII-1998, Mendonça \& al. 3538 (US); Fazenda Agua Fria, Alto Paraiso de Goias, ca. 10 km em direção a Teresina de Goias,

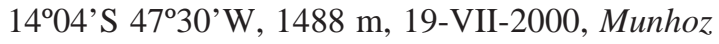
\& al. 1777 (CTES, IBGE); Chapada dos Veadeiros, $9 \mathrm{~km}$ de Alto Paraiso/Terezina de Goias, $1^{\circ} 03^{\prime} \mathrm{S} 47^{\circ} 30^{\prime} \mathrm{W}, 1520 \mathrm{~m}, 28-\mathrm{VII}-1994$, Silva \& al. 2115 (CTES). Minas Gerais: Mun. Diamantina, 20-26 km WSW de Diamantina, ca- 
mino a Conselheiro Mata, MG-220, ca. $18^{\circ} 17^{\prime} \mathrm{S}$ 4349'W, 1270-1300 m, 18-V-1990, Arbo \& al. 4396 (CTES, SPF); Grão Mogol, rod. para João Napoles, 900 m, 12-VI-1990, Hatschbach \& al. 54229 (C, CTES, MBM, MU); Furnas, area em torno das esclusas da represa, perto do posto meteorologico, 3-VII-1994, Lombardi 584 (CTES).

Distribución y fenología: Especie poco frecuente, propia de Goiás y Minas Gerais. Crece a 600-1520 m de altitud, en Niquelândia sobre rocas serpentinas. Florece y fructifica desde febrero a septiembre.

Obs.: Especie hiperacumuladora de niquel (com.pers. Robert R. Brooks), muy afín a Turnera trigona Urb., la cual se diferencia por sus tallos trígonos, sus hojas vegetativas con venas laterales y nectarios, y sus semillas más grandes.

El tallo primario de Turnera subnuda es marcadamente costado, en las costillas se encuentran haces conspicuos de fibras y macrosclereidas; la estela está formada por haces colaterales (Gonzalez, 2000; sub T. trigona).

\section{Turnera tenuicaulis Urb.}

Figs. 12 y 78

Urban, I., Bot. Jahrb. Syst., 25 Beibl., 40: 7. 1898. Typus: Brasil. Goiás: Serra dos Crystaes, 16-IX-1895, Glaziou 21447 (holotypus B+ fototipo F 13606!, isotypi BR!, C!, K!, LY!, P!, $\mathrm{R}$ !).

Hierba perenne, erecta, graminiforme, 10$36 \mathrm{~cm}$ alt., base leñosa, rizomatosa, 2-7 mm diám.; ejes 1-15 poco ramificados, sinuosos o rectos, cilíndricos, rojizos o verdes, punteados, 0,5-1,7 mm diám., estriados o angulados hacia el ápice, glabros en la base, luego con pelos simples, cortos, antrorsos, curvados o adpresos, a veces densos en la porción apical; entrenudos 2,5-48 mm long., acortándose en la porción florífera. Yemas axilares 1-2. Hojas herbáceas, erectas o patentes, opacas o algo lustrosas, verdes en seco, superficie de aspec- to arenáceo. Estípulas rudimentarias, a cada lado de la base foliar, con coléteres rojizos, 0,1-0,2 mm long., cónicos o cilíndricos. Pecíolo 0,3-1 mm long., estrigoso. Lámina foliar linear, elíptica, ovado-lanceolada u obovada, 2-6 x 0,6-1,5 mm en hojas basales, 4-18 x 0,6$4 \mathrm{~mm}$ en nomófilos, relación largo:ancho $=3$ 10:1; base atenuada glabra o con algunos pelos, margen plano o ligeramente revoluto, glabro o piloso en la porción basal, entero o con 1-3 dientes en la porción apical; haz y envés estrigosos o glabros, vena media conspicua en ambas caras, venas laterales a veces visibles en el envés; ángulo de divergencia 12-18 venación menor inconspicua. Nectarios raramente presentes. Hojas floríferas reducidas a brácteas uninervias, con 2 nectarios circulares, 0,3-0,6 mm diám., borde pubérulo, situados en la unión de pecíolo y lámina o ligeramente desplazados. Flores epifilas, heterostilas, agrupadas en el ápice en un racimo bracteoso hasta de $14 \mathrm{~cm}$ long. Alabastro obovoide, ápice agudo o apiculado con mucrones brevísimos libres. Pedúnculo 1-2 $\mathrm{mm}$ long., estrigoso, adnato brevemente al pecíolo en hojas floríferas basales, adnato casi hasta el ápice en las apicales. Profilos subulados 1,5-3,2 x 0,2-0,5 mm, denticulados, cara externa pilosa, insertos en la base del receptáculo. Pedicelo nulo. Cáliz 4,5-7 mm long.; tubo calicino de 1,5-2 mm long., glabro por dentro o velloso en la porción superior, por fuera con pelos largos sobre las venas en la base y en los lóbulos, o totalmente vestido con pelos simples, cortos, adpresos o curvadoerectos, laxos o densamente dispuestos; lóbulos angustiovados o triangulares, ápice a veces purpúreo, mucronulado $(0,1-0,3 \mathrm{~mm})$. Corola amarilla; pétalos con uña a veces vellosa, lámina obovada, 5-9 x 1,5-4,5 mm, glabra o con algunos pelos en la base. Filamentos estaminales lineares o subulados, glabros, soldados $0,5 \mathrm{~mm}$ en la base al tubo calicino, 3,5$5 \mathrm{~mm}$ long. en flores longistilas, 4-6 mm long. en flores brevistilas; anteras 0,5-1,2 mm long., base emarginada, filamento inserto dorsalmente a 0,3-0,5 $\mathrm{mm}$ de la base, ápice agudo, ligeramente recurvado después de la dehiscencia. Ovario ovoide, 0,76-1 mm long., hirsuto; placentas 2-3-ovuladas; estilos cilíndricos, glabros, 2,5-3,5 $\mathrm{mm}$ long. en flores 


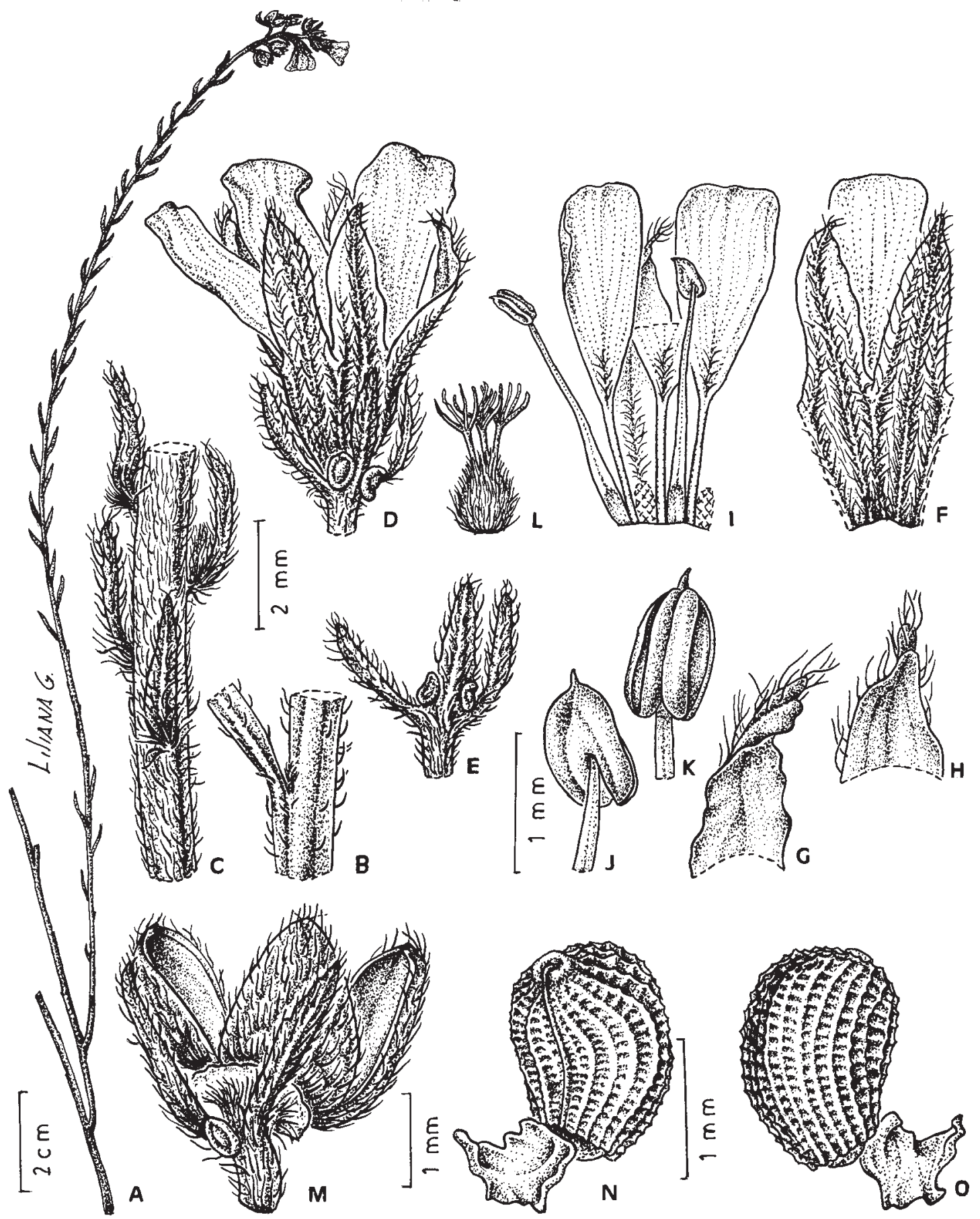

Fig. 78. Turnera tenuicaulis. A: planta. B: porción de tallo y hoja con estípula y yema axilar. C: porción de tallo y hojas. D: bráctea con nectarios, flor epifila y profilos. E: bráctea, cara abaxial y profilos. F: porción del cáliz, cara externa. G-H: ápice de los lóbulos del cáliz, cara interna. I: porción del tubo calicino, cara interna, con pétalos y estambres adnatos; se han cuadriculado las cicatrices dejadas al desprender dos estambres. J-K: anteras, vistas dorsal y ventral. L: gineceo. K: bráctea con fruto epifilo y profilo. N-O: semilla con arilo, vistas rafeal y lateral (Silva \& Nunes de Jesus 3035). Del. Liliana Gómez. 
longistilas, 1-2,5 en flores brevistilas; estigma 1,5-2,5 mm long., dividido en 4-8 ramas. En flores longistilas, gineceo 1,5-2,5 mm más largo que el androceo, y en flores brevistilas, 0,7-2 mm más corto. Fruto esférico o elipsoide, 2,5-4 mm long.; tubo floral desprendiéndose a 0,3-0,5 $\mathrm{mm}$ de la base, dejando un reborde anular persistente; valvas ovadas, ápice generalmente purpúreo, cara externa lisa, con pelos simples laxos, cara interna amarillenta con máculas castañas, glabra. Semilla obovoide, ligeramente curvada, 2-2,7 x 1-1,2 mm; exóstoma cónico; rafe linear, lado rafeal incurvo, recto o en parte convexo; cálaza apical saliente, a veces ligeramente deprimida en el centro, oscura. Episperma reticulado, nudos del retículo ligeramente elevados, aréolas rectangulares. Arilo unilateral, 1,5-2,4 mm long., de células lisas.

Material estudiado: BRASIL. Goiás. Serra dos Cristais, $3 \mathrm{~km}$ W of Cristalina, $17^{\circ} \mathrm{S} 48^{\prime} \mathrm{W}, 1175$ m, 3-XI-1965, Irwin \& al. 9831 (NY, P); ca. 5 km S of Cristalina, 1175 m, 3-XI-1965, Irwin \& al. 9849 (NY, P, UB); ca. $15 \mathrm{~km} \mathrm{~W}$ of Cristalina, $1200 \mathrm{~m}, 6-$ III-1966, Irwin \& al. 13610 (NY); Mun. Niquelandia, $1 \mathrm{~km}$ depois da mina de niquel da Companhia de Niquel Tocantins (CNT), 14²2'02"S 48²4'44"W, 15-VIII-1996, Mendonça \& al. 2596 (US), Mendonça \& al. 2597 (US), Mendonça \& al. 2598 (US) y Mendonça \& al. 2599 (RB, US); Serra dos Cristais, Pohl 868 (W); Mun.Niquelandia, ca. 5 km da Mina de Niquel Tocantins do lado direito da estrada, 31-V-1996, Silva \& Nunes de Jesús 3035 (CTES, IBGE). Minas Gerais: ca. $12 \mathrm{~km} \mathrm{~W}$ of Corinto, 600 m, 4-III-1970, Irwin \& al. 26882 (UB).

Distribución: Especie rara, fue colectada en flor y fruto entre marzo y noviembre en campo y «cerrado» en la Serra dos Cristais y en los alrededores de Niquelandia (Goiás) y cerca de Corinto (Minas Gerais) a 600-1200 m elev.

Obs.: Especie muy afín a Turnera subnuda Urb.

\section{Turnera trigona Urb.}

Figs. 23 y 79

Urban, I., Jahrb. Königl. Bot. Gart. Berlin 2:
111. 1883; Urban, Königl. Bot. Gart. Berlin 2: 111; Urban, en Martius C.F.P., Fl. Bras. 13 (3): 133. 1883. Typus: Brasil. Goiás. Corgo-Piau [Córrego Piaú], Pohl 2176 (lectotypus, aquí designado $\mathrm{W}$ !, isotypus $\mathrm{B}+$ fototipo $\mathrm{F} \mathrm{n}^{\circ} 13607$ !). $\mathrm{La}$ localidad tipo está situada cerca de la ciudad de Goiás, antiguamente llamada Vila Boa, donde Pohl estuvo desde el 6-XII-1819 hasta el 15-IV1820 (Urban, 1906).

Hierba perenne erecta, graminiforme, 0,15-1 m alt., base leñosa 1-5 mm diám., 1-3(15) ejes poco o no ramificados, 1-3 mm diám., cilíndricos, rojizos o negruzcos en la base, luego verdosos en seco, punteados y marcadamente angulados (sección sub-triangular a pentagonal), con aristas marcadas prolongándose en cada nudo en la vena media de la hoja; entrenudos 0,9-60 mm long. glabros o con pelos simples esparcidos. Hojas cartáceas, erectas o ligeramente incurvas en seco. Estípulas rudimentarias, pilosas, a cada lado de la base foliar, con coléteres $0,1-0,4$ $\mathrm{mm}$ long., cónicos, amarillentos o rojizos. Pecíolo 0-1 mm long. Lámina verde o castaña en seco, en hojas vegetativas totalmente glabra o con algunos pelos en la base, linear o linearlanceolada, 1,3-48 x 0,3-3 mm, relación largo:ancho = (4-)9-23(-30):1; haz punteada, base cuneada, ápice agudo, margen glabro, plano o ligeramente recurvo, entero o serrulado en la porción apical (hasta $80 \%$ de su longitud); vena media prominente en ambas caras, venas laterales 3-4, salientes en el envés; ángulo de divergencia 6-15; venación menor inconspicua. Nectarios $0-2$, circulares o elípticos, 0,3-1,5 x 0,3-0,7 mm, glabros o con el borde amarillento y pubérulo, el centro oscuro, situados en la unión de pecíolo y lámina o desplazados hasta $1 \mathrm{~mm}$ sobre el margen foliar. Hojas floríferas bracteiformes, pecíolo hasta 2,5 mm long., estrigosas especialmente en las venas y ápice, triangulares o lineares, 20-2 x 2,0-1,5 mm, base atenuada, ápice agudo muchas veces purpúreo, borde serrulado, generalmente con $1+1$ o $2+1$ nectarios notables en la unión de pecíolo y lámina. Flores epifilas, imperfectamente heterostilas, agrupadas hacia el ápice de las ramas en racimo bracteoso con entrenudos cortos $(8-0,1 \mathrm{~mm}$ long.). Alabastro subesférico o elipsoidal, ápi- 


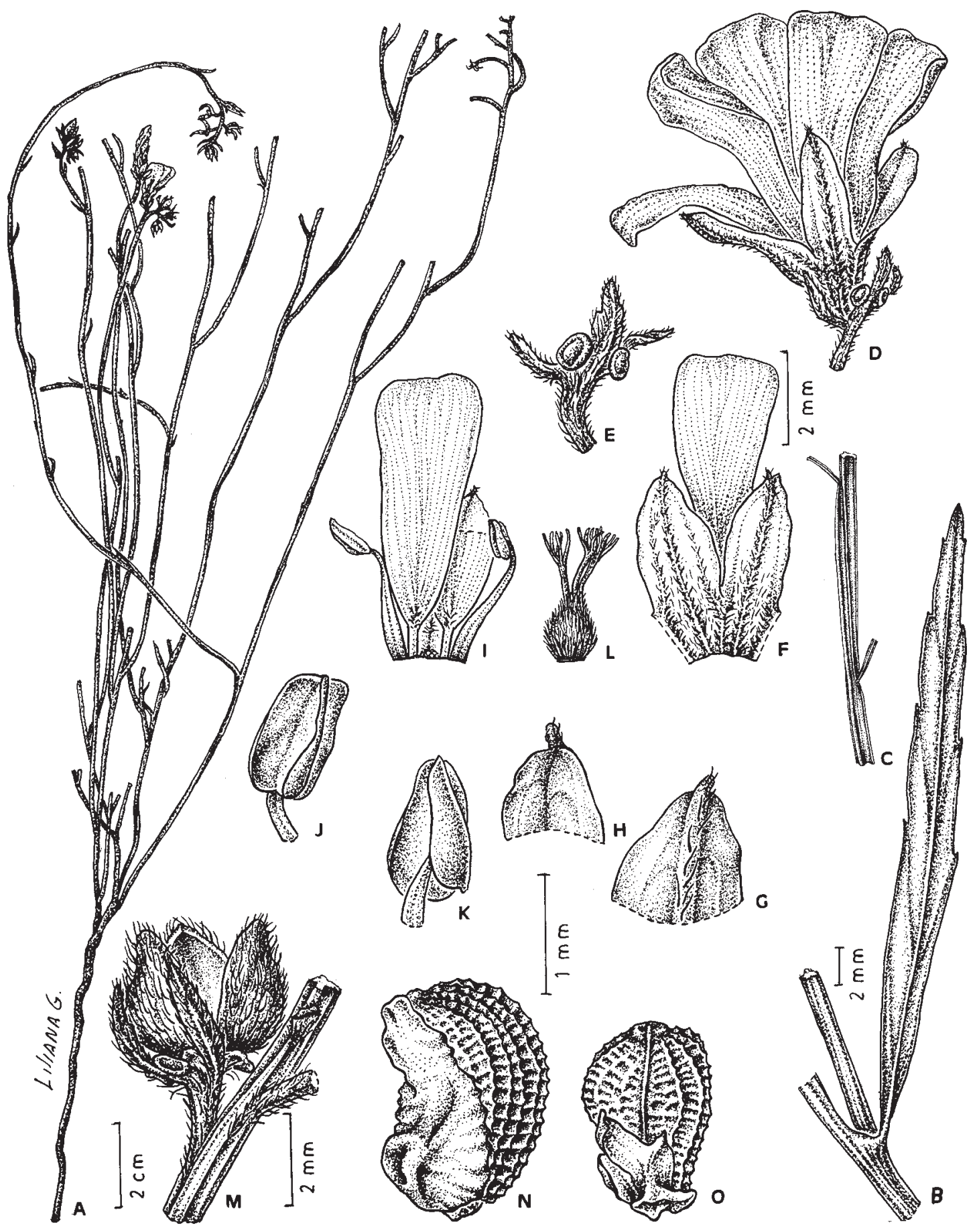

Fig. 79. Turnera trigona. A: planta. B: porción de tallo con hoja, cara abaxial, y rama axilar. C: porción de tallo y hojas. D: bráctea con flor epifila y profilos. E: bráctea con nectarios y profilos. F: porción del cáliz, cara externa, y pétalo. G-H: ápice de los lóbulos del cáliz, caras externa e interna. I: flor brevistila, porción del tubo calicino, cara interna, con pétalos y estambres adnatos; se ha cuadriculado la cicatriz dejada al desprender un estambre. J-K: anteras, vistas ventral y dorsal. L: gineceo. M: porción de tallo, bráctea con nectario, fruto epifilo y profilo. N-O: semillas con arilo, vistas lateral y rafeal (A, M: Arbo \& al. 4396; B-C: Hatschbach \& al. 60324; D-L, N-O: Hatschbach 36254). Del. Liliana Gómez. 
ce redondeado o agudo, general-mente purpúreo. Pedúnculo 1,7-3,0 mm long., totalmente adnato al pecíolo. Profilos opuestos, insertos en la base del receptáculo, 1,5-4,0 x 0,2-0,6 mm, subulados, generalmente estrigosos, a veces glabros excepto el ápice, borde entero o serrulado, ápice con frecuencia purpúreo. Pedicelo nulo. Cáliz verdosopurpúreo, 4-6 mm long., estriguloso a glabro; tubo calicino ca. 1/3, 1-2 mm long., por dentro velloso o glabro en la base; lóbulos de prefloración quincuncial, elípticos $u$ ovados, epider-mis a veces jaspeada, ápice mucronulado con frecuencia purpúreo. Corola más larga que el cáliz; pétalos con uña a veces vellosa, lámina elíptica u obovada, 59 x 1,7-3,5 mm, glabra, amarilla, base cortamente atenuada, generalmente carnosa y purpúrea o con venas violáceas, ápice truncado u obtuso. Filamentos estaminales glabros, soldados en la base $0,4-0,5 \mathrm{~mm}$ al tubo floral, $3 \mathrm{~mm}$ long. en flores longistilas, 3-4 mm long. en flores brevistilas; anteras dorsifijas, 1,0-1,5 x 0,4-0,6 mm, ovadas o elípticas, base emarginada, ápice obtuso, ligeramente curvadas después de la dehiscencia, filamento inserto en una cavidad a 0,4 $0,5 \mathrm{~mm}$ de la base. Ovario cónico, 0,8-1,5 $\mathrm{mm}$ long., estrigoso o en la base glabro; placentas 2-12 ovuladas; estilos cilíndricos, glabros, 2,5-2,8 $\mathrm{mm}$ long. en flores longistilas, 0,9-1,5 mm long. en flores brevistilas; estigma con 4-8 ramas 0,7-1,5 $\mathrm{mm}$ long. Fruto subesférico o elip-soide, a veces umbonado en el ápice, 3,0-4,5 x 3-5 $\mathrm{mm}$; tubo floral desprendiéndose a 0,3-0,5 $\mathrm{mm}$ de la base, dejando un reborde anular persistente; valvas latielípticas, estrigosas por fuera, glabras y jaspeadas por dentro, ápice generalmente purpúreo. Semilla ligeramente curvada, 1,8-2,1 x 0,9-1,2 mm, castaña; exóstoma redondeado; rafe linear, saliente, lado rafeal recto o incurvo; cálaza saliente, oscura, ligeramente deprimida en el centro. Episperma reticulado, nudos del retículo prominentes, aréolas cuadrangulares o rectangulares. Arilo 1,5-2,0 mm long., de células lisas.

Cromosomas: $2 \mathrm{n}=2 \mathrm{x}=14$, Arbo \& al. 3326 (Solís Neffa \& Fernández, 1993).
Material estudiado: BRASIL. Distrito Federal: Fercal, Brasília, 20-V-1967, Heringer 11516 (NY); margem do rio São Bartolomeu, Sucre \& al. 564 (UB). Goiás: Chapada dos Veadeiros, $24 \mathrm{~km}$ by road S of Terezina, ca. 1250 m, 16-III-1973, Anderson 7203 (NY, P, UB); Serra dos Cristais, BR 040, $10 \mathrm{~km}$ NW de Cristalina, camino a Brasília, ca. 1000 m, 1II-1990, Arbo \& al. 3326 (CTES, HRCB); GO-446, 3 km SW de Posse, camino a Iaciara, ca. 800 m, 3-II1990, Arbo \& al. 3512 (CTES, HRCB); GO-446, 42 km NW de Iaciara, camino a Nova Roma, ca. 500 m, 3-II-1990, Arbo \& al. 3543 (CTES, HRCB, K, MBM, MICH); alrededores de Colinas, sobre el camino a Cavalcante, 600-700 m, 5-II-1990, Arbo \& al. 3687 (C, CTES, F, G, GH, HRCB, K, LIL, MBM, MICH, MO); Caminho de Bacopary, 1847-1850, Burchell 6866 (K); As Lages to Rio Moquem, 24-IX1828, Burchell 7837 (K); Rio Moquem to As Araras, 25-IX-1828, Burchell 7861 (F, K, NY); nas margens do Rio Tocantinzinho, mun. Niquelandia, $13^{\circ} 59^{\prime} \mathrm{S}$ 48¹8'W, 400 m, 22-VII-1995, Cavalcanti \& al. 1576 (CEN, CTES); Mun. Posse, Vista Nova, 11-I1977, Hatschbach 39422 (CTES, MBM); $10 \mathrm{~km} \mathrm{~N}$ de São João da Aliança, 18-II-1975, Hatschbach \& al. 36254 (CTES, MBM, NY); mun. Teresina de Goiás, Rod. GO-118, próximo ao Rio Sucuri, 10-II1994, Hatschbach \& al. 60324 (CTES, K, MBM); Mun. Colinas do Sul, Rodovia Colinas do Sul a Niquelandia, entre Km 10-15, 500-600 m, 18-II2000, Hatschbach \& al. 70333 (CTES, MBM); ca. $10 \mathrm{~km}$ E of Cabeceiras, $16^{\circ} \mathrm{S} 47^{\circ} \mathrm{W}, 1000 \mathrm{~m}, 19-\mathrm{XI}-$ 1965, Irwin \& al. 10500 (E, NY, P); Serra dos Pirine-us, $70 \mathrm{~km} \mathrm{~N}$ of Corumbá de Goiás, on road to Niquelandia, in valley of rio Maranhão, ca. $700 \mathrm{~m}$, 20-I-1968, Irwin \& al. 18877 (NY, UB); Chapada dos Veadeiros: ca. $12 \mathrm{~km} \mathrm{~S}$ of Cavalcante, $1000 \mathrm{~m}$, 9-III1969, Irwin \& al. 24144 (NY, P), ca. $35 \mathrm{~km} \mathrm{~N}$ of Veadeiros, $1000 \mathrm{~m}$, 14-III-1969, Irwin \& al. 24345 (NY, $\mathrm{P}, \mathrm{UB}, \mathrm{UEC})$; Serra Geral do Parana, ca. $10 \mathrm{~km} \mathrm{~S}$ of S. João da Aliança, ca. 950 m, 17-III-1971, Irwin \& al. 32017 (NY, P, UB); ca. $5 \mathrm{~km} \mathrm{~W}$ of Niquelandia, ca. 750 m, 25-I-1972, Irwin \& al. 35005 (NY, P, UB); Chapada dos Veadeiros, Rodovia GO 118, próximo ao Rio das

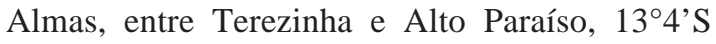
475'W, 8-II-1987, Pirani \& al. 1842 (K, SPF); mun. Minaçú, em frente ao antigo viveiro da Uhe Serra da Mesa, ca. $5 \mathrm{~km}$ da entrada $\mathrm{N}$ do Canteiro de obras, $13^{\circ} 48^{\prime} \mathrm{S}, 48^{\circ} 17^{\prime} \mathrm{W}, 500 \mathrm{~m}$, 9-XII-1991, Walter \& al. 902 (CEN, CTES); Fazenda Serra Negra (Niqueltocantins), arredores da Serra Negra em estrada para o rio Bagagem, $14^{\circ} 02^{\prime} \mathrm{S} 48^{\circ} 18^{\prime} \mathrm{W}, 450$ 
m, 8-VI-1992, Walter \& al. 1444 (CEN, RB). Minas Gerais: Diamantina, VI-1934, Brade 13888 (RB); Mun. Joaquim Felício, Serra do Cabral, 20-VII-1976, Davis \& al. 2416 (E, R, UEC); Mun. Buenopolis, Serra do Cabral, a $10-15 \mathrm{~km}$ da cidade, na estrada para Lapa Pintada, $17^{\circ} 53^{\prime} \mathrm{S} 4^{\circ} 4^{\circ} 15^{\prime} \mathrm{W}, 1100-1200 \mathrm{~m}$, 13-X-1988, Harley \& al. 24951 (CTES, K, SPF); Mun.Joaquim Felício: Serra do Cabral, 17-I-1996, Hatschbach \& al. 64249 (C, CTES, MBM); Fzda. Serra do Cabral Agro-Industria (Mun.Varzea da palma), 19-XI-1997, Hatschbach \& al. 67522 (CTES, MBM); mun. Francisco Dumont, Serra do Cabral, Rio Preto, 16-V-2001, Hatschbach \& al. 72142 (CTES, MBM, W); Serra do Espinhaço, $20 \mathrm{~km} \mathrm{~W} \mathrm{of}$ Montes Claros, road to Agua boa, 1000 m, 24-II1969, Irwin \& al. 23839 (MO, NY, P); S. Anna dos Alegres, IX-1834, Riedel 2608 (LE, P, sintipo); Joaquim Felício, Serra do Cabral, Comecha de Cima, ca. 1000 m, 2-IX-1985, Zappi \& al. s.n., CFCR 8191 (CTES, SPF). Tocantins: prope Arrayas, III-1840, Gardner 3751 (BM, K, W, sintipo).

Distribución y fenología: Turnera trigona es una especie propia de Distrito Federal, Goiás, Tocantins y Minas Gerais. Vive en cerrados, campos-cerrados, laderas y campo rupestre con suelo arenoso, pedregoso, o con afloramientos rocosos, entre 400 y $1520 \mathrm{~m}$ de elevación. Florece y fructifica todo el año.

Obs.: En dos especímenes: Anderson 7203 y Irwin \& al. 23947, hay flores con gineceo y androceo de igual longitud. Además, en ambos el androceo presenta anormalidades: una flor tiene 4 estambres normales y uno abortado, y otra tiene un estambre más largo que los demás. El ejemplar Burchell 7861 (K) tiene caracteres intermedios entre Turnera trigona y $T$. tenuicaulis.

Las hojas presentan estructura dorsiventral y son anfistomáticas, la vaina fascicular presenta elementos taníferos y esclerenquimáticos (Gonzalez, 2000).

\section{Turnera uleana Urb.}

Figs. 12 y 80

Urban, I., Fedde Repert. Spec. Nov. Regni Veg. 4: 132. 1907. Typus: Brasil. Bahia, in «taboleiro» prope Remanso, XII-1906, Ule 7502 (holotypus $\mathrm{B}+$ fototipo $\mathrm{F} \mathrm{n}^{\mathrm{o}} 13608$, isotypi $\mathrm{HBG}$ !, K!, PR!).

Hemicriptófita herbácea, eje subterráneo leñoso, tallos numerosos procumbentes o suberectos, hasta $20 \mathrm{~cm}$ alt., simples o ramosos, indumento blanquecino, villoso-hirsuto, lanoso hacia el ápice, con pelos simples $2 \mathrm{~mm}$ long. y otros crespos más cortos, cicatrices foliares salientes. Hojas discoloras, con frecuencia plegadas longitudinalmente. Estípulas no desarrolladas. Pecíolo 1-5 mm long. Lámina ovada o angustiovada, 1,5-4 x 1$2 \mathrm{~cm}$, relación largo:ancho $=1,5-2: 1$; base aguda o cuneada, ápice obtuso o agudo, margen revoluto, crenado o aserrado; haz grisácea en seco, con pelos simples, largos, delgados, blandos, sin orientación definida, y pelos más cortos crespos; envés totalmente cubierto de pelos lanosos blancos; 3-6 venas laterales a cada lado, prominentes en el envés, con pelos simples muy largos y adpresos, terminando en las escotaduras del margen; ángulo de divergencia $30-35^{\circ}$. Nectarios 2, marginales, orientados hacia el envés, cerca de la unión de pecíolo y lámina, sólo en las hojas superiores. Flores heterostilas, epifilas. Pedúnculo 2-3 $\mathrm{mm}$ long., adnato al pecíolo. Profilos linearsubulados, 5-10 x 0,5 mm, enteros, villosos. Pedicelo ausente. Cáliz 10-12 mm long.; tubo calicino 5-6 mm long., cara externa álbidovillosa, cara interna glabra o pubescente; lóbulos angustiovados, trinervados. Pétalos amarillo vivo, obovados, 10-12 x $7 \mathrm{~mm}$, base atenuada, ápice truncado, cara adaxial pilosa en la base. Filamentos estaminales soldados $0,5 \mathrm{~mm}$ en la base al tubo floral, $5 \mathrm{~mm}$ long. en flores longistilas, 7,5 mm long. en flores brevistilas; anteras ovadas, $0,9 \times 0,5 \mathrm{~mm}$, filamento inserto dorsalmente en la mitad, ápice obtuso. Ovario con placentas 2-3-ovuladas; estilos pilosos, $4 \mathrm{~mm}$ long. en flores longistilas, $3 \mathrm{~mm}$ long. en flores brevistilas; estigmas 2,7 mm long., con 15-20 ramas. En flores longistilas, el gineceo es $3 \mathrm{~mm}$ más largo que el androceo. Fruto globoso, 3-4 mm long., 3-seminado, liso, cara externa con pelos cortos en la base, más largos hacia el ápice. Semilla inmadura castaña, curvada, 2,2-2,5 x 1-1,1 mm; exóstoma brevemente apiculado; rafe linear, oscura, lado rafeal incurvo; cálaza 


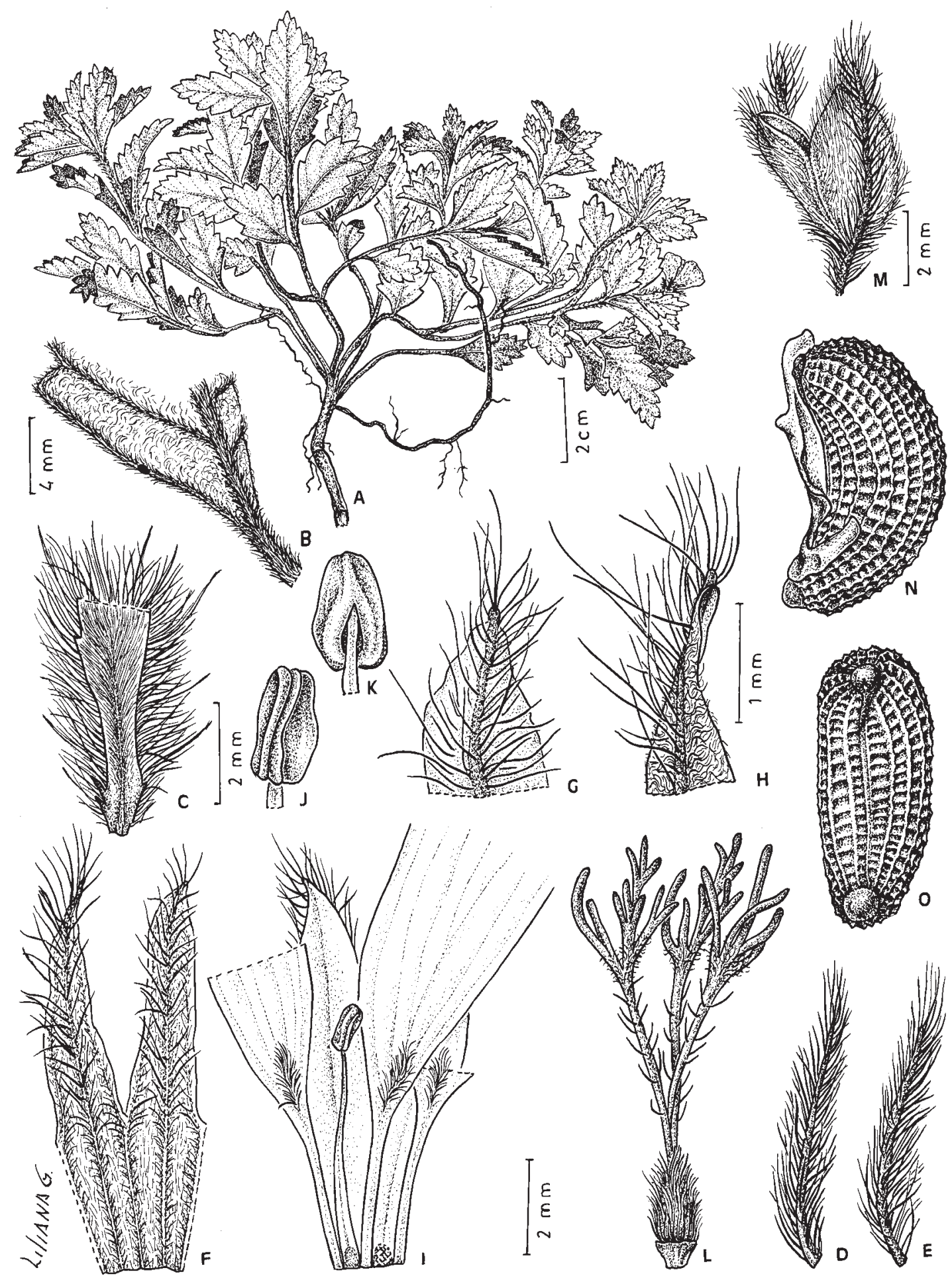

Fig. 80. Turnera uleana. A: planta. B: porción de hoja con nectario, cara abaxial. C: porción basal de hoja florífera, cara adaxial. D-E: profilos. F: porción del cáliz. G-H: ápice de los lóbulos del cáliz interno y externo, cara externa. I: flor longistila, porción del tubo calicino, cara interna, con pétalos y estambre adnatos; se ha cuadriculado la cicatriz dejada al desprender un estambre. J-K: anteras, vistas ventral y dorsal. L: gineceo. M: fruto y profilos. N: semilla con arilo, vista lateral. O: semilla, vista rafeal (Ule 4502) Del. Liliana Gómez. 
apical, redondeada, terminada en una prominencia oscura, prolongación de la rafe. Episperma reticulado, nudos no prominentes, aréolas transrectangulares, sin depresión punctiforme, epidermis papilosa. Arilo angosto, unilateral, más largo que la semilla, de células papilosas.

Material estudiado: BRASIL. Bahia: Mun. Agua Quente, Pico das Almas, vertente oeste, entre Paramirim das Crioulas e a face NNW do Pico, $13^{\circ} 31^{\prime} \mathrm{S} 42^{\circ} 00^{\prime} \mathrm{W}, 1100 \mathrm{~m}$, local chamado Morro do Chapéu, 17-XII-1988, Harley \& Stannard 27568 (CTES, K, SPF).

Distribución y fenología: Se conocen solamente el tipo, colectado en «taboleiro» y otro ejemplar recogido en Pico das Almas en «cerrado» de altitud.

Obs.: El ejemplar de Pico das Almas presenta el mismo indumento y características que el holotipo, pero se diferencia en el porte, se trata de un subarbusto erguido, hasta $40 \mathrm{~cm}$ de altura, con entrenudos bien desarrollados.

\section{Turnera vallsii Arbo, sp. nov.}

Figs. 7 y 81

Fruticulus ca. 40 cm altus, pilis crispulis brevibus et aliis curvato-erectis 1,2 $\mathrm{mm}$ longis indutus; stipulae rudimentariae. Folia tomentosa, suprema sensim decrescentia, flores et nectariis minutis gerentia. Flores heterostyli, apice caulium capituliformi-confertis; pedunculi petiolo adnati; pedicelli nulli; calyx 4-5,8 mm longus, extus densissime pilosus, in $1 / 2$ alt. coalitus; petala ad basin pilosa; filamenta glabra, basi tubo ca. 0,5 mm tota facie adnata, placentae 3-ovulatae. Fructus dorso laeve. Semina 2-2,3 mm longa, curvata vel subrecta, brunnea, reticulata, chalaza nigrescente prominente, arillo unilaterali.

Typus. Brasil. Goiás, $20 \mathrm{~km}$ E de Dianopolis, Faz. Água Limpa, $11^{\circ} 40^{\prime} \mathrm{S} 46^{\circ} 38^{\prime} \mathrm{W}, 17-\mathrm{III}-1982$, Krapovickas, Valls \& Silva 37868 (holotypus $\mathrm{CEN}$, isotypi CTES, K, MO).

Subarbusto ca. $40 \mathrm{~cm}$ alt., tallo leñoso en la porción basal, 3-4,5 mm diám., corteza pardooscura, longitudinalmente estriada, lenticelas elipsoides; ramas 1-1,7 mm diám., densamente pilosas, pelos amarillentos, curvadoantrorsos o más o menos patentes $1,2 \mathrm{~mm}$ long. mezclados con pelos simples, crespos, más cortos. Hojas pardo-grisáceas en seco, algo discoloras. Estípulas rudimentarias con coléteres oscuros, 0,2-0,6 mm long. Pecíolo 1$3 \mathrm{~mm}$ long., indumento más denso que el del tallo. Lámina elíptica u ovada, obovada o suborbicular, 9-20 x 8,5-13 mm, relación largo:ancho $=1-1,5: 1$; base cuneada, brevemente atenuada o redondeada, ápice agudo u obtuso, margen ligeramente revoluto, crenado excepto en la porción basal; haz tomentosa, con pelos simples largos y pelos crespos más cortos muy densos, vena media y venas laterales hundidas; envés tomentoso-hirsuto, con pelos más largos sobre las venas rojizas y prominentes; 4-5 pares de venas secundarias, incurvas, perdiéndose en los dientes y dando ramas hacia las escotaduras; ángulo de divergencia $40-45^{\circ}$; venas terciarias recurvas, poco visibles en el envés. Nectarios ausentes en hojas vegetativas, o diminutos, 0,2 $\mathrm{mm}$ diám, sobre el margen foliar. Hojas floríferas apicales bracteiformes, espatuladas, pecíolo ca. $2 \mathrm{~mm}$, lámina muy reducida, 1,5-2 mm, ápice dentado, con un par de nectarios rojizos 0,4 mm diám., asentados sobre el envés, junto al margen foliar. Flores dimorfas, reunidas en los ápices de las ramas en racimos bracteosos capituliformes. Pedúnculo $0,5 \mathrm{~mm}$, adnato al pecíolo. Profilos lineares, 3,5-5,3 $\mathrm{mm}$ x 0,3$0,5 \mathrm{~mm}$, enteros, insertos en la base del receptáculo. Pedicelo ausente. Cáliz 4-5,8 mm long.; tubo calicino 2-3 mm long., interiormente piloso en la porción apical, por fuera con pelos simples cortos crespos y pelos simples más largos $(0,7 \mathrm{~mm}$ long.) sobre las venas; lóbulos angustiovados o triangulares, con pelos más largos que el tubo (1 mm long.), 3-5 nervados, nervio medio prolongado en un breve mucrón. Corola más corta o casi igual que el cáliz; pétalos con uña pilosa en la mitad superior, lámina obovada, ca. $2 \mathrm{~mm}$ long., base subcuneada, con algunos pelos. Filamentos estaminales soldados en la base 0,4-0,5 $\mathrm{mm}$ al tubo calicino, glabros, subulados, $4 \mathrm{~mm}$ long. en flores brevistilas, $2 \mathrm{~mm}$ long. en flo- 


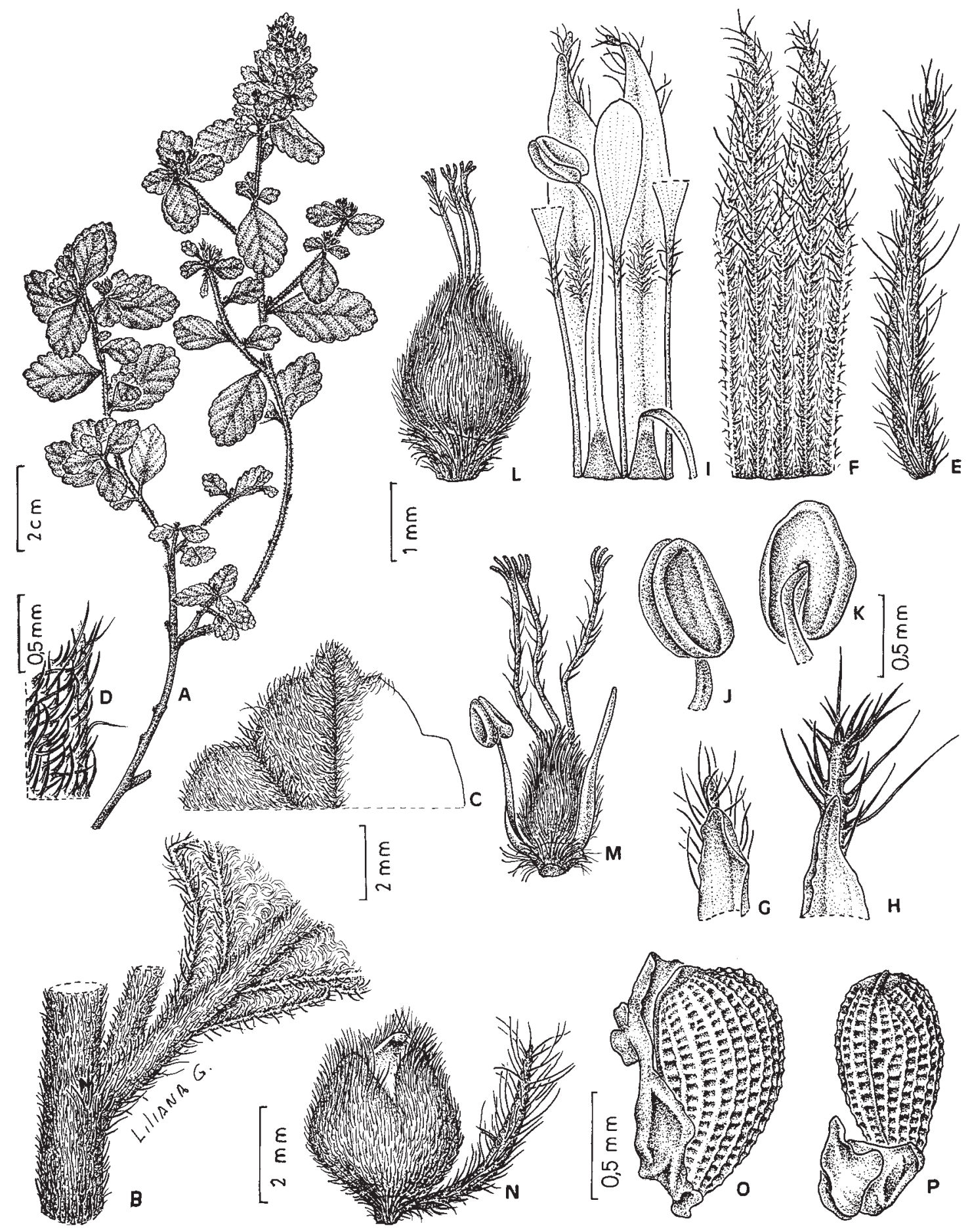

Fig. 81. Turnera vallsii. A: planta. B: porción de tallo, hoja, cara abaxial y rama axilar. C: ápice de lámina foliar, cara adaxial. D: detalle del indumento foliar. E: profilo. F: porción del cáliz, cara externa. G-H: ápice de los lóbulos del cáliz, cara interna. I: flor brevistila, porción del tubo calicino, cara interna, con pétalos y estambres adnatos; se ha punteado la porción adherida del filamento. J-K: anteras, vistas ventral y dorsal. L: receptáculo y gineceo. M: flor longistila, estambre y gineceo. N: fruto y profilo. O-P: semillas con arilo, vistas lateral y rafeal (Krapovickas \& al. 37868). Del. Liliana Gómez. 
res longistilas; anteras ovadas u ovado-oblongas, $0,8 \times 0,4 \mathrm{~mm}$, base emarginada, filamento inserto dorsalmente a $0,4 \mathrm{~m}$ de la base, ápice obtuso. Ovario ovoide, densamente piloso, 11,5 mm long.; placentas 3-ovuladas; estilos cilíndricos, pilosos, 1,6 $\mathrm{mm}$ long. en flores brevistilas, 2,6 mm long. en flores longistilas; estigmas paucirramosos, 0,2-0,3 mm long. En flores longistilas gineceo casi tan largo como la corola, $1,8 \mathrm{~mm}$ mayor que el androceo; en flores brevistilas androceo $1,2 \mathrm{~mm}$ más largo que el gineceo. Fruto ovoide, 2-3 mm long.; valvas de superficie irregular por la base cónica de los pelos simples, adpresos, entremezclados con pelos simples más cortos y crespos; por dentro glabras, nítidas. Semilla inmadura pardo-oscura, 2-2,3 x 1-1,1 mm, angustiobovoide, curvada; exóstoma cónico; rafe linear algo prominente, lado rafeal incurvo, recto o sigmoide; cálaza redondeada, con una protuberancia negruzca que es continuación de la rafe. Episperma reticulado, nudos no prominentes, aréolas sin depresión punctiforme, epidermis lustrosa, papilosa en las aréolas. Arilo más corto o ligeramente más largo que la semilla, amarillento en seco, de células papilosas.

Distribución: Se conoce solamente el ejemplar tipo, colectado en «cerrado» de suelo arenoso.

Obs. El aspecto vegetativo de Turnera vallsii es similar al de $T$. stachydifolia, que se diferencia por tener pelos glandulares capitado-sésiles, y los filamentos estaminales pilosos, y a $T$. angelicae, también con filamentos estaminales pilosos; pétalos con cara superior pilosa y anteras de ápice agudo.

Dedico esta especie a José Francisco de Montenegro Valls, botánico amigo quien participó en la colección del ejemplar tipo.

\section{Turnera venezuelana Arbo, sp. nov.}

Figs. 38 y 82

Fruticulus $20 \mathrm{~cm}$ altus, caules tereti, pilis brevibus densis et aliis erectis intermixtis; cicatrices foliorum prominentibus; stipulae rudimentariae; folia petiolata, ovata vel elliptica, subtus praeter nervis pilosis glabra, supra basin subtus nectariis stipitatis gerentibus. Flores dimorphi, apice caulium conferti, pedunculi toti adnati, calyx 6,5 $\mathrm{mm}$ longus, extus ad basin glabrus, filamenta glabra, basi tubo tota facie adnata, antherae 0,7 $\mathrm{mm}$ long., placentae 3ovulatae, styli glabri. Fructus dorso laeve, prophylla fructus superantia. Semina curvata, reticulata, chalaza vix prominula, arillo unilaterali, angusto.

Typus. Venezuela. Falcón: Sierra de San Luis, cerca del río San Antonio, 19 km SE de Coro, 160 m, 1-V-1979, Werff H.v.d. \& Wingfield R. 3464 (holotypus CTES, isotypi CORD, VEN, no vistos).

Sufrútice de $20 \mathrm{~cm}$, tallos cilíndricos, con pelos simples, largos, amarillentos, patentes o divaricados, $1 \mathrm{~mm}$ long., entremezclados con pelos simples crespos o curvados $0,2-0,3 \mathrm{~mm}$ long.; entrenudos de 1-3 cm, los apicales muy acortados, cicatrices foliares salientes. Hojas herbáceas. Estípulas rudimentarias, con 1-2 coléteres de 0,2-0,3 mm long. Pecíolo 1-55 mm long. Lámina foliar ovada o elíptica, en hojas basales obovada, 29-57 x 12-20 mm, relación largo:ancho $=2-3,2: 1$; base atenuada o cuneada, ápice agudo, margen doblemente crenado-aserrado, plano; haz parda, frecuentemente oscura, con pelos simples de 0,7-1,3 mm long., base abultada, curvado-antrorsos, orientados diagonalmente con respecto a la vena media; envés liso, glabro; 6-7 pares de venas laterales subimpresas en la haz, prominentes en el envés, laxamente pilosas, perdiéndose hacia el borde, con ramas hacia las escotaduras; ángulo de divergencia $30-45^{\circ}$; venas terciarias a veces visibles, venación menor inconspicua. Nectarios generalmente 2, circulares o elípticos, 0,2-0,4 mm long., pardos o negruzcos, ligeramente cóncavos y visiblemente estipitados $(0,2-0,3 \mathrm{~mm})$ en los nomófilos; sésiles, con reborde pilósulo, desplazados 2-4 $\mathrm{mm}$ sobre el margen foliar en hojas floríferas. Flores epifilas, heterostilas, reunidas en un racimo hojoso abreviado. Pedúnculo adnato al pecíolo, incluso a la base de la lámina, pedicelo nulo. Profilos insertos en la base del cáliz, lineares o linear-subulados, 3 mm long., uninervados, cara externa pilosa, 


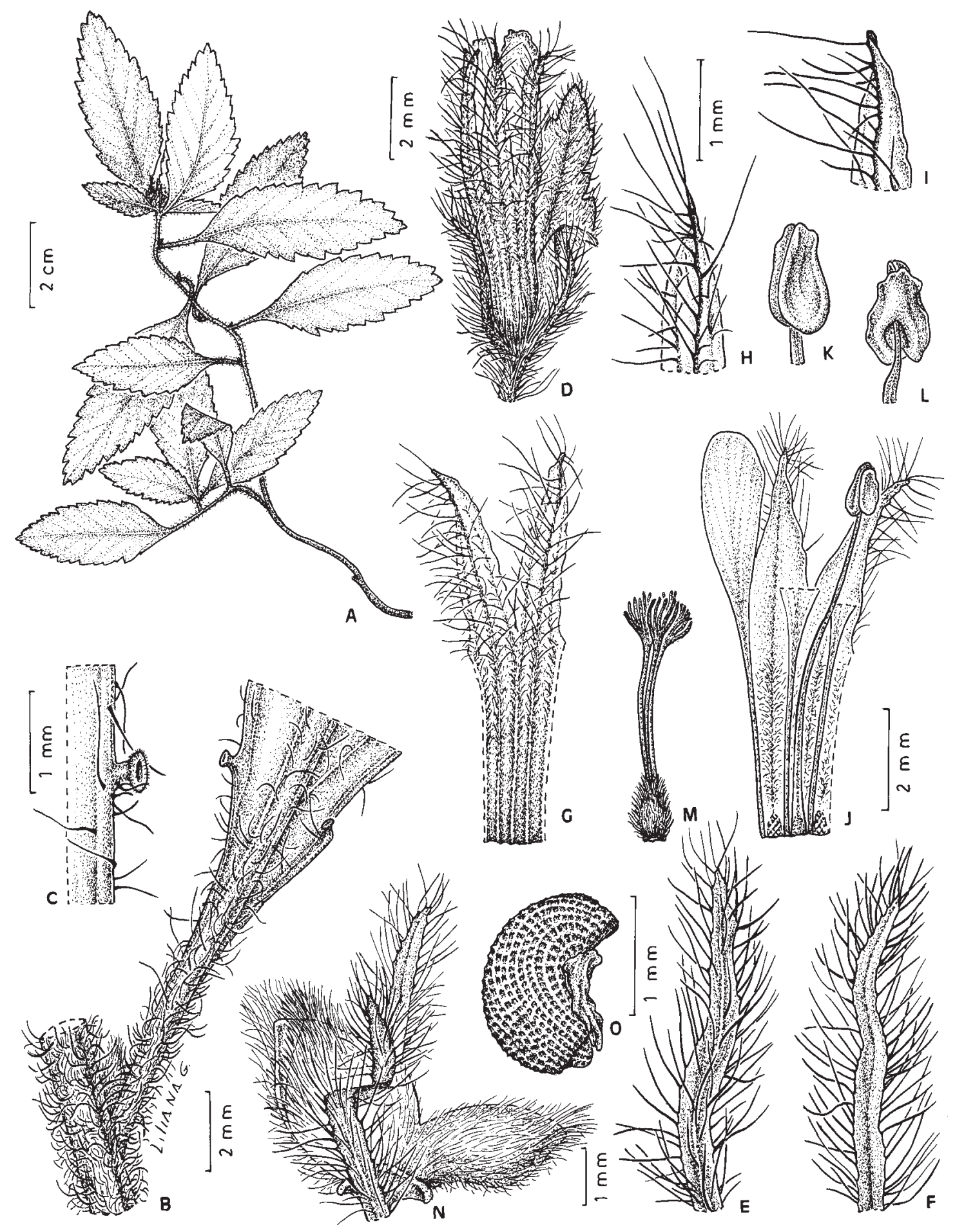

Fig. 82. Turnera venezuelana. A: planta. B: porción de tallo con hoja, cara abaxial, y yema axilar. C: nectario. D: bráctea con flor epifila y profilos. E-F: profilos. G: porción del cáliz, cara externa. H-I: ápice de los lóbulos del cáliz, cara externa. J: flor brevistila, porción del tubo calicino, cara interna, con pétalos y estambre adnatos; se ha cuadriculado la cicatriz dejada al desprender 2 estambres. K-L: anteras, vistas ventral y dorsal. M: gineceo. N: fruto y profilos. O: semilla con arilo, vista lateral (Werf \& Wingfield 3464). Del. Liliana Gómez. 
cara interna glabra. Cáliz 6,5 mm long.; tubo calicino 3-5 mm long., cara externa glabra en la base, luego con pelos simples laxos, cortos; cara interna álbido-pubescente; lóbulos 3nervados, triangulares o subulados, las venas con pelos simples, largos, 1,5 mm long., curvado-antrorsos o erectos, márgenes internos membranáceos, ápice brevemente mucronado. Pétalos amarillos, apenas más largos que el cáliz, $37 \mathrm{~mm}$ long., obovado-cuneados, glabros. Filamentos estaminales glabros, adnados $0,5 \mathrm{~mm}$ al tubo calicino, 5,5 $\mathrm{mm}$ long. en flores brevistilas; anteras ovadas o elípticas, $0,7 \times 0,4 \mathrm{~mm}$, rectas a la dehiscencia, base emarginada, ápice truncado, filamento inserto dorsalmente a $0,3 \mathrm{~mm}$ de la base. Ovario $1 \mathrm{~mm}$ long., hirsuto-piloso; placentas 3-ovuladas; estilos glabros, $3 \mathrm{~mm}$ long. en flores brevistilas; estigma penicilado, $1 \mathrm{~mm}$ long., glabro. En flores brevistilas el androceo es 1,5 mm más largo que el gineceo. Fruto ovoide, $2 \mathrm{~mm}$ long.; profilos acrescentes, $5 \mathrm{~mm}$ long., más largos que el fruto; valvas ovadas, amarillentas, cara externa con pelos simples cortos más largos hacia el ápice; cara interna glabra, lustrosa, amarillenta. Semilla inmadura parda, obovoide, 1,5 x 0,7 mm; exóstoma breve; rafe linear apenas marcada, lado rafeal incurvo; cálaza redondeada apenas prominente. Episperma reticulado, nudos del retículo algo prominentes, epidermis lisa, aréolas cóncavas. Arilo unilateral más corto que la semilla.

Distribución. Se conoce solamente el ejemplar tipo.

Obs. El aspecto vegetativo de esta especie es muy similar al de Turnera pumilea L., cuyas semillas se diferencian por las aréolas grandes y la cálaza cónica.

\section{Turnera vicaria Arbo, sp. nov.}

Figs. 43 y 83

Herba $35 \mathrm{~cm}$ alta, rami flavido velutini, cicatrices foliorum prominentibus; stipulae rudimentariae; folia elliptica vel angustielliptica, supra velutina, subtus tomentosa, margine plano, serrulato, nectariis nullis. Flores apice caulium conferti, pedunculi toti adnati, calyx velutinus 7 mm longus, ca. in $1 / 2$ coalitus, petalis flavis calycem paullo superantibus; filamenta glabra, basi tubo tota facie adnata, antherae ca. $1 \mathrm{~mm}$ longae, dorso in 1/2 affixae; ovarium dense pilosum, styli supra medium velutini. Fructus velutinus, $3 \mathrm{~mm}$ longus. Semina reticulata, curvata, chalaza parum prominula, arillo unilaterali.

Typus. BRASIL. Goiás: Cavalcante, Serra da Contenta, $13^{\circ} 37^{\prime} 48^{\prime \prime} \mathrm{S} 47^{\circ} 28^{\prime} 46^{\prime \prime} \mathrm{W}, 1186$ m, 13III-2007, Pastore J.F.B., Harley R.M. \& Santos A.A. 1825 (holotypus HUEFS, isotypus CTES).

Hierba $35 \mathrm{~cm}$ alt., ramas del año cilíndricas, velutinas con pelos simples, amarillos adpresos 0,5 mm long., y otros más cortos, crespos; cicatrices foliares salientes. Yemas seriales 2, ramas seriales desarrolladas. Hojas algo discoloras en seco. Estípulas rudimentarias, pilosas, con coléteres $0,1 \mathrm{~mm}$ long. Pecíolo 0-0,5 mm long., indumento como el del tallo. Lámina elíptica o angustielíptica, 12-22 x 2-5,5 mm, relación largo: ancho $=4-7,5: 1$; base cuneada, ápice agudo; margen piloso, plano, serrulado, cada diente generalmente terminado en un coléter; haz ocrácea, velutina, con pelos simples amarillos $0,5 \mathrm{~mm}$ long.; envés tomentoso, con pelos crespos blancos muy densos y pelos largos, amarillos, antrorsos sobre las venas; 3-4 pares de venas laterales ligeramente hundidas en la haz, prominentes en el envés, ascendentes, perdiéndose hacia el borde; ángulo de divergencia $20^{\circ}$. Nectarios ausentes. Flores epifilas, presumiblemente dimorfas (sólo se han visto flores longistilas), a veces reunidas en racimos hojosos apicales breves. Pedúnculo 0,5-1 $\mathrm{mm}$ long., totalmente adnato al pecíolo o con el ápice brevemente libre. Profilos subulados, 3-4 x 0,3-0,4 mm, densamente pilosos en ambas caras. Pedicelo nulo. Cáliz $7 \mathrm{~mm}$ long., sépalos soldados casi hasta la mitad; tubo calicino 3,2 mm long., velloso por dentro, por fuera velutino; lóbulos angustiovados o angusti-triangulares, velutinos, márgenes internos membranáceos, glabros, ápice agudo. Corola amarilla, apenas más larga que el cáliz; pétalos con la uña soldada al tubo calicino, 


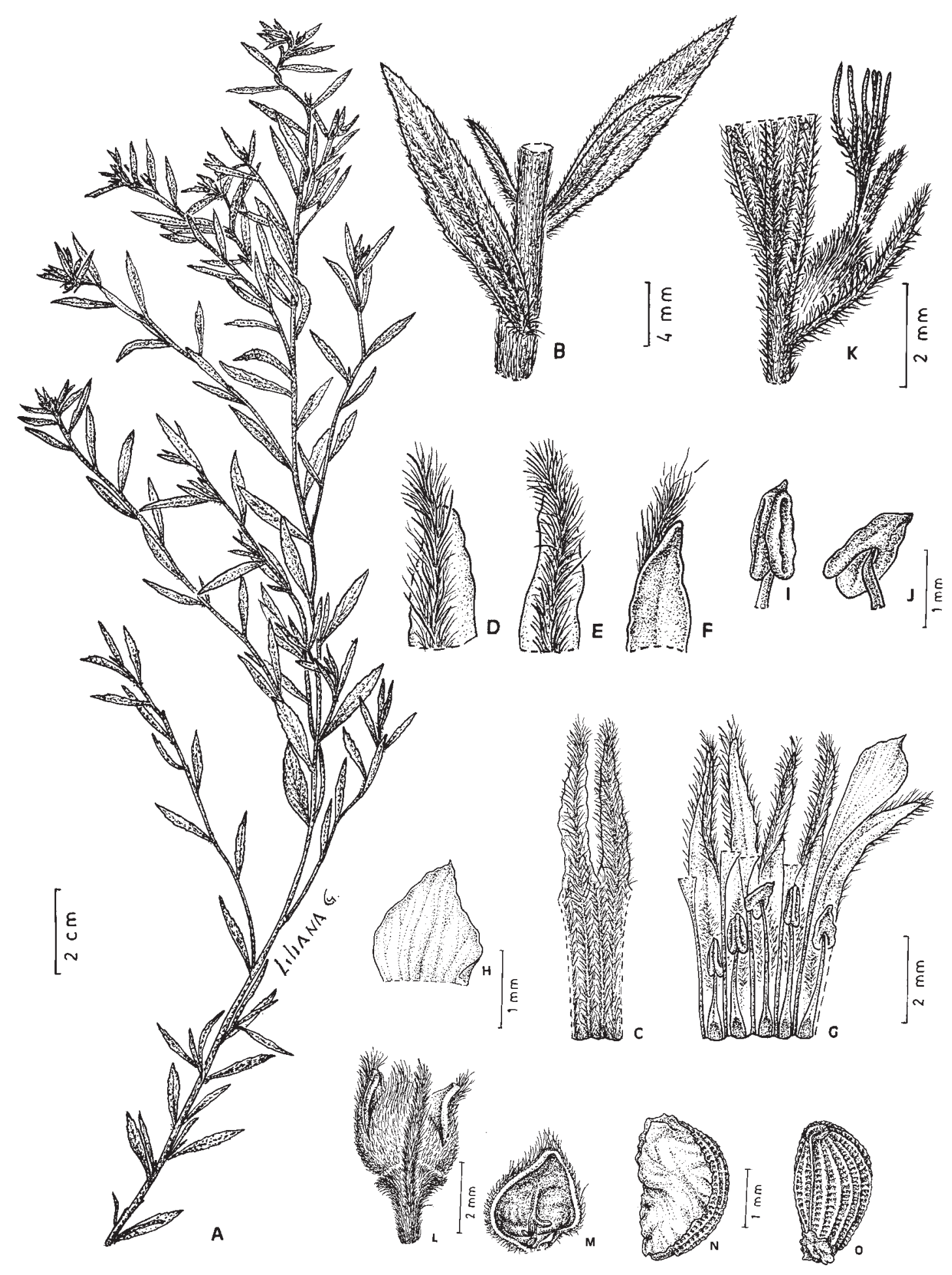

Fig. 83. Turnera vicaria. A: planta. B: porción de tallo con hojas. C: porción del cáliz, cara externa. D-F: ápice de lóbulos del cáliz, caras externas e interna. G: flor longistila, cáliz, cara interna, con pétalos y estambres adnatos; se ha sombreado la porción adherida en cada estambre. H: ápice del pétalo. I-J: anteras, vistas ventral y dorsal. K: porción basal de una hoja florífera con gineceo y profilos adnatos. L: fruto. M: valva del fruto, cara interna. N: semilla con arilo, vista lateral. O: semilla, vista rafeal (Pastore \& al. 1825). Del. Liliana Gómez 
lámina oblonga, amarilla, 4,5 x 1,5 mm, con pelos largos y antrorsos en la porción basal (1/ 3-1/2) de la vena media. Filamentos estaminales soldados $0,3 \mathrm{~mm}$ al tubo calicino en la base, glabros, de 3,5 mm long. en flores longistilas; anteras angustiovadas $1,1 \mathrm{x} 0,5$ $\mathrm{mm}$, dorsifijas, apiculadas. Ovario ovoide, 1 mm long., densamente piloso; placentas 3ovuladas; estilos 3,5 mm long., pilosos en la mitad basal, velutinos en la mitad apical; estigma glabro penicilado $1 \mathrm{~mm}$ long. con 5-6 ramas de diferente longitud. En flores longistilas el gineceo es 1-1,8 mm más largo que el androceo. Fruto ovoide, $3 \mathrm{~mm}$ long., cara externa velutina, cara interna glabra, impreso-reticulada; tubo floral desprendiéndose a $0,3 \mathrm{~mm}$ de la base, dejando un reborde anular persistente. Semilla inmadura curvada, 2,5 x $1,3 \mathrm{~mm}$; exóstoma hemisférico, lado rafeal cóncavo; cálaza algo prominente, superficie plana, pigmentada, de orientación intermedia. Episperma reticulado, aréolas transrectangulares o cuadrangulares cóncavas. Arilo unilateral, ancho, margen lobulado, células aparentemente papilosas.

Distribución: Se conoce solamente el material tipo, colectado en «cerrado» sensu stricto.

Obs.: Especie muy similar a Turnera lineata, de la que se diferencia por carecer de nectarios, por los estilos velutinos, y los estigmas paucirramosos. Una flor longistila del holotipo presenta 4 estambres largos $(2,2 \mathrm{~mm}$ long.) y uno corto (1,7 mm long.), situación que se ha encontrado ocasionalmente en otras especies. La única flor estudiada en el isotipo CTES es presumiblemente longistila, con gineceo $1 \mathrm{~mm}$ más largo que el androceo, pero presenta estambres de diferente longitud: 2 de 3,2 mm long., 2 de 2,5 mm long. y uno de 1,8 mm long.

\section{Serie Conciliatae Arbo, nov. ser.}

Fig. 84

Frutices, pilis simplicibus et glandularibus microcapitatis, stipulae laciniatae 1-2 mm longae. Folia integra, usque $9 \mathrm{~cm}$ longa; petiolum

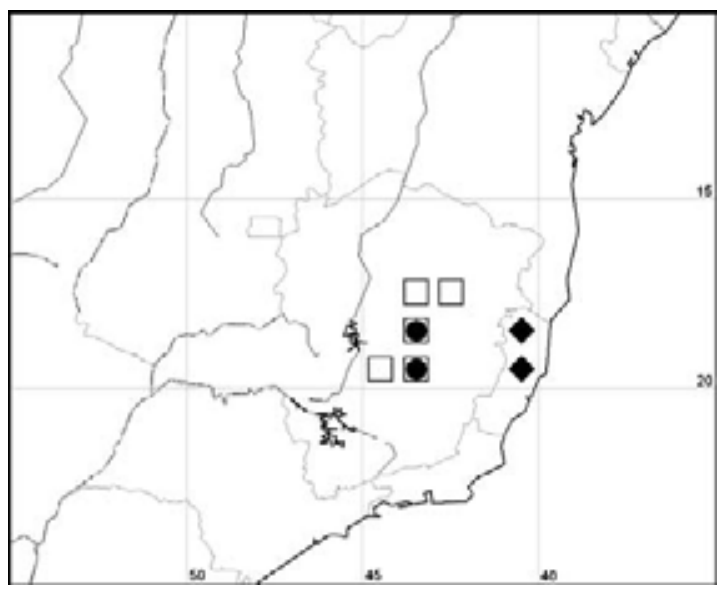

Fig. 84. Distribución de la Serie Conciliatae y de la Serie Sessiliflorae: Turnera dichotoma $\square$; T. revoluta

nectariis praeditum. Flores heterostyli, in racemum bracteatum apicali confertis; pedunculo cum petiolo coalito; pedicelli nulli; calyx in $2 / 3$ alt. coalitus; filamenta glabra, basi tubo tota facie adnata et inter sese inequaliter connata; antherae dorso in $1 / 2$ affixae. Fructus granulosus. Semina subrecta, reticulata, chalaza apical, prominente, concava, arillo unilaterali.

\section{Typus: Turnera rubrobracteata Arbo}

Arbustos de hasta $2 \mathrm{~m}$, pelos tectores simples, y pelos glandulares microcapitados (Gonzalez \& Arbo, 2004). Hojas de tamaño mediano (hasta $9 \mathrm{~cm}$ long.), enteras; estípulas laciniadas, 1-2 $\mathrm{mm}$ long. Nectarios extraflorales presentes, situados en el pecíolo. Flores epifilas agrupadas en inflorescencias racemosas terminales o axilares. Bracteas rojas o purpúreas. Pedúnculo floral adnato al pecíolo. Profilos opuestos y lineares, insertos en la base del receptáculo. Pedicelo ausente. Sépalos soldados entre sí 2/3 de su longitud; lóbulos de prefloración quincuncial. Pétalos rosados. Filamentos estaminales glabros, soldados al tubo floral solamente en la base y por la cara externa, y entre sí irregularmente, a diferentes alturas; anteras dorsifijas. Ovario y estilos pilosos. Fruto granuloso. Semilla curvada; cálaza prominente, ligeramente deprimida en el centro. Episperma reticulado, aréolas con una depresión punctiforme. Arilo 
unilateral, de células lisas.

La única entidad conocida de esta serie es una especie rupícola, endémica de Brasil, Espirito Santo.

\section{Turnera rubrobracteata Arbo}

Arbo, M. M., Bonplandia 7(1-4): 90-94, Fig. 8. 1993. Typus: Brasil. Espirito Santo: Rio Pancas, Colatina, 8-XII-1943, Kuhlmann 6656 (holotypus $\mathrm{RB})$.

\section{Serie Sessilifoliae Arbo, nov. ser.}

Fig. 84

Frutices usque $1 \mathrm{~m}$, pilis simplicibus et fasciculato-stellaribus. Folia parva, exstipulata, usque $16 \mathrm{~mm}$ longa, integra, sessilia, revoluta, nectariis nullis. Flores dimorphis, in axillis bractearum sessiles, in capitulis terminalis collectis; pedunculli et pedicelli nulli; calyx supra medium coalitus; filamenta glabra, basi tubo tota facie adnata, antherae dorso in $1 / 2$ affixae.Fructus dorso laeves. Semina curvata, reticulata vel estriato-reticulata, chalaza prominula, arillo unilaterali.

\section{Typus: Turnera dichotoma Gardner}

Arbustos de hasta $1 \mathrm{~m}$, pelos tectores simples y estrellados (Gonzalez \& Arbo, 2004). Hojas muy pequeñas (hasta $16 \mathrm{~mm}$ long.), sésiles, enteras, revolutas; estípulas ausentes, nectarios extraflorales ausentes. Flores sésiles agrupadas en inflorescencias racemosas terminales. Pedúnculo floral ausente. Profilos generalmente opuestos y lineares, insertos en la base del receptáculo. Pedicelo ausente. Sépalos soldados por encima de la mitad; lóbulos de prefloración quincuncial. Pétalos amarillos. Filamentos estaminales glabros, soldados al tubo floral solamente en la base y por la cara externa; anteras dorsifijas. Ovario con placentas uniovuladas. Fruto liso. Semilla curvada. Episperma reticulado, aréolas cóncavas, a veces con una depresión punctiforme. Arilo generalmente unilateral, de células lisas o papilosas.

Urban ubicó estas especies en la serie
Capitatae, de la cual las excluyó Arbo (2000), expresando que debían incluirse en la serie Leiocarpae. El análisis comparativo de dichas especies con las de la última serie demostró que no corresponden a la serie Leiocarpae. Por su aspecto vegetativo tan peculiar, con hojas sésiles, carentes de nectarios, se las incluye en una serie nueva.

Las dos especies que la constituyen son endémicas de Minas Gerais, Brasil, donde viven en «campo rupestre».

\section{Clave para las especies de Sessilifoliae}

1. Hojas ovadas, base cordada

T. dichotoma Gardner

1'. Hojas elípticas, base cuneada

T. revoluta Urb.

\section{Turnera dichotoma Gardner}

Figs. 84 y 85

Gardner, G. ex Hooker, Ic.Pl. t. 522. 1843. Typus: Brasil. Minas Gerais. Diamond district, VIII-1842, Gardner 4695 (holotypus K!, isotypi BM!, CGE!, E!, FI!, K!, OXF!, P!, R!, W!, B+ fototipo $\mathrm{F} \mathrm{n}^{\circ} 13577$ !).

Turnera decipiens Baill., Adansonia 10: 246. 1872. Typus: Brasil. Minas Gerais. Serra de Grumatai [Curimataí], Saint Hilaire B1 1993 (holotypus $\mathrm{P}$ !, isotypus $\mathrm{P}$ ).

Turnera dichotoma Gardner var. stenophylla Urb. En Taubert, P., Bot. Jahrb. Syst. 17: 506. 1893. Typus: Brasil. Minas Gerais, Biribiry, près Diamantina, 20-III-1892, Glaziou 19393 (holotypus P!, isotypi C!, K!, LY!, P!). En la descripción original, la localidad citada es Serra do Cipó, prope Mangabeira.

Turnera dichotoma Gardner var. stricta Urb., en Taubert, Bot. Jahrb. Syst. 17: 507. 1893. Typus: Brasil. Minas Gerais: Biribiry, près Diamantina, 20-III-1892, Glaziou 19393b (holotypus P!). En la misma hoja con el isotipo de la var. stenophylla).

Turnera schwackeana Urb., en Taubert, Bot. Jahrb. Syst. 17: 507. 1893. Typus: Brasil. Minas Gerais. Serra da Mangabeira, 23-IV-1892, Glaziou 


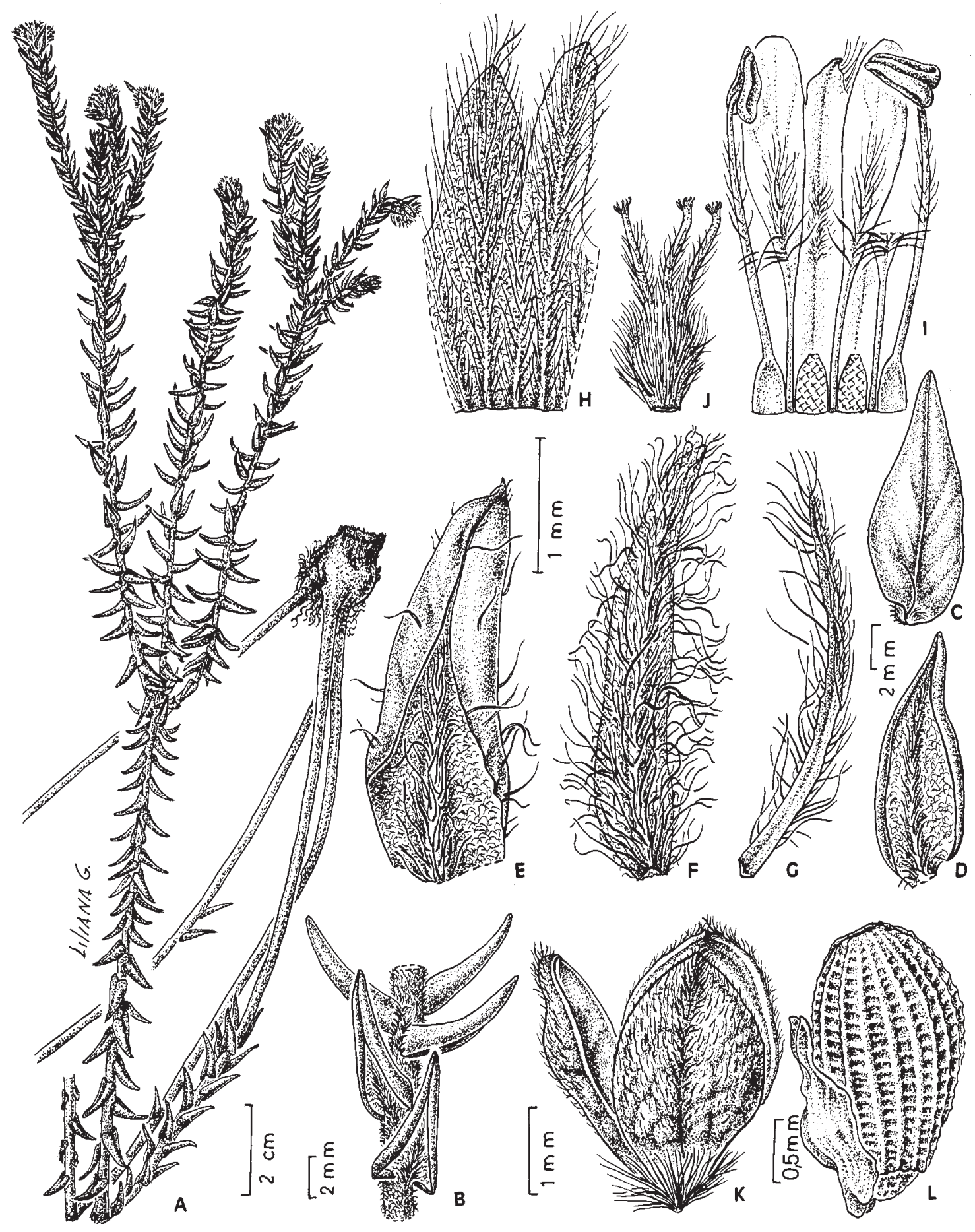

Fig. 85. Turnera dichotoma. A: planta. B: porción de tallo con hojas sésiles. C-D: hojas, caras adaxial y abaxial. E: bráctea inferior. F: bráctea apical. G: profilo. H: porción del cáliz, cara externa. I: flor brevistila, porción del tubo calicino, cara interna, con pétalos y estambres adnatos; se han cuadriculado las cicatrices dejadas al desprender dos estambres. J: gineceo. K: fruto. L: semilla con arilo, vista lateral (A-B: Irwin \& al. 22609; C-D: Pereira \& Lucca 20126; G-J: Hatschbach \& al. 36523; K-L: Hatschbach 27369). Del. Liliana Gómez. 
19394 (holotypus $\mathrm{B}+$ fototipo $\mathrm{F} \mathrm{n}^{\circ} 13602$ !, isotypi BR!, C!, F!, K!, LY!, P!, R!).

Arbusto virgado $10-60 \mathrm{~cm}$, simple a muy ramificado, ramas 2-6 furcadas, las viejas negruzcas o con restos de indumento ceniciento, con grietas longitudinales; ramas nuevas tomentosas, con pelos simples crespos o rectos, amarillentos o blanquecinos, entrenudos cortos. Yemas axilares raramente visibles. Hojas coriáceas, discoloras, generalmente patentes, en la porción apical dispuestas en ángulo agudo, sésiles o subsésiles, sin nectarios. Estípulas ausentes o reducidas a coléteres, insertos a ambos lados de la base foliar, visibles sólo en las cicatrices foliares, en la parte basal del tallo. Lámina ovada, angustiovada o triangular, 3-12 x 1-7,5 mm, relación largo:ancho $=1,1-3,7: 1$; base generalmente cordada, rodeando parcialmente al tallo; margen entero o paucidentado, marcadamente revoluto; ápice acuminado, agudo a veces obtuso o terminado en un mechón de pelos; epifilo lustroso, pardo-rojizo en seco, glabro o con algunos pelos simples blandos, vena media hundida, pilosa, venas laterales no o apenas visibles; hipofilo tomentoso o lanuginoso, pelos simples muy crespos blanquecinos o amarillentos (Fig. 2D); vena media prominente, venas laterales poco visibles, venación menor inconspicua. Hojas preflorales de tamaño menor, 3-5 x 1$1,5 \mathrm{~mm}$, angustiovadas, a veces lineares, cóncavas, porción basal del margen no revoluta y pubescente. Hojas floríferas reducidas a brácteas, las inferiores angustiovadas, margen a menudo paucidentado, ligeramente revoluto en la parte superior; brácteas superiores lanceoladas, espatulado-lanceoladas o lineares, 3-5,5 x 0,7-1,5 mm, ligeramente cóncavas a induplicadas, haz glabra a villosa, envés villoso-tomentoso, margen plano paucidentado. Flores heterostilas sésiles en la axila de las brácteas, reunidas en espigas capituliformes terminales, a su vez agrupadas en inflorescencias complejas. Profilos lineares, 2,1-5 x 0,2-0,6 mm, glabros por dentro o villosos apicalmente, envés villosotomentoso. Pedicelo nulo. Cáliz 3,3-5 mm long.; tubo calicino 1,8-3 mm long., $1 / 2$ o $2 / 3$ de su longitud, cara externa estrigosa o villoso-hirsuta, cara interna villosa en la parte superior; lóbulos angustiovados, 3-nervados, emucronados. Corola poco más larga que el cáliz; pétalos de lámina obovada, 1,5-2,3 x 0,6-1,2 mm, vena media hirsuta en la base de la cara adaxial, a veces también pilosa en la cara abaxial. Filamentos estaminales subulados, soldados en la base 0,5-0,9 $\mathrm{mm}$ al tubo calicino, glabros o pilosos en la porción apical, 2,5-3,7 mm long en flores brevistilas, 2-3,3 mm long. en flores longistilas; anteras elípticas u ovadas, 0,5-1x 0,3-0,6 mm, base emarginada, ápice apiculado, filamento inserto dorsalmente, a 0,2-0,4 $\mathrm{mm}$ de la base, ápice apenas curvado después de la dehiscencia. Ovario elipsoide, villoso, 0,7-1,5 mm long.; placentas 1-ovuladas; estilos rectos, hirsutos casi hasta el ápice, 1,5-3 mm long. en flores longistilas, 0,7-1,2 $\mathrm{mm}$ long. en flores brevistilas; estigma pluripartido, ramas filiformes 0,2-0,5 $\mathrm{mm}$ long. En flores longistilas, gineceo 0,5-1,2 mm más largo que el androceo, y en flores brevistilas 0,8-1,5 mm más corto. Fruto ovoide, 1,5-3 x 1,5-2 mm, 13 -seminado; valvas apenas recurvadas después de la dehiscencia, cara externa suavemente verrucosa, pilosa o sublanosa, pardoamarillenta, cara interna amarillenta o jaspeada, glabra, vena placentaria breve, funículo inserto cerca de la base. Semilla obovoide, apenas curvada, parda, glabra, 2-2,4 x 0,9-1,3 $\mathrm{mm}$, negruzca; exóstoma semigloboso; rafe linear saliente, lado rafeal recto o algo convexo; cálaza apical, prominente. Episperma reticulado, aréolas diminutas, transrectangulares o cuadrangulares, epidermis lisa. Arilo unilateral, blanquecino, 1-2 mm long., de células papilosas.

Material estudiado: BRASIL. Ceará: Barbalha, 21-VII-1964, Castellanos 33415 (UEC), probablemente localidad errada. Minas Gerais: Serra do Espinhaço, Mun. Diamantina, ca. $5 \mathrm{~km} \mathrm{SW}$ of Diamantina, Km 305 on MG-259, 1300 m, 5-II-1972, Anderson \& al. 35461 (MBM, NY, P, UB); Mun. Itamarandiba, Alto do Barro Preto, Serra do Ambrosio, Penha de França, 25XI-1937, Barreto 9994 (F, R); entre Serro e Diamantina, 1-II-1965, Duarte 9051 (BR, CTES, RB); Biribiry près Diamantina, Glaziou 18338 (C, K, LY, P, R); près Diamantina, 23-III-1892, 
Glaziou 19395 (BR, C, CTES, F, K, LY, MO, NY, P, R, RB, US); Mun. Diamantina, Guinda, 12001300 m, 7-IX-1971, Hatschbach 27369 (C, CTES, MBM, MU); mun. Couto Malgalhães, Vale do Jequitinonha, 26-II-1975, Hatschbach \& al. 36523 (C, CTES, M, MBM, P); Mun. Diamantina, Salto Cristal, 19-III-1987, Hatschbach \& al. 51121 (C, F, MBM, MO, MU, SPF, US); $15 \mathrm{~km} \mathrm{NE} \mathrm{of}$ Diamantina, on road to Mendanha, $1300 \mathrm{~m}, 26-\mathrm{I}-$ 1969, Irwin \& al. 22609 (CTES, NY); Rio Jequiti, ca. $15 \mathrm{~km}$ E of Diamantina, $975 \mathrm{~m}, 19-\mathrm{III}-1970$, Irwin \& al. 27929 (MO, NY, P, RB, US); Parque Estadual do Rio Preto, São Gonçalo do Rio Preto junto ao corrego da Lapa, $18^{\circ} 05^{\prime} 28^{\prime \prime S}$ 4320'32"W, 7-IV-2000, Lombardi \& al. 3724 (BHCB, CTES); Rio Vermelho, Pedra Menina, Plato Pedra Menina, 1570 m, 9-IX-1986, MelloSilva \& al. CFCR 10267 (CTES, SPF); Pico do Itambe, mun. Serro, 2044 m, 5-V-1942, Mendes Magalhaes 1791 (BHCB, US); Serra de Grão Mogol, IV-1960, Mendes Magalhaes 17977 (UB); Serra do Cipó, Santana do Riacho, na região de Congonhas, abaixo da casa de pedra e próximo ao Córrego Gavião, 1100 m, 9-VIII-1992, Pereira M. \& Lucca 885 (CTES, ESA, F, MBM, SPF); Diamantina, estrada para Conselheiro Mata, 18 $17^{\prime}$ 'S 4345W, 1300 m, 18-VII-1987, Pirani \& Mello-Silva CFCR 11042 (CTES, F, K, MBM, SPF); Serra da Lapa [Serra do Cipó], XI-1824, Riedel s.n. (CTES, NY); Rodovia Diamantina Curvelo, ca. 4,5 km de Diamantina, 4-VIII-1990, Sakuragui \& Souza 160 (ESA, K); Serra de Biribiry prope Diamantina, 24-III-1892, Schwacke 8211 (EM, RB); Serro, Milho Verde, VIII-1989, Sobral \& al. 6285 (CTES, F, MBM, SP); Mun. Diamantina, $2 \mathrm{~km}$ de Diamantina em direção a Mendanha, 6-VII-1996, Souza \& al. 11832 (CTES, ESA); mun. Diamantina, $19 \mathrm{~km}$ de Diamantina em direção a Datas, 6-VII-1996, Souza \& al. 12057 (ESA); Mun. Diamantina, estrada entre Diamantina e Curvelo, ca. $7 \mathrm{~km}$ de Diamantina, 7-VII-2001, Souza \& al. 25291 (CTES, ESA); Diamantina, Area de Proteção Ambiental Pau-de-Fruta, COPASA, 18¹5'01"S 43³9'08"W, 13-II-2001, Stehmann \& al. 2852 (BHCB, CTES); Tejuco [Diamantina], 1833, Vauthier 499 (P).

Distribución y fenología: Especie endémica de Minas Gerais, donde vive en «cerrado», campo de altura y «campo rupestre» con suelo areno-pedregoso, también en laderas rocosas, entre 900 y $2100 \mathrm{~m}$ de altitud. Florece todo el año.

Obs.: La inflorescencia es politélica, un dibotrio, a veces pleiobotrio. En Irwin \& al. 22609 se puede apreciar que la inflorescencia terminal (espiga capituliforme) madura primero, y luego las coflorescencias (también espigas capituliformes), dispuestas en racimo. En el ejemplar tipo la inflorescencia está muy contraída. La flor estudiada en Mendes Magalhaes 17977 es prácticamente homostila, el gineceo tiene casi la misma longitud del androceo.

Spencer \& al. (1985) investigaron la presencia de compuestos cianogénicos en esta especie con resultado negativo.

\section{Turnera revoluta Urb.}

Figs. 84 y 86

Urban, I., Bot. Jahrb. Syst. 17: 508. 1893. Typus: Brasil. Minas Gerais, Serra do Cipó prope Mangabeira, 23-IV-1892, Glaziou 19392 (holotypus $\mathrm{B}+$ fototipo $\mathrm{F} \mathrm{n}^{\circ} 13600$ !, isotypi $\mathrm{C}$ !, $\mathrm{F}$ !, $\mathrm{K}$ !, P!, R!).

Sufrútice de 3-40 cm, generalmente pluricaule, ramoso; base leñosa 1-10 mm diám., rizomas y tallos 1-5 mm diám., corteza pardo-negruzca con grietas longitudinales; entrenudos cortos, hasta $6 \mathrm{~mm}$ long., cicatrices foliares salientes, marcadas en ramas viejas por grietas transversales; ramas del año con pelos simples, sedosos, adpresos, amarillentos. Yemas axilares brevísimas, raramente visibles. Hojas coriáceas, numerosas, discoloras, subsésiles. Base foliar saliente y persistente. Estípulas nulas. Lámina ericoide, linear, erecto-patente, 10-16 x 1-3 mm, base angostada, borde marcadamente revoluto, entero, con 0-3 pares de coléteres sésiles, planos o cóncavos en seco, sobre la porción revoluta; ápice agudo u obtuso; haz lustrosa, a veces pardo-rojiza en seco, glabra, a veces con algunos pelos simples en la base, vena media ligeramente deprimida; envés seríceo-tomentoso, con pelos simples largos, pelos crespos y pe- 


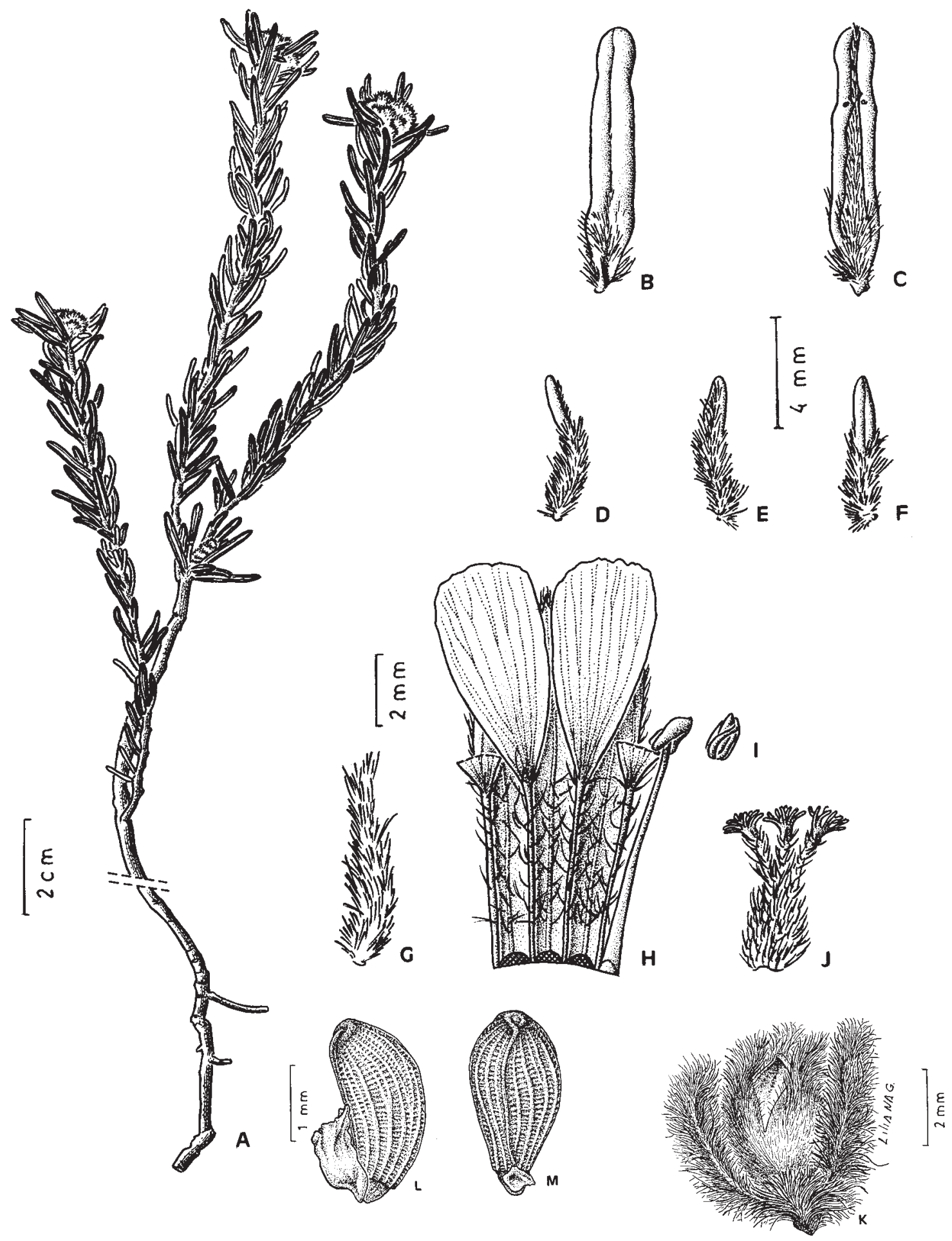

Fig. 86. Turnera revoluta. A: planta. B-C: hojas, caras adaxial y abaxial. D-F: brácteas, vistas lateral, abaxial y adaxial. G: profilo. H: flor brevistila, porción del tubo calicino, cara interna, con pétalos y estambre adnatos; se han cuadriculado las cicatrices dejadas al desprender tres estambres. J: gineceo. K: fruto con profilos. L-M: semillas con arilo, vistas lateral y rafeal (A-J: Lewis \& al. CFSC 7805; K-M: Pirani \& al. CFSC 12166). A-J: del. Ricardo Vispo; K-M: del. Liliana Gómez. 
los estrellados fasciculados cortos, vena media prominente, venas laterales no visibles. Hojas apicales bracteiformes con la porción basal induplicada, margen plano, haz villosa, envés villoso-hirsuto, porción apical como los nomófilos. Brácteas lineares, 4-6 x 0,5-0,7 $\mathrm{mm}$, induplicadas, margen plano, haz villosa, envés villoso-hirsuto, ápice agudo. Flores amarillas, dimorfas, sésiles, dispuestas en espigas capituliformes terminales, las basales en la axila de hojas bracteiformes, las siguientes en la axila de brácteas. Profilos lineares, 3-5 x 0,4-0,6 mm, induplicados, haz glabra, envés villoso-hirsuto, pelos blanquecinos o dorados, insertos en la base del receptáculo. Pedicelo nulo. Cáliz 5,5-8 mm long., villoso-hirsuto; tubo calicino subcilíndrico, 3-4,5 mm long., álbido-pubescente por dentro en la porción superior; lóbulos triangulares $\mathrm{u}$ angustiovados, 3-nervados, con pelos simples largos antrorsos y pelos cortos, crespos, simples y con 2-3-ramas, ápice agudo. Corola amarilla. Pétalos apenas más largos que el cáliz $(0,5$ $\mathrm{mm})$, uña pilosa soldada al tubo calicino, lámina obovada, $3,7-5 \times 2-3 \mathrm{~mm}$, pilosa en la base en la cara interna. Filamentos estaminales complanado-subulados en seco, soldados $0,3 \mathrm{~mm}$ en la base al tubo calicino, glabros, 3-5 mm long. en flores brevistilas, 2$2,5 \mathrm{~mm}$ long. en flores longistilas; anteras ovadas, 0,9-1 x 0,4-0,5 mm, base emarginada, filamento inserto dorsalmente casi en la mitad, ápice apiculado apenas recurvo después de la dehiscencia. Ovario villoso-hirsuto, elipsoide, 1-1,2 mm long.; placentas 1ovuladas, óvulos insertos cerca de la base; estilos rectos, villosos casi hasta el ápice, 2$2,5 \mathrm{~mm}$ long. en flores longistilas, 1-1,2 mm long. en flores brevistilas; estigma amarillo, penicilado, ramas $0,5 \mathrm{~mm}$ long. Gineceo ca. 1 $\mathrm{mm}>$ que androceo en flores longistilas, y 2$2,5 \mathrm{~mm}<$ que el androceo en flores brevistilas. Fruto ovoide, 3,4-3,5 mm long., 12-seminado, cara externa con pelos simples crespos y pelos simples largos, antrorsos, cara interna glabra, lustrosa, amarillenta. Semilla obovoide, 2,3 x 1,4 mm; exóstoma conoidal, asimétrico; rafe gruesa, saliente, lado rafeal plano o convexo; cálaza apical algo prominente, a veces deprimida en el centro. Episperma estriado-reticulado, muros transversales poco notables, epidermis lisa. Arilo unilateral, angosto, más corto que la semilla, de células lisas.

Material estudiado: BRASIL. Minas Gerais: Mun. Santana do Riacho: ao longo da rodovia Belo Horizonte-Conceição do Mato Dentro, prox. Fazenda Boa Vista, 17-II-1982, Lewis \& al. CFSC 7805 (CTES, SP); Mun. Congonhas do Norte: Serra do Cipó, Serra Talhada e Serra do Joaquim Gomes, Estrada para o vale do rio Preto, 11,4 km SO da estrada Congonhas do Norte - Gouveia, entrada a $3,7 \mathrm{~km} \mathrm{NW}$ de Congonhas do Norte, $18^{\circ} 15^{\prime} 19 \mathrm{~S} 43^{\circ} 44^{\prime} 55 \mathrm{~W}$, 1273 m, 20-I-2004, Mello-Silva \& al. 2402 (CTES, SPF); Serra da Lapinha, Maciço NW da Serra do Cipó, próximo a Lapinha, a ca. 50 $\mathrm{km}$ da Rodovia Belo Horizonte-Conceição do Mato Dentro, 1000 m, 27-III-1991, Pirani \& al. CFSC 12166 (CTES, SPF) y 12193 (CTES, SPF); Serra do Cipó, 23-IV-1892, Schwacke 8215 (RB); Mun. Santana do Riacho, estrada Santana do Riacho-Lapinha, ca. $7 \mathrm{~km}$ apos Santana do Riacho, $19^{\circ} 07^{\prime} 43,6 \mathrm{~S} 43^{\circ} 41^{\prime} 51,4 \mathrm{~W}, 1100 \mathrm{~m}, 1-\mathrm{III}-$ 2002, Souza \& al. 28690-A (CTES, ESA).

Distribución y fenología: Especie rara, endémica del «campo rupestre» de la Serra do Cipó, Cadeia do Espinhaço, Minas Gerais, Brasil, a 1000-1300 m de altitud. Los ejemplares conocidos se han recolectado entre enero y abril.

Obs.: Especie afín a Turnera dichotoma, que se diferencia por sus hojas ovadas, de base acorazonada. Las flores se disponen en espigas inicialmente capituliformes, cuyos ejes villoso-hirsutos persisten, mostrando las cicatrices de brácteas y flores. De las yemas axilares situadas en la base de las inflorescencias viejas nacen las ramas nuevas.

La planta florece rápido después de rebrotar, en el ejemplar Mello-Silva \& al. 2402 hay ejes florecidos de apenas $3 \mathrm{~cm}$ long.

Las hojas son dorsiventrales, la epidermis adaxial está formada por células esclerenquimatosas, y los estomas se encuentran únicamente en la epidermis abaxial, densamente cubierta de pelos estrellados fasciculados (Gonzalez, 2000). 


\section{Agradecimientos}

Para la realización de este trabajo conté con el apoyo de la Universidad Nacional del Nordeste, del CONICET, y de otras instituciones que me otorgaron becas y subsidios: International Federation of University Women, British Council, Missouri Botanical Garden, National Geographic Society y Myndel Botanica Foundation.

Deseo manifestar mi agradecimiento a todos los curadores de los herbarios que tuve la oportunidad de visitar y a los que me enviaron material en préstamo, algunos por mucho tiempo.

Agradezco a todos los compañeros del IBONE que de diversas maneras me han prestado apoyo y ayuda. A Antonio Krapovickas su permanente buena disposición para atender múltiples consultas. A Liliana Gómez el empeño y la escrupulosidad para preparar las ilustraciones. A Carlos Zanín y Camilo Quarin las correcciones de las diagnosis latinas. A Gelina Pieszko su ayuda para editar el índice de exsiccata, y a Carolina Peichoto los preparados y las fotos con MEB del indumento de varias especies.

También deseo agradecer a los árbitros que evaluaron el trabajo, sus indicaciones para mejorar la presentación del texto y las claves.

\section{Bibliografía}

ARBO, M. M. 1985. Notas taxonómicas sobre Turneráceas sudamericanas. Candollea 40: 175-191.

1987. Turneraceae en Spichiger R., Flora del Paraguay. Conservatoire et Jardin botaniques de Genève \& Missouri Botanical Garden. 65 págs.

1990. Turneraceae: Novedades para la Guayana Venezolana. Ann. Missouri Bot. Gard. 77: 340-352.

—. 1997a. Addenda a las Turneraceae de la Flora del Paraguay. Candollea 52: 200-211.

—_. 1997b. Estudios sistemáticos en Turnera (Turneraceae) I. Series Salicifoliae y Stenodictyae. Bonplandia 9(3-4): 151-208.

2000. Estudios sistemáticos en Turnera (Turneraceae) II. Series Annulares, Capitatae, Microphyllae y Papilliferae. Bonplandia 10: 1-82.

2005. Estudios sistemáticos en Turnera (Turneraceae) III. Series Anomalae y Turnera.
Bonplandia 14(3-4): 115-318.

\& S. M. ESPERT. Morphology, phylogeny and biogeography of Turnera (Turneraceae). Taxon (en prensa).

CULBERSON, C. H. 1995. Versamap (version 1. 51), shareware (www.versamap.com).

FERNÁNDEZ, A. 1987. Estudios cromosómicos en Turnera y Piriqueta (Turneraceae). Bonplandia 6: $1-21$.

GONZALEZ, A. M. 1993. Anatomía y vascularización floral de Piriqueta racemosa, Turnera hassleriana y T. joelii (Turneraceae). Bonplandia 7: 143-184.

—. 1996. Nectarios extraflorales en Turnera, series Canaligerae y Leiocarpae. Bonplandia 9: 129-143. 1998. Colleters in Turnera and Piriqueta (Turneraceae). Bot. J. Linn. Soc. 128: 215-228.

—. 2000. Estudios anatómicos en los géneros Turnera y Piriqueta (Turneraceae). Tesis doctoral. Universidad Nacional de Córdoba. Argentina.

2001. Nectarios y vascularización floral de Piriqueta y Turnera (Turneraceae). Bol. Soc. Argent. Bot. 36: 47-68.

\& M. M. ARBO. 2004. Trichomes in Piriqueta and Turnera (Turneraceae). Bot. J. Linn. Soc. 144(43): 85-97.

— \& M. M. ARBO. 2005. Anatomía de algunas especies venezolanas de Turneraceae. Acta Bot. Venezuelica 28(2): 369-394.

— \& M. N. OCANTOS. 2006. Nectarios extraflorales en Piriqueta y Turnera. Bol. Soc. Argent. Bot. 41(3-4): 269-284.

OLAFSDOTTIR, E. S., J. W. JAROSZEWSKI \& M. M. ARBO. 1990. Cyanohydrin Glucosides of Turneraceae. Biochem. Syst. Ecol. 18(48): 435-438.

PANSERI, A. F, J.G. SEIJO \& V. G. SOLÍS NEFFA. 2008. Análisis de la producción y frecuencia de micrósporas no reducidas en diploides de Turnera sidoides (Turneraceae). Bol. Soc. Argent. Bot. 43: 95-101.

SHORE, J. S., M. M. ARBO \& A. FERNÁNDEZ. 2006. Breeding system variation, genetics and evolution in the Turneraceae. New Phytologist 171: 539-551.

SOLÍS NEFFA, V. G. 1996. Cariotipos de especies de Turnera (Turneraceae). Bonplandia 9: 121-127.

—, M. FALOCI \& J. G. SEIJO. 2003. Cyanogenesis variation in the Turnera sidoides L. polyploid complex (Turneraceae). Bot. J. Linn. Soc. 141: 8594.

\& A. FERNÁNDEZ. 1993. Estudios cromosómicos en especies de Turnera (Turneraceae). Bonplandia 7: 101-118. 
2000. Chromosome studies in Turnera (Turneraceae). Genet. Molec. Biol. 23(4): 925-930.

2001. Cytogeography of the South American Turnera sidoides L. complex (Turneraceae, Leiocarpae). Bot. J. Linn. Soc. 137: 189-196.

—_. 2002. Karyotypic studies in Turnera sidoides complex (Turneraceae, Leiocarpae). Amer. J. Bot. 89(4): 551-558

, A. F. PANSERI, W. REYNOSO \& J. G. SEIJO. 2004. Variación del color de flores y números cromosómicos en el noroeste del área de distribución de Turnera sidoides (Turneraceae). Bonplandia 13(1-4): 117-128. 2004.

SPENCER, K. C., D. S. SEIGLER \& S. W. FRALEY. 1985. Cyanogenic Glycosides of the Turneraceae. Biochem.Syst.Ecol. 13(4): 433-435.

TRUYENS, S., M. M. ARBO \& J. S. SHORE. 2005. Phylogenetic relationships, chromosome and breeding system evolution in Turnera (Turneraceae): inferences from ITS sequence data. Amer.J.Bot. 92(10): 1749-1758.

URBAN, I. 1883 (Marzo). Monographie der familie der Turneraceen. Jahrb.Königl.Bot.Gart.Berlin 2: 1152.

1898. Symbolae antillanae. Vol. I. Berlin, 536 págs.

. 1906. Vitae Itineraque Collectorum Botanicorum en Martius C.F.P., Fl. bras. 1(1): 2-154. . 1910. XXXXXXXX FALTA.

\section{Índice de especies y variedades tratadas}

84. T. acaulis Griseb.

85. T. angelicae Arbo

86. $T$. argentea Arbo

87. T. callosa Urb.

88. T. cipoensis Arbo

89. T. coccinea Arbo

90. T. crulsii Urb.

91. T. curassavica Urb.

92a. T. dasytricha Pilger

92b. T. dasytricha var. crinita Arbo

93. T. diamantinae Arbo

94. T. discolor Urban

95. T. dolichostigma Urb.

96. T. elliptica Urb.

97. T. emendata Arbo ( nana sensu Urban)

98. T. fissifolia Arbo

99. T. foliosa Urb.
100. T. genistoides Cambess.

101. T. glabrata Arbo

102. T. gouveiana Arbo

103. T. guianensis Aublet

104. T. harleyi Arbo

105. T. hassleriana Urb.

106. T. hilaireana Urb.

107. T. huberi Arbo

108. T. humilis Arbo

109. T. incana Cambess.

110. T. iterata Arbo

111. T jobertii Arbo

112. T. lamiifolia Cambess.

113. T. lanceolata Cambess.

114. T. lineata Urb.

115. T. longiflora Cambess.

116a. T. luetzelburgii Sleumer var. luetzelburgii

116b. T. luetzelburgii Sleumer var. dubia Arbo

117a. T. melochia Triana \& Planch. var. melochia

117b. T. melochia var. ramosissima (Urb.) Arbo

118a. T. melochioides Cambess. var. melochioides

118b. T. melochioides var. arenaria Urb.

118c. T. melochioides var. latifolia Urb.

118d. T. melochioides var. rugosa Arbo

119. T. nervosa Urb.

120a. T. oblongifolia Cambess. var. oblongifolia

120b. T. oblongifolia var. goyazensis (Urb.)Arbo

121. T. opifera Mart.

122. T. paradoxa Arbo

123. T. paruana Arbo

124. T. patens Arbo

125. T. pinifolia Cambess.

126. T. pohliana Urb.

127. T. prancei Arbo

128a. T. pumilea L. var. pumilea

128b. T. pumilea L. var. piauhyensis Urb.

129. $T$. riedeliana $\mathrm{Urb}$.

130. T. rosulata Arbo

131a. T. sidoides L. subsp. sidoides

131b. T. sidoides subsp. carnea (Cambess.) Arbo

131c. T. sidoides subsp. holosericea (Urb.) Arbo

131d. T. sidoides subsp. integrifolia (Griseb.) Arbo

131e. T. sidoides ssp. pinnatifida (Juss. ex

Poir.)Arbo

132a. T. stachydifolia Urb. \& Rolfe

132b. T. stachydifolia var. flexuosa Urb.

133. T. subnuda Urb.

134. T. tenuicaulis Urb.

135. T. trigona Urb.

136. T. uleana Urb.

137. T. vallsii Arbo 
138. T. venezuelana Arbo

139. T. vicaria Arbo

140. T. rubrobracteata Arbo

141. T. dichotoma Gardner

142. T. revoluta Urb.

\section{Índice de Coleccionistas}

¿? 73HH2 (87)

¿? $123(131 \mathrm{e})$

¿? 130 (118a)

¿? $1445(131 b)$

¿? s.n. (103)

Adams C.D. 13883 (128a)

Aguilar R.M. 325 (131e); 1255 (131e)

Aguirre E. 454 (131e)

Ahumada O. 2306 (119); 2565 (131b)

Ahumada O. \& al. 1340 (131e); 3793 (131e)

Ahumada O. \& Schinini A. 3911 (131e); 3992 (131d)

Alain \& Clemente [Bros.] 1473 (128a)

Alboff N. 29 (131e)

Alencar M.E. 293 (118b); 655 (118b); 663 (118b); $723(118 b)$

Allem A. 440 (112); 470 (112); 547 (112); 560 (115)

Allemão Fr. s.n. (118)

Allemão Fr. \& Cysneiros M.de 90 (118); 105 (118); 743 (118); 744 (128a)

Allen C. 139 (128a)

Alonso \& al. 576 (131e)

Alvarenga D. \& al. 1130 (95); 1151 (95)

Alvarenga D. \& Oliveira F.C.A. 590A (112)

Alvares \& al. s.n. (131e)

Alvarez s.n. (131e)

Alves R. 4001 (120a)

Alves R.J.V. 6501c (121)

Amado \& al. 138 (105)

Amaral I.L. \& al. 870 (118a); 1391 (118b)

Ameghino C. s.n. (131e)

Anderson D.L. 1369 (131e)

Anderson W.R. 7203 (135); 7464 (115); 7566 (120a); 7580 (115); 7947 (115); 7969 (115); 8824 (121); 10026 (109); 10314 (115); 10440 (125); 12457 (112); 12495 (120a)

Anderson W.R. \& al. 6697 (109); 35461 (141); 35613 (121); 36382 (88); 36891 (120a)

Andersson N.J. s.n. (128a)

Andrade A.G. \& Emmerich M. 367 \& 359 (112)
Andrade-Lima D. \& al. 95 (128a); 58-2967 (115);

59-3373 (128a); 67-5013 (118); 74-6524 (118a)

Andre E. s.n. (131d)

Andreasen M. \& al. 620A (87)

Anetto L. s.n. (131e)

Anhanguera U.L.de 44 (112)

Anisits J.D. 1888 (105); 1980 (105); 2380 (105)

Antezana C. 1012 (131e)

Aplin O.V. s.n. p.p. (131d); s.n. p.p. (131e)

Appun C. 1874 (103)

Aragone \& Rosengurtt B. 526a (131d)

Araque J. \& al. 147 (131e); 469 (131e); 620 (131e)

Araque Molina J. 378 (123)

Araujo A.G. de s.n. (112)

Araujo A.P. \& Fonseca W.N.da 415 (118); 427 (116b)

Araujo D. \& al. 476 (118c)

Araujo F. 30 (128a); 68 (128b)

Araujo F.S. 1336 (128a)

Araujo F.S. \& Martins F.R. 1185 (118); 1193 (118)

Arbo M.M. 73 (131d); 234 (131d); 385 (131d); 514 (131d); 695 (131e); 2409 (128b); 2411 (131e); 2729 (131e); 2759 (131e); 8839 (128a)

Arbo M.M. \& al. 1735 (105); 1735 bis (105); 1804 (131d); 2076 (119); 2120 (128a); 2537 (128a); 2641 (105); 2697 (131e); 3044 (120a); 3127 (112); 3181 (124); 3201 (120b); 3302 (128a); 3204 (120b); 3216 (120a); 3217 (124); 3220 (124); 3223 (115); 3275 (120a); 3276 (115); 3298 (120a); 3326 (135); 3374 (112); 3375 (115); 3397 (112); 3413 (112); 3414 (115); 3427 (115); 3435 (112); 3437 (115); 3438 (120a); 3464 (112); 3495 (135); 3512 (135); 3525 (112); 3538 (118a); 3543 (135); 3553 (135); 3534 (128a); 3564 (135); 3567 (109); 3574 (109); 3603 (120a); 3619 (118d); 3642 (109); 3644 (109); 3658 (109); 3660 (133); 3677 (133); 3686 (109); 3687 (135); 3687-B (135); 3700 (115); 3764 (126); 3794 (115); 3803 (106); 3806 (109); 3807 (120a); 3817 (125); 3838 (120a); 3845 (120a); 3846 (115); 3847 (112); 3851 (113); 3865 (113); 3867 (113); 3912 (120a); 4005 (120a); 4052 (120a); 4117 (88); 4121 (120a); 4396 (133); 4406 (120a); 4408 (121); 4435 (121); 4437 (120a); 4443 (121); 4460 (121); 4472 (120a); 4583 (120a); 4631 (88); 4632 (120a); 4800 (120a); 4893 (120a); 4910 (120a); 4926 (128a); 5013 (95); 5077 (121); 5079 (128a); 5184 (120a); 5231 (120a); 5252 (121); 5409 (116b); 5456 (128a); 5463 (128a); 5525 (118c); 5611 (128a); 
5634 (116b); 5684 (116b); 5744 (116b); 5765 (118c); 5785 (118c); 6082 (105); 6156 (119); 6457 (119); 6704 (131d); 6974 (131d); 7372 (118c); 7396 (118c); 7398 (128a); 7426 (128a); 7456 (116b); 7523 (128a); 7536 (118c); 7625 (128a); 8401 (119); 8897 (105); 8912 (105); 8943 (131e)

Arbo M.M. \& Schinini A. 2417 (131b); 2418 (131d); 2418bis (131d); 2419 (131d); 2421 (131d); 2435 (131a); 2461 (131c); 2478 (131c); 2487 (131d); 2492 (131b); 2494 (131c); 2495 (131c); 2500 (131a); 2510 (131b); 2513 (131c); 2515 (131a); 2525 (131c)

Arbo M.M. \& Tressens S.G. 2562 (131d); 2562bis (131d)

Arbocz G.F. \& al. 3695 (118)

Arell E. 56 (105)

Arenas P. 220 (105); 1017 (119)

Argañaraz 3 (131e)

Argent G. \& al. 6639 (118c); 6681 (94)

Arima E. \& al. 15 (112)

Arnoldo Fr. 384 (128a)

Arrillaga 77 (131a); 525 (131a); 826 (131a)

Arrillaga B.R. \& al. 1631 (131b)

Arsène Fr. G. 5397 (87)

Asplund E. 5059 (128a); 15756 (128a); 15973 (128a)

Assis M.C. de \& al. 382 (109)

Atala F. 189 (120a)

Atkins S. \& al. PCD 5754 (116b)

Atui J.P. \& al. 15 (141)

Aublet J.B. s.n. (103)

August L. 117 (131e)

Aurelius 7 (131e)

Autran E. 2 (131e); 23 (131e)

Aymard G. 6130 (114)

Azevedo M.L. 184 (106)

B 982 (131d)

Bacigalupo N. \& al. 685 (131e)

Badini J. s.n. (120a); s.n. (120a); s.n. (120a); s.n. (120a); s.n. (120a)

Badini J. \& Kassis A. s.n. (120a)

Baer G.A. 120 (131e)

Baez J.R. 27 (131e); 185 (131e); 186 (131e); 187 (131d); 188 (131d)

Balansa B. 2341 (119); 2633 (95); 2633a (128a)

Baldwin J.T. 3035 (94)

Balegno B. 379 (131e); 519 (131e)

Balls E.K. 5928 (131e)

Barbosa A.A.A. \& Castro N.M. 174 (130)

Barbosa E. \& Silva J.M. 1572 (95); 1856 (105)
Barkley F.A. \& al. 7507 (87)

Barreto H.L. de Mello 1016 (120a); 8173 (120a); 8174 (120a); 8178 (120a); 8178 (120a); 8179 (120a); 8180 (88); 8947 (120a); 9541 (121); 9903 (120a); 9994 (141)

Barros F. de 2221 (115); 2780 (120a)

Barros M. \& al. 2279 (112); 2280 (115)

Barroso G.M. 564 (90); 594 (115); 626 (115); 672 p.p. (112); 675 (120a)

Barroso G.M. \& Elsie 8 (118b)

Bartlett H.H. 11728 (91); 19680 (131e); 19730 (131e)

Bastian E. 67 (131e); 109 (131e)

Basualdo I. 2809 (105); 3177 (105); 3284 (105); 3909 (105); 4810 (105); 5098 (119)

Bates W. s.n. (87)

Beck S.G. s.n. (131d)

Beck S.G. \& al. 22165 (131e)

Beck S.G. \& Haase 10204 (118c)

Bedi R. 217 (115)

Belem R.P. 3931 (112)

Benitez de Rojas 799 (128a)

Benoist R. 114 (103); 1409 (103)

Bernacci L.C. \& al. 19957 (129); 19968 (109); 19973 (120a)

Bernacci L.C. \& Arbocz G. 3531 (94)

Bernardello L. 519 (131e)

Bernardi L. 19392 (105)

Berndt M. s.n. (131e)

Berro M.B. 5413 (131e); 7490 (131e); 1615 (131b); 2235 (131b)

Bertoni M. 1906 (131b); s.n. (131b); s.n. (131b)

Betancur J. \& al. 10948 (117b)

Betancur J. \& Clavijo-R. L. 10948 (91); 10963 (117b)

Betancur J. \& Velasquez M.P. 1575 (117a); 1708 (91)

Bezerra P. s.n. (118a); s.n. (118a); s.n. (118c); s.n. (118c); s.n. (118c)

Biloni S. 6030 (131e)

Biraben M.I.H.S. 5060 (131d)

Biurrun F. 2926 (131e)

Black G.A. \& al. 51-12775 (103); 51-13444 (114); 54-16656 (118)

Blanchet J.S. 2873 (132b)

Blum K.E. \& Tyson E.L. 655 (114)

Boaventura M. 331 (120a); 475 (115)

Boaventura M. \& al. 423 (120a); 445 (120a)

Bodenbender W. s.n. (131e)

Boelcke O. 1318 (131e)

Boelcke O. \& al. 11770 (131e) 
Boelcke O. \& Nicora E. 7946 (131e); 8186 (131e)

Boffa P. 1006 (131e)

Boldingh I. 6543 (128a)

Bolland G. s.n. (118)

Bona Nascimento M.S. 1101 (118b)

Bona Nascimento M.S. \& Carvalho J.H. de 1102 (118b)

Bonifacino M. \& al. 1785 (131c)

Bonpland A. 793 (103)

Bordon A.O. s.n. (131e); s.n. (131e); s.n. (131e)

Bovini M.G. \& Kajima T. 1734 (118c); 1734bis (118c)

Brade A.C. 5922 (120a); 5923 (120a); 5924 (120a); 12413 (120a); 13092 (120a); 13884 (141); 13885 (141); 13886 (141); 13887 (100); 13888 (135); 14442 (120a); 16070 (120a)

Braga M.M.N. \& al. s.n. (121)

Brandegee T.S. 226 (128a)

Breedlove D.E. 37569 (91)

Bridgewater S. \& al. S72 (118b)

Britton N.L. \& al. 55 (103); 4659 (128a); 5959 (128a); 13180 (128a); 14280 (84)

Britton N.L. \& Shafer J.A. 3049 (128a)

Britton N.L. \& Wilson 426 (128a)

Brizuela E. 370 (131e)

Brizuela J. 462 (131e); 822 (131e)

Broadway W.E. s.n. (103)

Brochado A.L. 86 (106)

Brochado A.L. \& Filgueiras T.S. 8 (108)

Brooks R.R. \& al. Braspex 158 (118d); Braspex 181 (118d); Braspex 308 (133)

Brooks R.R. \& Zardini E.M. S266 (105)

Browne P. s.n. Linn. Herb. 384-4 (128)

Bruderreck B. 346 (92a)

Bunting G.S. \& al. 3502 (114)

Buratovich F. 712 (131e)

Burchell W.J. 5342 (106); 5910 (120a); 5997 (115); 6034 (115); 6048 (112); 6048-2 (115); 6866 (135); 7030 (109); 7837 (135); 7861 (135); 7879 (97); 8040 (109); 8480 (128a); 8860 (118a); 8914 (128a); 8979 (118a); 8983 (118a); 9247 (118a); 9250 (118a)

Burkart A. 647 (131e); 7322 (131e); 9890 (131e); 10364 (131e); 10917 (131e); 12769 (131e); 13155 (131e); 15326 (105); 15369 (105); 15412 (131b); 15852 (131e); 17257 (103); 19198 (131e); 19360 (131d); 20474 (131e); 22657 (131e); 24857 (131d); 25998 (131e); 28750 (131d)

Burkart A. \& al. 23412 (131e); 23754 (131e)

Burkart A. \& Crespo S. 23051 (131d)
Caballero Marmori G. 1556 (105); 3963 (119)

Cabral E.L. \& al. 216 (105)

Cabrera A.L. 1255 (131e); 2458 (131e); 6789 (131e); 7369 (131e); 8004 (131e); 11669 (131d); 12366 (131e); 14750 (131e)

Cabrera A.L. \& al. 15943 (131e); 19319 (131d); 27490 (131e); 27564 (131e); 29483 (131b); 34604 (131e)

Cabrera A.L. \& Fabris H. 16432 (131e)

Cáceres S. \& al. 384 (131b)

Caceres S. \& Zamudio C. 295 (131e)

Calago K. 158 (115); 167 (115)

Calderon \& al. 95 (131e); 343 (131e)

Cámbar I. 71 p.p. (91)

Campos Porto P. 1223 (120a); 3401 (120a)

Canela M. s.n. (128a)

Cañigueral J. 940 (131e)

Cano \& al. 276 (131e)

Caplan H. 27 (131e)

Capurro R.H. s.n. (131e)

Carambula M. 2688 (131d)

Cardenas M. 4074 (131e)

Cardona F. 740 (114); 757 (114)

Carneiro D.S. \& Oliveira R.P. 95 (118c)

Carnevali R. 4069 (131d); 4879 (119); 5648 (119); 6134 (119)

Carreira L.M.M. \& al. 956 (118)

Carvajal Hernandez S. 202 (87)

Carvalho A.M. \& al. 1731 (104); 3895 (118c)

Carvalho A.M. de \& Delphim C.F. de M. 2236 (112)

Carvalho J.H. de \& Bona Nascimento M.S. 463 (118c); 1103 (118b); 1104 (118b)

Carvalho M.G. 847 (121);

Carvalho M.G. \& Silva S.T. 666 (121)

Casco Varela J.R. 61 (91)

Castagnino A. s.n. (131e)

Castellanos A. 336 (131e); 16917 (131b); 17869 (131c); 17001 (131b); 18380 (131e); 22513 (118c); 25355 (118b); 25819 (128b); 33415 (141); 45710 (128); s.n. 30-XI-1915 (131e); s.n. 14-XI-1919 (131e); s.n. 20-I-1922 (131e); s.n. 10-XI-1924 (131e); s.n. 20-I-1925 (131e); s.n. 25-II-1925 (131e); s.n. 16-XII-1925 (131e); s.n. 1-I-1926 (131e); s.n. 26-XI-1926 (131e); s.n. 25-XII-1926 (131e); s.n. 19-IX-1927 (131e); s.n. 18-XII-1929 (131e); s.n. 27-I-1931 (131d); s.n. 29-I-1939 (131e); s.n. 12-I-1940 (131e); s.n. 29-XI-1940 (131e); s.n. 29-IX-1943; s.n. 28-I1944 (131e); s.n. 7-II-1944 (131e)

Castro N.M. \& Mayo S. CFSC 7197 (120a) 
Cavacanti G. \& al. 15 (128b)

Cavalcante P. 2106 (118)

Cavalcanti T. \& al. CFCR 10321 (120a)

Cavalcanti T.B. \& al. 623 (115); 1097 (126); 1356 (120a); 1576 (135); 2202 (120a); 2207 (109); 2215 (115); 3552 (106)

Cesar H.L. 45 (112); 128 (112); 226 (112)

Chaves E. \& al. 286 (120a)

Chaviel A. 452 (117b); 454 (114)

Chodat R. s.n. (131b); s.n. (105)

Chorley M. 51 (91)

Christison D. s.n. (131b)

Cid C.A. \& al. 4305 (118a); 4458 (118a)

Cid Ferreira C.A. 5602 (107)

Cid Ferreira C.A. \& al. 6056 (94)

Claussen P. 129 (120a)

Cobra L.Q. \& Oliveira J. 218 (112)

Combs R. 165 (128a)

Commerson P. s.n. (131e); s.n. (131e)

Coradin L. \& al. 6628 (118a)

Cordeiro I. \& al. CFCR 488 (121); CFCR 818 (121); 1828 (120a); CFCR 8898 (121)

Cordovil S.P. \& al. 133 (115); 151 (115)

Corradi L. s.n. (131e)

Correa A. 314 (131e)

Correa M.N. \& al. 2370 (131e)

Correa M.N. \& Nicora E. 3155 (131e)

Costa A.L. s.n. (128b); s.n. (131a)

Costa F.N. \& al. 3 (121)

Costa J. da S. 24 (94)

Costa Lima G. s.n. (128a)

Courbon A. s.n. (131a); (131e)

Covas G. \& Ragonese A. 4182 (131e)

Cowan C. 1667 (128a)

Cowan R.S. \& Wurdack J.J. 31488 (114)

Cremers G. 4910 (103); 9396 (103); 9455 (103)

Cremers G. \& Hoff M. 11465 (103)

Cristóbal C.L. \& al. 1550 (131e); 1953 (131e)

Cristóbal C.L. \& Krapovickas A. 659 (115); 665 (112); 672 (109); 693A (112); 1782 (131b); $2491(131 \mathrm{e})$

Croat T.B. \& al. 84861 (118c)

Crosa O. s.n. (131a)

Crovetto \& al. 4703 (131d)

Crovetto \& Grondona R. 4070 (131d)

Crovetto - ver Martínez Crovetto

Cruger 15 (103)

Cruz M.A.V. da 86 (100)

Cruz N.D. \& al. 6366 (120a)

Cuatrecasas J. 3837 (117a); 7641 (91)

Cuezzo A.R. 925 (131e); 7903 (131e)
Cuezzo A.R. \& al. 3462 L (131e); $11006 C$ (105)

Curtiss A.H. 503 (128a)

Daguerre J.B. 218 (131e)

Dahlgren B.E. 956 (118)

Daly D.C. \& al. 983 (118a); 1980 (118b)

Damazio L. 1811 (120a); s.n. (141)

Davidse G. 4261 (103)

Davidse G. \& al. 35106 (128a)

Davidse G. \& Gonzalez A.C. 12631 (103)

Davidse G. \& Huber O. 15217 (103)

Davidse G. \& Pohl R.W. 2370 (91)

Davis D.H. 799 (103); 871 (103)

Davis P. \& al. 2416 (135)

Dawson E.Y. 14980 (109)

Dawson G. 32 (131e); 187 (131e)

Dawson G. \& Calastremi A.H. 1826 (131e)

De Grande D.A. \& Lopes E.A. 207 (95)

De la Rua s.n. (131e)

Degen R. 1926 (105); 2146 (105); 2515 (105)

Del Castillo E. 65 (131e)

Del Puerto O. 200 (131b); 203 (131b); 12657

(131d); 14554 (131d); s.n. (131b)

Del Puerto O. \& al. 2155 (131e); 11436 (131e)

Del Puerto O. \& Codina 9307 (131a)

Del Puerto O. \& Marchesi E. 5678 (131e); 8932 (131e); 8955 (131e); 8996 (131e); 11363 (131e); 11473 (131d); 15878 (131d); 15923 (131d)

Delascio F. \& al. 9882 (103); 13339 (103)

Delascio F. \& Liesner R. 6905 (128a)

Dematteis M. 677 (131b)

Dematteis M. \& al. 1320 (131d); 1967 (128a); 2917 (105); 2919 (105)

Dematteis M. \& Schinini A. 1632 (131c); 1679 (131a); 1688 (131e); 1778 (131a); 1838 (131a); 1847 (131e)

Dematteis M. \& Seijo G.J. 774 (131e)

Desportes J.B.R.P. s.n. (128)

Dias da Rocha 37 (118)

Dias T.A.B. \& al. 379 (113); 416 (113)

Dodson C.H. \& Gentry A.H. 12458 (128a)

Doello-Jurado M. s.n. (131e)

Dominguez J.A. 94 (131e)

Dressler R.L. 2422 (128a)

Drouet F. 2440 (103); 2559 (118)

Duarte A. 551 (120a); 2027 (120a); 2080 (88); 2305 (120a); 2319 (106); 4001 (140); 4071 (120a); 4623 (120a); 6487 (99);6630 (128a); 7544 (120a); 9051 (141); 9953 (112); 10205 (109); 10236 (109); 11877 (141)

Duarte A.P. \& Ivone 1291 (118a) 
Duarte A.P. 8941-Pereira E. \& 9954 (141)

Duarte L. \& Castellanos A. 469 (118c)

Duke J.A. 13641-3 (114)

Dusen P. 6280 (131e); 16909 (120a); s.n. (120a)

Dwyer J.D. 11521 (91)

Dwyer J.D. \& al. 319 (91)

Earle F.S. 680 p.p. (128a)

Edwall G. CGGSP 3939 (120a)

Eggers H.F.A. 14777 (128a)

Egler W. s.n. (120a)

Eiten G. \& Eiten L.T. 3650 (118); 3665 (118c); 3709 (118); 3767 (128a); 3845 (118a); 3872 (118); 4125 (118); 4126 (118); 4193 (118); 4238 (118); 4421 (118c); 8602 (94); 8932 (118); 8957 (94); 8965 (118); 8969 (94); 8971 (118); 9336 (94); 10813 (118c)

Ekman E.L. 1969 (131e); 1972 (105); 1973 (131e); 4130 (128a); 6371 (128a); 9952 (128a); 10047 (128a); 10953 (128a); 11884 (84); 11955 (84); 12412 (128a); 13397 (128a); 14925 (128a); 16007 (128a); 18161 (128a); 2424 (128a)

Eliceche A. 123 (105)

Elisetch M. \& Cano 118 (131e)

Ellenberg N. 1309 (128a)

Emperaire L. 544 (128b); 2225 (128a); s.n. (118)

Ervendberg L.C. 134 (128a)

Esteves G. 2343 (118c)

Esteves G. \& Lyra-Lemos \& 2114 (118)

Esteves G.L. \& al. 1836 (118); 2293 (120a); CFCR 15497 (120a)

Esteves G.L. \& Barros C.S.S. 2582 (118a)

Esteves G.L. \& Kameyama C. 2510 (89); 2513 (121)

Estrada M. s.n. (131e)

Eyerdam W.J. \& Beetle A.A. 23151 (131e)

Fabris H. \& al. 6698 (131e); 7881 (131a)

Fabris H. \& Schwabe 4848 (131e)

Fabris H. 2578 (131e); 4999 (131e); 6119 (131e)

Faria G.M. \& Mazucato M. 78 p.p. (120a)

Faria J.G. \& al. 171 (110)

Farney C. \& Batista E.F. 2098 (118b)

Feddersen P. s.n. (131e)

Felippone F. 2493 (131e); 3246 (131e); 3310 (131e); 3376 (131e); 5056 (131e); 5065 (131b)

Fernandes A. 39 (118c); 2524 (103); 3016 (103); s.n. (118a); s.n. (118c)

Fernandes A. \& al. s.n. (118a); s.n. (128a)

Fernandes A. \& Martins P. s.n. (118)

Fernandes A. \& Nunes E. s.n. (118a)

Fernandez Casas J. \& Molero J. 4072 (105)

Fernandez F. 386 (131e)
Ferreira A.G. \& Marques M. 57 (121)

Ferreira M.B. 928 (112); 1419 (112)

Ferreyra / Herb. Lusit. 25 (120a)

Ferreyra R. 5920 (128a); 5981 (128a); 9106 (128a); 16262 (128a); 17984 (128a)

Ferrucci M.S. 827 (131e)

Ferrucci M.S. \& al. 981 (104); 983a (116b); 995 (118a); 996 (118a); 1552 (105); 1677 (105); 1685 (118a); 2472 (118a); 2546 (118c)

Feuillet C. 4035 (103)

Fiaschi P. \& al. 92 (120a); 2487 (104)

Fiebrig C. s.n. (105)

Fiebrig K. 853 (105); 4463 (105); 2528 (131e); 2538 (131e); 4409p.p. (105); 12654 (131e)

Filgueiras T.S. \& al. 3568 (118d)

Filipovich R. 54 (131e); 282 (131e)

Filliettaz A.M. \& al. 60 (120b)

Fisher G.L. 45199 (87)

Floyer E.A. 13 (131e)

Fonseca M.L. \& al. 183 (115); 313 (120a); 872 (120a); 974 (120a); 979 (118d); 1546 (90); 1637 (90)

Fonseca M.L. \& Alvarenga D. 2079 (106); 2088 (106); 2218 (112); 2238 (115)

Fonseca M.R. de 11 (118c)

Fonseca S.G. 375 (118)

Fonseca S.G. \& Onishi E. 1093 (127); 1146 (94); 1540 (94)

Fontella J. 1419 (112); 1428 (120a)

Forest. Dep. Brit. Guiana 5825 (114)

Fortuna J. 8 (131e)

Fortunato R. \& al. 857 (105); 1086 (105)

Forzza R.C. \& al. 1249 (116b); 3344 (106)

Fosberg F.R. 20179 (91); 38808 (118)

Fotius 3396 (128b); 3396a (128a)

Frangi J. 415 (131e)

Freire de Carvalho L. d'A. 1054 (106)

Freire de Carvalho L. d'A. \& al. 112 (120a); 147 (120a)

Freire-Fierro A. \& Fonseca Vaz A.M.S. da 3022 (115)

Fries R.E. 515 (131e)

Froes R. 1827 (118); 21593 (118)

Frommel \& al. s.n. (131e)

Frommel \& Lefebre s.n. (131e)

Fruchart 754 (131b); s.n. 6-VIII-1867 (131b); s.n. 1-XI-1869 (131e); s.n. I-1874 (131e); s.n. VI1874 (131b); s.n. 28-II-1875 (131e); s.n. 31VIII-1875 (131e); s.n. 9-XI-1876 (131e)

Fuentes A. \& Rojas L. 1515 (128a)

Galander C. 3686 (131e); 3699 (131e); s.n. (131e)

Gallardo C. s.n. (105) 
Gallinal H. \& al. PE-650 (131d)

Gallindo F. \& al. CFPE 510 (118); CFPE 513 (118)

Gamerro J.C. 1134 (131d)

Ganev W. 1783 (116b)

Gardner G. 1247 (118a); 1248 (118); 1664 (118a); 1667 (118a); 2171 (118b); 2176 (132a); 2180 (118a); 2415 (128a); 2419 (128a); 3201p.p. (115); 3201p.p. (118); 3747 (115); 3751 (135); 3752 (109); 4695 (141); 4696 (100); 6031 p.p. (118c); 6031 p.p. (128a); s.n. (128a)

Garolera Romero A. 101 (131e); s.n. 11-I-1947 (131e); Seclantas, s.n. (131e); Cachi, s.n. (131e)

Gassner 781 (131a)

Gates B. \& Estabrook 66 (120a); 141 (120a)

Gaudichaud C. /Herb.Imperial du Bresil 643 (120a); 2946 (131c); 3043 (131c)

Gavio-Zotta s.n. (131e)

Gay C. s.n. (131b)

Gentle P.H. 3875 (91)

Gentry A. 63200 (103)

Gentry A.H. 21384 (115)

Gentry A.H. \& Berry P. 14599 (114)

Germain R. 8899 (118)

Ghiesbrecht A.G. 148 (87); 219 (87)

Giambiagio D. s.n. (105)

Giardelli M.L. 90 (131e)

Gibbs P.E. \& al. 5216 (141)

Gibert E. 130 (131e); 131 (131e); 681 (131e); 754 (131b)

Gibson E. s.n. (131e)

Gillies J. s.n. (131e)

Ginzberger A. s.n. (118)

Girnos E. \& Cabral C. 38 (118c)

Giulietti A.M. \& al. CFCR 1286 (116b); CFCR 1808 (141); CFSC 12493 (88)

Glassman S.F. 1894 (128a)

Glaziou A. 9646 (111); 9646a (111); 9649 (118); 9856a (120a); 10299 (118); 10879 (118a); 13913 (121); 17014 (120a); 18259 (120a); 18338 (141); 18998 (141); 19390 (120a); 19391 (100); 19392 (142); 19393 (141); 19393b (141); 19394 (141); 19395 (141); 19396 (94); 20652a (120a); 21446 (133); 21447 (134); 21448 (90); 21449 (129); 21450 (99); 21450b (120b); 21450e (129); 21452 (120a); 21453 (120a); 21454 p.p. (120a); 21455 (99); 21455 (115); 21456 (109); 21457 (109); 21458 (112); 21460 (125); s.n. (118); s.n. (128a); s.n. (99); s.n. (99); s.n. (125)

Goldsmith B. 156 (118)

Gonçalves L.M.C. 83 (118); 213 (104)
Gonnot s.n. (131e)

Gonzalez s.n. (131e)

Gonzalez A.M. \& al. 22 (105); 31 (131b); 54 (105); 55 (118a)

Gonzalez Ortega J. 145 (128a); 609 (128a)

Goodall N. \& Tirel C. 35 (131d); 159 (131b)

Goodland R. 894 (103)

Gottsberger G. 13-12368 (120a)

Gottsberger G.K. \& Posey D.A. 318-22183 (114)

Gottsberger I. 13-191085 (121)

Gottsberger I. \& Gottsberger G. 11-8273 (115); 11 201082A (118c); 19-16782 (118c); 19-71182 (118c)

Goudot J. s.n. (91)

Graham V. 223 (103)

Granville J.J. de 2851 (103)

Graziela \& al. 805-68 (109)

Gregg J. 854 (87)

Grewal H. \& al. 363 (103)

Grijalva A. \& al. 1267 (128a)

Grondona E. 2489 (131e); 2516 (131e); 8080 (131e); s.n. (131e)

Groppo Jr. M. \& al. 548 (105)

Grosourdy R. de 13 (128a)

Guaglianone E.R. \& Ulibarri E. 843 (131e)

Guarino E.S.G. \& al. 217 (112); 527 (112)

Guarino E.S.G. \& Pereira J.B. 9 (108); 475 (120a)

Guillemin J.B.A. 344 (120a)

Guimaraes A.L. s.n. (112)

Guimaraes J.G. 328 (118c)

Guiñazu J.R. 135 (131e)

Gulich s.n. (131e)

Gutierrez J. 39 (131e)

Haase R. 862 (118c)

Haenke W. 8 (118)

Hagelund K. 4662 (131b); 7254 (131b)

Hahn W. 1779 (105)

${ }^{\circ}$ R.M. 16807 (104)

Harley R.M. \& al. 10577 (94); 15059 (118a); 15524 (116b);15827 (116b); 15849 (116b); 16956 (104); 18605 (118c); 19291 (118a); 20792 (116b); 20793 (116b); 21127 (104); 24650 (116a); 24858 (121); 24951 (135); 25096 (121); 25354 (116a); 25432 (141); 27845a (116b); 50418 (116b); 50674 (116b); 52114 (116b); 52748 (116b); 53740 (118a); 53901 (118a); CFCR 6139 (121); CFCR 6420 (120a); CFCR 6421 (116b); CFCR 6491 (121)

Harley R.M. \& Barroso G. 11334 (109)

Harley R.M. \& Giulietti A.M. 54165 (118a); 55020 (118a) 
Harley R.M. \& Giulietti A.M.

Harley R.M. \& Souza R. 10136 (94)

Harley R.M. \& Stannard B. 27568 (136)

Harmon W.E. \& Dwyer J.D. 3836 (128a)

Harris L. s.n. (120a)

Harris W. 12066 (128a)

Hassler E. 333 (105); 1712 (105); 1765 (105); 3877 (105); 5641p.p. (105); 6340 (128a); 6353p.p. (128a); 6450 (105); 6678 (105); 7171 (105); 7685 (119); 7891 (105); 8425 (105); 8443 (95); 8443a (95); 8862 (119); 12588 (105); 12642 (128a)

Hassler E. \& Rojas T. 2356 (105)

Hatschbach G. 11995 (120a); 24980 (128a); 27320 (121); 27369 (141); 27464 (121); 29039 (121); 31998 (118a); 32427 (118a); 34051 (118a); 35936 (118a); 36261 (115); 37413 (118a); 37819 (112); 39422 (135); 39473 (118a); 40767 (128a); 40842 (121); 41241 (116b); 41404 (121); 41450 (93); 42035 (112); 42078 (118a); 44772 (112); 44795 (115); 47352 (121)

Hatschbach G. \& Ahumada L.Z. 31646 (121); 31683 (121)

Hatschbach G. \& al. 36254 (135); 36523 (141); 36980 (112); 39515 (128a); 51121 (141); 53749 (115); 53815 (115); 53835 (120a); 53893 (98); 54164 (116b); 54194 (121); 54229 (133); 54376 (112); 54550 (120b); 54993 (121); 55871 (115); 55930 (112); 55948 (109); 56358 (112); 56556 (128a); 56602 (128a); 56642 (104); 56642B (118c); 56647B (128a); 56712 (116a); 56725 (118a); 56733 (116a); 56758 (116a); 56766 (116a); 56767 (118c); 56825B (116a); 56861 (118c); 56904 (118c); 56925 (118c); 56964 (118c); 58276 (112); 58416 (115); 58419 (113); 58803 (105); 58916 (105); 58935 (128a); 58984 (128a); 59311 (109); 59311 (112); 59479 (118d); 59874 (115); 59929A (112); 59941 (120b); 59949 (112); 59982 (120a); 60028 (120a); 60117 (120a); 60173 (135); 60207 (112); 60211 (120a); 60260 (112); 60324 (135); 60425 (112); 60480 (112); 62022 (118b); 62292 (118c); 62654 (118a); 63595 (94); 63674 (94); 64246 (120a); 64249 (135); 64251 (120a); 64638 (120a); 65099A (128b); 65163 (128b); 66209 (120a); 66430 (121); 66433 (121); 66801 (94); 66836 (118a); 66881 (118a); 67045 (118a); 67208 (120a); 67211 (120a); 67305 (116b); 67522 (135); 67584 (118a); 67838 (116b); 67851 (128a); 67858 (116a); 67966 (121); 68006 (121); 69437 (120a); 69662 (121);
70127 (109); 70130 (115); 70133 (109); 70240 (101); 70333 (135); 70348 (109); 70414 (109); 70644 (120a); 70650 (112); 70696 (120a); 70700 (118d); 70861 (109); 70927 (118b); 71049 (118a); 71061 (118a); 71220 (85); 72142 (135); 73741 (135); 73748 (120a); 73785 (121); 73822 (118a); 74505 (105); 76592 (95); 76965 (105); 77115 (95); 77129 (95); 77157 (95); 77511 (120a); 77692 (120a); 78871 (120a)

Hatschbach G. \& Cordeiro J. 51798 (115)

Hatschbach G. \& Haas H. 13993 (120a)

Hatschbach G. \& Kummrow R. 38385 (118a); 48041 (116b)

Hatschbach G. \& Pelanda P. 27791 (102); 27914 (120a); 28018 (121)

Hatschbach G. \& Silva 50172 (121)

Haught O. 149 (128a); 219 (128a); F-53 (128a)

Hauman L. 9168 (131d); s.n. (105); s.n. (131a); s.n. (131d); s.n. (131e); s.n. (131e)

Hauman-Merck s.n. (131e)

Heinonen S. \& al. 125 (119)

Heithaus E.R. 604 (128a)

Hensold N. \& al. CFCR 2073 (120a); CFCR 3509 (121)

Herb. Drake s.n. (128a)

Herb. Durand s.n. (91)

Herb. Linn. 384-5 (131)

Herb. Maille s.n. (128a)

Herb. Poiret s.n. (128a)

Herb. Poiteau s.n. (128a)

Herb. Smith 540-3 (131e)

Heringer E.P. 3761 (120a); 5855 (120a); 5869 (128a); 7844/38 (112); 7851 (115); 8222/416 (115); 8941/1135 (112);10584 (106); 11500 (112); 11516 (135); 12021 (115); 13048 (115); 14979 (112); 15426 (115); 16238A (112); 17212-A (120a); 17218A (112); 17981 (120a); 18018 (112); 18385A (112); 18386 (115); s.n. (120a)

Heringer E.P. \& al. 169 (128b); 312 (128b); 651 (128b); 780 (92a); 2158 (115); 3542 (135); 4443 (115); 4556 (115); 4654 (115); 4856 (115); 5041 (106); 5146 (112); 5643 (106); 7231 (90); 7462 (115); 7509 (106)

Heringer E.P. \& Salles A.E.H. 17923 (112)

Hermann H.A. 11199 (91)

Hernandez Magaña R. \& al. 9433 (87)

Herter G. 164 (131b); 717 (131e); 717a (131e); 717b (131e); 717f (131e); 5303 (131a); 10423 (131a)

Herzog T. s.n. (131e) 
Hicken C. 229 (131e); 673 (131e); s.n. 13-I-1898 (131e); s.n. 2-XII-1900 (131e); s.n. 23-XI-1907 (131e); s.n. 9-XI-1910 (131e)

Hieronymus G. 129 (131e)

Hind D.J.N. \& Queiroz R.F. H50905 (116b)

Hinton G.B. 744 (87); 8451 (128a)

Hladik A. 384 (114)

Hoehne F.C. \& Gehrt A. s.n. (120a); s.n. (120a); s.n. (120a); s.n. (120a)

Hoehne F.C. 1018 (120a); 1666 (120a); 5539 (127)

Hoff M. \& Cremers G. 5686 (103)

Hoff M. \& Granville J.J. 5469 (103)

Hofsten N.G. 608 (131e)

Holmberg E.L. 38 (131b); 61 (131e); 116 (131e); 1220 (131e)

Hopkins M.J.G. \& al. 108 (118c)

Horovitz S. 579 (131e)

Hosseus C.C. 67 (131e); 510 (131e); 522 (131e)

Hostmann F.W. 633a (103)

Hostmann F.W. \& Kappler A. 1880 (103)

Howard R.A. 5533 (128a)

Huaylla H. 1181 (131e)

Huber O. 641 (107); 693 (107); 1105 (103); 1960 (114); 3624 (114); 3804 (103); 4246 (117b); 4386 (123); 4423 (114); 4446 (114); 4938 (114); 5260 (117b)

Huber O. \& Tillett 2809 (86)

Huidobro A.M.R. 3135 (131e); 3185 (131e); 3847 (131d)

Hunt D.R. 217 (91)

Hunziker A.T. 1478 (131e); 4147 (131e); 7789 (131e); 8449 (131e); 8537 (131e); 10453 (131e); 13137 (131e); 14496 (131e); 16570 (131e); 17493 (131e); 20784 (131e); 21901 (131e); 25638 (131e); s.n. (131e)

Hunziker A.T. \& Cocucci A.E. 10825 (131e); 15748 (131e); 16571 (131e); 16573 (131e); 16574 (131e); 17162 (131e); 17264 (131e); 17670 (131e); 17693 (131e); 17707 (131e)

Hunziker A.T. \& Di Fulvio T.E. 21380 (131e)

Hunziker A.T. \& Subils R. 24980 (131e)

Hunziker A.T. \& Maldonado P. 16242 (131e)

Hunziker J.H. 543 (131e); 612 (131e); 1041 (131e); 1271 (131e); 4441 (131d); 8367 (131e)

Ibarrola T.S. 2496 (131e); 2535 (131e); 3261 (131e); 3356 (131e); 3985 (119)

Infantes Vera J. 4009 (128a)

Irigoyen J. \& Schinini J. 173 (131d)

Irnaldo \& al. s.n. (125)

Irwin H.S. 310 (103); 592 (103)

Irwin H.S. \& al. 7934 (120a); 7890 (112); 7993 (120a); 8091 (112); 8216 (90); 8337 (106); 8358 (112); 8518 (106); 8645 (106); 8707 (115); 8709 (120a); 9020 (120a); 9021 (112); 9084 (90); 9246 (120a); 9831 (134); 9849 (134); 9933 (120b); 10087 (99); 10500pp (120a); 10500pp (135);10529 (112); 10693 (112); 10775 (120a); 10862 (112); 11049 (115); 11068 (115); 11090 (112); 11171 (115); 11232 (112); 11714 (109); 12787 (120a); 13115 (112); 13158 (112); 13261 (115); 13504 (115); 13610 (134); 13630 (112); 13634A (112); 13909 (115); 14228 (112); 14896 (118a); 15083 (115); 16783 (118c); 16825 (118a); 17514 (115); 18627 (125); 18758 (120a); 18769 (109); 18819 (115); 18877 (135); 18987 (115); 19068 (115); 19353 (120b); 19751 (120a); 20104A (88); 20104B (120a); 20105 (120a); 20109 (88); 21954 (121); 22141 (95); 22142 (121); 22143 (120a); 22376 (120a); 22609 (141); 22780 (121); 22972 (121); 23048 (120a); 23144 (120a); 23418 (121); 23596 (121); 23839 (135);23848 (112); 23947 (135); 24105 (115); 24144 (135); 24291 (115); 24345 (135); 24409 (109); 24730 (133); 24984 (133); 25022 (120b); 25260 (115); 25287 (112); 25855 (112); 25891 (128a); 25955 (120b); 26012 (112); 26142 (120b); 26174 (124); 26362 (99); 26882 (134); 27929 (141); 28109 (121); 28312 (121); 28924 (120a); 29304 (120a); 29725 (115); 29726 (112); 31286 (118c); 31354A (118c); 31354B (122); 31818 (115); 32017 (135); 32057 (115); 32871 (120a); 34062 (109); 34100 (109); 34477 (120a); 34628 (115); 35005 (135)

Irwin H.S. \& Soderstrom T.R. 5246 (115); 5635 (112); 5747 (120a); 6113 (120a); 6696 (94)

Isabelle A. 65 (131e); 65a (131b)

Isler 139 (131e)

Izaguirre P. \& al. 2611 (131b/d); 9572 (131e); 19088 (131b); 20092 (131d); 21012B (131c); 21026B (131c); 23120 (131b/d)

Jansen-Jacobs M.J. \& al. 1096 (103); 1098 (103); 3861 (103); 4038 (103); 4045 (128a); 4398 (103)

Janzen D.H. 10125 (128a); 11770 (128a)

Jardim J.G. \& al. 759 (118a); 2317 (118); 3313 (118); 3553 (118c)

Jenman G.S. 537 (103); 1884 (103)

Jimenez J.J. 9063 (128a)

Job M.M. 218 (131d); 518 (131e); 549 (131e); 1075 (131e); 1458 (131e); 2853 (131e); 2932 (131e); s.n. (131d); s.n. (131e) 
Jobert C. 979 (111); 989 (118); 1072 (118)

Jobert C. \& Schwacke A.C. 950 (118); 1091 (118)

Joly A.B. \& al. 109 (88); 207 (120a); 208 (88); 552 (120a); 768 (88); 1047 (120a); 1752 (120a); 1784 (88); 2491-A (88); 2498 (120a); 2550 (88)

Joly A.B. \& Muller C. 3444 (120a)

Joly A.B. \& Semir J. 3016 (120a); 3079 (120a); 3216 (120a)

Joly C.A. \& al. 14867 (118b)

Jony 2581 (87)

Jorgensen P. 238 (131e); 1615 (131e); 2551 (131e); 3150 (131e); 3350 (131e); 4069 p.p. (105); 4071 (119); 4845 (119)

Jozami J.M. 148 (131e)

Juarez de Varela F. 2177 (131e)

Juarez F. 2178 (131e); 2207 (131e)

Kappler A. 633a (103); 1880 (103)

Kawasaki M.L. \& al. CFSC 7552 (120a)

Keller H.A. 3899 (131e)

Keller H.A. \& Gatti F.E. 4153 (105)

Kenoyer L.A. A607 (87)

Kerr W. s.n. (118c)

Killip E.P. 32364 (84); 37219 (103); 37235 (103); 37708 (103); 44023 (84); 45332 (128a)

Killip E.P. \& Smith A.C. 15179 (114)

King D.O. 98 (131e)

Kirkbride J.H. 3304 (109); 3973 (115); 5117 (115)

Kral R. \& Wanderley M.G.L. 75022 (94)

Krapovickas A. 191 (131e); 759 (131e); 801 (131e); 1347 (131e); 1806 (131e); 1906 (131e); 2172 (131e); 2616 (131e); 2648 (131e); 6521 (131e); 7364 (131e); 30165B (118a); 38176 (131e)

Krapovickas A. \& al. 12469 (105); 12609 (105); 14175 (105); 14238 (105); 16937 (131b); 18274 (105); 20762 (105); 21180 (131b); 21621 (131b); 22297 (131e); 24442 (119); 24815 (119); 25687 (131b); 25847 (131b);25943 (131b); 27425 (131e); 27446 (131e); 27757 (131e); 28675 (105); 30444 (131e); 30479 (131e); 32676 (105); 32862 (105); 33103 (128a); 33106 (112); 33168 (112); 33245 (112); 33264 (128a); 34267 (105); 34426 (105); 36081 (131e); 36444 (105); 37812 (112); 37877 (118c); 37879 (118c); 37932 (128a); 38606 (128a); 38619 (118c); 38621 (118b); 38621bis (118b); 38624 (128b); 38624bis (128a); 38695 (118c); 38713 (118a); 38732 (92b); 38754 (118b); 38761 (118c); 38761 bis (118c); 40237 (118a); 40248 (118a); 40270 (118a); 41011 (131b); 45230 (105); 45453 (128a)
Krapovickas A. \& Cristobal C.L. 13260 (131d); 13776 (131d); 13786 (131d); 16173 (131a); 16251 (131b); 16311 (131a); 17361 (131e); 17378 (131e); 17407 (131e); 20975 (131b); 21694 (131d); 21761 (131b); 24476 (131e); 27136 (131e); 27146 (131e); 28592 (131e); 29095 (131b); 33733 (131b); 37189 (128a); 37202 (118b); 37218 (118c); 37243 (118c); 40289 (131e); 42823 (120a); 42868 (128a); 42886 (120a); 42901 (120a); 42904 (113); 42965 (128a); 44236 (131e);44564 (105); 44970 (105); 45055 (105); 45133 (105); 46183 (131e); 46217 (131e); 46241 (131e); 46606 (131e); 46613 (131e); 44626 (105); 46965 (131b)

Krapovickas A. \& Schinini A. 30444 (131e); 30479 (131e); 31119 (128a); 31202 (128a); 31265 (131e); 32361 (128a); 32399 (118c); 32803 (95); 32966 (95); 33238 (112); 36081 (131e);36530 (128a); 36614 (128a); 36653 (118c); 37565 (131e)

Krapovickas A. \& Seijo G. 47514 (131e)

Krapovickas A., Valls J.F.M. \& Silva G.P. 37868 (137);

Kuhlmann J.G. 143 (103); 147 (103); 309 (140); 474 (103); 6656 (140); s.n. (140)

Kuhlmann M. \& Gehrt A. s.n. (106)

Kühnemann O. s.n. (131e)

Kullberg A. E. s.n. (131e)

Kuntze O. s.n. (118c); s.n. (131e); s.n. (131e)

Kurtz F. 583 (131e); 584 (131e); 2817 (131e); 4444 (131e); 7265 (131e)

Labat J.N. 198 (103)

Lahille F. 1783 (131e)

Lanfranchi A.E. 443 (131e); 1280 (131e)

Langenheim J.H. 3034 (114)

Langsdorf G.H. s.n. (120a)

Lanstyak L. s.n. (121)

Laruotte en Saint Hilaire s.n. (118a); 323 (100)

Lasser T. 185 (91)

Lavastre B.A. 2255 (128a)

Le Sueur D.H. 574 (128a)

Leeuwenberg A.J.M. 11841 (103)

Lefebre A. s.n. (131e)

Legaspi J. s.n. (131e)

Legname P.R. \& al. 4293 C (131e); 5959C (131e)

Leitao Filho H.F. \& al. 9696 (120a); 27483 (121); $27871(121)$

Lema 6431 (131a)

Lema \& al. 7869 (131b); 7980 (131c)

Lemee A. s.n. (103); s.n. (128a) 
Leon [Bro.] 9192 (128a)

Leon O. de 86 (91)

Leon R.J. 973 (131e)

Leprieur F.R. s.n. (128a)

Lewis G. \& al. CFCR 6811 (116a); CFSC 7751 (120a); CFSC G.P. 7805 (142)

Liesner R. 2647 (128a)

Liesner R. \& Gonzalez A.C. 5791 (103)

Liesner R. \& Lockwood 2561 (128a)

Lima A. 58-2967 (115); 307-68 (94)

Lima D. de A. 22 (118a)

Lima H.C. de \& al. 1035 (141)

Lima L. s.n. (128b)

Lima M.P.M. de \& al. 31 (118b); 71 (118b)

Lima V.C. 343 (118); 363 (118)

Lima-Verde L.W. 689 (128a); 772 (118c)

Lindberg G. 359 p.p. (106)

Lindeman J.C. 1979 (103); 6908 (131c)

Link P. s.n. (131e)

Liogier A.H. 17550 (128a)

Lisboa P. \& al. 1209 (118)

Llatas Quiroz S. 1092 (128a)

Lofgren A. 66 (128a)

Lofgren A. \& al. s.n. (120a)

Lofgren A. \& Edwall 2170 (120a)

Lombardi J.A. 584 (133); 1822 (120a); 2841 (120a); 2912 (121); 4325 (121)

Lombardi J.A. \& al. 3724 (141); 3749 (121)

López A. 8069 (128a)

López Palacios S. \& al. 4482 (103)

Lorentz P.G. 255 (131e); 257 (131d); 287b (131e); 959 (131d); 960 (131e); 1761 (131e); s.n. II1871 (131e); s.n. 27-II-1882 (131e); s.n. X-1875 (131e)

Lossen W. 40 (131e)

Lourteig A. \& al. 2743 (131d); 2880 (131b)

Luetzelburg G.A. 1683 (118)

Luetzelburg P.V. 186 (116a); 189 (116a); 23510 (128a); 23566 (128a); 23646 (128a); 23648 (128a); 23772 (128a); 27034 (128a)

Luna F.E. 1336 (131e)

Luna Ruiz s.n. (131e)

Lund P.W. s.n. (112); s.n. (120a); s.n. (128a)

Lurvey E. 100 (105); 388 (131b)

Luti R. 1255 (131e)

Lutz A. 1601 (120a)

Lyra-Lemos R.P. \& Sugiyama M. 1707 (115)

Maas P.J.M. \& al. 3675 (103); 4006 (103); 5499 (103); 7333 (103)

Maas P.J.M. \& Huber O. 5132 (117b)

Macedo A. 3303 (120a); 3304 (115); 3511 (115);
3531 (115); 3591 (106); 4311 (106); 4326

(109); 4345 (109); 4416 (118d)

Macedo W. 54 (112)

Magalhaes M. 1791 (141)

Magalhaes Gomes F. 1568 (120a)

Maguago H. 178 (120a)

Maguire B. \& al. 30949 (117b)

Maguire B. \& Maguire 44693a (88)

Maldonado R. 515 (131e); 1036 (131e)

Malicky s.n. (131e)

Malme G.A. 22 (106); 150 (131c); 160 (131c); 1972 (94); 2608 (128a); 2608A (128a); s.n. (127); s.n. (127); s.n. (131e)

Malvarez M.R. 71 (131e)

Mamede M.C.H. \& al. 54 (130)

Maranta A. 999 (131e)

Marchesi E. 272 (131a); 517 (131b/d); 101230 (131d); 18555 (131a)

Marchesi E. \& al. 19804 (131d)

Marchesi E. \& Armand-Ugon P. s.n. (131c)

Marchesi E. \& Bayce 19978 (131c)

Marchesi E. \& Ferres 14208 (131e)

Marcondes-Ferreira W. \& al. 1568 (113)

Marcondes-Ferreira W. \& al. 962 (120a)

Marcuzzi s.n. (91)

Markgraf F. \& al. 3223 (120a); 3427 (121)

Marquete R. \& al. 2433 (118d); 2722 (109)

Martens L. 281 (120a)

Martinelli G. \& al. 7467 (115)

Martinelli G. \& Smith G. 6211 (120a); 6270 (121)

Martinez Crovetto R. 9891 (105); 10432 (131e); 11241 (131b); 11423 (131b)

Martinez Crovetto R. \& Piccinini B. 7033 (131e); s.n. XI-1948 (131e)

Martinez O. 221 (131e)

Martinez S.E. 12037 (91)

Martins F.R. \& al. s.n. (100)

Martins M.V. 127 (115)

Martins P. s.n. (118c)

Martius C.F.P. 1405 (121); s.n. (100); s.n. (100); s.n. (118); s.n. (118b); s.n. (118c); s.n. (118c); s.n. (120a.); s.n. (120a); s.n. (120a); s.n. (120a); s.n. (120a); s.n. (120a); s.n. (128a)

Mattos J. s.n. (120a)

Mattos J. \& Mattos N. 14218 (120a)

Maxon W.R. \& al. 7578 (128a)

Mc Daniel S. 12948 (91)

McNab G. s.n. (128a)

Mello 4146 (118)

Mello Filho L.E. 554 (118); 563 (118); 585 (120a)

Mello-Silva R. \& al. 452 (89); 603 (120a); 636 
(121); 641 (121); 734 (121); 734-A (116b); 741 (116b); 749 (121); 764 (121); 1404 (120a); 2217 (109); 2402 (142); CFCR 9695 (121); CFCR 10267 (141); CFCR 11396 (121)

Mello-Silva R., Arbo M.M. \& Nunes J.V. 760 (89)

Mello-Silva R. \& Forzza R.C. 2712 (121)

Melo \& França 545 (115); 593 (115)

Melo F.A.S. de s.n. (88)

Melo R.M. s.n. (112)

Mendes Magalhaes G. 1790 (141); 1791 (141); 17977 (141)

Mendes P.T. s.n. (118)

Mendonca R.C. \& al. 1413 (118a); 2596 (134); 2599 (134); 3065 (90); 3116 (133); 3538 (133)

Mendonca R.C. \& Ribeiro M. 684 (106)

Menendez Sevillano \& al. 9357 C (131e); 9390 C (131e); 9419 C (131e); 9465 C (131e)

Menezes M.N.A. s.n. (112)

Menezes N.L. 499 (120a); 1235 (125); 1252 (125); CFCR 610 (115); CFCR 629 (109)

Menezes N.L. \& al. 1281 (118)

Mereles F. 3423 (105); 3750 (105); 3754 (105); 4263 (105); 4278 (105)

Mereles F. \& Degen R. 4833 (131e)

Meyer H. 471 (92a)

Meyer T. 10501 (131d); 10746 (131d); 10766 (131d)

MGC - ver Carvalho M.G.

MGC \& STS ver Carvalho M.G. \& Silva S.T.

Millan A.R. 404 (131e)

Millot 516 (131d)

Millot \& Del Puerto 1112 (131d)

Mimura I. 390 (120a); 530 (120a)

Miranda C.A. 155 (118a)

Molfino J.F. 182 (131e); s.n. (131e); s.n. (131e)

Molina A. 2538 (128a); 14359 (128a); 14445 (128a)

Monteiro J.R.B. 21 (127)

Montes J.E. 1044 (103); 3252 (131b); 3253 (131b); 9370 (131b); 10140 (131b); 12433 (131b); 16380 (105); 27268 (105); (131b); s.n. 11-IV1947 (131e)

Montes R.A. 1266 (103); 1957 (103); 2012-A (103)

Monticelli J. 46 (131e)

Moore S. 184 (94)

Moraes F.C. 820 (106)

Moraes J.C. de 2290 (118)

Moreira A.M. s.n. (120a)

Morello J. \& al. s.n. (131e); s.n. (131e)

Moreno F. \& Tonini s.n. (131e)
Morong T. 608 (105); 609 (119)

Moruz C.V.A. 102 (118); 154 (128b)

Mosen H. 529 (106)

Mostacedo B. \& al. 1681 (118a)

Motta s.n. (106)

Moura C. s.n. (120a)

Mroginski L.A. 47 (131d)

Mulgura de Romero M.E. \& al. 3446 (105)

Munhoz C. \& al. 1777 (133); 2098 (106); 2179 (106); 2286 (106)

Muniez A.A. 26 p.p. (131b)

Muñoz J.D. 2052 (131d)

Nadeaud J. s.n. (131e)

Nagel O. 8008 (87)

Nakajima J.N. \& al. 399 (106); 515 (120a); 1033 (120a); 1269 (120a); 1313 (120a); 1481 (106); 1582 (106)

Nakajima J.N. \& Romero R. 702 (106); 712 (106); 718 (106)

Narvaez Montes M. 609 (128a)

Nee M. 8181 (114); 41273 (92a); s.n. (131a)

Nee M. \& Miller J. 27555 (128a)

Neill D.A. 2944 (128a); 3104 (128a)

Nelson B. \& al. 1420 (114)

Nelson B.W. 1111 (118b); 1112 (118b); 1113 (118b)

Nelson C. 739 (91); 742 p.p. (91); 790 (91)

Nelson C. \& Andino R. 12628 (128a); 12935 (128a)

Nelson C. \& Vargas E. 5029 (91); 5145 (91)

Nelson E. s.n. (131e)

Nelson E.B. 4862 p.p. (91)

Nelson E.B. \& Seymour 47714771 (91)

Neuman 2 (131e); 8 (131e)

Neuvoied M. de s.n. (121)

Nicora E. 667 (131e); 1225 (131e); 1546 (131e); 3224 (131e); 4191 (131e); 5326 (131e); 6183 (131d); 6927 (131e)

Nicora E. \& al. 9775 (105); 9803 (118a)

Noblick L. 1794 (118c); 2678 (128a)

Nobrega M.G. \& al. 712 (115)

Novara L. 128 (131e); 2205 (131e); 2867 (131e); 4062 (131e); 4767 (131e)

Novara L. \& Bruno S. 9330 (131e)

Nuñez F. 1209 (131d); 1317 (131d)

Nunez V. 124 (131e)

Occhioni P. 2144 (112); 2145 (115); 2148 (115); s.n. (106); s.n. (120a); s.n. (120a); s.n. (120a)

Occhioni P. \& al. 5855 (120a)

O'Donnell C.A. 1484 (131e); 1611 (131e); 4344 (131e)

Olano \& al. s.n. (131a) 
Oldenburger F.H.F. \& Mecenas V.V. 1643 (112); 1644 (112); 1671 (112); 1673 (112); 1736 (112)

Oliveira A.V. s.n. (120a)

Oliveira E. 1560 (118)

Oliveira F.C.A. 222 (120a)

Oliveira F.C.A. \& al. 123 (115); 263 (115); 340 (115)

Oliveira F.C.A. \& Fonseca M.L. 6 (106)

Oliveira F.C.S. \& al. 237 (128b)

Oliveira J.A. 412 (128a)

Oliveira P.I. de 82 (94)

Oliveira R.C. \& Calago K. 907 (115)

Onishi E. \& al. 53 (125)

Onishi E. \& Fonseca S.G. 172 (90); 173 (120a)

Orbigny A. d' 32 (131b); 1253 (131e)

Ørsted A.S. 4261 (128a)

Osten C. 14290 (131b); 20062 (131e); 21662 (131a)

Pabst G. 6505 (131c)

Pabst G. \& al. 7199 (120a); 8837 (109)

Pabst G. \& Pereira E. 8345 \& 9456 (121)

Palacios M.A. 4285 (131e); 4589 (131e)

Palacios M.A. \& al. 3590 (88)

Palacios M.A.-Balegno-Cuezzo A.R. 3632 (88)

Palacios M.A.-Cuezzo A.R. 217 (131b); 1126 (131c); 1324 (131c); 1810 (131d); 1948 (131a); 2460 (131b)

Palmer E. 37 (87)

Panegai [Padre] s.n. (131a)

Parodi L.R. 13973 (131e)

Parodi L.R. \& Romero s.n. (131e)

Partridge W. 16 (131e); 34 (119); s.n. (119)

Pastore J.F.B. \& al. 1800 (118a)

Pastore J.F.B., Harley R.M. \& Santos A.A. 1825 (138)

Pastore O.J. 1191 (131e); s.n. (131e)

Pastore U. \& Oliveira J.N. 130 (118)

Paula-Souza J. \& al. 4160 (120a); 4202 (120a); 4400 (120a); 4439 (120a); 4969 (118c); 5017 (118c)

Paula-Souza J., Ferrucci M.S., Duarte A.R., Rando J.G. \& Tsuji R. 4522 (98);

Peck M.E. 695 (91)

Pedersen T.M. 17 (131d); 3106 (131d); 4334 (119); 6272 (131e); 6409 (131e); 7531 (105); 9935 (131e); 10266 (119); 11402 (131d); 11435 (131c); 11858 (131e); 13951 (131e); 15818 (131e); 16051 (105); s.n. 18-X-1961 (131b); s.n. 16-XII-1969 (131b); s.n. 20-XI1990 (131d)

Pelosi E. 24 (131e)
Peña M. \& al. 123 (118)

Peña M. \& Foster R. 332 (118a)

Pennell F.W. 1541a (114)

Pereira E. 1430 (100); 1543 (141); 1703 (100); 1738 (120a); 7459 (115); 7533 (120a); 7552 (115); 8897 (88); 8897D (120a); 9954 (141)

Pereira E. 2822-Pabst G. 3458 (141); 3021-Pabst G. 3857 (120a); 4729-Pabst 5055 (112); 4730Pabst G. 5056 (115)

Pereira M. \& Lucca M. 885 (141)

Pereira-Silva G. 1981 (112); 2302 (112); 5780 (115)

Pereira-Silva G. \& Guarino E.S.G. 5553 (112)

Pereyra s.n. XI-1931 (131e); s.n. 29-XII-1933 (131e)

Perez Moreau R. s.n. 26-X-1918 (131e); s.n. 10XI-1929 (131e); s.n. 29-XI-1936 (131e)

Perrone V.R. s.n. (131d)

Petersen E. \& Hjerting J.P. 1815 (131e)

Petitbon 87 (103)

Philcox D. \& al. 3456 (118); 3674 (118)

Philcox D. \& Onishi E. 4812 (115)

Philcox D. \& Philcox D.J. 8205 (103)

Philcox D. \& Stoelzel V. 8367 (103)

Piccinini B. \& Hilfer 3790 (131e); 3869 (131e); 3930 (131e); 3966 (131e); 4028 (131e); 4103 (131e); 4200 (131e)

Piccinini B. \& Petetin C.A. 2739 (131e); 2856 (131e); 2926 (131e); 3205 (131e); 3242 (131e); 3336 (131e)

Pickel B. 4525 (120a); 4188 (128a)

Pierotti A. s.n. (131e)

Pietrobom-Silva M.R. 2592 (115)

Piliackas V. \& al. CFSC 10903 (120a)

Pinto G. 42269 (118c)

Pinto G.C.P. 43/83 (118); 381/81 (121)

Pinto P. \& Sastre C. 1375 (103); 1516 (91)

Pipoly J.J. \& al. 11613 (103)

Pirani J.R. \& al. 1741 (109); 1842 (135); CFCR 896 (121); CFCR 897 (116b); CFCR 9018 (121); CFCR 11096 (100); CFSC 12125 (120a); CFSC12166 (142); CFSC12193 (142); CFSC 12827 (88); H51430a (116b)

Pirani J.R. \& Mello-Silva R. CFCR 11042 (141)

Pires J.M. 16065 (114)

Pires J.M. \& al. 8570 (115); 14725 (103)

Pires J.M. \& Black G.A. 1695a (118); 2100 (118); 2317 (118)

Pires J.M. \& Leite P. 14725 (103)

Pittier H. 10567 (128a); 14289 (103); 14314 (103); 14869 (103); 14914 (128a); 15085 (103) 
P-JU 13574 (131e)

Plowman T. \& al. 9601 (118b); 9615 (118b)

Pohl J.E. 324 (106); 640 (115); 835 (112); 868 (134); 989 (109);1019 (115); 1272 (97); 1630 (109); 1858 (126); 2176 (135); 2523 (120a); 2626 (120b); 2633 (120b); 2721 (115); 2869 (96); 5148 p.p. (126); s.n. (109); s.n. (115); s.n. (115); s.n. (120b)

Poiteau P.A. s.n. (128a)

Pollard G.R.M. 107 \& 113 (103)

Pott A. 1461 (118a)

Pott A. \& al. 4272 (118b)

Pott A. \& Pott V.J. 6631 (118a); 6776 (109)

Pott V.J. 1514 (105)

Pott V.J. \& Foster R. 3674 (118a)

Poveda A. \& al. PCD 682 (118c)

Pozner R. \& Belgrano M.J. 178 (131e)

PPD-152 (118c)

Prance G.T. \& al. 18897 (94); 25281 (127); 29984 (114); 30064 (114); 58541 (118)

Prance G.T. \& Prance A.E. 14725 (118)

Prance G.T. \& Silva N.T. 58201 (118d)

Pringle C.G. 4405 (87); 5128 (87); 9804 (87)

Proctor G.R. 34297 (128a); 38812 (91)

Proença C. 151 (112)

Proença C. \& Almeida 1353 (115)

Puleston E. 36 (131e)

Purpus C.A. 250 (128a); 6632 (128a); 7896 (128a)

Puyssegur H. s.n. (131e)

Quarin C. \& al. 1821 (119); 2106 (131e); 2711 (119)

Queiroz L.P.de 4876 (118a)

Queiroz L.P. de \& al. 5237 (104); 5378 (118a); 5863 (118a); 6041 (118a); 9209 (128a); 13612 (118c)

Quiroga H. s.n. (105)

Raffaelli A. 62 (131d)

Ragonese A. \& Piccinini B. 6113 (131e)

Rambo B. 27073 (131e); 33141 (131c)

Ramella L. \& al. 3072 (128a)

Ramos A.E. 61 (112)

Ramos P.C.M. 361 (112); 382 (112); 560 (112); 574 (112); 607 (112)

Rapini A. \& al. 349 (121); 381 (121)

Ratter J.A. \& al. 909 (118); 3343 (106); 3489 (120a)

Reeves R.D. \& al. 227 Braspex (118d); 235 Braspex (133)

Regnell A.F. I 100 (106)

Regnier 182 (131e)

Reineck E.M. \& Czermak J. 723 (131b)
Renolfi R. 182 (131e); 187 (131e)

Rentzell I. s.n. (131e)

Renvoize S. \& al. 3053 (131b)

Rezende J.M. de 128 (106); 136 (106); 190 (106); 217 (112); 468 (120a)

Rial Alberti F. \& al. 352 (131e); 403 (131e)

Ribas O.S. \& Pereira L.B.S. 2470 (105)

Ribeiro B.G.S. 1361 (118b)

Ribeiro T. \& al. 290 (121)

Richard L.C. s.n. (91); s.n. (103); s.n. (128a);

Richards P.W. 6858 (94)

Richards P.W. \& Souza R. 6681 (94)

Richardson W.D. 610 (103); 970 (103)

Riedel L. 503 (105); 811 (120a); 880 (141); 941 (95); 1403 (120a); 1544 (118b); 2539 (129); 2608 (135); 2609 (120a); 2611 (112); s.n., p.p. (95); s.n. (112); s.n. (120a); s.n. (128a); s.n. (128a); s.n. (141)

Risso J.L. 835 (131e)

Rizzo A. 4002 (109); 4110 (109); 4154 (109); 4343 (109); 4352 (109); 4694 (109)

Robert A. 310 (94); 459 (94)

Robertson K.R. \& Austin D.F. 176 (103)

Rocha Dias da 37 (118)

Rocha R. 3608 (131e); 3664 (131e); 3798 (131e)

Rocha R.F.A. 235 (118)

Rodarte A.T. 65 (118a); 130 (118c)

Rodrigo A.P. 337 (131e); 806 (131e); 1097 (131e); 2095 (131e); 2278 (131e); 2610 (131e)

Rodrigues J.C.E. \& Silva M.R. 361 (118a)

Rodrigues W.A. 10384 (94)

Rodriguez J.V. 144 (128a); 3489 (128a)

Rodriguez Lubary C. s.n. (131b)

Rohr J.P.B. von 4 (91)

Rojas Acosta N. s.n. (131e)

Rojas T. 2083 p.p. (119); 2635 (128a); 2637 (128a); 2638 (105); 4754 (119)

Rombouts J.E. 2570 (106)

Romero R. \& al. 940 (106); 1264 (120a); 2229 (120a); 2253 (120a); 2665 (120a); 2772 (106); 2959 (120a)

Romero R. \& Nakajima J.N. 1514 (120a)

Rondon en Kuhlmann J.G. 2185 (118a)

Roque N. \& al. 400 (121); 631 (128a)

Rosa E.B. 332 (131e)

Rosa N.A. \& al. 1141 (118c)

Rosa N.A. \& Santos M.R. 1958 (118c)

Rosales J. \& Valles J.L. 141 (103)

Rosário C.S. 66 (118b)

Rose J.N. 3562 (87)

Rose J.N. \& Hough W. 4765 (87) 
Rose J.N. \& Painter J.H. 7482 (87)

Rose J.N. \& Russell P.G. 20721 (128a)

Rosengurtt B. 2159 (131a); 5809 (131b)

Rosengurtt B. \& al. 10552 (131d)

Rosengurtt B. \& Del Puerto O. 8677 (131a); 9184 (131c)

Rosengurtt Gallinal 5809 (131d)

Rosillo R.D. 444 (131d)

Rossi \& al. 426 (131e)

Rossi L. \& al. CFCR L. 1041 (135)

Roth O. s.n. (131e)

Rotts L. 830 (120a)

Roubik 15 (103)

Rua J. de la 66 (131e); s.n. (131e)

Rueda R. \& al. 11322 (91)

Rugolo de Agrasar Z.E. 624 (131e)

Ruiz Leal A. 10436 (131e)

Rzedowski J. 39767 (87)

Rzedowski J. \& McVaugh R. 1326 (128a)

Saar E. \& al. PCD 5456 (118a)

Sacco J.C. \& Rambo B.S. 688 (131c)

Saer J. 487 (91)

Safford W.E. s.n. (131e)

Saint Hilaire A. 1551 (120a); 1558 (120a); B 331 (113); B1 1362 (121); B1 1558 (113); B1 1758 (120a); B1 1956 (121); B1 1993 (141); C (121); C 554 (121); C 2284 (131e); C1 250 (120a); C1 556 (115); C1 714 (109); C1 771 (109); C1 862 (112); C1 906 (113); C2 1428 (120a); C2 2068 (131a); C2 2171 (131e); C2 2577 (131b); D 676 (120a); s.n. (100); s.n. (109); s.n. (115); s.n. (120a); s.n. (120a); s.n. (120a); s.n. (125)

Sakuragui C.M. \& al. CFCR 15079 (121); CFCR 15258 (120a)

Sakuragui C.M. \& Souza V.C. 160 (141)

Sales M.F. 432 (118)

Salgado O.A. \& al. 397 (128b)

Salimena-Pires F.R. \& al. s.n. (120a)

Salis S.M. \& al. 858 (128a)

Sanchez E. 929 (131d)

Sanchez Vega I. \& al. 2417 (128a)

Sanchez Vega I. \& Guevara J. 6202 (128a)

Sano P.T. \& al. CFCR 14854 (116a)

Santos s.n. (105)

Santos A.A. \& al. 762 (106)

Santos E. \& al. 3223 (131c); 3269 (131b)

Santos T.S. dos 3508 (128a)

Santos Martinez J. 1500 (87)

Sanzin R. 2877 (131e)

Saravia Toledo C. 1721 (131e)

Saravia Toledo C. \& al. 11683 (128a); 12856 (131e); 12942 (131e); 13090 (131e); 13144 (131e); 13047 (131e); 13258 (131e); 13282 (131e)

Sastre C. 807 (117a)

Sastre C. \& Sastre F. 19 (103)

Saunders J. \& al. 3015 (115)

Sazima M. \& Semir J. 3844 (120a)

Scala A.C. s.n. (131e); s.n. (131e)

Scappini R.E. 1059 (131e)

Schessl M. \& Gottsberger G. 2245 (94)

Schickendantz F. 140 (131e)

Schiele de Clough J. s.n. (131e)

Schinini A. 1833 (105); 3899 (105); 5539 (131b); 7673 (131d); 7756 (131b); 9021 (105);10979 (131e); 13857 (131e); 14145 (131e); 19475 (131e); 19519 (131e); 19532 (131e); 19536 (131e); 19573 (131e); 19854 (105); 21449 (105); 21510 (105); 21530 (105); 21711bis (131b); 23982 (128a); 27560 (119); 30405 (131d); 30432 (131d)

Schinini A. \& Ahumada O. \& 20840 (131b); 20911 (131b)

Schinini A. \& al. 6326 (131d); 10200 (131e); 10242 (131e); 13056 (131d); 15210 (128a); 17378 (131d); 17539 (131d); 18269 (131d); 18688 (131b); 19532 (131e); 21232 (131e); 21648 (131e); 21648bis (131e); 21704 (131d); 21705 (131b); 21711 (131b); 21945 (131b); 23389 (131b); 23481 (131b); 27849 (119); 27892 (105); 28348 (131d); 28349 (119); 29142 (131e); 29142bis (131e); 29345 (105); 29414 (105); 29420 (105); 35536 (118a); 35543 (105); 35571 (105); 36428 (131e); 36448 (105)

Schinini A. \& Bernardello L. 24138 (131e)

Schinini A. \& Caballero Marmori G. 27279 (131d)

Schinini A. \& Dematteis M. 33420 (105)

Schinini A. \& Quarin C. 14479 (131b)

Schinini A. \& Palacios R. 25690 (128a)

Schinini A. \& Pire S.M. 24251 (131e)

Schinini A. \& Poletti M. 27502 (131e)

Schinini A. \& Quintana M. 36363 (105); 36391 (105); 36396 (105); 36398 (105)

Schinini A. \& Urbani M. 35770 (131e)

Schinini A. \& Vanni R. 22240 (131e)

Schipp W.A. 8-193 (91)

Schlindwein C. CS948 (118c)

Schlindwein C. \& al. CS935 (118)

Schnee G. s.n. (87)

Schomburgk R.H. 105 (103); s.n. (103)

Schreiner s.n. (128a)

Schreiter R. 119 (131e); 259 (131e); 266 (131e); 
362 (131e); 11114 (131e)

Schulz A.G. 21 (131e); 116 (131e); 613 (131e); 4051 (131e); 7083 (131b); 7114 (105); 8803 (131e); 8910 (131e); 10128 (131e); 10129 (131e); 15585 (131e); 18545 (131d); 18644 (131b)

Schwacke C.A.W. 8211 (141); 8214 (100); 8215 (142); s.n. (120a); s.n. (120b)

Schwarz G.J. 540 (131b); 5540 (105)

Secco R.S. \& al. 144 (118)

Seidel R. 538 (118c)

Seijo J.G. \& Solís Neffa V. 3106 (131e); 3107 (131e)

Seijo J.G. 1209 (131e); 1406 (131e); 1748 (131e); 2012 (131e); 2899 (131e); 2900 (131e); 2901 (131e); 2902 (131e); Seijo J.G. 2915 (131e)

Sellow F. 1000 (131e); 1566 (120a); 1570 (120a); 3034 (131c); 3043 (131c); 5088 (120a); d.68 (131e)

Sellow sub Gaudichaud F. 2946 (131c)

Semir J. \& al. . 20057 (115); 20541 (125); 20573 (120a); 20614 (125); 20615 (101); 20640 (120a); s.n. (109); CFCR 9703 (121)

Semir J. \& Sazima M. 494 (88); 2774 (88)

Sesse M. \& al. 5089 (87)

Shafer J.A. 10683 (84); 10703 (128a)

Shepherd G.J. \& al. 3587 (112); 3722 (120a); 7082 (106)

Sidney \& Onishi - ver Fonseca S.G. \& Onishi E.

Sigle M. 169 (131e)

Silva A.S.L. da \& al. 1867 (118b)

Silva F.H.M. \& al. 363 (118)

Silva G.P. da 1734 (106); 1777 (106); 1981 (112); 2302 (112)

Silva J.M. \& Barbosa E. 4890 (105); 5296 (95); 5388 (128a)

Silva M.A. da 2285 (133); 4682 (112)

Silva M.A. da \& al. 356 (115); 364 (112); 1867 (118b); 1884 (120b); 1939 (120a); 2115 (133); 2139 (109); 3764 (115); 4185 (118b)

Silva M.A. da \& Nunes de Jesus G. 2984 (118d); 3035 (134)

Silva M.A. da \& Oliveira F.C.A. 2990 (118d)

Silva M.A. da \& Simões M.C.B. 1064 (115)

Silva M.F.F. \& al. 1141 (118)

Silva M.G. 2913 (118)

Silva M.G. \& Rosario C.S. 5202 (118a)

Silva N.T. da 2347 (118c); 2498 (118); 4842 (118b); 4942 (118b)

Silva T.R.S. \& al. CFCR 12392 (121)

Silveira A. 133 (106); 1879 (106); 1924 (120a); s.n. (120a)
Silvia 1315 (105); 1322 (105)

Simão-Bianchini R. 89 (100)

Simão-Bianchini R. \& al. CFCR 13145 (121)

Simão Bianchini R. \& Bianchini S. 379 (106); CFSC 12780 (120a)

Sintenis P. 2995 (128a); 3236 (128a)

Skog L. \& al. 7025 (103)

Sleumer H.O. 2169 (131e); s.n. (131e)

Smith 59 (131e)

Smith H. s.n. (94)

Smith H.H. 1338 (128a)

Snethlage H. 153 (118c); 667 (118a)

Soares S.M. 329b (113)

Sobral M. \& al. 6285 (141)

Solbrig O.T. 171 (131e); s.n. (131e)

Solbrig O.T. \& Ornduff 4444 (87)

Solís Neffa V. 22 (131e); 387 (131e); 388 (131e); 483 (131d); 486 (131e); 501 (131a); 502 (131a); 505 (131e); 506 (131c); 561 (131e); 986 (131b);1994 (131e); 1999 (131b)

Solís Neffa V. \& al. 44 (131e); 271 (131b); 278 (131b); 307 (131e); 309 (131e); 310 (131d); 311 (131e); 315 (131e); 316 (131e); 332 (131e); 350 (131e); 356 (131e); 357 (131e); 358 (131e); 384 (131e); 395 (131b); 397 (131b); 399 (131d); 400 (131b); 407 (131a); 410 (131d); 414(131b/ d); 418 (131c); 424 (131b/d); 453 (131c); 454 (131b); 455 (131c); 456 (131d); 500 (131e); 521 (131d); 522 (131d); 523 (131e); 524 (131e); 525 (131c); 526 (131c); 527 (131c); 528 (131c); 529 (131d); 534 (131d); 535 (131b);536 (131b); 537A, B, C, D (131c); 539A,B (131a); 540 (131a); 541 (131c); 542 (131b); 543 (131e); 544 (131a); 545 (131a); 546 (131a); 547 (131a); 548 (131a); 549 (131b); 550 (131b); 552 (131c); 554 (131c); 555 (131a); 557 (131c); 559A, B (131b); 560 (131d); 583 (131e); 717B, L (131e); 720 (131e); 722 (131e); 767 (131e); 779 (131e); 788 (131e); 790 (131e); 820 (131e); 822 (131e); 823 (131e); 827 (131e); 829 (131e); 833 (131e); $836 \quad$ (131e); 837 (131e); 839 (131e);845A, B, C, D, E (131e); 852A, B, C, D (131e); 892 (131e); 895 (131e); 898 (131e); 903 (131e); 904 (131e); 905 (131e); 907 (131e); 911 (131e); 918 (131e); 924 (131e); 935 (131e); 938 (131d); 1025 (131e); 1033 (131e); 1035 (131e); 1042 (131e); 1048 (131e); 1200 (128a); 1218 (128a); 1219 (128a); 1222 (92a); 1227 (128a); 1246 (105); 1259 (105); 1293 (128a); 1327 (131e); 1346 (131e); 1355 (131e); 1363 (131e); 1366 (131e); 1377 (131e); 1378 (131e); 1379 
(131e); 1380 (131e); 1382 (131e); 1385 (131e); 1390 A,B,C (131e); 1396 (131e); 1398 (131e); 1402 (131e); 1403 (131e); 1405 (131e); 1406 (131e); 1407 (131e); 1409 (131e); 1412 (131e); 1413 (131e); 1415 (131e); 1416 (131e); 1417 (131e); 1419 (131e); 1423 (131e); 1427 (131e); 1436 (131e); 1438 (131e); 1441 (131e); 1450 (131e); 1463 (131e); 1466 (131e); 1467 (131e); 1469 (131e); 1472 (131e); 1477 (131e); 1479 (131e); 1480 (131e); 1498 (131e); 1499 (128a); 1500 (131e); 1501 (131e); 1504 (131e); 1505 (131e); 1508 (131e); 1510 (131e); 1511 (131e); 1514 (128a); 1526 (128a); 1527 (128a); 1528 (128a); 1532 (128a); 1538 (128a); 1540 (128a); 1543 (128a); 1553 (128a); 1555 (128a); 1556 (128a); 1565 (105); 1570 (105); 1577 (128a); 1637 (118b); 1641 (118); 1657 (128a); 1692 (128a); 1708 (128a); 1732 (105); 1738 (128a); 1741 (105); 1749 B (105); 1752 (105); 1753 (128a); 1756 (128a); 1759 (128a); 1761 (105); 1902 (128a); 1912 (105); 1928 (128a); 1933 (128a); 1938 (131e); 1962 (131e); 1968 (131e); 1969 (131e); 1971 (131e); 1979 (131e); 1986 (131e); 1988 (131e); 1989 (131e); 1992 (131e); 2003 (131b)

Solís Neffa V. \& Dematteis M. 306 (131e); 312 (131b)

Solís Neffa V. \& Seijo G.J. 958 (131e); 959 (131e); 966A, B (131e); 967 (131e); 968 (131e); 969A, B (131e); 973 (131d); 974 (131d); 977 (131e); 978 (131e); 979 (131d); 980 (131e); 981 (131b); 982 (131b); 983 (131e); 985 (131e); 1481 (131e); 1484 (131e); 1485 (131e); 1486 (131e); 1487 (131e); 1488 (128a); 1490 (105); 1491 (128a)

Soria N. 3615 (105); 4207 (105); 4438 (95); 4510 (105); 5217 (105); 7366 (105)

Soriano A. 1587 (131e)

Souza S.A. da \& al. M.Souza, O.C.Nascimento, M.C.da Silva \& Pedro 275 (118)

Souza V.C. \& al. 5084 (120a); 5374 (116b); 5377 (104); 5392 (128a); 7150 (120a); 7986 (120a); 8184 (120a); 11832 (141); 11876 (100); 12057 (141); 14249 (118); 14800 (118); 14816 (118b); 16343 (118); 16599 (118b); 16835 (118a); 18025 (118a); 18027 (118c); 20412 (94); 21286 (124); 21576 (120a); 22443 (120a); 22444 (120a); 22531 (120a); 23048 (118b); 25060 (120a); 25291 (141); 25446 (135); 28188 (121); 28690-A (142); 28764 (128a)

Souza V.C. \& Sakuragui C.M. 1996 (141); 3312 (120a)
Souza-Silva R.F. \& al. 221 (118a)

Sparre B. 16089 (128a)

Spegazzini C. 37 (131e); 101743 (131e); 10565 (131e); s.n. X-1897 (119); s.n. año 1902 (105); s.n. 30-I-1906 (131e)

Spegazzini R. 15 (131e)

Spegazzini R.A. 86 (131e); s.n. (131d)

Sperling C.R. \& al. 5724 (118b)

Splett S. 713 (109)

Splett S. \& al. 156 (109)

Sprague T.A. 39 (117a)

Spruce R. 743 (118b); 475 (118); 1075 (117b); 1278-2 (117b); 3574 (128a); 3645 (103); 4075 (128a); s.n. (117b); s.n. (117b)

Stahl A. 57 (128a)

Standley P.C. 11635 (128a); 12060 (128a); 14258 (128a); 21304 (128a); 22147 (128a); 22941 (128a); 73777 (128a); 74077 (128a); 75123 (128a); 75597 (128a); 77111 (128a)

Standley P.C. \& al. 1240 (128a)

Standley P.C. \& Chacón J. 5737B (91)

Stehmann J.R. \& al. 2852 (141); s.n. (88)

Stergios B. 10084 (114); 10479 (114); 10514 (103)

Stevens W.D. 4649 (128a); 5229 (128a); 7590 (91); 9756 (128a); 10799 (128a); 22271 (128a)

Stevens W.D. \& Moreno P.P. 19649 p.p. (91)

Steyermark J.A. 30194 (128a); 50864 (128a)

Steyermark J.A. \& al. 131119 (103); 131694 (103)

Stuckert T. 385 (131e); 2368 (131e); 3979 (131e); 5025 (131e); 8541 (131e);10009 (131e); 10716 (131e); 12581 (131e); 13581 (131e); 16557 (131e); 17038 (131e); 17856 (131e); 19284 (131e); 19708 (131e); 20897 (131e); 21274 (131e)

Suarez M.E. 44 (131e)

Subils R. 644 (131e)

Subils R. \& al. 2798 (131e)

Subils R. \& Artico L. 651 (131e)

Subils R. \& Bernardello L. 2489 (131e)

Sucre D. 865 (120a); 1910 (128a); 10329 (118b); 10471 (105)

Sucre D. \& al. 564 (135); 10245 (118)

Sucre D. \& Braga P.I.S. 7104 (106)

Sucre D. \& Silva J.F.da 9458 (118); 9472 (92b)

Svenson H.K. 11241 (128a)

Swartz O.P. s.n. (128a)

Taituba 6427 (118)

Tameirão Neto E. \& Werneck M.S. 1718 (120a)

Tate G.H.H. 79 (103)

Tatter O. 4306 (131e)

Taxonomy Class of Univ.Brasilia 534 (112) 
Taylor E.L. E1218 (118a)

Teixeira L.O.A. \& al. 271 (118c)

Teixeira W.A. s.n. (120a)

Tell G. s.n. (131e)

Tellechea M. 147 (131e)

Terán J.B.M. 109 (131e)

Thomas W.W. \& al. 5772 (109); 11670 (118a); 11692 (118a)

Thomas C. \& Magalhaes Gomes F. 1206 (120a)

Thurm s.n. (103)

Tirel C. 159 (131e); 229 (131e); 296 (131e)

Tolaba J. 227 (131e)

Tonduz A. 13821 (128a)

Torres M.A. 1105 (131e)

Traill J.W.H. 342 (128a); 343 (118); s.n. (128a)

Tressens S.G. \& al. 1689 (119); 2005 (131b); 2252 (131e); 2274 (131e); 2410 (131e); 2531 (131e); 2539 (131e); 2649 (119)

Tressens S.G. \& Vanni R. 1942 (131b)

Triana J.J. 5056 (117a)

Trinta Z.A. 1145 (131c)

Troncoso N. \& Bacigalupo N. 3010 (131e)

Trujillo B. \& Pulido J. 15152 (107)

Tweedie J. 391 (131e); 392 (131e); s.n. (131c); s.n. (131d); s.n. año 1837 (131e); s.n. Buenos Aires (131e)

Ule E. 486 (109); 2696 (120a); 2935 (109); 7502 (136); 7509 (118a); 7510 (128b); 7877 (128a); 7896 (103); 8901 (114); s.n. (109)

Usteri P.A. 19 (120a); 140b (120a)

Vaca A.A. 36 (131e)

Valentini A. 222 (131e)

Valverde J.L. 117 (128a)

Vanni R. \& al. 261 (105); 317 (105); 347 (105); 351 (105); 395 (105); 1274 (105); 1708 (119); 3882 (131b)

Varela 528 (131e); 657 (131e)

Varela R.R. s.n. (131e)

Vasconcellos \& Cunha 13533 (118a)

Vasconcelos M.F.de s.n. (120a)

Vattuone I.C. \& Bianchi A. 131 (105)

Vauthier 499 (141)

Vaz A.F. \& Alvarenga D. 906 (115)

Velayos M. \& al. 6469 (114)

Ventura F. 10410 (128a)

Venturi S. 468 (131e); 468a (131e); 2113 (131e); 2688 (131e); 4933 (131e); 5165 (131e); 7501 (131e)

Veyret Y. \& Cremers G. 4441 (103)

Vidal J. 1246 (120a); 1371 (131b); I-506 (120a); II-6078 (120a); II-6216 (120a); IV-860 (118); IV-908 (118); IV-1039 (118); IV-1238 (120a);
V-119 (120a); V-140 (120a); s.n. (100)

Vieira R.F. \& al. 1129 (118)

Vignatti M.A. 77 (131e); 192 (131e)

Vilaca A. \& Ribeiro 108 (118); 117 (118)

Villa A. \& al. 848 (131e); 3159 (131e)

Villa Carenzo M. \& al. 1665 (131e); 1852 (131e)

Wagner s.n. (131e)

Wall E.T.S. \& Sparre C.S.B. s.n. (131e)

Walter B.M.T. \& al. 902 (135); 903 (109); 918 (128a); 1195 (135); 1219 (120a); 1444 (135); 3508 (118a); 3869 (110)

Wanderley M.G.L. \& al. 888 (116a)

Wanderley M.G.L. \& Kral R. 75891 (115)

Warming E. 25 (128a); 845 (103); s.n. (120a); s.n. (120a)

Weberbauer A. 5948 (128a); 7732 (128a)

Weddell H.A. 1858 (120a); 2503 (112); 2617 (109); s.n. (120a)

Weigend M. \& al. 97/333 (128a)

Weir J. 333 (120a)

Werff H. van der \& al. 35 (91); 3256 (91)

Werff H. van der \& Wingfield R. 3464 (138)

Wiley J.R. 291 (91)

Williams L. 12988 (107); 12989 (107); 13009 (103)

Williamson J. s.n. (131e)

Wilson F.G. \& Browne S.J. 430 (114); 497 (103)

Wingfield R. 5074 (91); 7170 (91)

Wood J.R.I. 7719 (131e)

Wood J.R.I. \& Goyder D.J. 15813 (131e)

Woolston A.L. 345 (119); 1493 (119); 1494 (119)

Wright C. 27 (128a); 2606 (128a); 2607 (84); 3569 (128a); s.n. (128a)

Wullschlaegel H.R. 1399 (128a)

Wurdack J.J. \& Adderley L.S. 42863 (114)

Wurdack J.J. \& Monachino 39547 (103); 39801 (103); 40205 (103)

Xantus L.J. 37 (128a)

Yano O. \& Marcelli M.P. 18072 (118)

Zanoni T. \& al. 32028 (128a)

Zanoni T. \& Pimentel 25395 (128a)

Zappi D.C. \& al. CFCR 8110 (120a); CFCR 8191 (135)

Zardini E.M. 8715 (105); 8716 (105); 11840 (105)

Zardini E.M. \& Acosta A. 56134 (105)

Zardini E.M. \& al. 9140 (105)

Zardini E.M. \& Baez P. 52324 (105); 52428 (105)

Zardini E.M. \& forest ranger 10207 (105)

Zardini E.M. \& Espinoza L. 53667 (105)

Zardini E.M. \& Guerrero L. 31000 (105); 37325 (105); 37341 (105); 39836 (105); 39890B (105); 39891 (105); 57683 (105)

Zardini E.M. \& park guard 11840 (105) 
Zardini E.M. \& Quintana D. 54535 (95)

Zardini E.M. \& Tilleria T. 28912 (105); 37211 (119); 37492 (105)

Zardini E.M. \& Velasquez C. 10365 (105)

Zardini E.M. \& Velazquez R. 26414 (105); 26308 (105); 26474 (105)

Zardini E.M. \& Vera M. 44587 (105); 48121 (105); 53423 (105); 53529 (105); 54180 (105); 54206 (105); 54410 (105)

Zarucchi J.L. \& Barbosa C.E. 3662 (103); 3753 (117a)

Zelada s.n. (131e)

Ziliani G. \& al. s.n. (131c)

Zuloaga F.O. \& al. 6643 (105)

\section{Índice de nombres vulgares}

alfazema de periquito 217

amapolita 288

bruja 262

carrapicho 217

chanana 217

conejito 262

damiana 243

lamacelita 280

lidio 262

malva 217

malvavisco da costa 217

malvita crespa 288

mari-lopez 262

ranca-estrepe 264

sauce 217

vassourinha 217

verbenita 288

yerba del ciervo 288

\section{Índice de nombres científicos}

Chamaecistus luteus, foliis parvis serratis 256

Chamaecistus urticaefolio, flore luteo 256

Piriqueta cistoides 256

Pumilea minima subhirsuta foliolis angustis profunde serratis 256

Serie Anomalae 110, 288

Annulares 108, 109

Capitatae 108, 109, 110

Conciliatae 108, 109, 307
Leiocarpae 108, 109, 135, 262

Microphyllae 108, 109

Papilliferae 108, 109

Salicifoliae 108, 109, 110

Sessiliflorae 110, 307, 308

Stenodictyae 108, 109

Turnera 108, 110, 236, 243, 262, 288

Tribolacis juncea 168

Turnera 108

acaulis 113, 121, 122, 123, 186, 268

aff. uleana 209

angelicae 118, 122, 124, 125

arenaria 220

argentea 115, 126, 127, 182

callosa 110, 120, 123, 128, 129, 140

chrysodoxa 147

cipoensis 117, 130, 131

coccinea 115, 132, 133

crulsii 120, 131, 135, 136, 137

cuneiformis Juss. ex Poir. var. odorata 138

cuneiformis Juss. ex Poir. var. $\beta 138$

curassavica 118, 120, 123, 137, 138, 140

dasytricha 141

var. crinita 119, 143, 144, 145

var. dasytricha 119, 141, 142, 143

decipiens 308

diamantinae 116, 134, 144, 146

dichotoma 108, 307, 308, 309, 313

var. stenophylla 308

var. stricta 308

discolor 111, 120, 125, 147, 148, 150

dolichostigma 121, 140, 150, 151, 152, 174

elliptica 115, 153, 154, 155

emendata 120, 131, 137, 155, 156

fissifolia 114, 134, 157, 158, 171

foliosa 117, 159, 160, 161, 236

genistoides 114, 162, 163

glabrata 116, 155, 164, 165

gouveiana 120, 161, 166, 167

grisebachiana 278

guianensis 116, 123, 159, 168, 169, 256

harleyi 119, 143, 171, 172

hassleriana 121, 134, 140, 174, 175

var. lobulata 174

herteri 271

hilaireana 117, 132, 134, 178, 179, 200, 236

var. lanceolata 200, 230

var. minor 178, 200

var. oblongifolia 200, 239

var. ovatifolia 200, 230

hirsutissima 256 
holosericea 275

huberi 118, 120, 152, 181, 182

humboldtii 168

humilis 113, 183, 184, 185, 268

incana 115, 147, 186, 187

iterata 116, 161, 189, 190

jobertii 119, 120, 155, 191, 192

lamiifolia 111, 115, 120, 150, 194, 195

lanceolata 117, 134, 178, 182, 198, 199, 200, 236

lineata 115, 131, 200, 201

var. ramosissima 247

longiflora 114, 135, 152, 203, 204

luetzelburgii 114, 159, 206

var. dubia 118, 161, 209, 210

var. luetzelburgii 206, 207, 208

lutescens 239

melanorhiza 264

var. latifolia 264

melochia 140, 212

var. melochia 115, 152, 212, 213

var. ramosissima 116, 125, 214, 215

melochioides 144, 174, 216, 217

var. angustifolia 220

var. arenaria 119, 152, 218, 220, 224, 247

var. genuina 216

var. latifolia 119, 155, 217, 218, 223

var. melochioides 119, 131, 217, 218, 221

var. oblongifolia 218

var. ramosissima 214

var. rugosa 119, 143, 217, 226, 227

nana 239

nervosa 117, 143, 228, 229

oblongifolia 125, 178, 181, 200, 230

var. goyazensis 118, 161, 237, 238, 239

var. oblongifolia 118, 230, 231

odorata 137

opifera 118, 119, 135, 143, 174, 239, 240, 243

palmeri 128

paradoxa 119, 143, 243, 244

paruana 120, 185, 245, 246, 247

patens 117, 143, 247, 248

pinifolia 116, 143, 166, 249, 250

pinnatifida 271, 280

var. angustiloba 280

var. lycopifolia 280

var. $\beta 280$ var. carnea 272

var. $\beta$ angustifolia 280

pohliana 120, 252, 253

prancei 116, 134, 254

procumbens 162

pumilea 256

var. piauhyensis 119, 125, 262, 263

var. pumilea 119, 185, 256, 257

pumileoides 150

revoluta 108, 307, 308, 311, 312

riedeliana 117, 132, 208, 236, 255, 264, 265

rosulata 113, 185, 186, 266, 267

rubrobracteata 108, 307, 308

schwackeana 308

sedoides 271

setosa 280

var. entreriana 280

var. integrifolia 278

sidodes 280

sidoides 110, 268, 269

subsp. carnea 114, 125, 272, 273

subsp. holosericea 114, 143, 275, 276

subsp. integrifolia 114, 130, 152, 278

subsp. pinnatifida 114, 131, 159, 280, 281

subsp. sidoides 111, 114, 131, 269, 270

var. angustiloba 280

var. grisebachiana 278

var. herteriana 271

var. hispida 269

var. holosericea 275

var. incisa 272, 280

var. lycopifolia 280

var. lycopodifolia 280

stachydifolia 111, 243, 288

var. flexuosa 115, 134, 290, 291

var. stachydifolia 115, 134, 288, 289

subnuda 116, 208, 256, 290, 292, 294, 296

tenuicaulis 116, 134, 256, 294, 295, 299

trigona 116, 155, 256, 294, 296, 297, 299

uleana 116, 118, 134, 299, 300

ulmifolia f. serissima 200

ulmifolia var. cuneiformis 174

vallsii 118, 125, 301, 302

venezuelana $118,185,303,304$

vicaria 114, 305, 306

weddelliana 174

Turneraceae 307

Original recibido el 15 de octubre de 2008; aceptado el 12 de noviembre de 2008. 